"Fish Friendly" Hydropower Turbine Development and Deployment: Alden Turbine Preliminary

Engineering and Model Testing

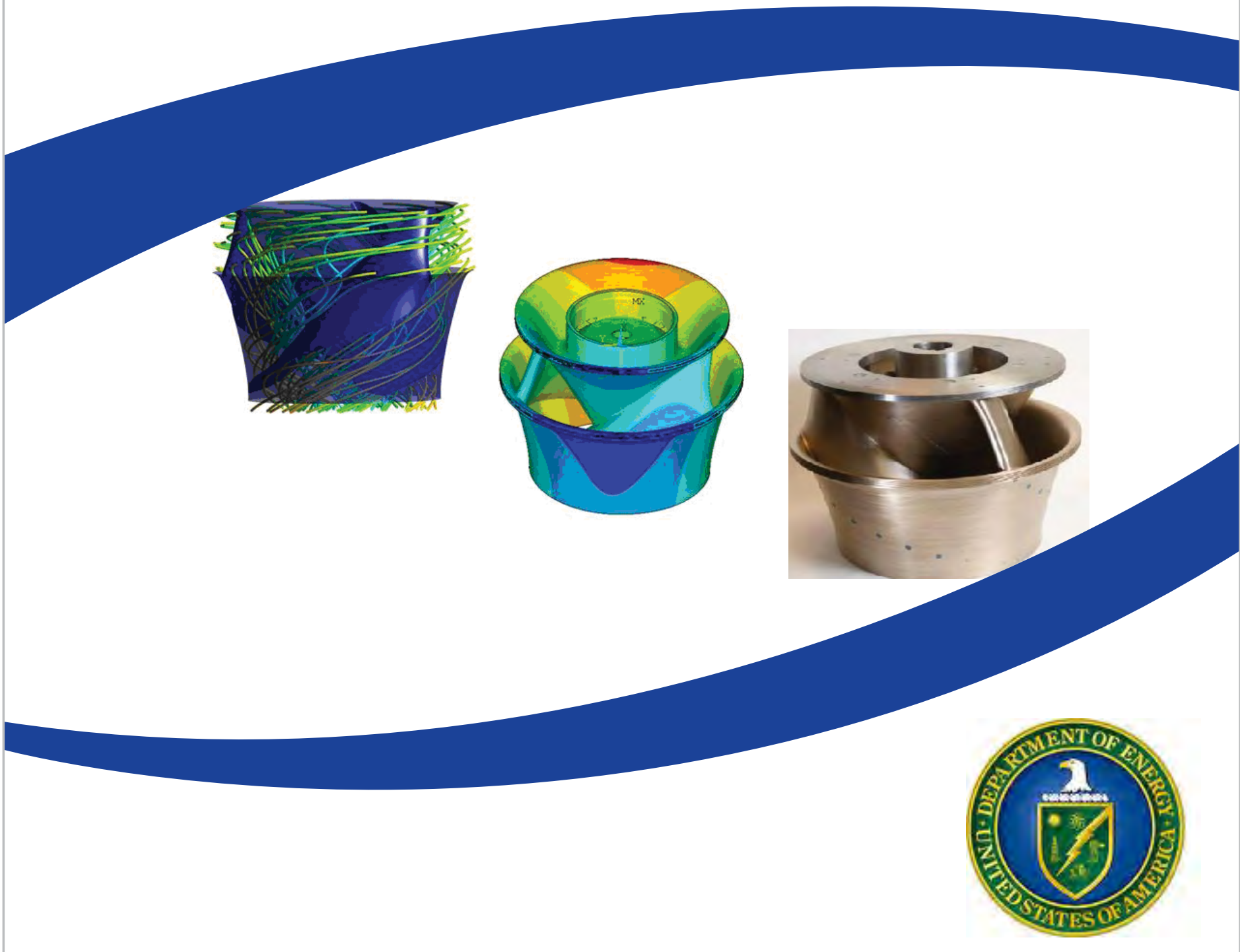





\section{"Fish Friendly" Hydropower Turbine Development and Deployment: Alden Turbine Preliminary Engineering and Model Testing}

1019890

Final Report, October 2011

Co-sponsor

U.S. Department of Energy

Energy Efficiency and Renewable Energy Office

Wind and Water Power Program

Grant Number: DE-FG36-08G018167

EPRI Project Manager

D. Dixon

U.S. Department of Energy Project Manager

R. Dham 


\section{DISCLAIMER OF WARRANTIES AND LIMITATION OF LIABILITIES}

THIS DOCUMENT WAS PREPARED BY THE ORGANIZATION(S) NAMED BELOW AS AN ACCOUNT OF WORK SPONSORED OR COSPONSORED BY THE ELECTRIC POWER RESEARCH INSTITUTE, INC. (EPRI). NEITHER EPRI, ANY MEMBER OF EPRI, ANY COSPONSOR, THE ORGANIZATION(S) BELOW, NOR ANY PERSON ACTING ON BEHALF OF ANY OF THEM:

(A) MAKES ANY WARRANTY OR REPRESENTATION WHATSOEVER, EXPRESS OR IMPLIED, (I) WITH RESPECT TO THE USE OF ANY INFORMATION, APPARATUS, METHOD, PROCESS, OR SIMILAR ITEM DISCLOSED IN THIS DOCUMENT, INCLUDING MERCHANTABILITY AND FITNESS FOR A PARTICULAR PURPOSE, OR (II) THAT SUCH USE DOES NOT INFRINGE ON OR INTERFERE WITH PRIVATELY OWNED RIGHTS, INCLUDING ANY PARTY'S INTELLECTUAL PROPERTY, OR (III) THAT THIS DOCUMENT IS SUITABLE TO ANY PARTICULAR USER'S CIRCUMSTANCE; OR

(B) ASSUMES RESPONSIBILITY FOR ANY DAMAGES OR OTHER LIABILITY WHATSOEVER (INCLUDING ANY CONSEQUENTIAL DAMAGES, EVEN IF EPRI OR ANY EPRI REPRESENTATIVE HAS BEEN ADVISED OF THE POSSIBILITY OF SUCH DAMAGES) RESULTING FROM YOUR SELECTION OR USE OF THIS DOCUMENT OR ANY INFORMATION, APPARATUS, METHOD, PROCESS, OR SIMILAR ITEM DISCLOSED IN THIS DOCUMENT.

(C) THIS REPORT WAS PREPARED AS AN ACCOUNT OF WORK SPONSORED BY AN AGENCY OF THE UNITED STATES GOVERNMENT. NEITHER THE UNITED STATES GOVERNMENT NOR ANY AGENCY THEREOF, NOR ANY OF THEIR EMPLOYEES, MAKES ANY WARRANTY, EXPRESS OR IMPLIED, OR ASSUMES ANY LEGAL LIABILITY OR RESPONSIBILITY FOR THE ACCURACY, COMPLETENESS, OR USEFULNESS OF ANY INFORMATION, APPARATUS, PRODUCT, OR PROCESS DISCLOSED, OR REPRESENTS THAT ITS USE WOULD NOT INFRINGE PRIVATELY OWNED RIGHTS. REFERENCE HEREIN TO ANY SPECIFIC COMMERCIAL PRODUCT, PROCESS, OR SERVICE BY TRADE NAME, TRADEMARK, MANUFACTURER, OR OTHERWISE DOES NOT NECESSARY CONSTITUTE OR IMPLY ITS ENDORSEMENT, RECOMMENDATION, OR FAVORING BY THE UNITED STATES GOVERNMENT OR ANY AGENCY THEREOF. THE VIEW AND OPINIONS OF AUTHORS EXPRESSED HEREIN DO NOT NECESSARILY STATE OR REFLECT THOSE OF THE UNITED STATES GOVERNMENT OR ANY AGENCY THEREOF.

REFERENCE HEREIN TO ANY SPECIFIC COMMERCIAL PRODUCT, PROCESS, OR SERVICE BY ITS TRADE NAME, TRADEMARK, MANUFACTURER, OR OTHERWISE, DOES NOT NECESSARILY CONSTITUTE OR IMPLY ITS ENDORSEMENT, RECOMMENDATION, OR FAVORING BY EPRI.

THE FOLLOWING ORGANIZATIONS, UNDER CONTRACT TO EPRI, PREPARED THIS REPORT:

Voith Hydro, Inc.

Alden Research Laboratory, Inc.

\section{NOTE}

For further information about EPRI, call the EPRI Customer Assistance Center at 800.313.3774 or e-mail askepri@epri.com.

Electric Power Research Institute, EPRI, and TOGETHER...SHAPING THE FUTURE OF ELECTRICITY are registered service marks of the Electric Power Research Institute, Inc.

Copyright (C) 2011 Electric Power Research Institute, Inc. All rights reserved. 


\section{ACKNOWLEDMENTS}

The following organizations, under contract to the Electric Power Research Institute (EPRI), prepared this report:

Voith Hydro, Inc. 760 East Berlin Road

York, PA 17408

Principal Investigator

J. Foust

Alden Research Laboratory, Inc.

30 Shrewsbury Street

Holden, MA 01520

Principal Investigators

G. Hecker

S. Li

G. Allen

This report describes research sponsored by EPRI and the U.S. Department of Energy. The U.S. Department of Energy, Energy Efficiency and Renewable Energy Office, Wind \& Water Power Program provided 50\% of project funding via grant number DE-FG36-08GO18167, "FishFriendly” Hydropower Turbine Development \& Deployment: Phase II Preliminary Engineering \& Model Testing. Long-term development of the Alden turbine including the accomplishments discussed herein would not have been possible without the support and vision of many DOE project managers since 1995.

This publication is a corporate document that should be cited in the literature in the following manner:

"Fish Friendly" Hydropower Turbine Development and Deployment: Alden Turbine Preliminary Engineering and Model Testing. EPRI, Palo Alto, CA and U.S. Department of Energy, Washington, DC: 2011. 1019890. 
EPRI would like to acknowledge the support of the following organizations: Brookfield Renewable Power, Dairyland Power Cooperative, Electricité de France, New York Power Authority, NewYork State Energy Research and Development Authority, Puget Sound Energy, SCANA Corporation, and Southern Company.

EPRI would like to thank the following individuals for their review and comments provided on the report:

Rajesh Dham

Gary Johnson

Marshall C. Richmond

Michael J. Sale

Brennan Smith

Qin Fen Zhang
U.S. Department of Energy, Wind \& Water Power Program

U.S. Department of Energy, Wind \& Water Power Program

Pacific Northwest National Laboratory

M.J. Sale \& Associates

Oak Ridge National Laboratory

Oak Ridge National Laboratory 


\section{PRODUCT DESCRIPTION}

This report presents the results of a collaborative research project funded by the Electric Power Research Institute (EPRI), the U.S. Department of Energy (DOE), and hydropower industry partners with the objective of completing the remaining developmental engineering required for a "fish-friendly" hydropower turbine called the Alden turbine. Earlier engineering and research that was started in 1995 and completed in 2008 established a viable conceptual design. Additional engineering completed in 2009 and 2010 included (1) converting a conceptual design with the use of computational fluid dynamics into a machine design that can be built and (2) constructing and testing a physical model of the turbine to evaluate its performance characteristics for economic analysis and mechanical layout. Completion of these efforts provides a mechanical and electrical design that can be readily adapted to site-specific conditions with additional engineering development comparable to costs associated with conventional turbine designs.

\section{Results and Findings}

Computational results for pressure change rates and shear within the runner passage were similar in the original and final turbine geometries, while predicted pressures were higher for the final turbine at the blade leading edges and within the draft tube cone below the deflector. These pressure improvements resulted in a new turbine setting that is over 9 feet $(2.7 \mathrm{~m})$ higher when compared to that originally planned for the pilot site. The final turbine geometry and resulting flow environments are expected to further enhance the fish passage characteristics of the turbine when compared to the original conceptual design due to improved flow alignment at the blade leading edges, improved runner-draft tube interaction, increased minimum pressures within the water passage, and improved component alignment between the stay vanes with the wicket gates. Computational results for the final hydraulic shapes were shown to improve turbine efficiencies by over $6 \%$ at the selected design condition when compared to the original concept. Prior to the release of the hydraulic components for model manufacture, finite element analysis (FEA) calculations were conducted for the stay vanes, wicket gates, and runner to verify that structural design criteria for stress and deflections were met. Performance of a physical model of the turbine tested for power and efficiency, cavitation, runaway speed, axial thrust, radial thrust, pressure pulsations, and wicket gate torque indicated that all parameters were observed to fall within ranges expected for conventional radial flow machines. Based on these measurements, the expected efficiency peak for the prototype application is almost 94\%. The preliminary turbine cost for the design specification is $\$ 1450 / \mathrm{kW}$ with a total supply schedule of 28 months. This supply includes turbine, generator, unit controls, limited balance of plant equipment, field installation, and commissioning.

\section{Challenges and Objectives}

The primary challenge for this project was to complete the requisite engineering necessary to convert a conceptual turbine design into a design that could be built and commercially 
competitive with existing hydropower turbine designs. The overall objective was to provide a turbine design ready for actual manufacture, field deployment, and testing. Future demonstration of the commercial and fish protection viability of the Alden turbine is vital for the ultimate acceptance of the Alden turbine by the resource and regulatory agencies, non-governmental organizations, and the hydropower industry.

\section{Applications, Value, and Use}

Hydropower planners, managers, and developers will find the information provided to be of value for planning new development, for adding capacity to existing projects and non-power dams, and for harnessing lost power associated with minimum flow (either below the dam or into the bypass reach for environmental values) and non-turbine discharges for downstream fish passage. The Alden turbine may also be used as a retrofit option where existing downstream fish passage mortality associated with conventional turbine operation is unacceptable to licensing stakeholders.

\section{Approach}

Starting with the previously engineered and researched conceptual design, computational fluid dynamics was used for the hydraulic development of the turbine and was accomplished with engineering design modifications to the spiral case, distributor (stay vanes and wicket gates), runner, and draft tube to improve turbine performance while maintaining high fish passage survival. A scaled (1:8.71) physical model of the turbine was manufactured and tested with data collected for power and efficiency, cavitation, runaway speed, axial thrust, radial thrust, pressure pulsations, and wicket gate torque. These data were used to determine the final sizing of the supporting mechanical and balance of plant equipment, estimate cost, and develop the supply schedule.

\section{Keywords}

Advanced hydro turbines

Downstream fish passage

Environmentally-enhanced turbines

Fish-friendly turbines

Hydropower 


\section{ABSTRACT}

The Alden turbine was developed through the U.S. Department of Energy's (DOE's) former Advanced Hydro Turbine Systems Program (1994-2006) and, more recently, through the Electric Power Research Institute (EPRI) and the DOE's Wind \& Water Power Program. The primary goal of the engineering study described here was to provide a commercially competitive turbine design that would yield fish passage survival rates comparable to or better than the survival rates of bypassing or spilling flow. Although the turbine design was performed for site conditions corresponding to $92 \mathrm{ft}(28 \mathrm{~m})$ net head and a discharge of $1500 \mathrm{cfs}(42.5 \mathrm{cms})$, the design can be modified for additional sites with differing operating conditions. During the turbine development, design modifications were identified for the spiral case, distributor (stay vanes and wicket gates), runner, and draft tube to improve turbine performance while maintaining features for high fish passage survival. Computational results for pressure change rates and shear within the runner passage were similar in the original and final turbine geometries, while predicted minimum pressures were higher for the final turbine. The final turbine geometry and resulting flow environments are expected to further enhance the fish passage characteristics of the turbine. Computational results for the final design were shown to improve turbine efficiencies by over $6 \%$ at the selected operating condition when compared to the original concept. Prior to the release of the hydraulic components for model fabrication, finite element analysis calculations were conducted for the stay vanes, wicket gates, and runner to verify that structural design criteria for stress and deflections were met.

A physical model of the turbine was manufactured and tested with data collected for power and efficiency, cavitation limits, runaway speed, axial and radial thrust, pressure pulsations, and wicket gate torque. All parameters were observed to fall within ranges expected for conventional radial flow machines. Based on these measurements, the expected efficiency peak for prototype application is 93.64\%. These data were used in the final sizing of the supporting mechanical and balance of plant equipment. The preliminary equipment cost for the design specification is $\$ 1450 / \mathrm{kW}$ with a total supply schedule of 28 months. This equipment supply includes turbine, generator, unit controls, limited balance of plant equipment, field installation, and commissioning.

Based on the selected head and flow design conditions, fish passage survival through the final turbine is estimated to be approximately $98 \%$ for 7.9 -inch (200-mm) fish, and the predicted survival reaches $100 \%$ for fish 3.9 inches $(100 \mathrm{~mm})$ and less in length. Note that fish up to 7.9inches $(200 \mathrm{~mm})$ in length make up more than $90 \%$ of fish entrained at hydro projects in the United States. Completion of these efforts provides a mechanical and electrical design that can be readily adapted to site-specific conditions with additional engineering development comparable to costs associated with conventional turbine designs. 



\section{CONTENTS}

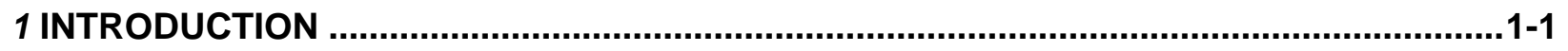

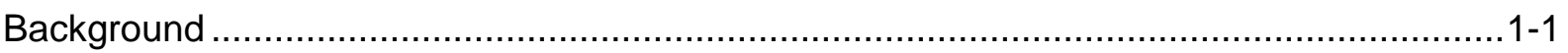

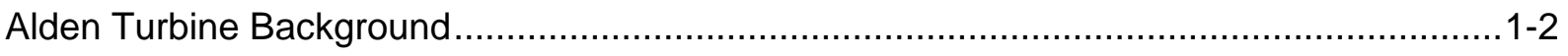

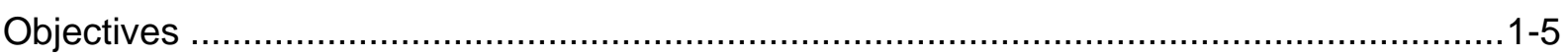

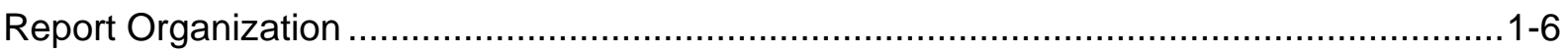

2 HYDRAULIC DEVELOPMENT: COMPUTATIONAL ANALYSIS OF GEOMETRY MODIFICATIONS FOR FISH FRIENDLINESS AND TURBINE PERFORMANCE ..................2-1

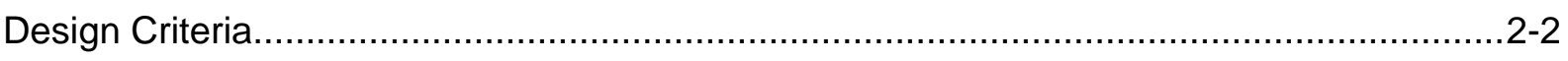

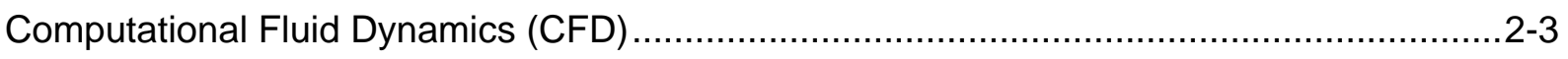

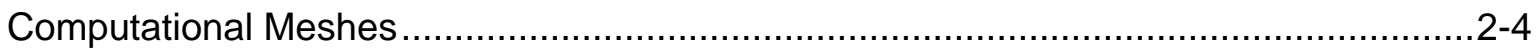

Calculation Methodology and Boundary Conditions .......................................... $2-4$

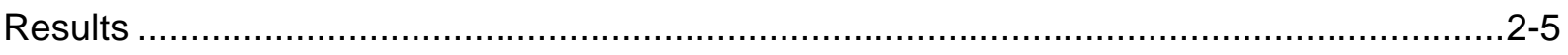

Overall Assessment of Original Alden Turbine .................................................... $2-6$

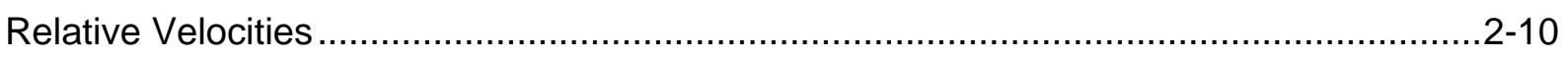

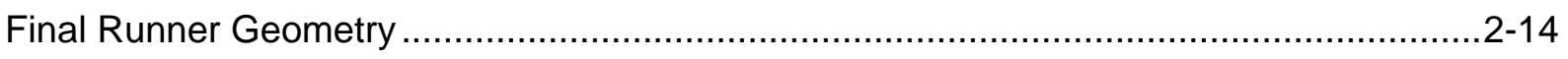

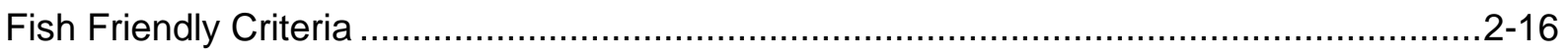

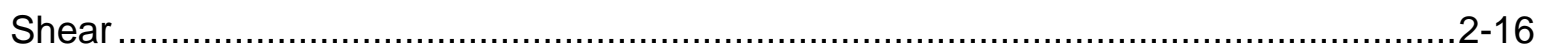

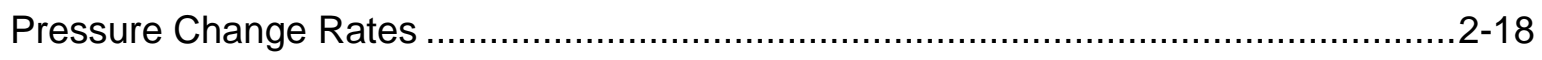

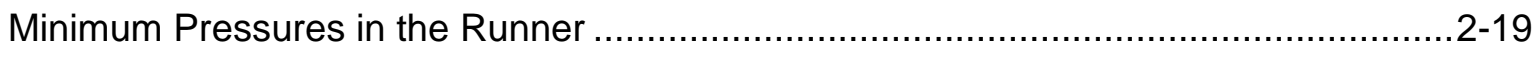

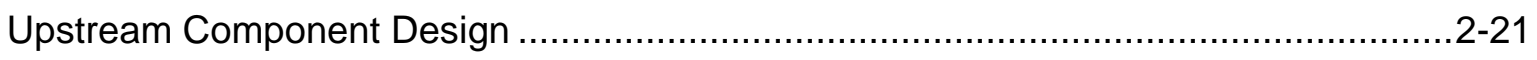

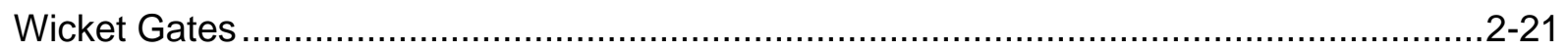

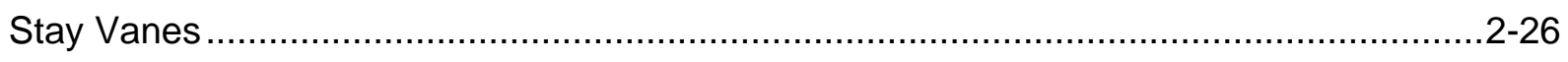

Distributor Velocity Documentation ............................................................... $2-28$

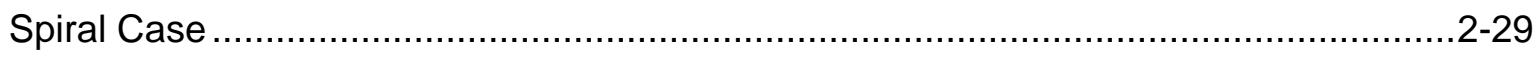

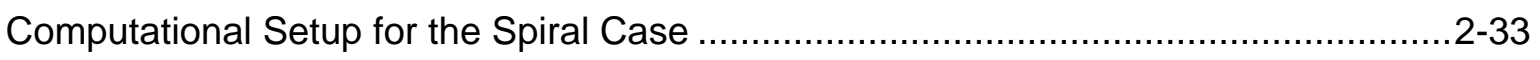

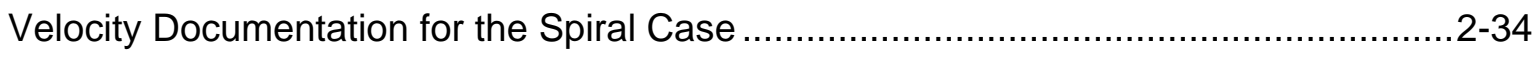

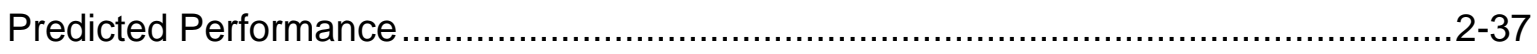


Runner and Draft Tube Performance ......................................................................

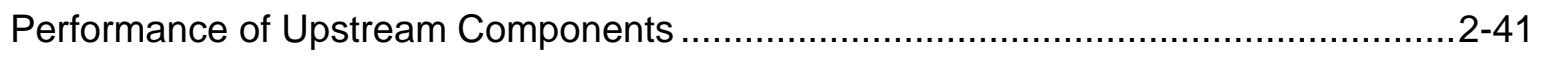

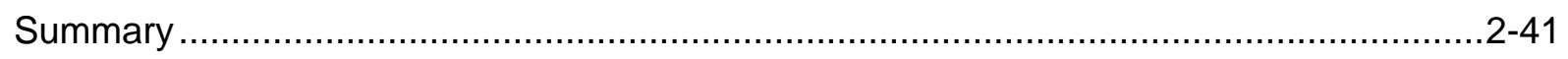

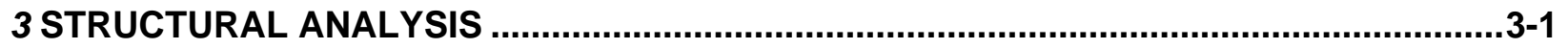

Turbine Component Mechanical Design Summary ………..........................................

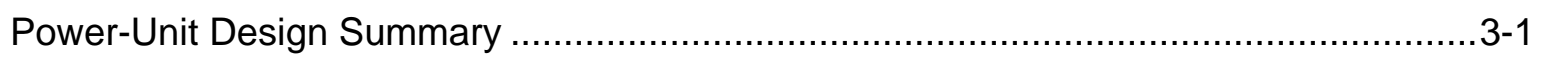

Other Component Design Considerations ........................................................... $3-2$

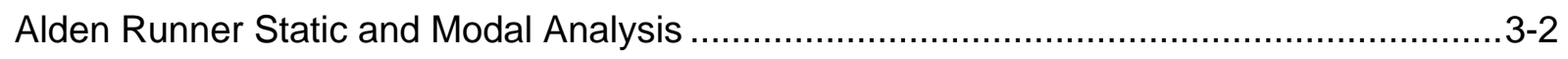

Static Finite Element Analysis ……….............................................................

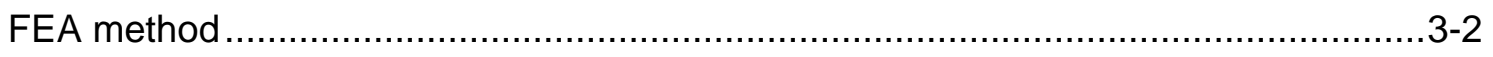

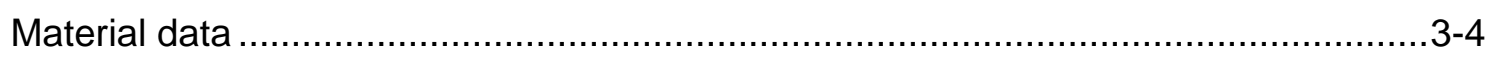

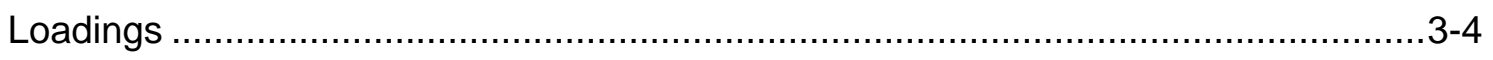

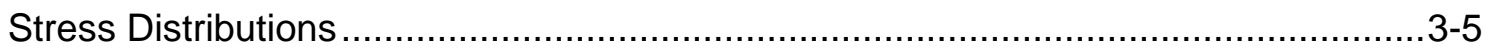

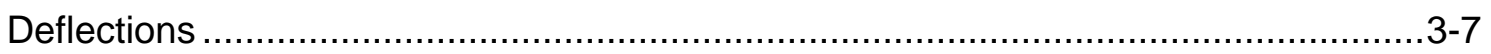

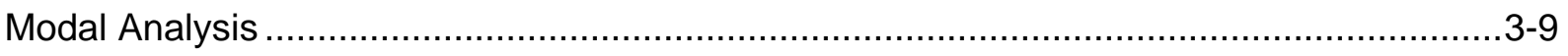

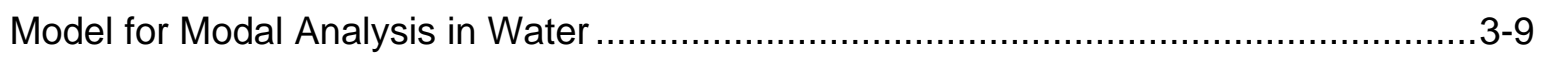

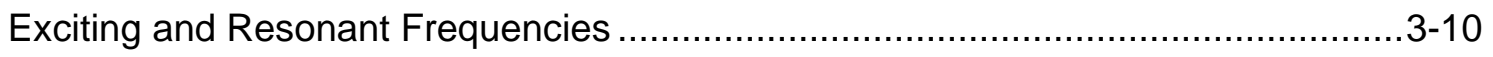

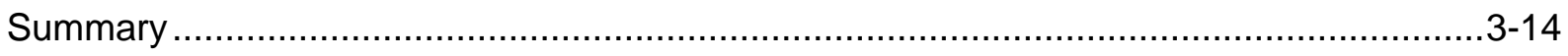

FEA Report - Shaft Critical Bending Speed and Bending Line Analysis ..........................3-15

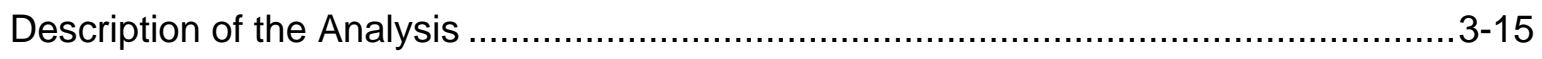

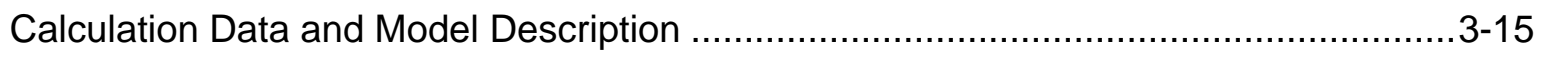

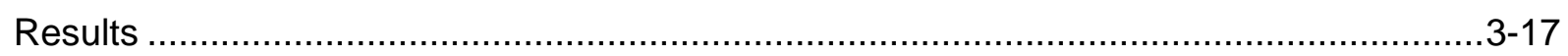

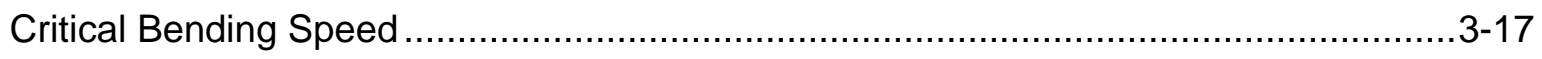

Static Bending Line

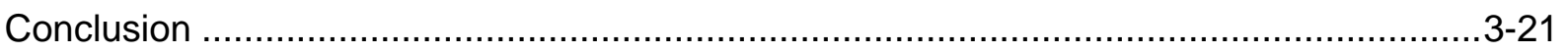

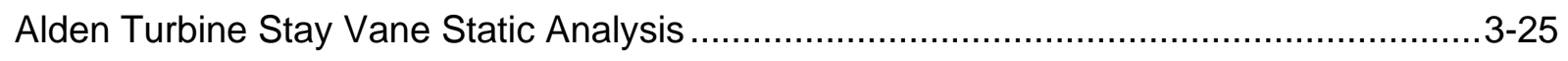

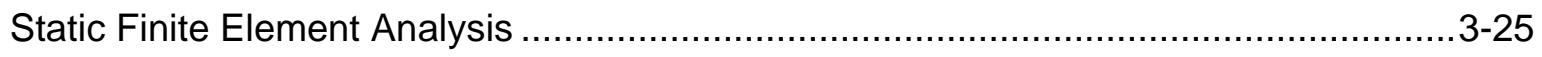

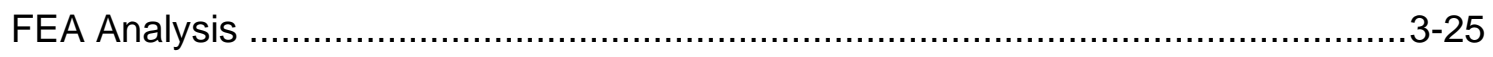

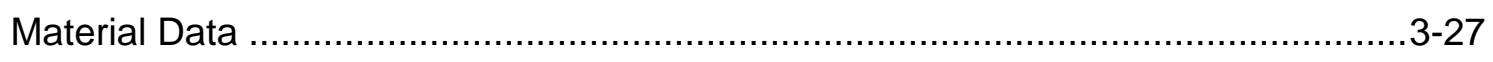

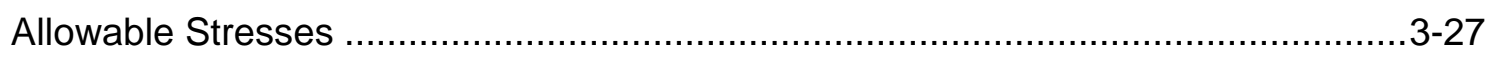

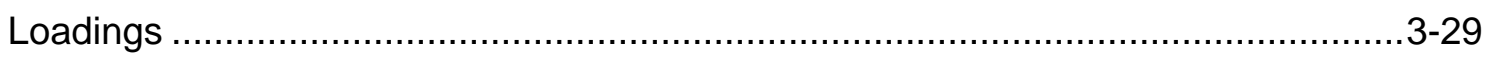

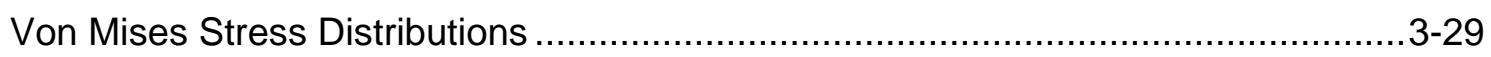

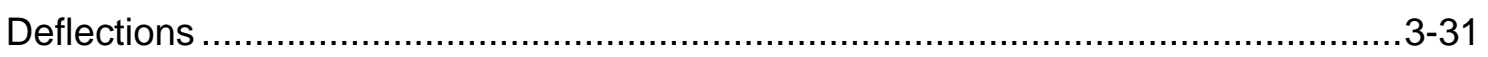

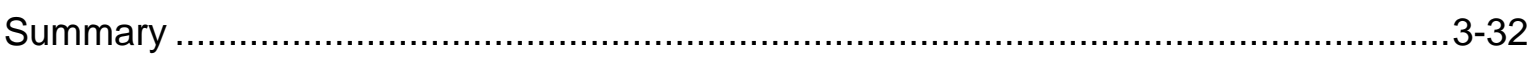




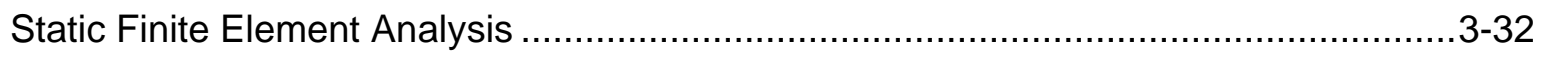

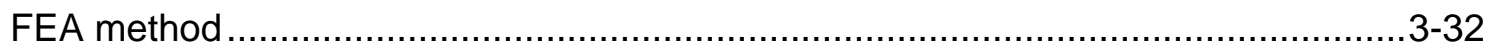

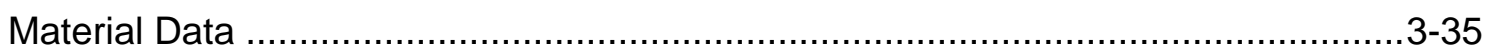

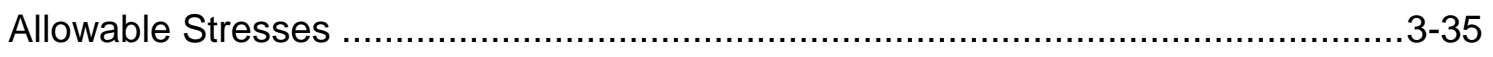

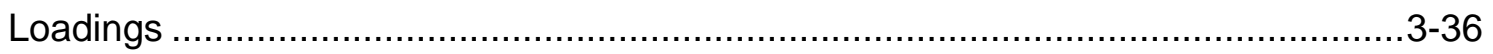

Von Mises Stress Distributions .......................................................................

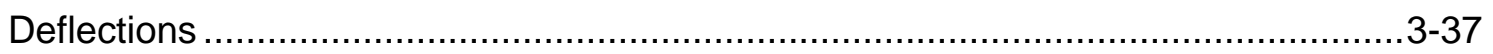

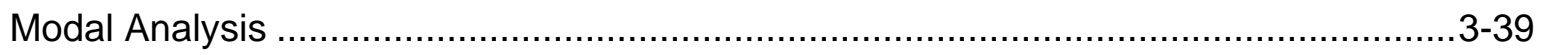

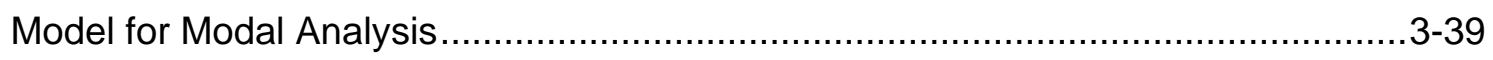

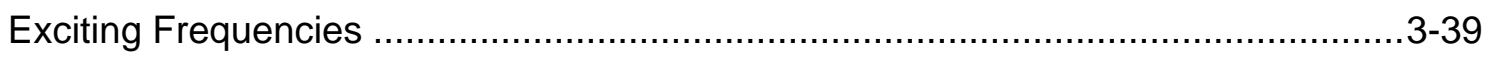

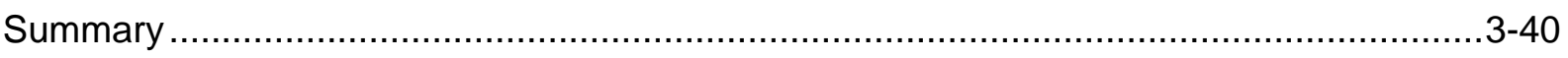

4 MODEL TEST REPORT

Statement of Purpose and Summary of Results …….............................................. 4-2

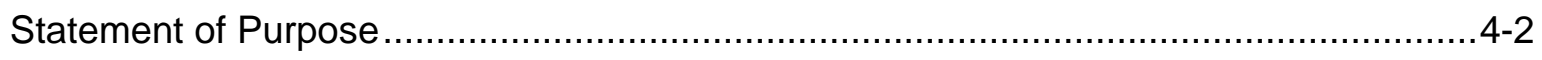

Performance Characteristics ……….......................................................... $4-3$

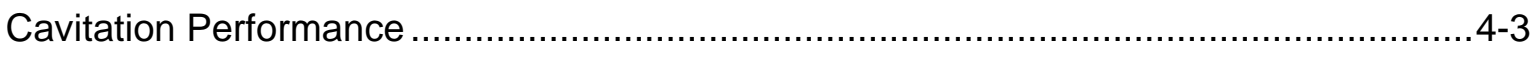

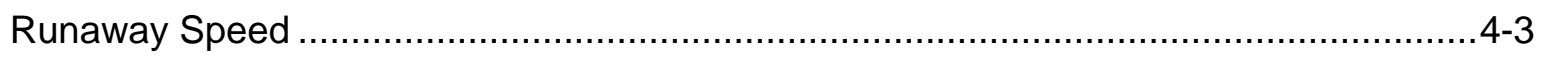

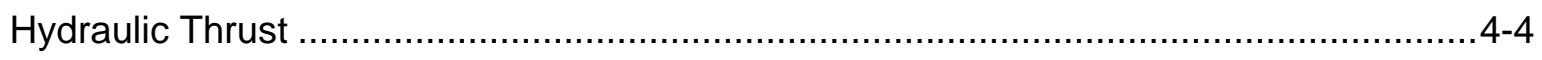

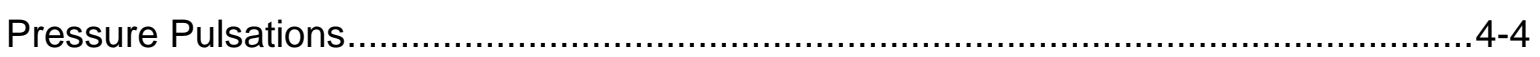

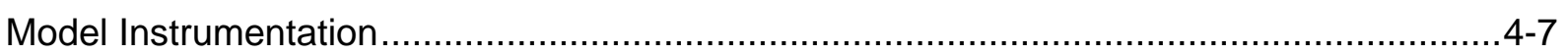

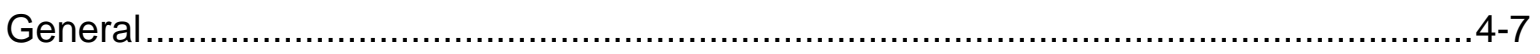

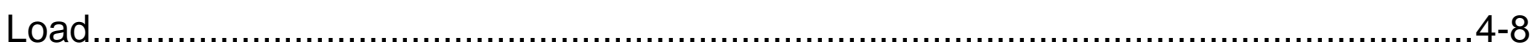

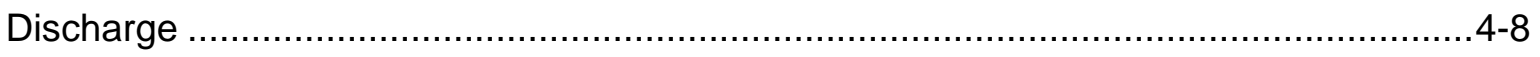

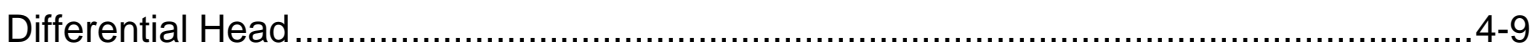

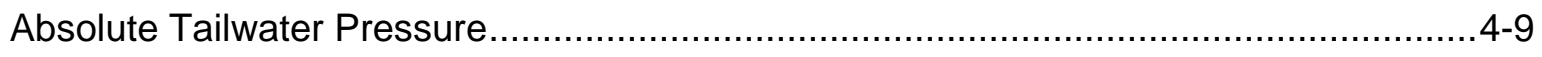

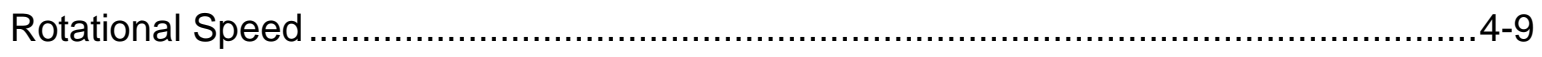

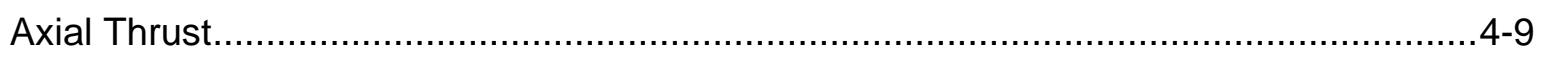

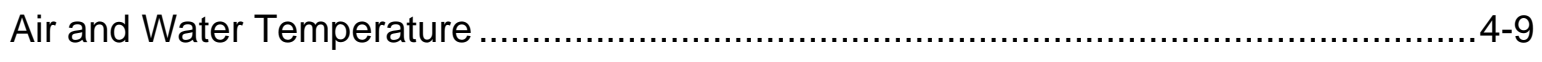

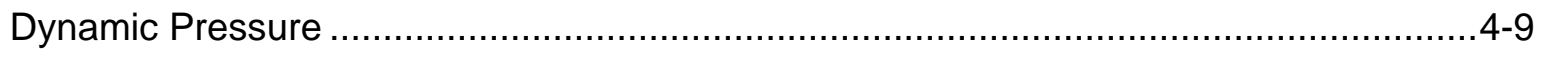

Wicket Gate Position ..........................................................................................

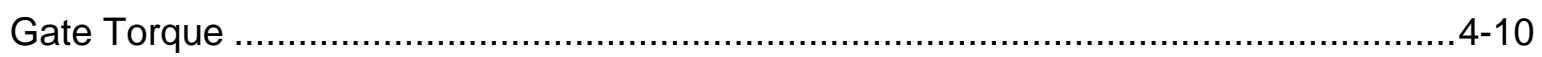

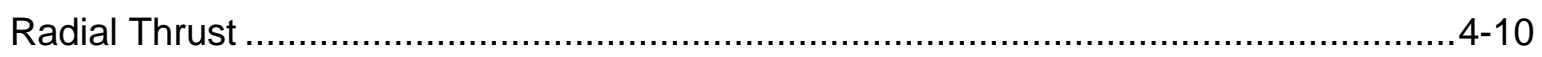

Plant Conditions, Nomenclature and Test Procedures ................................................ $4-12$

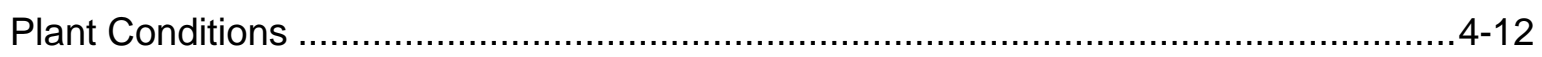




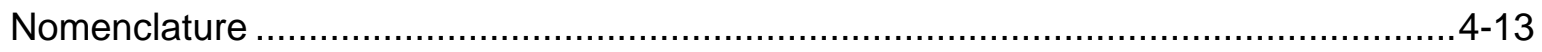

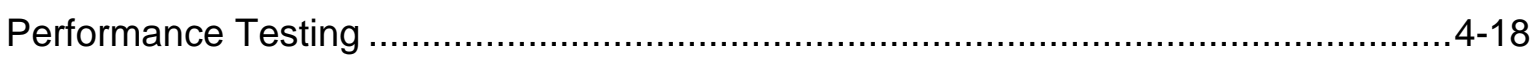

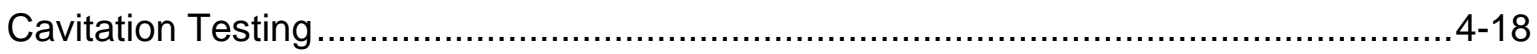

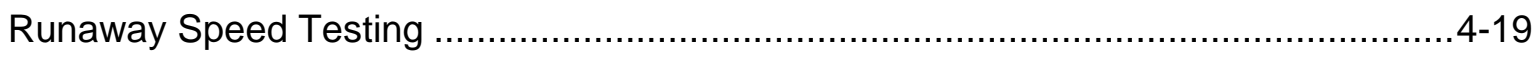

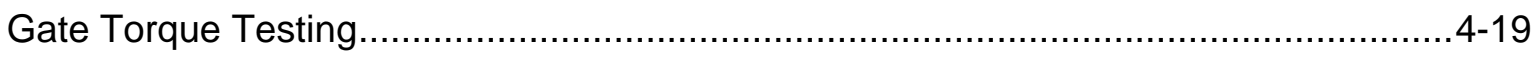

Pressure Pulsation Testing............................................................................. 4-21

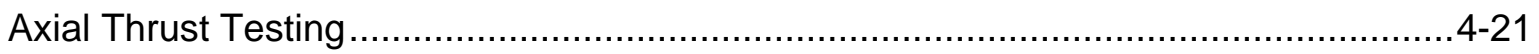

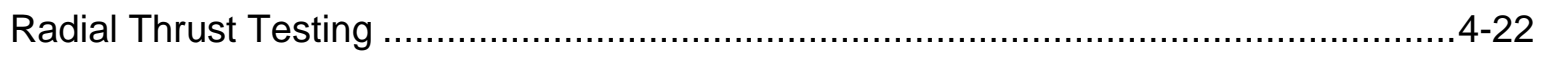

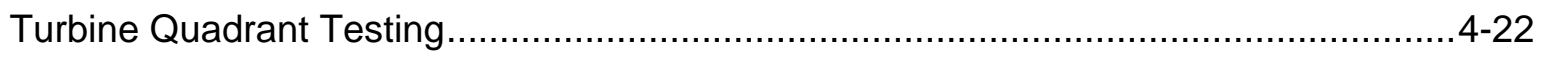

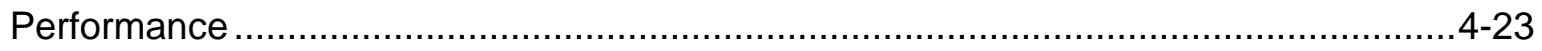

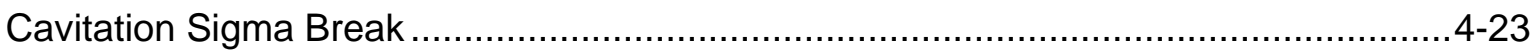

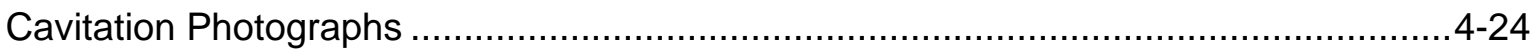

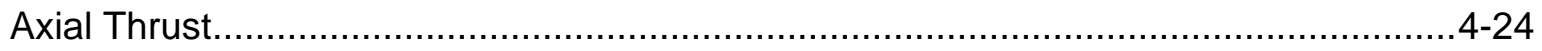

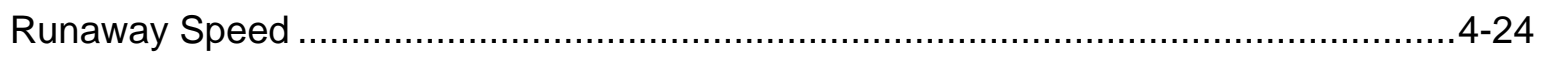

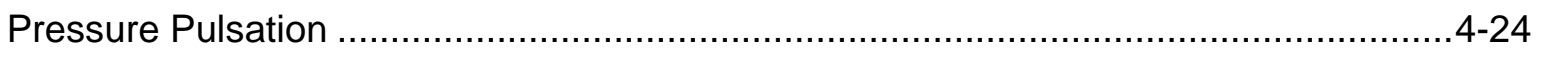

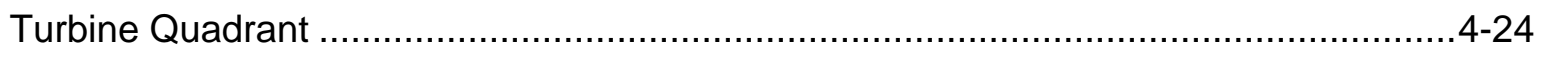

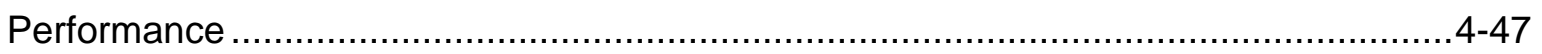

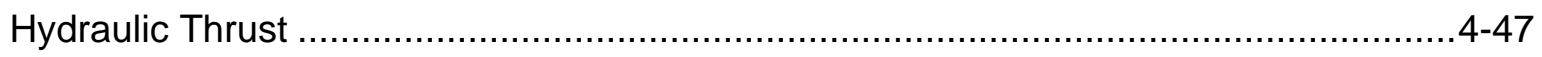

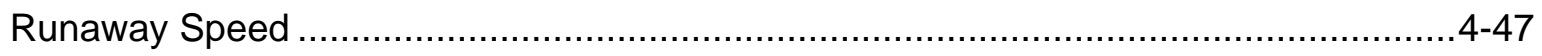

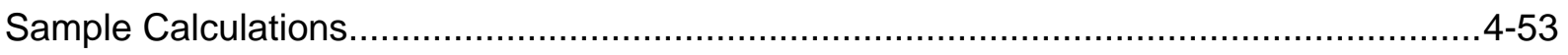

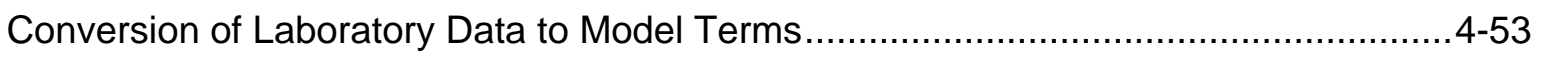

Conversion of Data from Model to Prototype ………......................................... $4-59$

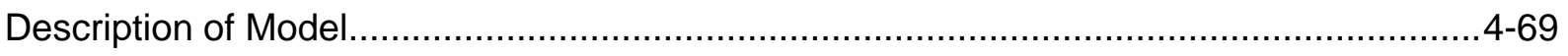

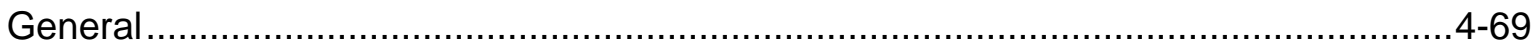

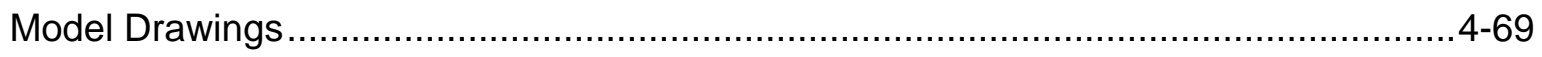

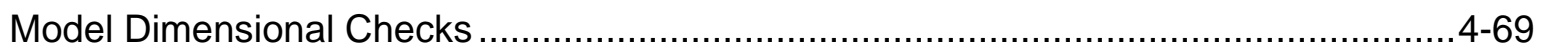

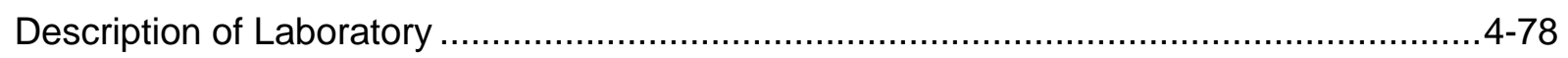

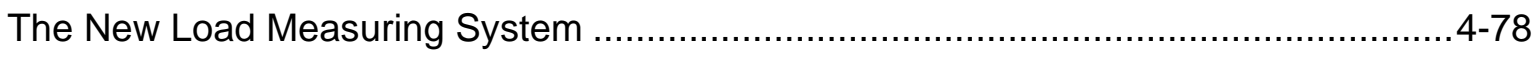

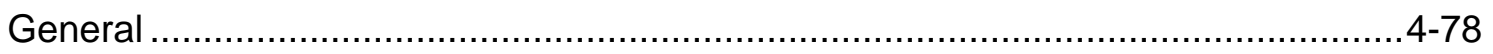

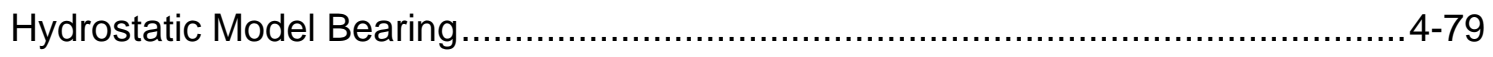

Hydrostatic Support For Dynamometer Base ………...................................... $4-80$

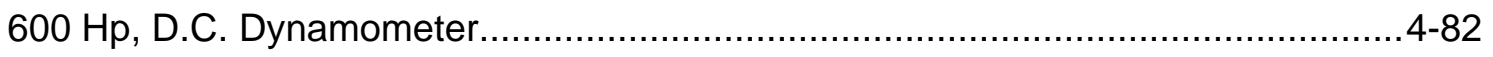

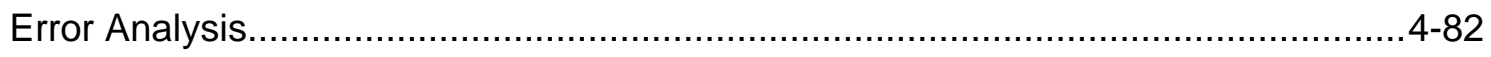

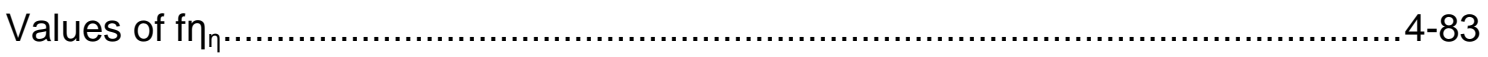

xvi 


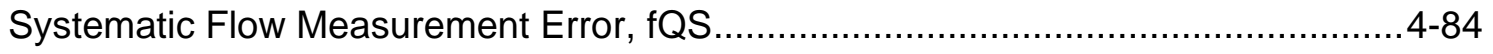

Systematic Head Measurement Error, fHS ............................................... 4-84

Systematic Torque Measurement Error, fTS ........................................... $4-85$

Systematic Speed Measurement Error, fNS ................................................ 4-85

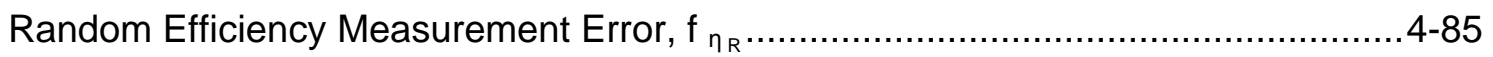

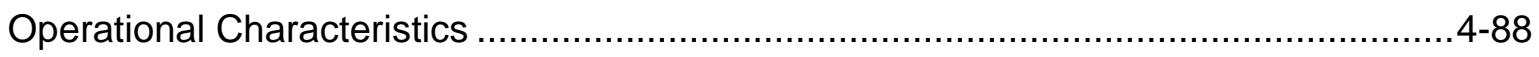

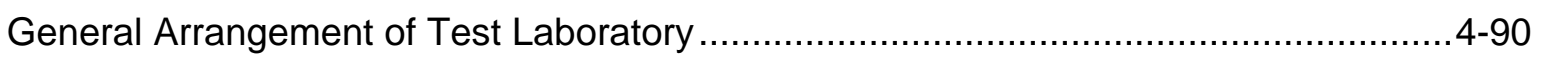

Test Circuit and Components ....................................................................... $4-91$

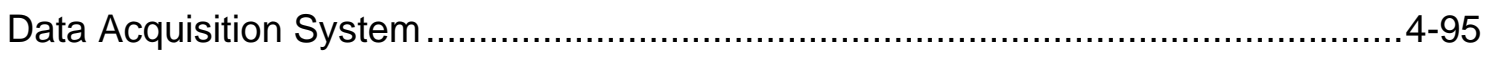

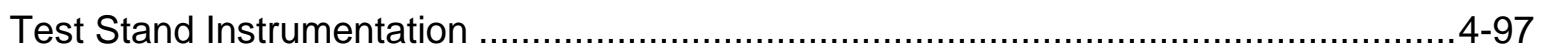

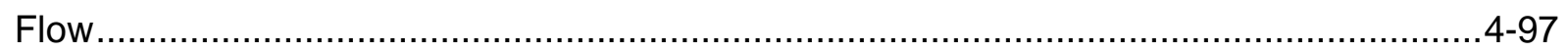

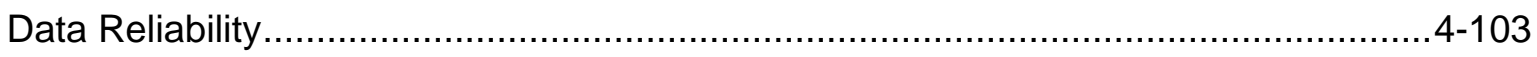

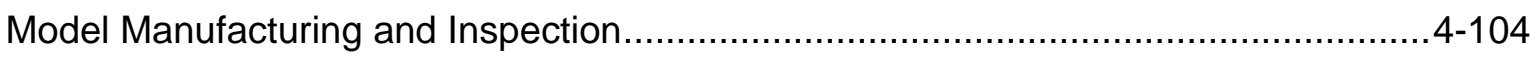

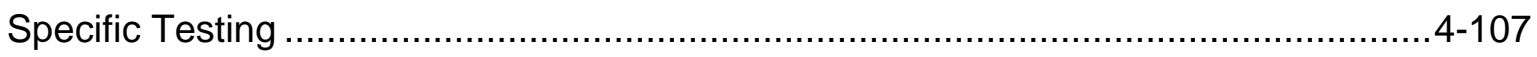

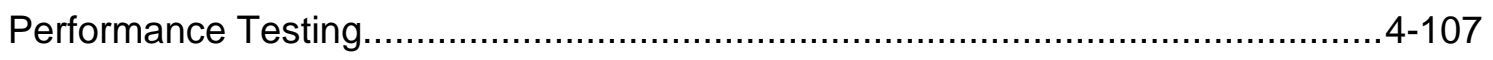

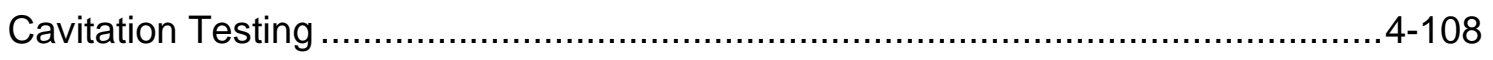

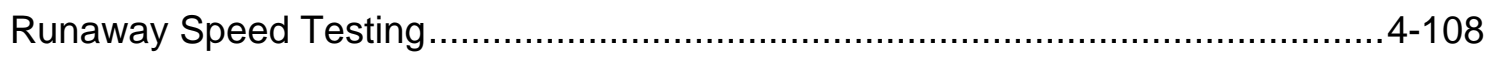

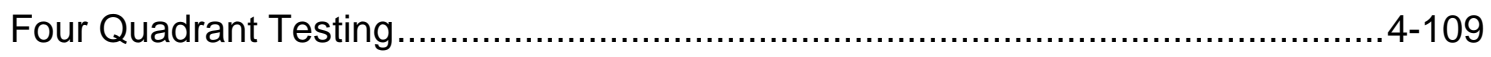

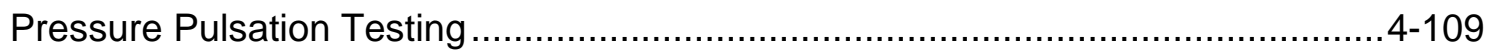

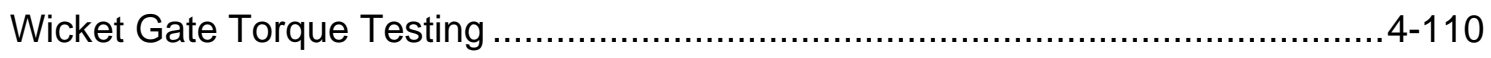

Kaplan Turbine Blade Spindle Torque .................................................... $4-110$

\section{CFD SIMULATIONS OF ALDEN TURBINE AND COMPARISON WITH PHYSICAL}

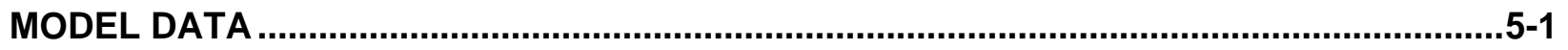

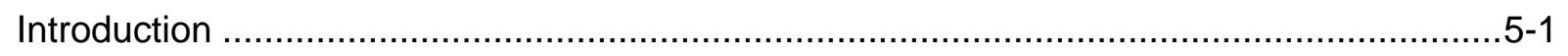

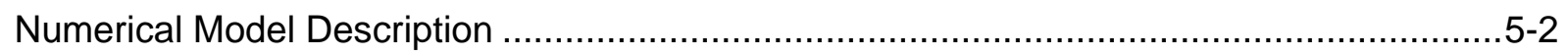

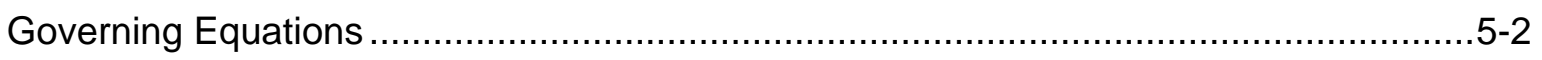

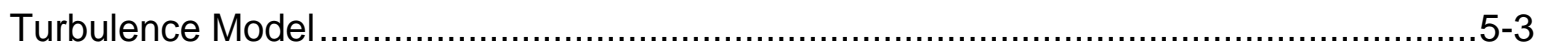

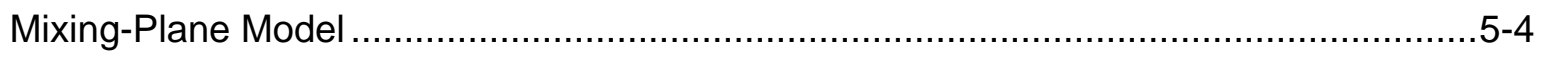

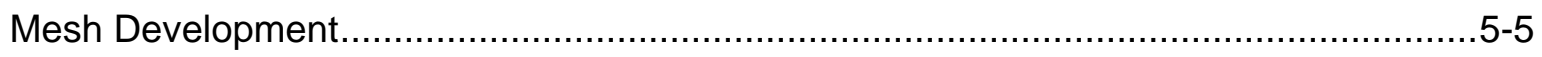

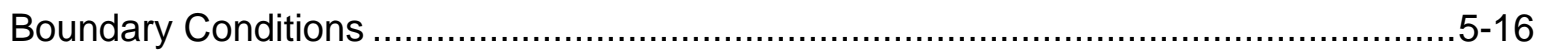

Method to Calculate Turbine Efficiency and to Compile Hill Chart.................................5-18

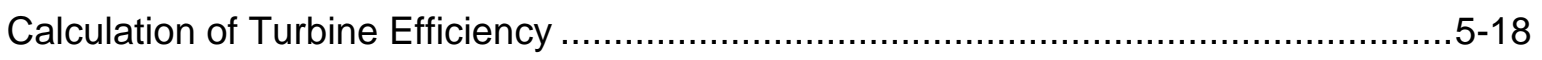

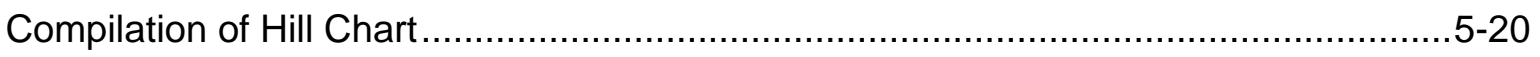

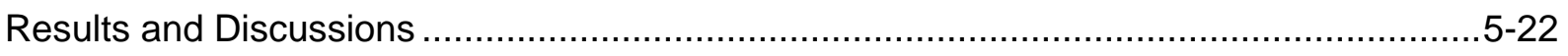


Wicket Gate Opening Angle of 18 Degrees......................................................... 5-22

Wicket Gate Opening Angle of 20 Degrees........................................................ 5-24

Wicket Gate Opening Angle of 21.1 Degrees....................................................... 5-24

Wicket Gate Opening Angle of 26 Degrees.......................................................... 5-27

Hill Chart Based on CFD and Comparison with Physical Test Data ............................5-30

Impact of Fluid in Space Between Shroud and Casing and Space Under Head

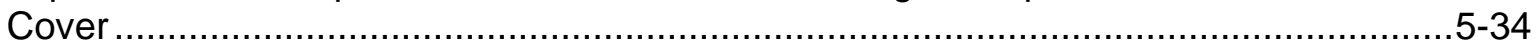

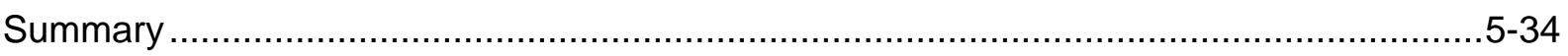

\section{ALDEN ADVANCED HYDRO TURBINE DEVELOPMENT: POWER UNIT SCOPE DEFINITION, PRICING, AND SCHEDULE}

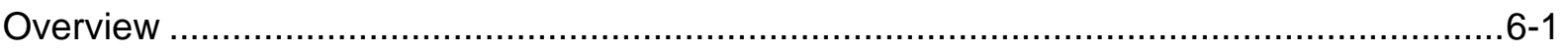

Equipment Description Overview .......................................................................... $6-1$

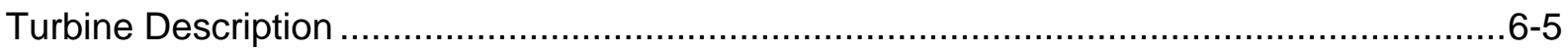

Runner

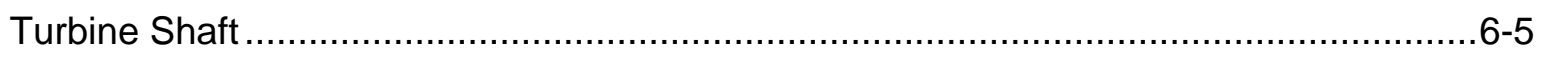

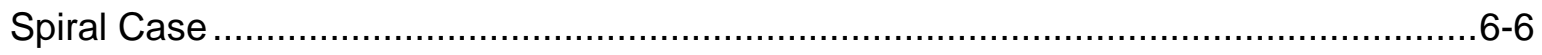

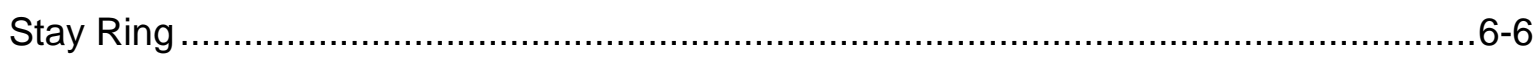

Wicket Gate Mechanism Assembly .....................................................................6-6

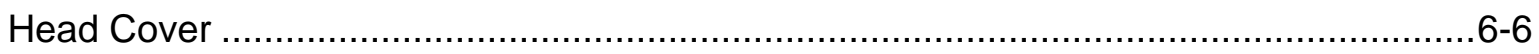

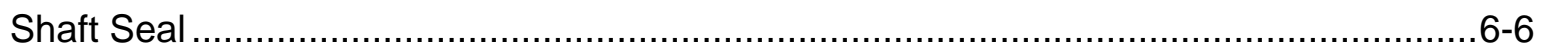

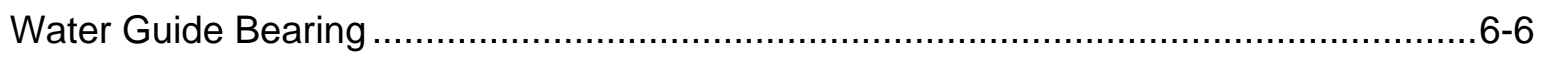

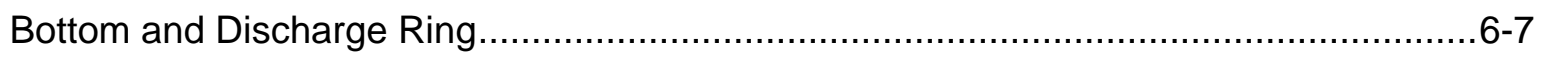

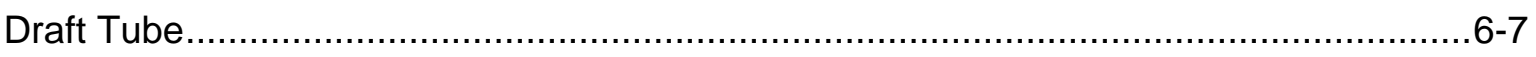

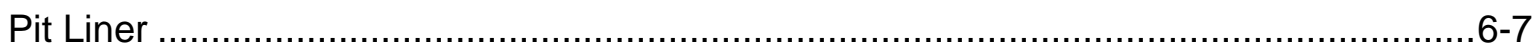

Installation and Maintenance Tooling ..................................................................

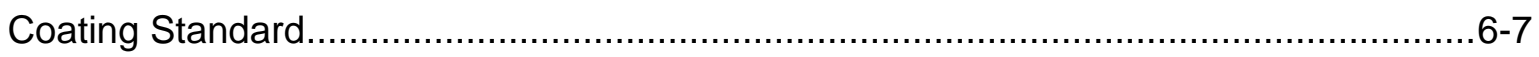

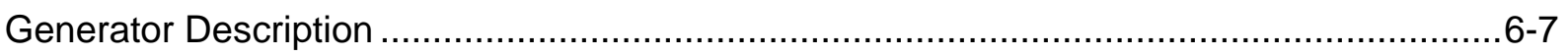

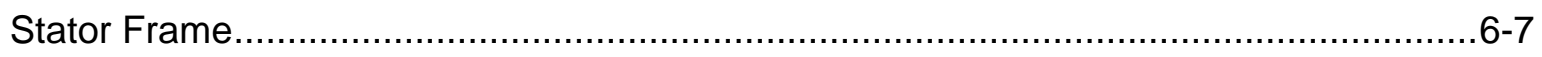

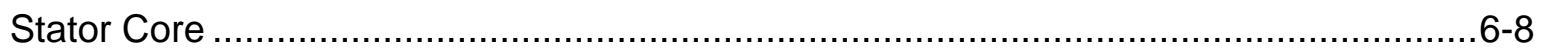

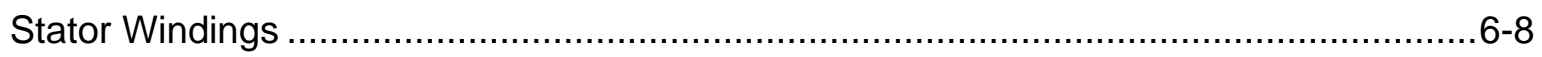

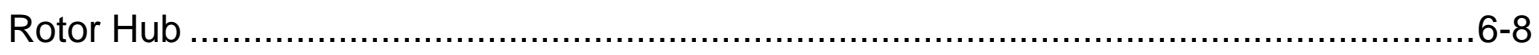

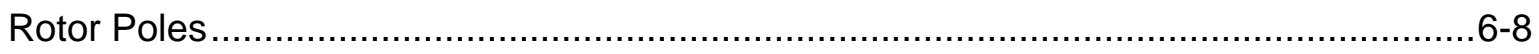

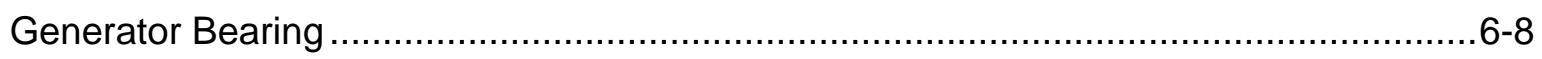

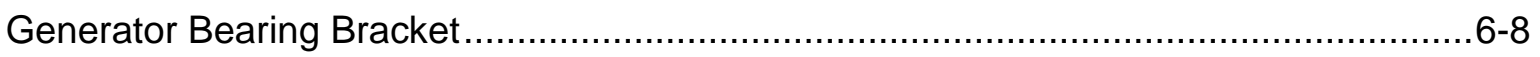




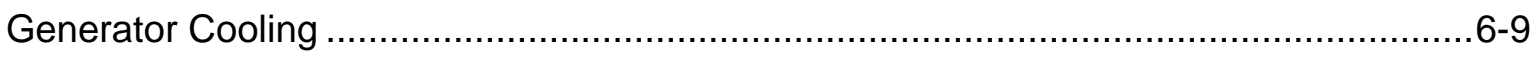

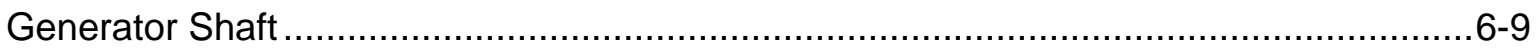

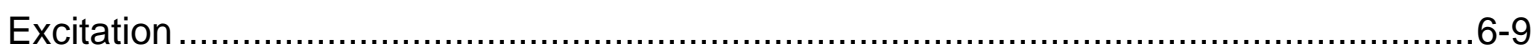

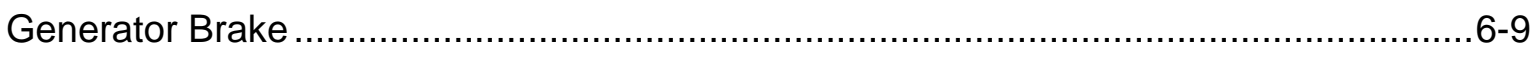

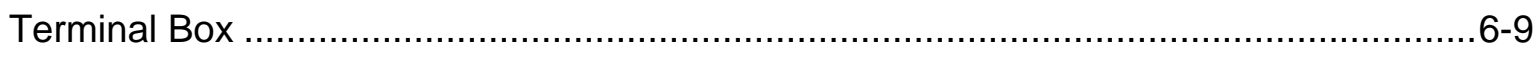

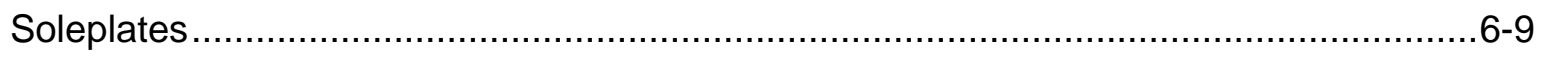

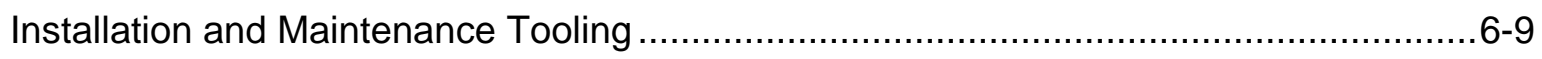

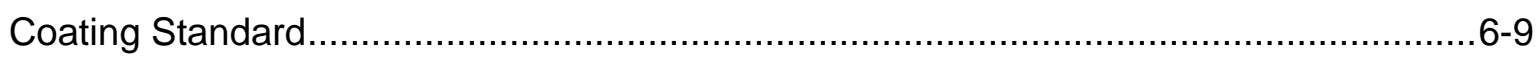

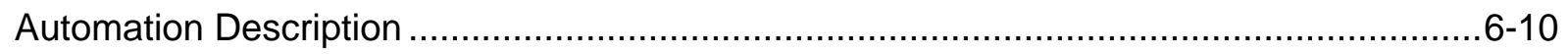

Unit Control and Digital Governor Panel .........................................................

Generator Floor Remote I/O Panel.................................................................. 6-10

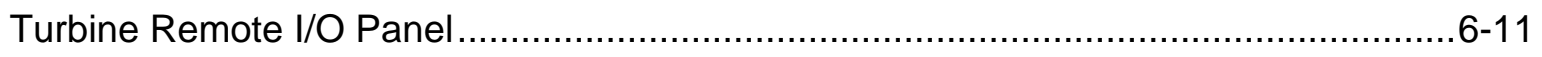

Miscellaneous Remote I/O Panel ........................................................................... 6-11

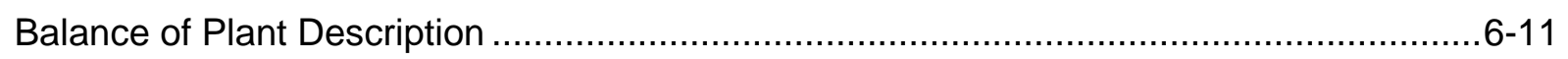

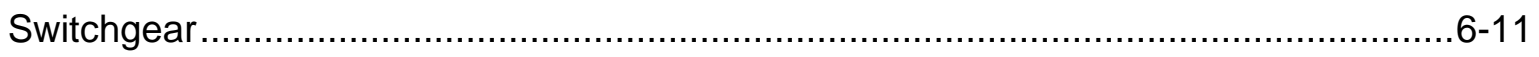

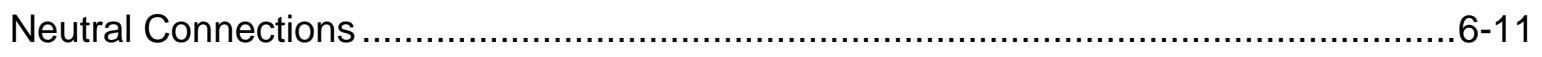

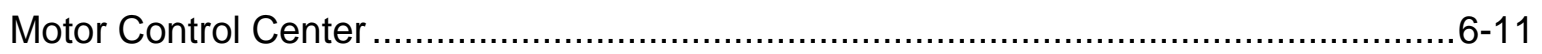

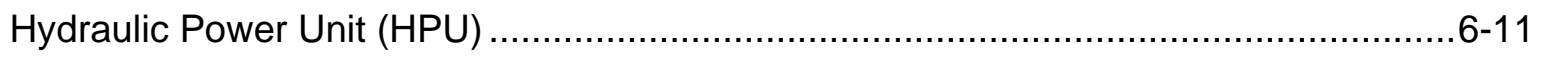

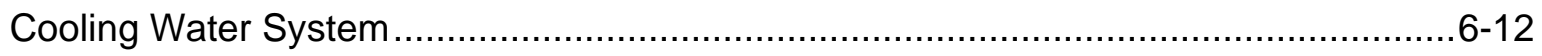

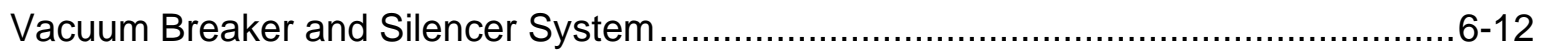

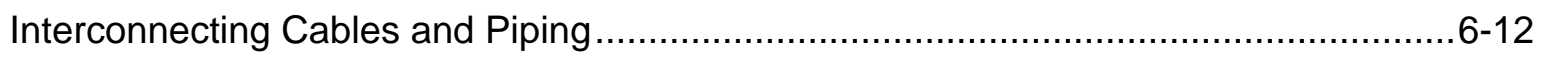

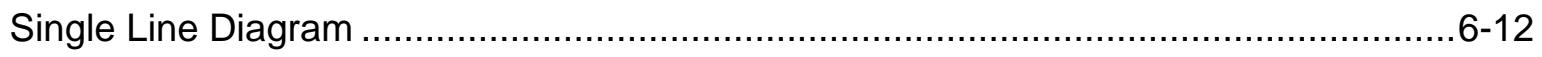

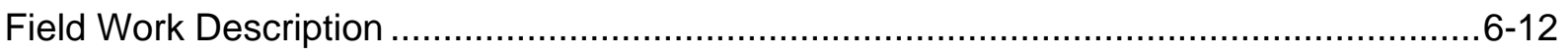

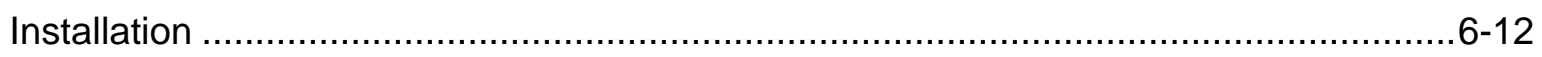

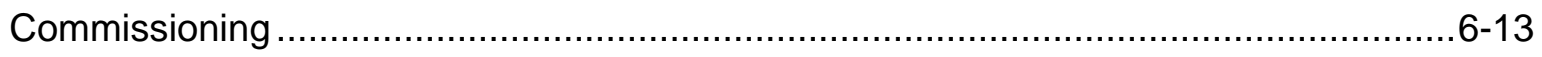

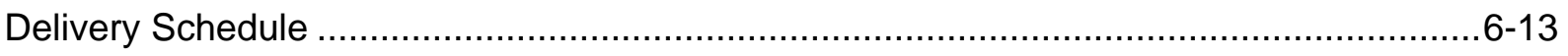

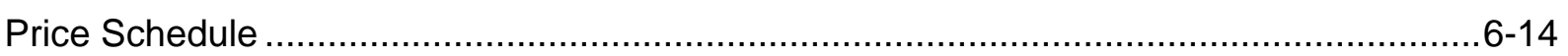

Pricing

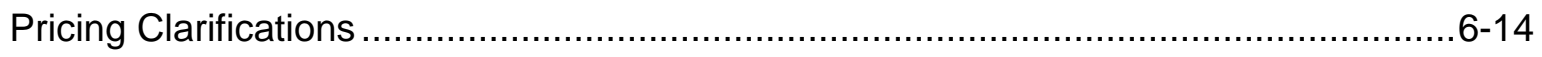

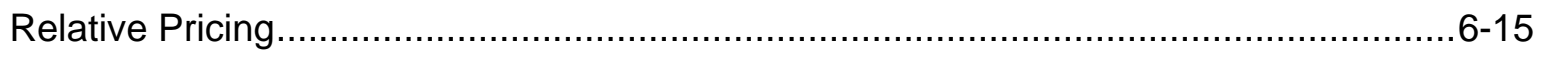

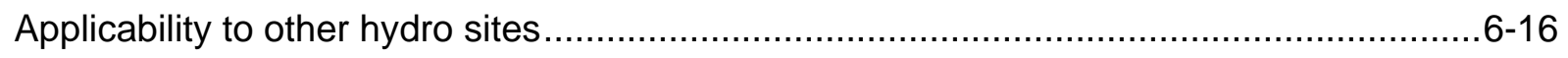

7 SUMMARY AND NEXT STEPS

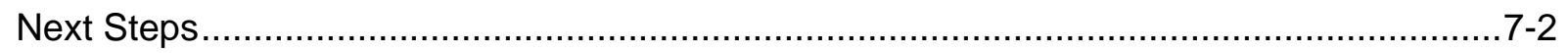




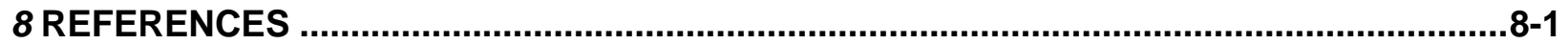




\section{LIST OF FIGURES}

Figure 1-1 Cutaway View of Alden Turbine

Figure 1-2 Computer Modeling of Alden Turbine Runner ............................................ 1-4

Figure 1-3 Photo of Assembled Model Turbine Runner with Band (prior to testing).................1-5

Figure 1-4 Work flow diagram for current Alden Turbine investigation

Figure 2-1 Alden Turbine Geometry Showing (i) Side and (ii) Plan View of Longer, Wrapping Blades Utilized to Minimize Pressure Change Rates and Shear through the Runner

Figure 2-2 Existing School Street Power House. The dashed box indicates the planned location for installation of the Alden turbine.

Figure 2-3 Alden Computational Domain Showing Original (i) Distributor, (ii) Runner, and (iii) Draft tube.

Figure 2-4 Computational Meshes Showing Original (i) Distributor, (ii) Runner, and (iii) Draft tube.

Figure 2-5 Normalized Axial (blue) and Tangential Velocity (red) Profiles for the Original Alden Runner at the Selected Design Condition (Hnet $=92 \mathrm{ft}, \mathrm{Q}=1500 \mathrm{cfs}$ ). Note that these velocity profiles are extracted from an evaluation plane that is located just downstream of the blade trailing edges.

Figure 2-6 Calculated Sigma Values on the Original Alden blades at the Selected School Street Design Condition ( $H_{\text {net }}=92 \mathrm{ft}, Q=1500 \mathrm{cfs}$ ). The horizontal red line represents the value for plant sigma.

Figure 2-7 Patterns of (i) Velocity and (ii) Streamlines Showing Incoming Flow Alignment at the Original Blade Leading Edge for the School Street Design Condition $\left(H_{n e t}=\right.$ $92 \mathrm{ft}, Q=1500 \mathrm{cfs})$.

Figure 2-8 Calculated Relative Velocities at the Entrance to the Original Alden Runner as Indicated in the Upper Left Schematic $\left(H_{n e t}=92 \mathrm{ft}, Q=1500 \mathrm{cfs}\right)$.

Figure 2-9 Meridional Curves for (i) Original and (ii) Final Alden Runner Geometry

Figure 2-10 Calculated Relative Velocities at the Entrance to the Final Alden Runner $\left(H_{\text {net }}=92 \mathrm{ft}, Q=1500 \mathrm{cfs}\right)$.

Figure 2-11 Original (Top Row) and Final (Bottom Row) Alden Turbine Geometry Showing (i) Side and (ii) Plan Views.

Figure 2-12 Computed Shear through the Original Alden Runner at the Selected Design Condition (Hnet $=92 \mathrm{ft}, \mathrm{Q}=1500 \mathrm{cfs}$ ).

Figure 2-13 Computed Shear through the Final Alden Runner at the Selected Design Condition $\left(H_{\text {net }}=92 \mathrm{ft}, Q=1500 \mathrm{cfs}\right)$.

Figure 2-14 Calculated Prototype Pressure Change Rate Iso-surfaces Showing $\Delta P=$ $500 \mathrm{psi} \mathrm{s}^{-1}$ for the (i) Original and (ii) Final Alden Runner $\left(H_{n e t}=92 \mathrm{ft}, Q=1500 \mathrm{cfs}\right) \ldots . . .2-19$ 
Figure 2-15 Calculated prototype minimum pressures showing $P_{\min }=7.4$ psia for the (i) original and (ii) final Alden runner $\left(H_{n e t}=92 \mathrm{ft}, Q=1500 \mathrm{cfs}\right.$ ).

Figure 2-16 Plan View of the Original Alden Turbine Showing Wicket Gate Position Corresponding to the Selected Design Point [wicket gate rotation $(\Delta \gamma)=18.4^{\circ}$ ].

Figure 2-17 Wicket Gate Leaf Shapes and Pin Circle Locations for the Original (Dashed) and Final (Solid) Alden Turbine at the (i) Closed Position and (ii) the Position Corresponding to the Selected Design Point. Note that the gate orientation is shown in the counter-clockwise direction, which is the standard orientation for computations at Voith Hydro.

Figure 2-18 Wicket Gate Leaf Shapes for the (i) Original and (ii) Final Alden Turbine, Illustrating the Difference in Nose Thickness and the Curved Versus Straight Profiles.....

Figure 2-19 Stay Vane Shapes for the (i) Original and (ii) Final Alden Turbine, Illustrating the Difference in Nose Thickness

Figure 2-20 Final Stay Vane - Wicket Alignment Showing Reduced Gap at the Gate Opening corresponding to the Selected Operating Point $\left(H_{n e t}=92 \mathrm{ft}, Q=1500 \mathrm{cfs}\right) \ldots . . .2-26$

Figure 2-21 Velocity Contours for the (i) Original and (ii) Final Distributor at the Selected Design Condition $\left(H_{\text {net }}=92 \mathrm{ft}, Q=1500 \mathrm{cfs}\right)$

Figure 2-22 (i) Plan and (ii) Side Views of the Original Alden Spiral Case

Figure 2-23 Side views of Original and Final Alden Spiral Case Showing (i) Circular Cross Cection and (ii) Rectangular Cross Section....

Figure 2-24 Pan Views of (i) Original and (ii) Final Alden Spiral Case Showing Equal Widths of $3.25 \mathrm{D}$.

Figure 2-25 (i) Plan and (ii) Side Views of Transitional Inlet Piece Necessary to Connect Circular Penstock with Rectangular Spiral Case.

Figure 2-26 Computational Meshes Showing (i) Plan and (ii) Side Views of Final Alden Spiral Case and Distributor.

Figure 2-27 Computed Velocity Distributions Evaluated on Several Vertical Planes throughout the Final Alden Spiral Case

Figure 2-28 Computed Velocity Distributions Evaluated on Several Horizontal Planes throughout the Final Alden Spiral Case

Figure 2-29 Streamline Patterns within the Final Alden Spiral Case and Distributor..... 2-35

Figure 2-30 Computed Axial and Tangential Velocity Extracted downstream of the (i) Original and (ii) Final Alden Runner Blades....

Figure 2-31 Predicted Draft Tube Flow Characteristics for the (i) Original and (ii) Final Alden Runner ....

Figure 2-32 Draft Tube Flow Visualization for the (i) Original and (ii) Final Alden Runner. .....2-38

Figure 3-1 Meshed Model ...................................................................................

Figure 3-2 Meshed Sector with Boundary Conditions...................................................... $3-4$

Figure 3-3 Von Mises Stress Distribution at Maximum Power and Flow ............................. 3-6

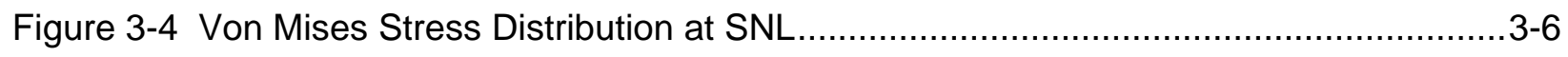

Figure 3-5 Von Mises Stress Distribution at Runaway ..................................................... $3-7$

Figure 3-6 Total Displacement Distribution at Maximum Flow and Power..............................3-8

xxii 
Figure 3-7 Total Displacement Distribution at SNL ..................................................

Figure 3-8 Total Displacement Distribution at Runaway .............................................. 3-9

Figure 3-9 FEA Model for Modal Analysis in Water, with Green Solid Elements and Blue

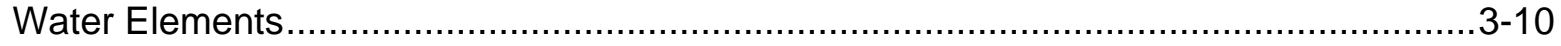

Figure 3-10 Typical k-mode Shapes which can be Associated with Structural Modes ............3-12

Figure 3-11 Modal Shapes for the First Four Resonating Frequencies for the Proposed Runner

Figure 3-12 Modal Shapes for the Remaining Four Resonating Frequencies for the Proposed Runner.....

Figure 3-13 Mode shape corresponding to $1^{\text {st }}$ critical bending speed for runaway with $10 \%$ residual magnetic pull

Figure 3-14 Mode Shape Corresponding to 1st Critical Bending Speed for Nominal Speed with 100\% Magnetic Pull................................................................... $3-19$

Figure 3-15 Static Bending Line .......................................................................... $3-20$

Figure 3-16 Meshed Model .....................................................................................

Figure 3-17 Meshed Vane with Boundary Conditions in Normal Operation..........................3-22

Figure 3-18 Meshed Vane with Boundary Conditions for Dewatered Unit............................3-23

Figure 3-19 Stress Distribution at Normal Operation ..................................................... 3-25

Figure 3-20 Stress Distribution at Unit Dewatered ................................................. $3-26$

Figure 3-21 Total Displacement Distribution at Normal Operation .................................... 3-26

Figure 3-22 Total Displacement Distribution at Unit Dewatered ...................................... 3-27

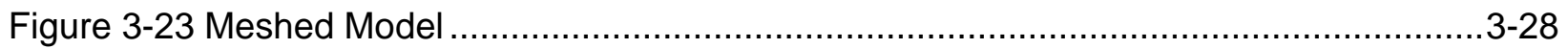

Figure 3-24 Meshed Gate with Boundary Conditions in Squeeze Condition ........................3-29

Figure 3-25 Meshed Gate with Boundary Conditions for Shear Pin Failure .........................3-30

Figure 3-26 Stress Distribution at Gate Squeeze Condition ..........................................3-32

Figure 3-27 Stress Distribution at Shear Pin Failure ...................................................... 3-32

Figure 3-28 Total Displacement Distribution at Gate Squeeze ........................................ 3-33

Figure 3-29 Total Displacement Distribution at Shear Pin Failure ..................................... 3-33

Figure 3-30 FEA Model for Modal Analysis ................................................................ $3-34$

Figure 3-31 Modal Shapes for the First 3 Resonating Frequencies for the Proposed Wicket Gate.

Figure 4-1 Alden Turbine Calculated Runaway Speed: Application to School Street Station

Figure 4-2 Alden Turbine Hydraulic Thrust (Design Seal Clearance): Application to

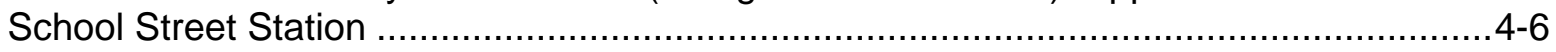

Figure 4-3 Alden Turbine Draft Tube Pressure Pulsations: Application to School Street Station

Figure 4-4 Alden Turbine Spiral Case Pressure Pulsations: Application to School Street Station .....

Figure 4-5 General Layout of the Test Loop and Instrumentation ................................... 4-11

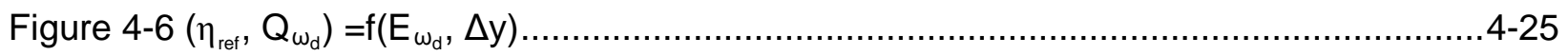




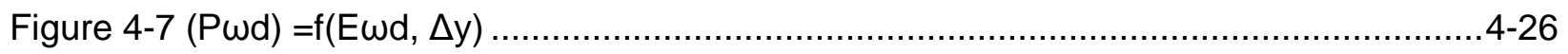

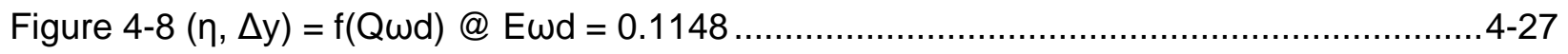

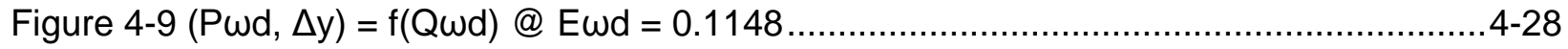

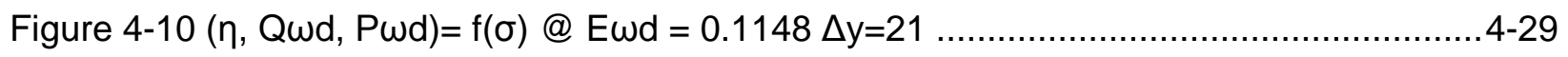

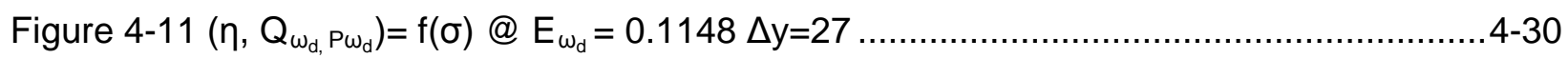

Figure 4-12 Photo @ Ewd = 0.1148, Qwd = 0.0686, .............................................4-31

Figure 4-13 Photo @ Ewd = 0.1148, Qwd = 0.0574 ..............................................4-32

Figure 4-14 Photo @ Ewd = 0.1148, Qwd = 0.0476 ...................................................4-33

Figure 4-15 Photo @ Ewd = 0.1148, Qwd = 0.0368 ..............................................4-34

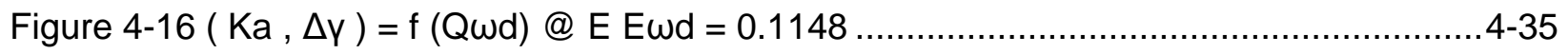

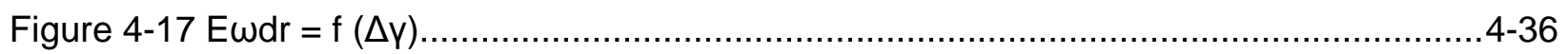

Figure 4-18 dp/2p * $100=f(Q \omega d) @ E \omega d=0.1148$ taps IN05, IN06 .............................4-37

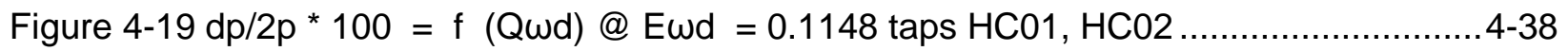

Figure 4-20 dp/2p * $100=f(Q \omega d) @ E \omega d=0.1148$ taps DT13, DT14 ..........................4-39

Figure 4-21 $($ Amplitude/p * 100$)=f(\Delta y$, freq/fn $)$, Location $=$ IN05 ..........................4-40

Figure 4-22 $($ Amplitude/ $p * 100)=f(\Delta y$, freq/fn $)$, Location $=$ IN06 .............................4-41

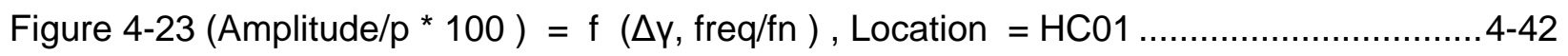

Figure 4-24 $($ Amplitude/p * 100$)=f(\Delta y$, freq/fn $)$, Location $=\mathrm{HCO} 2 \ldots \ldots \ldots \ldots \ldots \ldots \ldots \ldots \ldots . . . . . . .43$

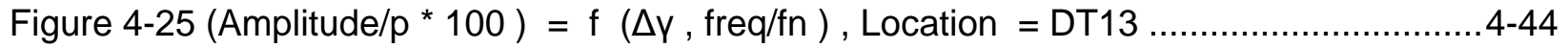

Figure 4-26 $($ Amplitude/p * 100$)=f(\Delta y$, freq/fn $)$, Location $=$ DT14 ...........................4-45

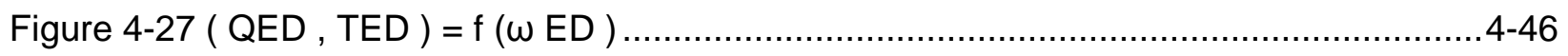

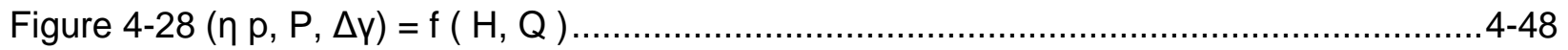

Figure 4-29 $(n \mathrm{p}, \Delta \mathrm{y})=\mathrm{f}(\mathrm{Q}) @ \mathrm{H}=92.0 \mathrm{ft}$ with step up .........................................4-49

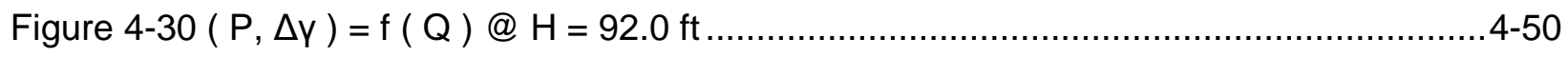

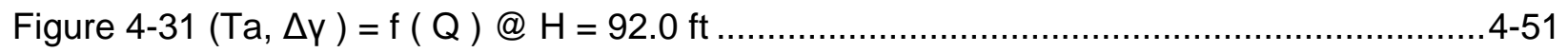

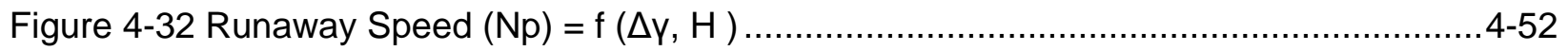

Figure 4-33 Sample Calculations ..................................................................... $4-68$

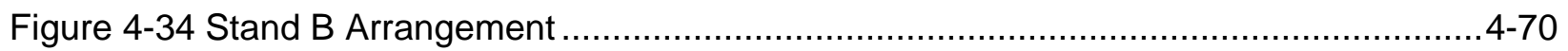

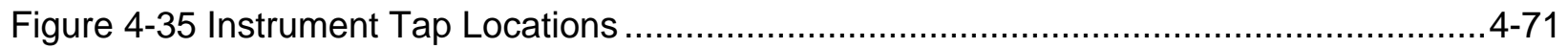

Figure 4-36 Model Dimensional Checks: Nomenclature and Locations of Inspection ............4-72

Figure 4-37 Representative Dimensional Check of the Suction Side of Runner Blade \#1 ......4-73

Figure 4-38 Representative Dimensional Check of the Pressure Side of Runner Blade \#1 ....4-74

Figure 4-39 Representative Dimensional Check of Wicket Gate \#1 Side a.........................4-75

Figure 4-40 Representative Dimensional Check of Wicket Gate \#1 Side b..........................4-76

Figure 4-41 Representative Dimensional Check of Stay Vane \#8 Side a.............................4-77

Figure 4-42 Representative Dimensional Check of Stay Vane \#8 Side b............................4-78

Figure 4-43 S. Morgan Smith Memorial Hydraulic Laboratory - Test Stands......................4-87

Figure 4-44 Model in Test Stand ........................................................................... 4-88 


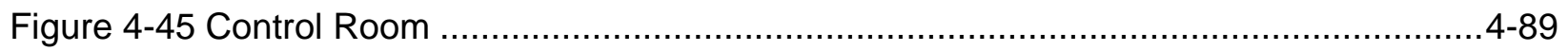

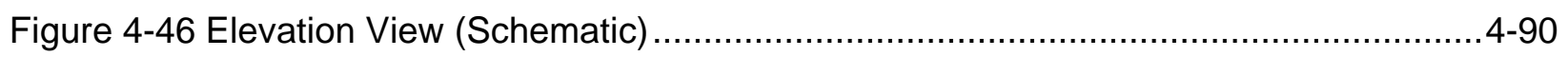

Figure 4-47 3D View of Test Circuit ...................................................................... $4-91$

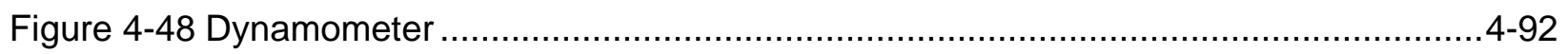

Figure 4-49 Dynamometer Performance Characteristics..........................................4-93

Figure 4-50 Service Pump Performance Characteristics .............................................4-94

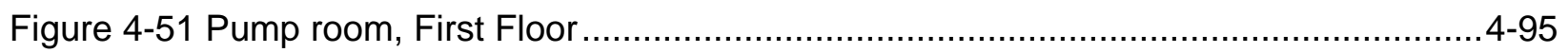

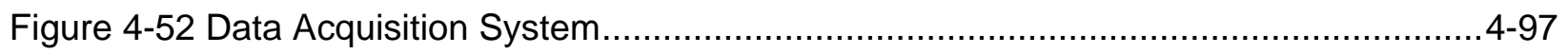

Figure 4-53 Operating Principle of Electromagnetic Flowmeter.................................... 4-98

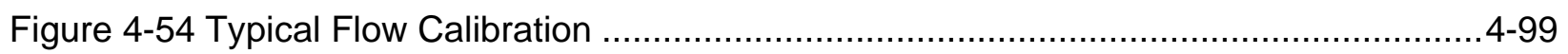

Figure 4-55 Typical Load Calibration .............................................................. 4-101

Figure 4-56 Typical Differential Pressure Head Calibration ............................................4-101

Figure 4-57 Typical Suction Head Calibration ....................................................... 4-103

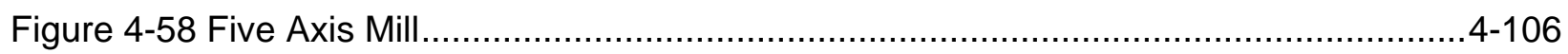

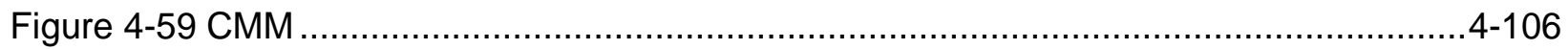

Figure 4-60 Typical Pump/Turbine Four Quadrant Characteristics................................. 4-109

Figure 4-61 Wicket Gate Instrumented with Strain Gage for Gate Torque Measurement .....4-110

Figure 4-62 Kaplan Turbine Blade Instrumented with Strain Gage for Blade Torque Measurement

Figure 5-1 General Configuration of the Simulated Hydraulic Turbine ...............................5-5

Figure 5-2 Vertical View of the Spiral Case: Gradual Decrease in Height .............................5-6

Figure 5-3 Plan View of the Spiral Case: Gradual Decrease in Width ................................... 5-7

Figure 5-4 Plan Dimensions of the Turbine in Terms of the Runner Diameter D....................5-8

Figure 5-5 Vertical Dimensions of the Turbine in Terms of Runner Diameter D.....................5-9

Figure 5-6 Internal View of Simulated Turbine Components: The Spiral Case, Stationary Vanes, Wicket Gates, Runner Blades, Crown, Shroud, Head Cover, and Draft Tube.

Figure 5-7 The Annular Space between the Outer Runner Shroud and the Casing, and Space between the Runner Top and the Head Cover ............................................ $5-11$

Figure 5-8 Mesh View from the Top of Spiral Case .................................................. 5-12

Figure 5-9 Mesh View from the Bottom of Spiral Case and Draft Tube ................................5-13

Figure 5-10 Detailed View of Mesh on Wicket Gates and Stationary Vanes and Their

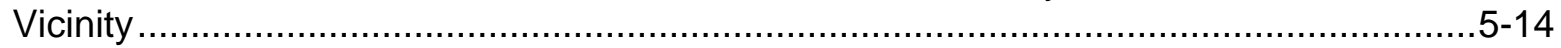

Figure 5-11 Mesh on the Runner Blades and Shroud ..............................................5-15

Figure 5-12 Mesh under the Head Cover (Top of the Runner) and the Crown.....................5-16

Figure 5-13 Pressure Distribution at Downstream Cross Section of Tailwater ......................5-17

Figure 5-14 Schematic Diagram of the Three Turbine Components and Corresponding Mixing Planes.....

Figure 5-15 Hill Chart From Physical Model Data (Scaled up to Prototype) Overlaid with Alden CFD Results: The pink diamonds are for $18^{\circ}$ gate opening, the blue circles 
are for $20^{\circ}$ gate opening, the red circles are for $21.1^{\circ}$ gate opening, the dark blue squares are for $26^{\circ}$ gate opening.

Figure 5-16 Efficiency Contours Based on Interpolation of CFD Results ............................5-27

Figure 5-17 Comparison Between CFD Results and Test Data Hill Chart...........................5-28

Figure 5-18 Efficiency Differences Between CFD and Physical Test Data (positive values mean CFD simulations had higher efficiencies; negative values indicate CFD simulations had lower efficiencies than physical test data)

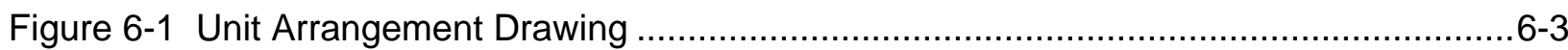

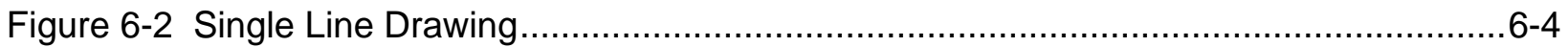

Figure 6-3 Alden Turbine Application Range .......................................................... 6-17 


\section{LIST OF TABLES}

Table 2-1 Simulated Runner Size and Speed for Original Turbine. .................................... 2-5

Table 2-2 Simulated Runner Size and Speed for Final Turbine ........................................2-13

Table 2-3 Original and Final Wicket Gate Rotation at the Selected Design Condition for

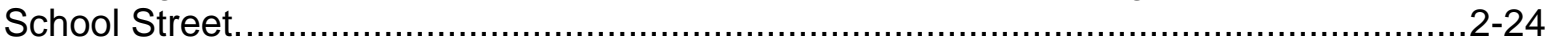

Table 2-4 Predicted Runner and Draft Tube Losses for the Original and Final Alden Turbine at $H_{\text {net }}=92 \mathrm{ft}, Q=1500 \mathrm{cfs}$.

Table 2-5: Predicted Spiral Case (SC), Stay Vane (SV) and Wicket Gate (WG) Losses for the Original and Final Alden Turbine at $H_{\text {net }}=92 \mathrm{ft}, Q=1500 \mathrm{cfs}$.........................2-39

Table 3-1 Number of Nodes and Elements of the Calculated Models ....................................3

Table 3-2 Material Properties..............................................................................

Table 3-3 Hydraulic Data of Load Cases Calculated with CFX ....................................... $3-5$

Table 3-4 Maximum von Mises Stresses and Their Locations.......................................... 3-5

Table 3-5 Displacements for Each Load Case ............................................................

Table 3-6 Water Properties ..................................................................................

Table 3-7 List of Potential Forcing Frequencies ..................................................... $3-11$

Table 3-8 RSI Table for Potential Exciting Frequencies ............................................... $3-11$

Table 3-9 Frequency Estimation in Water............................................................... $3-12$

Table 3-10 Turbine and Generator Mass Properties ............................................... $3-16$

Table 3-11 Generator Magnetic Properties.......................................................... $3-16$

Table 3-12 Turbine Forces.................................................................................. $3-16$

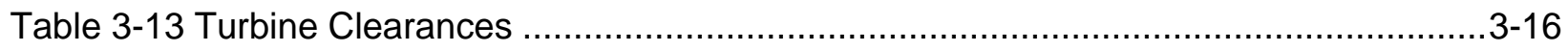

Table 3-14 Bearing Stiffness (Nominal/runaway) ..................................................... $3-16$

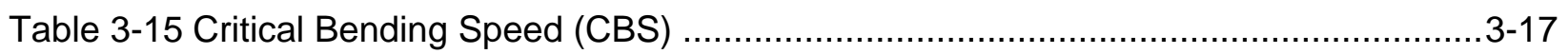

Table 3-16 Runner Seal Check .......................................................................... $3-17$

Table 3-17 Number of Elements and Nodes of the Calculated Models ............................... $3-21$

Table 3-18 Material Properties............................................................................... 3

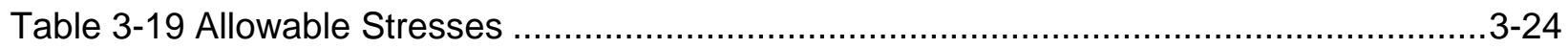

Table 3-20 Loading on the Vane for Both Load Conditions ......................................... 3-24

Table 3-21 Maximum Stresses and Their Locations..................................................... $3-24$

Table 3-22 Number of Nodes and Elements of the Calculated Models ..............................3-28

Table 3-23 Material Properties........................................................................... 30

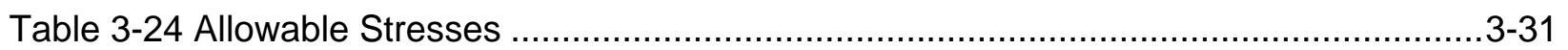

Table 3-25 Loading on the Gate for Both Load Conditions............................................. 3-31 
Table 3-26 Maximum Stresses and Their Location

Table 3-27 List of Potential Forcing Frequencies

Table 4-1 Expected Turbine Prototype Hydraulic Efficiency for School Street Station 4-4

Table 4-2 Expected Cavitation Inception for School Street Station Best Efficiency Point (BEP).

Table 4-3 Inaccuracy Levels

Table 4-4 Total Estimated Error in Efficiency at 95\% Probability 4-104

Table 5-1 Efficiency Comparison for Gate Opening Angle of 18 Degrees $5-22$

Table 5-2 Efficiency Comparison for Gate Opening Angle of 20 Degrees. $5-24$

Table 5-3 Efficiency Comparison for Gate Opening Angle of 21.1 Degrees $5-25$

Table 5-4 Efficiency Comparison for Gate Opening Angle of 26 Degrees $5-26$

Table 5-5 Comparison of Turbine Efficiency with and without Fluid inside the Runner Side Space and Head Cover. $5-30$

Table 6-1 Preliminary Schedule for Installation of the School Street Equipment 6-14

Table 6-2 Alden Turbine Relative Pricing Comparison at School Street Station 6-16 


\section{1 \\ INTRODUCTION}

\section{Background}

A natural outgrowth of the population declines in high profile wild stocks of Pacific and Atlantic salmon and American shad was the belief that U.S. public and private hydropower systems were contributing to the decline of these important species (Office of Technology Assessment 1995). A 1991 U.S. Department of Energy (DOE) sponsored survey (Sale et al. 1991) of non-federal projects documented the extent of the environmental concerns and found that fish passage (upstream and downstream) and instream protection were two key issues requiring mitigation. As Sale et al. (1991) noted, determination of instream minimum flow requirements was the most common issue and fish passage at hydroelectric stations was the most costly.

Fish passing through turbines are subjected to injury and mortality which can negatively impact fish populations especially in river systems with multiple dams where impacts can be cumulative for fish passing through multiple projects. Typical downstream passage measures require water to be spilled or bypassed around the turbines to provide safe passage flows for downstream migrants. However, spill and bypass flows also equate to loss of generation for a project. The economic impact of lost generation is not trivial on large river systems like the main stem Columbia River where generation losses have been estimated at approximately $693 \mathrm{MW}$ of power capacity (potentially $\$ 237$ million per year) due to spill required to safely pass juvenile salmon downstream (Coutant et al. 2006).

Technology development to preclude turbine fish passage began in earnest in the 1990s (OTA 1995, EPRI 1998) and continues to this day. Overall, however, the effectiveness of many technologies is less than optimal, extremely expensive, or resulted in lost generation. In many cases, direct spill for downstream fish passage is preferred to other downstream passage technologies; however, as mentioned above, spill results in significant generation loss (Coutant et al. 2006). Francfort et al. (1994) reviewed the costs of fish protection (greater than $\$ 700,000$ per project in 1991 U.S. dollars) and lost generation (greater than 6,000 MWhrs per year for downstream passage and 2,500 MWhrs per year for instream flow) at non-federal projects, based on the aforementioned 1991 survey. The frequency and costs of environmental mitigation have undoubtedly gone up since that survey.

At a meeting in 1993 in Denver, CO among DOE, EPRI, and the R\&D Committee of the National Hydropower Association (NHA), the idea for developing "fish-friendly" turbines was born. The principle idea was to improve the survival of fish passage through turbines to the point where fish bypass systems and spill were no longer preferred, thereby maintaining (possibly improving) hydropower generation. NHA formed the non-profit Hydropower Research Foundation (HRF) to support the turbine development and with an initial financial contribution of $\$ 500,000$ from EPRI and a coalition of industry supporters that was matched by 
DOE, the Advanced Hydropower Turbine System (AHTS) program began. This program included a three-phase, multi-year effort: Phase I - conceptual designs; Phase II - detailed designs and model testing; and Phase III - construction and testing of full-sized prototypes.

Phase I included competitive DOE solicitations with awards made to two teams; one led by Voith Hydro, Inc. and the other by Alden Research Laboratory, Inc. The Voith concept (Odeh 1999) focused on how existing designs could be modified to improve efficiency and reduce fish injury and mortality. Voith's concepts were applicable for rehabilitating or upgrading existing projects or for new turbine designs. Voith's concepts moved rapidly through Phase II and III including several field projects to test concepts, most notably the new minimum gap runner (MGR) currently installed and tested at federal and private projects on the Columbia River. The Alden turbine had not emerged from the Phase II stage when DOE's support of this and other related projects essentially came to an end in 2006 as DOE’s Hydropower Program was canceled by Congress.

\section{Alden Turbine Background}

The Alden project focused on a radical new turbine runner design. The Alden turbine was designed to enable fish passage with high survival through an operating unit, a feature which would offset the need for alternative downstream fish bypasses and thus increase hydropower generation. Its runner is designed to provide features and flow conditions that significantly improve fish survival with high power generation efficiency.

To reduce injury to fish, the Alden runner (see Figure 1-1) minimizes the number of blades (to three), has no clearances between the runner blades and the crown or housing and, with the exception of some small areas around the blade leading edges, has pressure and velocity (shear) gradients that meet established bio-criteria for safe fish passage (Odeh 1999; Cook et al. 2003; Lin et al. 2004). Computational fluid dynamics (CFD) modeling was performed to develop the initial runner design and to evaluate its hydraulic performance (Cook et al. 1997, 2003; Lin et al. 2004; Hecker and Cook 2005).

Because this runner was a completely new design, DOE supported building a one third scale test facility at Alden to evaluate the turbine performance. Biological and engineering testing began in 2001 and ran through 2003 (Cook et al. 2003). Based on the test results and compared to field data from traditional turbines, the Alden turbine is predicted to have substantially higher fish survival rates for comparable flows, heads, and fish types. Engineering performance indicated that the turbine power conversion efficiency can be expected to be about $90 \%$ in full-size runners (Hecker and Cook 2005; Hecker and Allen 2005). Field deployment and testing of this new turbine design, was not accomplished because a site was not available at the time and the closeout of the DOE Hydropower Program in 2006 further diminished that possibility. 
Introduction

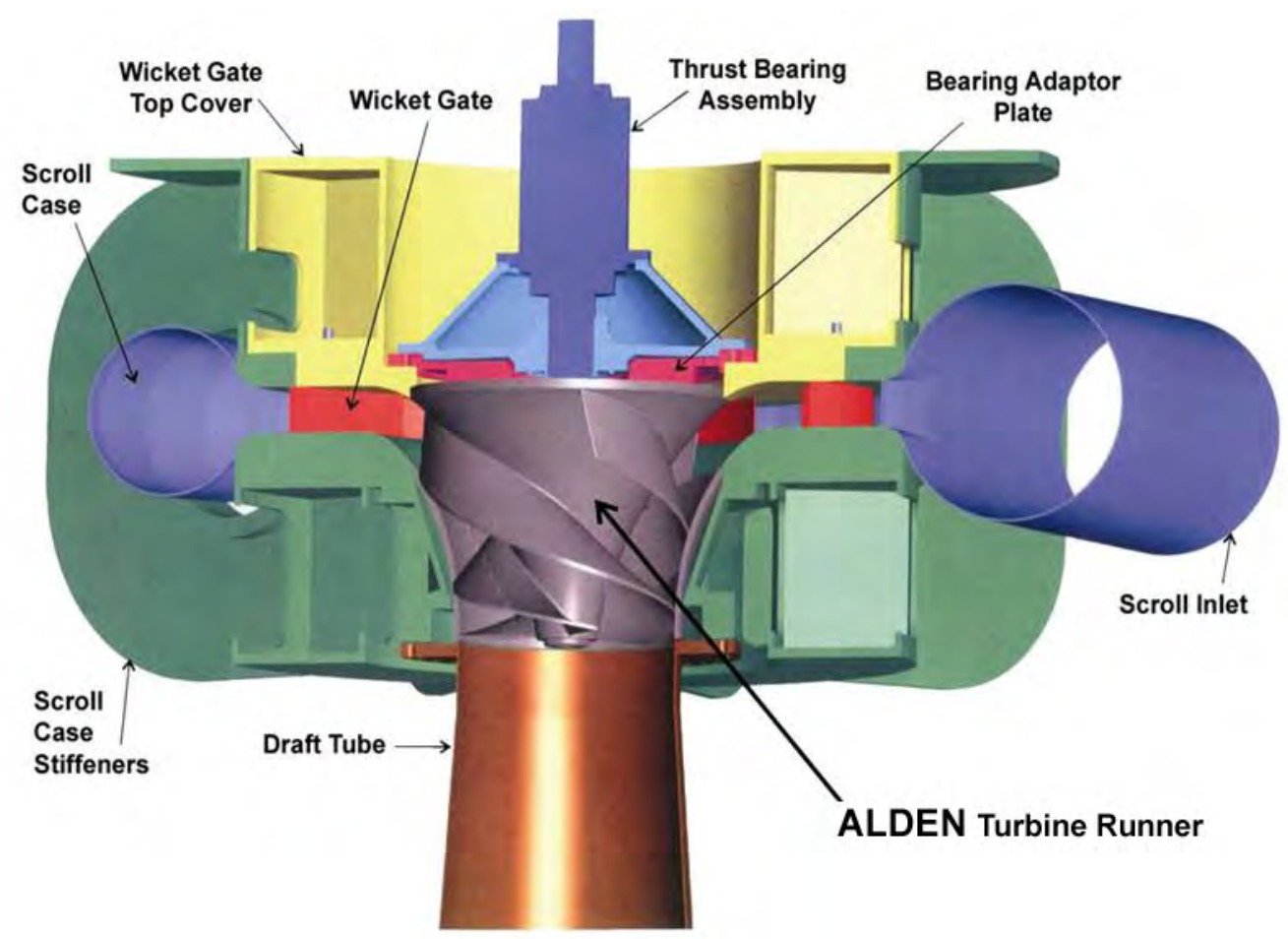

Figure 1-1

Cutaway View of Alden Turbine

The results of the pilot-scale laboratory testing demonstrated that turbine passage survival was primarily dependent on fish length and operational turbine head (Cook et al. 2003; Amaral et al. 2003). There were no statistical differences in survival rates among typical teleost species (trout, salmon, bass, alewife) of a similar size. However, white sturgeon (cartilaginous skeleton and no true scales) and American eel (long, flexible, sinuous, and lacking scales) had significantly greater survival rates than the other species (97\% immediate survival for sturgeon and $100 \%$ for eels). Using the results of the pilot-scale survival tests, predicted survival rates for the prototype (full scale) Alden turbine indicated that fish less than $200 \mathrm{~mm}$ in length, which comprise more than $90 \%$ of fish entrained at hydro projects in the U.S. (Winchell et al. 2000), would be expected to have survival rates greater than about $95 \%$ for heads of 40 and $80 \mathrm{ft}$. These conclusions are based on pilot-scale laboratory tests measuring direct (96 hour) survival; results from tests under actual field conditions may differ. As discussed below, direct fish survival rates are expected to be higher ( $97 \%$ to $100 \%$ ) for the redesigned turbine, primarily due to thicker leading blade edges which increase survival from blade strike.

Recognizing the benefits to industry, EPRI initiated additional conceptual turbine development efforts in 2006 (Hecker et al. 2009). Initially, this effort focused on re-design of the spiral case (EPRI 2007) to double its flow-handling capability and has since moved on to re-design of the runner and draft tube and overall conceptual optimization of the spiral-runner-draft tube system. EPRI also supported computational fluid dynamic (CFD) simulations and laboratory experiments that examined the relationship between turbine blade leading edge geometry and fish injury/survival after blade strike (Amaral et al. 2008; EPRI 2008). A semicircular leading edge 
profile compared to a sharper elliptical profile was derived from the CFD study. The experimental studies examined the effects of leading edge thickness, fish length, fish orientation at impact, and fish taxon (using trout as model bony fish and white sturgeon as model cartilaginous fish, and eels).

Experimental results revealed that strike survival was relatively high when the leading edge thickness was similar to the fish length (Amaral et al. 2008; EPRI 2008). EPRI's turbine blade strike research significantly expanded the knowledge of how blade design affects fish injury and mortality. These findings were incorporated into the Alden runner when EPRI funded subsequent redesign of the runner (see Figure 1-2) for the higher flow capacity of the larger spiral case. This redesign effort included adding a draft tube into the system to allow CFD simulation of the complete turbine (EPRI 2007; EPRI 2009).

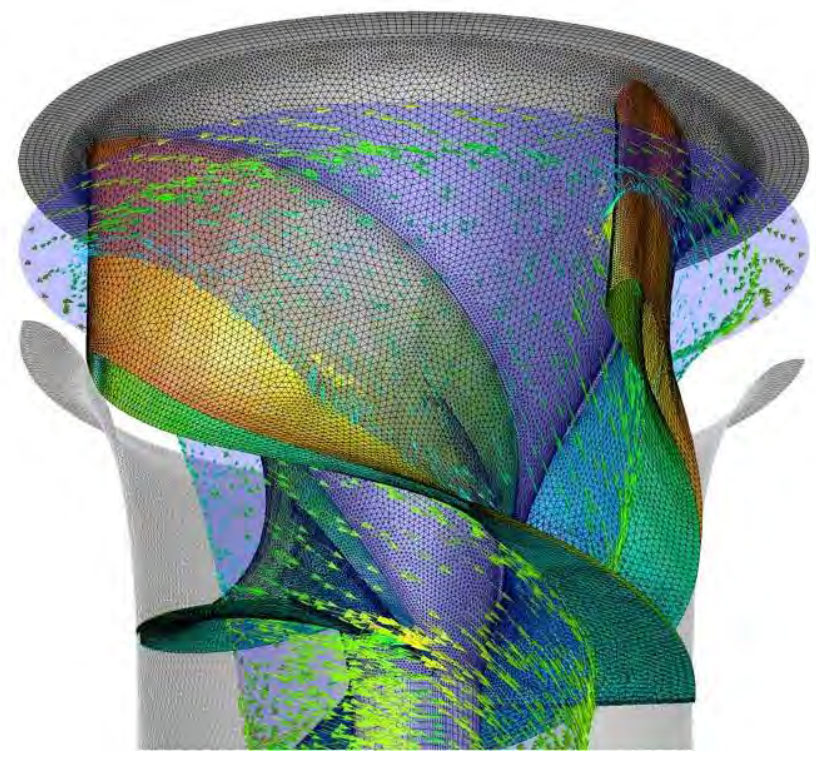

Figure 1-2

Computer Modeling of Alden Turbine Runner

These studies provided the framework for the additional engineering design and performance model studies described in this report. The main goals of the additional development supported by the DOE and EPRI was to complete engineering efforts necessary to move the turbine to commercial viability and to provide baseline engineering data for future deployment. Voith Hydro (Voith) utilized their engineering design and analysis methods and manufacturing experience to develop design adaptations for a further revised Alden turbine design.

As part of this engineering effort, a physical scale model (1:8.71) of the Alden turbine was tested by Voith in York, PA to assess engineering performance before installation in the field. Model testing results indicate that the peak efficiency is near $94 \%$ when scaled up to a full size turbine, competitive with existing conventional designs. A photo of the model runner during the manufacturing process is included in Figure 1-3. 


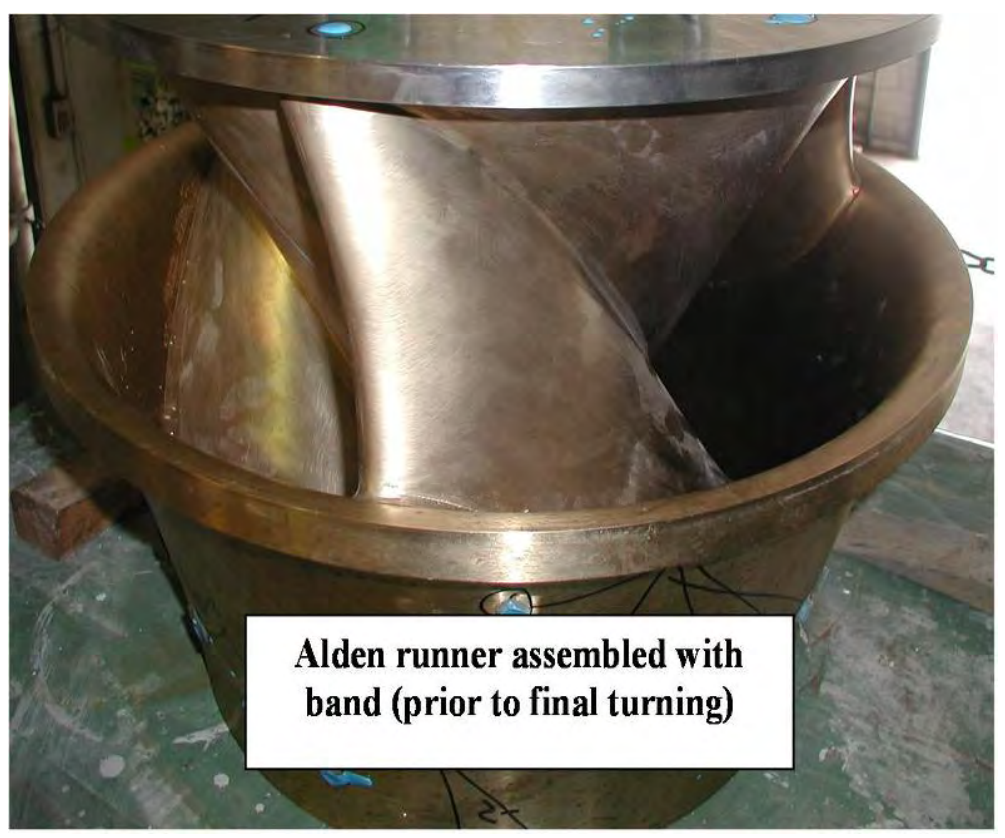

Figure 1-3

Photo of Assembled Model Turbine Runner with Band (prior to testing)

The final Alden turbine design discussed in this report is more efficient and fish-friendly than the original design while remaining economically competitive with commercially available turbines. Completion of these efforts provides a mechanical and electrical design that can be readily adapted to site-specific conditions with additional engineering development comparable to costs associated with conventional turbine designs. Also, the completed work was sufficient to derive a cost estimate for the turbine/generator and auxiliary systems and provides estimates of manufacturing and equipment supply scheduling.

The following chapters discuss Alden's and Voith's collaboration in the revised design of the Alden turbine and results from this work. In addition, future steps including the potential installation at a demonstration site are discussed.

\section{Objectives}

In 2009, EPRI, in response to a 2008 DOE Funding Opportunity Announcement (DE-PS3608GO98030) with cost-sharing support from the hydropower industry, was awarded a grant (DEFG36-08GO18167) from the DOE to conduct engineering development and physical scale model performance testing of the Alden turbine. The objective of the project was to complete the remaining developmental engineering required for the Alden turbine for full-scale demonstration deployment and ultimately to make it commercially competitive with existing designs. The additional developmental engineering included (1) using computational fluid dynamics to convert a conceptual design into a design that a machine can be built from and (2) constructing and testing a physical model of the turbine to evaluate its performance characteristics for economic analysis and continued mechanical layout. An overview of the design process is given below in Figure 1-4. 


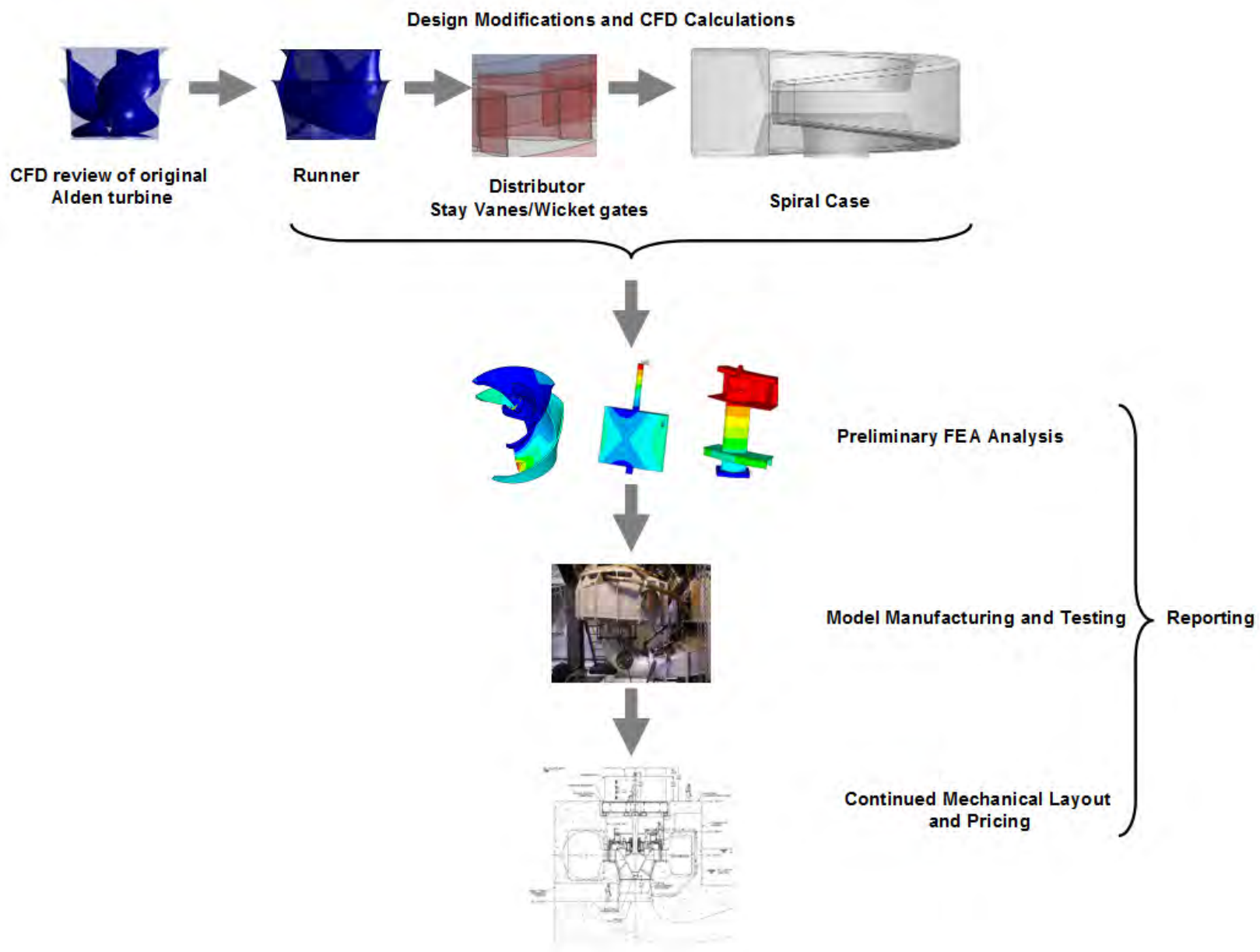

Figure 1-4

Work flow diagram for current Alden Turbine investigation

Completion of these efforts would ensure a robust design that will be viable in the commercial market and lead to actual field demonstration.

\section{Report Organization}

This report is organized into seven chapters. The first chapter provides background information and the development history of the Alden turbine. Chapters 2 through 4 describe the hydraulic and structural design efforts and physical model testing of the turbine. Chapter 5 contains a comparison of computational simulations and physical model data. Chapter 6 includes budgetary and preliminary technical information for the turbine's installation at the design site. The final chapter contains a description of the anticipated tasks to be completed in 2011 to further develop the Alden turbine demonstration project. 


\section{HYDRAULIC DEVELOPMENT: COMPUTATIONAL ANALYSIS OF GEOMETRY MODIFICATIONS FOR FISH FRIENDLINESS AND TURBINE PERFORMANCE}

The Alden runner reduces blade strike mortality by (1) limiting the blade number to three, (2) rotating slower than conventional applications, and (3) employing special blade entrance edge geometries. The blade shapes were also developed to meet criteria for pressure change rates, shear rates, and minimum pressures through the runner (Cook et al. 2003). As a result, the Alden blades featured relatively thick semi-circular entrance edges to minimize strike damage to a passing fish, extremely long blades with nearly 180 degrees of blade wrap, and a runner height that is larger than a conventional turbine of similar diameter (Amaral et al. 2008). An overview of the Alden runner geometry provided to Voith at the beginning of the current development is given in Figure 2-1. Each blade is fixed to a central hub (crown) and an external shroud (band), eliminating all gaps and resulting leakage vortices within the runner passage.

Original Alden Runner Geometry

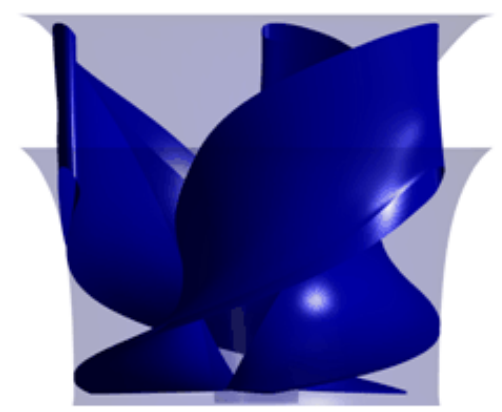

(i)

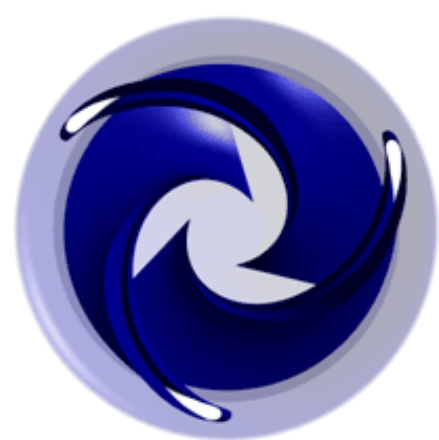

(ii)

Figure 2-1

Alden Turbine Geometry Showing (i) Side and (ii) Plan View of Longer, Wrapping Blades Utilized to Minimize Pressure Change Rates and Shear through the Runner

Throughout this report, the initial Alden turbine geometry provided to Voith at the beginning of the study is referred to as the "Original Alden Turbine".

Geometry modifications to the turbine components, including the spiral case, distributor, runner and draft tube, have been defined using Computational Fluid Dynamics (CFD). In the second phase of development, Voith Hydro designed and constructed a physical model of the modified 
Hydraulic Development: Computational Analysis of Geometry Modifications for Fish Friendliness and Turbine Performance

turbine for performance testing. The final portion of the engineering study included the design of the supporting mechanical, electrical, and balance of plant equipment to implement the turbine at a pilot site. Finite Element Analysis (FEA) was utilized to verify the structural integrity of the mechanical components.

\section{Design Criteria}

Modifications to the Alden runner geometry were evaluated according to three distinct design criteria, with fish friendliness being the most important, followed by increased power production, and finally reduced supply costs. Blade geometries were selected according to fish survival criteria for maximum shear, maximum pressure change rate, and minimum absolute pressure through the runner passage, with these thresholds corresponding to $360 \mathrm{~s}-1,500 \mathrm{psi} \mathrm{s}-1$ (3.5 MPa $\mathrm{s}-1)$, and $7.4 \mathrm{psia}(51.0 \mathrm{kPa})$, respectively. A maximum change in velocity of $30 \mathrm{ft} / \mathrm{sec}$ over a distance of $0.083 \mathrm{ft}$ (one inch) was used for development of the Alden turbine, based on tests with alewife at Alden in the 1970s. This corresponds to a value of $360 \mathrm{~s}-1$. Tests by PNNL (Nietzel et al. 2000) indicated that a higher value, about 500 s-1, is acceptable for salmonids. The maximum allowed rate of pressure reduction for the turbine design was established at 500 psi s- 1 based on tests conducted by PNNL wherein salmon survived a reduction from $4 \mathrm{~atm}$ to $0.5 \mathrm{~atm}$ in $0.1 \mathrm{sec}$ with no significant injuries (Abernethy 2002). This rate is equal to about 500 psi s-1. A goal of the Alden turbine design was to establish a minimum absolute pressure anywhere in the runner of $0.5 \mathrm{~atm}$ or about $7.4 \mathrm{psia}(51 \mathrm{kPa})$. More recent tests by PNNL indicate this value should be closer to 0.6 atm (Stephenson et al. 2010).

Although the Alden runner is being developed to provide a new family of fish friendly hydro turbines for smaller machines across a range of head and flow applications, Alden and Voith focused the design effort for potential pilot application at Brookfield Renewable Power's School Street Station in upstate New York (Hecker et al. 2009). The selected operating condition corresponds to $92 \mathrm{ft}$ of net head with a discharge rate of $\mathrm{Q}=1500 \mathrm{cfs}$. An aerial photo of the existing plant, showing the intake structure and penstocks to the five existing vertical Francis turbines, is given in Figure 2-2.

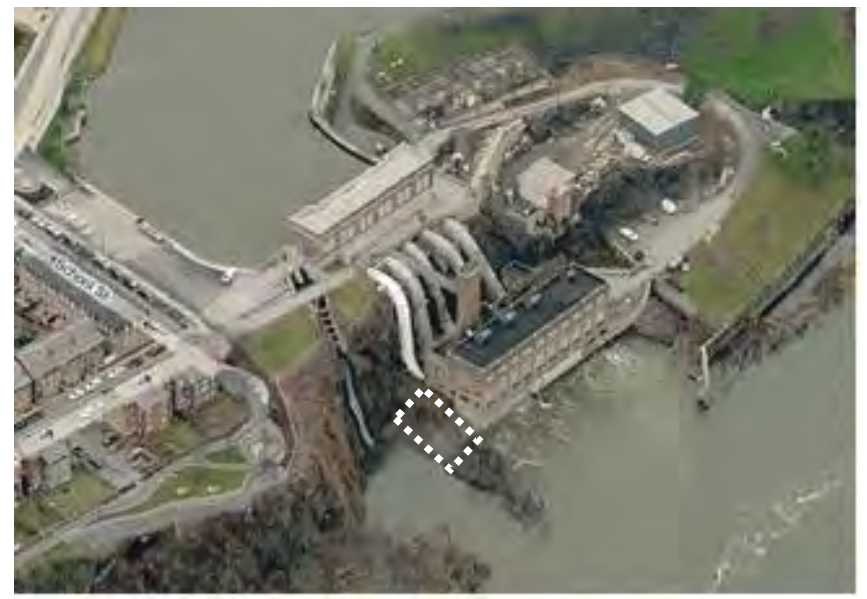

Figure 2-2

Existing School Street Power House. The dashed box indicates the planned location for installation of the Alden turbine 


\section{Computational Fluid Dynamics (CFD)}

Once Voith received the proposed (original) turbine geometry from Alden, the hydraulic profiles were immediately incorporated into Voith's computational tools. In order to provide a baseline for future design modifications, simulations were performed using Computational Fluid Dynamics (CFD) at specified operating conditions to document shear rates, pressure change rates, and minimum pressures throughout the runner passage, in addition to predicted component losses. These numerical simulations were carried out with the commercial ANSYS CFX 12.1 software package (ANSYS, 2009) which is widely accepted as a standard flow solver within the hydropower industry. For the runner investigation, the computational domain consists of a single flow channel within the distributor, i.e., flow between a set of adjacent stay vane and wicket gates, before continuing between two adjacent runner blades. The full distributor consists of 14 stay vanes and wicket gates, while the runner is comprised of 3 blades that are attached to an inner hub (crown) and an outer shroud (band) to eliminate gaps. As the design modifications progressed, a draft tube model was incorporated into the calculations. A representation of the computational domain for the sector model, showing the original Alden distributor, runner and draft tube provided to VH, is given in Figure 2-3.

Original Alden Turbine Geometry

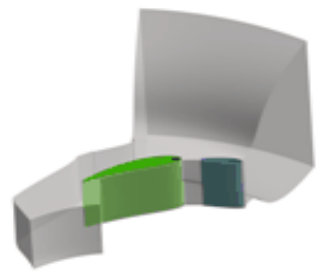

(i)
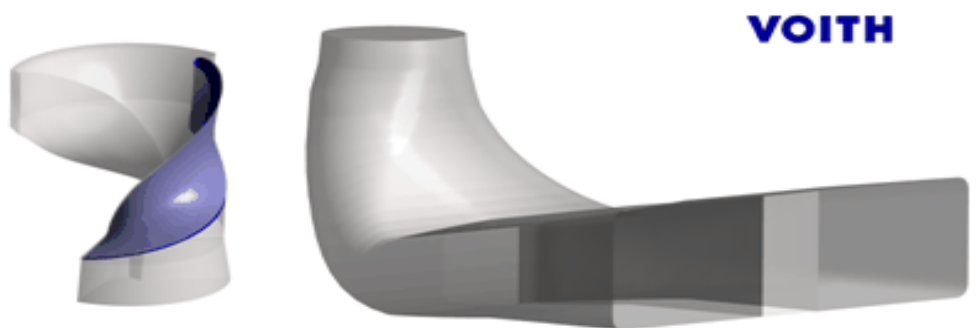

(ii) (iii)

Figure 2-3

Alden Computational Domain Showing Original (i) Distributor, (ii) Runner, and (iii) Draft tube.

The simplified sector model geometry illustrated in Figure 2-3 was selected to take advantage of the symmetry of the Alden distributor and runner, and represents the standard calculation domain for Francis turbine design at Voith Hydro. By including only the relevant components of the turbine, the computational meshes employed in the runner investigation could be refined in order to provide high quality grids for loss prediction without significantly impacting the calculation run times. 
Hydraulic Development: Computational Analysis of Geometry Modifications for Fish Friendliness and Turbine Performance

\section{Computational Meshes}

For the sector model investigation, the meshes were created completely from a hexahedral block structure using an in-house automated meshing procedure. Representations of the meshes associated with the original distributor, runner and draft tube are given below in Figure 2-4.

\section{Original Alden Turbine Geometry}

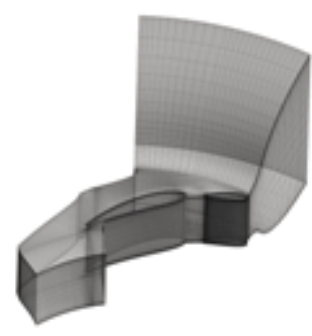

(i)

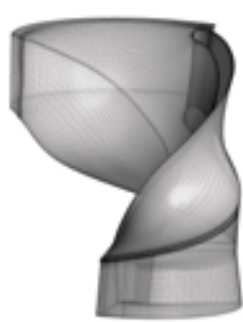

(ii)

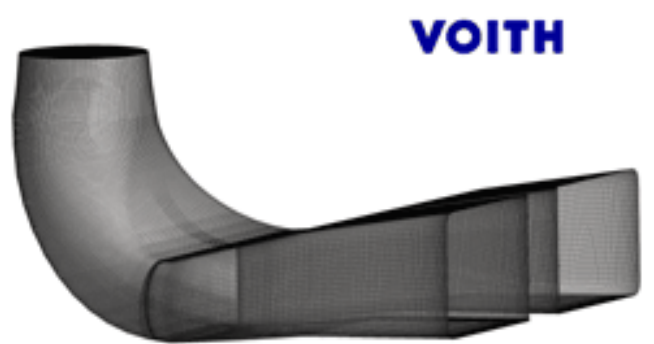

(iii)

Figure 2-4

Computational Meshes Showing Original (i) Distributor, (ii) Runner, and (iii) Draft tube.

For the runner calculations included herein, the distributor, runner and draft tube domains contain 0.4, 0.9, and 3.1 Million nodes, respectively, totaling 4.3 Million nodes for the entire model. During design and analysis of the final runner geometry, all efforts were made to provide a consistent computational setup for the original and final turbine geometries to provide the most accurate comparison between computational results.

As the design of the runner progressed, focus shifted to the upstream components that make up the distributor. While design modifications to the stay vanes and wicket gates were evaluated during the sector model calculations, simulations involving the spiral case incorporated a full $360^{\circ}$ model, including a portion of the intake, the outer casing, and the final stay vanes and wicket gates. Further details of the computational setup for the upstream components will be discussed in the section Computational Setup for Spiral Case.

\section{Calculation Methodology and Boundary Conditions}

Throughout the computational domain, the three-dimensional Reynolds-Averaged Navier-Stokes (RANS) equations are solved in conservative form on the structured multi-block grids. A finite volume based discretisation scheme is used, which is up to second order accurate for the convective fluxes and truly second order accurate for the diffusive fluxes. A turbulence model is needed to close the equation system which results from the Reynolds-averaging. Here, a two-layer model was used which takes advantage of the strength of the k- $\varepsilon$ and $k-\omega$ model. For each operating condition, mass flow and flow direction relative to the inlet plane normal to the distributor section entrance were specified. At the outlet of the calculation domain, an averaged 
pressure boundary condition of 0 Pa was set, allowing for entrainment of flow. For all walls contained within the computational domain, both stationary as well as rotating, a no slip boundary condition was applied. The interface between the stationary and rotating domains was modeled by stage interfaces which average the flow properties in the circumferential direction.

During the analysis, calculations were performed using a scaled version of the turbine geometry corresponding to 1:10.6. The smaller length scale allows for further refinement of the computational grids to better resolve the developing flow structures within the water passage. In order to ensure that the static pressure gradient within the model runner passage matches that of the prototype, the angular speed of the model runner, $\omega\left[\mathrm{s}^{-1}\right]$, was adjusted so that Froude similitude and the gravitational influence was maintained for the two different length scales. This dimensionless scaling parameter is expressed as

$$
F r=\frac{U^{2}}{g D}
$$

with $U, g$, and $D$ representing the velocity in the draft tube cone, the acceleration due to gravity, and the characteristic diameter of the runner, respectively. Because there can only be one velocity scale for the model, the tip speed (proportional to rpm) also scales with the Froude number. A summary of the calculation setup for the original Alden runner geometry is given below in Table 2-1.

Table 2-1

Simulated Runner Size and Speed for Original Turbine.

\begin{tabular}{|c|c|c|c|c|}
\hline $\begin{array}{c}\text { Prototype } \\
\text { Speed } \\
\text { [rpm] }\end{array}$ & $\begin{array}{c}\text { Prototype } \\
\text { Runner } \\
\text { Diameter [ft] }\end{array}$ & $\begin{array}{c}\text { Froude } \\
\text { Number } \\
{[\mathrm{rpm}]}\end{array}$ & $\begin{array}{c}\text { Computational } \\
\text { Model Speed } \\
\text { [rpm] }\end{array}$ & $\begin{array}{c}\text { Computational } \\
\text { Model Diameter } \\
\text { [ft] }\end{array}$ \\
\hline 112.5 & 11.8 & 0.72 & 365.9 & 1.1 \\
\hline
\end{tabular}

Based on the aforementioned scaling, simulations were performed utilizing a $1.1 \mathrm{ft}$ diameter runner rotating at $365.9 \mathrm{rpm}$.

\section{Results}

One of the primary advantages of computational fluid dynamic simulations is the whole field velocity and pressure distributions that are provided from the calculations. These variables can then be post-processed to evaluate various design criteria such as relative velocities, shear rates, pressure change rates, and minimum pressures within the computational domain. Once the model flow fields were determined for the Alden turbine, scaling was performed to determine to expected conditions within the prototype water passage. In the discussion that follows, fish friendly and performance characteristics are presented for both the original and final Alden runner at prototype size. 
Hydraulic Development: Computational Analysis of Geometry Modifications for Fish Friendliness and Turbine Performance

\section{Overall Assessment of Original Alden Turbine}

After the original turbine geometry was received from Alden, the first step of the investigation was to evaluate the flow characteristics produced by the runner shape. This runner geometry was incorporated into a sector model and a simulation was completed at the selected design condition for School Street Station $\left(\mathrm{H}_{\mathrm{net}}=92 \mathrm{ft}, \mathrm{Q}=1500 \mathrm{cfs}\right)$. The initial calculation was performed to first evaluate (1) the velocity profile at the runner exit and (2) the calculated pressure levels along the blade surface.

As the flow exits the runner blades and continues into the upper portion of the draft tube cone, the developing flow characteristics within the draft tube can have a significant influence on the overall turbine performance. This runner-draft tube interaction is governed by the velocity profiles located at the runner exit. If desired velocity profiles are not produced by a given blade shape, the draft tube will optimize at another flow rate that was not intended and therefore alter the performance characteristics (and fish friendliness) of the turbine. Discharge axial and tangential velocity profiles associated with the original Alden runner operating at $\mathrm{H}_{\mathrm{net}}=92 \mathrm{ft}, \mathrm{Q}$ $=1500 \mathrm{cfs}$ are given below in Figure 2-5. These velocity profiles were extracted from an evaluation plane located within the simulated draft tube cone and circumferentially averaged. 
Original Alden Runner Geometry

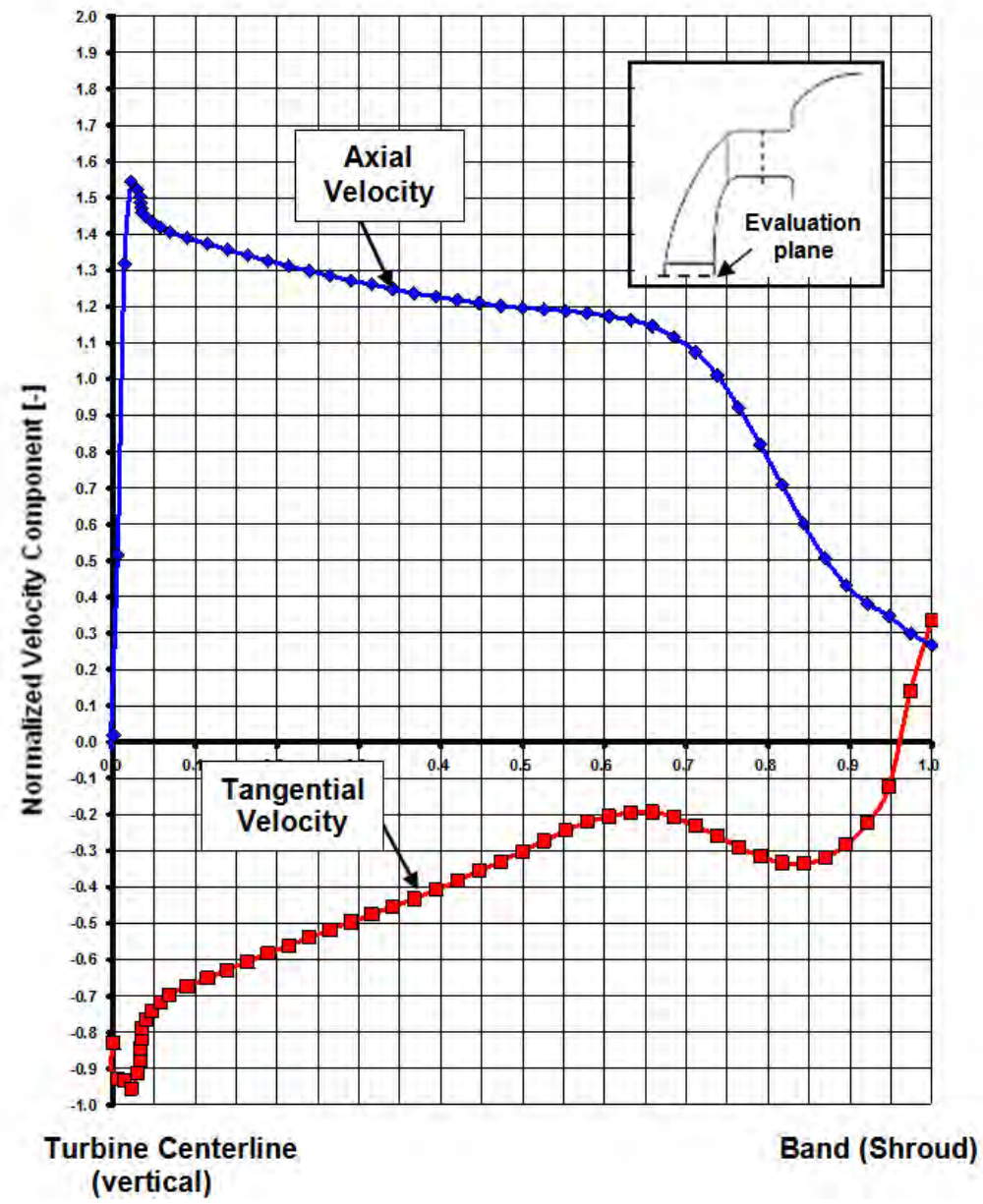

Dimensionless Distance[-]

Figure 2-5

Normalized Axial (blue) and Tangential Velocity (red) Profiles for the Original Alden Runner at the Selected Design Condition (Hnet $=92 \mathrm{ft}, \mathrm{Q}=1500 \mathrm{cfs}$ ). Note that these velocity profiles are extracted from an evaluation plane that is located just downstream of the blade trailing edges.

Note that the velocity values reported in Figure 2-5 normalized by the average velocity in the draft tube cone $(\mathrm{Q} / \mathrm{A}$ at extraction location). A typical axial velocity profile for a conventional runner is essentially uniform across the draft tube cone. The axial profile associated with the original Alden turbine dips significantly near the periphery. These lower velocities along the wall of the draft tube cone can have a negative impact on the resulting flow quality within the remaining portion of the draft tube, causing large regions of separation or recirculation. 
The tangential velocity profile illustrated in Figure 2-5 shows values that are below zero across the majority of the runner exit. These negative tangential velocities indicate swirl that is rotating in the opposite direction of the runner rotation and is characteristic of a runner operating in overload, i.e., the simulated discharge rate is larger than that which optimizes the draft tube flows. Based on these calculation results, the original runner will produce peak turbine efficiencies at a discharge rate that is lower than the selected $Q=1,500 \mathrm{cfs}$.

In order to evaluate the pressure distribution across the original blades, the sigma (Thoma coefficient) values were calculated from the simulated pressure fields within the runner. Sigma is a non-dimensional parameter used to evaluate whether vaporization (cavitation) will occur at the given location by comparing the calculated sigma with the theoretical plant sigma. Sigma plant is related to the site characteristics, the runner submergence, and the net head and is defined as:

$$
\text { Sigma plant }=\left(\mathrm{H}_{\text {barometric }}-\mathrm{H}_{\text {vapor }}+\text { TWE }- \text { Ref Elev. }\right) / \text { Net Head }
$$

For the purpose of the Alden investigation, representative barometric $\left(\mathrm{H}_{\text {barometric }}\right)$ and vapor $\left(\mathrm{H}_{\text {vapor }}\right)$ pressures of $10.35 \mathrm{~m}$ and $0.24 \mathrm{~m}$ were employed. The sigma reference elevation was determined as the distributor centerline, while the minimum tailwater elevation for School Street Station occurred just below the original runner band ( $8.5 \mathrm{ft}$ below the distributor centerline elevation).

If the simulated sigma levels, determined from the Net Positive Suction Head (NPSH)/Net Head, are below sigma plant, vaporization will not occur for the given tailwater elevation. The sigma distributions along the blade surfaces of the original runner are given in Figure 2-6 for $H_{\text {net }}=92$ $\mathrm{ft}, Q=1500 \mathrm{cfs}$. 
Original Alden Runner Geometry

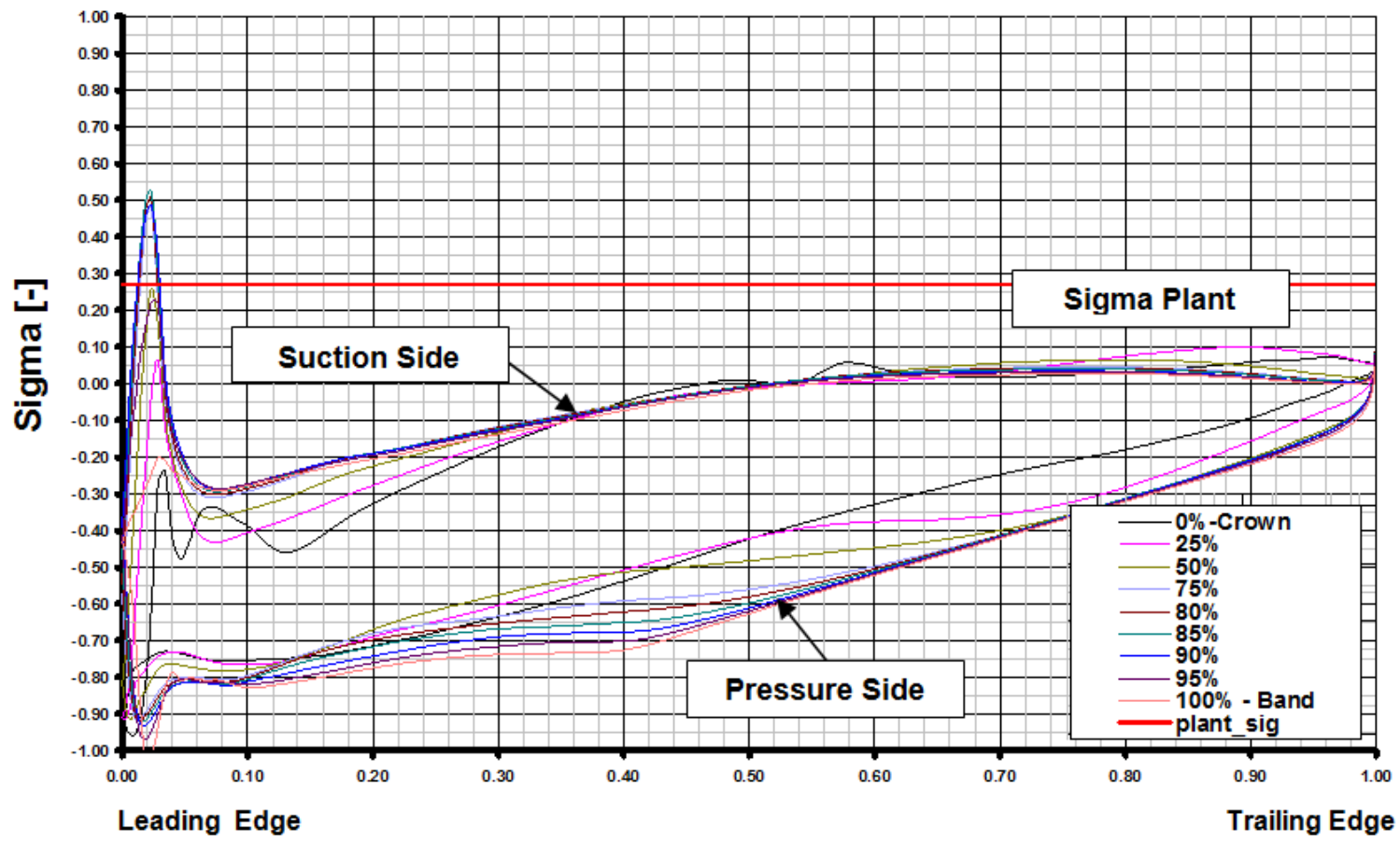

Dimensionless Distance [-]

\section{Figure 2-6 \\ Calculated Sigma Values on the Original Alden blades at the Selected School Street Design Condition $\left(H_{n e t}=92 \mathrm{ft}, Q=1500 \mathrm{cfs}\right.$ ). The horizontal red line represents the value for plant sigma.}

Figure 2-6 indicates that a region of low pressure is present across the suction side of the original blade leading edges, producing sigma levels that exceed plant sigma. Not only do these low pressure regions violate the half atmosphere fish passage criteria, vaporization is expected to occur along the leading edge, potentially causing damage to the runner through cavitation.

The information contained in Figure 2-5 and Figure 2-6 represents standard evaluations utilized during runner design at Voith Hydro. The aforementioned plots provide insight into the flow characteristics produced by the original runner and any issues that need to be addressed during the design modification phase. Further insight into the calculated fish passage quantities and loss predictions for the original runner will be addressed in upcoming sections.

Based on the preliminary assessment of the original runner geometry, the low pressure region at the blade leading edges is a primary concern for design. One cause of the low pressures is a misalignment of the flow entering the runner with the blade entrance edge geometries. If the 
Hydraulic Development: Computational Analysis of Geometry Modifications for Fish Friendliness and Turbine Performance

incoming flow is not aligned properly with the blade leading edge, the fluid will separate from the blade surface, causing low pressures to develop. An illustration of the computed flow alignment at the original blade leading edges is given in Figure 2-7 for the selected design condition of $H_{n e t}=92 \mathrm{ft}, Q=1500 \mathrm{cfs}$.

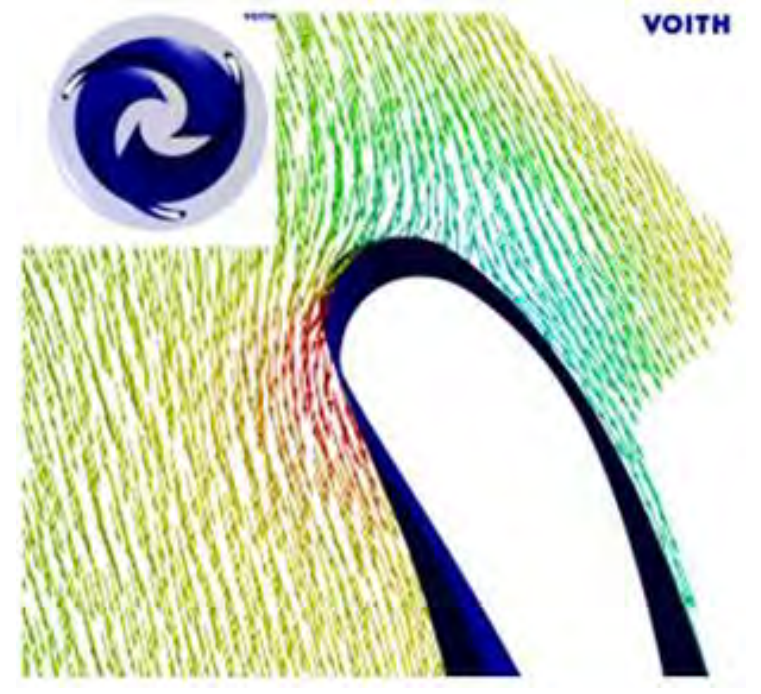

(i)

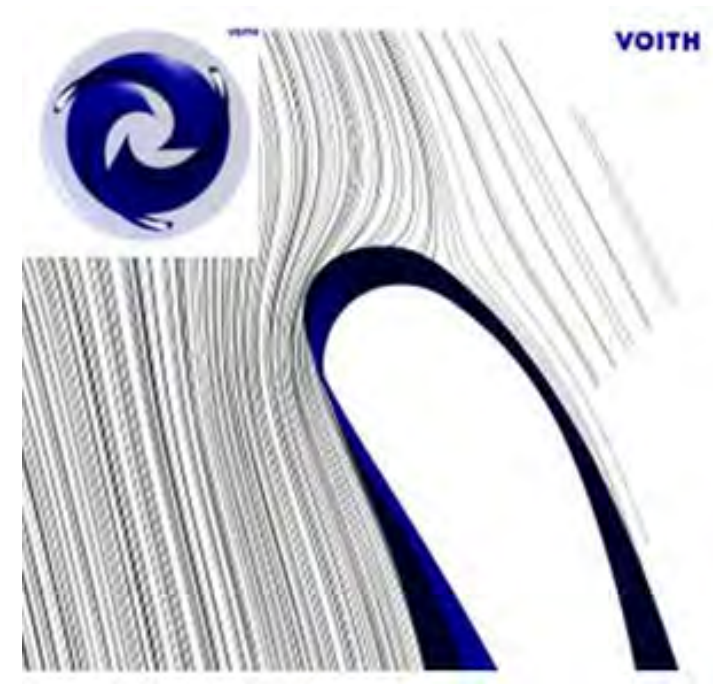

(ii)

Figure 2-7

Patterns of (i) Velocity and (ii) Streamlines Showing Incoming Flow Alignment at the Original Blade Leading Edge for the School Street Design Condition $\left(H_{n e t}=92 \mathrm{ft}, Q=1500\right.$ cfs).

The plots illustrated in Figure 2-7 correspond to a plane located $1.7 \mathrm{ft}$ below the distributor centerline (note that the leading edge intersects the band $2.2 \mathrm{ft}$ below the distributor centerline). These flow representations show an inflow angle relative to the original runner blades that is too steep for the blade entrance edge geometry. To improve the flow alignment with the runner entrance edge, Voith proposed an increase in the rotational speed of the runner from $112.5 \mathrm{rpm}$ to $120 \mathrm{rpm}$. This increase to runner speed was implemented into the strike prediction modeling conducted by Alden. While the relative blade velocities increased somewhat as a result of the speed rise, the influence on predicted fish strike mortality was determined to be negligible. In the discussion that follows, velocity triangles for the original (112.5 rpm) and final (120 rpm) Alden runner will be presented.

\section{Relative Velocities}

As passing fish move from the distributor into the runner, the rotating runner blades create the potential for strike. The probability of blade strike is related to several factors, including the rotational speed of the runner, $n$, the number of blades, $N$, the fish length, $l$, the fluid angle relative to the blade entrance angle, $\beta$, and the meridional velocity through the blades, $V_{m}(r)$ (Hecker and Allen 2005). Strike probability can be interpreted as the ratio of time it takes the effective fish length $(I \sin \beta)$ to pass normal to the blade leading edges, relative to the time it takes 
for a single blade to rotate through a single flow channel $\left(360^{\circ} / N\right)$. Note that this simplified strike model only accounts for the strike at the blade leading edge, which is appropriate for the Alden runner since there are no gaps downstream of the leading edges.

To reduce the occurrence of blade strike, and therefore increase the fish survivability through the turbine, the Alden runner concept features a reduced number of blades (three). In the event that strike occurs, Alden has shown through previous investigations that the resulting damage to the fish is directly related to the ratio of the fish length to the blade leading edge thickness, i.e., l/t, and the velocities of the fish relative to the rotating blades (EPRI 2008). As a result, the relative velocities at the blade entrance edges are part of the fish-friendly design criteria. Any modifications to the runner design should not have a significant influence on the calculated relative velocities at the runner entrance. Figure 2-8 shows the relative velocity w(r) [and its tangential component $\mathrm{w} \theta(\mathrm{r})]$ distributions along the original blade entrance edges for Hnet $=92$ $\mathrm{ft}, \mathrm{Q}=1500 \mathrm{cfs}$. These velocities are presented in the rotating frame of reference, i.e., what an incoming fish will experience within the runner. The relationship between the velocities in the stationary (distributor) and the rotating (runner) frame of reference is illustrated in the velocity triangle given in the upper right of Figure 2-8. Note that the original blade entrance edges are located within the runner downturn and are not symmetric about the distributor centerline (Entrance Height $=0.0 \mathrm{ft}$ ). As the blade entrance edge diameter increases in Figure 2-9 and Figure 2-8 the blade entrances are more centered about the distributor centerline.

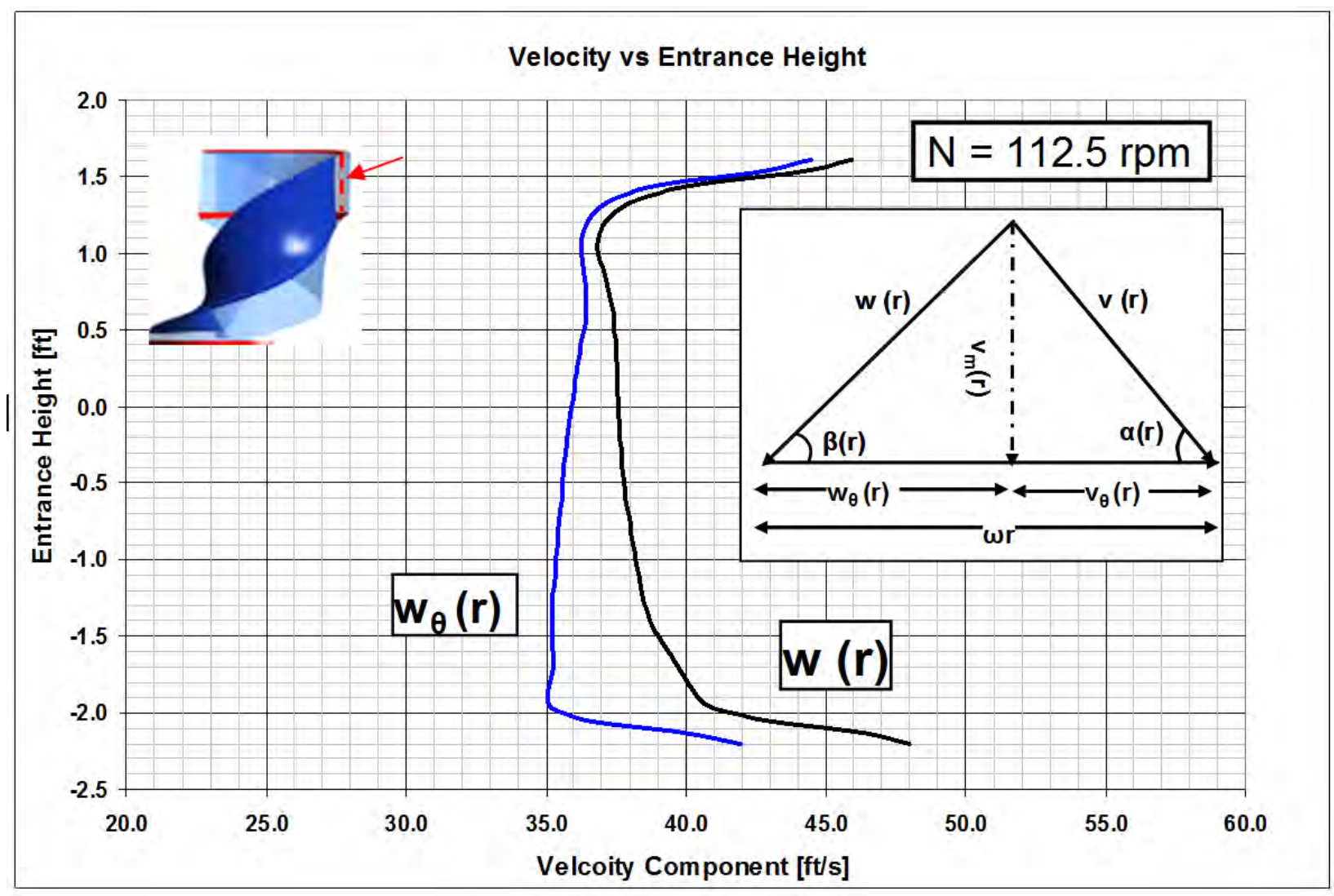

Figure 2-8

Calculated Relative Velocities at the Entrance to the Original Alden Runner as Indicated in the Upper Left Schematic $\left(H_{n e t}=92 \mathrm{ft}, Q=1500 \mathrm{cfs}\right)$. 
As the flow leaves the wicket gates, the stationary velocities are represented by $\mathrm{v}(\mathrm{r})$ and its component $\mathrm{v}_{\theta}(\mathrm{r})$, with a fluid angle of $\alpha(\mathrm{r})$. As this flow approaches the runner with a rotational speed of $\omega r$, the velocities relative to the runner are transformed to $\mathrm{w}(\mathrm{r})$ and $\mathrm{w}_{\theta}(\mathrm{r})$, with an incidence of $\beta(r)$. In the event that strike does occur at the runner entrance edge, the resulting damage will be dictated by the relative velocity w(r). Figure 2-8 shows that the original Alden runner, with a rotational speed of $112.5 \mathrm{rpm}$ and a blade entrance diameter of $11.8 \mathrm{ft}$, produces $\mathrm{w}(\mathrm{r})$ values in the range of about 37 to $41 \mathrm{ft} / \mathrm{s}$ across the majority of the entrance edge. Note that near the upper (crown) and lower (band) blade intersections (Entrance Height $=1.6$ and $-2.2 \mathrm{ft}$ respectively), the velocities leaving the distributor decrease due to boundary effects. As previously indicated, the relative velocities given in Figure 2-8 for the original Alden runner serve as a baseline to compare the relative velocities resulting from runner modifications.

With the preliminary velocity profiles, sigma levels, and relative velocities documented for the original Alden turbine, the process of defining modifications to the runner geometry was initiated. Based on the preliminary calculations, the inflow to the runner was demonstrated to be too steep for the original blades, producing low pressure regions along the blade suction sides of the leading edge. In addition to the aforementioned runner rotational speed increase to $120 \mathrm{rpm}$, Voith also proposed a small increase to runner entrance edge diameter at the band. Both modifications increase the relative velocity at the blade entrance edges, w(r). As the rotational speed of the runner increases, the angle $\beta_{\theta}$ becomes more shallow which acts to improve flow alignment with the final Alden blade entrance edges. An overview of the original and final hydraulic passageways, showing the blade entrance shapes is given below in Figure 2-9.

Original Alden Runner

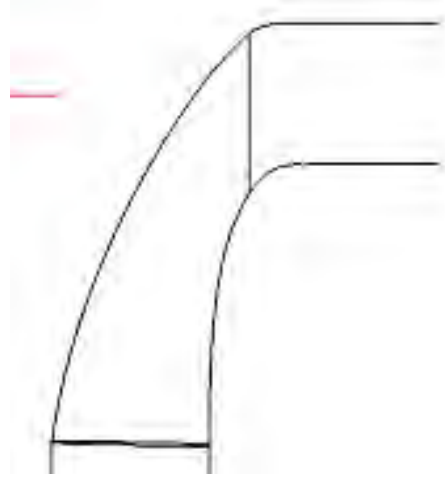

(i)

\section{Final Alden Runner}

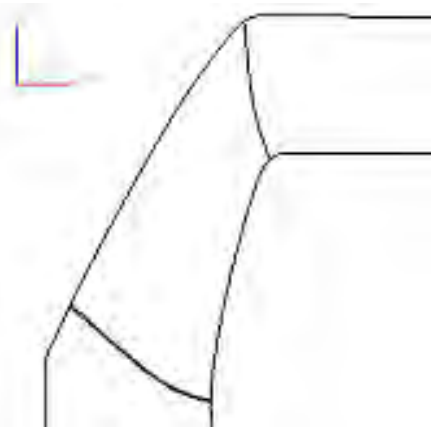

Figure 2-9

Meridional Curves for (i) Original and (ii) Final Alden Runner Geometry

While the average diameters of the original and final Alden runners are similar near the middle of the blade entrance edge, the final blade position was pushed out near the band (shroud) where the sigma values were most severe (Figure 2-6 contours $75 \%$ to $90 \%$ ). The final runner inlet diameter at the intersection with the band corresponds to $12.8 \mathrm{ft}$. 
Hydraulic Development: Computational Analysis of Geometry Modifications for Fish Friendliness and Turbine Performance

The aforementioned geometry modification and faster rotational speed was incorporated into the computational model for the final Alden runner. An overview of the altered calculation setup is given below in Table 2-2.

Table 2-2

Simulated Runner Size and Speed for Final Turbine

\begin{tabular}{|c|c|c|c|c|}
\hline $\begin{array}{c}\text { Prototype } \\
\text { Speed } \\
\text { [rpm] }\end{array}$ & $\begin{array}{c}\text { Prototype } \\
\text { Runner } \\
\text { Diameter } \\
\text { [ft] }\end{array}$ & $\begin{array}{c}\text { Froude } \\
\text { Number } \\
{[-]}\end{array}$ & $\begin{array}{c}\text { Computational } \\
\text { Model Speed } \\
\text { [rpm] }\end{array}$ & $\begin{array}{c}\text { Computational } \\
\text { Model Diameter } \\
\text { [ft] }\end{array}$ \\
\hline 120 & 12.8 & 0.87 & 390.3 & 1.2 \\
\hline
\end{tabular}

The computed relative velocities for the final runner geometry are given in

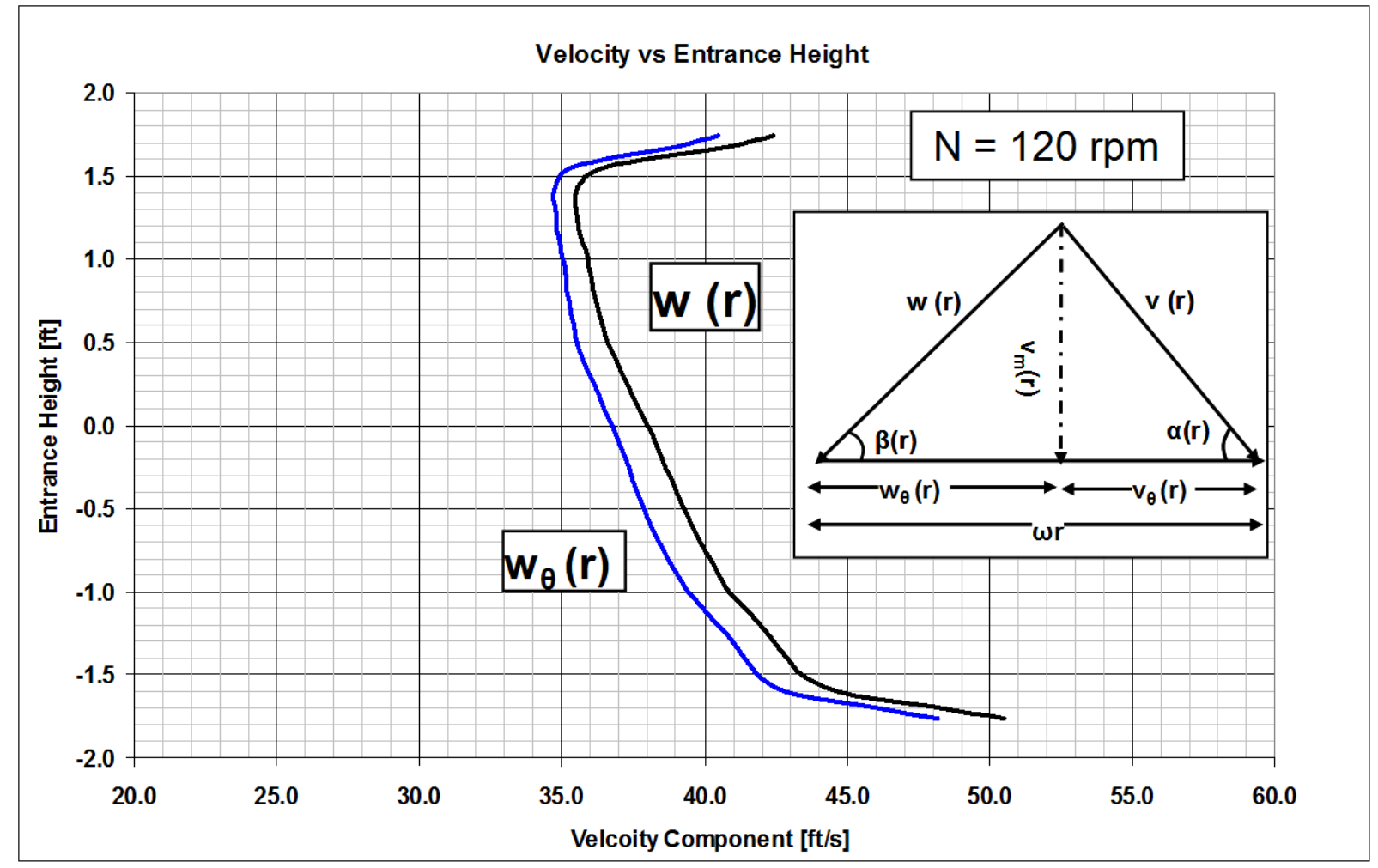

Figure 2-10 for the selected design condition of Hnet $=92 \mathrm{ft}, \mathrm{Q}=1500 \mathrm{cfs}$. 
Hydraulic Development: Computational Analysis of Geometry Modifications for Fish Friendliness and Turbine Performance

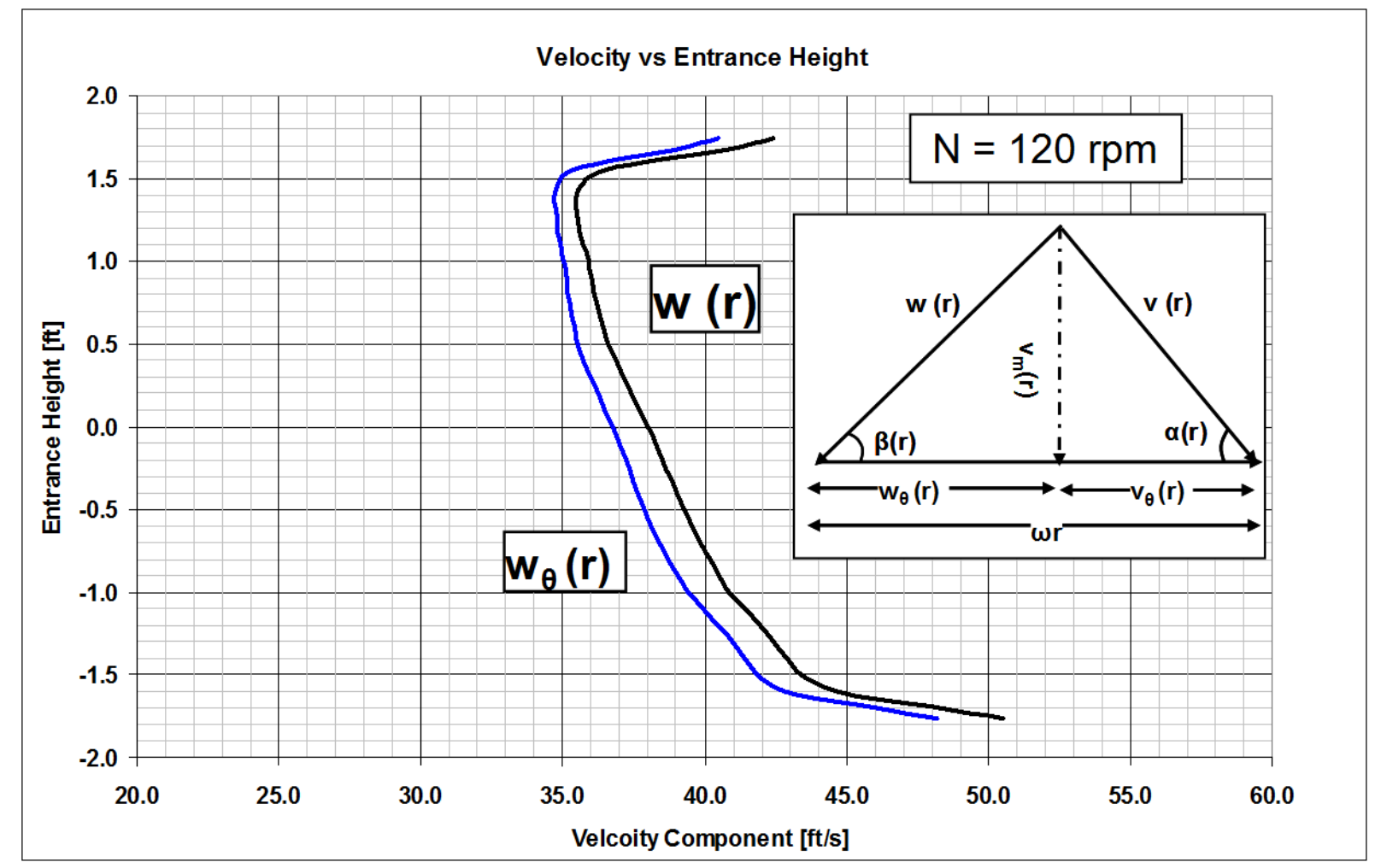

Figure 2-10

Calculated Relative Velocities at the Entrance to the Final Alden Runner $\left(H_{n e t}=92 \mathrm{ft}, Q=\right.$ 1500 cfs).

The shape of the final runner entrance edge is reflected in the relative velocities. Near the upper portion of the water passage $(0.5 \leq$ Entrance Height $\leq 1.5)$, the relative velocities are very similar to those of the original runner $(\mathrm{w}(\mathrm{r}) \sim 38 \mathrm{ft} / \mathrm{s})$. Near the lower third of the water passage, the effects of the speed and diameter increase are more pronounced, with relative velocities that approach $\mathrm{w}(\mathrm{r})=44 \mathrm{ft} / \mathrm{s}$ away from the boundary effects. This relative velocity increase corresponds to roughly ten percent when compared to those of the original Alden runner, but is limited to a relatively small portion of the leading edge close to the intersection with the band. In order to check whether the increase in relative velocity would have a significant influence on the strike damage for fish, Alden incorporated the relative velocities associated with the runner modifications into the aforementioned strike modeling calculations. These predictions indicated that the small increase in relative velocities would have only a minor impact on fish mortality due to the thick leading edge of the blades.

\section{Final Runner Geometry}

With the speed and position of the entrance edge defined, further geometry modifications were identified according to the calculated shear rates, pressure changes rates, minimum pressures throughout the runner domain, and computed losses. The evaluations focused primarily on the selected design condition of $92 \mathrm{ft}$ net head and a discharge of $Q=1500 \mathrm{cfs}$. Geometry modifications were also intended to address the manufacturing challenges of the runner. An overview of the original and final Alden runner geometry is given in Figure 2-11. 


\section{Original Alden Runner}

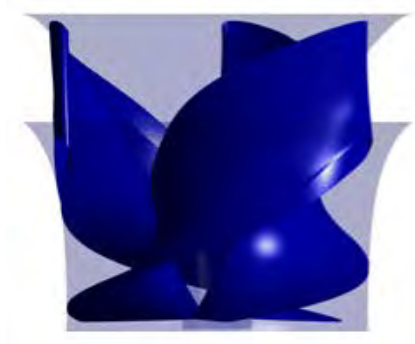

(i)

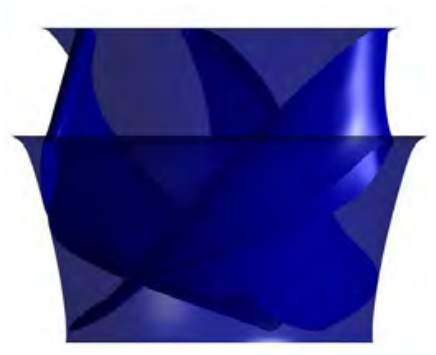

(i)

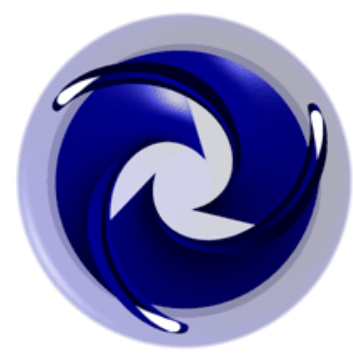

(ii)

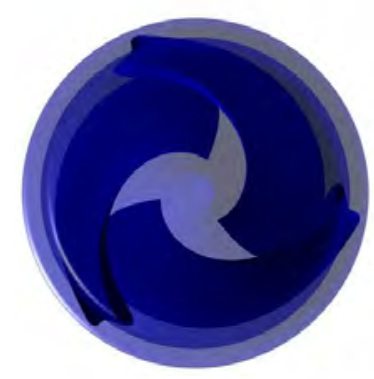

(ii)

Figure 2-11

Original (Top Row) and Final (Bottom Row) Alden Turbine Geometry Showing (i) Side and (ii) Plan Views.

As illustrated in Figure 2-11, the overall Alden concept remains similar between the original and final geometries, featuring three extended blades, with much longer wraps than a conventional fixed blade turbine. During the analysis, it was determined that these large wraps could be reduced moderately and still maintain the desired fish friendly characteristics. The final blades also incorporate different entrance edge characteristics, including steeper blade angles and a rotated leading edge camber definition. The nose thickness of each blade for both runners was kept at six inches, but the original Alden blades incorporate a half round definition. For the final blade, the blade thickness was increased beyond six inches further down the blade to help avoid flow separation and the lower pressures that result from the half round shape.

The final blades are significantly flatter in the middle portion of the runner relative to the original blade geometry. The aforementioned design modifications are expected to improve the overall fish friendliness of the Alden turbine, increase the calculated efficiency levels of the machine, and reduce supply costs. Further details of the calculation results for the final runner are discussed in the upcoming sections. 
Hydraulic Development: Computational Analysis of Geometry Modifications for Fish Friendliness and Turbine Performance

\section{Fish Friendly Criteria}

Once the simulations were completed for the final Alden runner, the model flow fields were scaled-up to represent the actual conditions within the prototype machine. Post-processing provided the computed shear, pressure change rates and minimum pressures within the runner passage. In the evaluation that follows, the aforementioned fish friendly and performance characteristics are presented for both the original and final Alden runner, corresponding to prototype size.

\section{Shear}

The magnitude of shear that fish are exposed to is related to the velocity gradients within the water passage. The shear rate threshold utilized in the current investigation is $360 \mathrm{~s}^{-1}$, with larger values identified as being harmful to fish. This represents a change in velocity of $30 \mathrm{ft} / \mathrm{s}$ over a distance of $0.083 \mathrm{ft}$ (one inch), corresponding to tests with water jets conducted by Alden in the 1970s. Later tests by PNNL resulted in a higher allowable shear, so $360 \mathrm{~s}^{-1}$ is a conservative value (Guensch 2002, Neitzel 2000, Neitzel 2004). The calculated shear rates for the original Alden runner are given in Figure 2-12. These shear contours are illustrated on horizontal planes at various elevations through the runner. 
Final Alden Runner

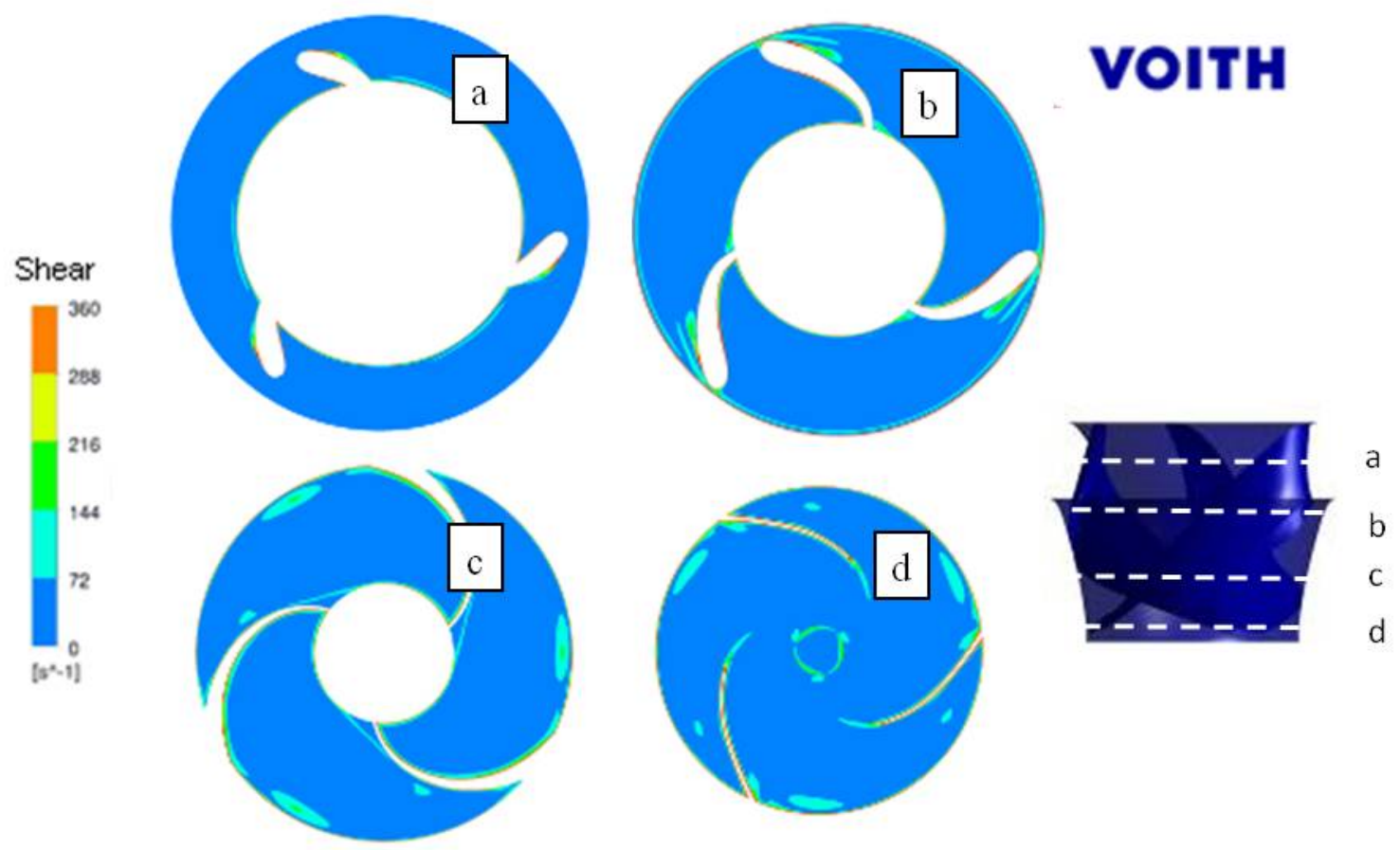

Figure 2-12

Computed Shear through the Original Alden Runner at the Selected Design Condition (Hnet $=92 \mathrm{ft}, \mathrm{Q}=1500 \mathrm{cfs}$ ).

Generally speaking, the computed shear at all four elevations fall below the $360 \mathrm{~s}^{-1}$ threshold for safe fish passage. Although elevated shear levels are present along the blade surfaces due to the no-slip boundary condition, these regions are small and do not extend far into the water passage. High shear levels are also present along the hub (crown) and shroud (band) surfaces (not shown), but are once again confined to the wall region. For the vast majority of the original runner passage, the shear levels are well below those that are anticipated to have a negative influence on fish survival. An overview of the shear associated with the final runner is given in Figure 2-13 
Hydraulic Development: Computational Analysis of Geometry Modifications for Fish Friendliness and Turbine Performance

Final Alden Runner

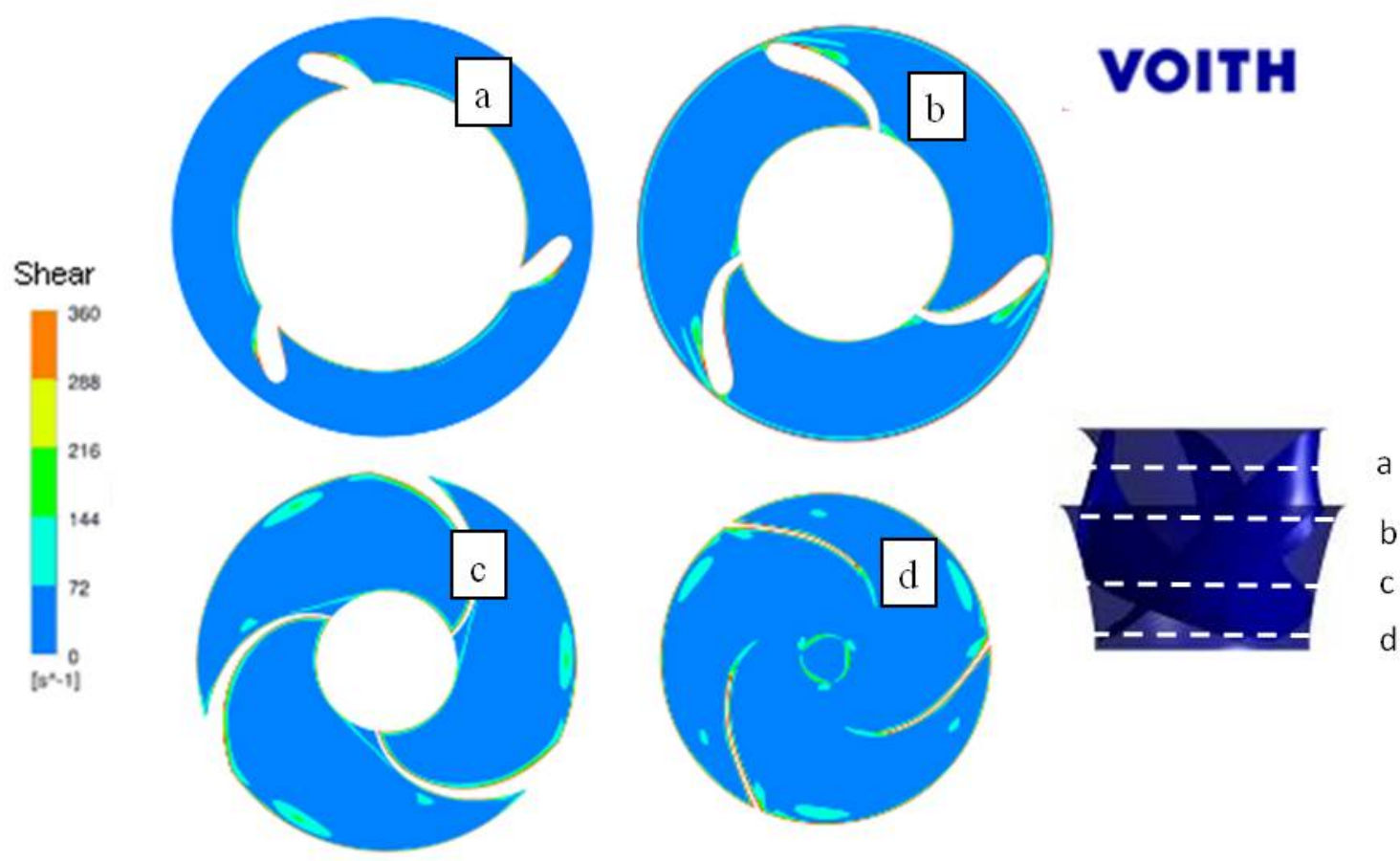

Figure 2-13

Computed Shear through the Final Alden Runner at the Selected Design Condition $\left(H_{n e t}=\right.$ $92 \mathrm{ft}, \mathrm{Q}=1500 \mathrm{cfs})$.

The computed shear for the original and final runners are similar, with elevated values developing near the blade surface for both designs due to the boundary effects. The most significant difference in the shear patterns for the two blade geometries occurs near the lower portion of the leading edge (location b), at the intersection with the band. Here the elevated shear levels for the original blade extend further downstream from the entrance edge along the high pressure (upstream) side of the blade. The corresponding region on the final blades is slightly smaller with lower magnitudes.

For both runner designs, the calculated shear magnitudes are not anticipated to have a negative influence on fish passage due to the volume of the regions with shear values above the $360 \mathrm{~s}^{-1}$ threshold.

\section{Pressure Change Rates}

The second fish passage criteria evaluated during the Alden turbine investigation involves the pressure change rates through the runner. Large pressure drops over short periods of time can cause gas volumes within the fish to expand excessively, resulting in internal damage. The fish friendly threshold for pressure change rate in the Alden turbine was defined as $500 \mathrm{psi} \mathrm{s}^{-1}$ 
(Abernethy 2002). Iso-contours corresponding to this upper limit of the pressure change rate for the original and final Alden turbine are given in Figure 2-14. Note that in this figure, the hub (crown) and shroud (band) have been removed to demonstrate the size of the affected zones.

Original Alden Runner

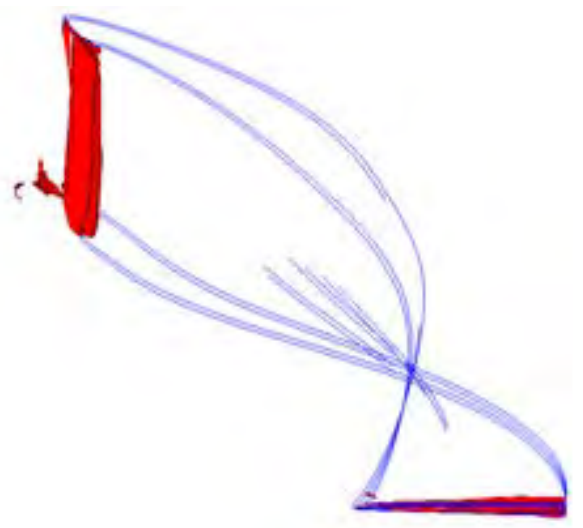

(i)

Figure 2-14

Calculated Prototype Pressure Change Rate Iso-surfaces Showing $\triangle P=500 \mathrm{psi} \mathrm{s}^{-1}$ for the (i) Original and (ii) Final Alden Runner $\left(H_{n e t}=92 \mathrm{ft}, Q=1500 \mathrm{cfs}\right)$.

As the flow enters the runner, it accelerates around the entrance edge of each blade, giving rise to the large pressure drops illustrated in Figure 2-14. Although these pressures are in excess of the 500 psi s $^{-1}$ design criteria, the extent is limited to a very small portion of the water passage adjacent to the blades. Just downstream of the nose, the pressure change rates recover to acceptable levels before rising again along the trailing edge. Although the $500 \mathrm{psi} \mathrm{s}^{-1}$ iso-surface corresponding to the final runner geometry to the right is slightly larger and extends further down the blade, the pressure change rates for the original blade are more concentrated, with a peak value along that blade surface that is approximately $20 \%$ larger than that of the final blade. Additionally, the pressure change rate at the blade trailing edge is smaller for the final runner. In general, the pressure change rate characteristics of both Alden runner designs are very similar, with elevated levels in the vicinity of the leading and trailing edges. These regions make up only a small portion of the water passage and are expected to have a minimal impact on fish survival.

\section{Minimum Pressures in the Runner}

The final fish friendly design criteria used in evaluating geometry modifications to the Alden runner is the minimum pressures occurring in the runner passage. This desired pressure threshold is half an atmosphere, or 7.4 psia (pounds per square inch absolute). Iso-contours illustrating regions of 7.4 psia and below for the original and final Alden turbine are given in Figure 2-15. Once again, the hub (crown) and shroud (band) have been removed from the illustration. 
Hydraulic Development: Computational Analysis of Geometry Modifications for Fish Friendliness and Turbine Performance

Original Alden Runner

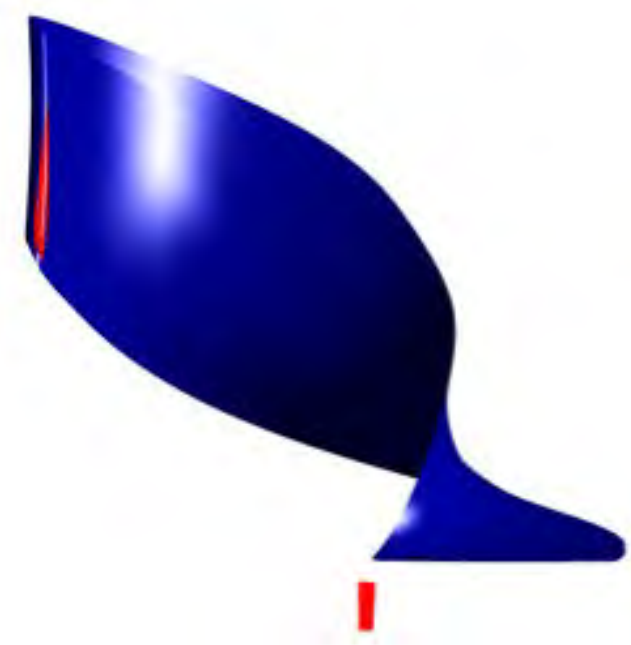

(i)
Final Alden Runner

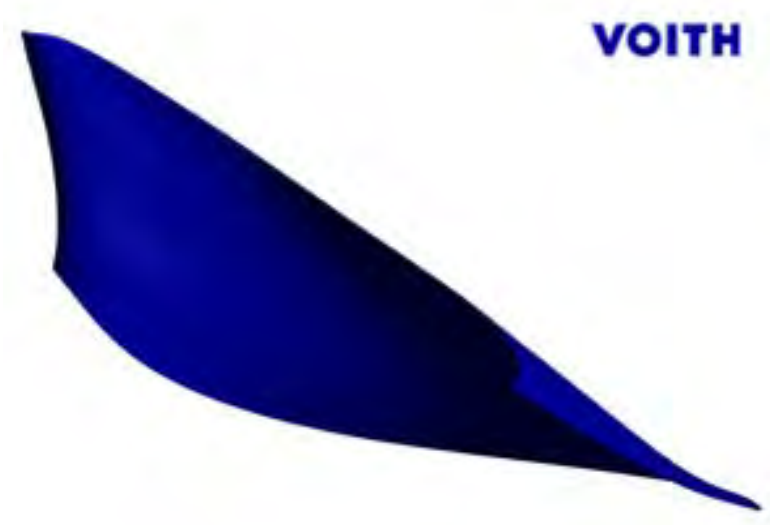

(ii)

\begin{abstract}
Figure 2-15
Calculated prototype minimum pressures showing $P_{\min }=7.4$ psia for the (i) original and (ii) final Alden runner $\left(H_{n e t}=92 \mathrm{ft}, Q=1500 \mathrm{cfs}\right)$.
\end{abstract}

The calculated pressure iso-surfaces in Figure 2-15 correspond to a tailwater that is located just below the elevation of the original trailing edge, or $8.5 \mathrm{ft}$ below the distributor centerline. The original Alden blade with the half-round leading edge shows a small region where the pressure dips below the 7.4 psia criteria (location $a$ ). Just below the blade trailing edge, another region of sub-7.4 psia pressure is visible near the vertical centerline of the runner (location $b$ ).

The minimum pressure associated with the final Alden blade is above the 7.4 psia threshold and is therefore not visible in Figure 2-15. This calculated minimum pressure for the final blade is 9.7 psia, providing a calculated pressure margin of 2.3 psi. The higher pressure associated with the final Alden runner translates into a higher machine setting and lower powerhouse costs than necessary for the for the original turbine geometry. It should be noted that calculated pressures for the final runner geometry are significantly higher than vapor pressure. The high pressures maintained for fish passage also translate into excellent cavitation behavior, which is favorable for runner longevity.

The aforementioned Alden runner development was based solely on optimizing the fish passage criteria for the selected design condition of $H_{n e t}=92 \mathrm{ft}, Q=1500 \mathrm{cfs}$. Once the final runner geometry was identified, other off-design conditions were simulated to determine the computed pressure distributions on the blades for structural analysis and will be provided in the Finite Element Analysis (FEA) results section. These off-design conditions are not intended for fish passage and therefore not subject to the fish passage criteria outlined in the current report. The anticipated operating range for the Alden turbine was based on cavitation and operation 
characteristics measured during the physical model test and is provided in the model test report section.

\section{Upstream Component Design}

As the design of the runner neared completion, the focus of the turbine development shifted to the upstream components, including the spiral case, stay vanes and wicket gates. For the School Street site, installation of the Alden turbine would involve extending the existing power house. The civil costs associated with this construction constitute a cost driver for application of the Alden turbine. During design of the upstream components, water passage modifications were selected to reduce the cost of the power house extension, while maintaining or improving the fish friendly characteristics of the upstream components.

The procedure for defining the upstream components was to first determine beneficial wicket gate modifications, followed by the stay vane geometries, and finally the outer casing crosssection. An overview of these design considerations is provided in the upcoming sections.

Computational fluid dynamic simulations were utilized to determine the flow characteristics through the distributor, in terms of component alignment and velocities, as well as predicted losses. Modifications to the stay vanes and wicket gates were evaluated using the sector model approach, as described in the section Computational Fluid Mechanics (CFD), while calculations involving the spiral case incorporated a full $360^{\circ}$ model of the outer casing and distributor. The computational setup and gridding procedures utilized in the spiral case analysis will be discussed in upcoming sections.

\section{Wicket Gates}

Fish strike is not limited to the rotating runner blades and can also involve stationary components within the distributor. For this reason, the number of stay vanes and wicket gates was reduced by Alden to fourteen (each), as opposed to the eighteen to twenty four components (each) typical of a conventional hydro turbine. Due to this smaller number of wicket gates and the larger pin circle diameter (distance from runner rotational axis to wicket gate rotation axis) necessary to accommodate the Alden runner, the length of the Alden wicket gates is significantly greater than that of conventional gates. The wicket gate profiles associated with the original Alden turbine is given in Figure 2-16. 
Hydraulic Development: Computational Analysis of Geometry Modifications for Fish Friendliness and Turbine Performance

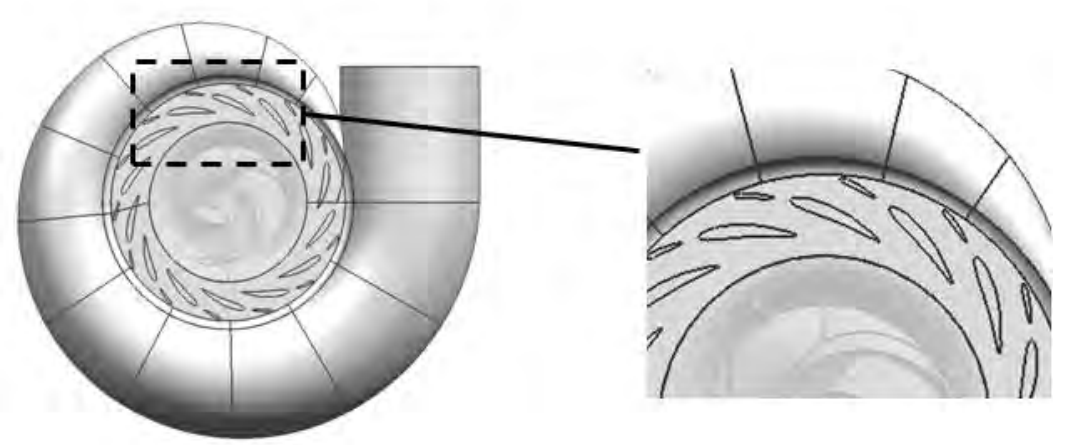

Figure 2-16

Plan View of the Original Alden Turbine Showing Wicket Gate Position Corresponding to the Selected Design Point [wicket gate rotation $(\Delta \gamma)=18.4^{\circ}$ ].

The original Alden gates shown in Figure 2-16 feature a cambered profile that is thicker on the upstream side. This gate profile also curves back toward the runner at the leading edge, producing more of a radial shape when compared to profiles that do not show as much curvature. The curvature of the Alden gates follows the inflow streamline spiral that would be present without gates.

Modification of the wicket gates started with the location of the pin circle diameter, $\mathrm{D}_{\mathrm{z}}$. Pulling the wicket gate pin circle diameter in toward the runner entrance edge provides more flexibility for the design of the outer casing. However, if the distance between the wicket gate trailing edge and the runner entrance edge becomes too small, passing fish can become caught between moving and non moving components and be damaged. For the current investigation, Alden specified that the minimum clearance between the wicket gate trailing edges and the blade entrance edges should be maintained at 15 inches for the selected design point $(H=92 \mathrm{ft}, Q=$ $1500 \mathrm{cfs}$ ) and fish to be protected. During the wicket gate investigation, it was determined that the pin circle diameter $\mathrm{D}_{\mathrm{z}}$ could be reduced from $17.6 \mathrm{ft}$ (original) to $16.6 \mathrm{ft}$ (final) and still maintain a 15 inch clearance between the wicket gate trailing edges and the runner blade entrance edges at the selected design point. A comparison of the wicket gate leaf shapes and pin circle diameters for the original (dashed) and final (solid) geometries, at both the closed position (left image) and the rotation corresponding to the design condition (right image), is given in Figure 2-17. 


\section{Closed position}

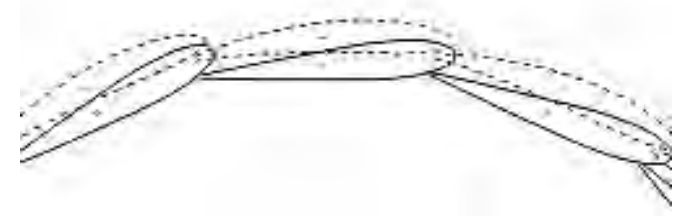

(i)

Figure 2-17

Wicket Gate Leaf Shapes and Pin Circle Locations for the Original (Dashed) and Final (Solid) Alden Turbine at the (i) Closed Position and (ii) the Position Corresponding to the Selected Design Point. Note that the gate orientation is shown in the counter-clockwise direction, which is the standard orientation for computations at Voith Hydro.

The large distance between the wicket gate trailing edges and the runner entrance edges also eliminates the occurrence of wicket gate overhang for $\Delta \gamma$ up to $48^{\circ}$ (the maximum anticipated wicket gate opening for normal operation at School Street Station is $\Delta \gamma=37^{\circ}$ ). If the trailing edges of the wicket gates extend beyond the bottom ring, small gaps develop within this region. These gaps can lead to the formation of leakage vortices, resulting in elevated shear levels and pressure change rates, in addition to lower absolute pressures. Eliminating the aforementioned wicket gate overhang during operation is expected to further enhance the fish passage environment associated with the final Alden turbine.

After performing distributor simulations for various gate profiles, the symmetric shape shown in Figure 2-17 was selected over the cambered gate shape associated with the original distributor. Note that the changes to gate shape (cambered vs. symmetric) had an influence on the required gate rotation $(\Delta \gamma)$ for the selected design point. As the flow passes through the distributor, the wicket gates provide angular momentum. This angular momentum is a function of gate position, i.e., opening, and is referred to as the inlet whirl $\left(\mathrm{H}_{\mathrm{e} 1}\right)$ to the runner. During operation, the turbine will optimize when a specific flow and inlet whirl is provided to the runner. Because the cambered leaf shape is more radial than the symmetric profile, the final gates need to be opened further to provide the same inlet whirl as the original gates. The required rotation at the selected design condition for both the original and final Alden wicket gates is given below in Table 2-3. 
Hydraulic Development: Computational Analysis of Geometry Modifications for Fish Friendliness and Turbine Performance

Table 2-3

Original and Final Wicket Gate Rotation at the Selected Design Condition for School Street.

\begin{tabular}{|c|c|}
\hline Wicket Gate Design & $\begin{array}{l}\Delta \gamma \text { for Selected Design Condition of } H_{n e t}=92 \mathrm{ft}, Q=1,500 \\
\text { cfs }\left[{ }^{\circ}\right]\end{array}$ \\
\hline Original (cambered) & 18.4 \\
\hline Final (symmetric) & 21.1 \\
\hline
\end{tabular}

At the openings provided in Table 2-3, the minimum distance between two adjacent wicket gates is 13.7 inches for both the original and final profiles. Note that this clearance is adequate for the 12 inch fish length targeted for survival during the Alden development.

The final consideration for the Alden wicket gate relates to the nose thickness and resulting strike mortality. Previous strike investigations conducted by Alden show that thicker nose profiles reduce mortality, given equal fish lengths and strike velocities. Based on these findings, Alden requested that the wicket gate nose diameter be increased from 2.4 inches (original) to 4.0 inches (final) to help minimize the impact of strike. Figure 2-18 illustrates the original and final nose vane thickness.

Original Alden Wicket Gate

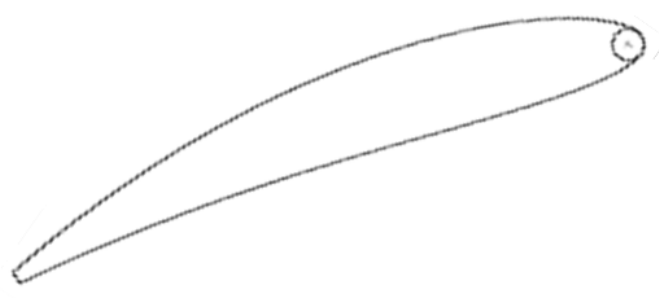

(i)

Figure 2-18

Wicket Gate Leaf Shapes for the (i) Original and (ii) Final Alden Turbine, Illustrating the Difference in Nose Thickness and the Curved Versus Straight Profiles

The thicker nose associated with the final wicket gate lowers the degree of bending that a fish body will experience in the event of strike. These final gates should further improve upon the fish friendliness of the Alden turbine, while having minimal impacts on the performance losses 
due to the relatively low distributor velocities. These velocities and associated component losses will be given in upcoming sections.

\section{Stay Vanes}

The second distributor component evaluated for fish friendliness during the recent Alden turbine development involves the stay vane geometries. While the primary function of the stay vanes is structural support for the unit, these stationary vanes help to guide the flow from the outer casing into the wicket gate passage. To optimize the fish passage environment, the stay vanes and wicket gates should be properly aligned at the selected design condition. Any misalignment between components exposes additional edges and creates cross flow within the hydraulic passageway that could ultimately lead to more strike and abrasion events. The original stay vane-wicket gate alignment corresponding to $H_{\text {net }}=92 \mathrm{ft}, Q=1,500$ cfs can be seen in Figure 2-16 although the original wicket gates are properly aligned with the stay vanes at $\Delta \gamma=18.4^{\circ}$, this stay vane orientation had to be final to align with the symmetric wicket gates at $\Delta \gamma=21.1^{\circ}$. During the stay vane development, additional modifications were defined by Alden to further enhance the fish friendliness of the upstream components, including thicker stay vane nose profiles (similar to the wicket gate modifications) and minimal spacing between the wicket gate leading edges and stay vane trailing edges to prevent fish from passing between these components. A comparison of the original and final stay vane profiles is given below in Figure 2-17.

Original Alden Stay Vane

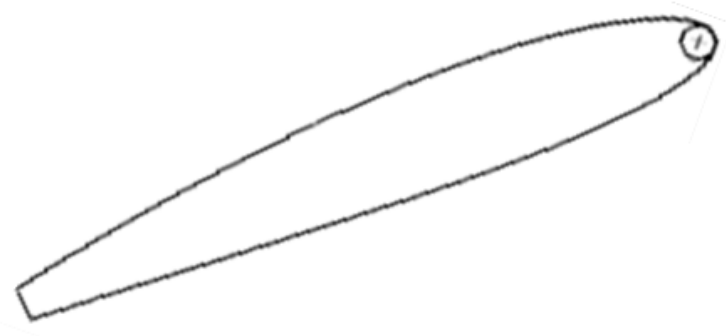

(i)

Figure 2-19

Stay Vane Shapes for the (i) Original and (ii) Final Alden Turbine, Illustrating the Difference in Nose Thickness
Final Alden Stay Vane

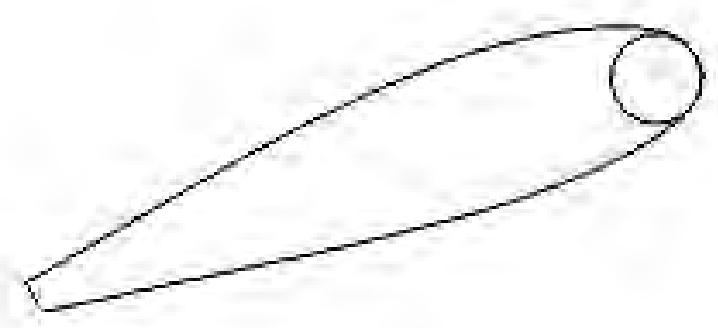

(ii) 
Hydraulic Development: Computational Analysis of Geometry Modifications for Fish Friendliness and Turbine Performance

During the modification process, the stay vane nose diameters were increased from 1.0 inch (original) to 2.4 inches. As before, the thicker stay vane nose profiles are extended downstream to reduce the degree of bending that a fish body would experience in the event of strike.

Because the final wicket gates feature symmetric profiles that do not flatten out at the leading edges, a steeper stay vane orientation is required to maintain proper alignment between the gates and vanes. The gap between components was addressed by extending the final stay vane trailing edges downstream to provide a 0.33 inch clearance with the wicket gate leading edges at $\Delta \gamma=$ $21.1^{\circ}$. These design modification are illustrated in Figure 2-20.

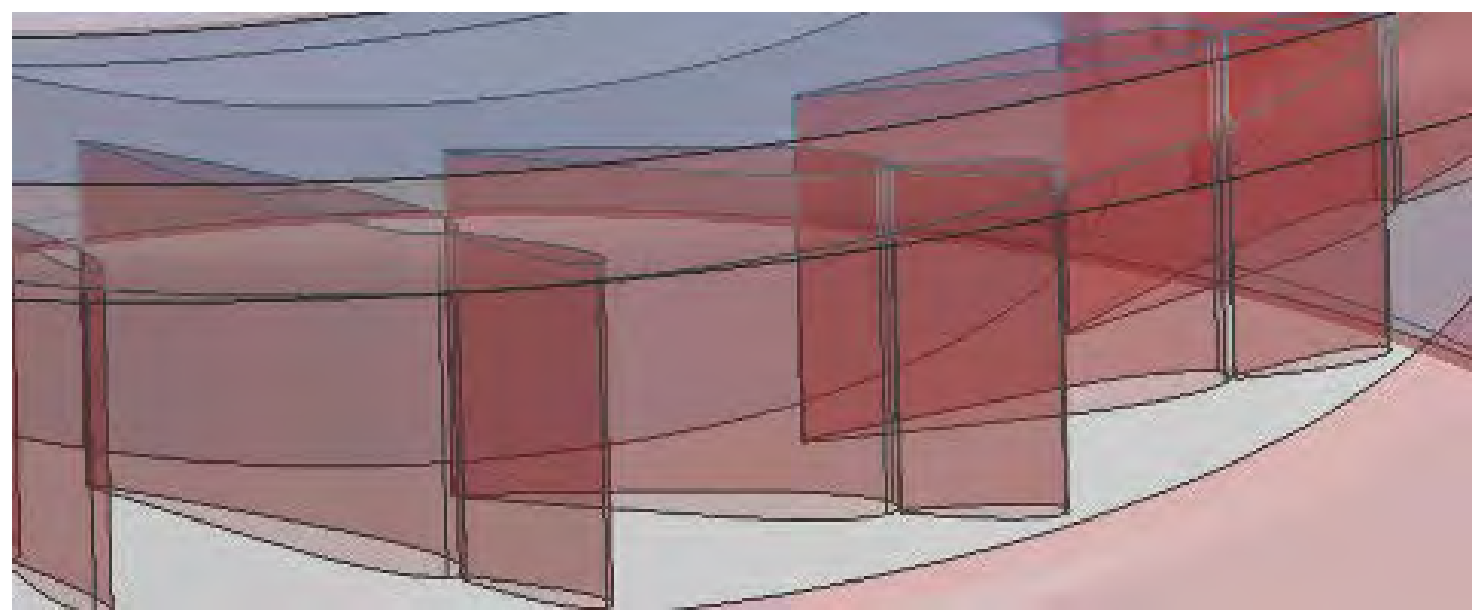

Figure 2-20

Final Stay Vane - Wicket Alignment Showing Reduced Gap at the Gate Opening corresponding to the Selected Operating Point $\left(H_{\text {net }}=92 \mathrm{ft}, Q=1500 \mathrm{cfs}\right)$.

The final Alden distributor provides optimal alignment between the stay vanes and wicket gates, with a reduced gap between components. These features will decrease the probability for strike through the final distributor, while the thicker stay vane and wicket gate nose profiles are expected to reduce the resulting damage in the event that strike occurs.

The final Alden distributor provides optimal alignment between the stay vanes and wicket gates, with a reduced gap between components. Subsequent CFD analysis showed no cross flow through the small remaining gap between these components (see Figure 2-21). These features will decrease the probability for strike through the final distributor, while the thicker stay vane and wicket gate nose profiles are expected to reduce the resulting damage in the event that strike occurs.

\section{Distributor Velocity Documentation}

Up to this point, Alden distributor geometry modifications have been described relative to fish friendly characteristics without documenting the flow characteristics through the machine. The aforementioned modifications were verified computationally through the use of sector models. Plots of velocity contours for the original and final distributor geometries are given in Figure 2-21 at the selected design condition $\left(H_{n e t}=92 \mathrm{ft}, Q=1500 \mathrm{cfs}\right)$. Note that these velocity contours are illustrated on a plane that is located at the distributor centerline. 
Original Alden Distributor

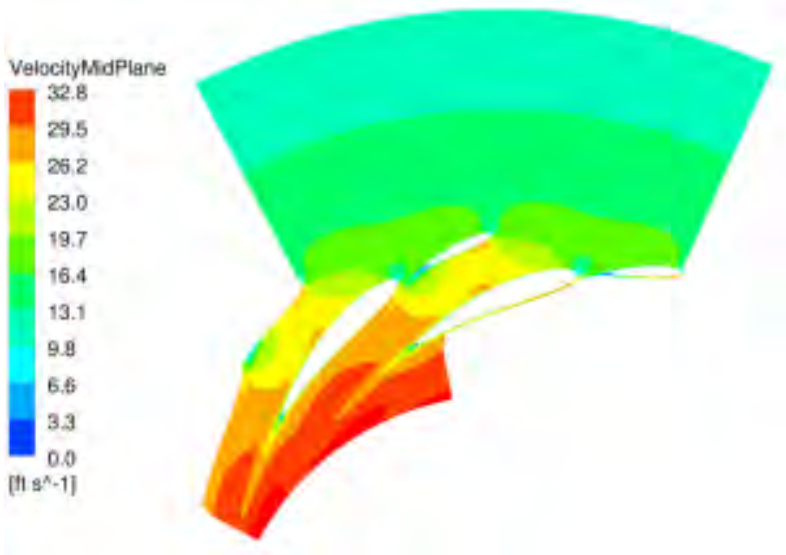

(i)
Final Alden Distributor

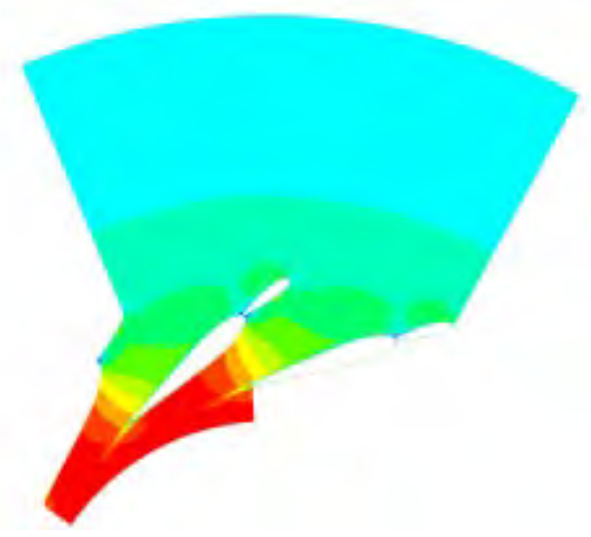

Figure 2-21

Velocity Contours for the (i) Original and (ii) Final Distributor at the Selected Design Condition $\left(H_{n e t}=92 \mathrm{ft}, Q=1500 \mathrm{cfs}\right)$

While the velocity contours are similar between the original and final distributors, it is apparent that the flow through the final distributor is more uniform in the vicinity of the upstream side of the wicket gates. Here the cambered profile associated with the original gates cause the flow to accelerate within this region, showing a localized region of high velocity along the curved surface.

At the stay vane noses, calculated velocities are in the neighborhood of $16 \mathrm{ft} / \mathrm{s}$ for the both the original and final distributor geometries. At the wicket gate noses, the reduced gaps of the final distributor keep the gates in the wake of the upstream stay vanes, resulting in lower velocities. These velocities at the final wicket gate noses fall between 3-6 ft/s, while those of the original wicket gates are about 10-13 ft/s. The uniform flow patterns associated with the final Alden distributor and reduced velocities at the wicket gate noses are expected to improve the fish friendliness of the Alden turbine, while also benefiting machine performance. These loss details will be given in upcoming sections.

\section{Spiral Case}

With the runner and distributor nearly complete, the final considerations for the intake and spiral case were implemented. This outer casing takes the incoming flow from the penstock and delivers it to the distributor. As the casing wraps around the distributor, the area continually decreases to provide relatively uniform radial and tangential velocity components to the distributor entrance. For the case of the Alden turbine, the casing had to be designed to provide distributor inflows that match the aforementioned final stay vane orientation. The original 
Hydraulic Development: Computational Analysis of Geometry Modifications for Fish Friendliness and Turbine Performance

concept for the Alden casing involves a full spiral manufactured from plate steel. An overview of the original spiral case is given in Figure 2-22.

\section{Original Alden Spiral Case}
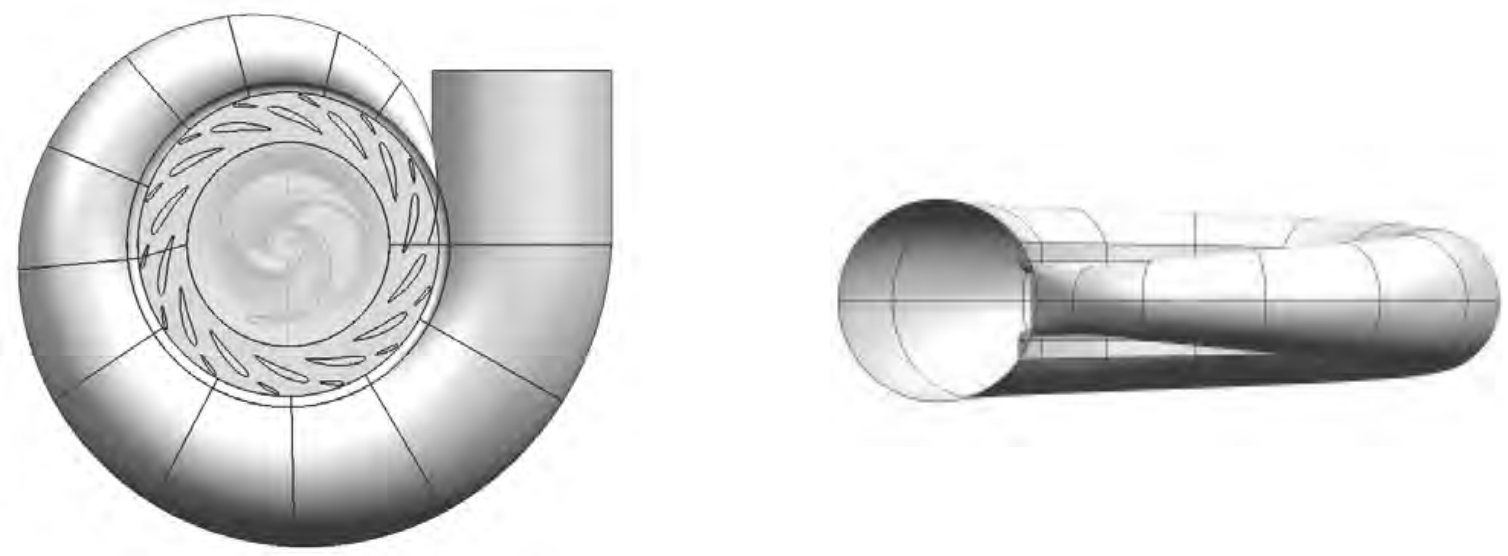

(i)

(ii)

Figure 2-22

(i) Plan and (ii) Side Views of the Original Alden Spiral Case

The circular cross section of the original Alden casing is suitable for larger heads associated with conventional Francis turbines. However, for the lower net heads corresponding to the School Street plant, a concrete semi spiral case with rectangular cross sections is adequate. To take advantage of the lower installation costs associated with the concrete design, a hybrid spiral case concept was developed for application at School Street which incorporates rectangular cross sections that wrap around the entire distributor. A comparison between the original Alden spiral case (circular cross sections) and the final concept (rectangular cross sections) is given in Figure 2-23. The predicted velocity patterns indicate that the flow field is uniform and free from reverse flow. 


\section{Original Alden Spiral Case}

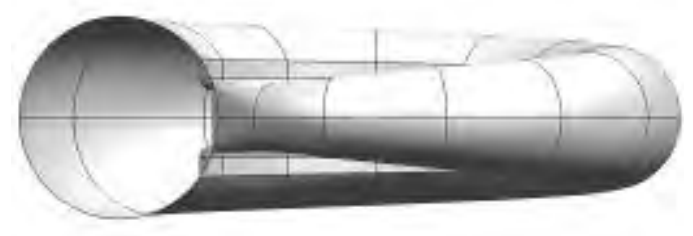

$3.25 \mathrm{D}$
Final Alden Spiral Case

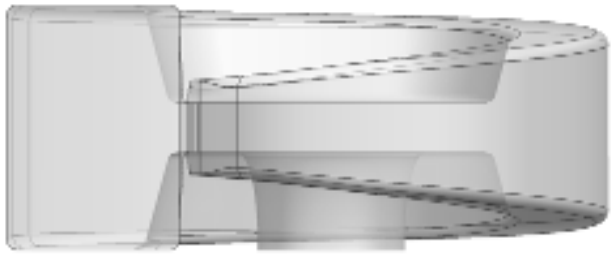

$3.25 \mathrm{D}$

(i)

(ii)

Figure 2-23

Side views of Original and Final Alden Spiral Case Showing (i) Circular Cross Cection and (ii) Rectangular Cross Section

Although the concrete concept was selected over the plate steel to help reduce material cost considerations, the casing width dictates the size of the power house and represents a cost driver for installation of the Alden turbine. To produce the steeper inflows required by the final distributor, the casing had to be designed to provide small tangential velocities at the distributor entrance. These smaller tangential velocities can be achieved by increasing the cross sectional areas of the spiral case. For the original spiral case featuring circular cross sections, an area increase results in a large casing width. However, for the rectangular concept, increased cross sectional areas can be achieved by changing the aspect ratio of the sections. By employing a spiral case that is taller than the original (see Figure 2-23), the final casing is capable of providing steeper inflows to match the final stay vane orientation while still maintaining the original casing width. Plan views of the original and final spiral cases are illustrated in Figure 224. 
Hydraulic Development: Computational Analysis of Geometry Modifications for Fish Friendliness and Turbine Performance

Original Alden Spiral Case

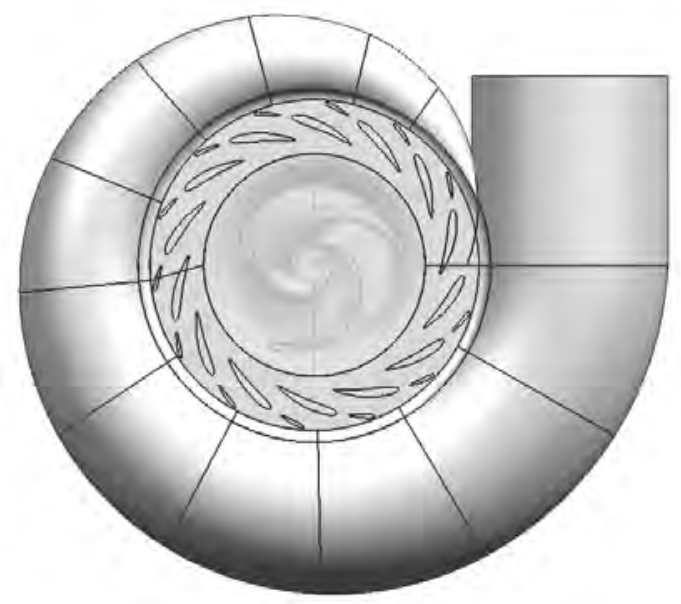

(i)

Figure 2-24

Pan Views of (i) Original and (ii) Final Alden Spiral Case Showing Equal Widths of 3.25 D

To minimize the potential impact of the corners on passing fish, Alden specified the use of fillets for the rectangular cross sections (see Figure 2-24, right image). A ten inch fillet radius was incorporated into the computational domain before tapering off at the entrance to the spiral case and then again upstream of the nose vane. Although the presence of the fillets was predicted to have a negligible influence on the overall flow patterns within the spiral case and resulting performance, the fillets will be included in field installations to enhance the fish passage environment. It should be noted that these fillets were not included in the physical model test described in upcoming report sections.

While the spiral case width could be reduced further by increasing the aspect ratio of the rectangular section, it is anticipated that the spiral case will be attached to a circular penstock located farther upstream. In order to keep the flow in this transition manageable, the final casing was designed without any further reductions to its width. The geometry of the proposed transition piece utilized to connect the circular penstock to the rectangular cross section is given below in Figure 2-25. 


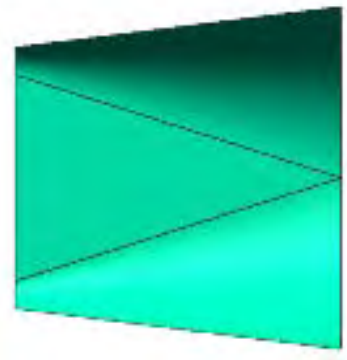

(i)

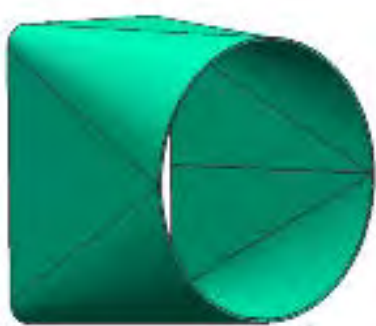

(ii)

\section{Figure 2-25}

(i) Plan and (ii) Side Views of Transitional Inlet Piece Necessary to Connect Circular Penstock with Rectangular Spiral Case.

Once the spiral case geometry was defined, a full $360^{\circ}$ model of the outer casing, along with transition piece and the final distributor components, was evaluated with computational fluid dynamics to document the flow characteristics and loss values at the selected design condition of $92 \mathrm{ft}$ of net head and a discharge rate of $1500 \mathrm{cfs}$.

\section{Computational Setup for the Spiral Case}

The computational setup associated with the $360^{\circ}$ model of the spiral case is more complex than that described in the section Computational Fluid Dynamics (CFD) for the sector model. Instead of setting the inflow at a representative distributor location, the mass flow and flow direction for each operating point is applied normal to the inlet of the transition piece. For the full spiral case geometry, the computational mesh was created manually with a combination of tetrahedral and hexahedral elements. An illustration of the mesh associated with the full model of the final Alden spiral case is given below in Figure 2-26. 
Hydraulic Development: Computational Analysis of Geometry Modifications for Fish Friendliness and Turbine Performance

Final Alden Spiral Case

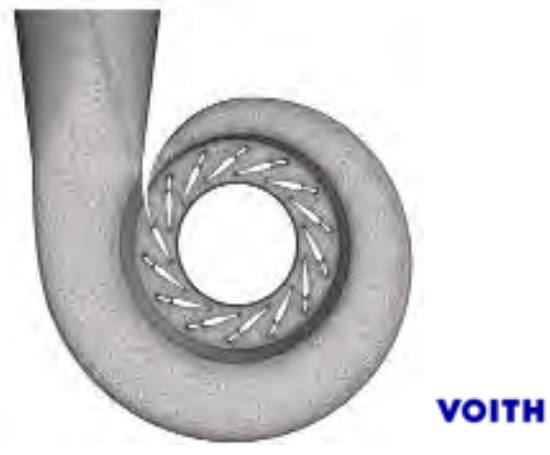

(i)

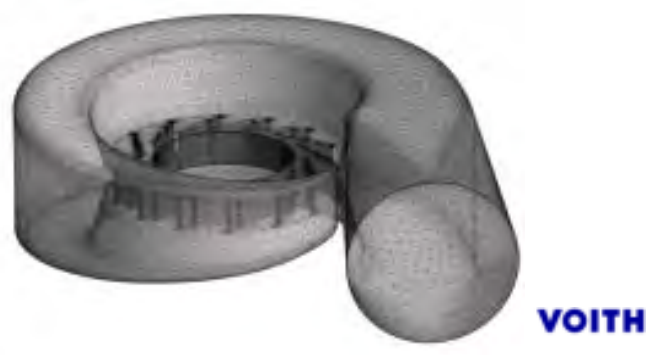

(ii)

Figure 2-26

Computational Meshes Showing (i) Plan and (ii) Side Views of Final Alden Spiral Case and Distributor.

For the calculations associated with the final Alden spiral case geometry illustrated in Figure 2-26, the meshes consisted of 4.1 million tetrahedral, 2.6 million prisms, and 42 thousand pyramids for a total of 6.7 million elements. A sector of model of the runner consisting of 0.9 Million additional hexahedral elements was also included in the simulation. As before, the interface between the stationary (distributor) and rotating (runner) domains was modeled with stage interfaces which average the flow properties in the circumferential direction. These upstream calculations included a runner with the relative (gauge) outlet pressure set equal to $0 \mathrm{~Pa}$ (i.e. atmospheric pressure).

\section{Velocity Documentation for the Spiral Case}

During design of the final spiral case, it was essential to provide a smooth inflow that aligns with the final stay vanes. In order to document these velocity fields within the spiral case, computed velocity contours are presented in Figure 2-27 and Figure 2-28 on various planes located throughout the transition piece, the final spiral case and the final distributor. 

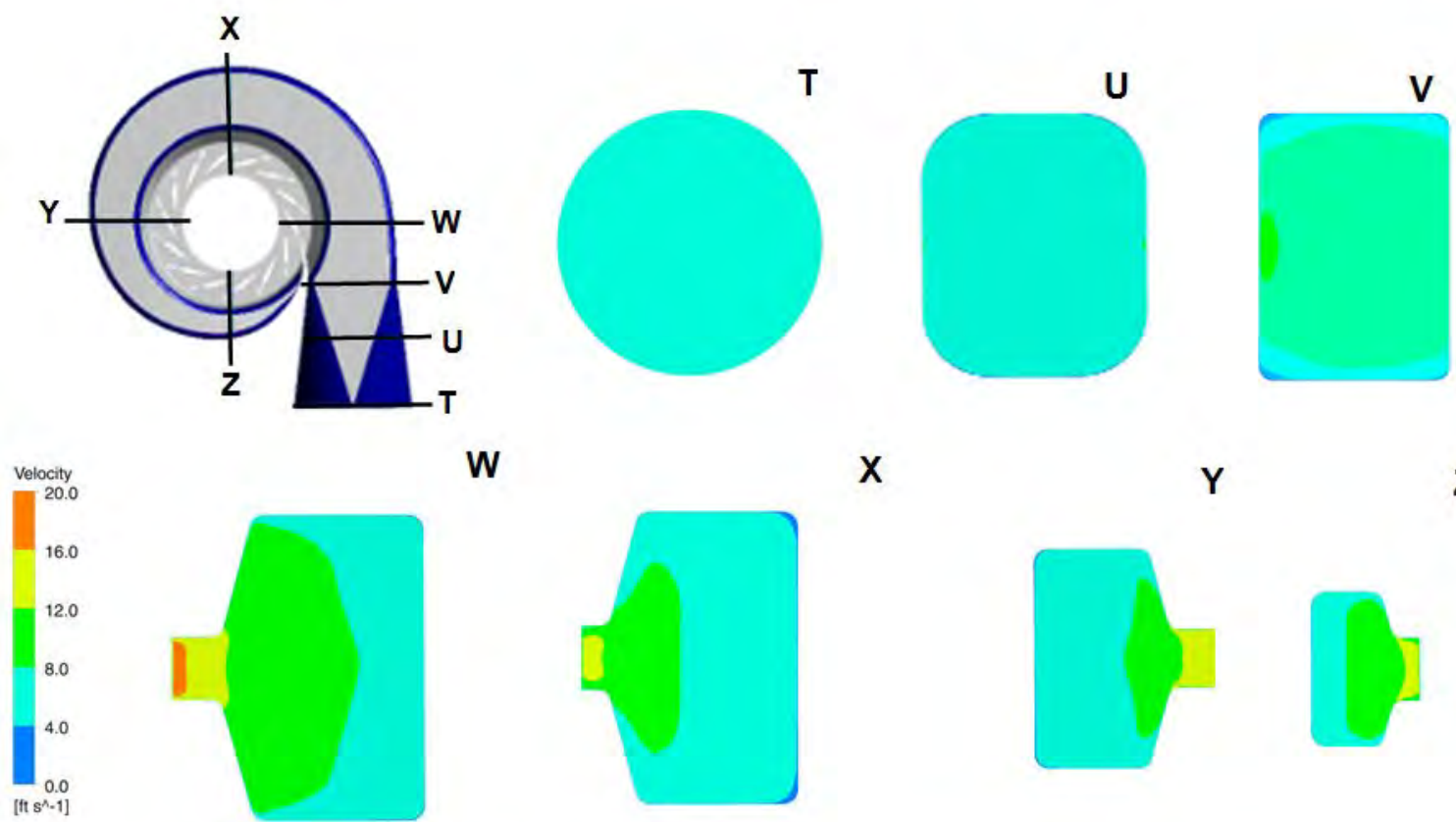

W

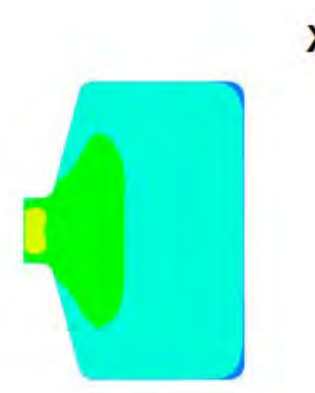

$\mathbf{x}$

Y

$\mathbf{Z}$
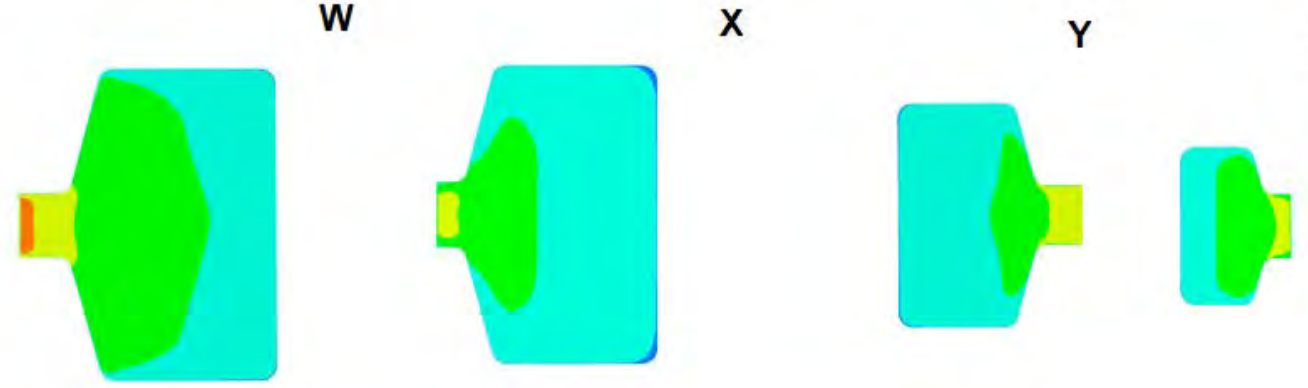

Figure 2-27

Computed Velocity Distributions Evaluated on Several Vertical Planes throughout the Final Alden Spiral Case 
Hydraulic Development: Computational Analysis of Geometry Modifications for Fish Friendliness and Turbine Performance

Final Alden Spiral Case
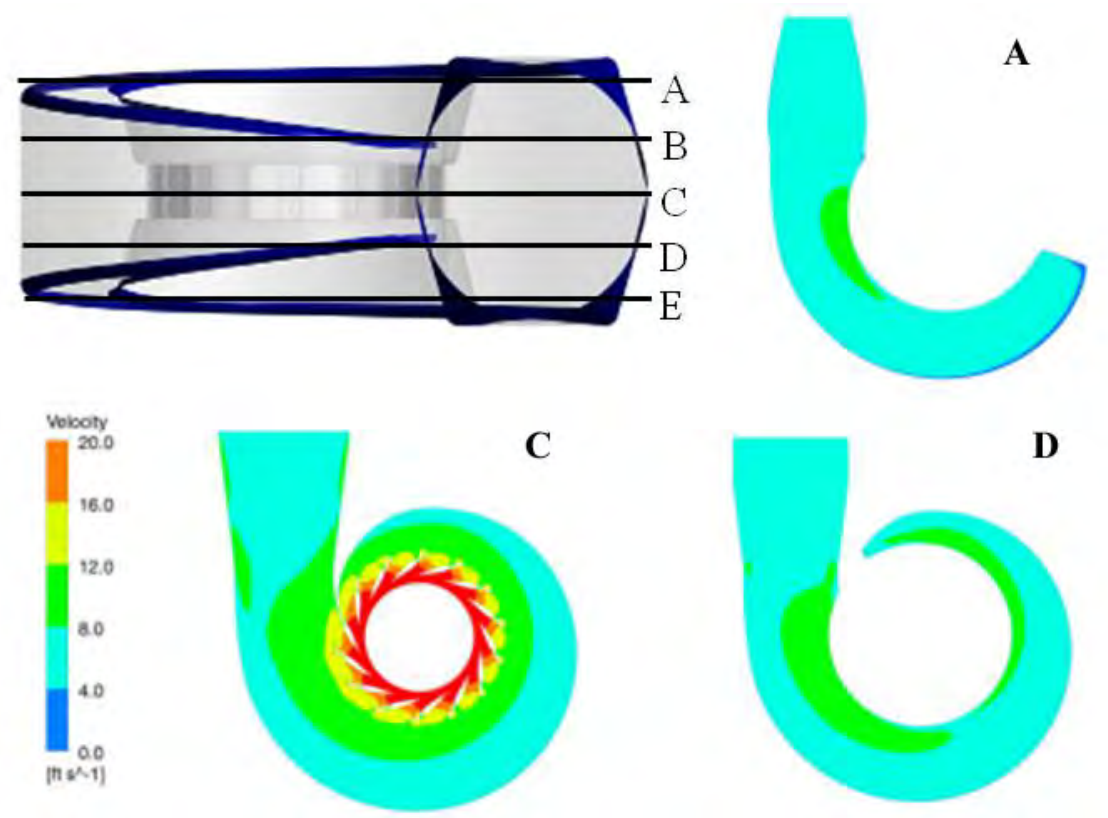

\section{VoITH}

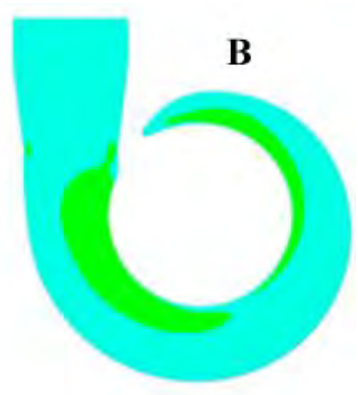

D

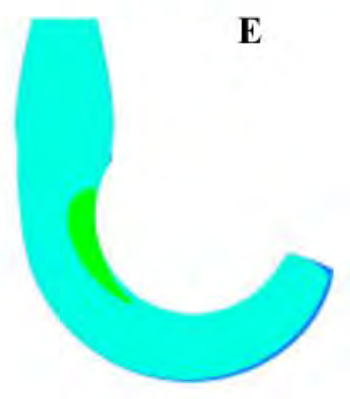

Figure 2-28

Computed Velocity Distributions Evaluated on Several Horizontal Planes throughout the Final Alden Spiral Case

Within the vertical planes illustrated in Figure 2-27, the velocity contours indicate that the inflow through the transition piece and into the rectangular casing is uniform, showing velocities in the neighborhood of $6 \mathrm{ft} / \mathrm{s}$. Moving around the case from sections $\mathrm{w}$ to $\mathrm{z}$, the velocity distributions are very similar to one another, with lower velocities within the outer part of the casing $(v \approx 4$ $\mathrm{ft} / \mathrm{s})$ that gradually increase at the entrance to the distributor $(v \approx 12 \mathrm{ft} / \mathrm{s})$.

The velocity distributions illustrated on the horizontal planes in Figure 2-28 also show a relatively uniform flow distribution within the spiral case. Within the mid-span of the spiral case (section $C$ ), the velocities are largest around the distributor. This region of elevated velocities $(v$ $\approx 8$ to $12 \mathrm{ft} / \mathrm{s}$ ) decreases above and below the horizontal centerline (section $B$ and $D$, respectively). At the top and bottom of the spiral case (sections $A$ and $E$, respectively), this region of elevated velocities is limited to the upstream portion of the spiral case, near the connection with the transition piece.

Overall, the flow within the final spiral case and transition piece is uniform through the entire geometry. Although the velocities are somewhat lower than those of a conventional hydro turbine, the casing does not give rise to any large regions of low velocities where fish could rest and potentially tire before continuing into the spiral case. Further illustration of the flow characteristics within the final Alden turbine is given in Figure 2-29 showing streamlines on the horizontal mid-plane. 


\section{VOITH}

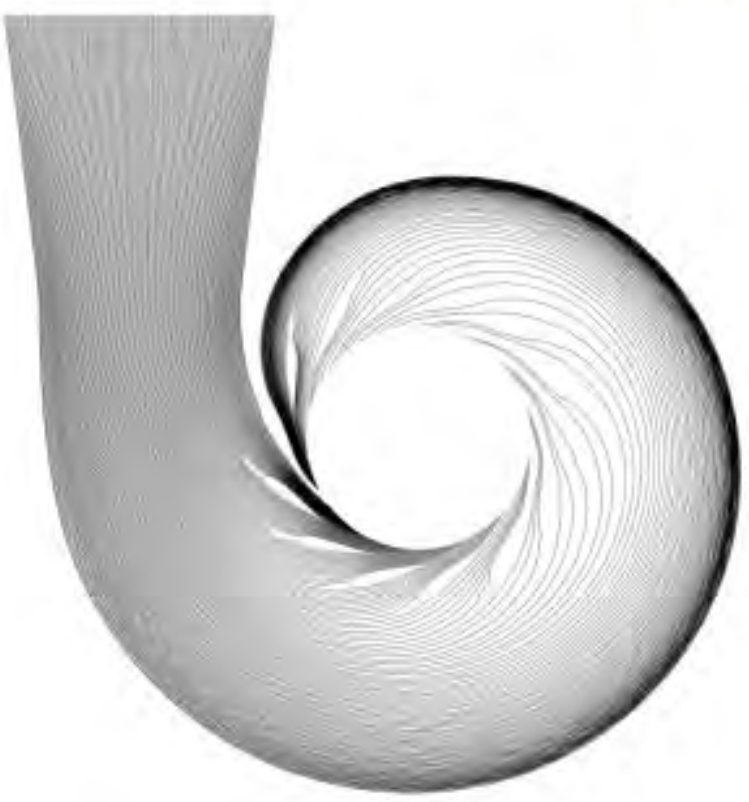

Figure 2-29

Streamline Patterns within the Final Alden Spiral Case and Distributor

The streamline patterns within the transition piece indicate smooth, uniform flow without any disturbances that could be harmful to fish. As the flow continues around the spiral case and into the distributor, the streamlines show that the incoming flow is properly aligned with the stay vanes. The aforementioned flow features illustrated within the upstream components indicate that the final spiral case and distributor satisfy the fish friendly features of the original design concept, while being significantly cheaper to implement at the pilot site due to the change from plate steel to concrete.

\section{Predicted Performance}

In addition to the aforementioned fish friendly characteristics of the Alden turbine, geometry modifications to the turbine components were also evaluated according to their influence on machine performance. These performance impacts are discussed in the upcoming section.

\section{Runner and Draft Tube Performance}

One of the key factors in determining overall turbine performance relates to the velocity profile at the runner exit and how the flow interacts with the draft tube. Initial calculations for the original Alden runner and draft tube indicate that the flow leaving the runner does not optimize with the draft tube at the selected design condition. During the current investigation, runner geometry modifications were selected to improve this runner-draft tube interaction through manipulation of the exit velocity profile. A comparison of the computed axial and tangential velocities for the original and final Alden runner is given below in Figure 2-30. 
Hydraulic Development: Computational Analysis of Geometry Modifications for Fish Friendliness and Turbine Performance

Original Alden Geometry

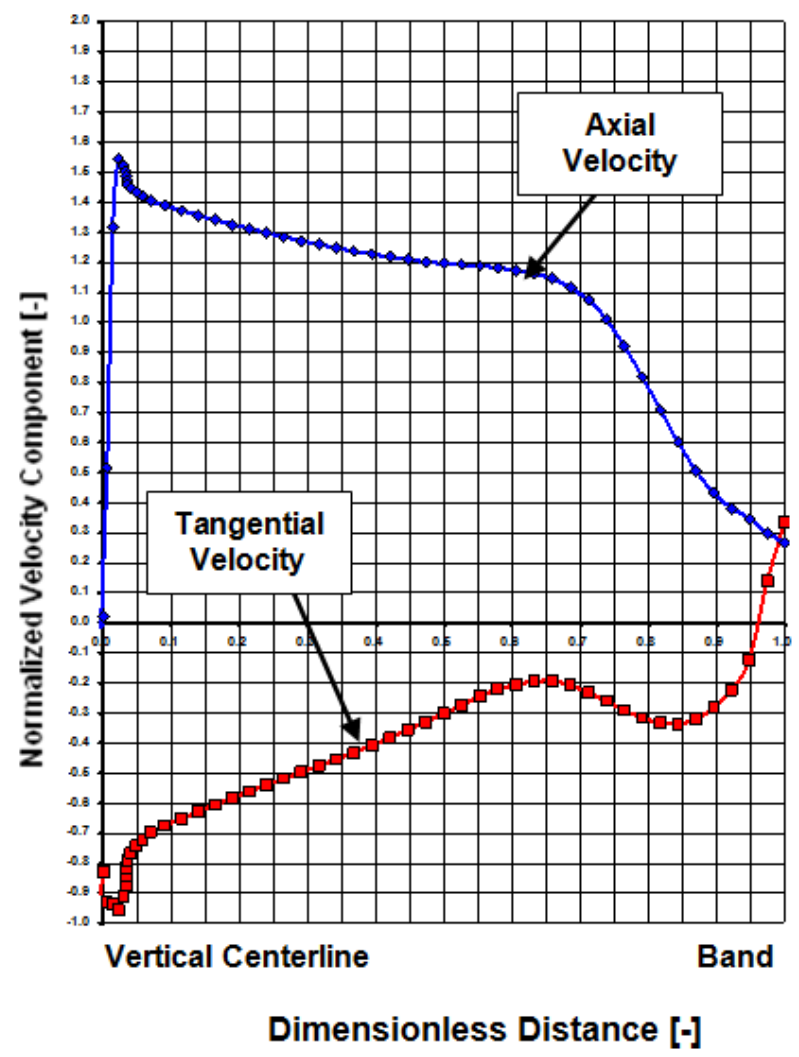

(i)
Final Alden Geometry

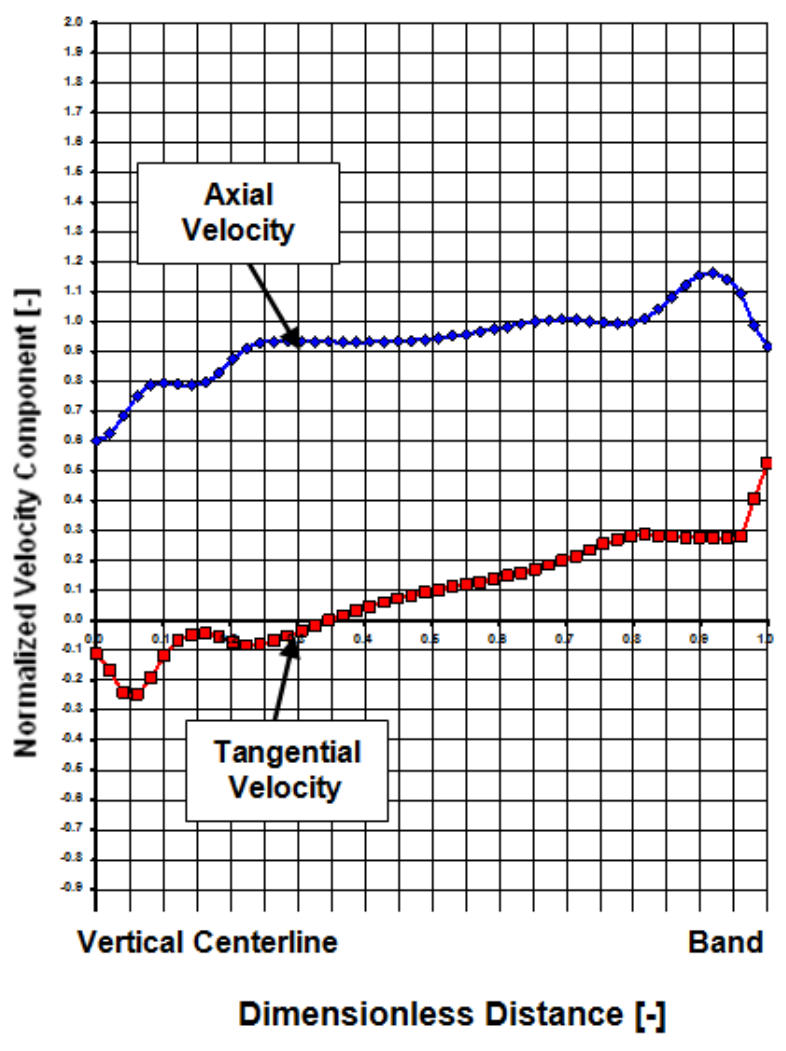

(ii)

\section{Figure 2-30 \\ Computed Axial and Tangential Velocity Extracted downstream of the (i) Original and (ii) Final Alden Runner Blades}

The computed axial and tangential velocities corresponding to the final Alden runner are more uniform across the draft tube cone. These flatter profiles are linked with improved runner draft tube interaction and resulting machine performance. As previously described, the large negative tangential velocity values associated with the original Alden runner indicate that peak performance occurs at a lower flow rate than $Q=1,500 \mathrm{cfs}$. An illustration of the draft tube flows associated with the original and final Alden runners is given in Figure 2-31. 
Original Alden Geometry

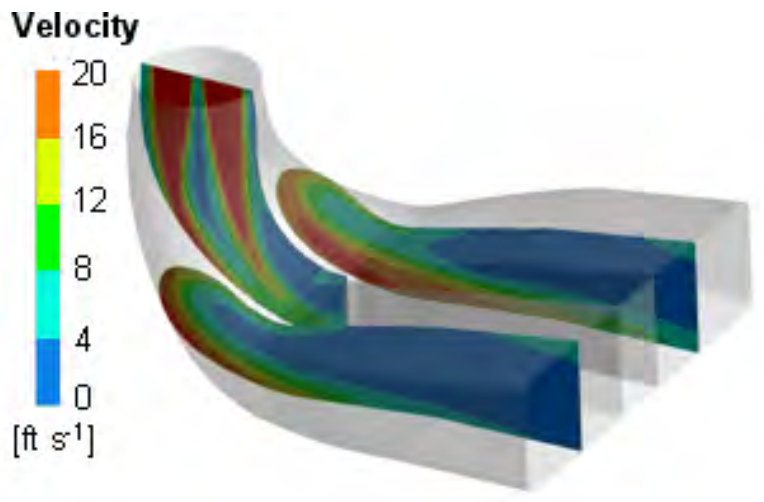

(i)
Final Alden Geometry

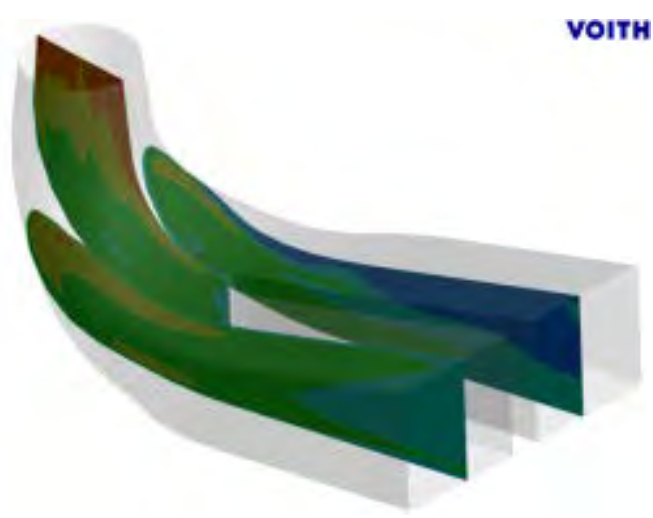

(ii)

Figure 2-31

Predicted Draft Tube Flow Characteristics for the (i) Original and (ii) Final Alden Runner

In each draft tube, velocity contours are plotted on three vertical planes, showing flow within the center of the draft tube cone and elbow, as well as along the center of both the left and right bays. The flow within the final draft tube (right image) is more uniform when compared to corresponding locations in the original turbine. One of the most significant areas of improvement relates to the flow as it leaves the draft tube elbow, where flow separation creates a large region of low velocity that continues the length of both original bays. The flow within the final elbow remains attached, providing a more uniform velocity field within the bays. Although some separation does occur in the left bay of the final draft tube, the low velocity region is significantly smaller than that of the original runner and draft tube. Further illustration of the draft tube flows associated with the original and final runner geometries is given in Figure 2-32 in the form of streamline representations. 
Hydraulic Development: Computational Analysis of Geometry Modifications for Fish Friendliness and Turbine Performance

Original Alden Geometry

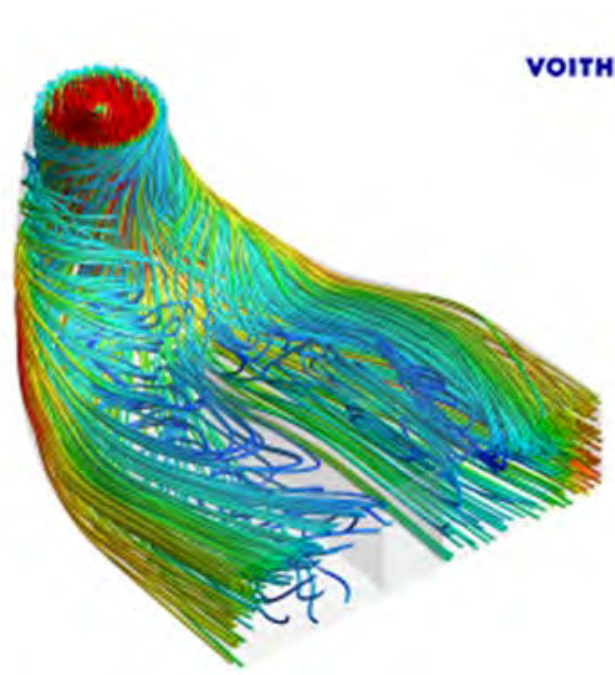

Final Alden Geometry

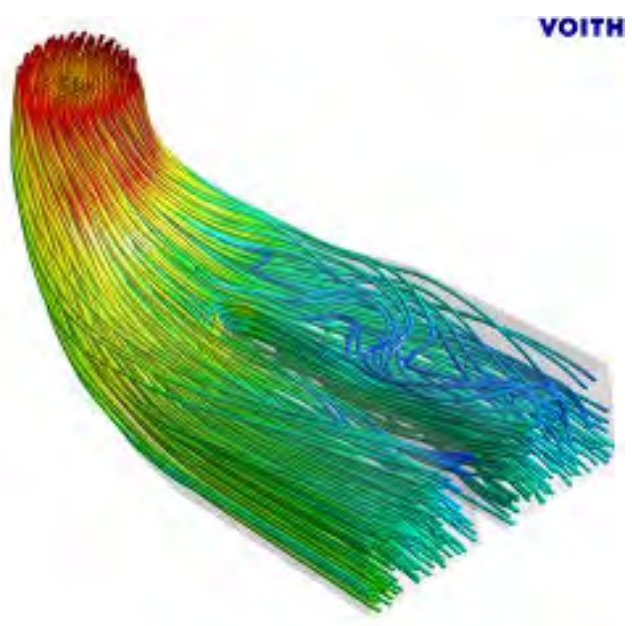

Figure 2-32

Draft Tube Flow Visualization for the (i) Original and (ii) Final Alden Runner.

The draft tube streamline patterns given in Figure 2-32 are consistent with the velocity contours shown in Figure 2-31. Large regions of flow separation are present in the original draft tube cone, elbow and both draft tube bays. The streamline patterns associated with the final geometry significantly improved, showing uniform flow in the cone, elbow and right bay (looking downstream). Although a small flow distortion is present in left bay, it is not expected to have a negative impact on fish passage in the draft tube and tailrace.

The runner modifications outlined in the current investigation have been shown to reduce the losses within the runner itself, which also has a large impact on the calculated draft tube losses. A comparison of the predicted losses within the runner and draft tube domains is given in Table 2-4. These losses represent expected efficiency improvements between the original and final Alden turbine geometries.

Table 2-4

Predicted Runner and Draft Tube Losses for the Original and Final Alden Turbine at $\boldsymbol{H}_{\text {net }}=$ $92 \mathrm{ft}, Q=1500 \mathrm{cfs}$.

\begin{tabular}{|c|c|c|}
\hline Geometry & RU Losses [\%] & DT Losses [\%] \\
\hline Original Turbine & 4.96 & 6.26 \\
\hline Final Turbine & 4.17 & 0.77 \\
\hline$\Delta \eta[\%]$ & 0.79 & 5.49 \\
\hline
\end{tabular}

The component losses associated with the final runner and draft tube are significantly lower than the original turbine at the selected design point. As indicated in Table 2-4, the efficiency improvements are more pronounced within the draft tube. Together, these new flow 
characteristics are expected to improve the final Alden turbine efficiency by more than six percent at the selected design point.

\section{Performance of Upstream Components}

The aforementioned design modifications to the upstream components were selected to maintain a high level of fish friendliness by providing minimum clearances between the Alden stay vanes and wicket gates, while providing thicker nose profiles. A secondary consideration relates to the performance impacts induced by skin friction and secondary losses through the distributor. For conventional turbine designs, thicker nose profiles tend to have a negative impact on performance by increasing the friction losses. However, for the Alden turbine, the velocities through the distributor are small enough that the friction losses are negligible. These distributor losses associated with the original and final Alden turbine is given in Table 2-5.

Table 2-5:

Predicted Spiral Case (SC), Stay Vane (SV) and Wicket Gate (WG) Losses for the Original and Final Alden Turbine at $H_{\text {net }}=92 \mathrm{ft}, Q=1500 \mathrm{cfs}$

\begin{tabular}{|l|l|l|l|}
\hline Geometry & SC Losses [\%] & SV Losses [\%] & WG Losses [\%] \\
\hline Original Turbine & 0.14 & 0.16 & 0.80 \\
\hline Final Turbine & 0.14 & 0.10 & 0.56 \\
\hline$\Delta \eta[\%]$ & 0.0 & 0.06 & 0.14 \\
\hline
\end{tabular}

For the spiral case and stay vanes, performance differences between the original and final geometry are negligible. Due to the improved flow characteristics associated with the final wicket gate shapes, the predicted losses are slightly lower than those associated with the cambered gate shapes of the original distributor. Overall, the final upstream turbine components were shown to produce $0.2 \%$ higher turbine efficiencies.

Geometry modifications to the spiral case, stay vanes and wicket gates were selected primarily to improve the flow environment for passing fish. Thicker entrance edge profiles, improved alignment and minimized gaps between components are expected to reduce strike events on these components. In addition to these fish passage enhancements, the geometry modifications are expected to improve performance and reduce supply and installation costs.

\section{Summary}

During this design phase, CFD simulations were utilized to evaluate the influence of geometry modifications on predicted shear, pressure change rates, and minimum pressures through the runner passageway, as well as component losses for a design point corresponding to an anticipated full scale demonstration site. While the calculated shear and pressure change rates were observed to be similar between the original and final runner geometries, the minimum pressures within the runner were predicted to be higher than the desired 7.4 psia. 
Hydraulic Development: Computational Analysis of Geometry Modifications for Fish Friendliness and Turbine Performance

During the design phase of the current Alden turbine development, geometry modifications were defined for the spiral case, stay vanes and wicket gates. These hydraulic shapes were selected to improve the fish passage environment within the Alden turbine.

The improved flow environment through the final Alden turbine is also expected to produce significant efficiency improvements. While some small performance improvements are predicted for the final distributor, the majority of the efficiency improvements are realized in the final runner and draft tube due to the improved runner-draft tube interaction at the selected design condition of $H_{\text {net }}=92 \mathrm{ft}, Q=1500 \mathrm{cfs}$. Ultimately, calculations show that the final Alden turbine is expected to have the same or slightly improved fish friendly characteristics with improved turbine performance and efficiency.

After the release of the final Alden turbine geometry, a physical model of the turbine was designed and constructed for performance testing in Voith Hydro's hydraulic laboratory in York Pennsylvania. During the time period from September to November 2010, efficiency, power, cavitation inception, cavitation breakdown, axial thrust, stability, runaway speed and steady radial thrust data was collected across a range of head and flows corresponding to application at Brookefield Renewable Power's School Street Station. Details of the Alden turbine model testing and corresponding results will be presented in Chapter 5 of this report.

The final aspect of the developmental engineering phase relates to the design for the supporting mechanical and balance of plant equipment for supply of the complete unit. In this phase, Finite Element Analysis (FEA) was performed to determine the static stresses for the stay vanes, wicket gates and runner modifications. Mechanical design and analysis of the final spiral case and stay ring decks was completed. Estimates of the scope of supply, manufacturing and installation costs, as well as the supply schedule corresponding to the application at School Street are documented in Chapter 7 of this report. 


\section{STRUCTURAL ANALYSIS}

\section{Turbine Component Mechanical Design Summary}

The mechanical design of the Alden Hydro Turbine is a hybrid of what is typically found in conventional Francis and Kaplan turbines. The large flow, low head, and large diameter characteristics of the unit are similar to a vertical Kaplan unit. The overall layout, however, is similar to a vertical Francis configuration. Three major turbine components unique to this hydraulic design were identified early on for in-depth mechanical analysis and design. Several design iterations occurred to optimize both the hydraulic and mechanical design aspects for these major wetted turbine components. These analyses also took into consideration the costs associated with manufacturing the components for an optimal complete solution.

The first component selected for in-depth analysis was the runner. It was unknown how the tall runner, with only three blades, would perform structurally. An FEA analysis was performed on the runner. The FEA results of the final runner configuration are presented in the upcoming section "Alden Runner Static and Modal Analysis". To minimize damage to the fish and maintain performance, the leading edge of the blade is very thick and the trailing edge is as thin as practical. The large blade wrap and thickness provided sufficient structural rigidity and low overall stress.

The second component selected for in-depth analysis was the stay ring. It was determined during the hydraulic design to have a full concrete spiral case in order to reduce cost. Additionally, to minimize strike locations for the fish, the unit only has fourteen (14) stay vanes, at a larger diameter to accommodate the high flows. The combination of these criteria leads to large spans between the stay vanes. Several iterations of rib design and weld sizing were performed using FEA to optimize this design. The FEA results of the final stay ring configuration are presented in the upcoming section "Alden Stay Vane Static Analysis”.

The third component selected for in-depth analysis was the wicket gate. As with the stay vanes, there are only fourteen (14) wicket gates, leading to large spans and increased forces. Stem sizes were designed in accordance with Voith design guidelines for radial forces, torques, and bearing pressures. The gate was then analyzed using FEA. The FEA results of the final wicket gate configuration are presented in the upcoming section "Wicket Gate Static and Modal Analysis".

\section{Power-Unit Design Summary}

In addition to the significant turbine components mentioned above, the overall power-unit design was developed. The overall unit arrangement is shown in the Appendix in the "Unit Arrangement Drawing". This arrangement was developed considering the installation of this unit as the new unit at the School Street Station plant incorporating such features as maintaining 
the powerhouse crane hook / rail height of the existing plant. The most significant design parameter verified as part of this analysis was the stability of the overall power-unit shaft line. The generator design incorporates a combined vertical thrust and radial guide bearing located below the generator rotor. Due to the long overhang of the runner, and to make the design as environmentally friendly as possible, a water bearing was selected for the turbine guide bearing. This arrangement allows the turbine guide bearing to be as close to the runner as possible with the shaft seal located immediately above the water bearing. Thus, this shaft line includes two (2) radial guide bearings and one (1) vertical thrust bearing. The power-unit shaft line analysis was then performed, using a program developed by Voith, to ensure that runner deflections were small enough to meet hydraulic requirements on the seal clearance and sufficient critical shaft speed for the proper dynamic operation of the unit. The results of the shaft line analysis are presented in the upcoming section "FEA Report - Shaft Critical Bending Speed and Bending Line Analysis". The shaft was sized in accordance with Voith and industry design guidelines.

\section{Other Component Design Considerations}

Other than the unique requirements presented above, the design of the other power unit components is very similar to that of a conventional unit. In addition to the in-depth analysis performed above, the remainder of the unit was designed using Voith and industry design guidelines and sizing rules, including codes from the American Society for Testing and Materials (ASTM), the American Society of Mechanical Engineers (ASME), the International Electrotechnical Commission (IEC), the National Electrical Manufacturers Association (NEMA), the Institute of Electrical and Electronics Engineers (IEEE), the International Organization for Standardization (ISO), and the American National Standards Institute (ANSI).. The turbine wicket gate mechanism layout was performed to determine servomotor size and oil volume to complete the auxiliary support systems sizing. A simple analysis of the turbine head cover was performed to check deflections and verify plate thicknesses. The combined turbine bottom ring / discharge ring and draft tube cone were sized using simple spread sheet calculations. Please note however, that Voith has not performed any concrete or civil design calculations or considerations for the powerhouse structure.

\section{Alden Runner Static and Modal Analysis}

\section{Static Finite Element Analysis}

This report details the findings of a Finite Element Analysis (FEA) performed on the Alden runner. The stresses and deflections are investigated, as well as the resonant frequencies in water.

\section{FEA method}

To investigate the stress and deflection of the Alden runner, a static finite element analysis was performed. The geometry is taken from a detailed 3-dimensional CAD model and meshed automatically with finite elements for the calculation. Pressure loads are put onto the model according to the load case specifications. Fillets were adjusted as needed to ensure both allowable stresses and product optimization. 
All preprocessing, solution and post processing steps were done with ANSYS Rev. 12.1, ANSYS Inc.

The geometry model was imported from the CAD program UniGraphix using the parasolid interface. Because of the cyclic symmetry a sector model of $1 / 3$ of the crown and band and one blade was created. With respect to that a fine mesh could be created. The mesh of the geometry is shown in Figure 3-1. Details of the mesh are in Table 3-1.

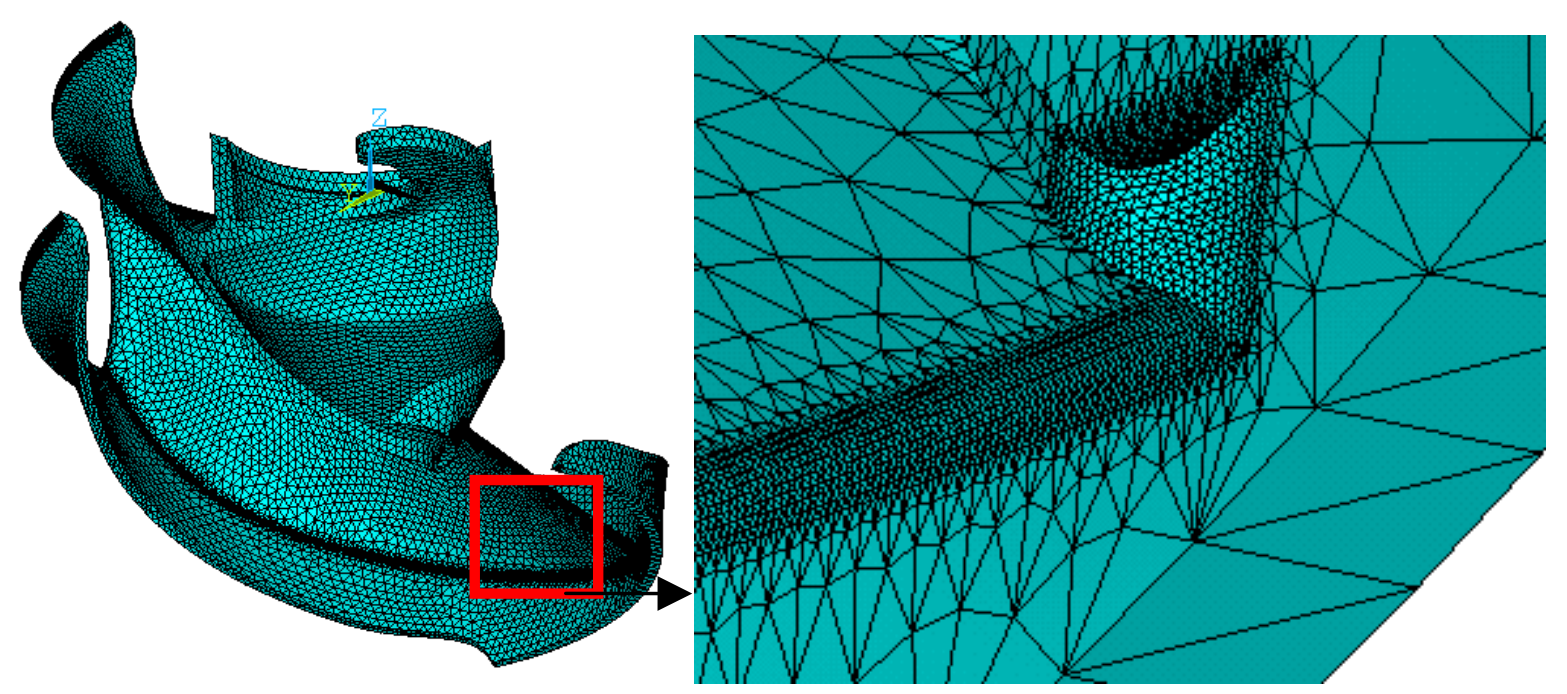

Figure 3-1 Meshed Model

Table 3-1 Number of Nodes and Elements of the Calculated Models

\begin{tabular}{|c|c|c|c|}
\hline No. Elements & No. Nodes & $\begin{array}{c}\text { Element Size @ } \\
\text { Critical Areas }\end{array}$ & Software Version \\
\hline 266067 & 421688 & $2.63 \mathrm{~mm}$ & ANSYS 12.1 \\
\hline
\end{tabular}

The nodes of the lateral faces are coupled for all displacements. The model is fixed in circumferential and axial direction at the bolt circle. These conditions can be seen in Figure 3-2. 


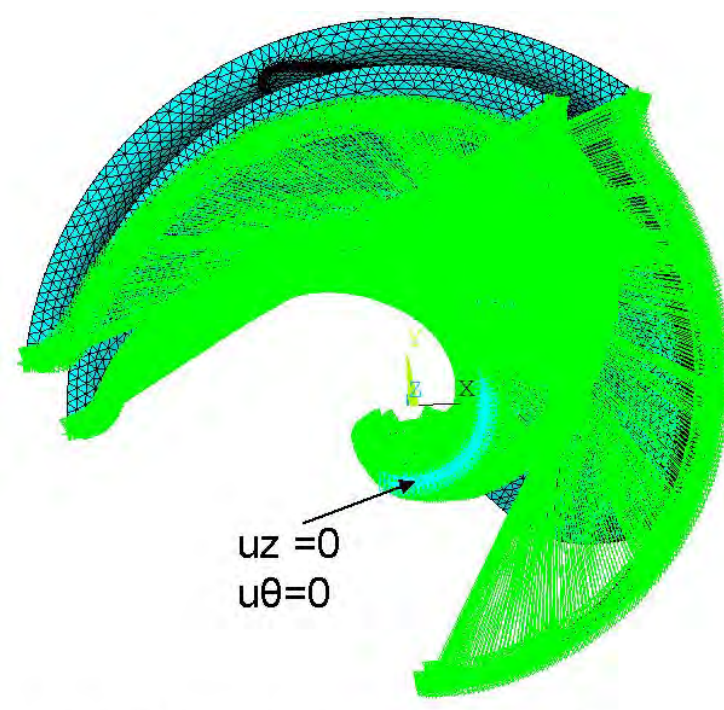

Boundary conditions of runner

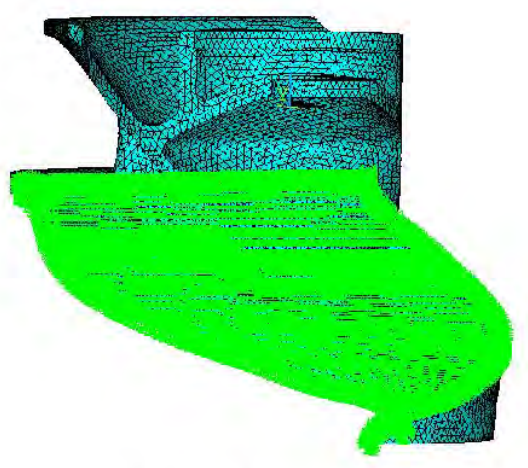

Band coupling

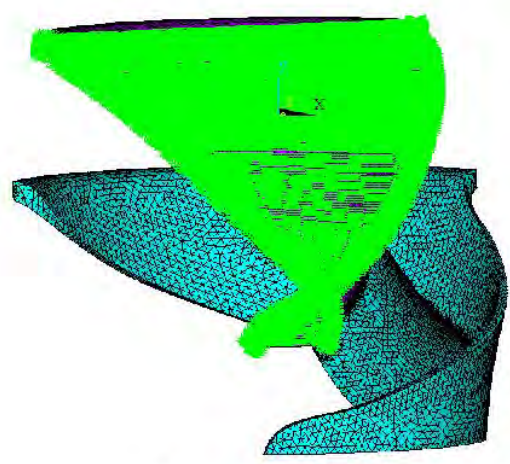

Crown coupling

Figure 3-2

Meshed Sector with Boundary Conditions

\section{Material data}

The material data for this runner is found in Table 3-2. This data is gathered from the 2006 Annual Book of ASTM Standards.

Table 3-2

Material Properties

\begin{tabular}{|c|c|c|c|c|c|c|}
\hline Component & Material & $\begin{array}{c}\text { Yield } \\
\text { Stress } \\
\text { (MPa) }\end{array}$ & $\begin{array}{c}\text { Ultimate } \\
\text { Stress } \\
\text { (MPa) }\end{array}$ & $\begin{array}{c}\text { Young's } \\
\text { Modulus } \\
\text { (MPa) }\end{array}$ & $\begin{array}{c}\text { Poisson's } \\
\text { Ratio }\end{array}$ & $\begin{array}{c}\text { Density } \\
\mathbf{( k g / m}^{\mathbf{3}} \mathbf{(}\end{array}$ \\
\hline $\begin{array}{c}\text { Crown, band, } \\
\text { blade }\end{array}$ & $\begin{array}{c}\text { ASTM A743 } \\
\text { CA6-NM }\end{array}$ & 550 & 755 & 203000 & 0.3 & 7700 \\
\hline Weld material & E410 & 741 & 877 & 203000 & 0.3 & 7700 \\
\hline
\end{tabular}

\section{Loadings}

The pressure distribution is applied according to the three following operating points:

- Maximum head and flow 
- Speed no load (SNL)

- Runaway

The different load cases data are summarized in Table 3-3.

Table 3-3

Hydraulic Data of Load Cases Calculated with CFX

\begin{tabular}{|c|c|c|c|}
\hline & Hmax, Qmax & SNL & Runaway \\
\hline $\mathbf{P}$ (MW) & 13.271 & - & - \\
\hline $\mathbf{Q}$ (ft's) & 1758.3 & 342.6 & - \\
\hline $\mathbf{H}$ (ft) & 101.2 & 92 & - \\
\hline $\mathbf{N}$ (rpm) & 120 & 120 & 190 \\
\hline
\end{tabular}

Stress Distributions

The maximum von Mises stresses for each load case and their locations on the runner are given in Table 3-4.

Table 3-4

Maximum von Mises Stresses and Their Locations

\begin{tabular}{|c|c|c|c|}
\hline & $\begin{array}{c}\text { Stress @ Critical } \\
\text { Area (MPa) }\end{array}$ & $\begin{array}{c}\text { \% of Yield } \\
\text { Stress }\end{array}$ & Location \\
\hline Hmax Qmax & 90.2 & 16.4 & Band, DE \\
\hline SNL & 110.6 & 20.1 & Crown, DE \\
\hline Runaway & 79.8 & 14.5 & Crown fillet \\
\hline
\end{tabular}

The von Mises stress plots are in MPa and are shown in Figure 3-3, Figure 3-4 and Figure 3-5. 


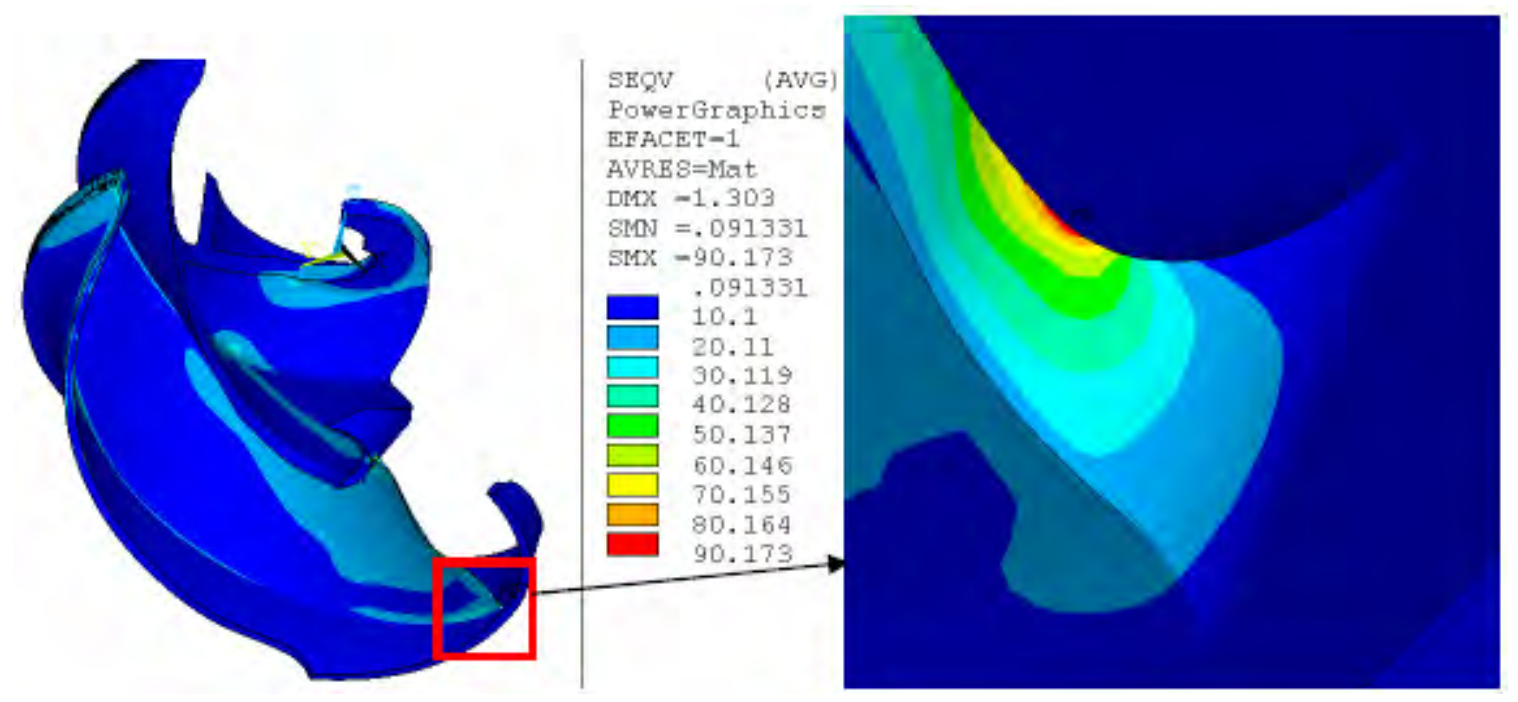

Figure 3-3

Von Mises Stress Distribution at Maximum Power and Flow

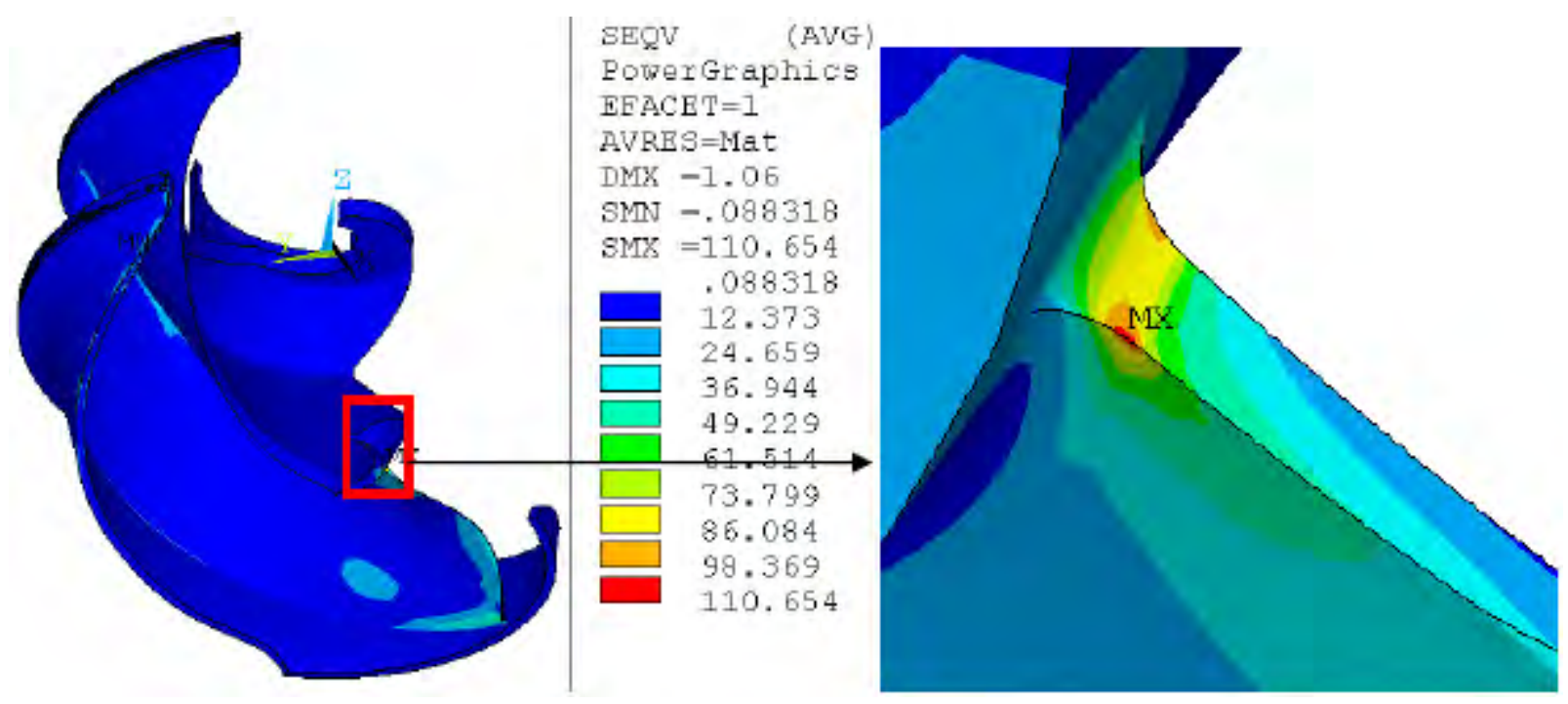

Figure 3-4

Von Mises Stress Distribution at SNL 


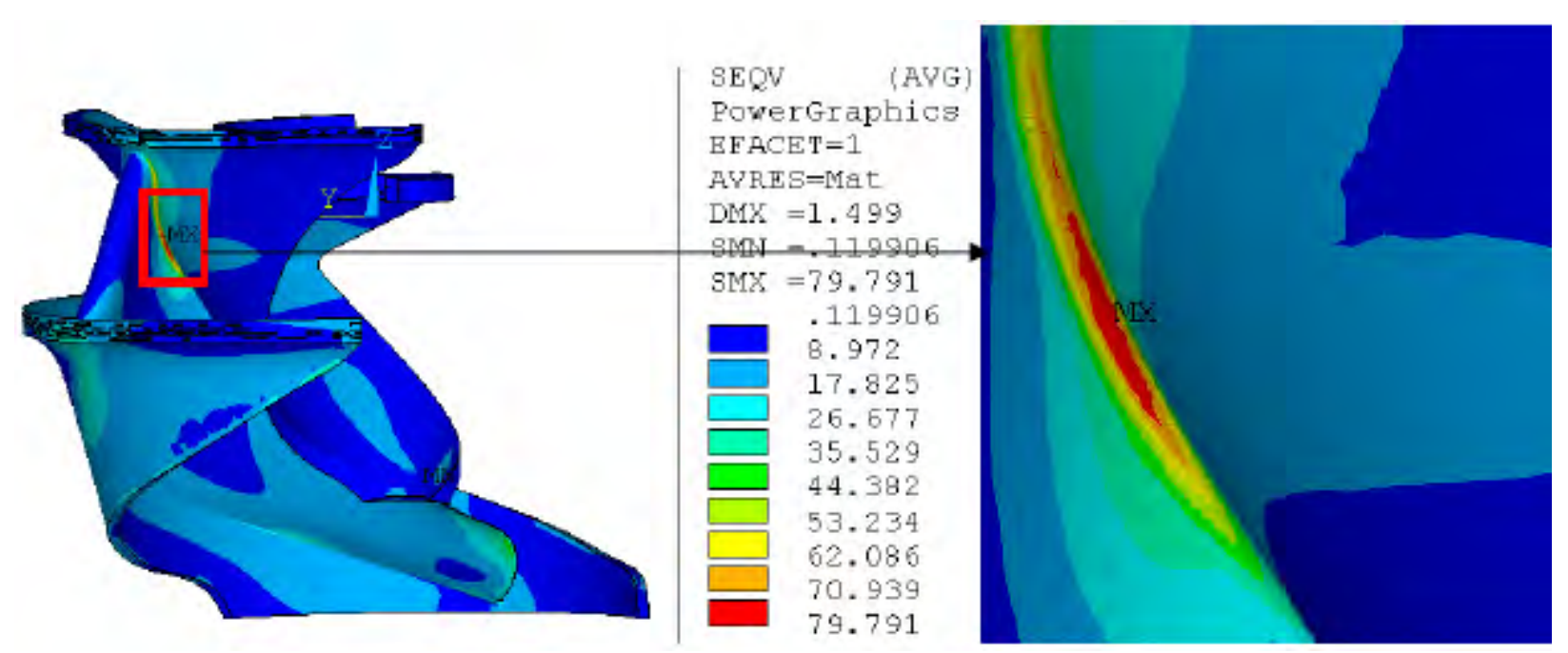

Figure 3-5

Von Mises Stress Distribution at Runaway

Deflections

The maximum radial displacements of the crown and band seals as well as the overall maximum global displacements are listed in Table 3-5:

Table 3-5

Displacements for Each Load Case

\begin{tabular}{|c|c|c|c|c|}
\hline & $\mathbf{U}_{\text {total }}(\mathbf{m m})$ & $\mathbf{U}_{\text {radial, crown }}(\mathbf{m m})$ & $\mathbf{U}_{\text {radial, band }}(\mathbf{m m})$ & Seal Clearance $(\mathbf{m m})$ \\
\hline Hmax Qmax & 1.303 & 0.0752 & 0.2626 & 1.524 \\
\hline SNL & 1.060 & 0.0957 & 0.2169 & 1.524 \\
\hline Runaway & 1.499 & 0.1785 & 0.2543 & 1.524 \\
\hline
\end{tabular}

Figure 3-6, Figure 3-7 and Figure 3-8 are plots of the total deflection, and are done in millimeters. 


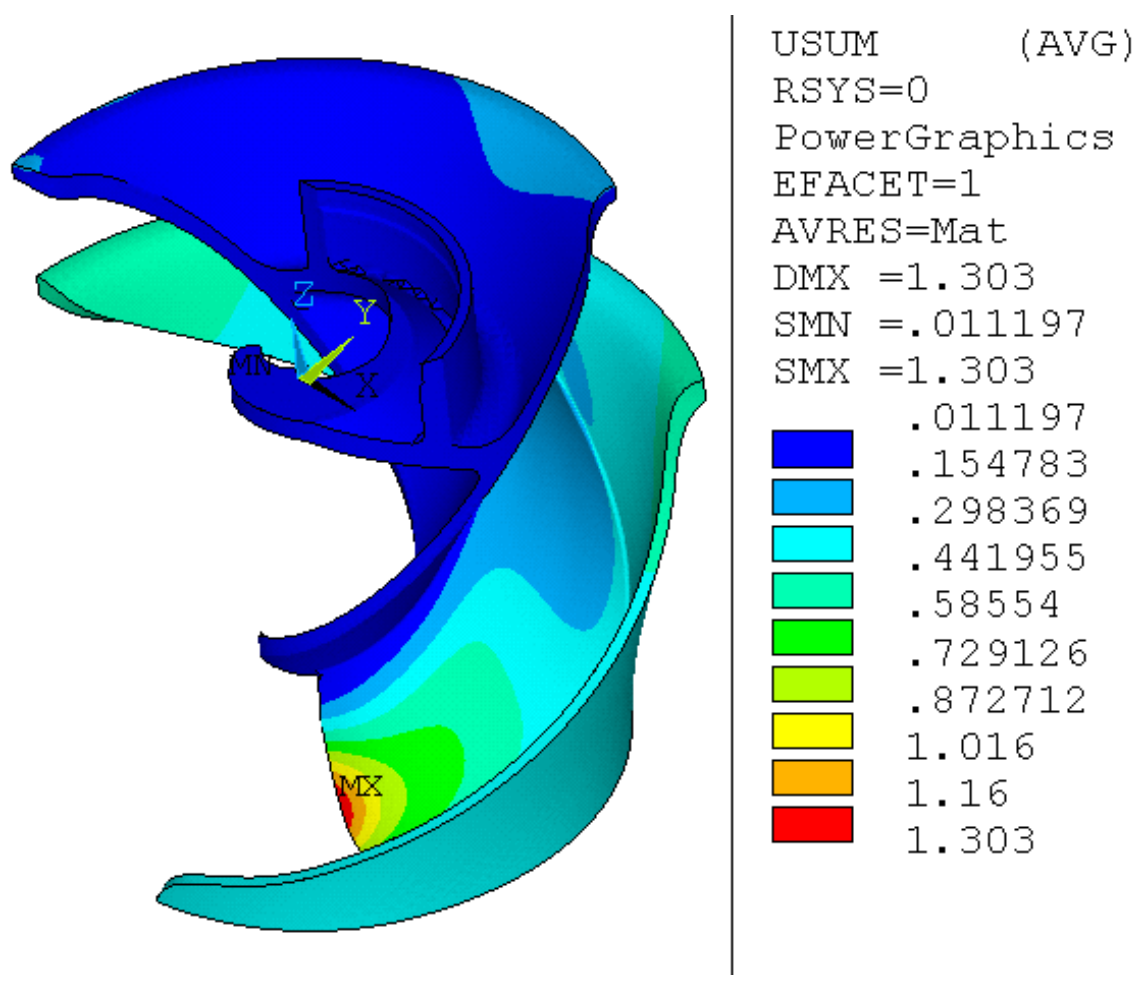

Figure 3-6

Total Displacement Distribution at Maximum Flow and Power

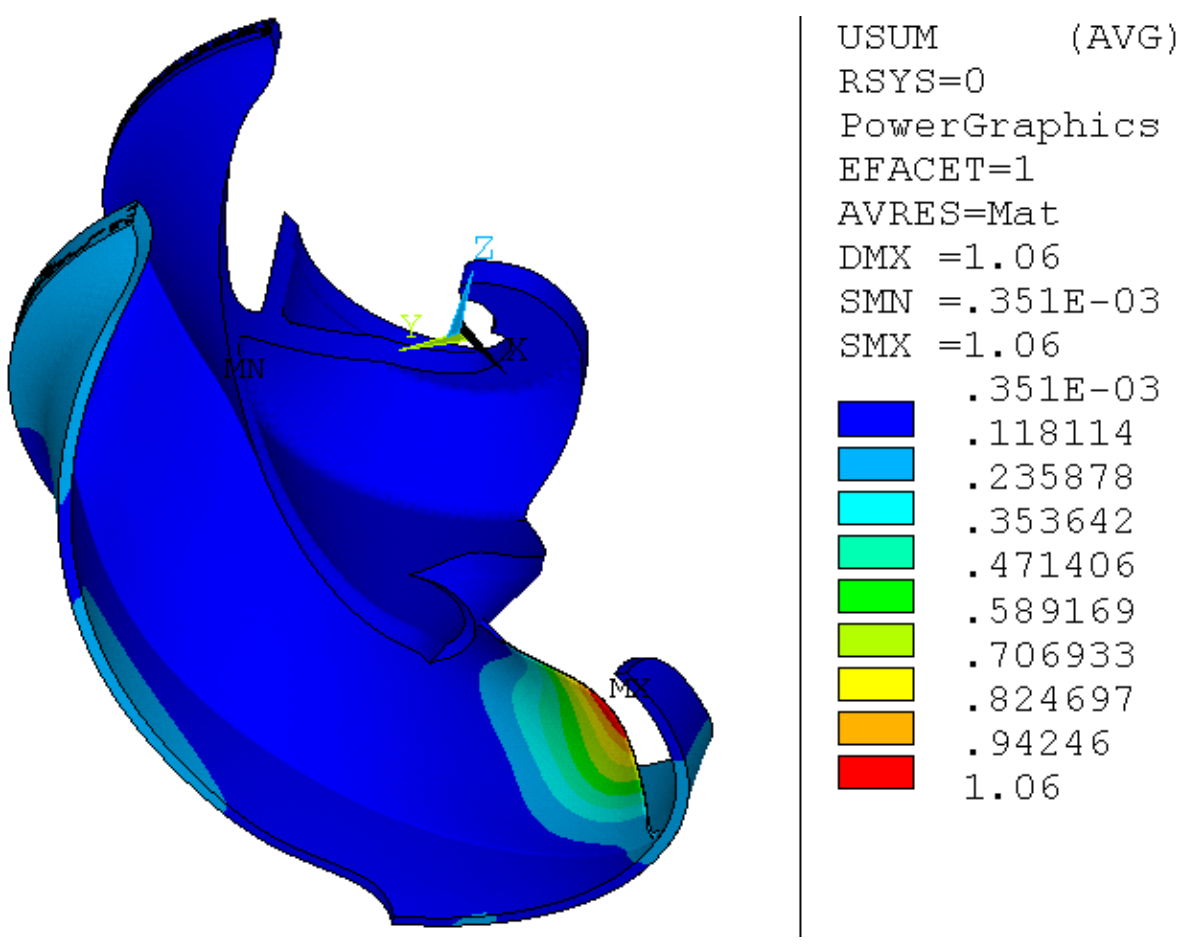

Figure 3-7

Total Displacement Distribution at SNL 


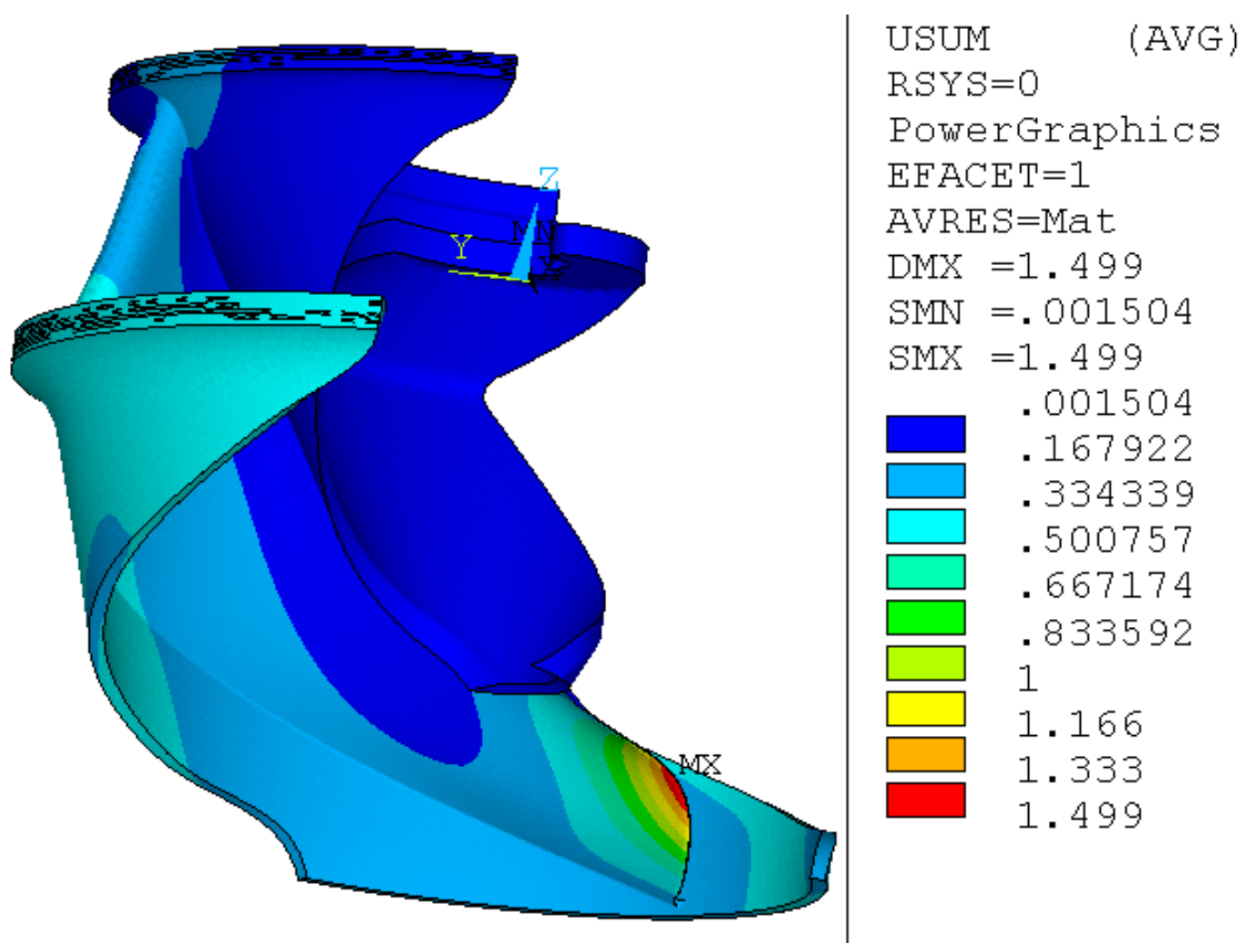

Figure 3-8

Total Displacement Distribution at Runaway

Since the radial clearance $(1.5 \mathrm{~mm})$ is greater than the maximum radial displacement of either seal, interference due to runner deflection is not anticipated.

\section{Modal Analysis}

\section{Model for Modal Analysis in Water}

Figure 3-9 shows the FEA model used for modal analysis in water with 548900 water elements, 125735 solid elements and 315777 nodes. The same material properties and boundary conditions as above are used for the runner. For this analysis, the turbine's connection to the generator shaft was given axial and tangential constraints. Table 3-6 shows the water properties used in this analysis.

Table 3-6

Water Properties

\begin{tabular}{|c|c|}
\hline Sonic Velocity (m/s) & Density (N/mm $\left.{ }^{\mathbf{3}}\right)$ \\
\hline 1100 & $1 \mathrm{e}-9$ \\
\hline
\end{tabular}




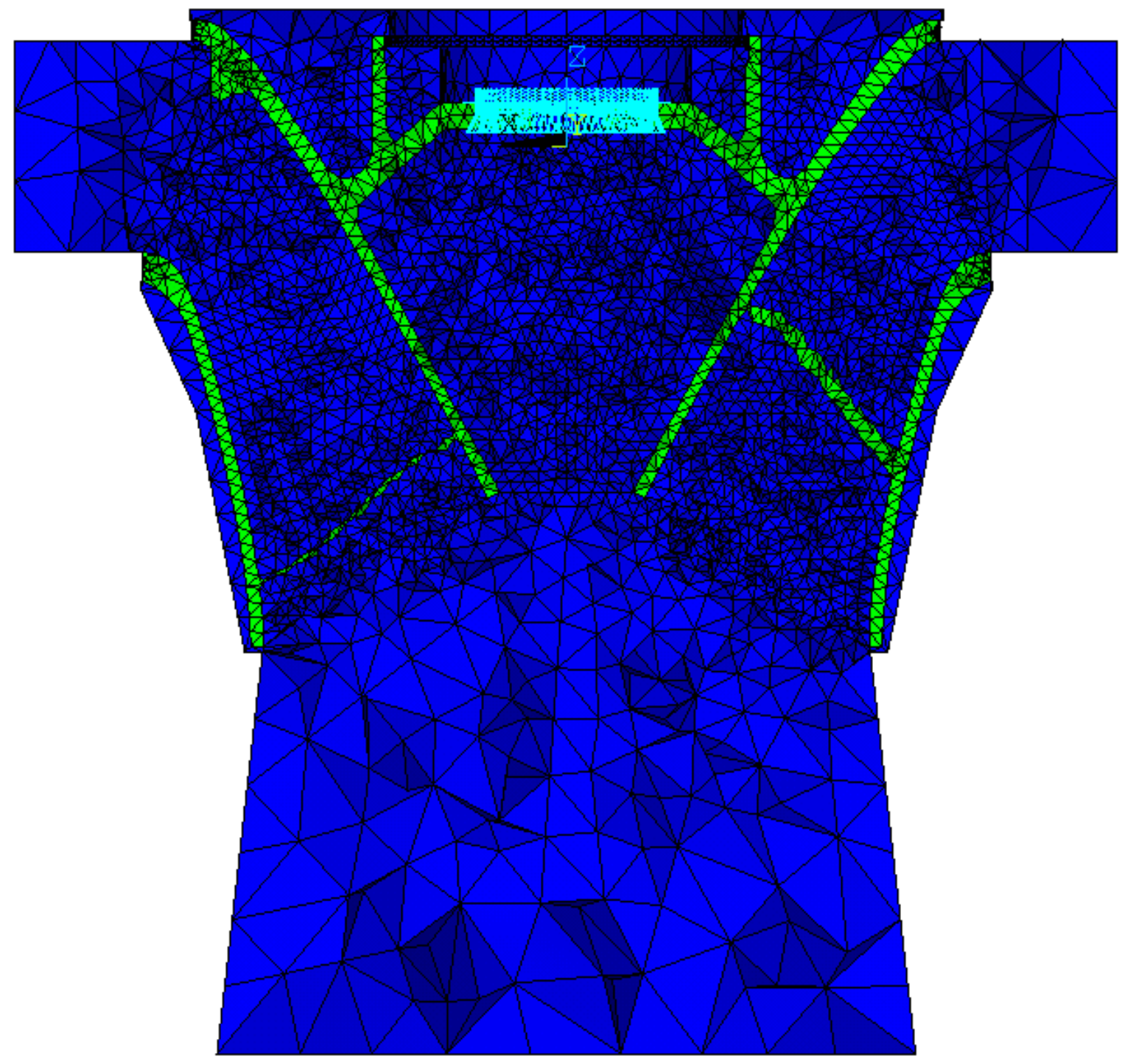

Figure 3-9

FEA Model for Modal Analysis in Water, with Green Solid Elements and Blue Water Elements

Exciting and Resonant Frequencies

A list of potential forcing frequencies is found in Table 3-8. 
Table 3-7

List of Potential Forcing Frequencies

\begin{tabular}{|c|c|c|}
\hline Phenomena & Value in terms of $\mathbf{f}$ & Frequency in $\mathbf{~ z z}$ \\
\hline Rotational Speed & $\mathrm{f}$ & 2.00 \\
\hline Rheingan & $\mathrm{f} / 3.6$ & 0.56 \\
\hline Rotating Vortex & $\sim 2 / 3 \mathrm{f}$ & 1.33 \\
\hline Rotation Speed Harmonics & $2 \mathrm{f}, 3 \mathrm{f}$ & $4.00,6.00$ \\
\hline Gate Passing & (\# wicket gates) * $\mathrm{f}$ & See Table 3-8 \\
\hline
\end{tabular}

Table 3-8

RSI Table for Potential Exciting Frequencies

\begin{tabular}{|c|c|c|c|}
\hline \multicolumn{2}{|c|}{ Number of Cycles } & $\begin{array}{c}\text { Number of } \\
\text { Diametral Nodes }\end{array}$ & $\begin{array}{c}\text { Rotating } \\
\text { Frequency }\end{array}$ \\
\hline Stationary Gate-Gate & Runner Blade-Blade & $(-)$ & $(\mathrm{Hz})$ \\
\hline 1 & 3 & -5 & 28.00 \\
\hline 1 & 4 & -2 & 28.00 \\
\hline 1 & 5 & 1 & 28.00 \\
\hline 1 & 6 & 4 & 28.00 \\
\hline \multicolumn{2}{|c|}{ Synchronous Speed } & 0 & 2 \\
\hline \multicolumn{2}{|r|}{ Rotating Vertex } & 1 & 1.33 \\
\hline
\end{tabular}

Visualization of k-modes can be seen in Figure 3-10. 


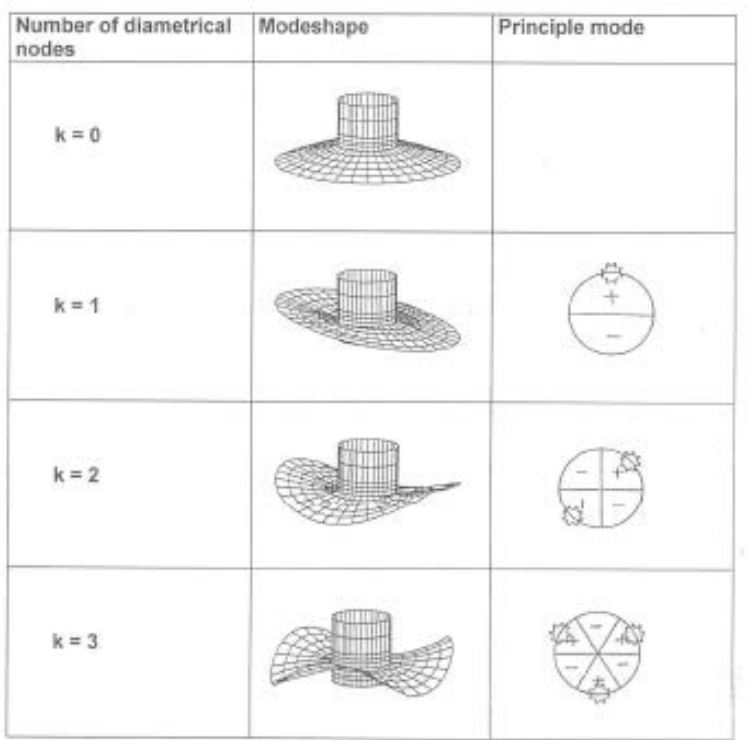

Figure 3-10

Typical k-mode Shapes which can be Associated with Structural Modes

Table 3-9 reports the first 12 natural frequencies and corresponding mode shape descriptions of the runner, where ki means that mode shape of the runner is equal to i. A mode shape noted bsymm denotes that all blades are bending symmetrically.

Table 3-9

Frequency Estimation in Water

\begin{tabular}{|c|c|c|}
\hline Mode \# & Mode Shape & Frequency (Hz) \\
\hline 1 & k1 & 12.305 \\
\hline 2 & Axial & 16.986 \\
\hline 3 & b-symm & 34.864 \\
\hline 4 & k1 & 35.328 \\
\hline 5 & k2 & 42.573 \\
\hline 6 & b-symm & 49.635 \\
\hline 7 & k2 & 55.412 \\
\hline 8 & b-symm & 58.143 \\
\hline 9 & b-symm & 62.64 \\
\hline 10 & k1 & 62.951 \\
\hline 11 & b-symm & 68.25 \\
\hline 12 & k1 & 70.222 \\
\hline
\end{tabular}

Table 3-9, Figure 3-11 and Figure 3-12 demonstrate that the calculated runner natural frequencies near the RSI rotating exciting frequency of $28 \mathrm{~Hz}$ does not correspond to the modes 
$\mathrm{k}=1,-2,4$ or -5 , or any of the values in Table 3-8. Hence high vibration amplification problems are not anticipated for this runner.
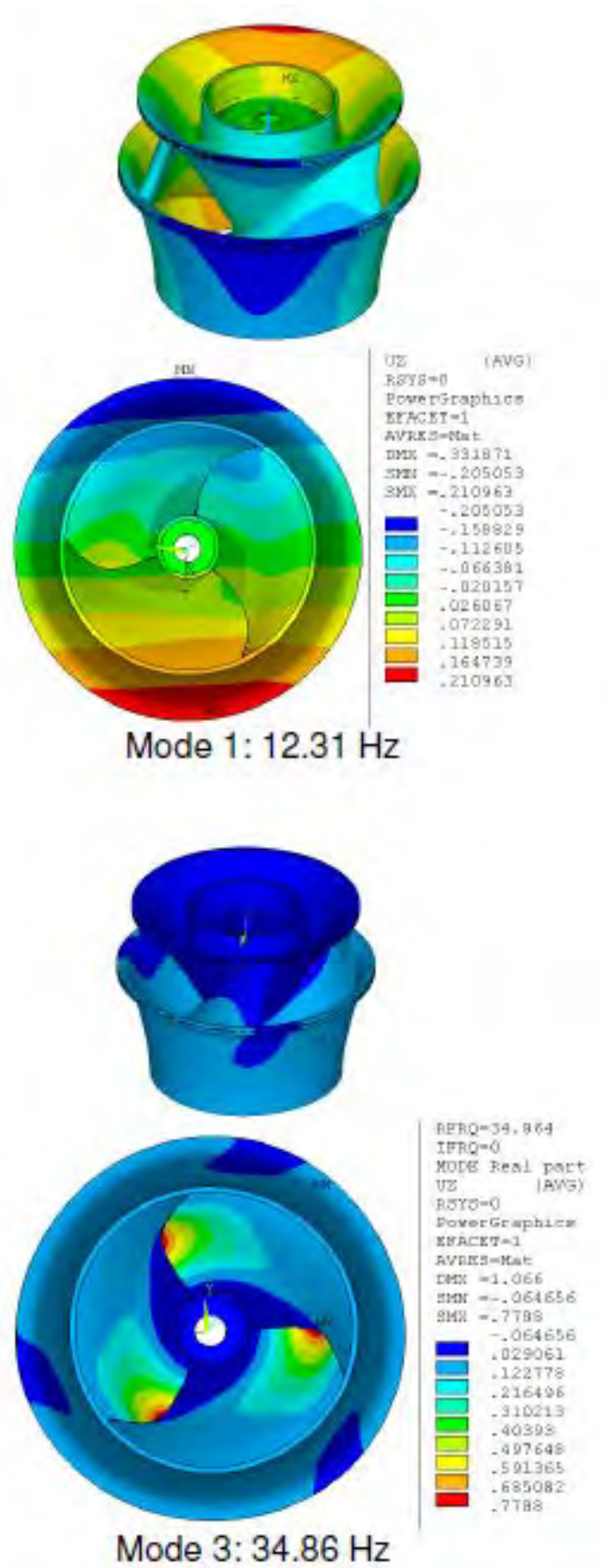
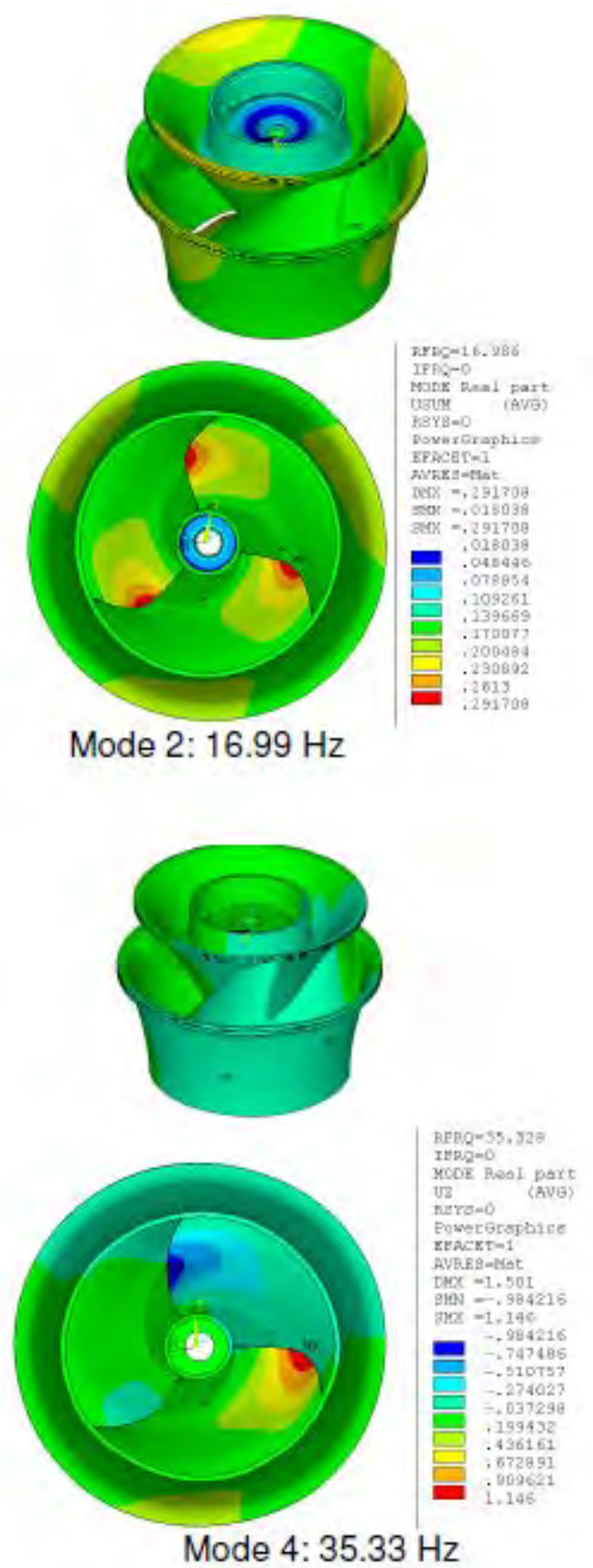

Figure 3-11

Modal Shapes for the First Four Resonating Frequencies for the Proposed Runner 

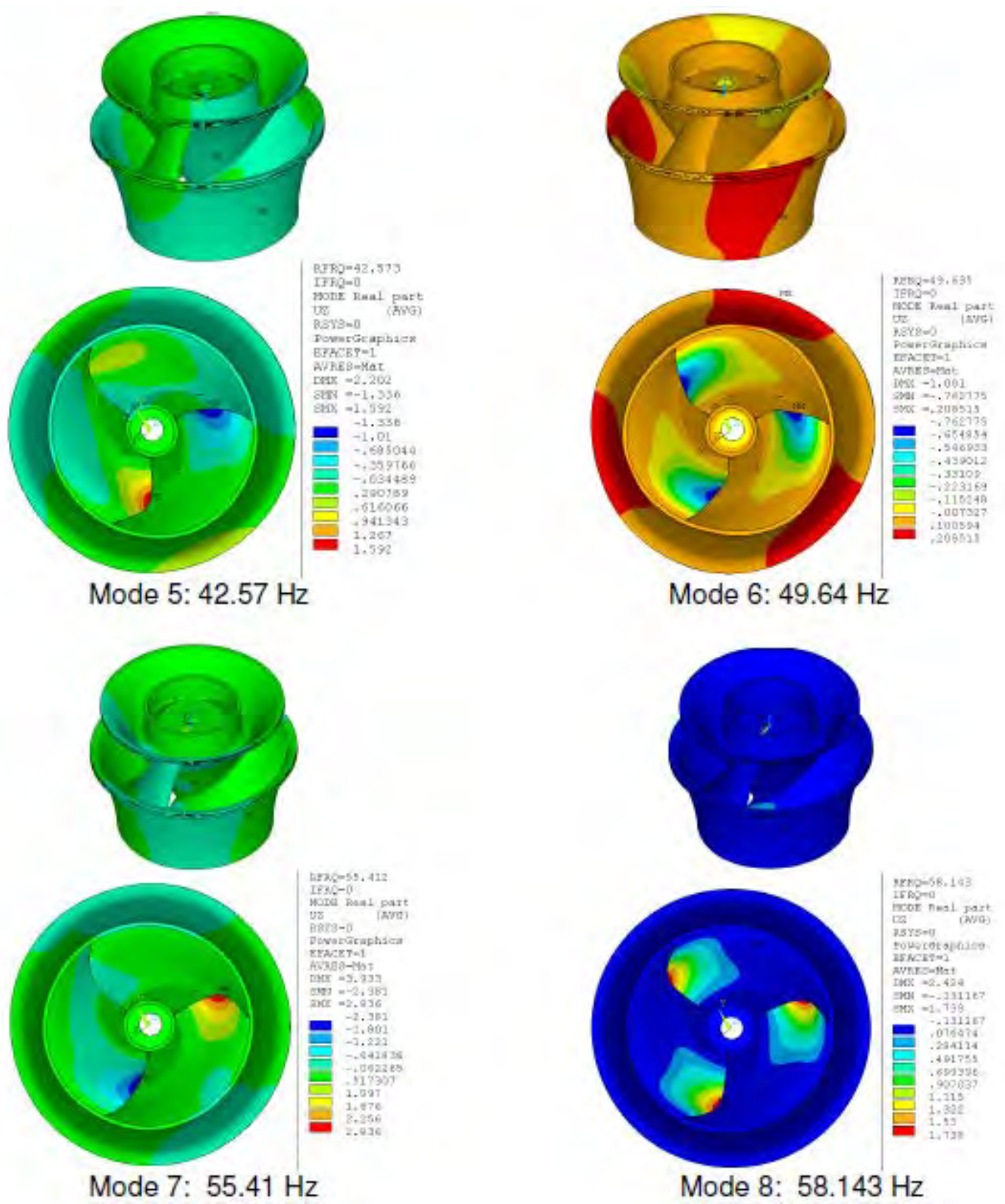

Figure 3-12

Modal Shapes for the Remaining Four Resonating Frequencies for the Proposed Runner

\section{Summary}

This runner design has adequate safety factors against yielding for all load cases, and the stresses are accepted.

In the Modal Analysis section, it was shown that no resonant frequencies were expected to be excited by the blade passing the wicket gates in water. Therefore, problems with high vibration amplification problems are not anticipated for this runner. 


\section{FEA Report - Shaft Critical Bending Speed and Bending Line Analysis \\ Description of the Analysis}

An engineering study of Alden shaft was performed by finite element method. The following Voith Hydro mechanical calculation tools were applied to determine critical bending speeds and corresponding mode shapes, and static deflections.

- BIKRI - Calculation critical bending speed;

- $\quad$ STABI - static bending line.

The following are the conditions used in our analysis:

1. Critical bending speeds;

- Flexibilities for runaway (see Table 3-13 below), 10\% magnetic pull;

- Flexibilities for normal operation (see Table 3-14 below), 100\% magnetic pull (see Table 3-11 below).

2. Static bending line;

- $100 \%$ magnetic pull;

- electromagnetic force (10\% eccentricity) (see Table 3-11 below);

- hydraulic radial force at partial load condition (see Table 3-12 below);

- bearing stiffness at nominal speed (see Table 3-14 below).

\section{Calculation Data and Model Description}

The following are the shaft material properties:

Young's Modulus: $\mathrm{E}=2.1 \mathrm{E} 11 \mathrm{~N} / \mathrm{m}^{2}$

Poisson ratio: $\mu=0.3$

Density: $\rho=7850 \mathrm{~kg} / \mathrm{m}^{3}$ 
Table 3-10 through Table 3-14 show the parameters used in this analysis.

Table 3-10

Turbine and Generator Mass Properties

\begin{tabular}{|c|c|c|}
\hline & Mass (m) kg & $\mathbf{J}_{\text {ax }}\left(\mathbf{k g m}^{2}\right)$ \\
\hline Runner & 39,671 & 86,429 \\
\hline Rotor & 51,000 & 500,000 \\
\hline
\end{tabular}

Table 3-11

Generator Magnetic Properties

\begin{tabular}{|c|c|c|c|}
\hline & Speed (rpm) & $\begin{array}{c}\text { Magnetic Pull } \\
(\mathbf{K n / m m})\end{array}$ & $\begin{array}{c}\text { Magnetic Eccentricity Force } \\
\text { (kN) @ 10\% of Airgap }\end{array}$ \\
\hline Nominal Speed (nN) & 120 & 197 & 197 \\
\hline Runaway Speed (nD) & 190 & 19.7 & - \\
\hline
\end{tabular}

Table 3-12

Turbine Forces

\begin{tabular}{|l|c|}
\hline & Static Part (kN) \\
\hline Hydraulic Radial Thrust for Normal Operation & 15.6 \\
\hline
\end{tabular}

Table 3-13

Turbine Clearances

\begin{tabular}{|l|c|}
\hline & Clearance (mm) \\
\hline Radial Blade to Discharge Ring Clearance & 1.52 \\
\hline
\end{tabular}

Table 3-14

Bearing Stiffness (Nominal/runaway)

\begin{tabular}{|l|c|c|}
\hline & $\begin{array}{c}\text { Nominal Condition Lower } \\
\text { Value (N/mm) }\end{array}$ & $\begin{array}{c}\text { Runaway Condition Higher } \\
\text { Value (N/mm) }\end{array}$ \\
\hline Upper Blade Bearing & $0.5556 \mathrm{E} 6$ & $0.6250 \mathrm{E} 6$ \\
\hline Turbine Guide Bearing & $0.8333 \mathrm{E} 6$ & $1.0000 \mathrm{E} 6$ \\
\hline
\end{tabular}




\section{Results}

\section{Critical Bending Speed}

Table 3-15

Critical Bending Speed (CBS)

\begin{tabular}{|l|c|c|c|c|}
\hline & $\begin{array}{c}\mathbf{1}^{\text {st }} \text { CBS } \\
\text { [rpm] }\end{array}$ & Safety Factor & $\begin{array}{c}\text { Required Safety } \\
\text { Factor }\end{array}$ & Conclusion \\
\hline $\begin{array}{l}\text { CBS 1 } \\
\begin{array}{l}\text { Stiffness and magnetic } \\
\text { pull based on runaway } \\
\text { condition }\end{array}\end{array}$ & 293 & $\begin{array}{c}\text { CBS1 / (Runaway } \\
\text { speed) }=1.5\end{array}$ & $\begin{array}{c}\text { CBS1 / (Runaway } \\
\text { speed) }=1.2\end{array}$ & OK \\
\hline $\begin{array}{l}\text { CBS 2 } \\
\begin{array}{l}\text { Stiffness and magnetic } \\
\text { pull based on normal } \\
\text { operation }\end{array}\end{array}$ & 290 & $\begin{array}{c}\text { CBS2 / (Normal } \\
\text { speed) }=2.4\end{array}$ & $\begin{array}{c}\text { CBS2 / (Normal } \\
\text { speed) }=2.0\end{array}$ & OK \\
\hline
\end{tabular}

The mode shapes corresponding to CBS1 and CBS2 are shown in Figure 3-13 and Figure 3-14, respectively.

\section{Static Bending Line}

Table 3-16

Runner Seal Check

\begin{tabular}{|c|c|c|c|c|}
\hline $\begin{array}{c}\text { Shaft Displacement } \\
\text { at Runner Seal ds } \\
(\mathbf{m m})\end{array}$ & $\begin{array}{c}\text { Runner Seal Clearance } \\
\text { (Min Required } \\
\text { Mechanical Clearance) } \\
\mathbf{d c}_{\mathrm{c}}[\mathrm{mm}]\end{array}$ & $\begin{array}{c}\text { Safety } \\
\text { Factor }\end{array}$ & $\begin{array}{c}\text { Required } \\
\text { Safety } \\
\text { Factor }\end{array}$ & Conclusion \\
\hline 0.93 & 1.52 & $\mathrm{~d}_{\mathrm{c}} / \mathrm{d}_{\mathrm{s}}=1.6$ & $\mathrm{~d}_{\mathrm{c}} / \mathrm{d}_{\mathrm{s}}=1.6$ & $\mathrm{OK}$ \\
\hline
\end{tabular}

The static bending line is shown in Figure 3-15.

\section{Conclusion}

This analysis demonstrates that the critical bending speeds and static bending line of this shaft system meet design criteria. 


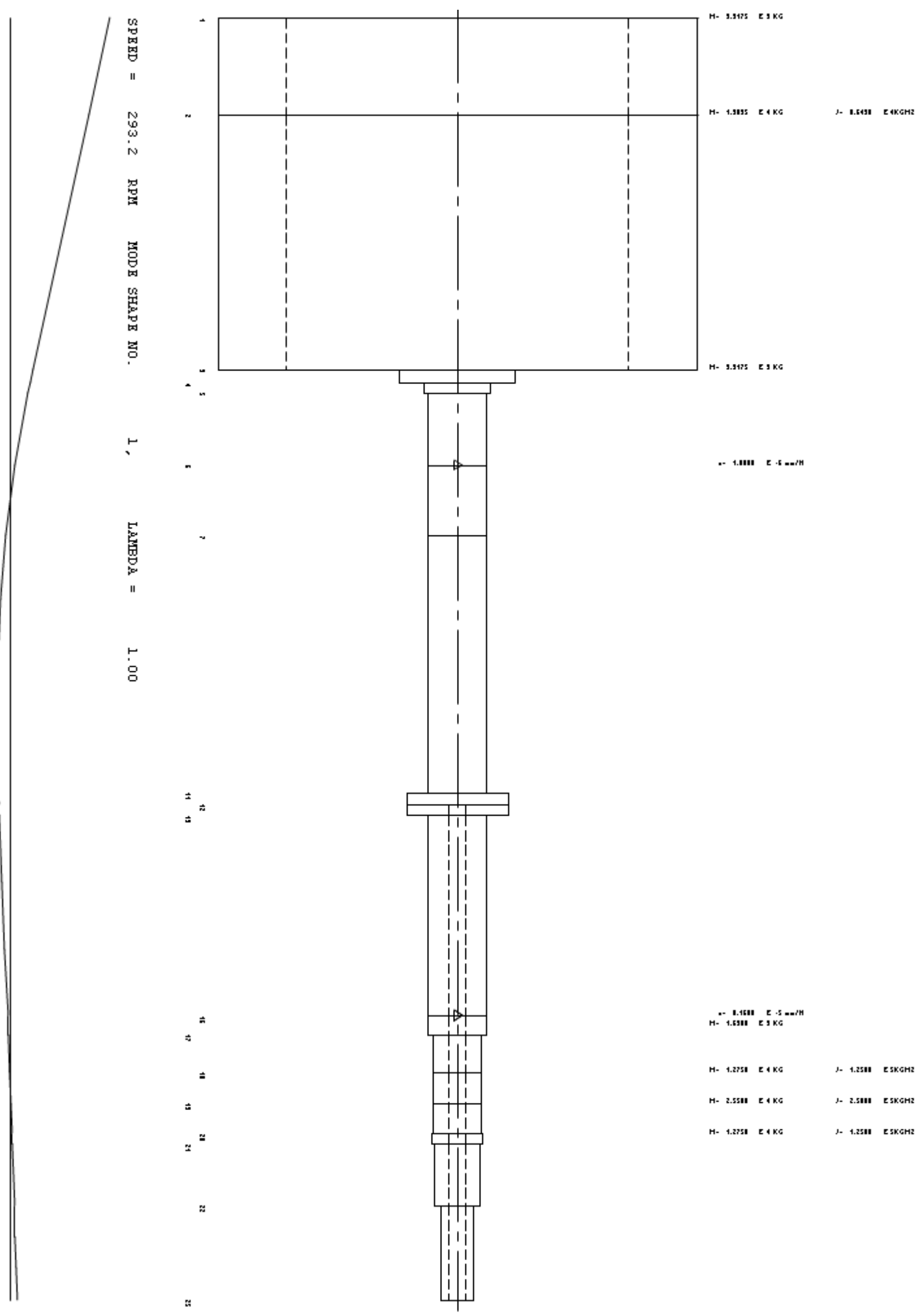

Figure 3-13

Mode shape corresponding to $1^{\text {st }}$ critical bending speed for runaway with $10 \%$ residual magnetic pull 


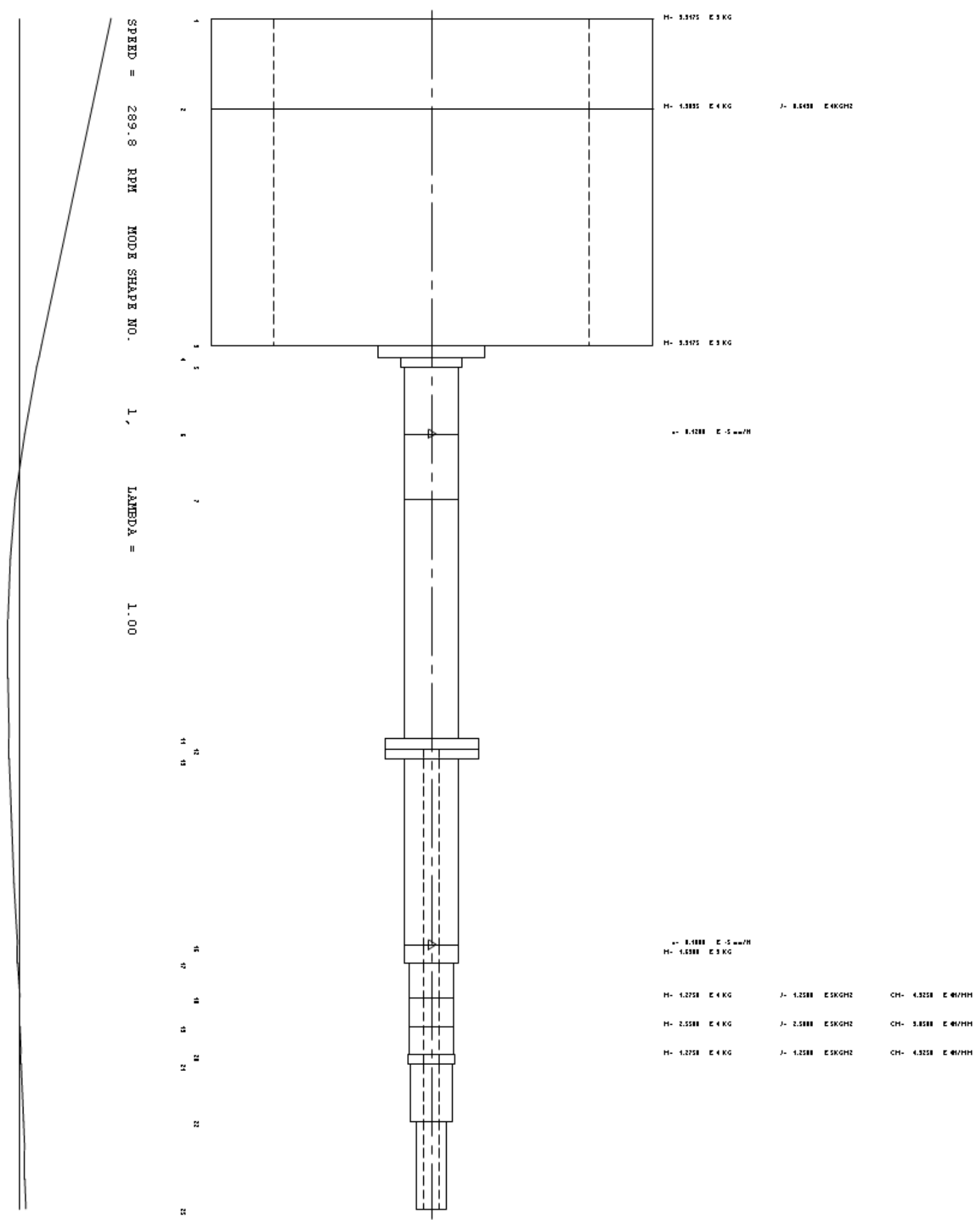

Figure 3-14

Mode Shape Corresponding to 1st Critical Bending Speed for Nominal Speed with $100 \%$ Magnetic Pull 
Structural Analysis

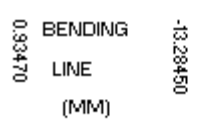

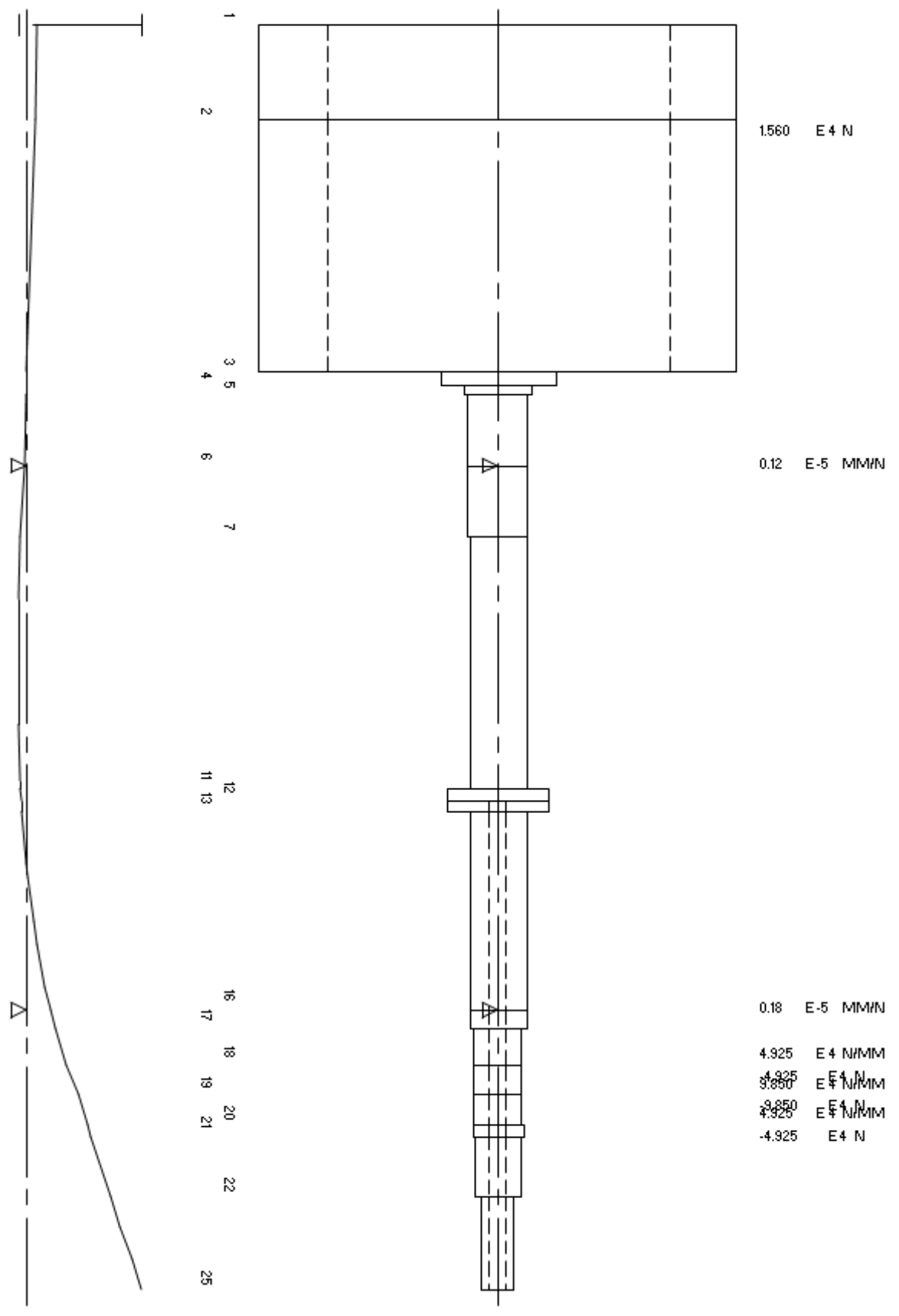

Figure 3-15

Static Bending Line 


\section{Alden Turbine Stay Vane Static Analysis}

\section{Static Finite Element Analysis}

This report details the findings of an analysis performed on the Alden stay vane. The stresses and deflections in normal operation and the dewatered case are checked.

\section{FEA Analysis}

To investigate the deflection of the Alden stay vane, a static finite element analysis was performed. The geometry is taken from a detailed 3-dimensional CAD model and meshed automatically with finite elements for the calculation.

The mesh of the geometry is shown in the following figure (Figure 3-16). Details of the mesh are in Table 3-17.

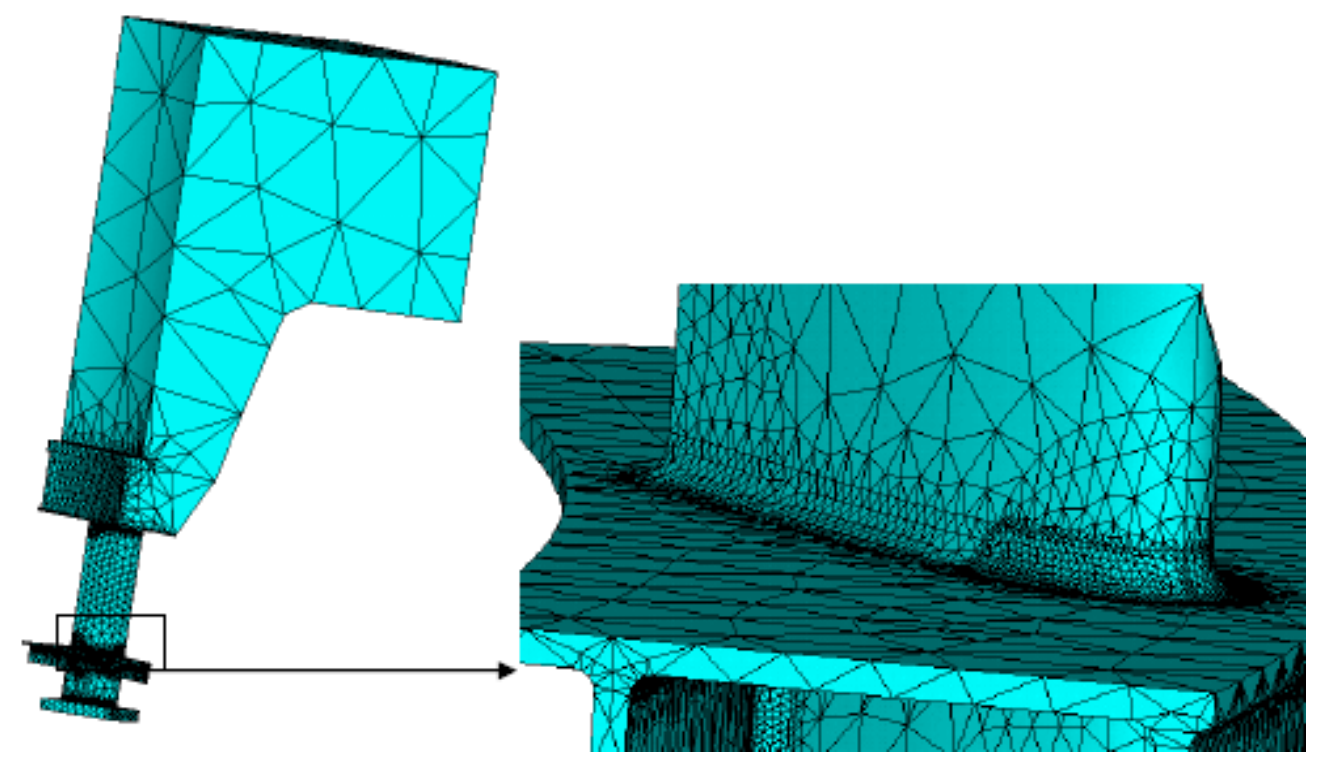

Figure 3-16

Meshed Model

Table 3-17

Number of Elements and Nodes of the Calculated Models

\begin{tabular}{|l|c|c|c|c|}
\hline \multicolumn{1}{|c|}{ Component } & No. Elements & No. Nodes & $\begin{array}{c}\text { Element Size @ } \\
\text { Critical Areas }\end{array}$ & Software Version \\
\hline Stay Vane & 368375 & 528313 & $3 \mathrm{~mm}$ & ANSYS 12.1 \\
\hline Concrete & 21485 & 39273 & $5 \mathrm{~mm}$ & ANSYS 12.1 \\
\hline
\end{tabular}

In this analysis, normal operation and a dewatered case were analyzed. The outside of the concrete was constrained as shown in Figure 3-17, and the stay ring at the anchor bolt locations is fixed at the base plate. The sector cutting surfaces of the stay ring are coupled. We bonded the concrete to the stay ring together. Since one-fourteenth of the total stay ring was considered, 
one-fourteenth the weight of the head cover and all components that it supports was placed on the top ring. For normal operation, all wet surfaces received the maximum head pressure of 304 $\mathrm{kPa}$, while this was not done for the dewatered case. These conditions can be seen in Figure 3-17 for normal operation, and Figure 3-18 for the dewatered condition.

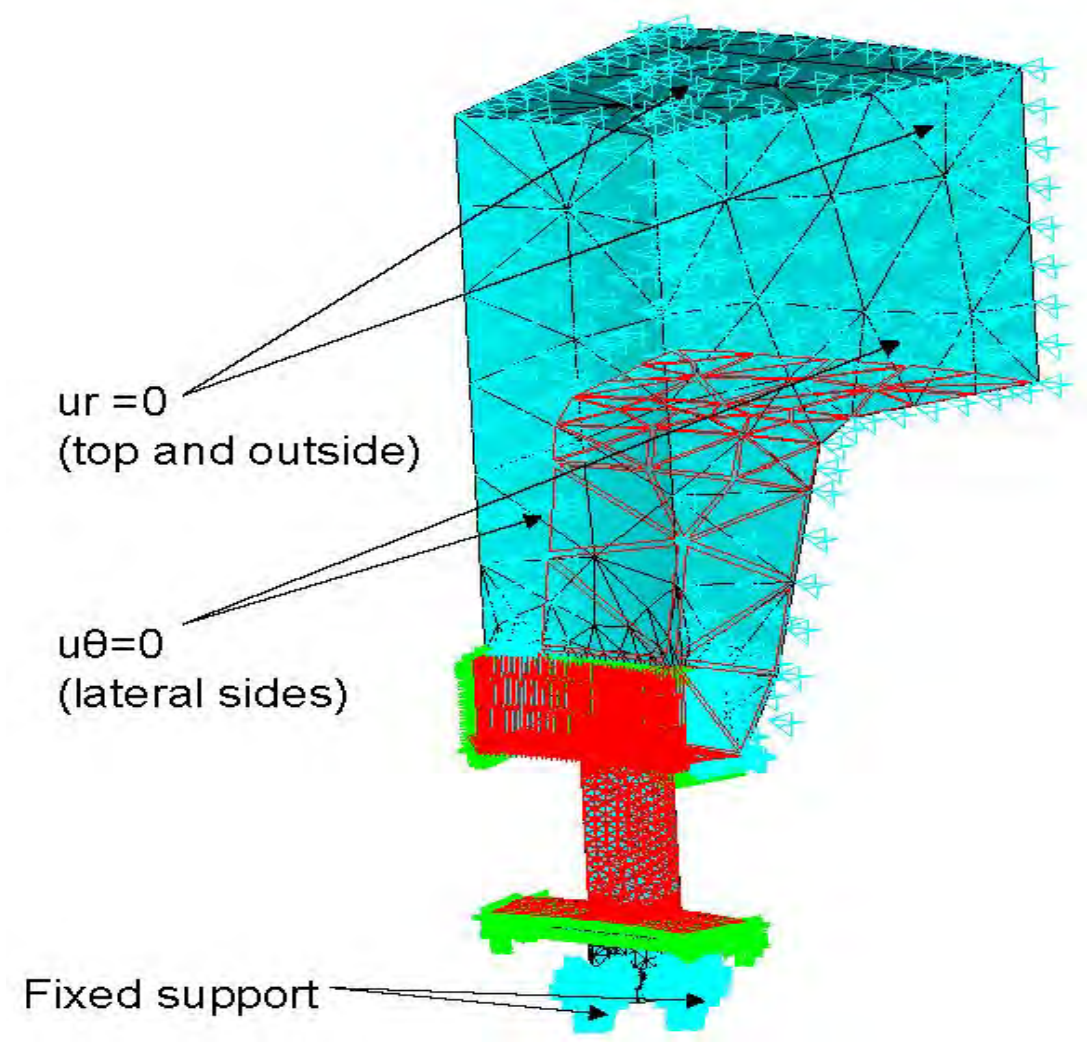

Figure 3-17

Meshed Vane with Boundary Conditions in Normal Operation 


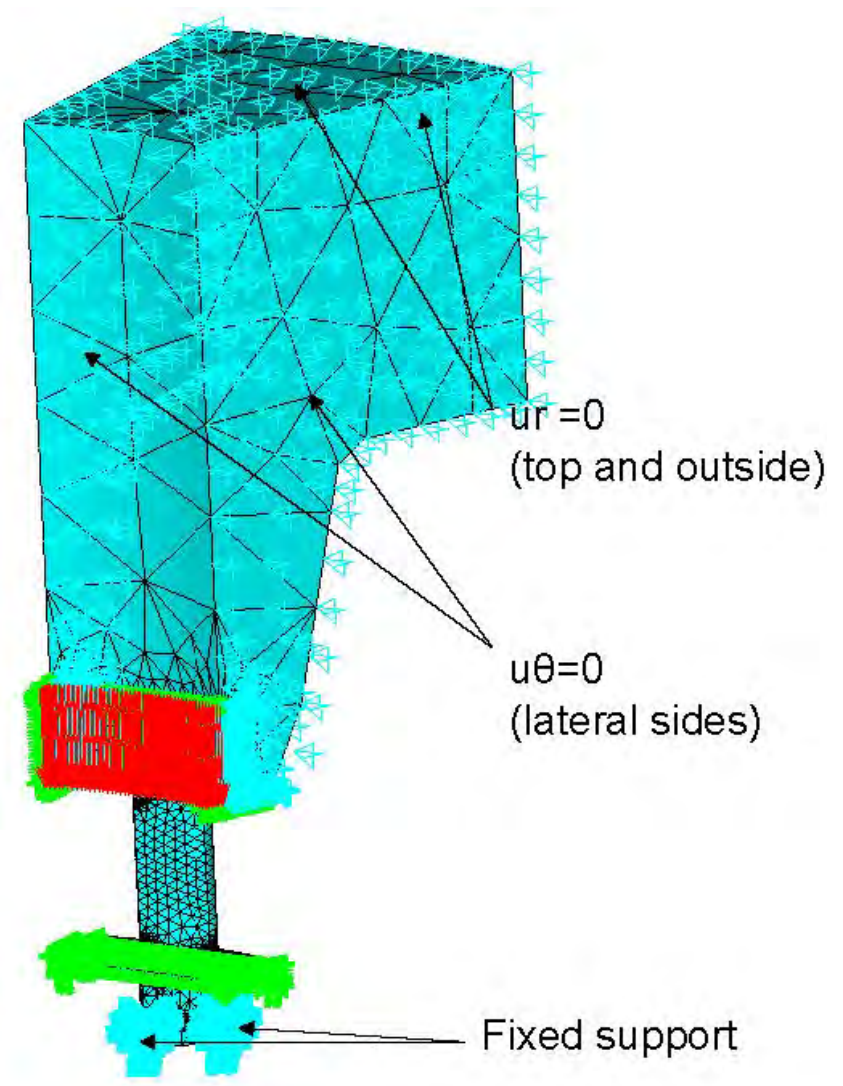

Figure 3-18

Meshed Vane with Boundary Conditions for Dewatered Unit

\section{Material Data}

The material data for this stay vane is found in Table 3-18. This data is gathered from the 2010 Book of ASTM Standards.

Table 3-18

Material Properties

\begin{tabular}{|c|c|c|c|c|c|c|}
\hline Component & Material & $\begin{array}{c}\text { Yield } \\
\text { Stress } \\
(\mathbf{M P a})\end{array}$ & $\begin{array}{c}\text { Young's } \\
\text { Modulus } \\
\mathbf{( P a )}\end{array}$ & $\begin{array}{c}\text { Poisson's } \\
\text { Ratio }\end{array}$ & $\begin{array}{c}\text { Density } \\
\left(\mathbf{k g} / \mathbf{m}^{3}\right)\end{array}$ & $\begin{array}{c}\text { Ultimate } \\
\text { Stress } \\
\mathbf{( M P a}\end{array}$ \\
\hline $\begin{array}{c}\text { Stay Vane } \\
\text { and Ring }\end{array}$ & $\begin{array}{c}\text { ASTM A516 } \\
\text { Gr. 70 }\end{array}$ & 260 & 203000 & 0.3 & 7830 & 485 \\
\hline Concrete & Concrete & - & 30000 & 0.2 & 2400 & - \\
\hline
\end{tabular}

\section{Allowable Stresses}

The allowable stress for dewatered not exceed $78 \%$ of the yield strength of the material. For normal operation, maximum stress should not exceed $65 \%$ of the yield stress of the material. The allowable stresses can be seen in Table 3-19. 
Table 3-19

Allowable Stresses

\begin{tabular}{|c|c|}
\hline Load Case & Allowable Stress (MPa) \\
\hline Normal Operation & 169 \\
\hline Dewatered & 203 \\
\hline
\end{tabular}

\section{Loadings}

The loadings for this vane can be seen in Table 3-20. For the head cover weight, a force of 250 $\mathrm{kN}$ was applied to the top stay ring. Gravity was also applied for this analysis.

Table 3-20

Loading on the Vane for Both Load Conditions

\begin{tabular}{|c|c|}
\hline Load Case & Pressure (MPa) \\
\hline Normal Operation & 0.304 \\
\hline Dewatered & 0.000 \\
\hline
\end{tabular}

Von Mises Stress Distributions

The calculated maximum von Mises stresses and their locations are reported in Table 3-21.

Table 3-21

Maximum Stresses and Their Locations

\begin{tabular}{|c|c|c|c|c|c|}
\hline $\begin{array}{c}\text { Load } \\
\text { Case }\end{array}$ & $\begin{array}{c}\text { Allowable } \\
\text { Stress (MPa) }\end{array}$ & $\begin{array}{c}\text { Stress @ Critical } \\
\text { Area (MPa) }\end{array}$ & $\begin{array}{c}\text { \% of Allowable } \\
\text { Stress }\end{array}$ & $\begin{array}{c}\text { \% of Yield } \\
\text { Stress }\end{array}$ & Location \\
\hline $\begin{array}{c}\text { Normal } \\
\text { Operation }\end{array}$ & 169.0 & 131.5 & 77.6 & 50.5 & $\begin{array}{c}\text { Vane-inner } \\
\text { rib fillet }\end{array}$ \\
\hline Dewatered & 203.0 & 169.0 & 83.3 & 65.0 & $\begin{array}{c}\text { Vane-base } \\
\text { plate fillet }\end{array}$ \\
\hline
\end{tabular}

The stress distribution for either case is shown in Figure 3-19 and Figure 3-20, in MPa. 

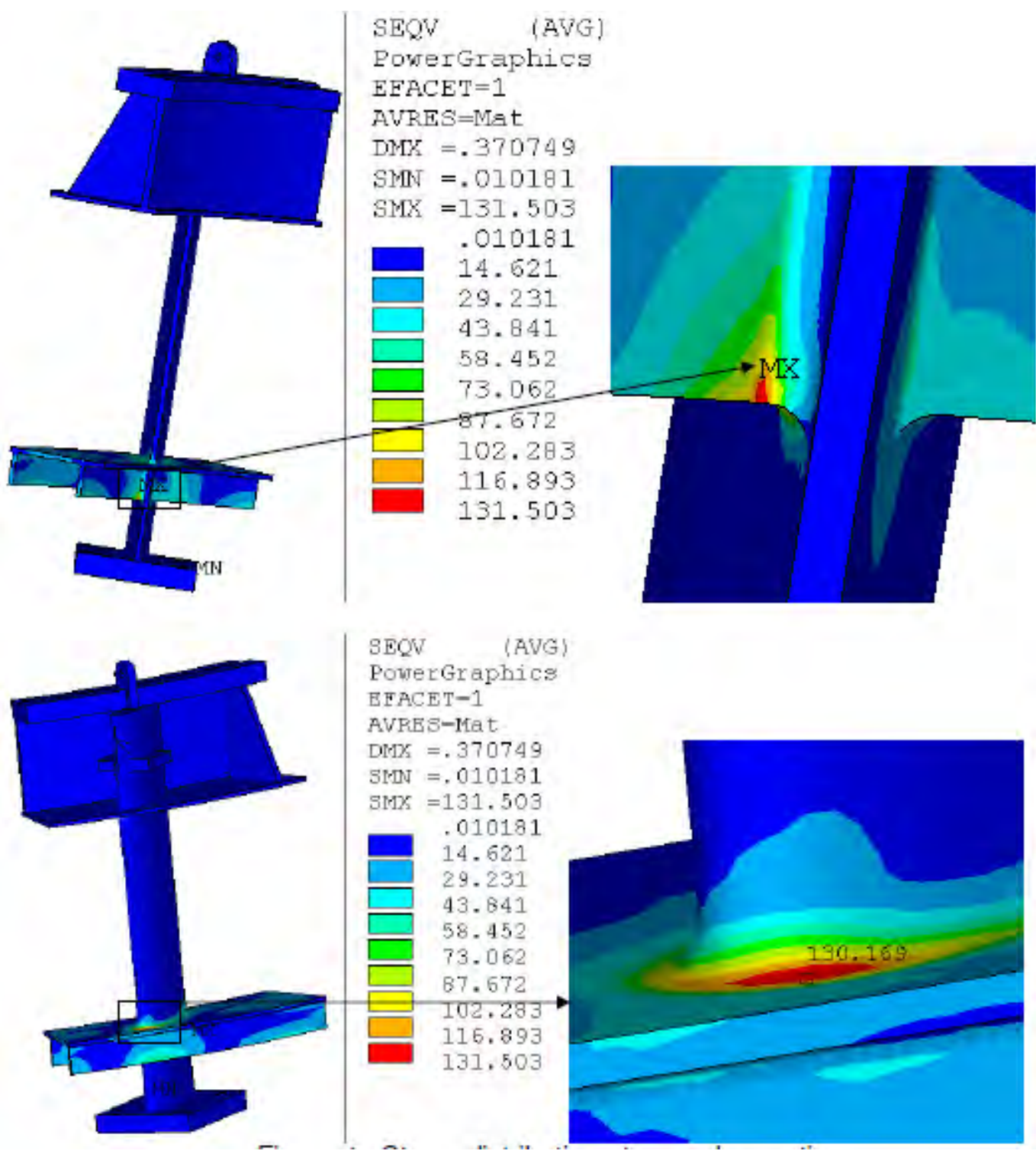

AVG)

Poveraphics BACET-1

AVREB-1tat

$=.370749$

$\mathbb{P D N}=.010181$

$1 \times=131.507$

010181

4.621

29.23

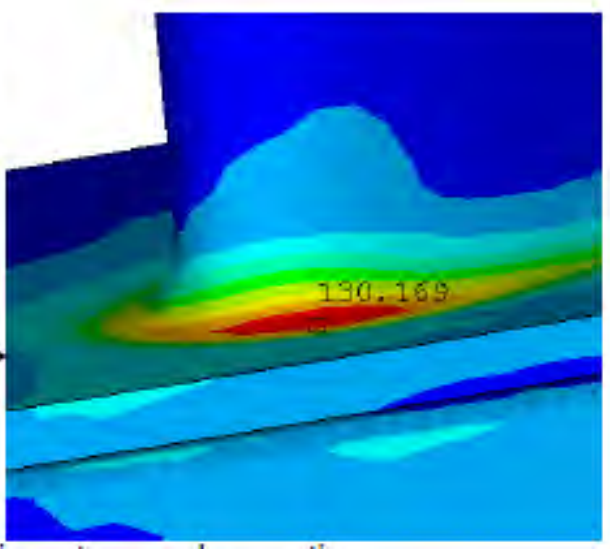

Figure 3-19

Stress Distribution at Normal Operation 


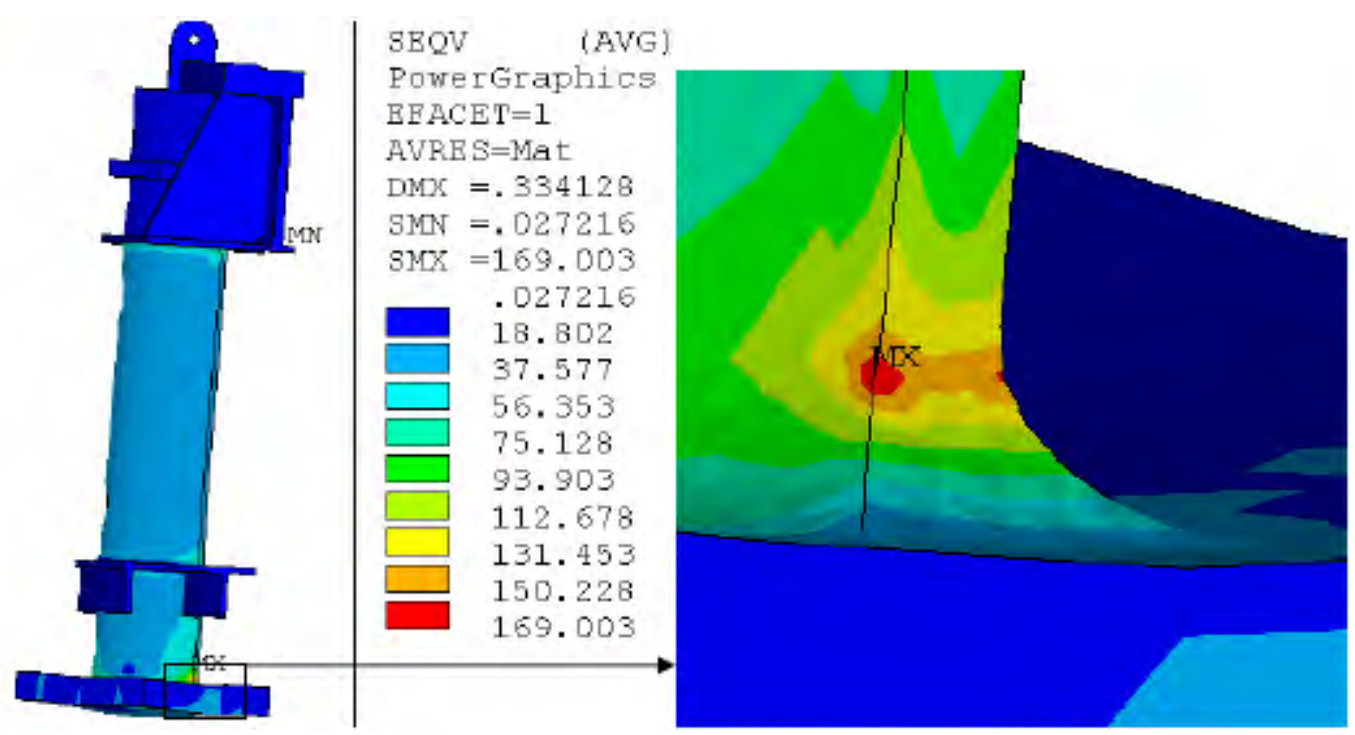

Figure 3-20

Stress Distribution at Unit Dewatered

\section{Deflections}

Figure 3-21 exhibits the total deflection in millimeters of the stay vane for normal operation, Figure 3-22 shows the total defection of the stay vane with a dewatered unit.

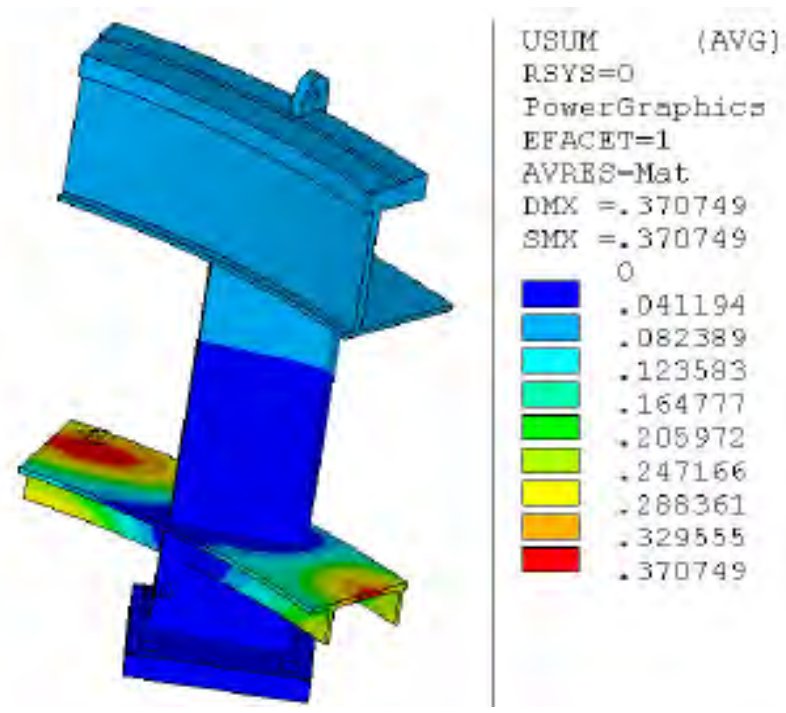

Figure 3-21

Total Displacement Distribution at Normal Operation 


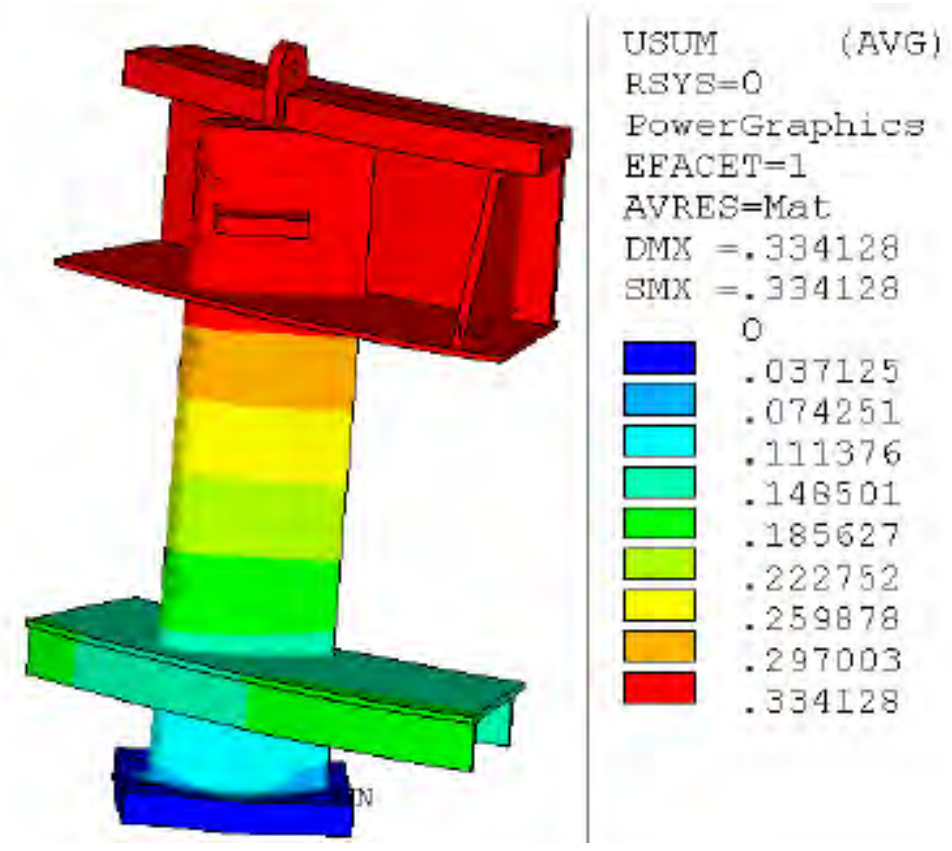

Figure 3-22

Total Displacement Distribution at Unit Dewatered

\section{Summary}

This stay vane design meets the allowable stresses as stated in section titled Allowable Stresses, and both stresses and deflections are acceptable.

Wicket Gate Static and Modal Analysis

\section{Static Finite Element Analysis}

This report details the findings of an analysis performed on the proposed Alden wicket gate. The stresses and deflections in squeeze condition and when the shear pin fails are checked, as well as any potential resonant frequencies.

\section{FEA method}

To investigate the deflection of the proposed Alden wicket gate, a static finite element analysis was performed. The geometry is taken from a detailed 3-dimensional CAD model and meshed automatically with finite elements for the calculation.

All preprocessing, solution and post processing steps were done with ANSYS Rev. 12.1, ANSYS Inc.

The mesh of the geometry is shown in the following figure. Details of the mesh are in Table 3-6. 


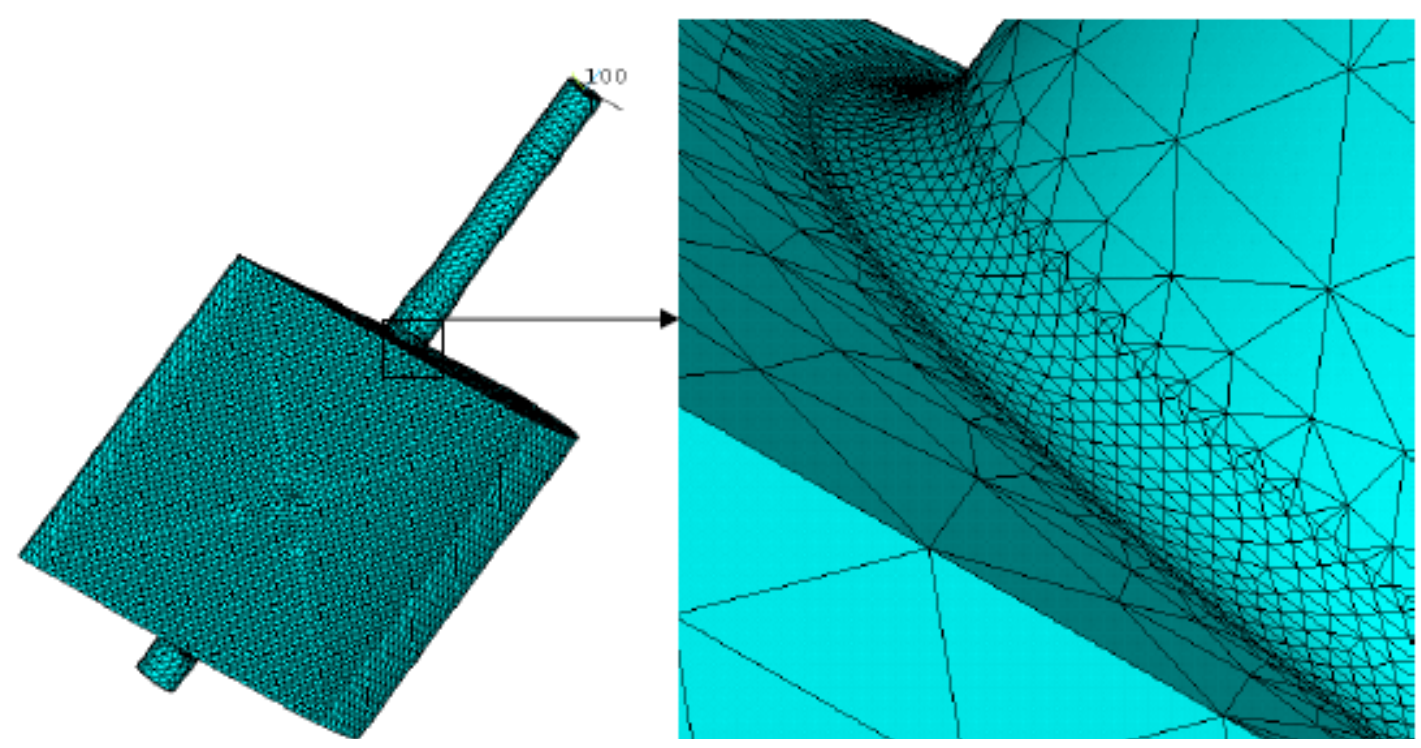

Figure 3-23

Meshed Model

Table 3-22

Number of Nodes and Elements of the Calculated Models

\begin{tabular}{|c|c|c|c|}
\hline No. Elements & No. Nodes & $\begin{array}{c}\text { Element Size @ } \\
\text { Critical Areas }\end{array}$ & $\begin{array}{c}\text { Software } \\
\text { Version }\end{array}$ \\
\hline 268446 & 379590 & $0.75 \mathrm{~mm}$ & ANSYS 12.1 \\
\hline
\end{tabular}

In this analysis, gate squeeze condition, gates closed and shear pin failure are analyzed. The loading for both load cases had axial and radial constraints at the thrust bearing and radial constraints at the radial bearings. Contact elements were placed on the trailing edge and couple with nodes where seal is created to simulate contact between two gates for gate squeeze. These conditions can be seen in Figure 3-24.

For shear pin failure, the top third of the nodes on the trailing edge was constrained in the tangential direction. This condition can be seen in Figure 3-25. 


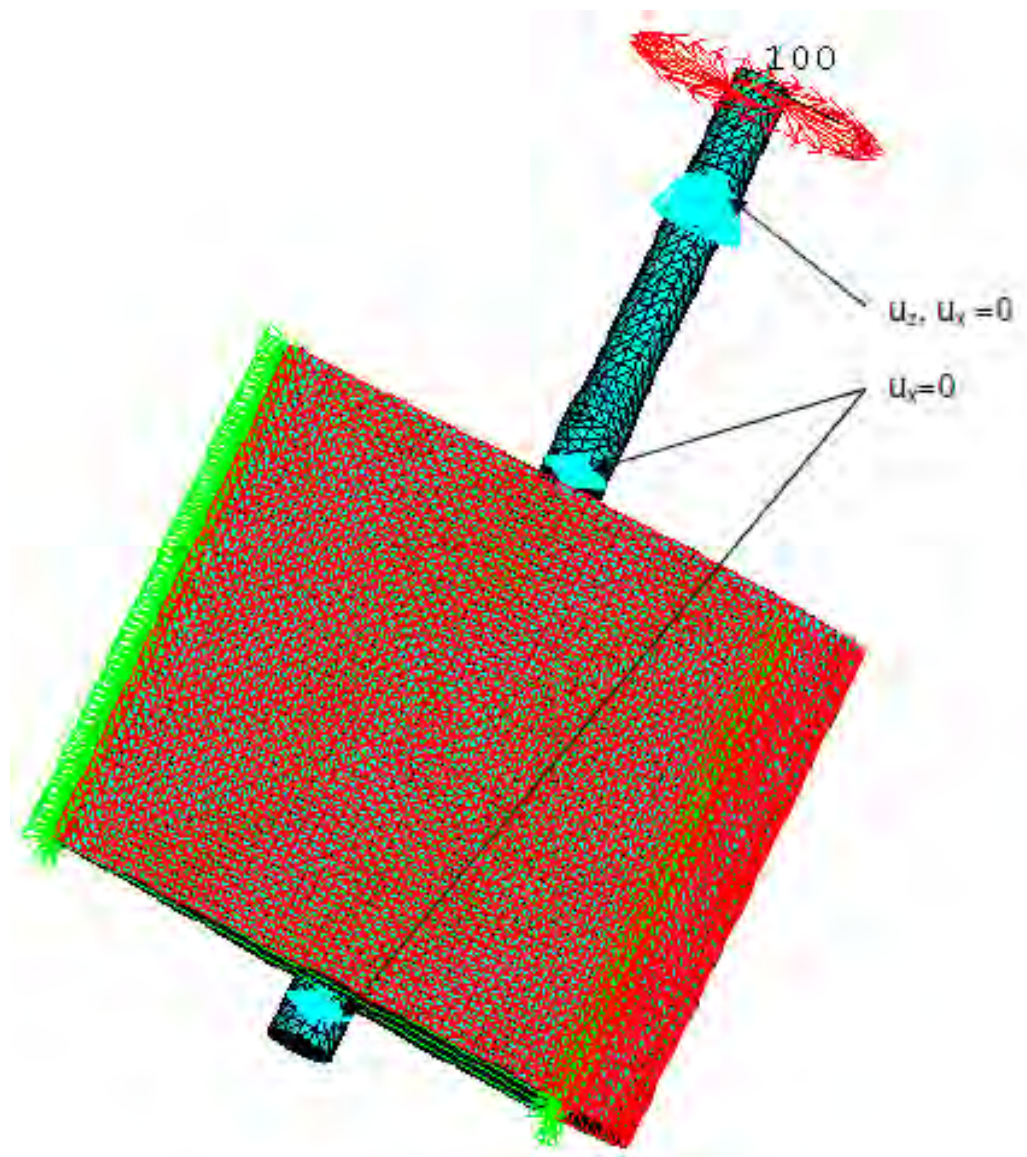

Figure 3-24

Meshed Gate with Boundary Conditions in Squeeze Condition 


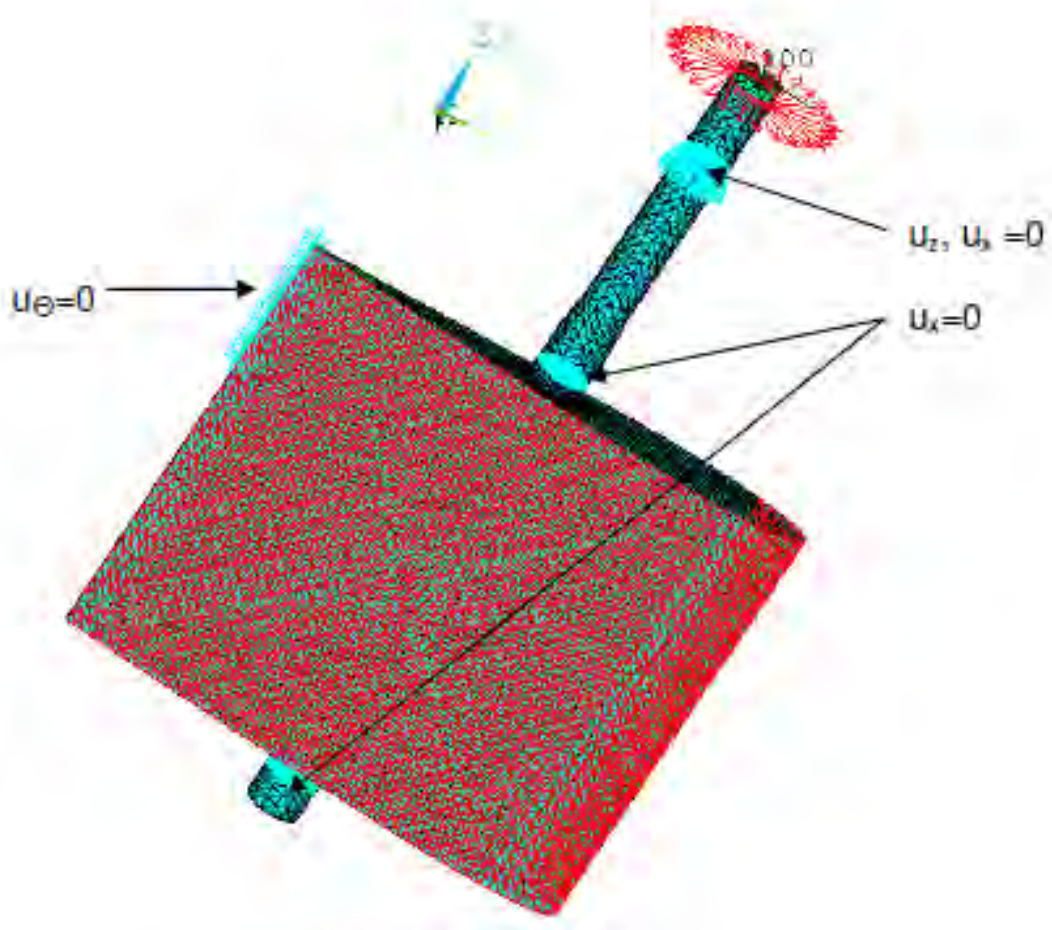

Figure 3-25

Meshed Gate with Boundary Conditions for Shear Pin Failure

\section{Material Data}

The material data for this wicket gate is found in Table 3-23. This data is gathered from the 2010 Book of ASTM Standards.

Table 3-23

Material Properties

\begin{tabular}{|c|c|c|c|c|c|c|}
\hline Component & Material & $\begin{array}{c}\text { Yield } \\
\text { Stress } \\
\mathbf{( M P a )}\end{array}$ & $\begin{array}{c}\text { Young's } \\
\text { Modulus } \\
\mathbf{( M P a )}\end{array}$ & $\begin{array}{c}\text { Poisson's } \\
\text { Ratio }\end{array}$ & $\begin{array}{c}\text { Density } \\
\mathbf{( k g / m}^{\mathbf{3}} \mathbf{)}\end{array}$ & $\begin{array}{c}\text { Ultimate } \\
\text { Stress (MPa) }\end{array}$ \\
\hline All & $\begin{array}{c}\text { ASTM A743 } \\
\text { CA-6NM }\end{array}$ & 550 & 203000 & 0.3 & 7700 & 755 \\
\hline
\end{tabular}

\section{Allowable Stresses}

The allowable stress for shear pin failure should not exceed $78 \%$ of the yield strength of the material. For gate squeeze, maximum stress should not exceed $65 \%$ of the yield stress of the material. The allowable stresses can be seen in Table 3-24. 
Table 3-24

Allowable Stresses

\begin{tabular}{|c|c|}
\hline Load Case & Allowable Stress (MPa) \\
\hline Gate Squeeze & 357.0 \\
\hline Shear Pin Break & 0.3952 \\
\hline
\end{tabular}

\section{Loadings}

The loadings for this gate can be seen in Table 3-25.

Table 3-25

Loading on the Gate for Both Load Conditions

\begin{tabular}{|c|c|c|}
\hline Load Case & Torque $\mathbf{( k N m )}$ & Pressure (MPa) \\
\hline Gate Squeeze & 24.19 & 0.304 \\
\hline Shear Pin Failure & 54.0 & 0.3952 \\
\hline
\end{tabular}

Von Mises Stress Distributions

The calculated maximum von Mises stresses and their locations are reported in Table 3-26.

Table 3-26

Maximum Stresses and Their Location

\begin{tabular}{|l|c|c|c|c|c|}
\hline & $\begin{array}{c}\text { Allowable } \\
\text { Stress (MPa) }\end{array}$ & $\begin{array}{c}\text { Stress @ Critical } \\
\text { Area (MPa) }\end{array}$ & $\begin{array}{c}\text { \% of Allowable } \\
\text { Stress }\end{array}$ & $\begin{array}{c}\text { \% of Yield } \\
\text { Stress }\end{array}$ & Location \\
\hline $\begin{array}{l}\text { Gate } \\
\text { Squeeze }\end{array}$ & 357 & 205.4 & 57.5 & 37.3 & $\begin{array}{c}\text { Stem-leaf } \\
\text { Collar }\end{array}$ \\
\hline $\begin{array}{l}\text { Shear Pin } \\
\text { Failure }\end{array}$ & 429 & 429.3 & 100.1 & 78.1 & $\begin{array}{c}\text { Stem-leaf } \\
\text { Collar }\end{array}$ \\
\hline
\end{tabular}

The stress distribution for either case is shown in Figure 3-26 and Figure 3-27, in MPa. 


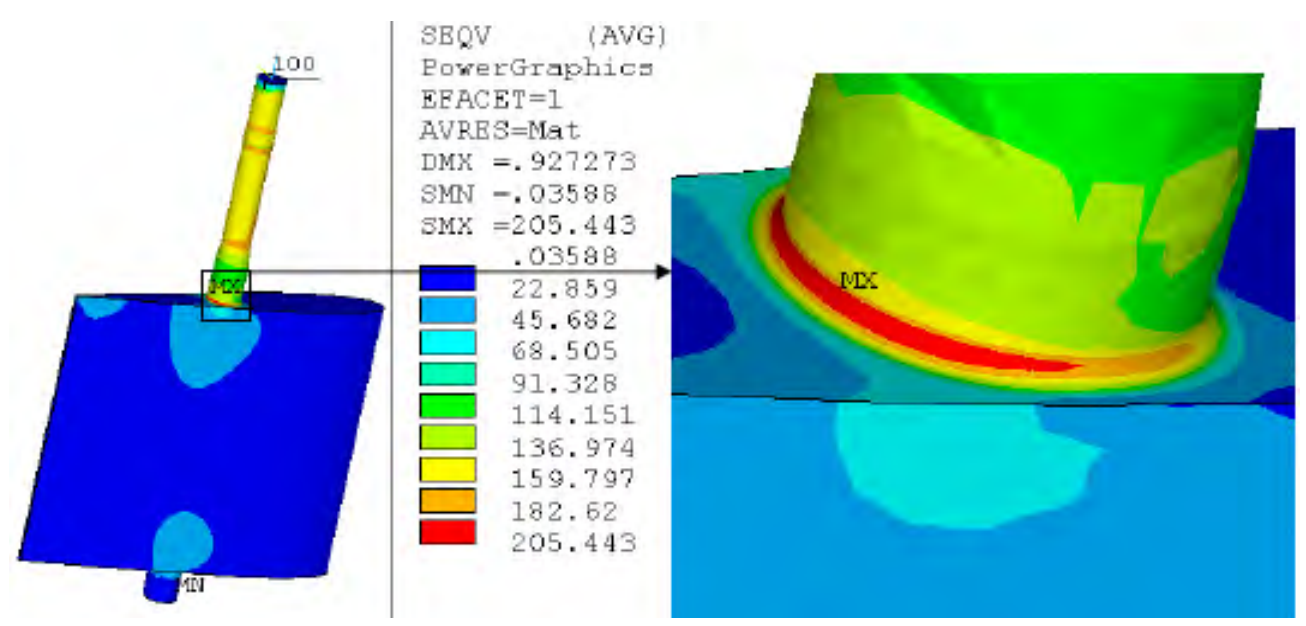

Figure 3-26

Stress Distribution at Gate Squeeze Condition

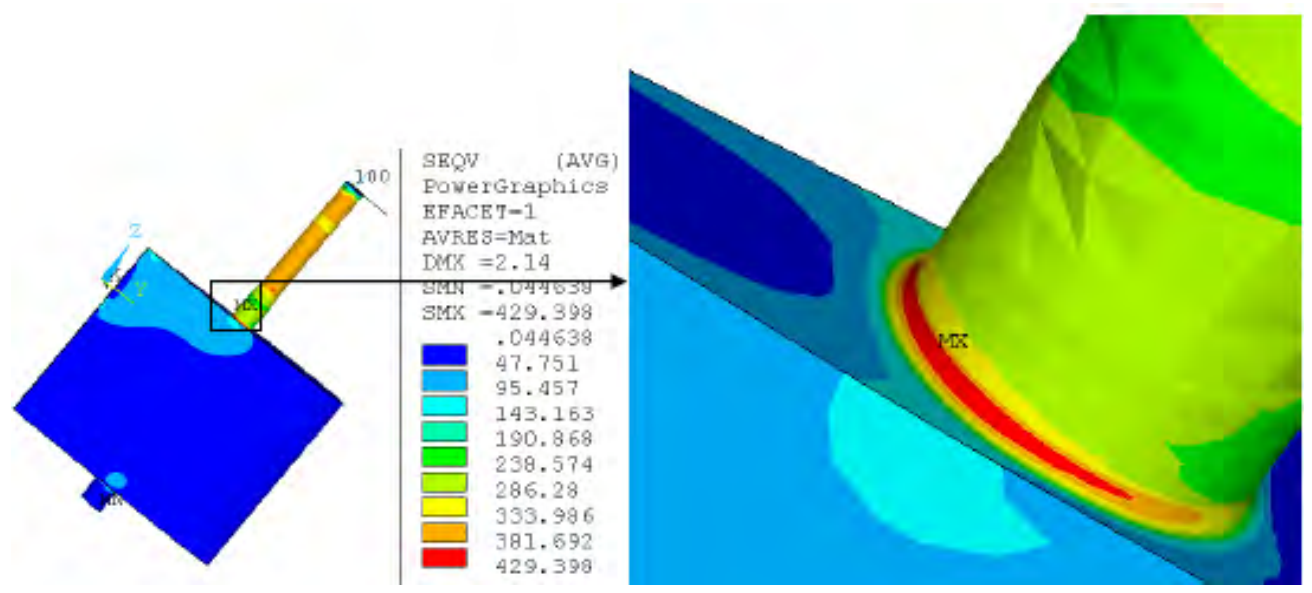

Figure 3-27

Stress Distribution at Shear Pin Failure

\section{Deflections}

Figure 3-28 exhibits the total deflection in millimeters of the wicket gate for the gate squeeze load case, Figure 3-29 shows the total defection of the wicket gate with shear pin failure. 


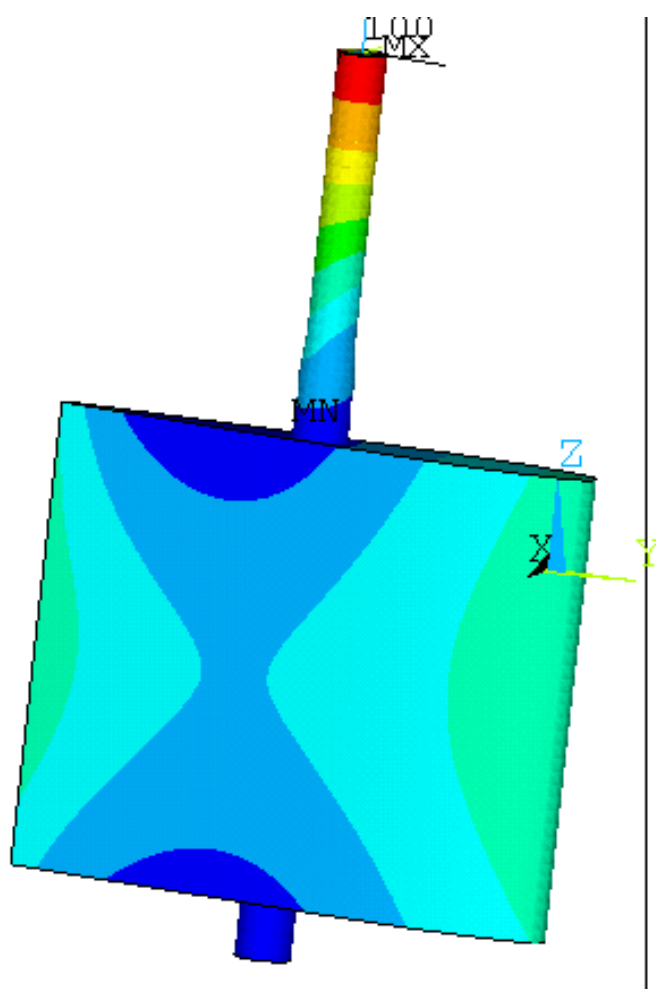

USUM

(AVG)

RSYS $=0$

PowerGraphics

$\mathrm{EFACET}=1$

AVRES=Mat

$\mathrm{DMX}=.927273$

SMN $=.001375$

SMX $=.927273$

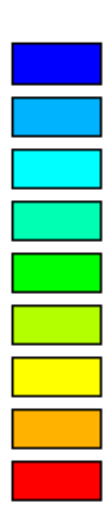

.001375

.104252

.20713

.310008

.412885

.515763

.61864

.721518

.824395

.927273

Figure 3-28

Total Displacement Distribution at Gate Squeeze

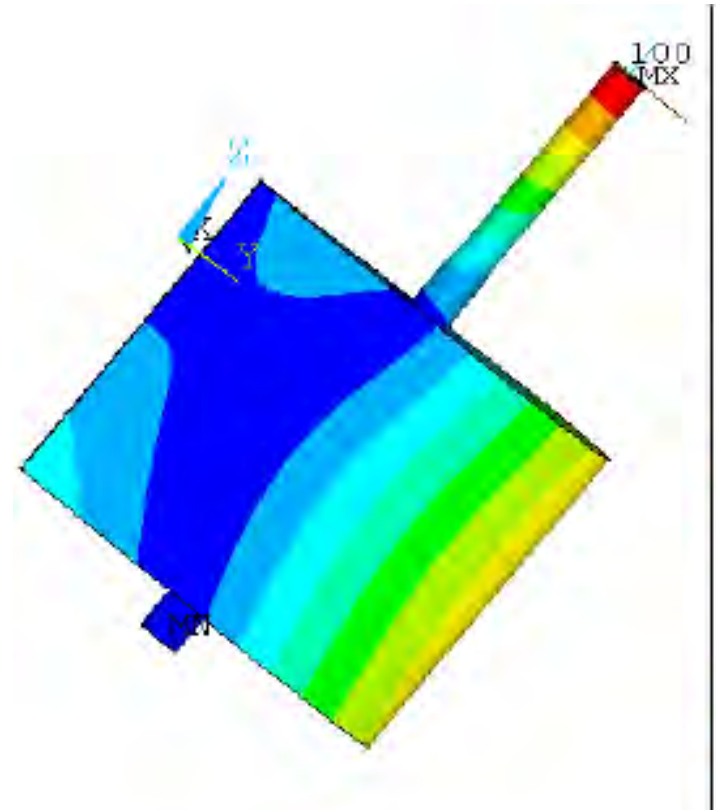

USTM

(AVG)

RSY $B=0$

PowerGraphics

EEACET $=1$

AVRES=Mat

$\mathrm{DMX}=2.14$

SMN $=.012817$

$\operatorname{SMX}=2.14$

.012817

.24915

.485503

.721846

.958189

1.195

1. 431

1.667

1.904

2.14

Figure 3-29

Total Displacement Distribution at Shear Pin Failure 


\section{Modal Analysis}

\section{Model for Modal Analysis}

For the modal analysis, the same CAD model was meshed with 109510 elements and 160687 nodes, with the same material properties as above. The gate is fully fixed where the torque was applied at the previous model, with the other constraints from the previous model used. Figure 3-30 shows the meshed model with the constraints.

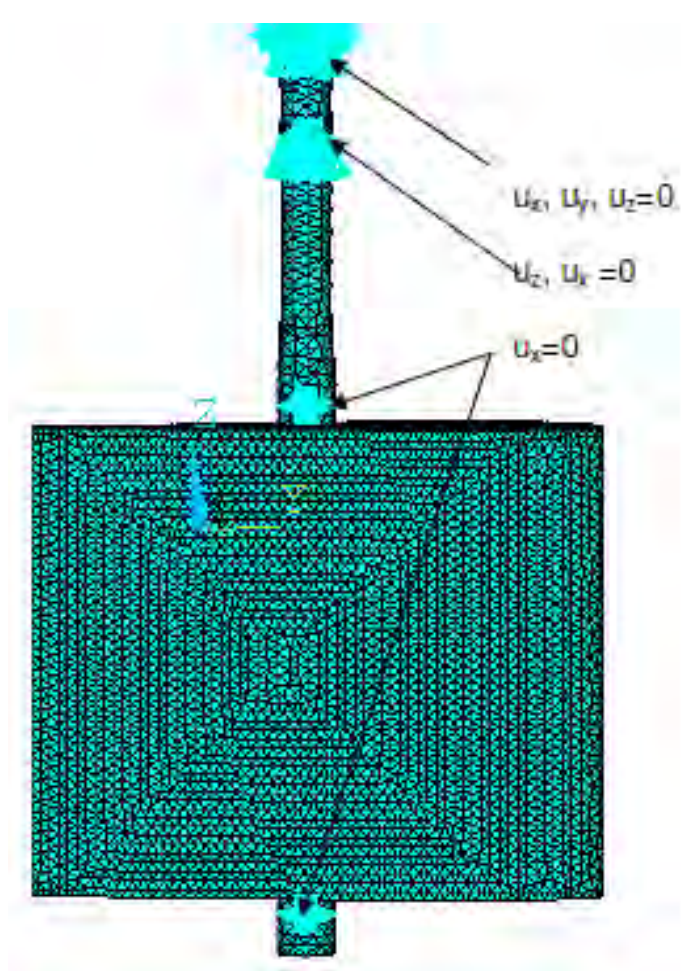

Figure 3-30

FEA Model for Modal Analysis

\section{Exciting Frequencies}

To ensure that no high dynamic response due to the blade passing frequency would be expected for this gate, the gate should have no mode shapes in air less than twice the gate passing frequency. This was done as a way to account for any reduction factor experienced by the mode frequencies due to being in water. 
Table 3-27

List of Potential Forcing Frequencies

\begin{tabular}{|c|c|c|c|}
\hline $\begin{array}{c}1^{\text {ts }} \text { Natural Torsional } \\
\text { Frequency } \mathrm{ft}_{\mathrm{t}}(\mathrm{Hz}) \text { in } \\
\text { Air }\end{array}$ & $\begin{array}{c}\mathbf{2} \times \text { Blade Passing } \\
\text { Frequency fb }(\mathrm{Hz})\end{array}$ & Design Criteria & Comment \\
\hline 15.74 & 12 & $\mathrm{ft}_{\mathrm{t}}>2 \times \mathrm{fb}$ & OK \\
\hline
\end{tabular}

Figure 3-31 illustrates the first 3 mode shapes in air. The first mode shape exhibits a torsional mode, the second a bending mode in the leaf, and the third, an axial shape.
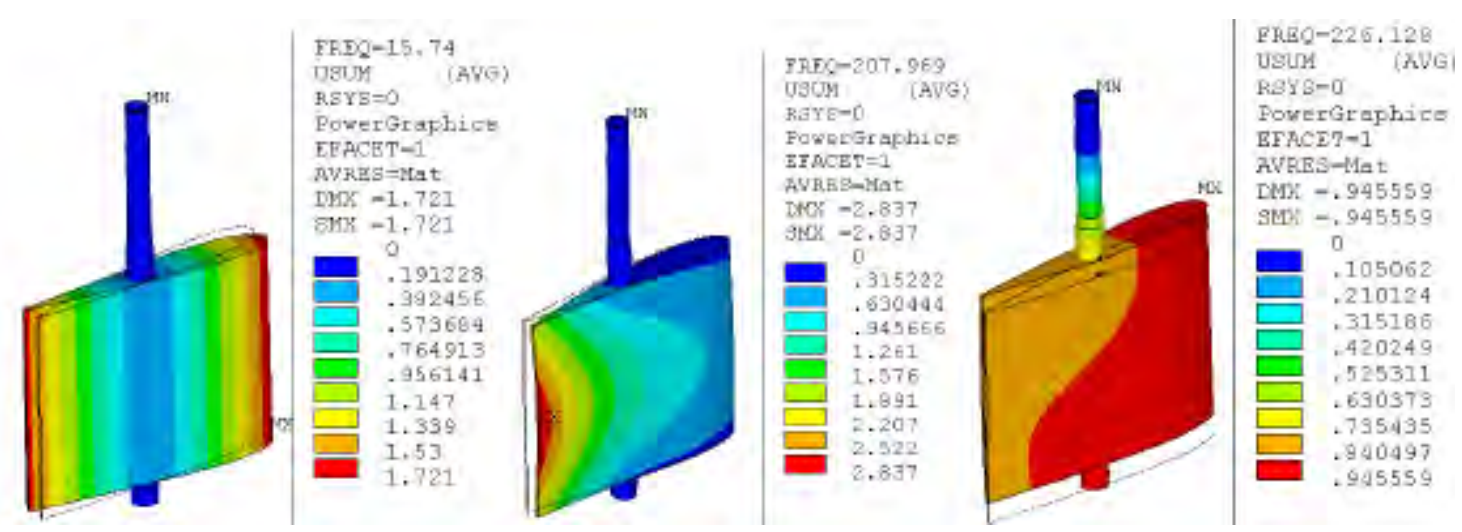

Figure 3-31

Modal Shapes for the First 3 Resonating Frequencies for the Proposed Wicket Gate

\section{Summary}

The wicket gate under investigation meets design criteria for stress.

As seen in the section Modal Analysis of this chapter, no problems due to high dynamic response are anticipated for this wicket gate. 



\title{
4
}

\section{MODEL TEST REPORT}

\author{
MODEL TEST REPORT \\ FOR \\ ALDEN TURBINE 3X (EPRI - DOE AHTS) \\ APPLICATION AT SCHOOL STREET STATION \\ SHOP ORDER NO. 2000234 \\ PDM NAME 2TEN60-0202-00643666
}

PREPARED BY:
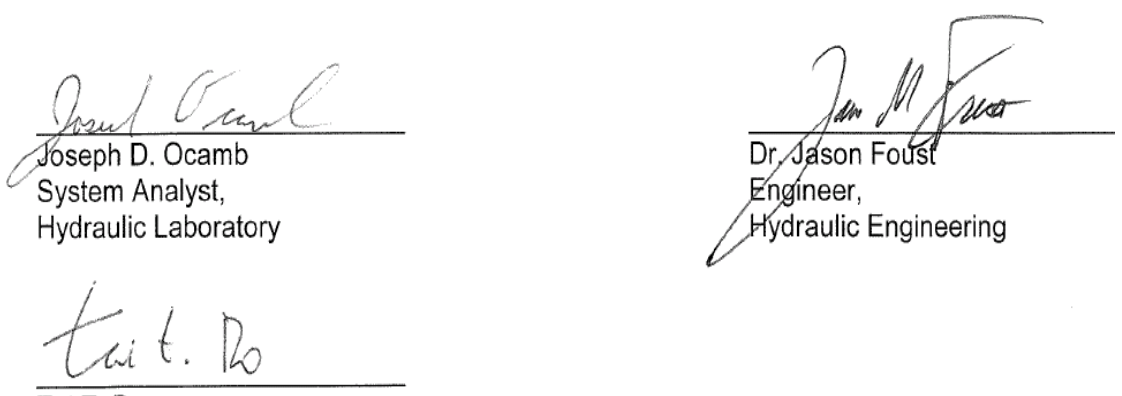

Tai T. Do

Manager,

Hydraulic Laboratory

APPROVED BY:

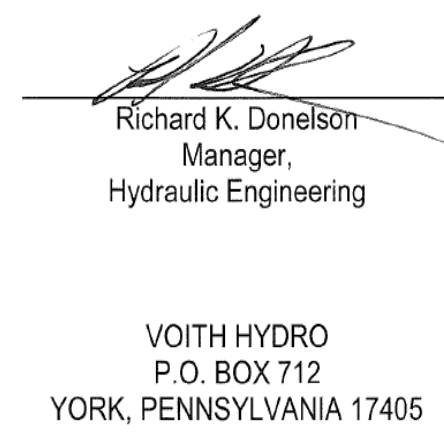

February 2011 


\section{Statement of Purpose and Summary of Results}

\section{Statement of Purpose}

After the modified Alden turbine hydraulic passageways were defined and structural analysis was performed for the anticipated School Street operating range (phase one of the Alden turbine development), the hydraulic shapes were released for model manufacture, including the inlet pipe, transition piece, spiral case, stay ring, wicket gates, runner and draft tube. Details of the Computational Fluid Dynamic (CFD) results for the modified shapes, as well as the corresponding Finite Element Analysis (FEA) calculations are summarized in previous chapters of this report.

Phase two of the Alden turbine development project involves design, manufacturing and physical model testing of the modified Alden turbine components in Voith Hydro's S. Morgan Smith Memorial Hydraulic Laboratory in York, Pennsylvania. From August to November 2010, data was collected on performance, thrust, runaway speed, pressure pulsations, minimum pressures, cavitation and wicket gate torques in order to characterize the hydraulic behavior of the Alden turbine and identify the acceptable operating range for the aforementioned School Street Station design. Results of the hydraulic testing were also incorporated into the final sizing of the mechanical equipment (phase three of the Alden turbine development).

The purpose of this chapter is to document the phase two test results and present the test procedures followed in acquiring the Alden turbine model data.

Voith Hydro manufactured the physical model at a scale of 1:8.71 and conducted the tests at a speed of $900 \mathrm{rpm}$. The tested model reference diameter is $17.6 \mathrm{in}$. (0.4472 m), corresponding to the runner inlet diameter, $\mathrm{D}_{1 \mathrm{a}}$. Throughout the current test description, dimensionless coefficients for head $\left(\mathrm{E}_{\omega \mathrm{d}}\right)$, flow $\left(\mathrm{Q}_{\omega \mathrm{d}}\right)$ and power $\left(\mathrm{P}_{\omega \mathrm{d}}\right)$ are calculated using $\mathrm{D}_{1 \mathrm{a}}$.

The Alden model testing was conducted in accordance with IEC test code 60193, which specifies that performance step-up from model to prototype be calculated according to the runner discharge diameter, $\mathrm{D}_{2 \mathrm{a}}$. Using the Alden model discharge diameter of $13.6 \mathrm{in}$. (0.3456 m) and the aforementioned $900 \mathrm{rpm}$ model rotational speed, the tested Reynolds number was $\mathrm{Re}=$ 5.5653+06, while the prototype Alden turbine application at School Street Station is planned to operate at a Reynolds number of $\mathrm{Re}=5.6729+07$. During testing, a model peak efficiency of 91.85\% was recorded. Using the IEC step-up calculation methodology, the prototype efficiency adjustment translates into an increase of $1.79 \%$, yielding a maximum calculated prototype efficiency of 93.64\% for School Street Station. This peak corresponds to a prototype net head and flow of $92.0 \mathrm{ft}$ and $1503.8 \mathrm{cfs}$, respectively.

The remaining portion of the Statement of Purpose and Summary of Results will present an executive summary of the test results. A description of the model instrumentation is given in the Model Instrumentation section, followed by the relevant plant conditions and test procedures in the section Plant Conditions, Nomenclature, and Test Procedures. Details of the test results are outlined in the Model Results section, with the corresponding expected prototype results for School Street Station in the section Expected Prototype Results. Sample calculations are 
illustrated in the section Sample Calculations. Descriptions of the Alden Turbine model, as well as the hydraulic laboratory are given in the Description of Model section and the Description of Laboratory section, respectively.

In total, the complete Alden turbine model test report length is over several hundred pages. For the sake of brevity, the aforementioned sections have been condensed down to include only representative test procedures and results.

\section{Performance Characteristics}

As previously described, the expected Alden turbine efficiency peak for prototype application at School Street Station is 93.64\%. One of the features of the Alden runner is the thicker entrance edges utilized to reduce fish mortality during strike. These thicker entrance edges have the added benefit of being less sensitive to incidence angle changes that result from net head variations. As a result, the calculated peak efficiency levels for the School Street Station prototype remain above $91.5 \%$ across the anticipated head range from 73.6 to $101.2 \mathrm{ft}\left(\mathrm{H} / \mathrm{H}_{\mathrm{opt}}=\right.$ 0.8 to 1.1). A summary of the calculated peak efficiencies and power outputs for prototype net head values of 73.6, 82, 92 and $101.2 \mathrm{ft}$ is given in Table 5-1. These prototype efficiencies are presented without any test tolerances or mechanical losses.

In general, the performance levels demonstrated for the modified Alden turbine hydraulic components exceed levels anticipated prior to the current Alden development work.

\section{Cavitation Performance}

The Alden runner was designed to provide a safety margin on plant sigma that correlates to 7.4 psi $(0.5 \mathrm{~atm})$ at the selected design condition of $\mathrm{H}_{\text {net }}=92 \mathrm{ft}, \mathrm{Q}=1500 \mathrm{cfs}$. During testing, visual observations verified that this 7.4 psi design criteria was met at the design condition. Near the design flow, changes to net head had a small influence on the calculated sigma safety. An overview of the sigma value corresponding to cavitation inception and the corresponding pressure margin within the water passage is given in Table 5-2 for the discharges corresponding to peak efficiency for $\mathrm{H}_{\text {net }}=73.6,82,92$ and $101.2 \mathrm{ft}$.

At off-design conditions, the minimum pressures within the runner passage decreased due to the development of vortical structures within the water passage. These vortical structures are characteristic of off-design operation for all fixed blade runners. Although the observed minimum pressures at these operation conditions do not meet fish passage criteria, the resulting vaporization for the Alden runner is significantly less than that associated with conventional Francis applications. Off-design operation of the Alden turbine, illustrated in the form of photos taken below the runner, is shown in Figure 5-12 through Figure 5-15.

\section{Runaway Speed}

The maximum runaway speed of the turbine must be accounted for when performing the runner structural analysis, in addition to the generator design. Prior to testing, this maximum runaway speed could only be estimated due to the unique geometry of the Alden runner. To be 
conservative, preliminary FEA incorporated a runaway speed of $240 \mathrm{rpm}$ (twice the nominal speed). During testing, the maximum runaway speed corresponding to conditions of plant sigma $(\mathrm{TWE}=63 \mathrm{ft}$ ) was determined to be $189.8 \mathrm{rpm}$ at the maximum achievable mechanical wicket gate opening of $37.0^{\circ}$ and the net head of $101.2 \mathrm{ft}$. A summary of the calculated runaway speed vs. sigma for the net head values of $H_{\text {net }}=73.6,82,92$ and $101.2 \mathrm{ft}$ at the wicket gate opening of $37.0^{\circ}$ is given in Figure $5-1$. It should be noted that during operation, the maximum gate opening required within the anticipated operating range corresponds to $33.0^{\circ}$. The tested runaway speed for the model does not include the influence of generator friction or windage, which will result in a small reduction in prototype runaway speed.

\section{Hydraulic Thrust}

The modified Alden turbine features external thrust relief pipes that transport the seal leakage from above the runner crown to a single pipe that exhausts into the draft tube elbow. The maximum calculated hydraulic thrust of the modified Alden runner is 281,641 lbs at the maximum net head of $101.2 \mathrm{ft}$. An overview of the calculated prototype axial thrust for the four net heads of 73.6, 82, 92 and $101.2 \mathrm{ft}$ is given in Figure 5-2. Documentation of the hydraulic thrust is essential for final mechanical layout calculations corresponding to Alden turbine installations.

\section{Pressure Pulsations}

As with the maximum runaway speed for the Alden turbine, the influence that the Alden runner geometry has on draft tube pressure pulsations was unknown prior to the current model testing. An overview of the measured pressure amplitudes is given in Figure 5-3 for net heads of 73.6, 82, 92, $101.2 \mathrm{ft}$. Note that the data corresponds to the draft tube tap location DT13, which is positioned on the downstream side of the cone toward the elbow. Near the peak discharge rate of $1,500 \mathrm{cfs}$, the pressure amplitudes remain below 1\%. As expected, the pressure amplitudes increase during conditions of part load and overload due to the characteristic vortices associated with off-design operation of a fixed blade runner. The amplitudes measured for the modified Alden turbine are consistent with those expected for high specific speed Francis turbines.

Pressure fluctuations were also measured in the entrance to the modified spiral case entrance (IN06). An overview of the pressure amplitudes across the anticipated School Street Station operating range is given in Figure 5-4 for net heads of 73.6, 82, 92, $101.2 \mathrm{ft}$.

Table 4-1

Expected Turbine Prototype Hydraulic Efficiency for School Street Station

\begin{tabular}{|c|c|c|c|}
\hline $\begin{array}{c}\text { Prototype Net } \\
\text { Head (ft) }\end{array}$ & $\begin{array}{c}\text { Prototype } \\
\text { Discharge (cfs) }\end{array}$ & $\begin{array}{c}\text { Prototype Best } \\
\text { Efficiency (\%) }\end{array}$ & $\begin{array}{c}\text { Prototype Power } \\
\text { (kW) }\end{array}$ \\
\hline 73.6 & 1408.7 & 91.56 & 8,283 \\
\hline 82.0 & 1505.9 & 92.75 & 9,677 \\
\hline 92.0 & 1503.8 & 93.64 & 10,946 \\
\hline 101.2 & 1473.2 & 93.52 & 11,780 \\
\hline
\end{tabular}


Table 4-2

Expected Cavitation Inception for School Street Station Best Efficiency Point (BEP)

\begin{tabular}{|c|c|c|c|c|c|}
\hline $\begin{array}{c}\text { Prototype Net } \\
\text { Head [ft] }\end{array}$ & $\begin{array}{c}\text { Prototype } \\
\text { Discharge } \\
\text { [cfs] }\end{array}$ & $\begin{array}{c}\text { Minimum } \\
\text { Tailwater } \\
\text { Elevation [ft] }\end{array}$ & $\begin{array}{c}\text { Plant } \\
\text { Sigma } \\
{[-]}\end{array}$ & $\begin{array}{c}\text { Sigma } \\
\text { Inception } \\
{[-]}\end{array}$ & $\begin{array}{c}\text { Cavitation } \\
\text { Safety Margin } \\
\text { [atm] }\end{array}$ \\
\hline 73.6 & 1454.8 & 56.0 & 0.44 & 0.21 & 0.5 \\
\hline 82.0 & 1505.9 & 56.0 & 0.40 & 0.19 & 0.5 \\
\hline 92.0 & 1503.8 & 56.0 & 0.35 & 0.17 & 0.5 \\
\hline 101.2 & 1473.2 & 56.0 & 0.32 & 0.18 & 0.4 \\
\hline
\end{tabular}

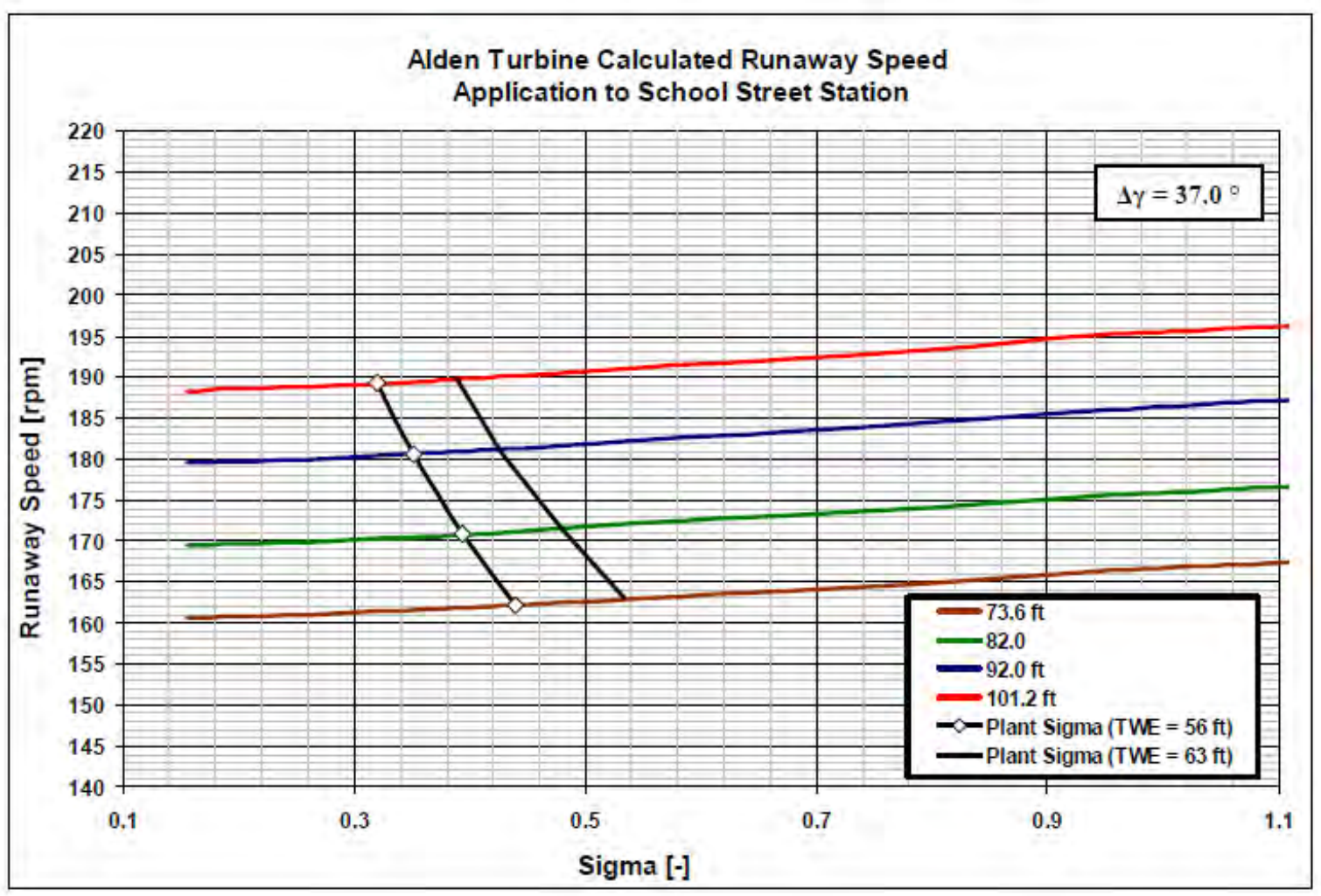

Figure 4-1

Alden Turbine Calculated Runaway Speed: Application to School Street Station 
Model Test Report

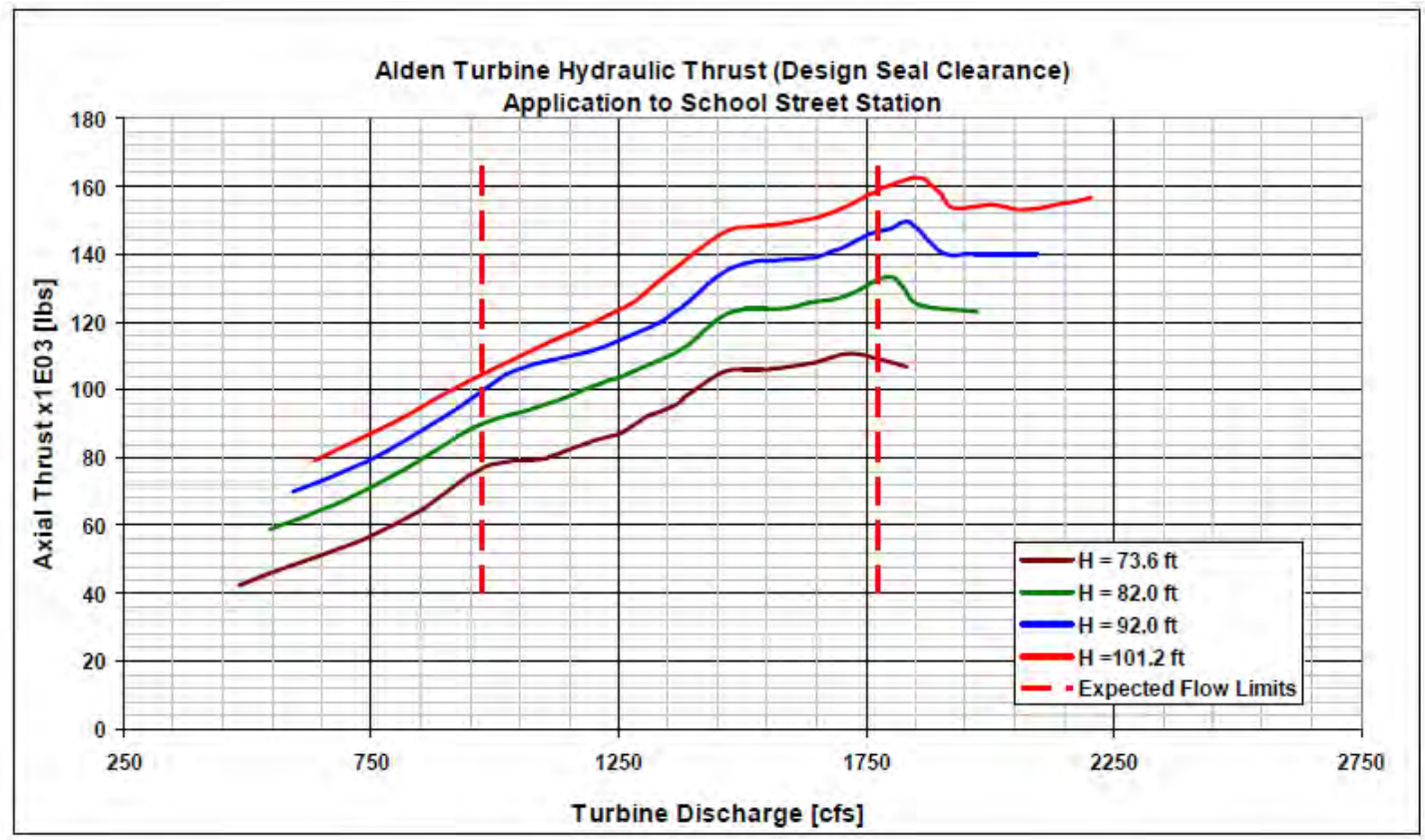

Figure 4-2

Alden Turbine Hydraulic Thrust (Design Seal Clearance): Application to School Street Station

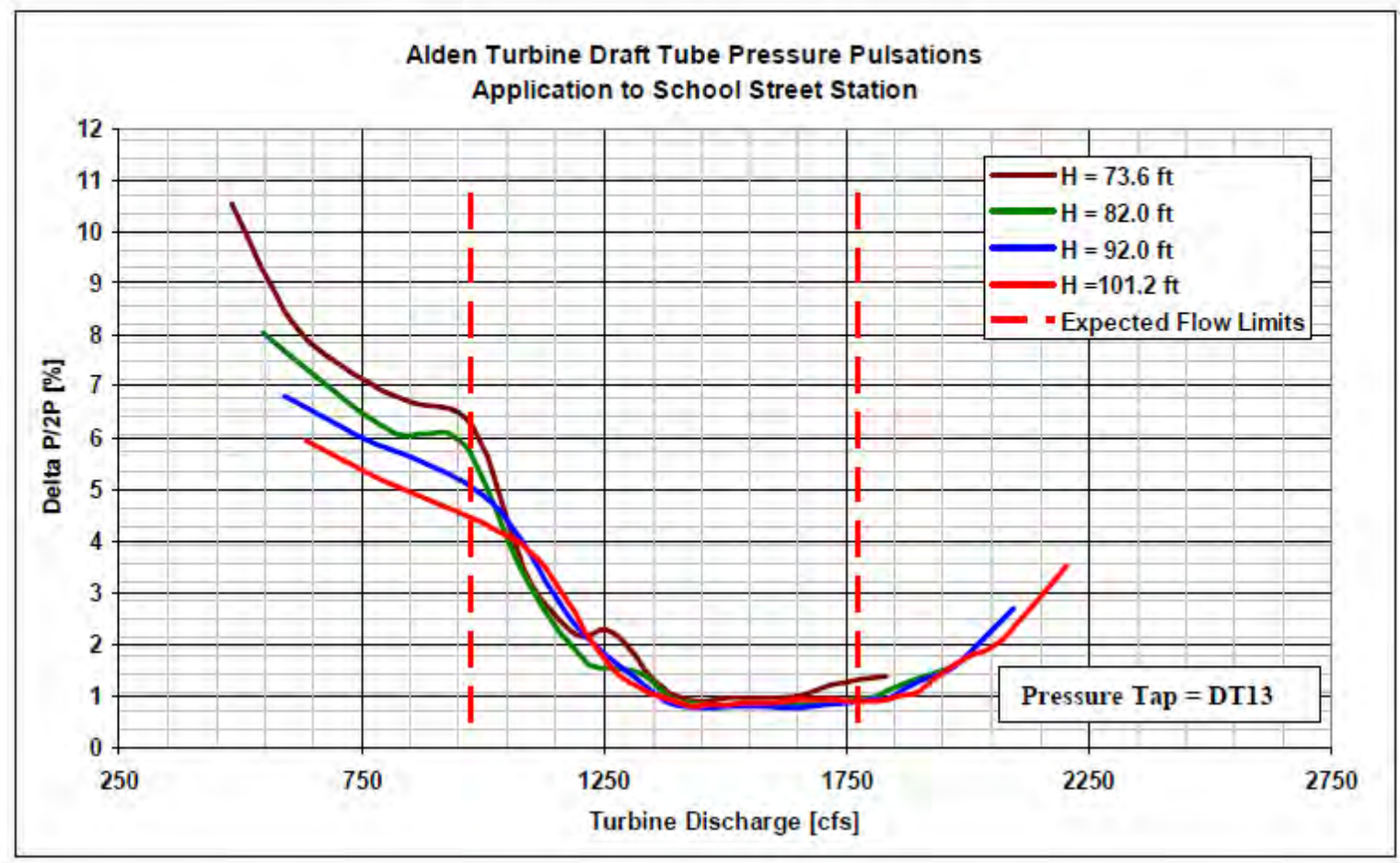

Figure 4-3

Alden Turbine Draft Tube Pressure Pulsations: Application to School Street Station 


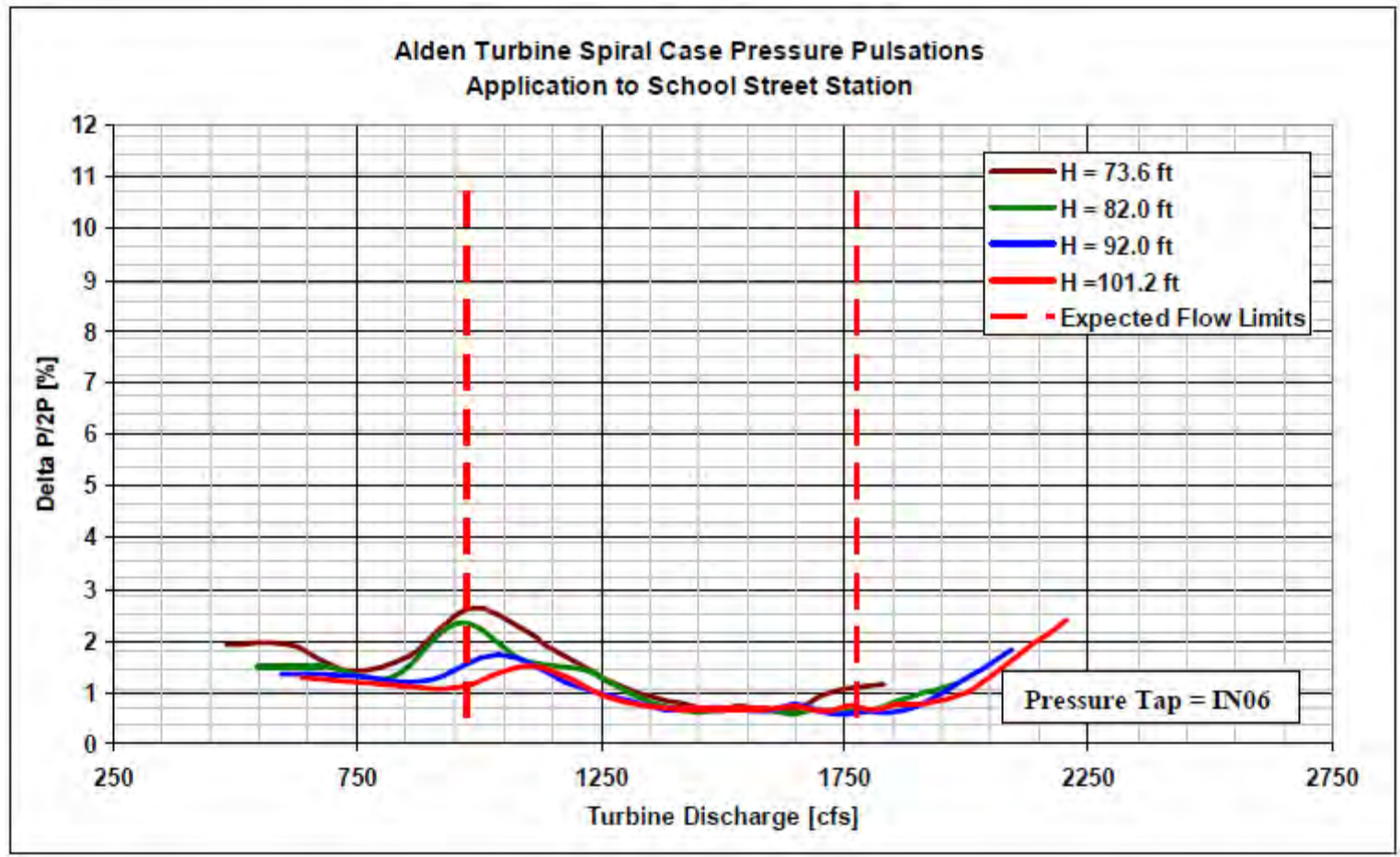

Figure 4-4

Alden Turbine Spiral Case Pressure Pulsations: Application to School Street Station

\section{Model Instrumentation}

\section{General}

This section gives typical calibration curves and certificates for the measuring instruments and the laboratory standards.

A general layout of the test loop and instrumentation is given in Figure 5-5. As previously indicated, instrumentation specifications and calibration information were omitted from the current version of the test report. These additional details are available upon request. 
All calibrations use a first degree curve fit of the form $y=a{ }^{*} V_{D C}+b$ :

Where:

$$
\begin{array}{ll}
\mathrm{a} & =\text { span factor } \\
\mathrm{b} & =\text { zero correction } \\
\mathrm{V}_{\mathrm{DC}} & =\text { transducer voltage } \\
\mathrm{y} & =\text { engineering unit }
\end{array}
$$

Percent error, local and full scale is defined as follows:

$$
\begin{aligned}
& \% \text { ERR LOC }=\frac{\text { Measured Transducer Value }- \text { Stan dard Applied }}{\text { Stan dard Applied }} \times 100 \\
& \% \text { ERR FS }=\frac{\text { Measured Transducer Value }- \text { Stan dard Applied }}{\text { Maximum Stan dard Applied }} \times 100
\end{aligned}
$$

\section{Load}

Calibration is performed by loading and unloading of dead weights.

The motor-generator portion of the dynamometer is supported by a hydrostatic bearing. Two load cells in series are connected to an arm extending radially from the motor-generator housing to measure the turbine output. The HBM load cells are Model No. Z3H3/1kN.

\section{Discharge}

The volumetric tank is calibrated with a weigh tank of smaller capacity. The capacity of the weigh tank is calculated using a calibrated load sensing transducer. When this calibration is finished, the data is fit to a second order equation to establish a volume versus depth relationship for flow meter calibration.

The load sensing transducer is calibrated using the same dead weights used to calibrate the axial thrust transducer.

A Fischer \& Porter magnetic flow meter is in the water supply line between the pumps and the head tank. The signal converter for the flow meter is located in the Control Room. The flow meter Model No. is 10D1435AX-20.

The magnetic flow meter is checked periodically against the 50,000 gallon volumetric tank. 


\section{Differential Head}

The high pressure side of the head transmitter is connected to piezometer taps IN01 - IN04, which are manifolded together in the high pressure pot. The low pressure side of the head transmitter is connected to piezometer taps DT05-DT12, which are manifolded together in the low pressure pot. The location of the high and low pressure taps can be found on Figure 5-34.

The differential head transmitter is calibrated against a Pressurements deadweight tester.

A Rosemount transmitter, Model No. 3051C is used.

\section{Absolute Tailwater Pressure}

The transmitter is calibrated using a mercury manometer. A Rosemount absolute pressure transmitter, Model No. 3051CA, is used to measure the static pressure at piezometer taps DT05DT12 in the draft tube foot.

\section{Rotational Speed}

A magnetic pickup is mounted on the dynamometer to read a 60 tooth gear mounted on the shaft. Figure 5-5 shows the location of the pickup.

The model rotational speed was checked against the Omega Digital Stroboscope, Model No. HHT32.

\section{Axial Thrust}

The axial thrust transducer is calibrated against dead weights.

\section{Air and Water Temperature}

Air and water temperature measurements are taken with the same instrumentation. The temperature sensing element is an RdF Corporation Industrial Platinum Resistance Temperature Detector (RTD) model number 21C-10-D-4-A-O-B. The RTD is connected to a Pyromation temperature transmitter. This instrumentation is calibrated using a certified precision thermometer.

\section{Dynamic Pressure}

The dynamic pressure transducers are calibrated using a Model 903A Dynamic Pressure Calibrator.

Six (6) flush mounted dynamic pressure transducers are used to measure pressure pulsation and their locations can be found on Figure 5-34. The six tap locations are HC01, HC02, IN05, IN06, DT13 and DT14. 
Model Test Report

\section{Wicket Gate Position}

Wicket gate position is measured with a Computer Conversions Corporation DS series absolute encoder that is directly connected to one wicket gate. This encoder gives 4000 counts for 360 degrees of gate rotation. Its specified accuracy is 1 part in 4000.

Based on the design, a high degree polynomial curve fit equation is developed to convert model gate opening in millimeter to angle in degree. The actual model gate openings are measured with lollipop and feeler gage in millimeters for several positions, converted to angles in degree and compared to the design values.

\section{Gate Torque}

The strain gage wicket gates are manufactured by Voith Hydro, Hydraulic Laboratory. Calibration of the wicket gates is done by cantilevering a series of small weights off the gate shaft while supporting the gate leaf below the instrumented section.

\section{Radial Thrust}

A load cell is calibrated against the same dead weights as previously described.

Two transducers are used to measure radial thrust at $90^{\circ}$ apart from each other. The root sum of the square of these two forces is yielding total radial thrust. 


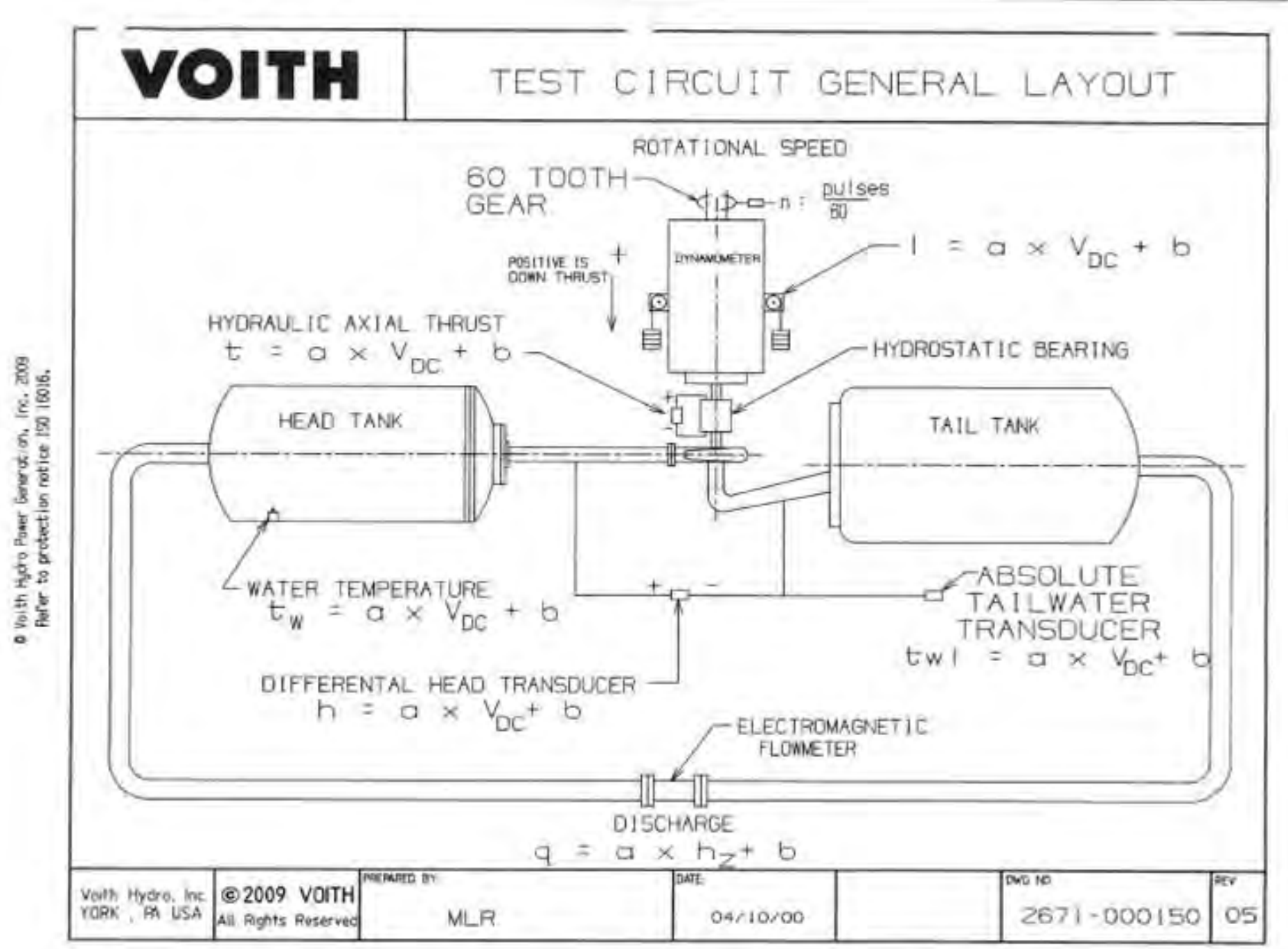

Figure 4-5

General Layout of the Test Loop and Instrumentation 


\section{Plant Conditions, Nomenclature and Test Procedures \\ Plant Conditions}

All model testing was conducted within the guidelines detailed in IEC Publication 60193 dated 1999.

The scale ratio from model to prototype is: $\lambda=8.710000$

The prototype hydraulic conditions are as follows:

\begin{tabular}{|c|c|c|}
\hline & Metric & English \\
\hline Rated speed & $\mathrm{N}_{\mathrm{p}}=120.0 \frac{1}{\mathrm{~min}}$ & $\mathrm{~N}_{\mathrm{p}}=120.000 \frac{1}{\mathrm{~min}}$ \\
\hline Runner characteristic diameter $\left(D_{1 a}\right)$ & $\mathrm{D}=3.89472 \mathrm{~m}$ & $\mathrm{D}=153.335 \mathrm{in}$ \\
\hline Shaft diameter & $\mathrm{D}_{\text {shaft }}=0.508 \mathrm{~m}$ & $\mathrm{D}_{\text {shaft }}=20$ in \\
\hline Maximum net head & $\mathrm{H}_{\max }=30.8 \mathrm{~m}$ & $\mathrm{H}_{\max }=101.2 \mathrm{ft}$ \\
\hline Minimum net head & $\mathrm{H}_{\min }=22.4 \mathrm{~m}$ & $\mathrm{H}_{\min }=73.6 \mathrm{ft}$ \\
\hline Mass density of water & $\rho_{p}=998.243509 \frac{\mathrm{kg}}{\mathrm{m}^{3}}$ & $\rho_{p}=1.93691 \frac{\text { slug }}{\mathrm{ft}^{3}}$ \\
\hline Gravity & $\mathrm{G}=9.804145 \frac{\mathrm{m}}{\mathrm{sec}^{2}}$ & $\mathrm{G}=32.16583 \frac{\mathrm{ft}}{\sec ^{2}}$ \\
\hline Maximum wicket gate rotation & $\Delta \gamma_{-} \max =37 \mathrm{deg}$ & $\Delta \gamma_{-} \max =37 \mathrm{deg}$ \\
\hline Barometric head & $\mathrm{H}_{\mathrm{b}}=10.3235 \mathrm{~m}$ & $\mathrm{H}_{\mathrm{b}}=33.870 \mathrm{ft}$ \\
\hline Vapor head & $H_{v}=0.2388 \mathrm{~m}$ & $\mathrm{H}_{\mathrm{v}}=0.783 \mathrm{ft}$ \\
\hline Reference elevation for $\sigma$ calculations & $Z_{c}=17.3068 \mathrm{~m}$ & $Z_{C}=56.781 \mathrm{ft}$ \\
\hline Normal maximum tailwater elevation & $\mathrm{TWE}_{\max }=19.20 \mathrm{~m}$ & $\mathrm{TWE}_{\max }=63 \mathrm{ft}$ \\
\hline Normal minimum tailwater elevation & $\mathrm{TWE}_{\min }=17.07 \mathrm{~m}$ & $\mathrm{TWE}_{\min }=56 \mathrm{ft}$ \\
\hline
\end{tabular}




\section{Nomenclature}

Small letters and subscript m denote model dimensions, capital letters and subscript p denote prototype dimensions.

\section{Definition}

Generic term for any span factor

Model pressure area, spiral case or inlet taps

Model suction area, draft tube foot taps

Generic term for any zero $(0)$ correction

Pad height

Wicket gate torque coefficient (dimensionless)

Absolute pressure coefficient (dimensionless)

Runner characteristic diameter $\left(D_{1 a}\right)$

IEC Runner discharge diameter $\left(D_{2 a}\right)$

Shaft diameter

Pressure pulsation as amplitude in $\%$ of net head

Specific Energy

Energy coefficient (dimensionless)

Energy coefficient at runaway (dimensionless)

Frequency from FFT

Rotational frequency of the runner

\section{Model}

a (EU/volt)

$a_{1}=0.245425 m^{2}$

$a_{2}=0.320620 m^{2}$

$b$ (engineering units)

$\mathrm{b}_{\mathrm{O}}=0.120472 \mathrm{~m}$

$B_{O}=1.049 m$

$\mathrm{C}_{\mathrm{g}}, \mathrm{K}_{\mathrm{g}}$

$\mathrm{C}_{\mathrm{p}}$

$d=0.447155 m$

$\mathrm{D}=3.8947 \mathrm{~m}$ or $\mathrm{D}_{\text {ref, } \mathrm{P}}$

$\mathrm{d}_{\mathrm{iec}}=0.345604 \mathrm{~m}$

$\mathrm{D}_{\text {iec }}=3.01021 \mathrm{~m}$

$D_{\text {shaft }}=0.508 \mathrm{~m}$

$\mathrm{dp} / 2 \mathrm{p} \times 100$

$D P / 2 P \times 100$

$E_{m}\left(\frac{\mathrm{J}}{\mathrm{kg}}\right)$

$E_{p}\left(\frac{J}{k g}\right)$

$E_{\omega \mathrm{d}}$

$E_{\omega d r}$

freq $(\mathrm{Hz})$

$\mathrm{f}_{\mathrm{n}}(\mathrm{Hz})$ 


\section{Definition}

Uncertainty

Local gravitational constant, IEC 60193

Standard gravitational constant, IEC 60193

Barometric head

Maximum net head

Minimum net head

Submergence

Net Head

Vapor head

Headwater elevation

Axial thrust coefficient (dimensionless)

Radial thrust coefficient (dimensionless)

Total load

Rotational speed

Tested speed at optimum efficiency

Net positive suction head

Shaft power
Model

f

\section{Prototype}

$\mathrm{g}_{\mathrm{o}}=9.80665 \frac{\mathrm{m}}{\mathrm{sec}^{2}}$

$h_{b}(m)$

$\mathrm{H}_{\mathrm{b}}=10.3235 \mathrm{~m}$

$\mathrm{H}_{\max }=30.84576 \mathrm{~m}$

$\mathrm{H}_{\min }=22.43328 \mathrm{~m}$

$h_{s}(m)$

$\mathrm{H}_{\mathrm{s}}(\mathrm{m})$

$h(m)$ or $(\mathrm{kPa})$

$H(m)$

$h_{v}(m)$

$H_{v}=0.239 m$

HWE (m)
$\mathrm{K}_{\mathrm{a}}$

$\mathrm{K}_{\mathrm{rb}}$

$\mathrm{L}(\mathrm{N})$

$\mathrm{n}\left(\frac{1}{\min }\right)$ or $\left(\frac{1}{\mathrm{sec}}\right) \quad \mathrm{N}_{\mathrm{p}}=120.000 \frac{1}{\min }$

$\mathrm{n}_{\mathrm{optM}}\left(\frac{1}{\mathrm{sec}}\right)$

npsh

NPSH

P, POWER (kW) 


\section{Definition}

Power coefficient (dimensionless)

Differential pressure

Absolute pressure at transducer location

Winter-Kennedy differential pressure

Discharge

Discharge coefficient (dimensionless)

Discharge coefficient at runaway (dimensionless)

Model tested Reynolds number at optimum efficiency, IEC 60193

Reference Reynolds number, IEC 60193

Model Reynolds number @ test

conditions, IEC 60193

Prototype Reynolds number, IEC 60193

Axial thrust (+ is down thrust)

Average wicket gate torque

(+ is opening torque)

Radial thrust

Model shaft torque

Model shaft torque at maximum

power output

Sigma reference level below runner centerline

Model tailwater absolute pressure referenced to $Z_{c}$

\section{Model}

$P_{\omega d}, P_{\omega d}$ ref

$\mathrm{p}(\mathrm{kPa})$

$P_{\text {transducer }}(\mathrm{kPa})$

$\mathrm{P}_{\text {wk }}$ (bar)

q $\left(\frac{\mathrm{m}^{3}}{\mathrm{sec}}\right)$

Q $\left(\frac{\mathrm{m}^{3}}{\mathrm{sec}}\right)$

$Q_{\omega \mathrm{d}}$

$Q_{\omega d r}$

$\mathrm{Re}_{\mathrm{optM}}$

$\operatorname{Re}_{\text {ref }}=7 \times 10^{6}$

$\mathrm{Re}_{\mathrm{m}}$

$\operatorname{Re}_{p}=5.672926 \times 10^{7}$

$t_{a}(N)$

$\mathrm{T}_{\mathrm{a}}(\mathrm{N})$

$\mathrm{t}_{\mathrm{g}}(\mathrm{Nm})$

$\mathrm{T}_{\mathrm{g}}(\mathrm{Nm})$ $t_{r b}(N)$

$\mathrm{t}(\mathrm{Nm})$

$\mathrm{T}_{\text {ref }}(\mathrm{Nm})$

$\mathrm{t}_{\mathrm{S}}=0.1476 \mathrm{~m}$

$\mathrm{T}_{\mathrm{S}}=1.286 \mathrm{~m}$

tw $(\mathrm{kPa})$ 


\section{Definition}

Tailwater elevation

Normal maximum tailwater elevation

Normal minimum tailwater elevation, $\sigma_{95 \%}$

Loss distribution coefficient for turbine

Transducer voltage

Water temperature

Tested water temperature at optimum efficiency

Generic term for any engineering unit

Absolute reference elevation for $\sigma$ calculations

Absolute elevation of the distributor center line

Number of runner blades

Number of wicket gates

Wicket gate rotation

Maximum wicket gate rotation

Optimum (best) wicket gate rotation

Reference Model efficiency to prototype efficiency step-up adder

Tested Model to corrected model efficiency step-up adder

Differential pressure or peak to peak

Peak to peak torque fluctuation $\underline{\text { Model }}$

$\underline{\text { Prototype }}$

TWE (m)

$\mathrm{TWE}_{\max }=19.202 \mathrm{~m}$

$\mathrm{TWE}_{\min }=17.069 \mathrm{~m}$

VDC

wt $\circ \mathrm{C}$

$\mathrm{WT}=20$

$w_{\mathrm{optM}}{ }^{\circ} \mathrm{C}$

$y$ (engineering units)
$Z_{c}=17.3068 m$

$\mathrm{Z}_{\mathrm{Cl}}=18.5928 \mathrm{~m}$

$Z_{r}=3$

$\mathbf{z}_{0}=14$

$Z_{0}=14$

$\Delta \gamma$ (degrees)

$\Delta \gamma_{-} \max =37 \mathrm{deg}$

$\Delta \gamma_{-} \max =37 \mathrm{deg}$

$\Delta \gamma_{-}$opt $=21 \mathrm{deg}$

$\Delta \gamma_{-}$opt $=21 \mathrm{deg}$

$\Delta \eta M_{-} P \quad$ in $\%$

$\Delta \eta_{M s p} \quad$ in $\%$

dp or $\Delta p(k P a)$ or $\Delta \mathrm{H}(\mathrm{m})$

dt or $\Delta \mathrm{t}(\mathrm{Nm})$ 


\section{Definition}

Torque fluctuation as $\%$ of torque at maximum power output $P_{c m}$

Relative scaleable losses, IEC 60193

Efficiency (\%)

Reference Model Efficiency (tested model

efficiency corrected to $\mathrm{Re}=7 \times 10^{6}$ )

Optimum efficiency (\%)

Prototype to model scale ratio

Mass density of water

Standard mass density of water at $15^{\circ} \mathrm{C}$

Kinematic viscosity, IEC 60193

Model kinematic viscosity at optimum efficiency, IEC 60193

Thoma cavitation coefficient (dimensionless)

Sigma begin (incipient)

Critical sigma where efficiency

decreases by $1 \%$

Plant sigma

Sigma when efficiency deviates from constant value

Speed in radians per second

\section{Model}

$\mathrm{dt} / \mathrm{t} * 100$ or

$\Delta \mathrm{t} / \mathrm{t} * 100$

$\delta_{\text {ref }}$

$\eta_{\mathrm{m}}$, Eff

$\eta_{\mathrm{Msp}}, \eta_{\text {ref }}$

$\eta_{\text {optM }}$

$\frac{\mathrm{D}_{\mathrm{z}}}{\mathrm{d}_{\mathrm{z}}}=\lambda=8.710000$

$\rho_{\mathrm{m}}\left(\frac{\mathrm{kg}}{\mathrm{m}^{3}}\right)$

$\rho_{\mathrm{O}}=999.100 \frac{\mathrm{kg}}{\mathrm{m}^{3}}$

$v_{\mathrm{m}}\left(\frac{\mathrm{m}^{2}}{\mathrm{sec}}\right)$

$v_{p}=1.003614 \times 10^{-6} \frac{\mathrm{m}^{2}}{\mathrm{sec}}$

\section{Prototype}

$\eta_{p} \quad$, Eff_p

$\eta_{\text {optP }}$

$v_{\text {optM }}\left(\frac{m^{2}}{s e c}\right)$

$\sigma$

$\sigma_{\mathrm{b}}, \sigma_{\mathrm{i}}$

$\sigma_{1}, \sigma_{c}$

$\sigma_{\mathrm{p}}$

$\sigma_{0}$

$\omega_{m}\left(\frac{1}{\sec }\right)$

$\omega_{\mathrm{p}}\left(\frac{1}{\mathrm{sec}}\right)$

Note: Subscript opt denotes optimum condition. 


\section{Performance Testing}

The homologous turbine model was tested over the required operating range to determine its performance characteristics. The test data covered operating range of $73.6 \mathrm{ft}$ to $101.2 \mathrm{ft}$ net head with sufficient data taken above and below these levels to allow adequate definition of the operating characteristics.

Performance tests were run at fixed wicket gate position. Each wicket gate position was run across the head range by varying the speed of the service pumps while maintaining a constant rotational speed of $900 \mathrm{rpm}$ and a constant npsh of $245 \mathrm{kPa}$ referenced to the elevation of 147 $\mathrm{mm}$ below the centerline of the distributor. Each wicket gate position consisted of approximately 20 to 30 data points each resulting from a 20 second scan in which 1000 samples were taken and averaged for the performance calculations.

Efficiency ( $\eta$ ), discharge coefficient ( $Q_{d}$ ), power coefficient ( $\left.P_{d}\right)$, versus energy coefficient $\left(E_{\omega d}\right)$ was plotted. These factors are defined as:

$$
\begin{aligned}
& E_{\omega d}=\frac{g \cdot h}{\left(\omega_{\mathrm{m}} \cdot d\right)^{2}} \\
& Q_{\omega d}=\frac{q}{\omega_{\mathrm{m}} \cdot d^{3}} \\
& P_{\omega d}=\frac{p}{\rho_{m} \cdot \omega_{\mathrm{m}}{ }^{3} \cdot d^{5}} \\
& \eta=\frac{p \cdot 100}{\rho_{m} \cdot g \cdot h \cdot q}=\frac{P_{\alpha d} \cdot 100}{E_{\alpha d l} \cdot Q_{\alpha d}}
\end{aligned}
$$

Where: $\quad \mathrm{d}=$ Characteristic model diameter $(\mathrm{m})$

$\mathrm{g}=$ Gravitational constant $\left(\mathrm{m} / \mathrm{sec}^{2}\right)$

$\mathrm{h}=$ Model net head $(\mathrm{m})$

$\omega_{\mathrm{m}}=$ Model speed $(1 / \mathrm{sec})$

$\mathrm{p} \quad=\quad$ Model power $(\mathrm{kW})$

$\mathrm{q}=$ Model discharge $\left(\mathrm{m}^{3} / \mathrm{s}\right)$

$\rho_{\mathrm{m}}=$ Mass density of water $\left(\mathrm{kg} / \mathrm{m}^{3}\right)$

\section{Cavitation Testing}

Cavitation tests were run on the model by setting a fixed wicket gate position and running the model at a constant net head while varying the absolute pressure in the tail tank in a closed loop 
test stand to vary the Thoma cavitation coefficient, sigma ( $\sigma$ ). The reference elevation for sigma is $147 \mathrm{~mm}$ below the centerline of the distributor. The tailwater pressure is obtained from the piezometer taps located in the draft tube foot.

The absolute pressure was lowered sufficiently to produce a drop in efficiency, to the limit of the test stand, which is $12 \mathrm{kPa}$. This limit allows the sigma level to be considerably less than plant sigma.

Sufficient data points were taken to define the values of critical sigma $\left(\sigma_{\mathrm{c}}\right)$ where the efficiency decreases one percentage point from a constant value. The relationship of critical sigma to plant sigma is determined from this testing.

During cavitation testing, visual observations were made to determine incipient sigma $\left(\sigma_{\mathrm{c}}\right)$ through a plexiglass cone of the draft tube.

Procedures for data collection and sampling are identical to performance testing described in the section Plant Conditions, Nomenclature and Test Procedures: Performance Testing. Efficiency $\left(\eta_{\mathrm{m}}\right)$, discharge coefficient $\left(\mathrm{Q}_{\omega \mathrm{d}}\right)$, power coefficient $\left(\mathrm{P}_{\omega \mathrm{d}}\right)$ versus $(\sigma)$ were plotted.

$$
\sigma=\frac{\mathrm{h}_{\mathrm{b}}-\mathrm{h}_{\mathrm{v}}-\mathrm{h}_{\mathrm{s}}}{\mathrm{h}}=\frac{\mathrm{npsh}}{\mathrm{h}}
$$

Where: $\quad$ npsh $=$ Net Positive Suction Head

$$
\begin{aligned}
& \text { hb }=\text { Barometric Pressure } \\
& \text { hV }=\text { Vapor Pressure } \\
& \text { hS = Submergence }=\text { CL of distributor }- \text { Tailwater Elevation }- \text { ts } \\
& \text { h }=\text { Net Head }
\end{aligned}
$$

\section{Runaway Speed Testing}

Runaway speed tests were run by setting selected wicket gate position and running the model at constant speed and approximately zero torque while varying the absolute tail tank pressure in a closed test loop to vary the Thoma coefficient, sigma. The corresponding turbine discharge and axial hydraulic thrust are simultaneously measured.

Data collection and sampling are identical to performance testing described in the section Plant Conditions, Nomenclature and Test Procedures: Performance Testing. Energy coefficient ( $\mathrm{E}_{\omega \mathrm{dr}}$ ), discharge coefficient ( $Q_{\omega d r}$ ), thrust coefficient ( $K_{a}$ ) versus sigma ( $\sigma$ ) was plotted.

\section{Gate Torque Testing}

A special test was run to determine the wicket gate torque. Six (6) special strain gaged model wicket gates are manufactured to minimize friction on the head cover and bottom ring. These 
special wicket gates replaced the normal wicket gates for the testing. The location of the special wicket gates are at the positions numbered 1, 2, 4, 7, 11, and 14 as shown on Figure 4-35.

The test was run measuring the wicket gate torque at several wicket gate positions, from a nearly closed position to beyond the maximum wicket gate position. The test was run twice in order to eliminate the effects of friction and/or hysteresis. First, starting at a small wicket gate position and opening the wicket gates, and secondly by starting at a large wicket gate position and closing the wicket gates.

The weighted average is calculated as follows:

$$
\mathrm{t}_{\mathrm{g}}=\frac{\mathrm{t}_{\mathrm{g} 1}+\mathrm{t}_{\mathrm{g} 2}+\mathrm{t}_{\mathrm{g} 4}+\mathrm{t}_{\mathrm{g} 7}+\mathrm{t}_{\mathrm{g} 11}+\mathrm{t}_{\mathrm{g} 14}}{6}
$$

Data collection and sampling are identical to performance testing described in the section Plant Conditions, Nomenclature and Test Procedures: Performance Testing. Wicket gate torque coefficient, $\mathrm{C}_{\mathrm{g}}$, a dimensionless wicket gate torque factor, is plotted against wicket gate position $(\Delta \gamma)$ in degrees.

The coefficient is defined as:

$$
\mathrm{Cg}=\frac{\mathrm{t}_{\mathrm{g}}}{\frac{\rho_{m} \cdot q^{2}}{d}}
$$

Where: $\quad d=$ Characteristic model diameter $(\mathrm{m})$

$$
\begin{aligned}
& \mathrm{q}=\text { Discharge }(\mathrm{m} 3 / \mathrm{s}) \\
& \rho \mathrm{m}=\text { Mass density of water }(\mathrm{kg} / \mathrm{m} 3) \\
& \mathrm{tg}=\text { Gate torque }(\mathrm{Nm})
\end{aligned}
$$

Asynchronous wicket gate torque data was collected for gates numbered 14, 1, and 2. Gate numbered 1 is in asynchronous position and gates numbered 14 and 2 are in synchronous positions. Tests were run at the equivalent prototype head of $92 \mathrm{ft}$. A hill chart of dimensionless coefficient $\mathrm{Kg}$ is plotted and the coefficient is defined as:

$$
\mathrm{Kg}=\frac{\mathrm{t}_{\mathrm{g}}}{\rho_{\mathrm{m}} \cdot \mathrm{g} \cdot \mathrm{h} \cdot \mathrm{b}_{\mathrm{o}} \cdot\left(\frac{\mathrm{d} \cdot \pi}{\mathrm{Z}_{\mathrm{o}}}\right)^{2}}
$$

Where: $\quad \operatorname{tg}=$ Gate torque $(\mathrm{Nm})$

$$
\mathrm{m}=\text { Mass density of water }(\mathrm{kg} / \mathrm{m} 3)
$$


$\mathrm{g}=$ Gravitational constant $(\mathrm{m} / \mathrm{sec} 2)$

bo = Pad height $(\mathrm{m})$ is defined as the difference between the inner and outer gate barrel radius measured along the gate axis of rotation

$\mathrm{d}=$ Characteristic model diameter $(\mathrm{m}$ )

Zo $=$ Number of wicket gates

\section{Pressure Pulsation Testing}

Measurements are made to obtain the following information:

- Peak to peak of pressure pulsation within operating range. Peak to peak data of pressure pulsation is recorded with each data point collected during performance testing described in the section Plant Conditions, Nomenclature and Test Procedures: Performance Testing.

- Dominant frequency and amplitude for selected operating conditions.

Characteristic amplitude with a probability distribution of $97 \%$ was established out of the time signals. Pressure pulsation ( $\Delta \mathrm{P} / 2 \mathrm{P}$ in $\%$ ) versus $\mathrm{Q}_{\omega \mathrm{d}}$ are plotted.

It is more meaningful to evaluate data in frequency domain for the maximum amplitudes occurring at hydraulic relevant frequencies. Hydraulic relevant frequencies, depending on operating points, are usually between $0.2 f_{n}$ and $f_{n}$, where $f_{n}$ is the rotational frequency of the runner. Frequencies at multiple of $\mathrm{f}_{\mathrm{n}}$ are also quite common.

The analog data was subjected to fast Fourier Transform, giving the amplitude in $\Delta \mathrm{P} / \mathrm{P}$ in $\%$ and frequency in freq/fn, with the following set up:

- Sampling rate is at four times the maximum frequency analyzed. For example, if the full scale frequency data is $100 \mathrm{~Hz}$, then the sampling rate is 400 samples per second.

- Amplitude is given in engineering unit. Four ( 4 ) FFT are obtained and then averaged to obtain a single FFT plot. The averaging is done for FFT plot to reduce noise. No averaging is done for analog data.

- Pressure pulsation amplitude $\Delta \mathrm{P} / \mathrm{P}(\%)$ is defined as follows:

Where: $\quad \mathrm{P}=$ Peak to peak pressure pulsation $(\mathrm{kPa})$

$\mathrm{P}=$ Net differential pressure between high and low pressure taps $(\mathrm{kPa})$

\section{Axial Thrust Testing}

The configuration of our dynamometer allows for the recording of axial thrust with each data point collected during performance testing described previously. The hydraulic thrust was measured by the difference of the oil pressures of the upper and lower oil supply chambers of the hydrostatic bearing. The differential pressure on the model shaft between the normally varying tailwater pressure and atmospheric pressure creates a thrust imbalance. To account for this imbalance a tailwater pressure correction is made to the measured thrust value. 
Thrust coefficient ( $K_{a}$ ) versus energy coefficient ( $E_{\omega d}$ ) are plotted for various gate positions. Dimensionless thrust coefficient is defined as follows:

Where: $\quad$ ta $=$ Hydraulic axial thrust $(\mathrm{N})$

$$
\begin{aligned}
& \mathrm{d}=\text { Characteristic model diameter }(\mathrm{m}) \\
& \rho \mathrm{m}=\text { Mass density of water }(\mathrm{kg} / \mathrm{m} 3) \\
& \mathrm{g}=\text { Gravitational constant }(\mathrm{m} / \mathrm{sec} 2) \\
& \mathrm{h}=\text { Model net head }(\mathrm{m})
\end{aligned}
$$

\section{Radial Thrust Testing}

The configuration of our dynamometer allows for the recording of radial thrust with each data point collected during performance testing described previously. The radial thrust was measured by the difference of the oil pressures of the supply chambers of the hydrostatic bearing. Two supply chambers located 180 degrees apart are connected to a differential pressure transducer to measure the force along $\mathrm{X}$ axis. Similarly another two supply chambers allow measurement of radial force along the $\mathrm{Y}$ axis.

Radial thrust coefficient ( $K_{r b}$ ) versus energy coefficient ( $E_{\omega d}$ ) are plotted for various gate positions.

Dimensionless radial thrust coefficient is defined as follows:

$$
\mathrm{K}_{\mathrm{a}}=\frac{\mathrm{t}_{\mathrm{a}}}{\rho_{\mathrm{m}} \cdot \mathrm{g} \cdot \mathrm{h} \cdot \frac{\mathrm{d}^{2} \cdot \pi}{4}}
$$

Where: $\quad$ trb $=$ Radial thrust $(\mathrm{N})$

$$
\begin{aligned}
& \mathrm{d}=\text { Characteristic model diameter }(\mathrm{m}) \\
& \mathrm{\rho m}=\text { Mass density of water }(\mathrm{kg} / \mathrm{m} 3) \\
& \mathrm{g}=\text { Gravitational constant }(\mathrm{m} / \mathrm{sec} 2) \\
& \mathrm{h}=\text { Model net head }(\mathrm{m}) \\
& \text { bo = Pad height }(\mathrm{m})
\end{aligned}
$$

\section{Turbine Quadrant Testing}

The hydraulic transient data was plotted as unit discharge ( QED ) and unit torque. The hydraulic transient data was plotted as unit discharge ( QED ) and unit torque ( TED ) versus unit speed $(\omega \mathrm{ED})$. These coefficients are defined as: 


$$
\begin{aligned}
& \omega E D=\frac{\omega_{m} \cdot d}{(g h)^{0.5}} \\
& \text { QED }=\frac{q}{d^{2}(g h)^{0.5}} \\
& \text { TED }=\frac{\text { torq }}{\rho_{m}(g h) d^{3}}
\end{aligned}
$$

Where: $\quad \mathrm{h}=$ Model net head $(\mathrm{m})$

$$
\begin{aligned}
& \omega=\text { Model rotational speed }(1 / \mathrm{sec}) \\
& \mathrm{d}=\text { Characteristic model diameter }(\mathrm{m}) \\
& \mathrm{q}=\text { Model discharge }(\mathrm{m} 3 / \mathrm{s}) \\
& \mathrm{g}=\text { Gravity }(\mathrm{m} / \mathrm{s} 2) \\
& \rho \mathrm{m}=\text { Mass density of water }(\mathrm{kg} / \mathrm{m} 3)
\end{aligned}
$$

Test procedure was similar to performance testing described previously. For all gates, data was collected from higher than maximum head down to beyond runaway speed.

Model Results

List of Figures

\section{Performance}

Figure 5-6: $(\eta \mathrm{ref}, \mathrm{Q} \omega \mathrm{d})=\mathrm{f}(\mathrm{E} \omega \mathrm{d}, \Delta \gamma)$

Figure 5-7: $(\mathrm{P} \omega \mathrm{d})=\mathrm{f}(\mathrm{E} \omega \mathrm{d}, \Delta \gamma)$

Figure 5-8: $(\eta, \Delta \gamma)=f(Q \omega d) @ E \omega d=0.1148$

Figure 5-9: $(\mathrm{P} \omega \mathrm{d}, \Delta \gamma)=\mathrm{f}(\mathrm{Q} \omega \mathrm{d}) @ \mathrm{E} \omega \mathrm{d}=0.1148$

\section{Cavitation Sigma Break}

Figure 5-10: $(\eta, \mathrm{Q} \omega \mathrm{d}, \mathrm{P} \omega \mathrm{d})=\mathrm{f}(\sigma) @ \mathrm{E} \omega \mathrm{d}=0.1148 \Delta \gamma=21$ 
Model Test Report

Figure 5-11: $(\eta, \mathrm{Q} \omega \mathrm{d}, \mathrm{P} \omega \mathrm{d})=\mathrm{f}(\sigma) @ \mathrm{E} \omega \mathrm{d}=0.1148 \Delta \gamma=27$

\section{Cavitation Photographs}

Figure 5-12: Photo @ Ewd=0.1148, Qwd=0.0686

Figure 5-12: Photo @ Ewd=0.1148, Qwd=0.0574

Figure 5-13: Photo @ Ewd=0.1148, Qwd = 0.0476

Figure 5-14: Photo @ Ewd=0.1148, Qwd=0.0368

\section{Axial Thrust}

Figure 5-16: $(\mathrm{Ka}, \Delta \gamma)=\mathrm{f}(\mathrm{Q} \omega \mathrm{d}) @ \mathrm{E} \omega \mathrm{d}=0.1148$

\section{Runaway Speed}

Figure 5-17: $\mathrm{E} \omega \mathrm{dr}=\mathrm{f}(\Delta \gamma)$

\section{Pressure Pulsation}

- . From time domain data

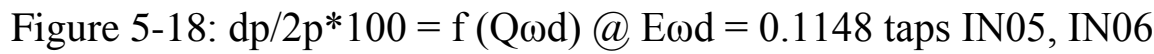

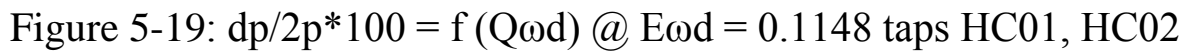

Figure 5-20: dp/2p*100=f(Q $(\omega d) @ E \omega d=0.1148$ taps DT13, DT14

- Waterfall diagram from FFT data @ E $\omega d=0.1148$, maximum freq $/ \mathrm{fn}=25$

Figure 5-21: $($ Amplitude/p $* 100)=\mathrm{f}(\Delta \gamma$, freq/fn $)$, Location = IN05

Figure 5-22: $($ Amplitude/p $* 100)=\mathrm{f}(\Delta \gamma$, freq/fn $)$, Location $=$ IN06

Figure 5-23: $($ Amplitude/p $* 100)=\mathrm{f}(\Delta \gamma$, freq/fn $)$, Location $=$ HC01

Figure 5-24: $($ Amplitude/p $* 100)=\mathrm{f}(\Delta \gamma$, freq/fn $)$, Location $=$ HC02

Figure 5-25: $($ Amplitude/p * 100$)=\mathrm{f}(\Delta \gamma$, freq/fn $)$, Location = DT13

Figure 5-26: $($ Amplitude/p $* 100)=\mathrm{f}(\Delta \gamma$, freq/fn $)$, Location = DT14

\section{Turbine Quadrant}

Figure 5-27: $(\mathrm{QED}, \mathrm{TED})=\mathrm{f}(\omega \mathrm{ED})$ 


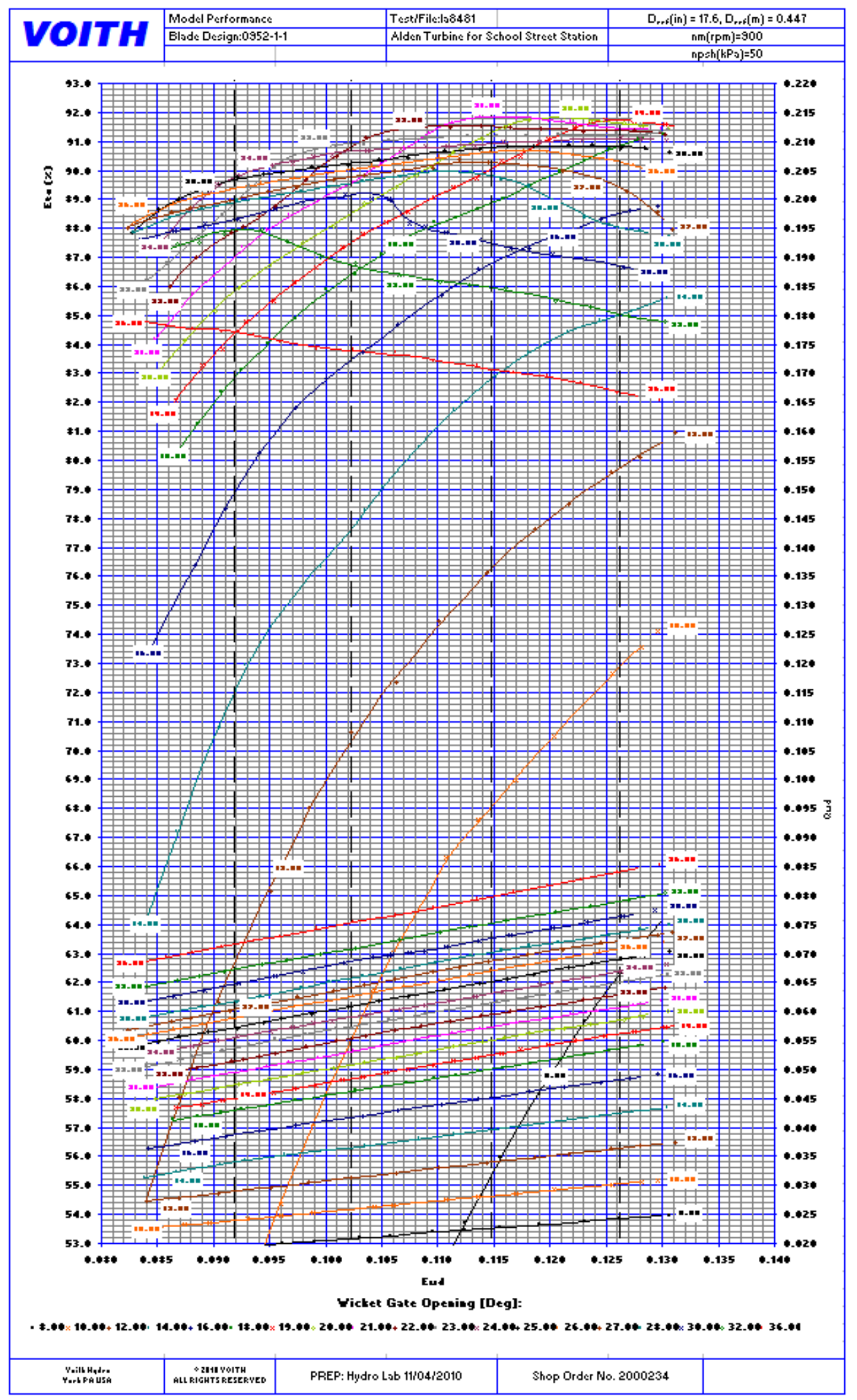

Figure 4-6

$\left(\eta_{\text {ref }}, Q_{\mathrm{cd}}\right)=f\left(E_{\mathrm{c}}, \Delta y\right)$ 


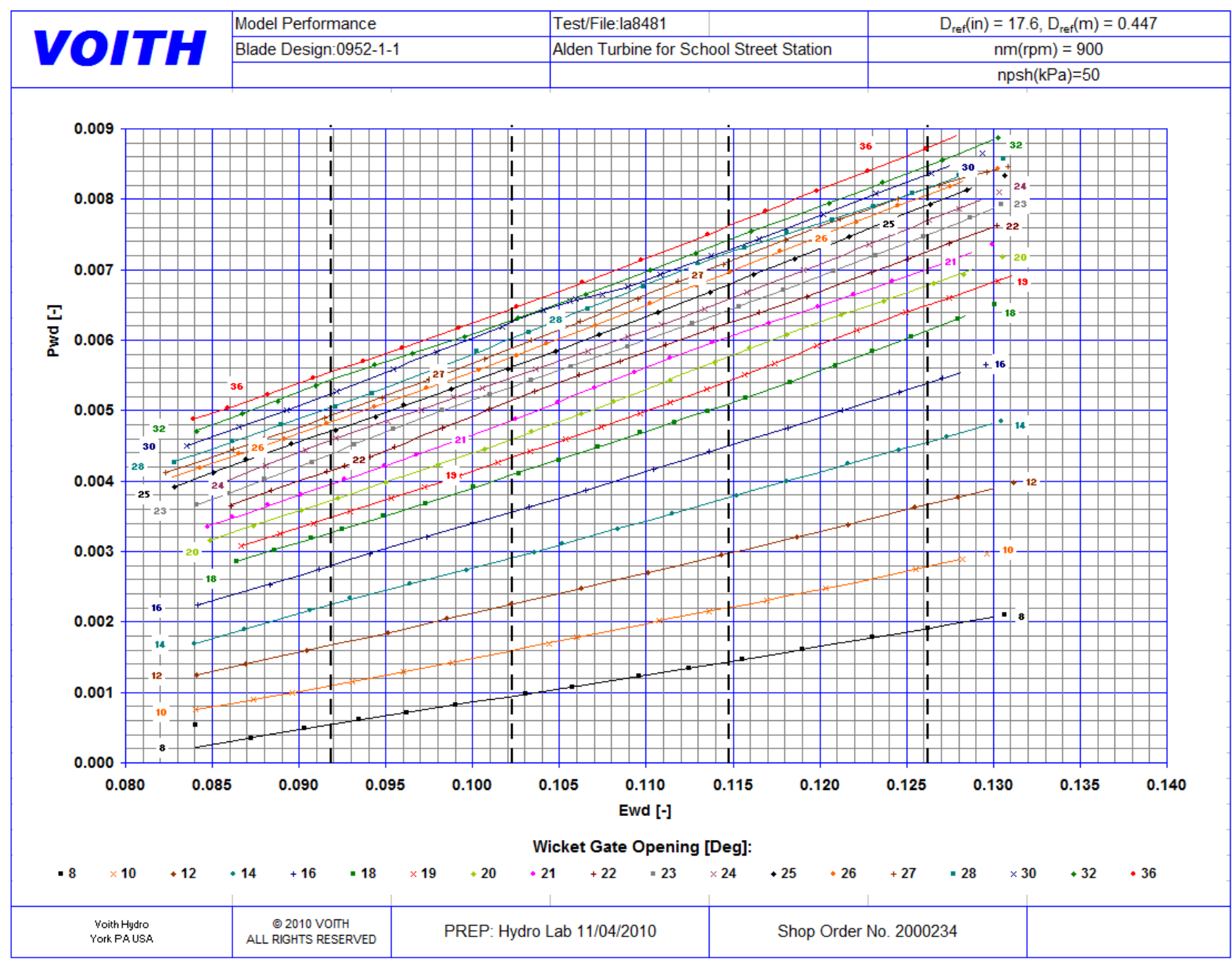

Figure 4-7

$(P \omega d)=f(E \omega d, \Delta y)$ 


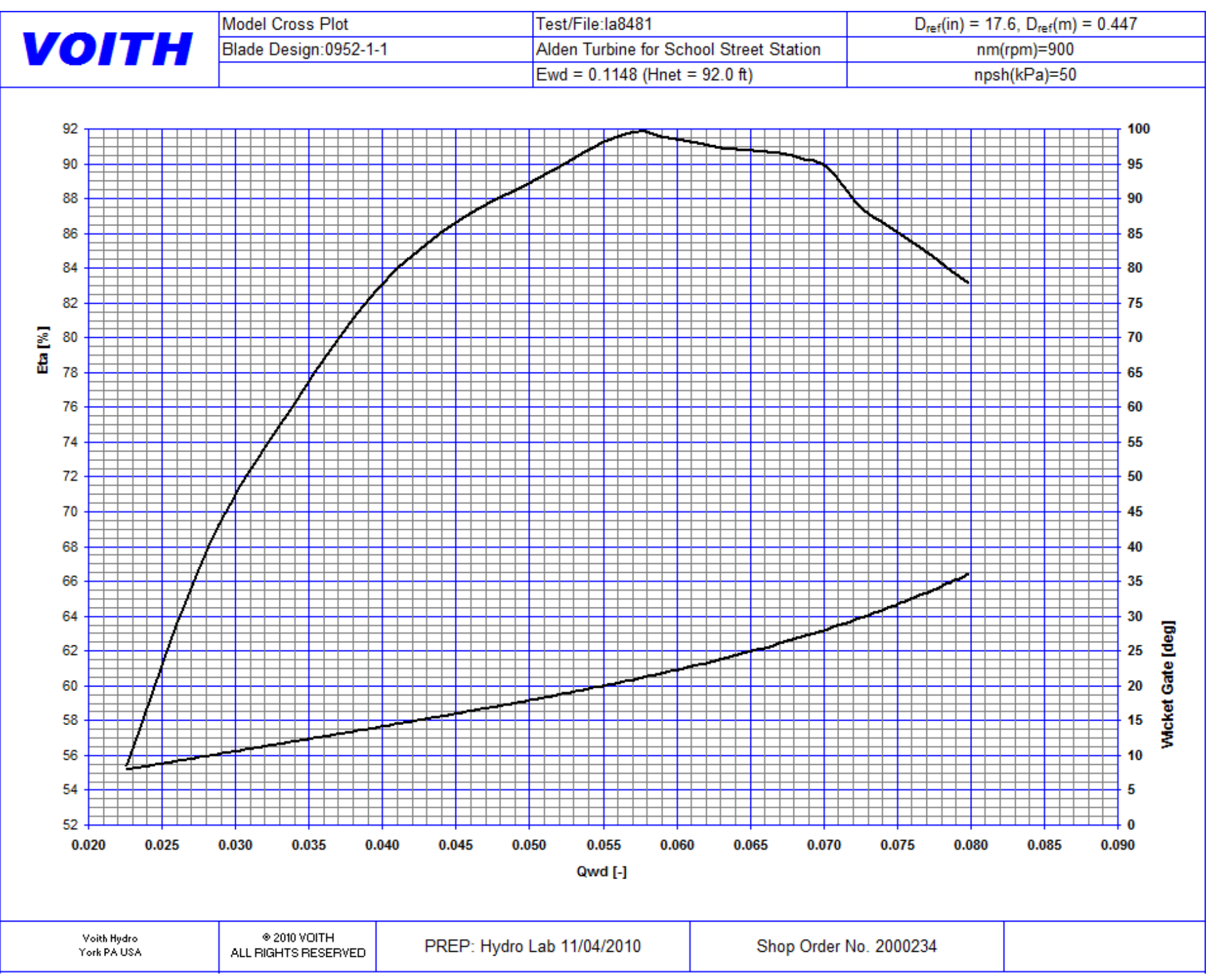

Figure 4-8

$(n, \Delta y)=f(Q \omega d) @ E \omega d=0.1148$ 


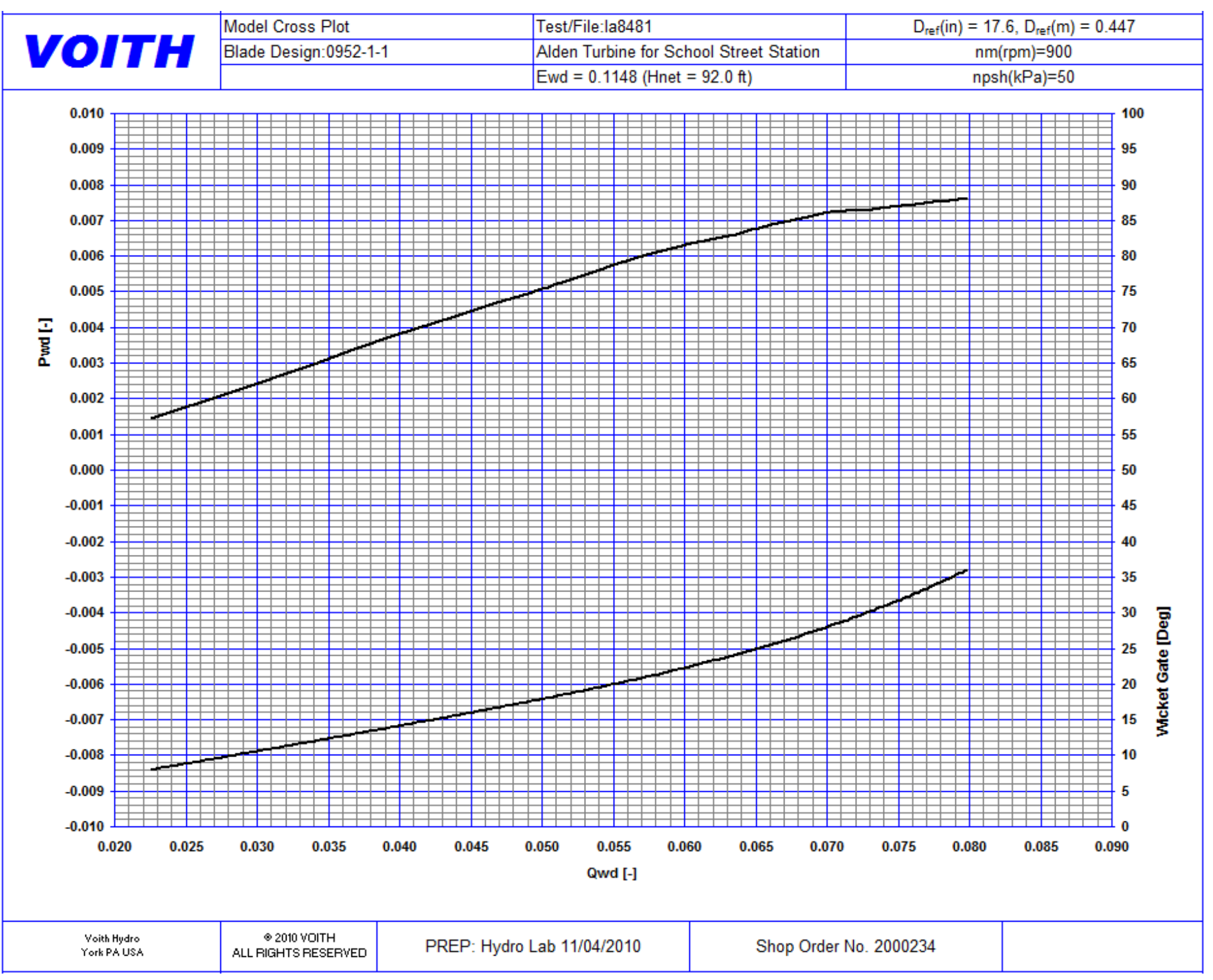

Figure 4-9

$(P \omega d, \Delta y)=f(Q \omega d) @ E \omega d=0.1148$ 


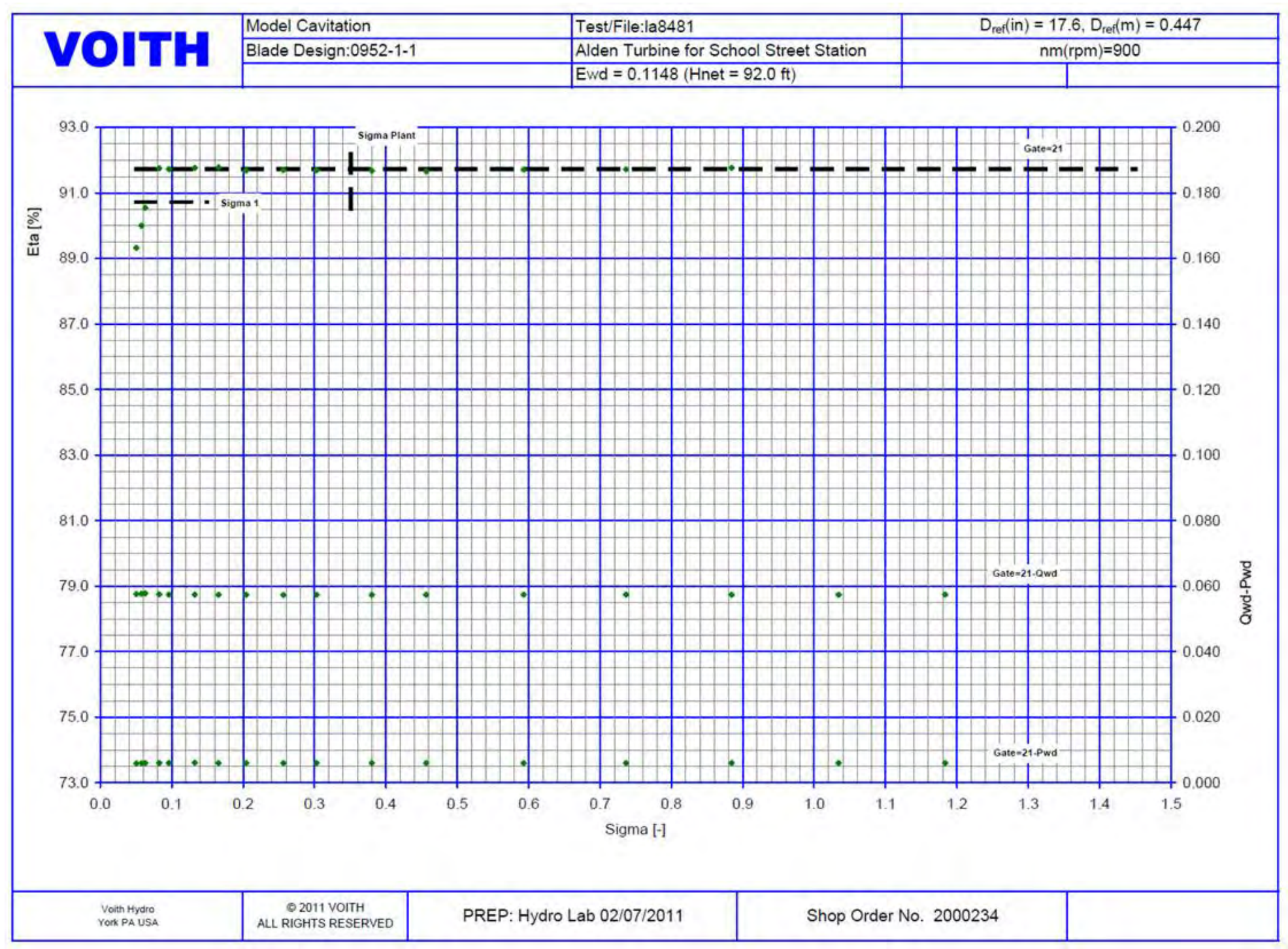

Figure 4-10

$(n, Q \omega d, P \omega d)=f(\sigma) @ E \omega d=0.1148 \Delta y=21$ 


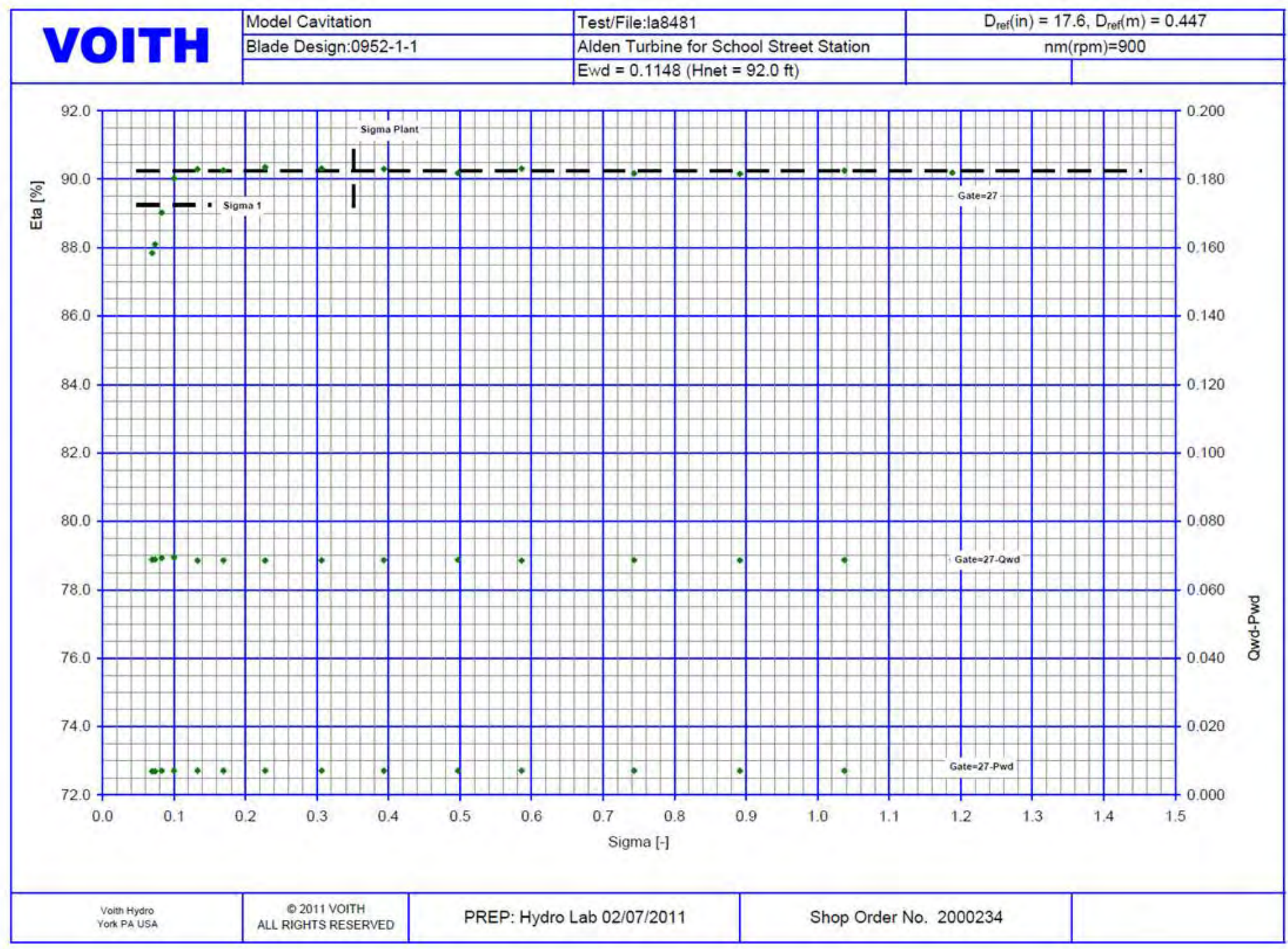

Figure 4-11

$\left(\eta, Q_{c d}, P_{c d}\right)=f(\sigma) @ E_{c d}=0.1148 \Delta y=27$ 


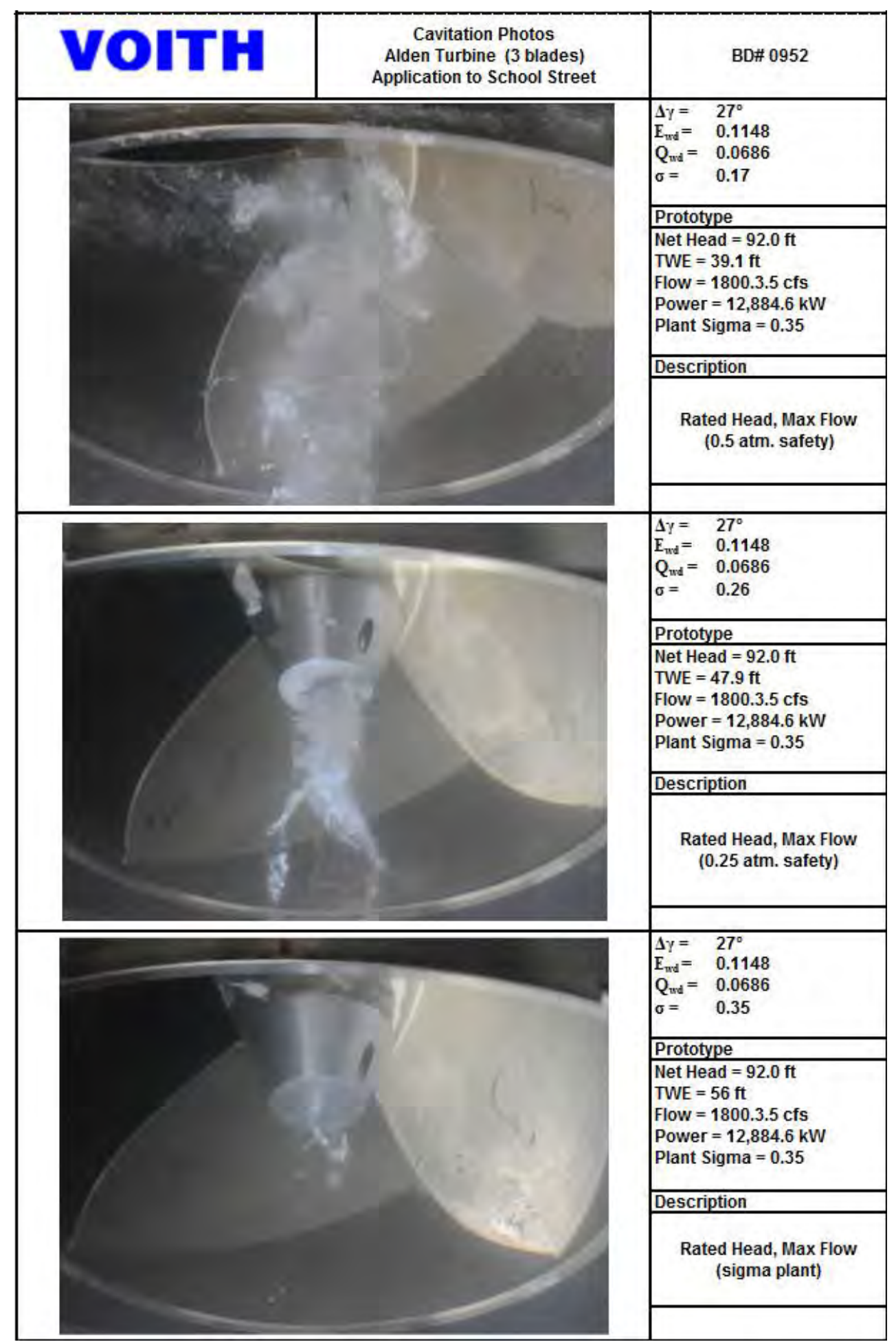

Figure 4-12

Photo @ Ewd = 0.1148, Qwd = 0.0686, 


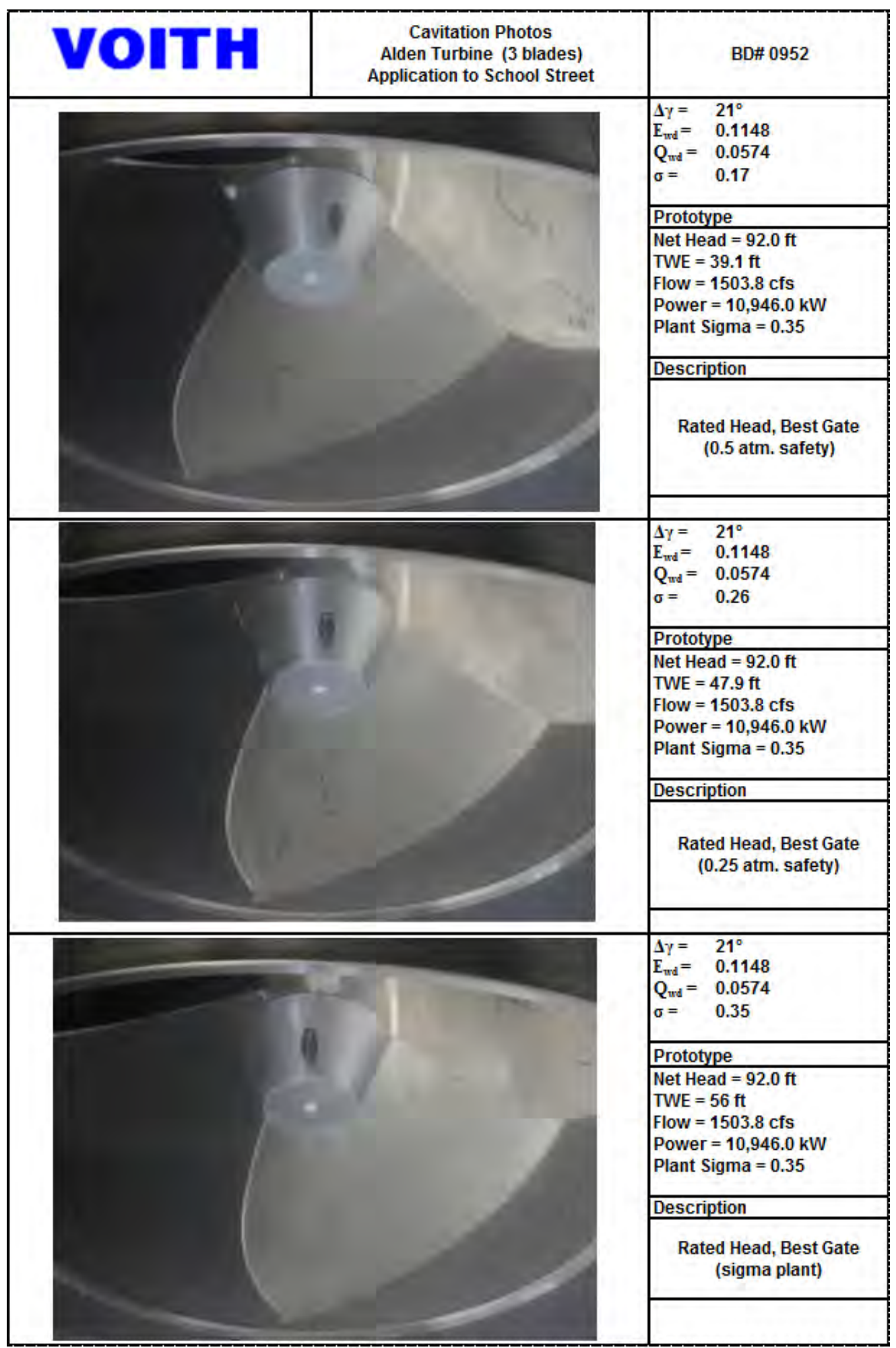

Figure 4-13

Photo @ Ewd = 0.1148, Qwd = 0.0574 


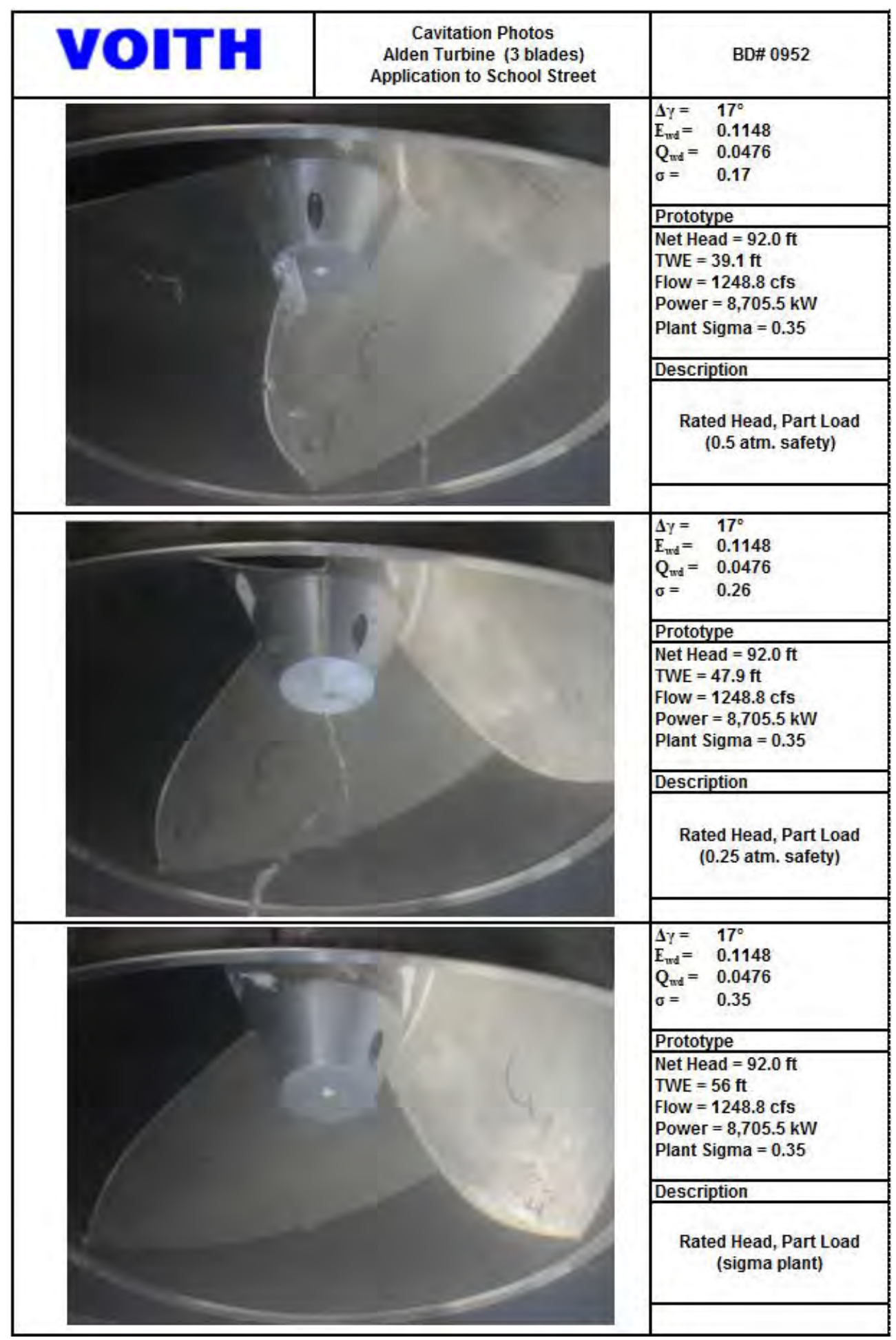

Figure 4-14

Photo @ Ewd = 0.1148, Qwd = 0.0476 


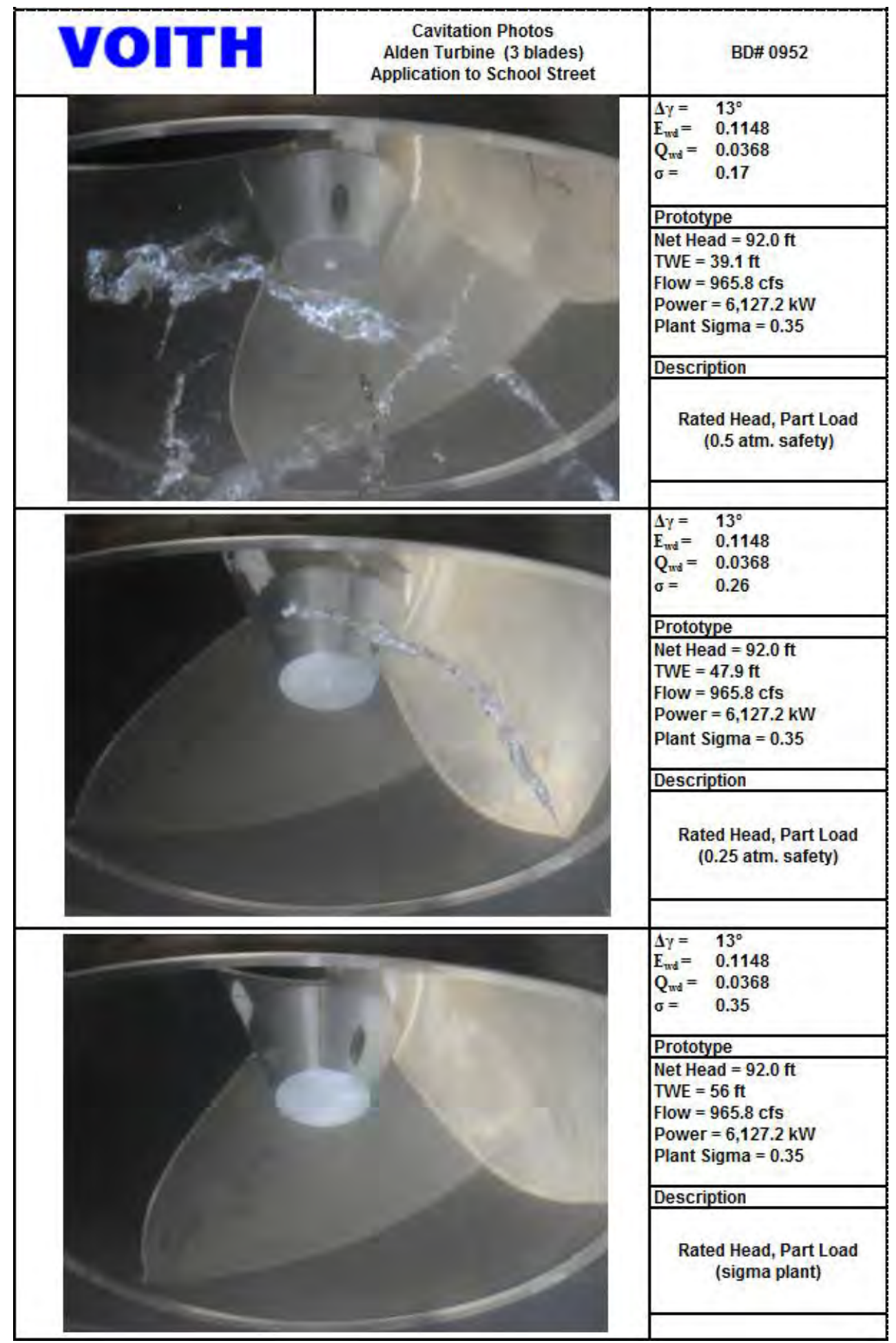

Figure 4-15

Photo @ Ewd = 0.1148, Qwd = 0.0368 


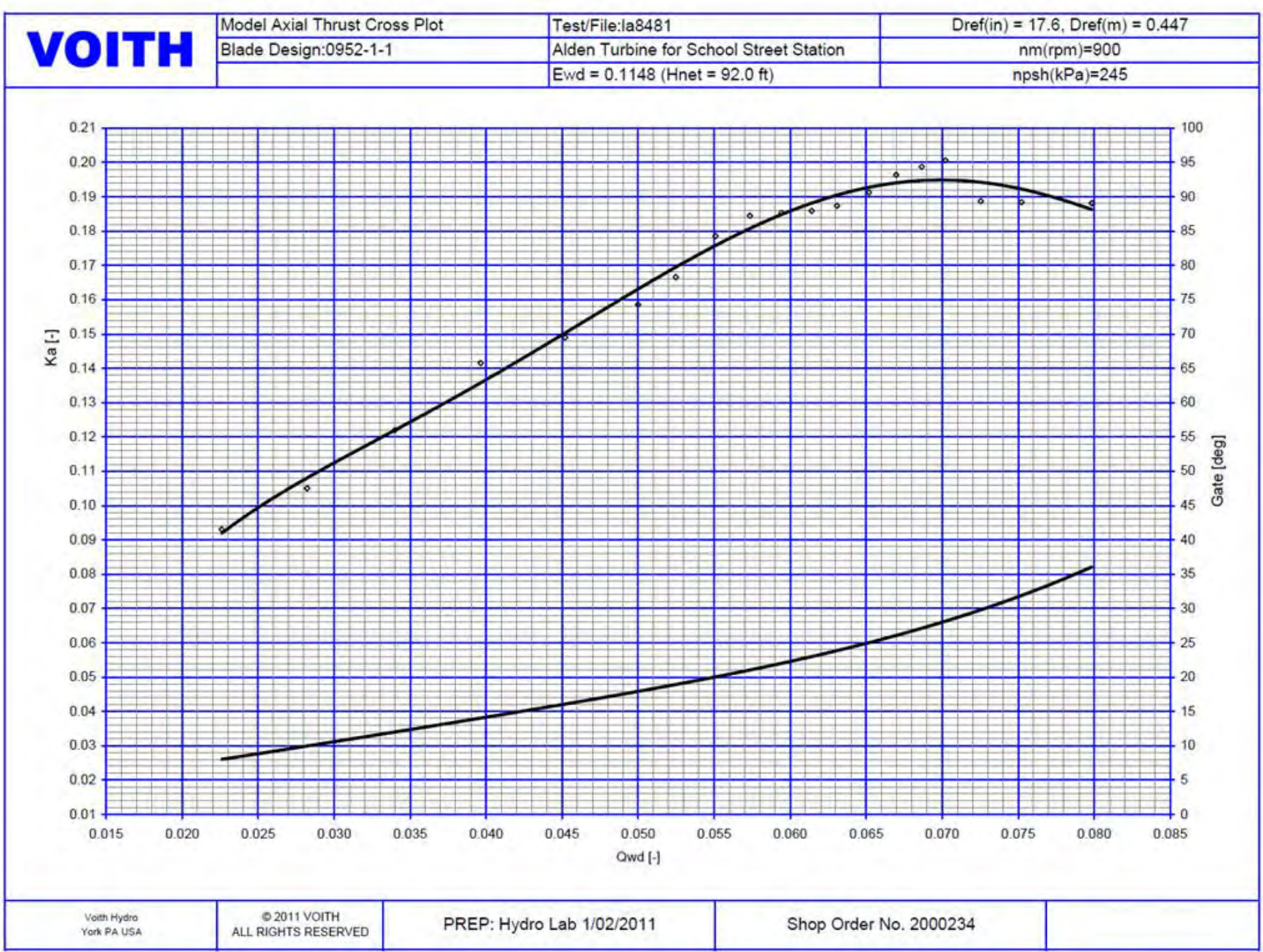

Figure 4-16

$(K a, \Delta y)=f(Q \omega d) @ E E \omega d=0.1148$ 


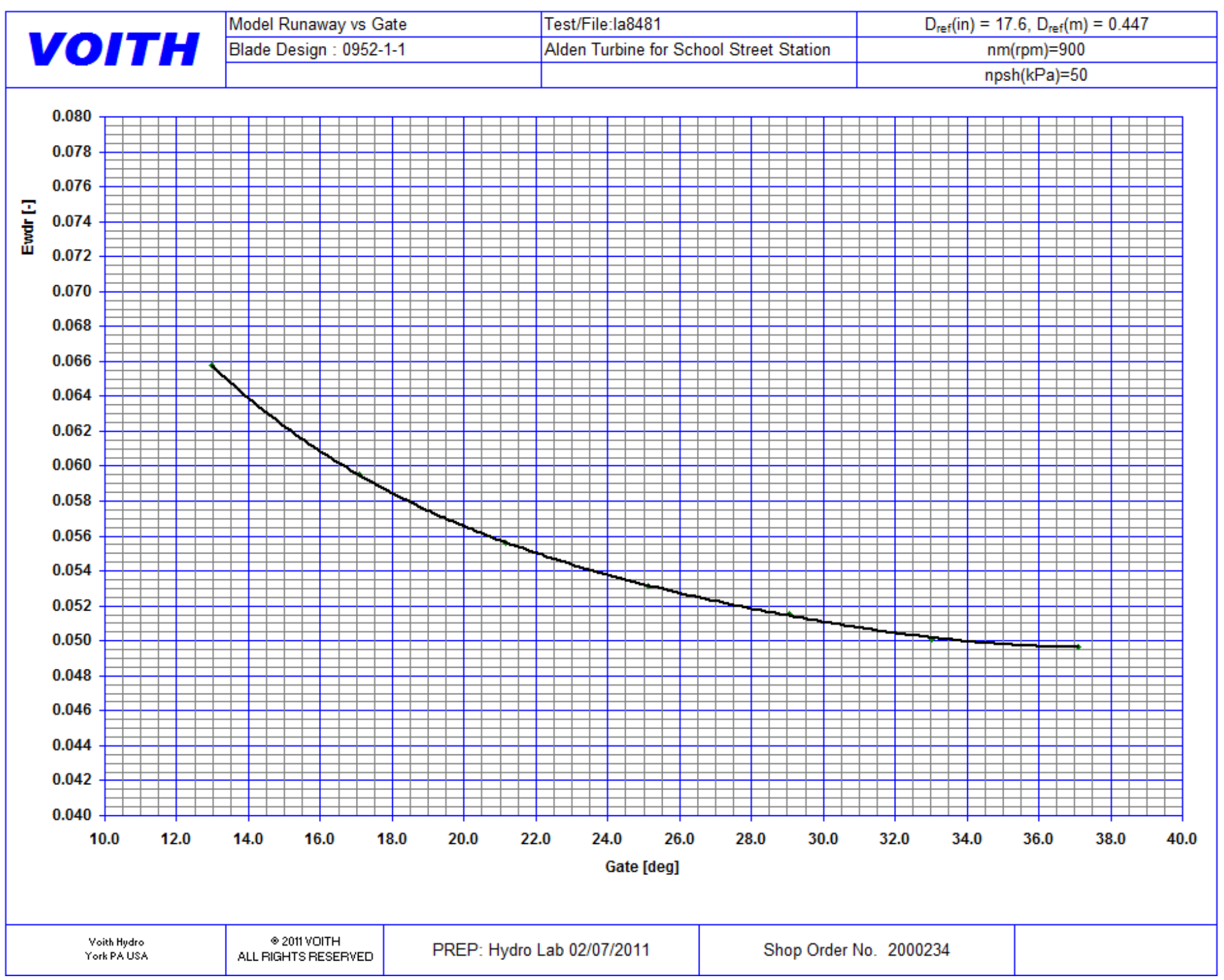

Figure 4-17

$E \omega d r=f(\Delta y)$ 


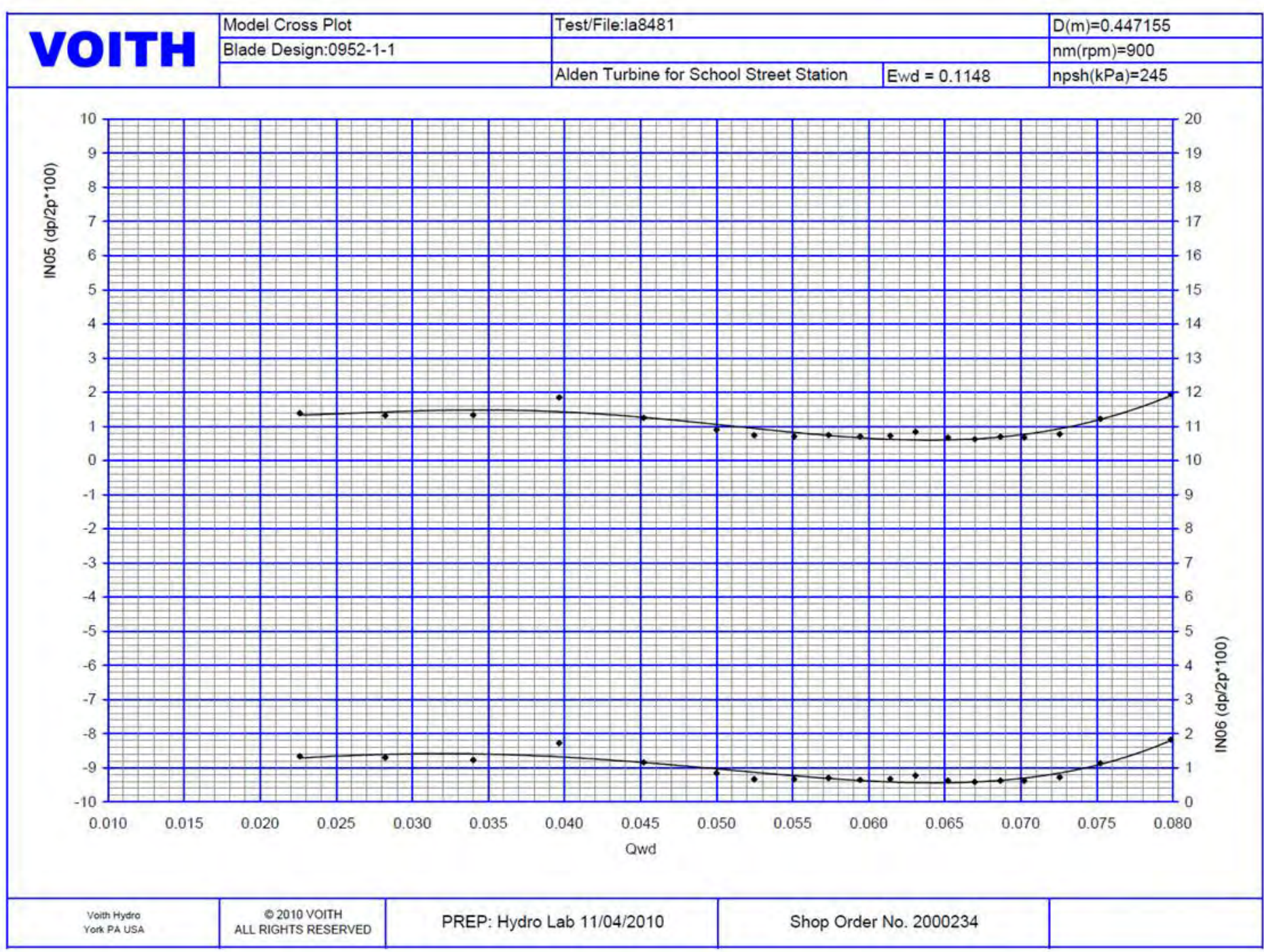

Figure 4-18

$d p / 2 p * 100=f(Q \omega d) @ E \omega d=0.1148$ taps IN05, IN06 


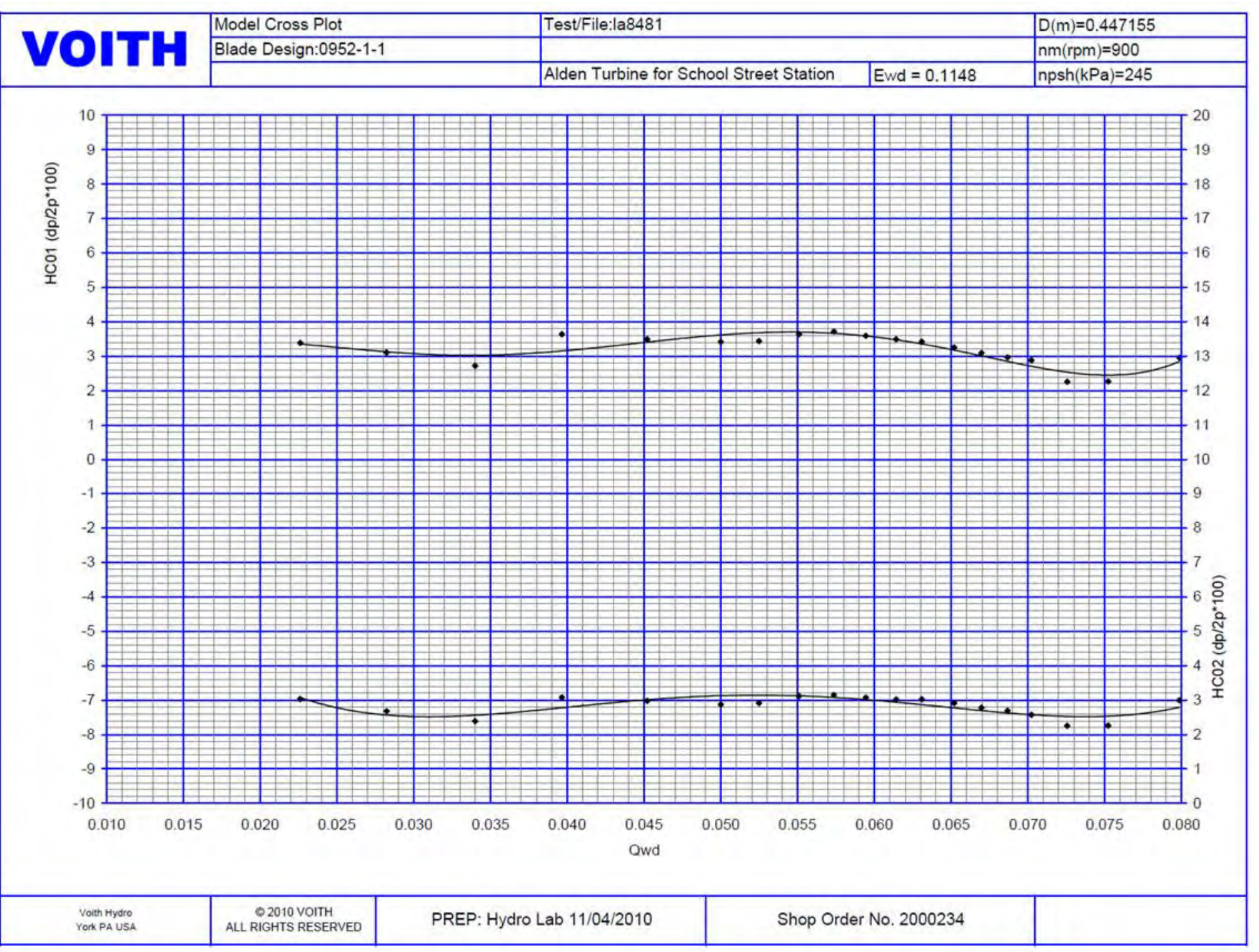

Figure 4-19

$d p / 2 p * 100=f(Q \omega d) @ E \omega d=0.1148$ taps HC01, HC02 


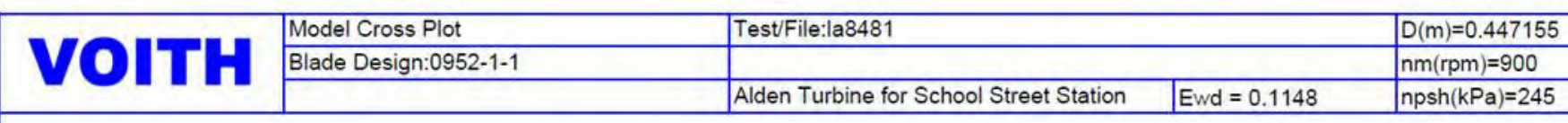

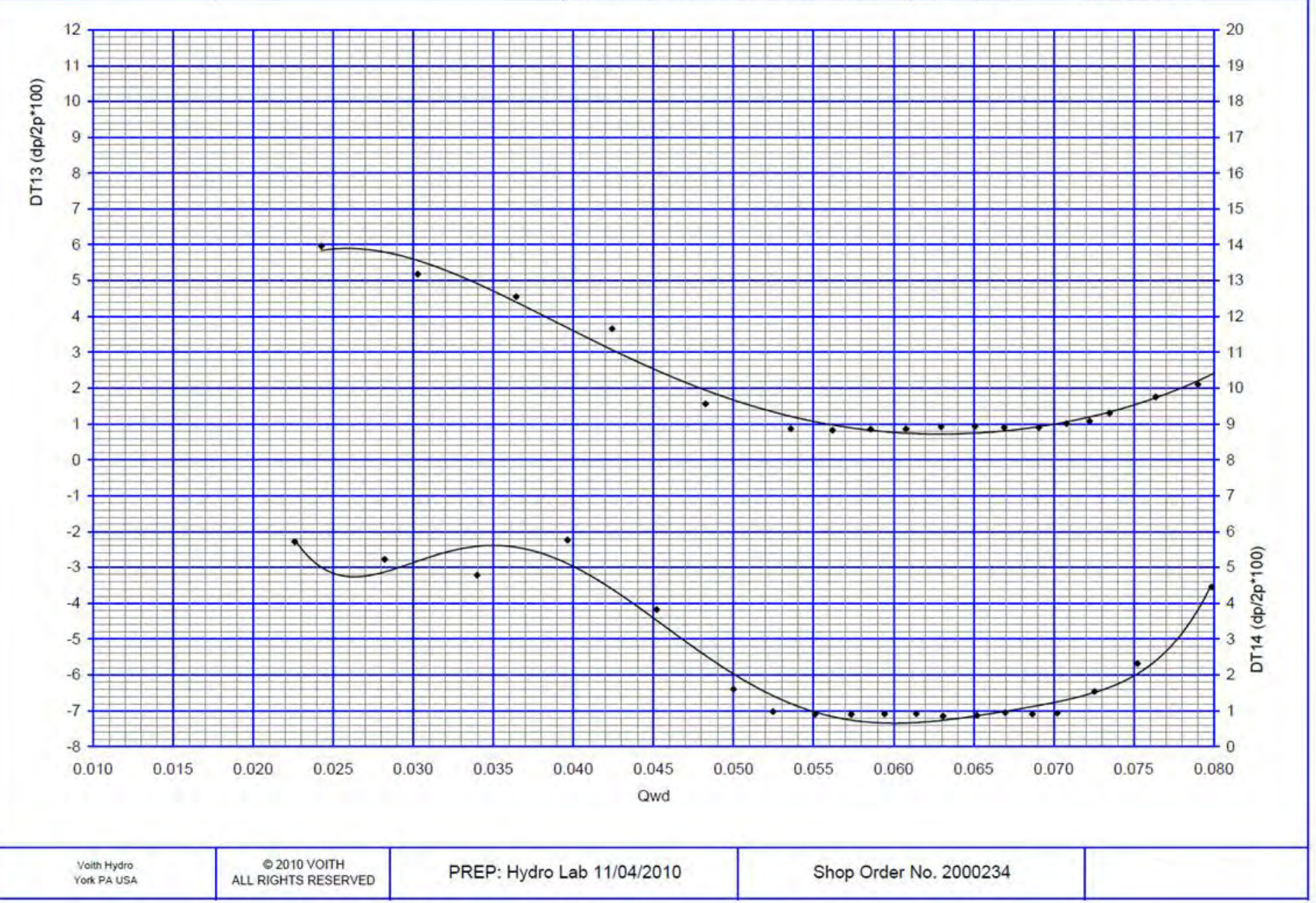

Figure 4-20

$d p / 2 p * 100=f(Q \omega d) @ E \omega d=0.1148$ taps DT13, DT14 


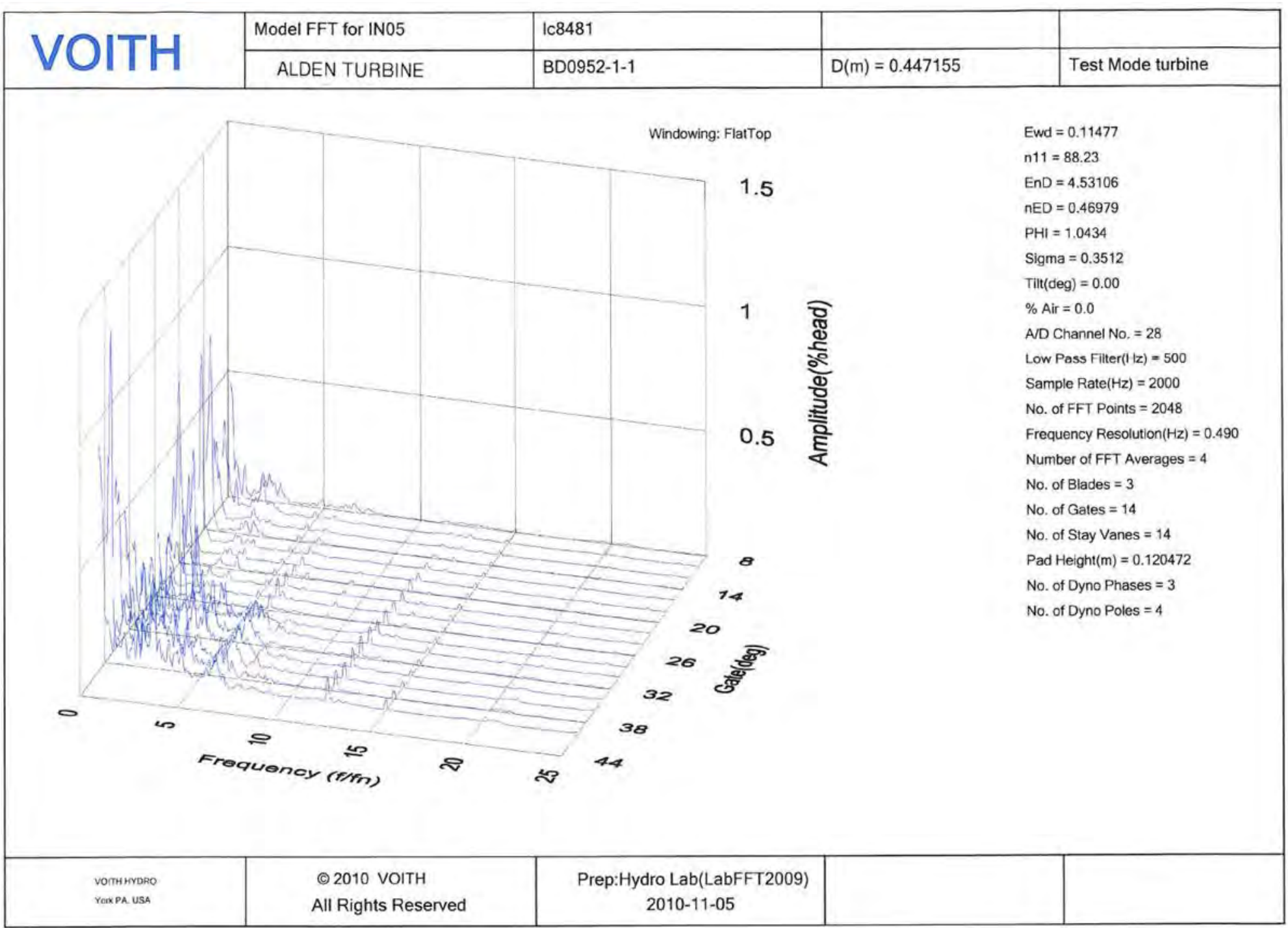

Figure 4-21

$($ Amplitude $/ p * 100)=f(\Delta y$, freq/fn $)$, Location $=$ IN05 


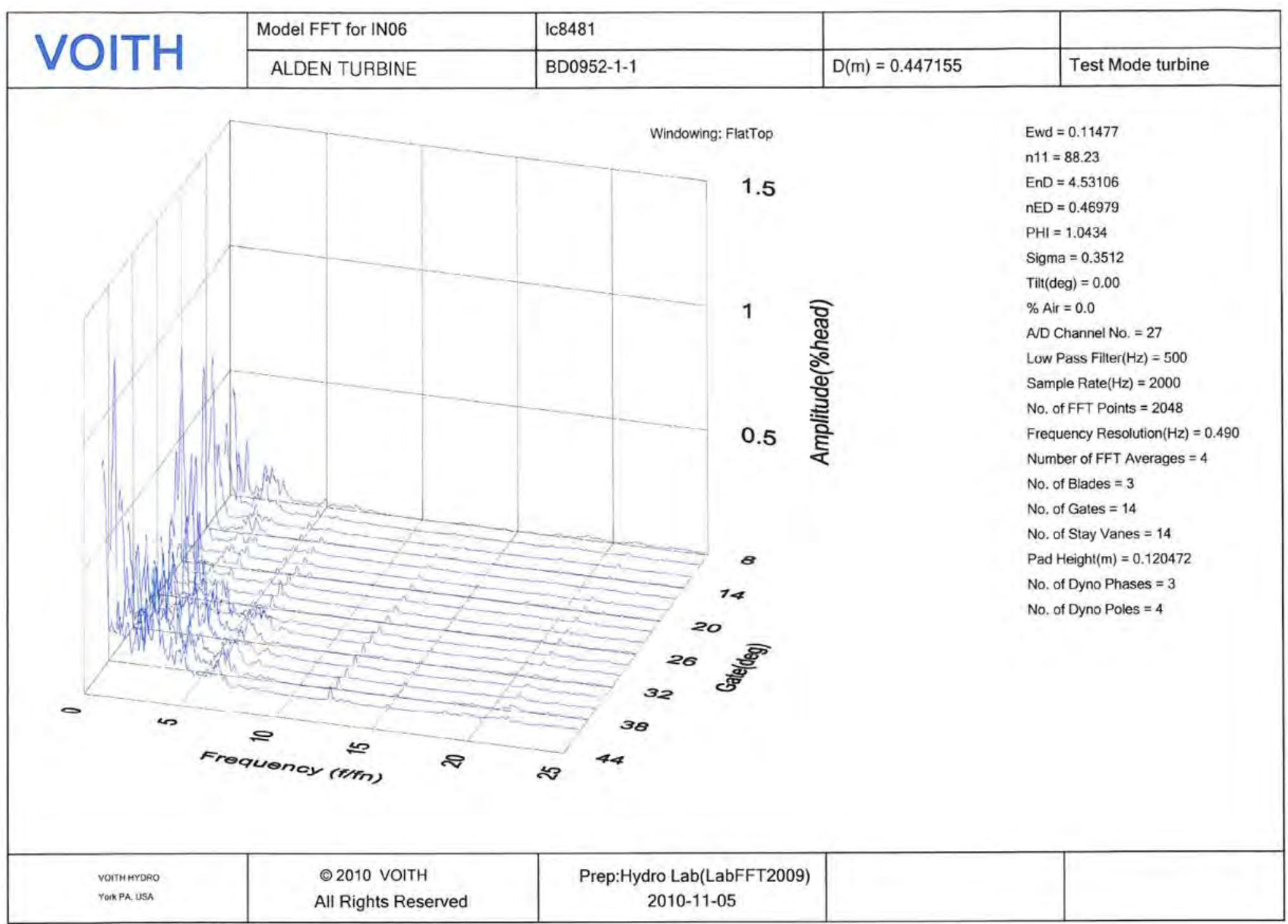

Figure 4-22

$($ Amplitude $/ p * 100)=f(\Delta y$, freq/fn $)$, Location $=$ IN06 


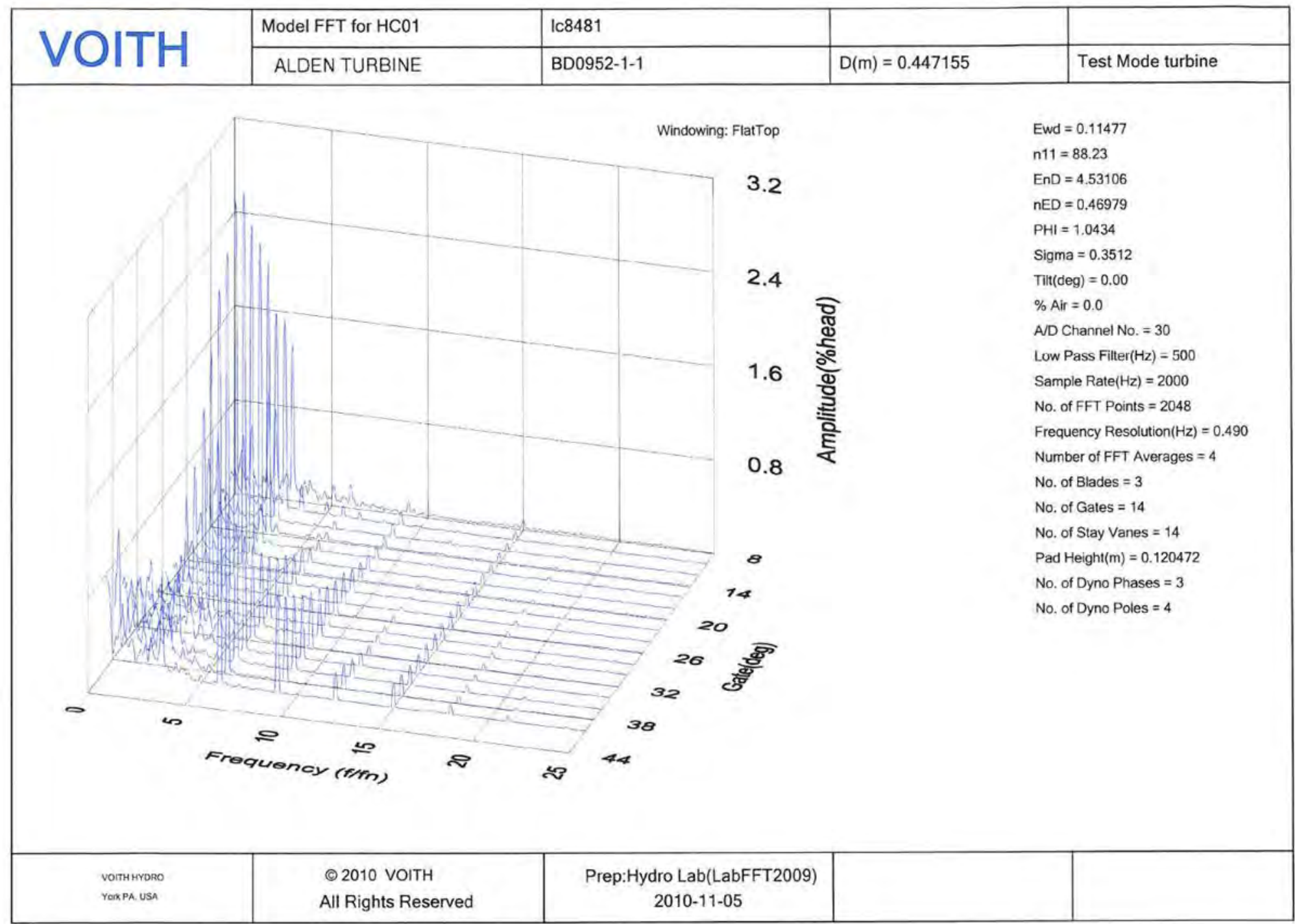

Figure 4-23

$($ Amplitude $/ p * 100)=f(\Delta y$, freq/fn $)$, Location $=$ HC01 


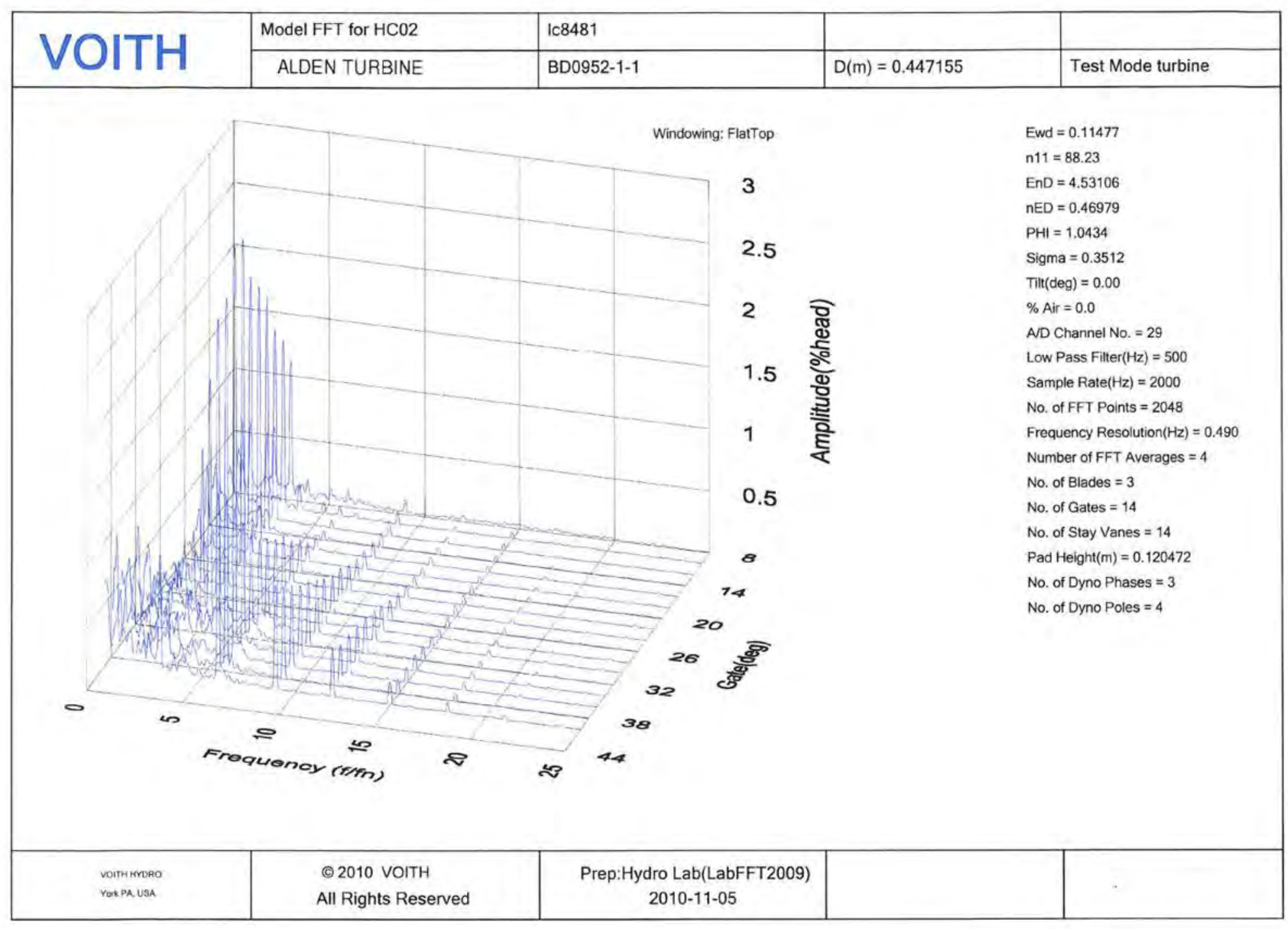

Figure 4-24

$($ Amplitude/p $* 100)=f(\Delta y$, freq/fn $)$, Location $=\mathrm{HCO2}$ 


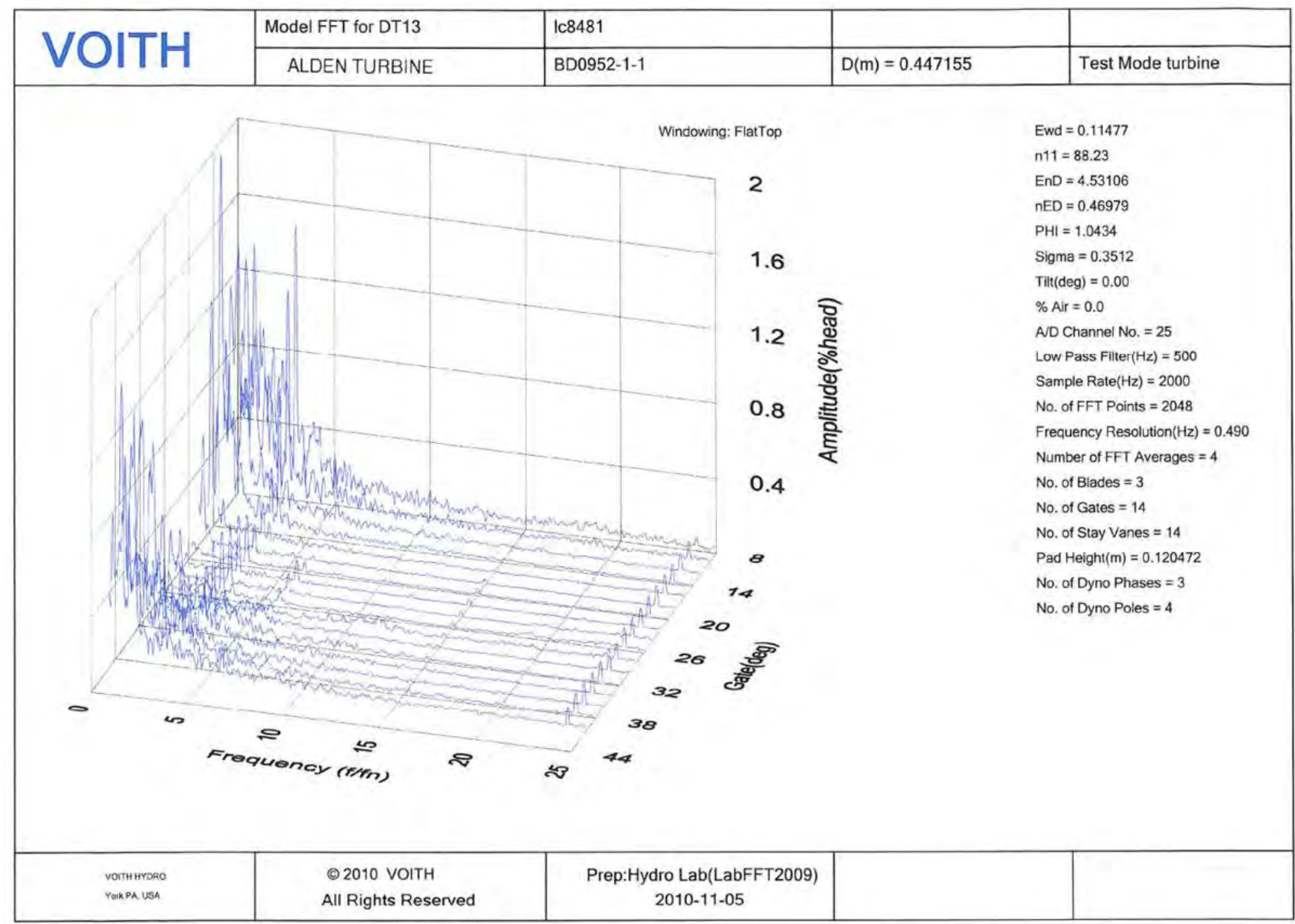

Figure 4-25

$($ Amplitude $/ p * 100)=f(\Delta y$, freq/fn $)$, Location $=$ DT13 


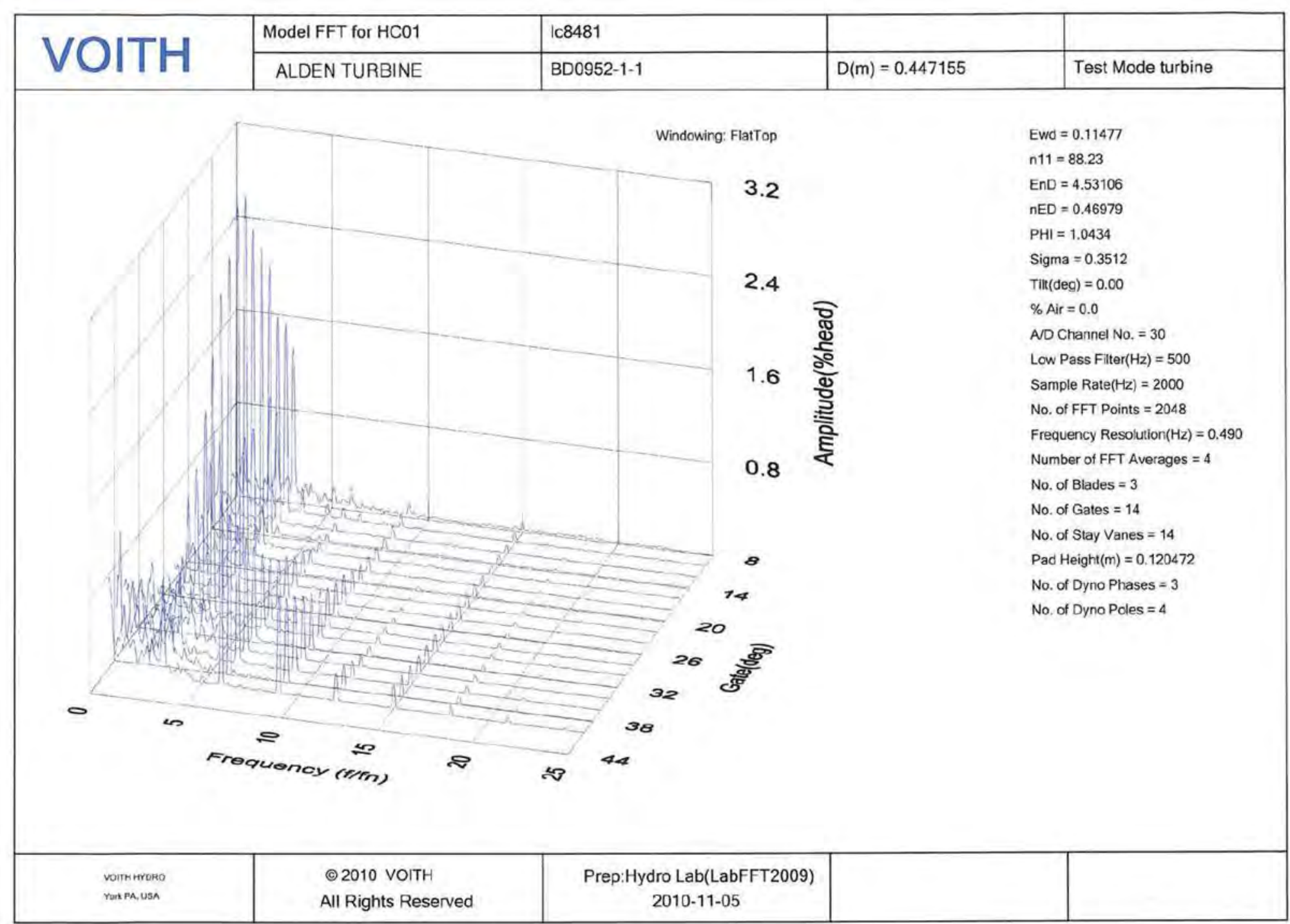

Figure 4-26

$($ Amplitude/p $* 100)=f(\Delta y$, freq/fn $)$, Location $=$ DT14 


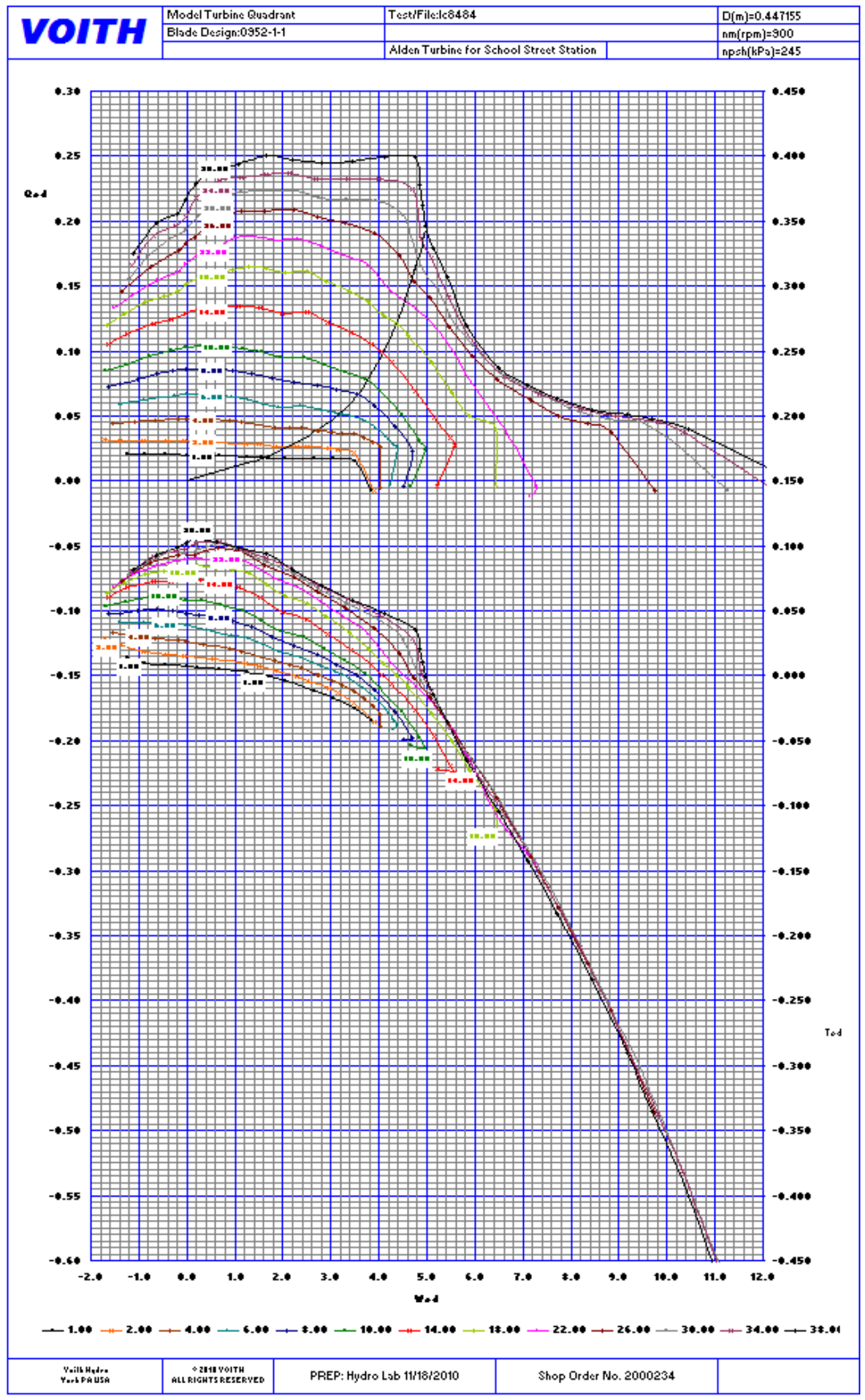

Figure 4-27

$($ QED , TED $)=f(\omega$ ED ) 
Expected Prototype Results

Performance

Figure 5-28: ( $\eta p, P, \Delta \gamma)=f(H, Q)$

Figure 5-29: ( $\eta p, \Delta \gamma)=f(\mathrm{Q}) @ \mathrm{H}=92.0 \mathrm{ft}$ with step up

Figure 5-30: ( P, $\Delta \gamma$ )=f ( Q ) @ $\mathrm{H}=92.0 \mathrm{ft}$

Hydraulic Thrust

Figure 5-31: $(\mathrm{Ta}, \Delta \gamma)=\mathrm{f}(\mathrm{Q}) @ \mathrm{H}=92.0 \mathrm{ft}$

\section{Runaway Speed}

Figure 5-32: $\mathrm{N}_{\mathrm{p}}=\mathrm{f}(\Delta \gamma, \mathrm{H})$ 


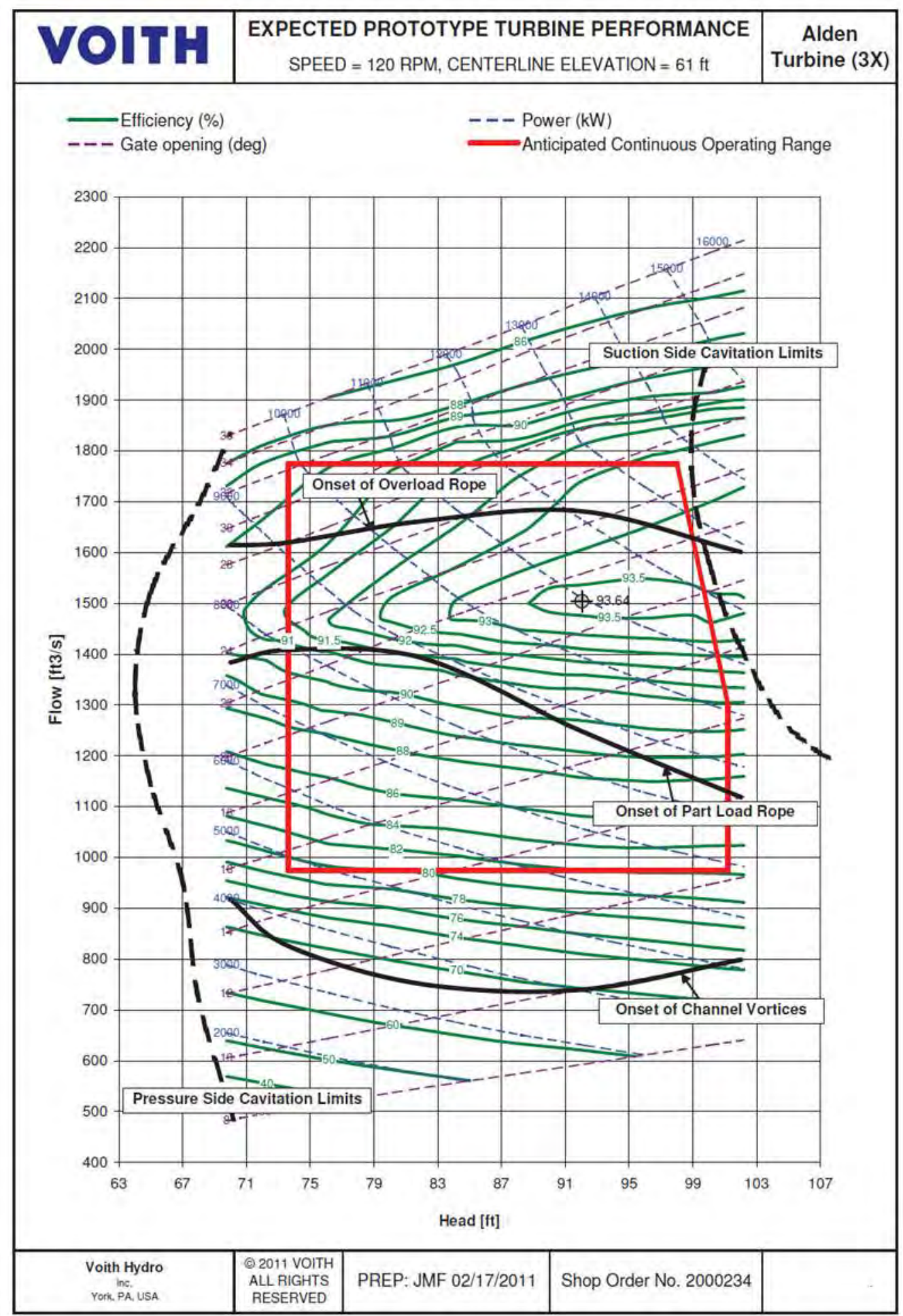

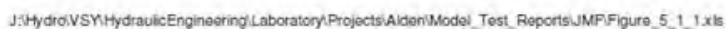

02.17.2011 10.36 AM

Figure 4-28

(n $p, P, \Delta y)=f(H, Q)$ 


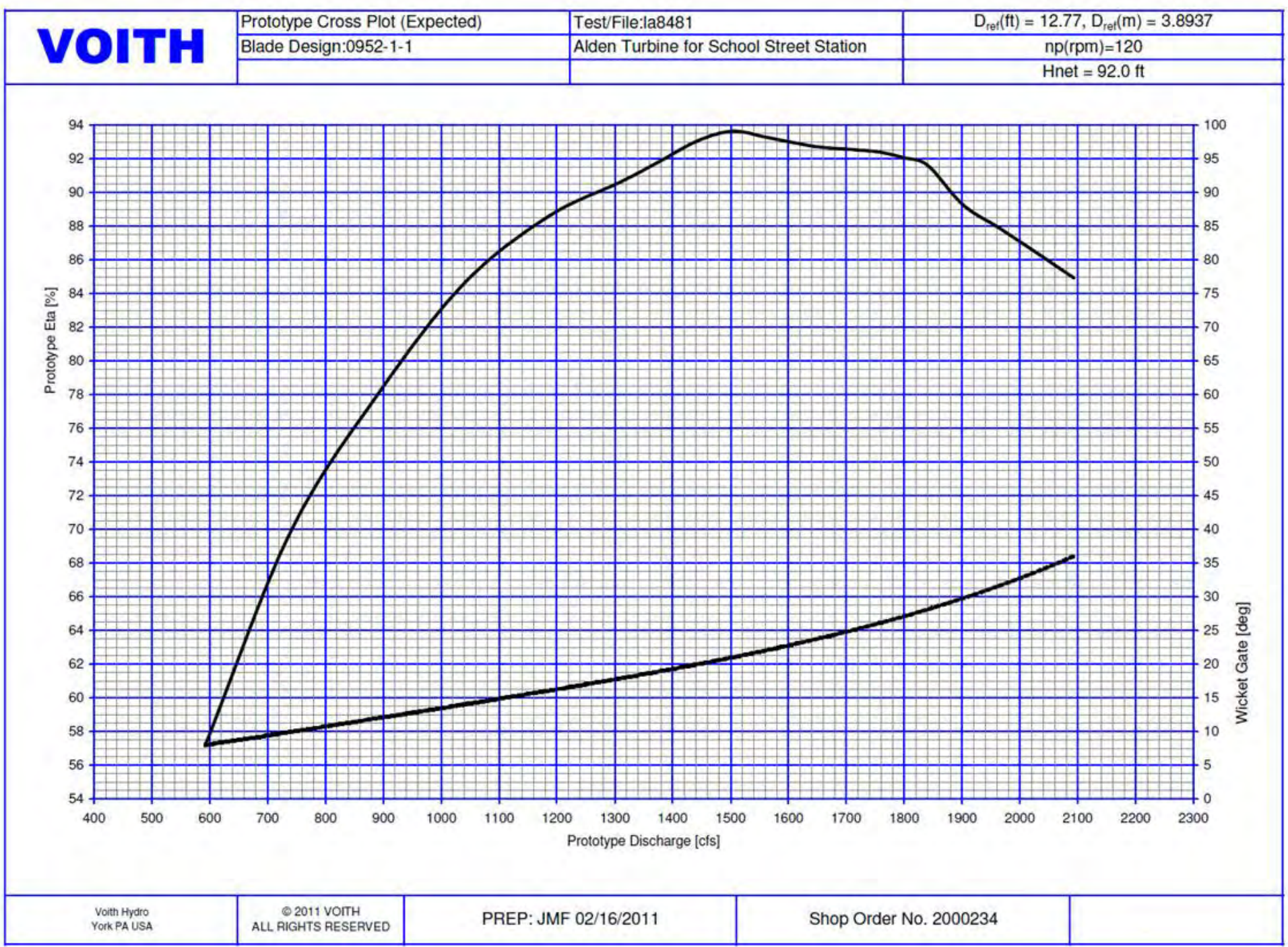

Figure 4-29

$(n p, \Delta y)=f(Q) @ H=92.0 \mathrm{ft}$ with step up 


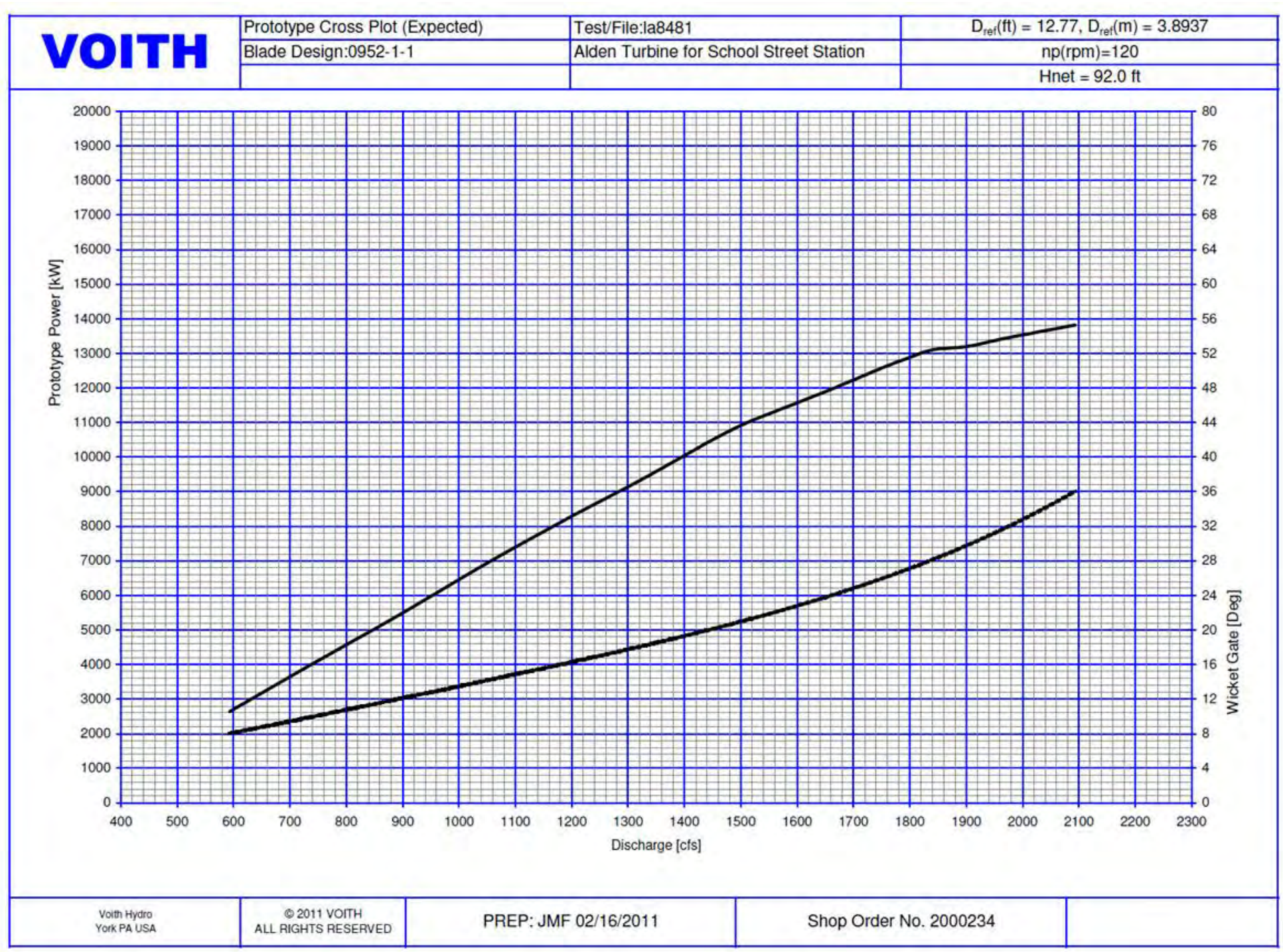

Figure 4-30

$(P, \Delta Y)=f(Q) @ H=92.0 \mathrm{ft}$ 


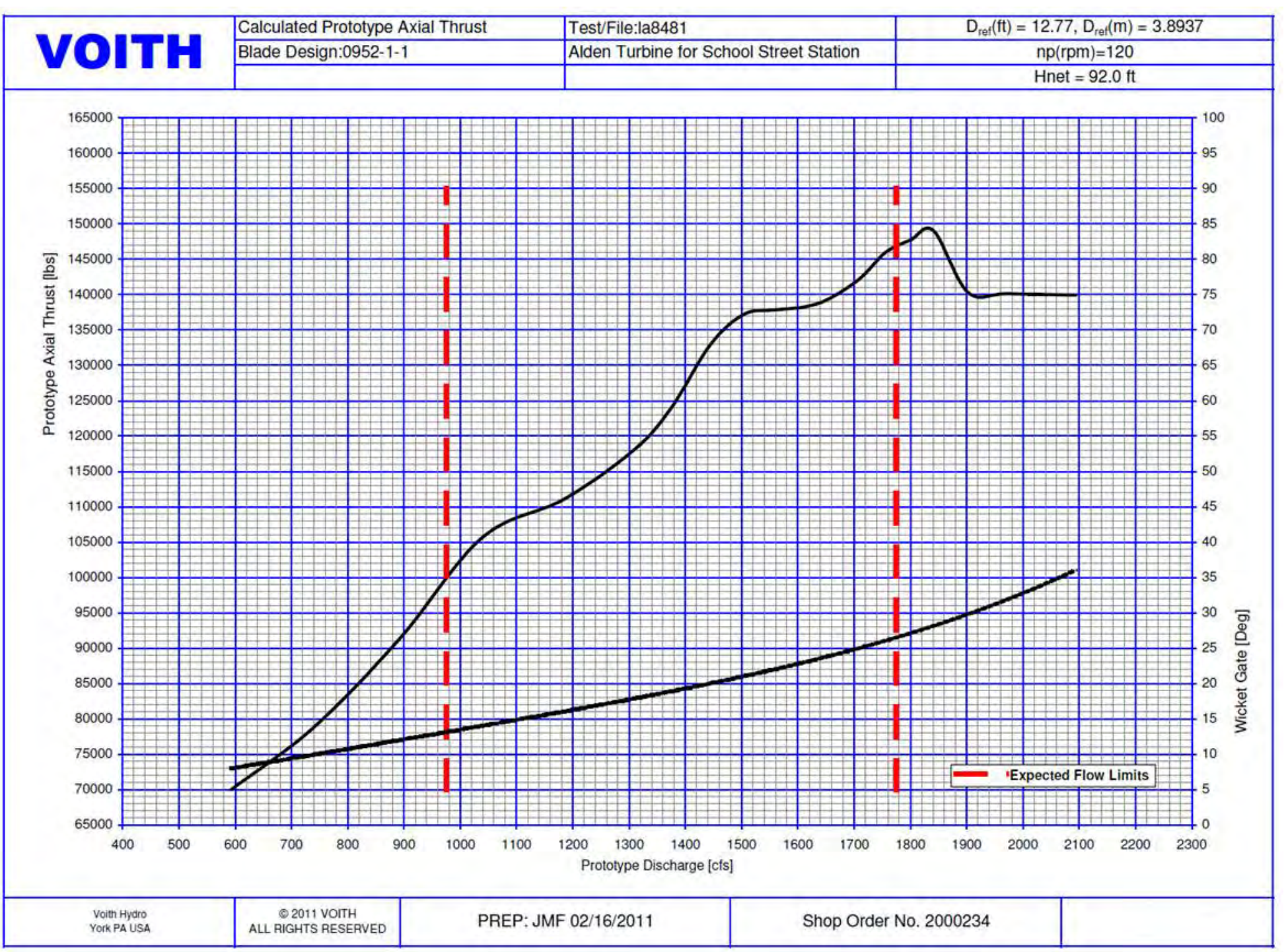

Figure 4-31

$(T a, \Delta Y)=f(Q) @ H=92.0 \mathrm{ft}$ 


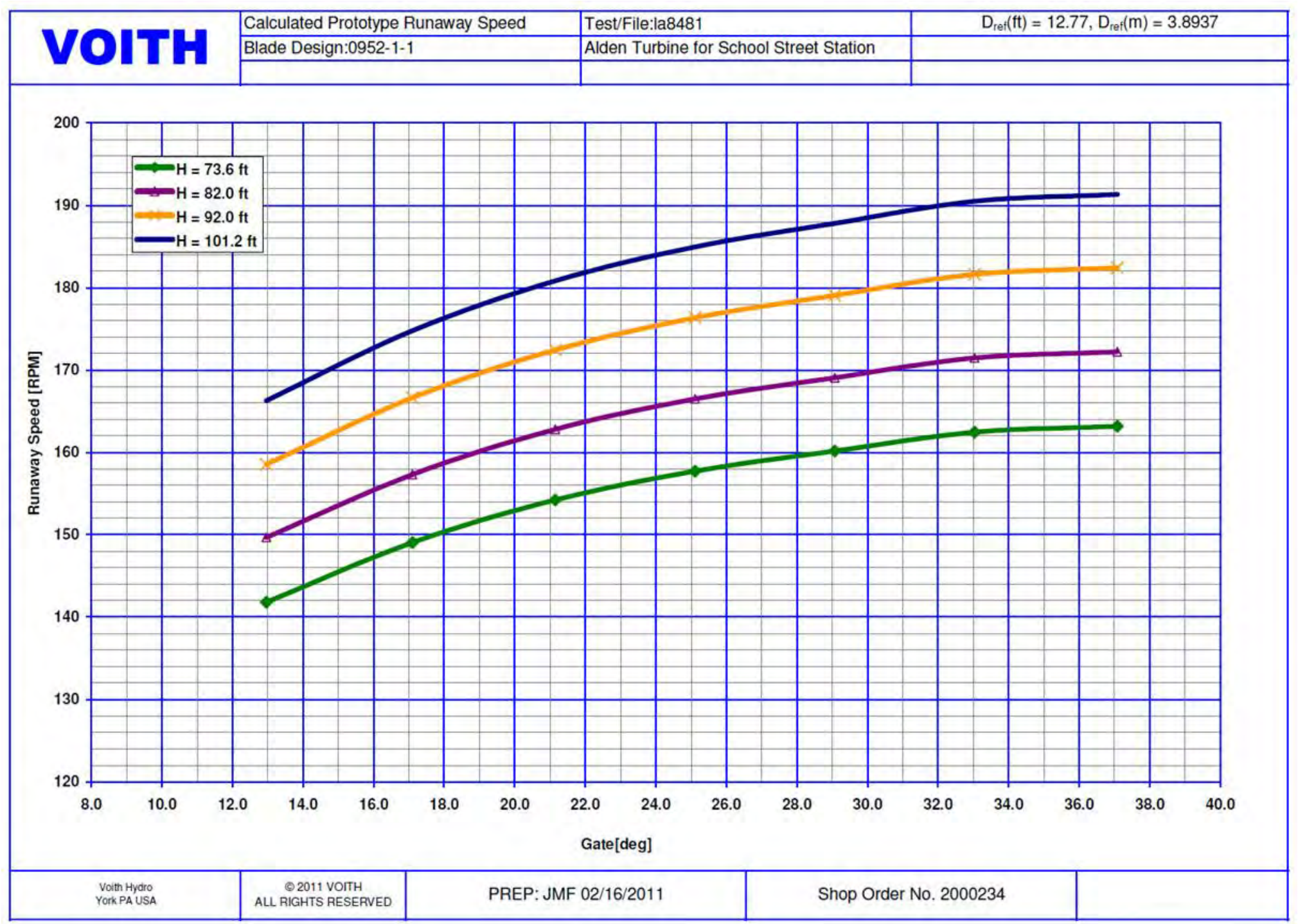

Figure 4-32

Runaway Speed $(N p)=f(\Delta y, H)$ 


\section{Sample Calculations}

\section{Conversion of Laboratory Data to Model Terms}

The following is an example of the input and output from the lab's data acquisition system. Figure 5-33 shows the actual computer printout.

$\begin{array}{ll}\frac{\text { INPUT }}{\Delta p-223.90430 \mathrm{kPa}} & \underline{\text { OUTPUT }} \\ q-0.49437 \frac{\mathrm{m}^{3}}{\mathrm{sec}} & \sigma-1.085 \\ n=900.63910 \frac{1}{\mathrm{~min}} & \eta_{\mathrm{m}}-91.64 \% \\ \text { torq }-1079.59596 \mathrm{~N} \times \mathrm{m} & \mathrm{E}_{\mathrm{cd}}=0.12657 \\ \mathrm{tw}-244.99998 \mathrm{kPa} & \mathrm{Q}_{\omega d}-0.05863 \\ \mathrm{wt}-19.62406 \quad{ }^{\circ} \mathrm{C} & \mathrm{P}_{\mathrm{cd}}-0.006800 \\ \mathrm{t}_{\mathrm{a}}-6400.62954 \mathrm{~N} & \mathrm{~K}_{\mathrm{a}}-0.181\end{array}$

Sample Calculations:

Mass Density of Water:

Mass density of water is calculated using the empirical equation of Weber per IEC 60193.

$$
\rho_{m}:=\frac{1}{0.001 \times(C 1+C 2-C 3)} \times \frac{\mathrm{kg}}{\mathrm{m}^{3}}
$$

Where:

$$
\begin{aligned}
& \mathrm{C} 1:=1-4.6699 \times 10^{-7} \times \mathrm{tw} \\
& \mathrm{C} 2:=8 \times 10^{-6} \times\left(w t-4+2.1318913 \times 10^{-4} \times \mathrm{tw}\right)^{2} \\
& \mathrm{C} 3:=6 \times 10^{-8} \times\left(w t-4+2.1318913 \times 10^{-4} \times \mathrm{tw}\right)^{3}
\end{aligned}
$$

Using :

$$
\mathrm{tw}=244.999980 \mathrm{kPa} \quad \mathrm{wt}=19.62406 \quad{ }^{\circ} \mathrm{C}
$$

We obtain :

$$
\rho_{\mathrm{m}}=998.382208 \frac{\mathrm{kg}}{\mathrm{m}^{3}}
$$


Net Head:

$$
\mathrm{h}:=\frac{\Delta \mathrm{p}+0.5 \times \rho_{\mathrm{m}} \times\left[\left(\frac{\mathrm{q}}{\mathrm{a}_{1}}\right)^{2}-\left(\frac{\mathrm{q}}{\mathrm{a}_{2}}\right)^{2}\right]}{\rho_{\mathrm{m}} \times \mathrm{g}}
$$

Using :

$$
\begin{array}{ll}
\Delta \mathrm{p}=223904.3000 \mathrm{~Pa} & \mathrm{Pm}_{\mathrm{m}}=998.382208 \frac{\mathrm{kg}}{\mathrm{m}^{3}} \quad \mathrm{q}=0.494370 \frac{\mathrm{m}^{3}}{\mathrm{sec}} \quad \mathrm{a}_{1}=0.245425 \mathrm{~m}^{2} \\
\mathrm{a}_{2}=0.320620 \mathrm{~m}^{2} & \mathrm{~g}=9.80123 \frac{\mathrm{m}}{\mathrm{sec}^{2}}
\end{array}
$$

We obtain :

$$
\mathrm{h}=22.967225 \mathrm{~m}
$$

Specific Energy:

$$
E_{m}:=g \times h
$$

Using :

$$
\mathrm{g}=9.801234 \mathrm{~m} \mathrm{sec}^{-2} \quad \mathrm{~h}=22.967225 \mathrm{~m}
$$

We obtain :

$$
E_{m}=225.107 \frac{\mathrm{J}}{\mathrm{kg}}
$$


Temperature Corrected Vapor Pressure of Water

$$
\mathrm{h}_{\mathrm{V}}:=\frac{10^{\left(2.7862+0.0312 \times \mathrm{wt}-0.000104 \times w t^{2}\right)} \times \mathrm{Pa}}{\rho_{\mathrm{m}} \times \mathrm{g}}
$$

Using :

$$
w t=19.62406{ }^{\circ} \mathrm{C} \quad \rho_{\mathrm{m}}=998.382208 \frac{\mathrm{kg}}{\mathrm{m}^{3}} \quad \mathrm{~g}=9.80123 \frac{\mathrm{m}}{\mathrm{sec}^{2}}
$$

We obtain :

$$
h_{V}=0.233261 m
$$

Sigma (Dimensionless)

$$
\sigma:=\frac{\frac{t w}{\rho_{m} \times g}+\frac{0.5}{g}\left(\frac{q}{a_{2}}\right)^{2}-h_{v}}{h}
$$

Using :

$$
\begin{array}{lll}
\mathrm{tw}=244.999980 \mathrm{kPa} & \mathrm{h}_{\mathrm{v}}=0.233261 \mathrm{~m} & \rho_{\mathrm{m}}=998.382208 \frac{\mathrm{kg}}{\mathrm{m}^{3}} \quad \mathrm{~g}=9.80123 \frac{\mathrm{m}}{\mathrm{sec}^{2}} \\
\mathrm{~h}=22.967225 \mathrm{~m} & \mathrm{q}=0.494370 \mathrm{~m}^{3} \mathrm{sec}^{-1} \quad \mathrm{a}_{2}=0.320620 \mathrm{~m}^{2}
\end{array}
$$

We obtain :

$$
\sigma=1.085
$$

$\omega_{\mathrm{m}}$ Model Speed

$$
\omega_{\mathrm{m}}:=\mathrm{n} \times 2 \times \pi
$$

Using :

$$
\mathrm{n}=15.010652 \frac{1}{\mathrm{sec}} \quad \pi=3.141593
$$

We obtain :

$$
\omega_{\mathrm{m}}=94.314706 \frac{1}{\mathrm{sec}}
$$


$\mathrm{E}_{\omega \mathrm{d}}$ Energy Coefficient (Dimensionless)

$$
E_{\omega d}:=\frac{g \times h}{\left(\omega_{m} \times d\right)^{2}}
$$

Using :

$$
\mathrm{g}=9.801234 \frac{\mathrm{m}}{\mathrm{sec}^{2}} \quad \mathrm{~h}=22.967225 \mathrm{~m} \quad \omega_{\mathrm{m}}=94.314706 \frac{1}{\mathrm{sec}} \quad \mathrm{d}=0.44716 \mathrm{~m}
$$

We obtain :

$$
E_{\omega d}=0.126565
$$

$\mathrm{Q}_{\omega \mathrm{d}}$ Discharge Coefficient (Dimensionless)

$$
Q_{\omega d}:=\frac{q}{\omega_{m} \times d^{3}}
$$

Using :

$$
q=0.494370 \frac{\mathrm{m}^{3}}{\mathrm{sec}} \quad \omega_{\mathrm{m}}=94.314706 \frac{1}{\mathrm{sec}} \quad \mathrm{d}=0.447155 \mathrm{~m}
$$

We obtain :

$$
Q_{\omega d}=0.058627
$$


$\mathrm{P}_{\omega \mathrm{d}}$ Power Coefficient (Dimensionless)

$$
P_{\omega d}:=\frac{\text { torq } \times \omega_{m}}{\rho_{m} \times \omega^{3} m^{3} \times d^{5}}
$$

Using :

$$
\text { torq }=1079.59596 \mathrm{~N} \times \mathrm{m} \quad \omega_{\mathrm{m}}=94.314706 \frac{\mathrm{l}}{\mathrm{sec}} \quad \rho_{\mathrm{m}}=998.382208 \frac{\mathrm{kg}}{\mathrm{m}^{3}} \quad \mathrm{~d}=0.447155 \mathrm{~m}
$$

We obtain :

$$
P_{\omega d}=0.006800
$$

Turbine Efficiency as \%

$$
\eta_{\mathrm{m}}:=\frac{\text { torq } \times \mathrm{n} \times 2 \times \pi}{\rho_{\mathrm{m}} \times \mathrm{g} \times \mathrm{h} \times \mathrm{q}}
$$

Using :

$$
\begin{array}{ll}
\text { torq }=1079.59596 \mathrm{~N} \times \mathrm{m} & \mathrm{n}=15.010652 \mathrm{sec}^{-1} \quad \rho_{\mathrm{m}}=998.382208 \frac{\mathrm{kg}}{\mathrm{m}^{3}} \quad \mathrm{~g}=9.80123 \frac{\mathrm{m}}{\mathrm{sec}^{2}} \\
\mathrm{~h}=22.967225 \mathrm{~m} & \mathrm{q}=0.494370 \frac{\mathrm{m}^{3}}{\mathrm{sec}}
\end{array}
$$

We obtain :

$$
\eta_{m}=91.644 \%
$$


Axial Thrust Coefficient (Dimensionless)

$$
\mathrm{K}_{\mathrm{a}}:=\frac{\mathrm{t}_{\mathrm{a}}}{\rho_{\mathrm{m}} \times \mathrm{g} \times \mathrm{h} \times \frac{\pi \times \mathrm{d}^{2}}{4}}
$$

Using :

$$
\begin{array}{ll}
\mathrm{t}_{\mathrm{a}}=6400.62954 \mathrm{~N} & \rho_{\mathrm{m}}=998.382208 \frac{\mathrm{kg}}{\mathrm{m}^{3}} \quad \mathrm{~g}=9.80123 \frac{\mathrm{m}}{\mathrm{sec}^{2}} \quad \mathrm{~h}=22.967225 \mathrm{~m} \\
\pi=3.141593 & \mathrm{~d}=0.447155 \mathrm{~m}
\end{array}
$$

We Obtain:

$$
\mathrm{K}_{\mathrm{a}}=0.181355
$$

Wicket Gate Torque Coefficient (Dimensionless)

The following data is from test file LO8481:

$$
\begin{aligned}
& \Delta \gamma:=30 \\
& \rho_{\mathrm{m}}:=998.544 \times \frac{\mathrm{kg}}{\mathrm{m}^{3}} \\
& q:=0.54666 \times \frac{\mathrm{m}^{3}}{\mathrm{sec}} \\
& C_{g}:=\frac{\frac{t_{g 1}+t_{g 2}+t_{g 4}+t_{g}+t_{g 11}+t_{g 14}}{6}}{\frac{\rho_{m} \times q^{2}}{d}}
\end{aligned}
$$

Using :

$$
\begin{array}{lll}
\mathrm{t}_{\mathrm{g} 1}=2.87 \mathrm{~N} \times \mathrm{m} & \mathrm{t}_{\mathrm{g} 2}=3.758 \mathrm{~N} \times \mathrm{m} & \mathrm{t}_{\mathrm{g} 4}=2.688 \mathrm{~N} \times \mathrm{m} \\
\mathrm{t}_{\mathrm{g} 7}=2.1885 \mathrm{~N} \times \mathrm{m} & \mathrm{t}_{\mathrm{g} 11}=2.654 \mathrm{~N} \times \mathrm{m} & \mathrm{t}_{\mathrm{g} 14}=4.0895 \mathrm{~N} \times \mathrm{m} \\
\rho_{\mathrm{m}}=998.544000 \frac{\mathrm{kg}}{\mathrm{m}^{3}} & \mathrm{q}=0.546660 \frac{\mathrm{m}^{3}}{\mathrm{sec}} & \mathrm{d}=0.447155 \mathrm{~m}
\end{array}
$$

We Obtain:

$$
C_{g}=0.004557
$$




\section{Conversion of Data from Model to Prototype}

The following procedure was used to obtain prototype data from the results of the model test:

Prototype Efficiency:

The efficiency was stepped up from the model using IEC 60193 as a guideline. This step up is used as a constant adder.

Model Kinematic Viscosity at Optimum Turbine Efficiency

$$
v_{\text {optM }}:=\mathrm{e}^{\left[-16.921+\frac{396.13}{\left(107.41+\mathrm{wt}_{\mathrm{optM}}\right)}\right]} \times \frac{\mathrm{m}^{2}}{\mathrm{sec}}
$$

Using:

$$
\mathrm{e}=2.7183 \quad \mathrm{wt}_{\mathrm{OptM}}=19.82679 \quad{ }^{\circ} \mathrm{C}
$$

We obtain:

$$
v_{\text {optM }}=1.007870 \times 10^{-6} \frac{\mathrm{m}^{2}}{\mathrm{sec}}
$$

Model Tested Reynolds Number at Optimum Turbine Efficiency

$$
\operatorname{Re}_{\text {optM }}:=\frac{\pi \times d_{i e c}{ }^{2} \times n_{\text {optM }}}{v_{\text {optM }}}
$$

Using:

$$
\mathrm{d}_{\mathrm{iec}}=0.345604 \mathrm{~m} \quad \pi:=3.141593 \quad \mathrm{n}_{\mathrm{optM}}=15.015263 \frac{1}{\mathrm{sec}} \quad v_{\mathrm{optM}}=1.007870 \times 10^{-6} \frac{\mathrm{m}^{2}}{\mathrm{sec}}
$$

We obtain:

$$
\mathrm{Re}_{\mathrm{optM}}=5.590307 \times 10^{6}
$$

Model Kinematic Viscosity of Sample Calculation Point 


$$
v_{m}:=e^{\left[-16.921+\frac{396.13}{(107.41+w t)}\right] \times \frac{m^{2}}{s e c}}
$$

Using:

$$
\mathrm{e}=2.7183 \quad \text { wt }=19.62406{ }^{\circ} \mathrm{C}
$$

We obtain:

$$
v_{\mathrm{m}}=1.012890 \times 10^{-6} \frac{\mathrm{m}^{2}}{\mathrm{sec}}
$$

Model Tested Reynolds Number of Sample Calculation Point

$$
\operatorname{Re}_{\mathrm{m}}:=\frac{\pi \times \mathrm{diec}^{2} \times \mathrm{n}}{v_{\mathrm{m}}}
$$

Using:

$$
\mathrm{d}_{\mathrm{iec}}=0.345604 \mathrm{~m} \quad \pi:=3.141593 \quad \mathrm{n}=15.010652 \frac{1}{\mathrm{sec}} \quad v_{\mathrm{optM}}=1.007870 \times 10^{-6} \frac{\mathrm{m}^{2}}{\mathrm{sec}}
$$

We obtain:

$$
\operatorname{Re}_{\mathrm{m}}=5.560892 \times 10^{6}
$$


Prototype Kinematic Viscosity

$$
v_{p}:=e^{\left[-16.921+\frac{396.13}{(107.41+W T)}\right]} \times \frac{m^{2}}{s e c}
$$

Using:

$$
e=2.7183 \quad W T=20.00 \quad{ }^{\circ} \mathrm{C}
$$

We obtain:

$$
v_{p}=1.003614 \times 10^{-6} \frac{\mathrm{m}^{2}}{\mathrm{sec}}
$$

Prototype Reynolds Number

$$
\operatorname{Re}_{p}:=\frac{\pi \times D_{i e c}{ }^{2} \times N_{p}}{v_{p}}
$$

Using:

$$
\begin{aligned}
& \mathrm{D}_{\mathrm{iec}}=3.010211 \mathrm{~m} \quad \pi=3.141593 \quad \mathrm{~N}_{\mathrm{p}}=2.000000 \frac{1}{\mathrm{sec}} \\
& v_{\mathrm{p}}=1.003614 \times 10^{-6} \frac{\mathrm{m}^{2}}{\mathrm{sec}}
\end{aligned}
$$

We obtain:

$$
\operatorname{Re}_{p}=5.672927 \times 10^{7}
$$


Relative Scalable Losses

$$
\delta_{\text {ref }}:=\frac{1-\eta_{\text {optM }}}{\left(\frac{\text { Re }_{\text {ref }}}{\operatorname{Re}_{\text {optM }}}\right)^{0.16}+\left(\frac{1-V_{\text {ref }}}{V_{\text {ref }}}\right)}
$$

Using :

$$
\eta_{\text {optM }}=0.9185 \quad \operatorname{Re}_{\text {ref }}=7.0000 \times 10^{6} \quad V_{\text {ref }}=0.7 \quad \operatorname{Re}_{\text {optM }}=5.5903 \times 10^{6}
$$

We Obtain:

$$
\delta_{\text {ref }}=0.055624
$$

Tested Model to Reference Model Efficiency Step-Up

$$
\Delta \eta_{\text {Msp }}:=\delta_{\text {ref }} \times\left[\left(\frac{R e_{\text {ref }}}{\operatorname{Re}_{m}}\right)^{0.16}-\left(\frac{R e_{\text {ref }}}{\operatorname{Re}_{\text {ref }}}\right)^{0.16}\right]
$$

Using :

$$
\delta_{\text {ref }}=0.055624 \quad \operatorname{Re}_{\text {ref }}=7.000000 \times 10^{6} \quad \operatorname{Re}_{\mathrm{m}}=5.56089 \times 10^{6}
$$

We Obtain:

$$
\Delta \eta \mathrm{Msp}=0.209 \%
$$


Reference Model Efficiency

$$
\eta \mathrm{Msp}:=\eta_{\mathrm{m}}+\Delta \eta \mathrm{Msp}
$$

Using :

$$
\eta_{m}=91.644 \% \quad \Delta \eta \mathrm{Msp}=0.209 \%
$$

We Obtain:

$$
\eta \mathrm{Msp}=91.852 \%
$$

Reference Model Efficiency to Prototype Efficiency Step-Up

$$
\Delta \eta M_{-} P:=\delta_{\text {ref }} \times\left[\left(\frac{R e_{\text {ref }}}{\operatorname{Re}_{\text {ref }}}\right)^{0.16}-\left(\frac{R e_{\text {ref }}}{R e_{p}}\right)^{0.16}\right]
$$

Using :

$$
\delta_{\text {ref }}=0.055624 \quad \operatorname{Re}_{\text {ref }}=7.000000 \times 10^{6} \quad \operatorname{Re}_{\mathrm{p}}=5.672927 \times 10^{7}
$$

We Obtain:

$$
\Delta \eta M_{-} \mathrm{P}=1.583 \%
$$

Prototype Efficiency

$$
\eta_{p}:=\eta_{M s p}+\Delta \eta_{M} P
$$

Using :

$$
\eta \mathrm{Msp}=91.852 \% \quad \Delta \mathrm{M} \mathrm{M} \_\mathrm{P}=1.583 \%
$$

We Obtain:

$$
\eta_{p}=93.435 \%
$$

$\omega_{\mathrm{p}}$ Prototype Speed 
Model Test Report

$$
\omega_{p}:=N_{p} \times 2 \times \pi
$$

Using:

$$
\mathrm{N}_{\mathrm{p}}=2.000000 \frac{1}{\mathrm{sec}} \quad \pi=3.141593
$$

We obtain:

$$
\omega_{p}=12.566372 \frac{1}{\mathrm{sec}}
$$

Prototype Head

$$
H:=\frac{E_{\omega d} \times \omega_{p}^{2} \times D^{2}}{G}
$$

Using:

$$
E_{\omega d}=0.126565 \quad \omega_{p}=12.566372 \frac{1}{\mathrm{sec}} \quad D=3.894720 \mathrm{~m} \quad \mathrm{G}=9.804145 \frac{\mathrm{m}}{\mathrm{sec}^{2}}
$$

We obtain:
$\mathrm{H}=30.923 \mathrm{~m}$
or
$H=101.452 \mathrm{ft}$

Prototype Specific Energy

$$
E_{p}:=G \times H
$$

Using :

$$
\mathrm{G}=9.804145 \mathrm{~m} \mathrm{sec}^{-2} \quad \mathrm{H}=30.922661 \mathrm{~m}
$$

We obtain :

$$
E_{p}=303.170 \frac{\mathrm{J}}{\mathrm{kg}}
$$


Prototype Discharge

$$
Q:=Q_{\omega d} \times \omega_{p} \times D^{3}
$$

Using:

$$
Q_{\omega d}=0.058627 \quad \omega_{p}=12.566372 \sec ^{-1} \quad D=3.894720 \mathrm{~m}
$$

We obtain:

$$
Q=43.525 \frac{\mathrm{m}^{3}}{\mathrm{sec}}
$$

or

$$
Q=1537.065 \frac{\mathrm{ft}^{3}}{\mathrm{sec}}
$$

Prototype Power

$$
\text { POWER : }=\rho_{p} \times \mathbf{G} \times \mathbf{H} \times \mathbf{Q} \times \eta_{p}
$$

Using:

$$
\begin{aligned}
& \rho_{p}=998.243509 \frac{\mathrm{kg}}{\mathrm{m}^{3}} \quad \mathrm{G}=9.80415 \frac{\mathrm{m}}{\mathrm{sec}^{2}} \quad \mathrm{H}=30.922661 \mathrm{~m} \quad Q=43.525 \frac{\mathrm{m}^{3}}{\mathrm{sec}} \\
& \eta_{p}=93.4348 \%
\end{aligned}
$$

We obtain:

$$
\text { POWER }=12307.474 \mathrm{~kW} \quad \text { or } \quad \text { POWER }=16504.594 \mathrm{hp}
$$


Prototype Axial Thrust

$$
T_{a}:=\frac{K_{a} \times \rho p \times G \times H \times \pi \times D^{2}}{4}+\frac{\rho p \times G \times\left(Z_{c}-T W E_{\text {min }}\right) \times \pi \times D_{\text {shaft }}{ }^{2}}{4}
$$

Using:

$$
\begin{array}{llll}
K_{a}=0.181355 & \rho_{p}=998.243509 \frac{\mathrm{kg}}{\mathrm{m}^{3}} & \mathrm{G}=9.80415 \frac{\mathrm{m}}{\mathrm{sec}^{2}} & \mathrm{H}=30.922661 \mathrm{~m} \\
\pi=3.141593 & \mathrm{D}=3.894720 \mathrm{~m} & \mathrm{Z}_{\mathrm{c}}=17.306800 \mathrm{~m} & \text { TWE }_{\min }=17.069 \mathrm{~m} \\
D_{\text {shaft }}=0.508000 \mathrm{~m} &
\end{array}
$$

We obtain:
$\mathrm{T}_{\mathrm{a}}=654349.0 \mathrm{~N}$
or
$\mathrm{T}_{\mathrm{a}}=147103.5 \mathrm{lbf}$

Prototype Runaway Speed

Maximum runaway speed was determined for the following condition:

$$
\begin{aligned}
& \sigma_{\text {pmin }}=0.3192 \\
& T_{W E} E_{\text {min }}=56 \mathrm{ft} \\
& H=101.2 \mathrm{ft} \\
& \Delta \gamma=37^{\circ}
\end{aligned}
$$


Maximum Runaway Speed

$$
E_{\omega d r}:=\frac{G \times H}{\left(N_{p} \times 2 \times \pi \times D\right)^{2}}
$$

The following data is from test file LK8481:

$$
\begin{array}{ll}
E_{\omega d r}:=0.0508 & H:=30.84576 \times m \\
N_{p}:=\frac{1}{2 \times \pi \times D} \times\left(\frac{G \times H}{E_{\omega d r}}\right)^{0.5} &
\end{array}
$$

Using :

$$
\mathrm{D}=3.894720 \mathrm{~m} \quad \mathrm{G}=9.80415 \frac{\mathrm{m}}{\mathrm{sec}^{2}} \quad \mathrm{H}=30.846 \mathrm{~m} \quad \mathrm{E}_{\omega \mathrm{dr}}=0.0508
$$

We Obtain:

$$
\mathrm{N}_{\mathrm{p}}=189.18 \frac{1}{\min }
$$




\section{Prototype Gate Torque}

$$
\begin{aligned}
& \Delta \gamma:=30 \quad Q:=54.115 \times \frac{\mathrm{m}^{3}}{\mathrm{sec}} \\
& \mathrm{T}_{\mathrm{g}}:=\frac{\mathrm{C}_{\mathrm{g}} \times \rho_{\mathrm{p}} \times \mathrm{Q}^{2}}{\mathrm{D}}
\end{aligned}
$$

Using:

$$
\begin{aligned}
& C_{g}=0.004557 \quad \rho_{p}=998.243509 \frac{\mathrm{kg}}{\mathrm{m}^{3}} \quad Q=54.115000 \frac{\mathrm{m}^{3}}{\mathrm{sec}} \\
& D=3.894720 \mathrm{~m}
\end{aligned}
$$

We obtain:

$$
\mathrm{T}_{\mathrm{g}}=3420.7 \mathrm{~N} \times \mathrm{m} \quad \text { or } \quad \mathrm{T}_{\mathrm{g}}=2523.0 \mathrm{ft} \times \mathrm{lbf}
$$

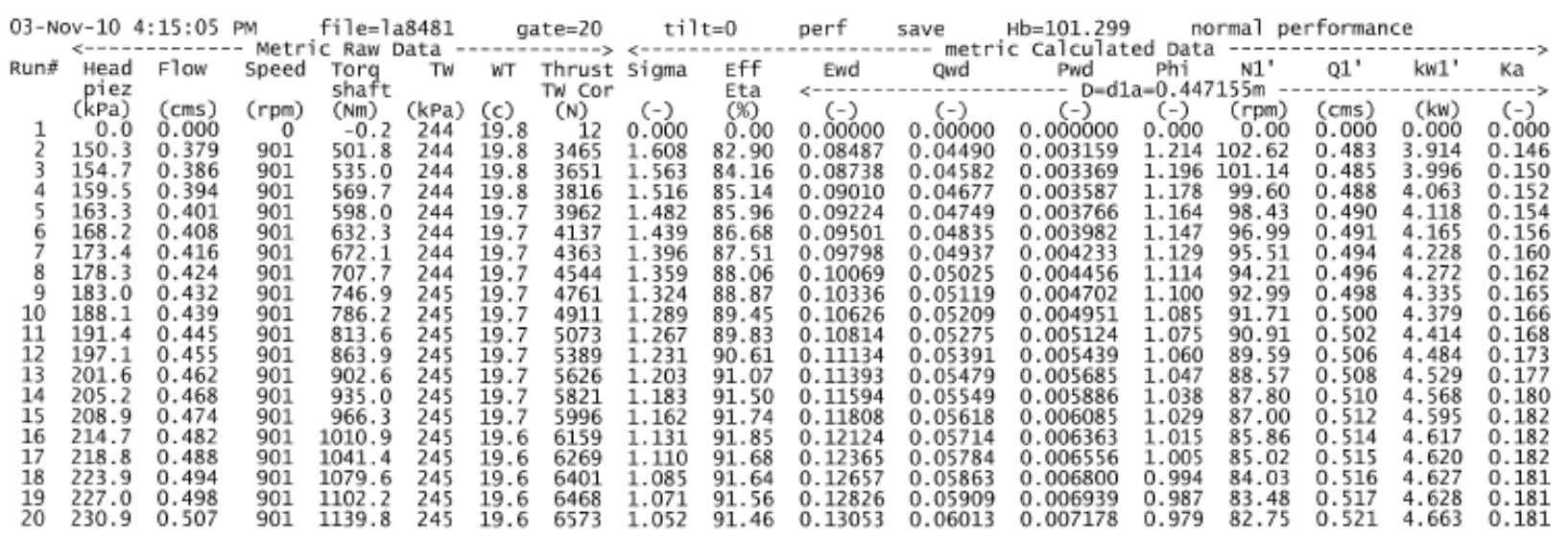

Figure 4-33

Sample Calculations 


\section{Description of Model}

\section{General}

The model to prototype scale (l) is 8.7100 . The model is completely homologous to the proposed prototype in all the primary water passageway areas.

Model Drawings

\begin{tabular}{|l|l|l|l|}
\hline \multicolumn{1}{|c|}{ Description } & \multicolumn{1}{|c|}{ Figure No. } & \multicolumn{1}{c|}{ Rev. No } & \multicolumn{1}{c|}{ Drawing No } \\
\hline Stand B Arrangement & Figure 5-34 & B & 2TEN60-0361-00547981 \\
\hline Instrument Tap Locations & Figure 5-35 & B & 2TEN60-0361-00584528 \\
\hline
\end{tabular}

\section{Model Dimensional Checks}

All major model components including Inlet, Spiral Case, Stay Ring, Wicket Gate, Runner Draft Tube Cone, Draft Tube Elbow, and Draft Tube Foot were carefully inspected to assure accuracy according to tolerances established by IEC code.

Figure 5-36 showed nomenclature and locations of inspection.

Inspection results for the major dimensions of the inlet, spiral case, stay ring, wicket gates and draft tube, including the cone, elbow and foot, are within the aforementioned IEC tolerances. These inspection results are available upon request. Representative dimensional checks of the suction and pressure sides of runner blade \#1 are included in Figure 5-37 and Figure 5-38.

Representative dimensional checks of the profiles for wicket gate \#1 are included in Figure 5-39 and Figure 5-40.

Representative dimensional checks of the profiles for stay vane \#8 are included in Figure 5-41 and Figure 5-42. 


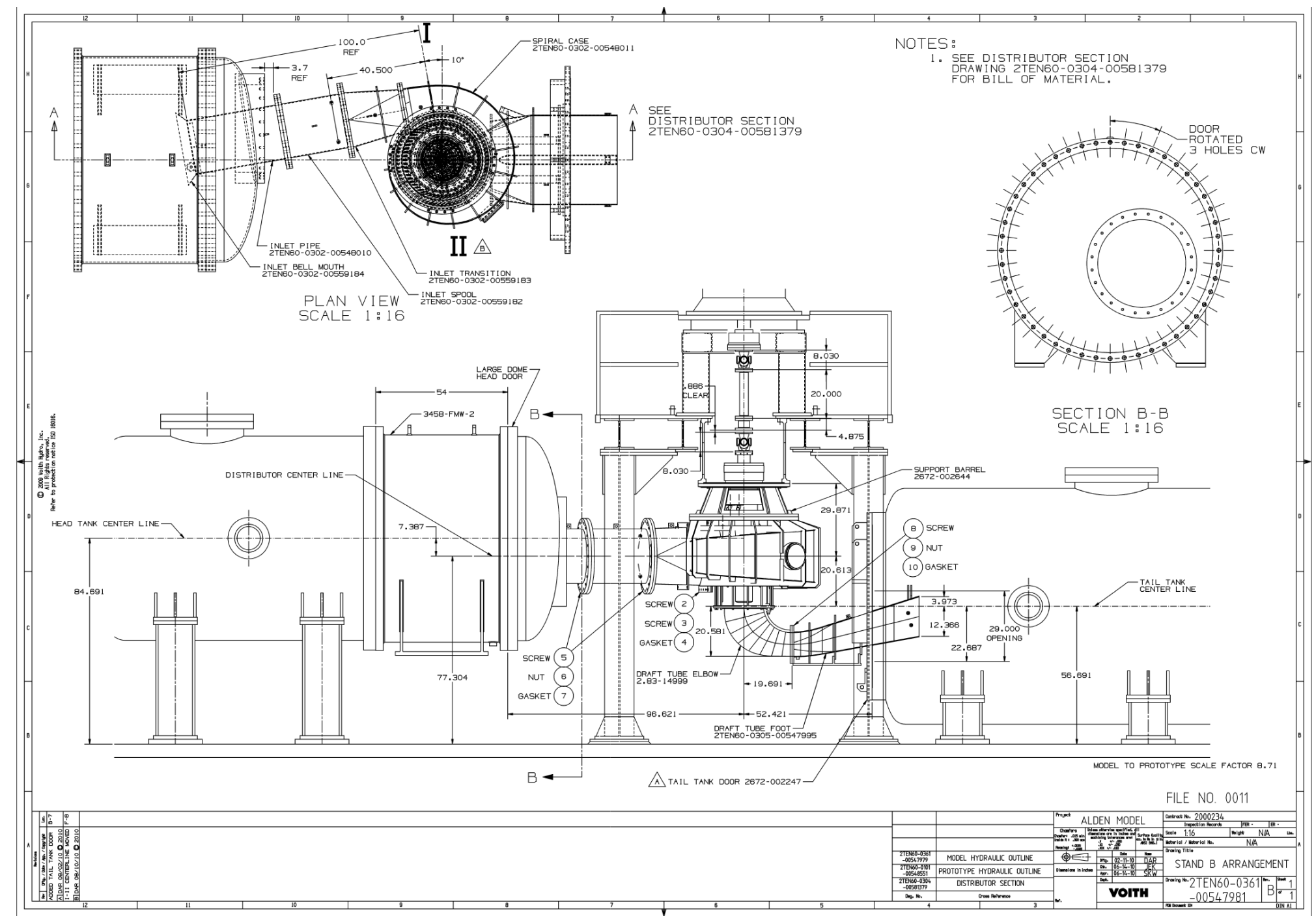

Figure 4-34

Stand B Arrangement 


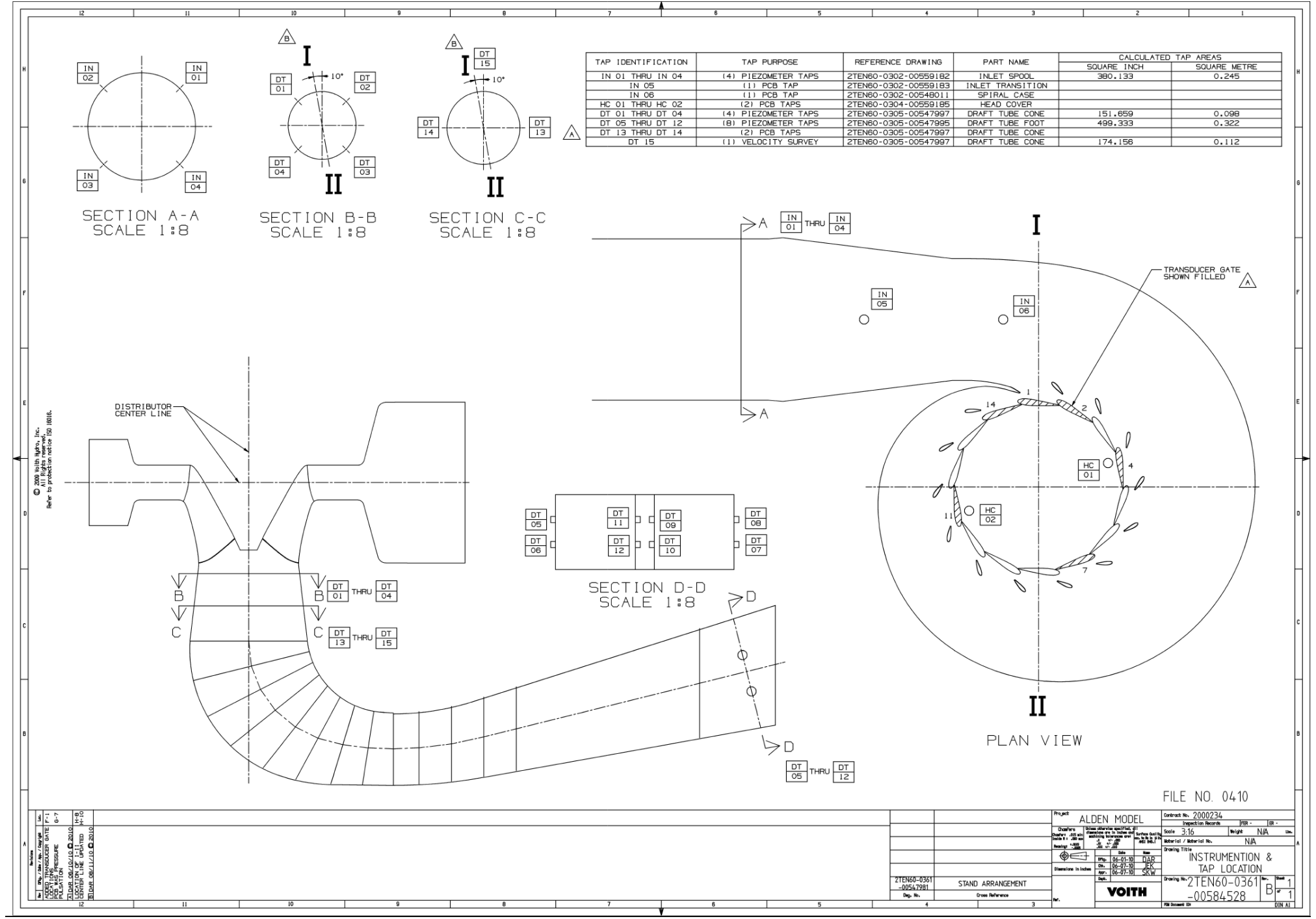

Figure 4-35

Instrument Tap Locations 


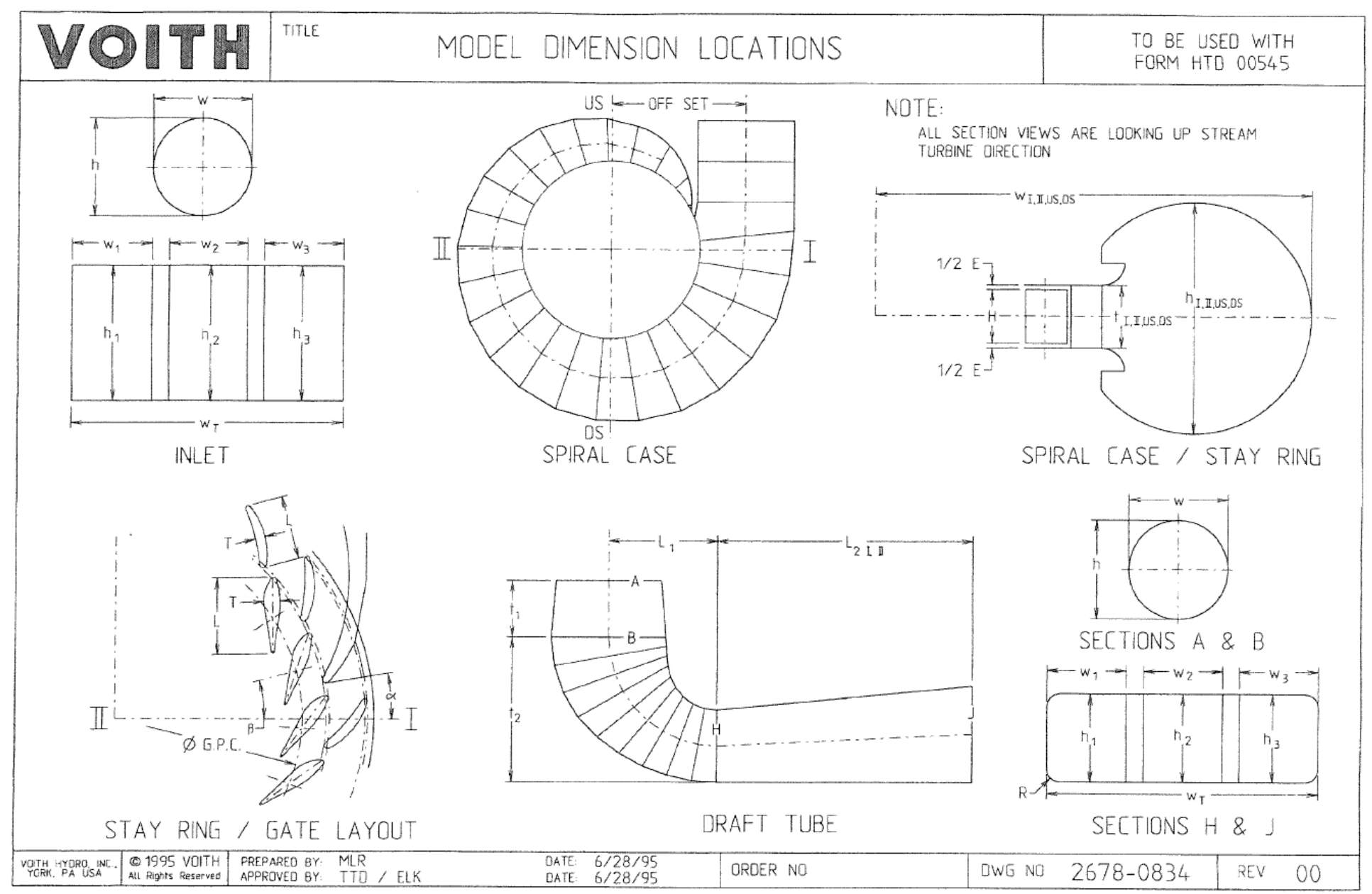

Figure 4-36

Model Dimensional Checks: Nomenclature and Locations of Inspection 


\begin{tabular}{|c|c|}
\hline & $\begin{array}{l}\text { Hydraulic Laboratory Inspection Report } \\
\text { CORDAX 1815 CMM Gage Number 70036 } \\
\text { Inspecton sotwware - METRIS CMM-Manager 2.3.0. }\end{array}$ \\
\hline Report Name & Alden Turbine Application at School Street Station \\
\hline Part Name & Blade 1 \\
\hline Part No. & 2TEN60-0301-00574327-MFD_0331 \\
\hline Inspector & Ocamb \\
\hline Company & Voith Hydro \\
\hline Date & Tuesday, July 20,2010 \\
\hline Time & $8: 44 \mathrm{AM}$ \\
\hline Unit & $\mathrm{MM}$ \\
\hline CAD File & ALDN-2TEN60-0301-00574327-MDF_0331_RUNNER_BLADE.igs \\
\hline Project File & ALDN-2TEN60-0301-00574327-MDF_0331_RUNNER_BLADE_b1.cmp \\
\hline
\end{tabular}

\#1 Graphical Report

\begin{tabular}{|l|l}
\hline Name & Blade 1 Suction Side \\
\hline
\end{tabular}

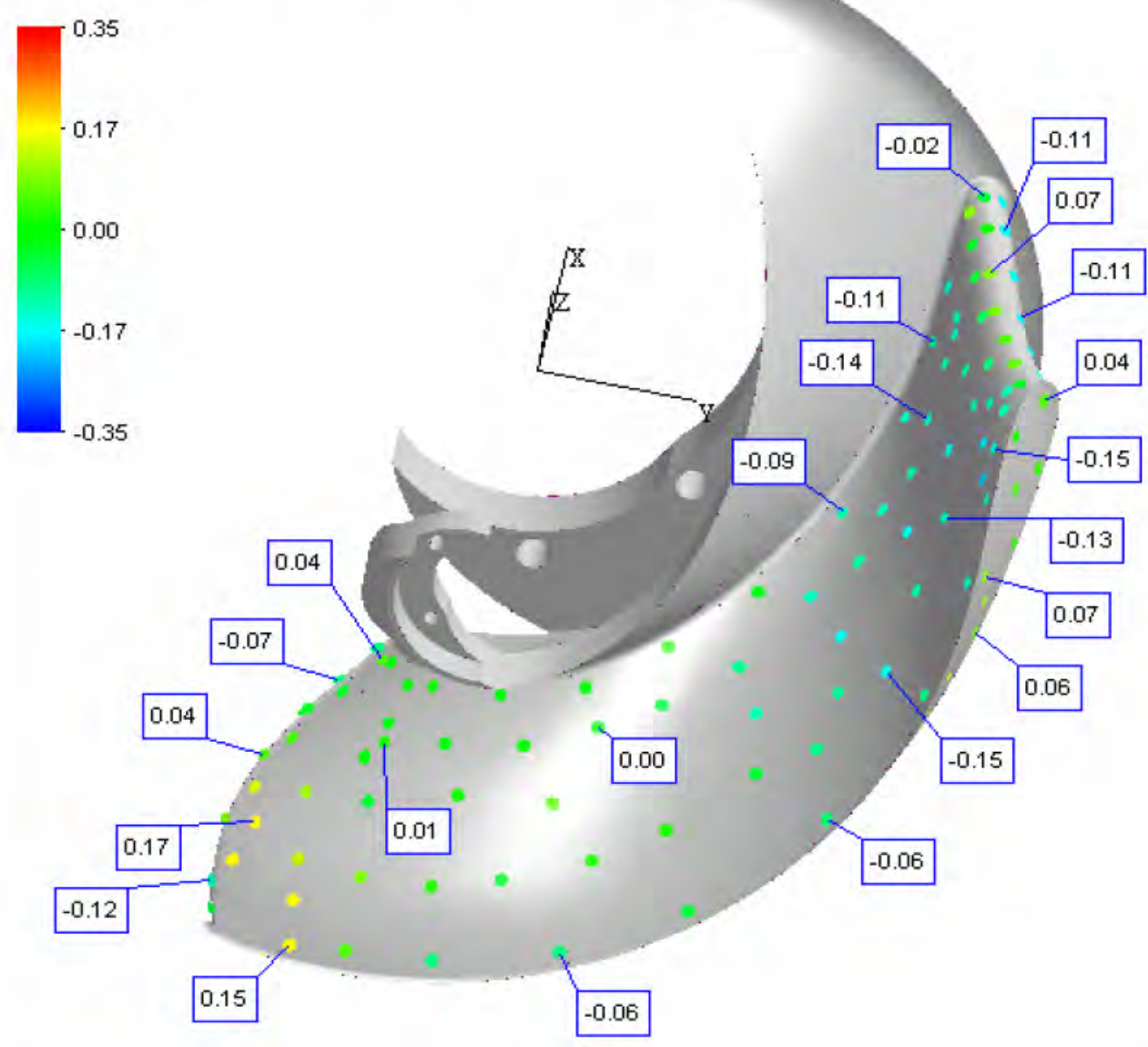

Figure 4-37

Figure 7.3 .2

Representative Dimensional Check of the Suction Side of Runner Blade \#1 


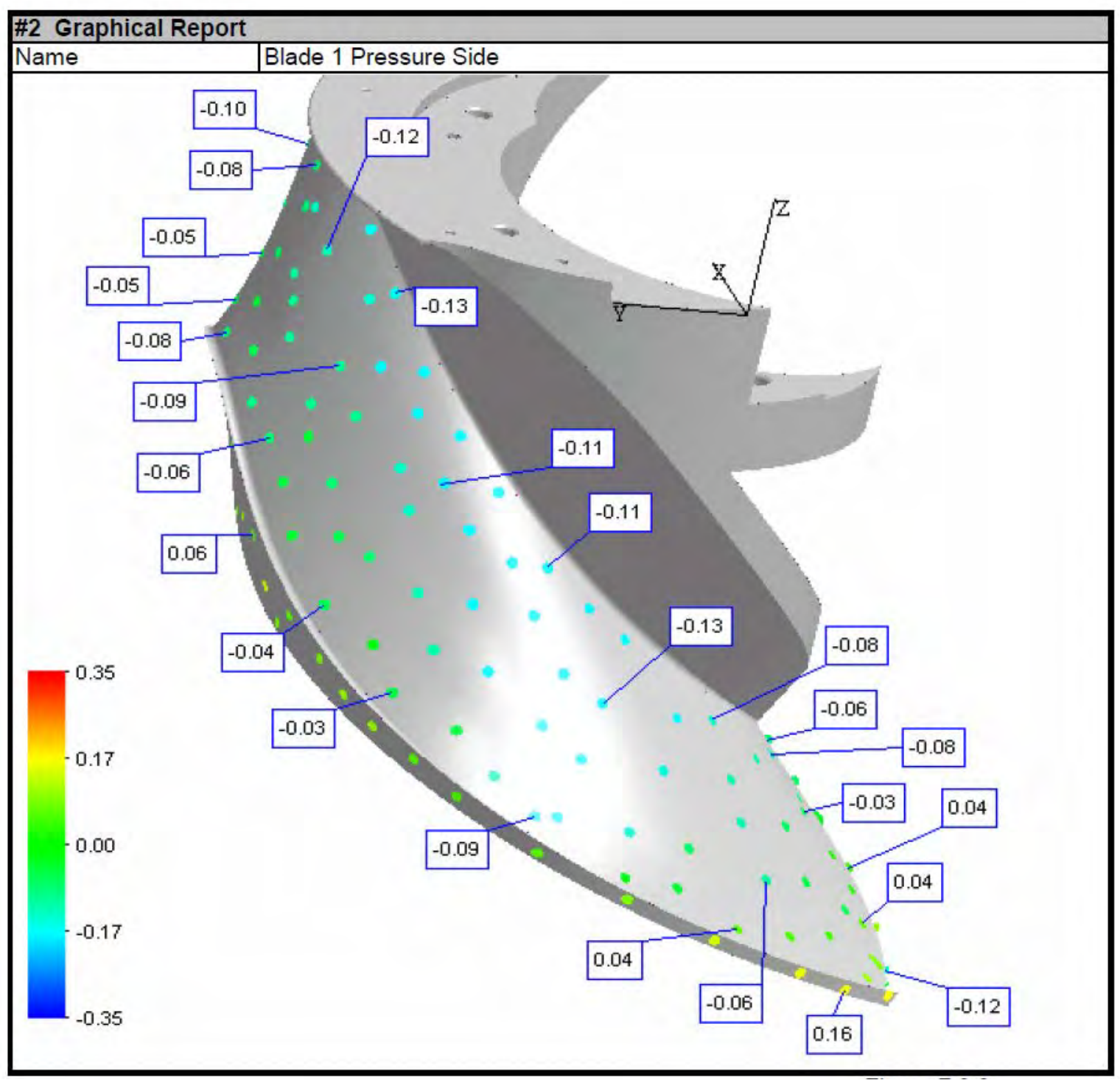

Figure 4-38

Representative Dimensional Check of the Pressure Side of Runner Blade \#1 


\begin{tabular}{|c|c|}
\hline & $\begin{array}{l}\text { Hydraulic Laboratory Inspection Report } \\
\text { CORDAX } 1 \text { 1 } 15 \text { CMM Gage Number } 70036 \\
\text { Inspection sothware - METRIS CMM-Manager } 2.3 .0 .0\end{array}$ \\
\hline Report Name & Alden \\
\hline Part Name & Gate \#1 \\
\hline Part No. & Alden_Wicket_Gate_00564214_0291 \\
\hline Inspector & Ocamb \\
\hline Company & Voith Hydro \\
\hline Date & Monday, June 28,2010 \\
\hline Time & $8: 40 \mathrm{AM}$ \\
\hline Unit & $\mathrm{INCH}$ \\
\hline CAD File & Alden_Wicket_Gate_00564214_0291.igs \\
\hline Project File & Alden_Wicket_Gate_00564214_0291_Gate1b.cmp \\
\hline Tmax & $T \max =0.879^{\prime \prime}$ or $22.327 \mathrm{~mm}$ \\
\hline
\end{tabular}

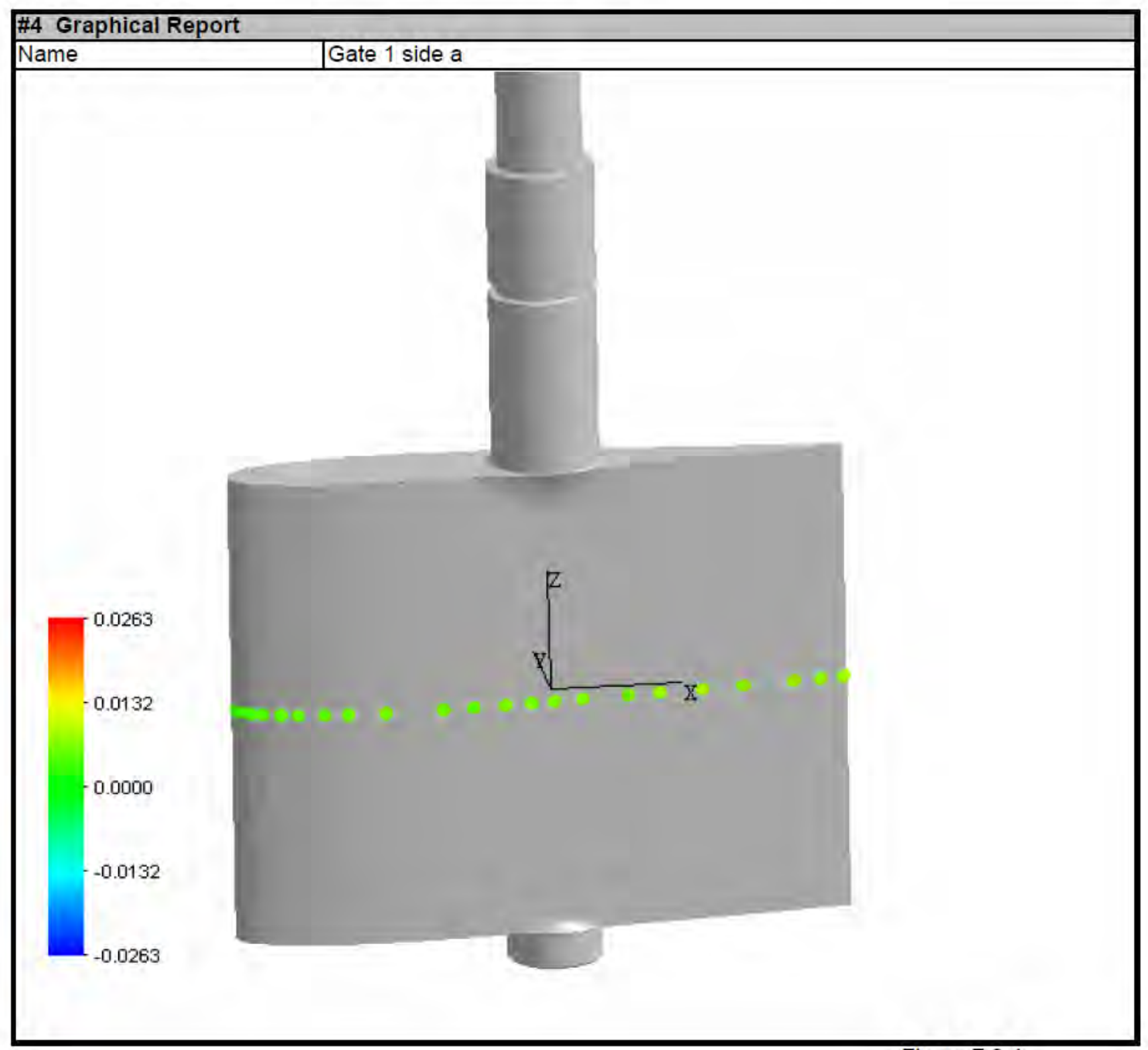

Figure 4-39

Representative Dimensional Check of Wicket Gate \#1 Side a 


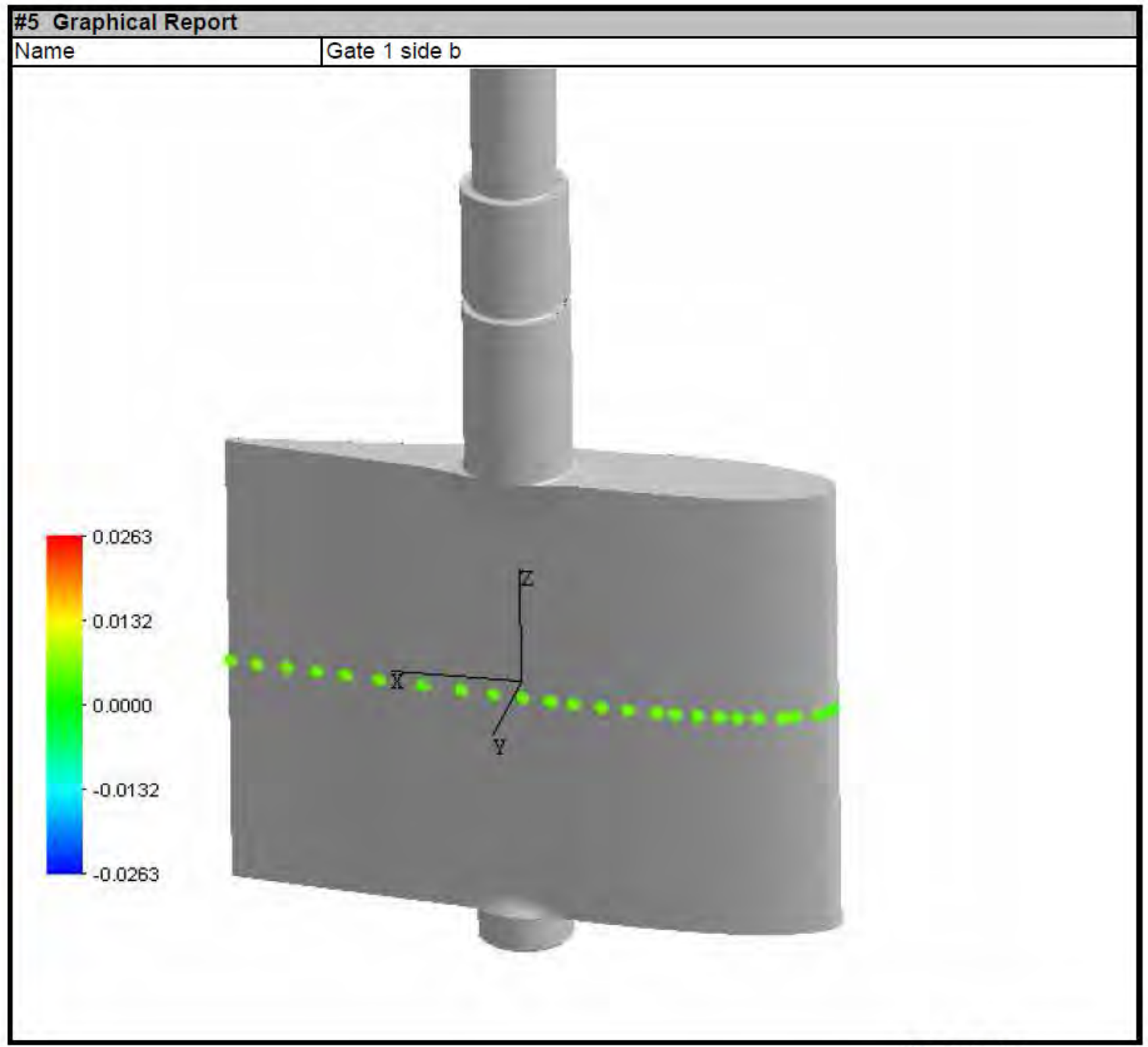

Figure 4-40

Representative Dimensional Check of Wicket Gate \#1 Side b 


\begin{tabular}{|c|c|}
\hline & $\begin{array}{l}\text { Hydraulic Laboratory Inspection Report } \\
\text { CORDAX } 1815 \text { CMM Gage Number 70036 } \\
\text { Inspection softhware - METRIS CMM-Manager } 2.2 .0 .0\end{array}$ \\
\hline Report Name & Alden \\
\hline Part Name & Stay Vanes \\
\hline Part No. & aldn-2ten60-0303-00555689-mfd_Stay_ring \\
\hline Inspector & Ocamb \\
\hline Company & Voith Hydro \\
\hline Date & Monday, April 26, 2010 \\
\hline Time & 12:04 PM \\
\hline Unit & MM \\
\hline CAD File & ALDN-2TEN60-0303-00555689-MDF_0221_STAY_RINGx_t.igs \\
\hline Project File & ALDN-2TEN60-0303-00555689-MDF_0221_STAY_RINGx_t_Vane8.cmp \\
\hline
\end{tabular}

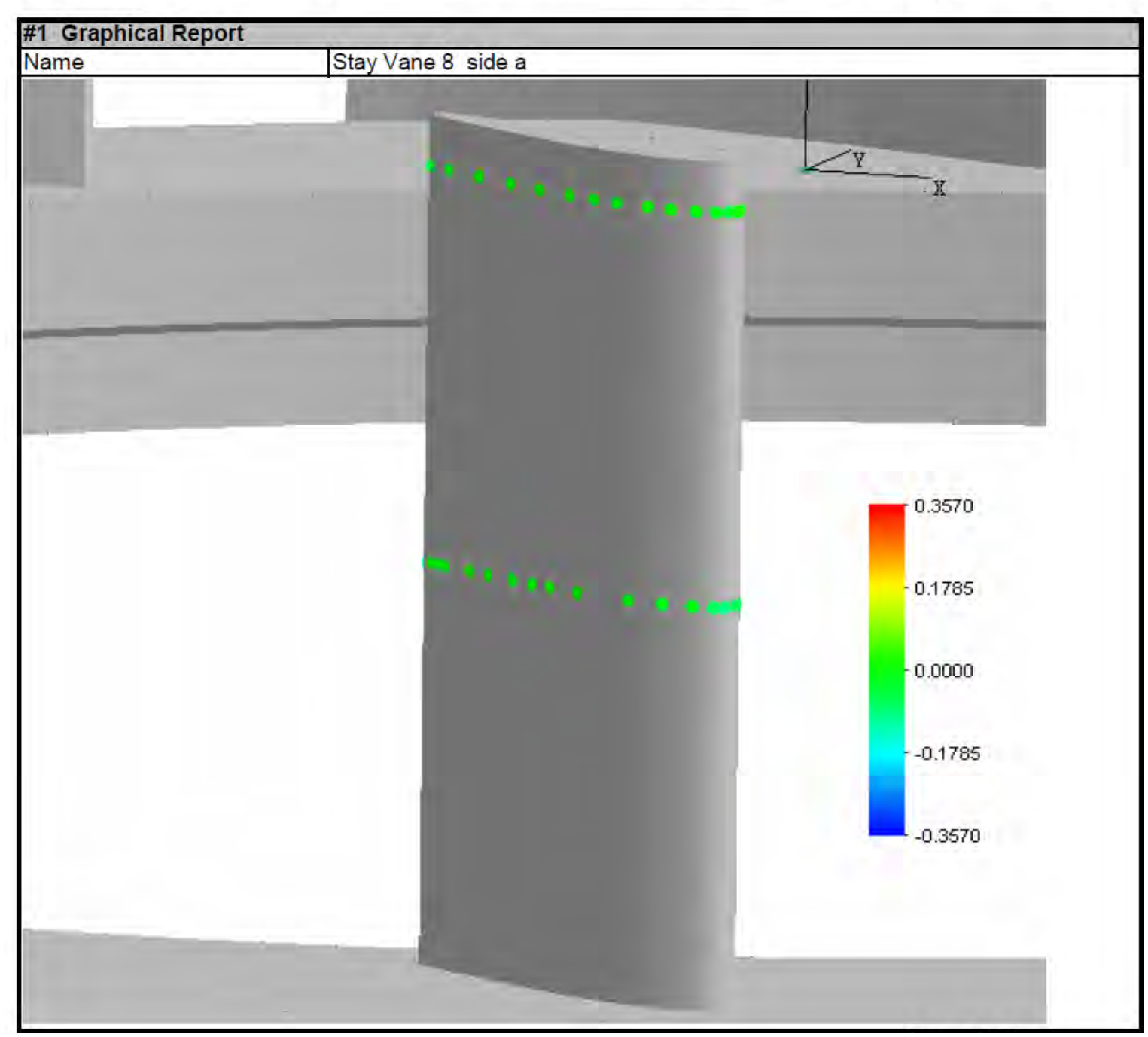

Figure 4-41

Representative Dimensional Check of Stay Vane \#8 Side a 


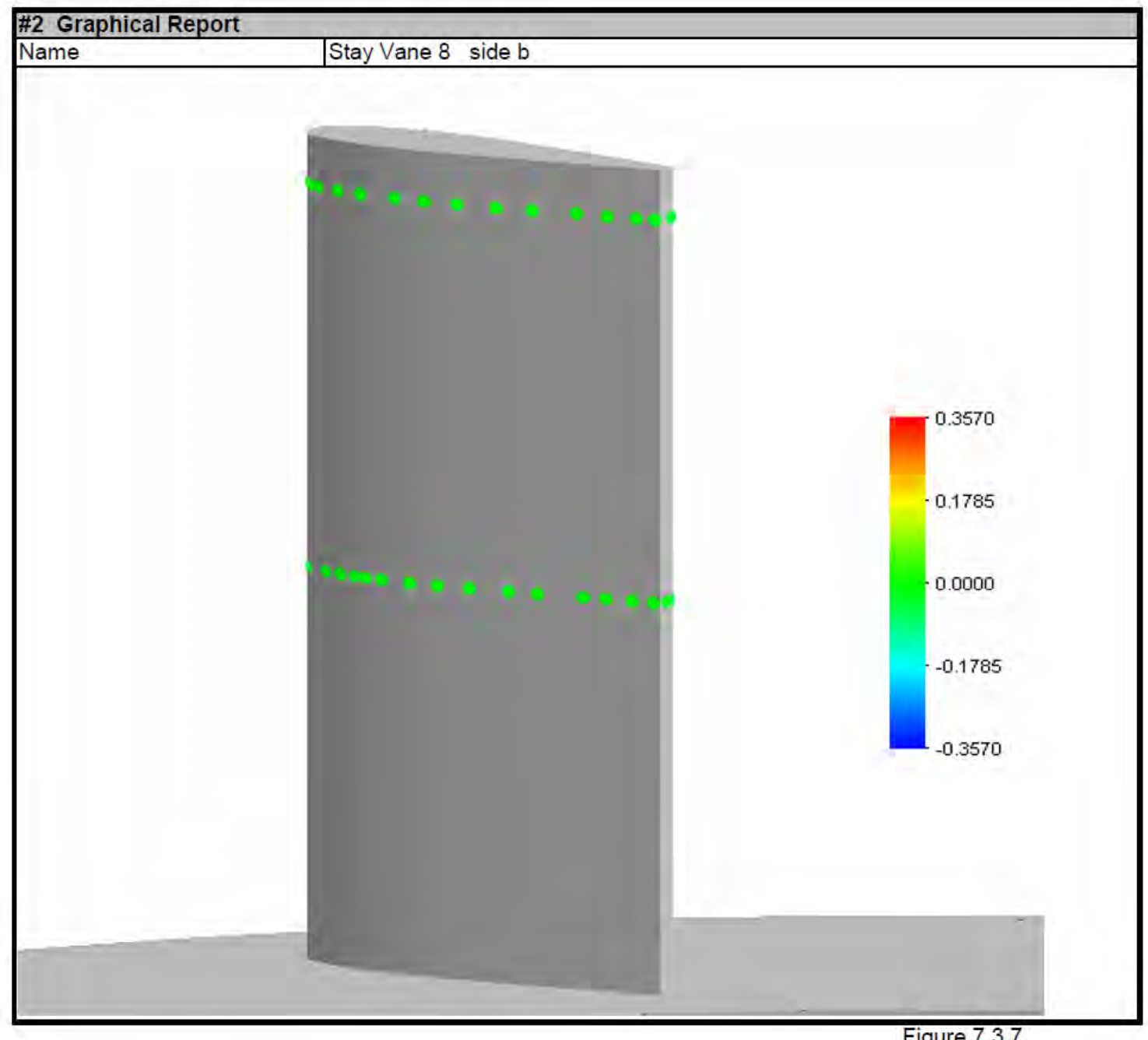

Figure 4-42

Representative Dimensional Check of Stay Vane \#8 Side b

\section{Description of Laboratory}

The test facilities and test equipment are described in the attached publication, "S. Morgan Smith Memorial Hydraulic Laboratory".

\section{The New Load Measuring System}

\section{General}

On August 2006 Voith Siemens Hydro Power Generation installed a new load measuring system at the S. Morgan Smith Memorial Hydraulic Laboratory in York, Pennsylvania, USA. The system consists of four (4) major components: 
- Hydrostatic model bearing

- Hydrostatic support for dynamometer base

- Reaction force measuring system

- 600 HP, D.C. dynamometer

Repeatability of the new load measuring system is $+/-0.2 \mathrm{Nm}$.

The model bearing assembly is designed for driving or retarding model turbines and pump turbines with the dynamometer.

For measuring the reaction torque, the dynamometer is supported by a hydrostatic bearing and connected to two load cells in series via a lever arm and a steel strap.

One load cell is for efficiency calculation and the other is for backup and quality control. The horizontal force on the steel strap is changed to a vertical force by using two hydrostatic deflection rollers. One end is connected to a weigh pan, which holds calibrated masses, while the other end is connected to the load cells and the suppression masses.

To reduce the friction of the hydrostatic bearings, the reaction force measuring system may be oscillated using a crank gear.

The friction of the model bearing is transmitted to the reaction force measuring system from the bearing to the lever arm via a transmission rod.

Maximum accuracy of torque measurement is attained by installing load cells which have a very low range. When approaching the limit of the load cell, calibrated weights are added to the weight box using an electro-mechanical feeder.

A special terminal box, consisting of a static and pendulum part, is mounted for supplying the current to the dynamometer with low torque. Flexible copper cords are connected between these parts to eliminate force on the measuring system.

During axial thrust measurement, via the pressure difference in the bearing pockets of the hydrostatic thrust bearing, no friction force shall disturb these measurements. Therefore, a "thrust-free coupling" is mounted between the motor-shaft and the cardan-shaft.

Hydrostatic Model Bearing

The vertical bearing for model tests of water turbines and pump turbines is designed for direct connection to the casting of the model.

Power transmission to the "Dynamometer" is done with a cardan shaft. The bearing consists of four main parts:

- Rotating parts

- Swinging part 
- Outer casing

- $\quad$ Sealing system

The shaft (rotating parts), supported in the swinging part, transmits the torque from the runner to the cardan shaft. The swinging part casing is supported in the outer casing by means of hydrostatic bearings and the measurement of the reaction torque of the bearing is transmitted to the bearing of the dynamometer with a connection rod.

Technical Data

Max. system pressure

$1,000,000 \mathrm{~N} / \mathrm{m}^{2}$

Max. torque

$3,000 \mathrm{Nm}$

Sensitivity for torque measurement

$+/-0.1 \mathrm{Nm}$

Max. axial thrust downwards

$50,000 \mathrm{~N}$

Max. axial thrust upwards

$10,000 \mathrm{~N}$

Max. radial force(reduced to the middle of the journal)

$15,000 \mathrm{~N}$

Operating speed

$1,500 \mathrm{rpm}$

Max. speed

$2,500 \mathrm{rpm}$

Direction of rotation

Both

Connection for pressurized oil

Working pressure

30 bar

Max. rate of flow

$27 \mathrm{I} / \mathrm{min}(\mathrm{nM}=1700)$

Viscosity of the oil

$100 \mathrm{~mm} 2 / \mathrm{sec} / 40^{\circ} \mathrm{C}$

Oil working temperature

$30-40{ }^{\circ} \mathrm{C}$

Connection for the water

Max. water run in

$3 \mathrm{I} / \mathrm{min}$

Max. water run out

$20 \mathrm{l} / \mathrm{min}$

\section{Hydrostatic Support For Dynamometer Base}

The main parts of the "dynamometer base" are:

- The hydrostatic bearing of the dynamometer (supporting 4 tons)

- The nearly torque free electrical supply via a special "terminal box"

- The lever arm for transmitting the reaction torque via a steel strap to the "measuring system"

An oil-supply unit with a working pressure of approximately 30 bar must be connected to the oildistributor, which is welded to the base plate. 
The oil distributor has eight pipes which lead the oil to the "axial-radial bearing ring" (four connections to the axial bearing pockets and four to the axial-radial bearing pockets).

For the right functions of the hydrostatic bearing, the pressure in the pockets must be lower than the working pressure (approximately the half value).

Therefore, throttles were screwed into the eight bores behind the feeding pipe. The pocket pressures are shown at the pressure gauges. The oil leakage back to the oil-supply unit enters a collecting pipe throughout the base frame.

Technical Data:

Max. torque

Max. dynamometer weight

Lever arm length

Accuracy of lever arm length

Sensitivity for torque measurement

Direction of rotation

Oil working pressure

Max. oil flow rate

Viscosity of the oil

Oil working temperature

$3,000 \mathrm{Nm}$
$40 \mathrm{kN}$
$1800.032 \mathrm{~mm}$
$+/-0.05 \mathrm{~mm}$
$+/-0.1 \mathrm{Nm}$
Both
$30 \mathrm{Bar}$
$30 \mathrm{l} / \mathrm{min}$
$100 \mathrm{Mm} / \mathrm{sec} / 40^{\circ} \mathrm{C}$
$30{ }^{\circ} \mathrm{C}$

Reaction Force Measuring System

The system consists of four (4) major components:

- Hydrostatic deflection rollers

- Suppression weight

- Load cells

- Crank gear

Throttles positioned at the inlet of the six bearing pockets in the two conical bearing bodies divide the oil, coming from the oil supply, approximately in half. The supply pressure of approximately 30 bar is the same as the supply pressure of the dynamometer base.

For measuring the reaction torque at the lever arm of the dynamometer base, a steel strap has to transmit the force to the load cells via the deflection roller.

For stretching the steel strap, with a force of about $250 \mathrm{~N}$, a second deflection roller is mounted on the opposite side of the frame to carry the counterweight pan. 
This pan is also needed to add additional calibrated masses to measure negative torque (i.e. runaway speed measurement) or for calibration of the load cells.

The counterweight pan and the casing, with the suppression masses, can be mounted on both sides of the frame in accordance to the direction of rotation of the model turbine or pump turbine.

For reaching a very high accuracy of the measurement, the range of the load cells is chosen relatively small (load cell range minus counterweight = approximately $750 \mathrm{~N}$ ).

A rubber compensator is mounted between the load cells and the suppression masses box as a shock absorber.

$\begin{array}{ll}\text { Technical data: } & \\ \text { Min. load } & -25 \mathrm{~kg} \\ \text { Max. load } & 75 \mathrm{~kg} \\ \text { Load cells } & 2100 \mathrm{~kg} \\ \text { Suppression weights } & 215 \mathrm{~kg} \\ & 430 \mathrm{~kg} \\ \text { Max. load with suppression weights and load cell } & 2,250 \mathrm{~N} \\ \text { Max. torque with 1800.032 mm lever arm } & 4,050 \mathrm{Nm} \\ \text { Accuracy of suppression weight } & 0.005 \% \\ \text { Accuracy of load cell } & 0.02 \% \text { of full scale } \\ \text { Crank gear oscillator } & 60 \mathrm{rpm}\end{array}$

600 Hp, D.C. Dynamometer

The 600 HP, D.C. dynamometer consists of a vertical, flange-mounted DC motor and solid state controller. It has four-quadrant capability in either CW or CCW rotation, with a speed range of 0 to $2000 \mathrm{rpm}$. Speed regulation is $0.01 \%$.

\section{Error Analysis}

In all measurements, a difference exists between the measured value and the actual value as defined by a standard such as the National Institute of Standards and Technology. The probable inaccuracy is the maximum expected error for a given measurement. In recent IEC Codes, this is established at 95 percent probability.

The total inaccuracy in the efficiency measurement is made up of two elemental errors; systematic (bias) errors, and random (precision) errors for each of the parameters going into the efficiency calculation. IEC Code recognizes these errors and the need to account for the inaccuracies in measurement in a suitable manner when comparing test results to guarantees. 
Values of $f \eta_{\eta}$

The following Table shows the IEC guideline along with values for 95 percent probability obtained from typical test measurements and calibrations of the Voith Hydro measurement systems to primary standards.

The total error is summarized in Table 4-3

Table 4-3

Inaccuracy Levels

\begin{tabular}{|l|c|c|c|}
\hline \multicolumn{1}{|c|}{ Parameter } & $\begin{array}{c}\text { IEC 60193 } \\
\text { Minimum (\%) }\end{array}$ & $\begin{array}{c}\text { IEC 60193 } \\
\text { Maximum (\%) }\end{array}$ & $\begin{array}{c}\text { Voith Hydro } \\
\text { York, USA (\%) }\end{array}$ \\
\hline Flow & 0.1 & 0.2 & 0.141 \\
\hline Head & 0.1 & 0.5 & 0.112 \\
\hline Torque & 0.15 & 0.25 & 0.116 \\
\hline Speed & 0.01 & 0.05 & 0.011 \\
\hline Random Error & 0.10 & 0.10 & 0.10 \\
\hline Efficiency & 0.23 & 0.60 & 0.24 \\
\hline
\end{tabular}

The inaccuracy band on the square root of the sum of the squares of the four major parameters measured to calculate efficiency combined with random error to yield total uncertainty in efficiency:

$$
\mathrm{f}_{\eta \mathrm{s}}= \pm \sqrt{\mathrm{f}_{\mathrm{QS}}{ }^{2}+\mathrm{f}_{\mathrm{HS}}{ }^{2}+\mathrm{f}_{\mathrm{TS}}{ }^{2}+\mathrm{f}_{\mathrm{NS}}{ }^{2}+\mathrm{f}_{\eta \mathrm{R}}{ }^{2}}
$$

Where: $f_{Q S}, f_{H S}, f_{T S}$, and $f_{N S}$ are bias errors for each respective parameter and $f_{\eta R}$ is random error at or near optimum efficiency point:

$$
f_{\eta S}= \pm \sqrt{0.141^{2}+0.112^{2}+0.116^{2}+0.011^{2}+0.100^{2}}
$$

$= \pm 0.24 \%$ 
Model Test Report

Systematic Flow Measurement Error, fos

\begin{tabular}{||l|c||}
\hline \multicolumn{1}{|c||}{ Operation } & $\mathrm{f}_{\mathrm{QS}}$ \\
\hline Primary Standard Dead Weights & \pm 0.007 \\
\hline Load Cell Calibration for Weight Tank & \pm .000 \\
\hline Fit Equation for Volume versus Elevation & \pm .080 \\
\hline Reading the Elevation $\pm 0.001 \mathrm{~m} / 3.5 \mathrm{~m}$ & \pm 0.057 \\
\hline Data Acquisition System Time \& Counting & $\pm .01 \& \pm .01$ \\
\hline Random error in calibration & \pm 0.1 \\
\hline $\mathrm{f}_{\mathrm{QS}}=\sqrt{0.007^{2}+0^{2}+0.080^{2}+0.057^{2}+0.01^{2}+0.01^{2}+0.1^{2}}$ \\
$\mathrm{f}_{\mathrm{QS}}=$ \\
\hline
\end{tabular}

Systematic Head Measurement Error, fHS

\begin{tabular}{||l|c||}
\hline \multicolumn{1}{|c||}{ Operation } & $\mathrm{f}_{\mathrm{HS}}$ \\
\hline Primary Standard (Dead Weight Tester) & \pm 0.022 \\
\hline Data Acquisition System & \pm 0.044 \\
\hline Piston Area of Dead Weight Tester & \pm 0.015 \\
\hline Random error in calibration & 0.1 \\
\hline $\mathrm{f}_{\mathrm{HS}}=\sqrt{0.022^{2}+0.044^{2}+0.015^{2}+0.1^{2}}$ & \\
$\mathrm{f}_{\mathrm{HS}}=$ & $\pm 0.112 \%$ \\
\hline \hline
\end{tabular}


Systematic Torque Measurement Error, fTS

\begin{tabular}{||l|c||}
\hline \multicolumn{1}{||c||}{ Operation } & $\mathrm{f}_{\mathrm{TS}}$ \\
\hline Primary Standard Dead Weights & \pm 0.005 \\
\hline Momentum Arm Measurement & \pm .020 \\
\hline Temperature Effects & \pm .033 \\
\hline Data Acquisition System & \pm .044 \\
\hline Random error in calibration & \pm 0.10 \\
\hline $\mathrm{f}_{\mathrm{TS}}=\sqrt{0.005^{2}+0.02^{2}+.033^{2}+.044^{2}+0.1^{2}}$ & \\
$\mathrm{f}_{\mathrm{TS}}=$ & $\pm 0.116 \%$ \\
\hline
\end{tabular}

Systematic Speed Measurement Error, fNS

Speed is by far the easiest measurement to make involved with calculating the turbine performance. A 60 teeth gear, located on the shaft, outputs 60 pulses per revolution. This is accumulated by the data acquisition system over the 20 second scan period. The estimated systematic errors are listed below:

Estimated systematic error:

Frequency counting $\pm .003 \%$ or \pm 1 count at 1500 RPM using 60 teeth gear

Time for period $\pm .01 \%$

Systematic Error:

$\mathrm{f}_{\mathrm{NS}}= \pm \sqrt{.003^{2}+.01^{2}}= \pm .011 \%$

Random Efficiency Measurement Error, $f_{n R}$

Repeated tests of our test rig, at best efficiency point, showed that the random error in efficiency at $95 \%$ confidence level is less than $0.10 \%$. 


\section{Voith Hydro}

\section{S. Morgan Smith Memorial Hydraulic Laboratory}

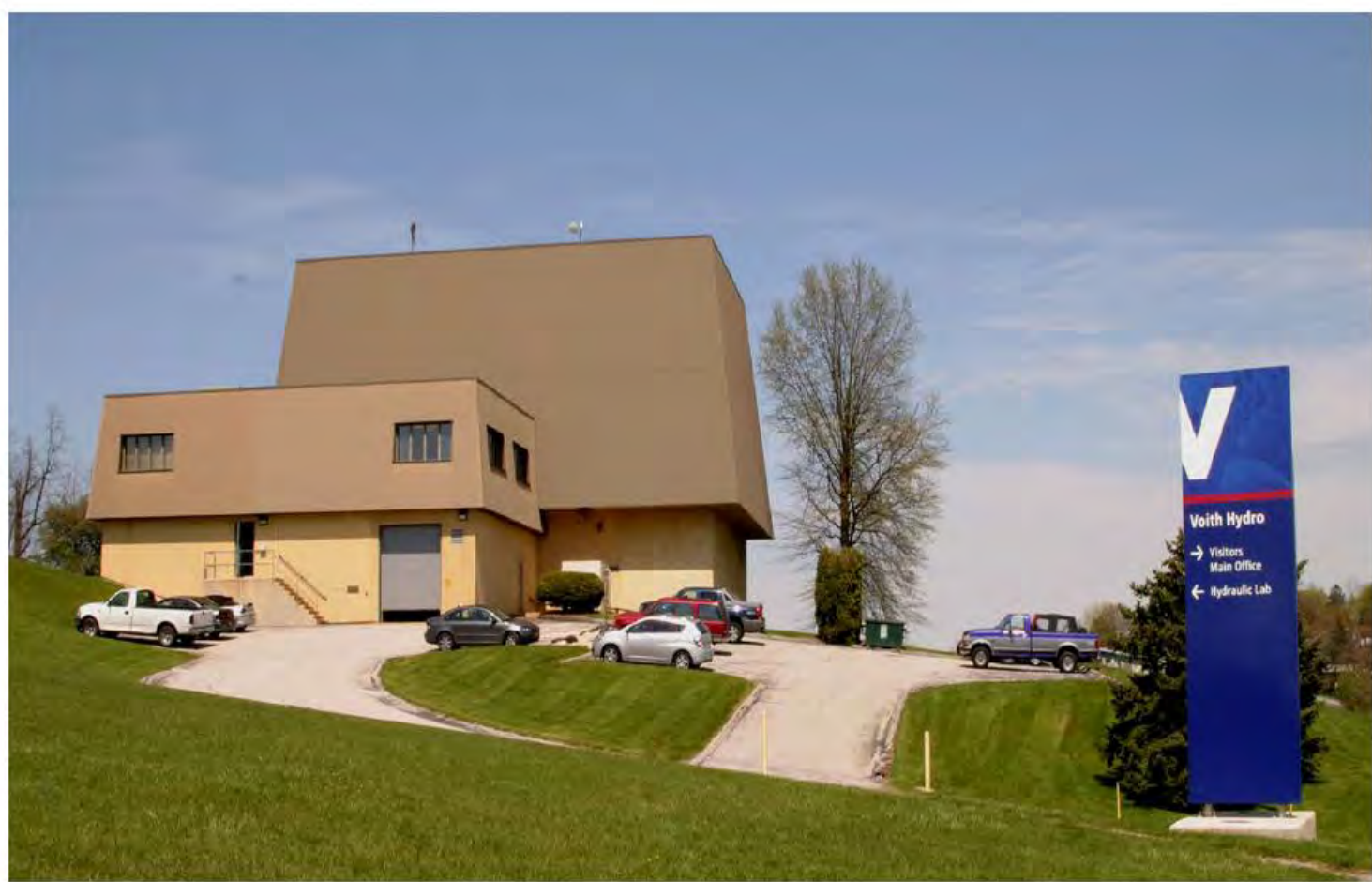

York, Pennsylvania, U.S.A. 
Model testing of hydraulic turbines began at York, Pennsylvania in 1921 with the S. Morgan Smith Company, which is now an operating unit of Voith Hydro. Prior to that time, performance testing of small prototype turbines was done at the Water Power Company of Holyoke test facility located at Holyoke, Massachusetts. The increases in business volume and requirements for frequent and more detailed testing under closer observation resulted in the commissioning of York's first "modern” hydraulic laboratory facility for performance testing of model turbines in 1921. In 1930 model testing to study the effects of design changes on turbine cavitation was begun at the nearby Holtwood Dam of the Pennsylvania Power \& Light Co. on the Susquehanna River, and by 1941 design changes had been made to the S. Morgan Smith Company Hydraulic Laboratory, to permit the study of cavitation there. Additional improvements continued to be made to that original facility to advance the state-of-the-art in model testing until it was decommissioned in 1988.

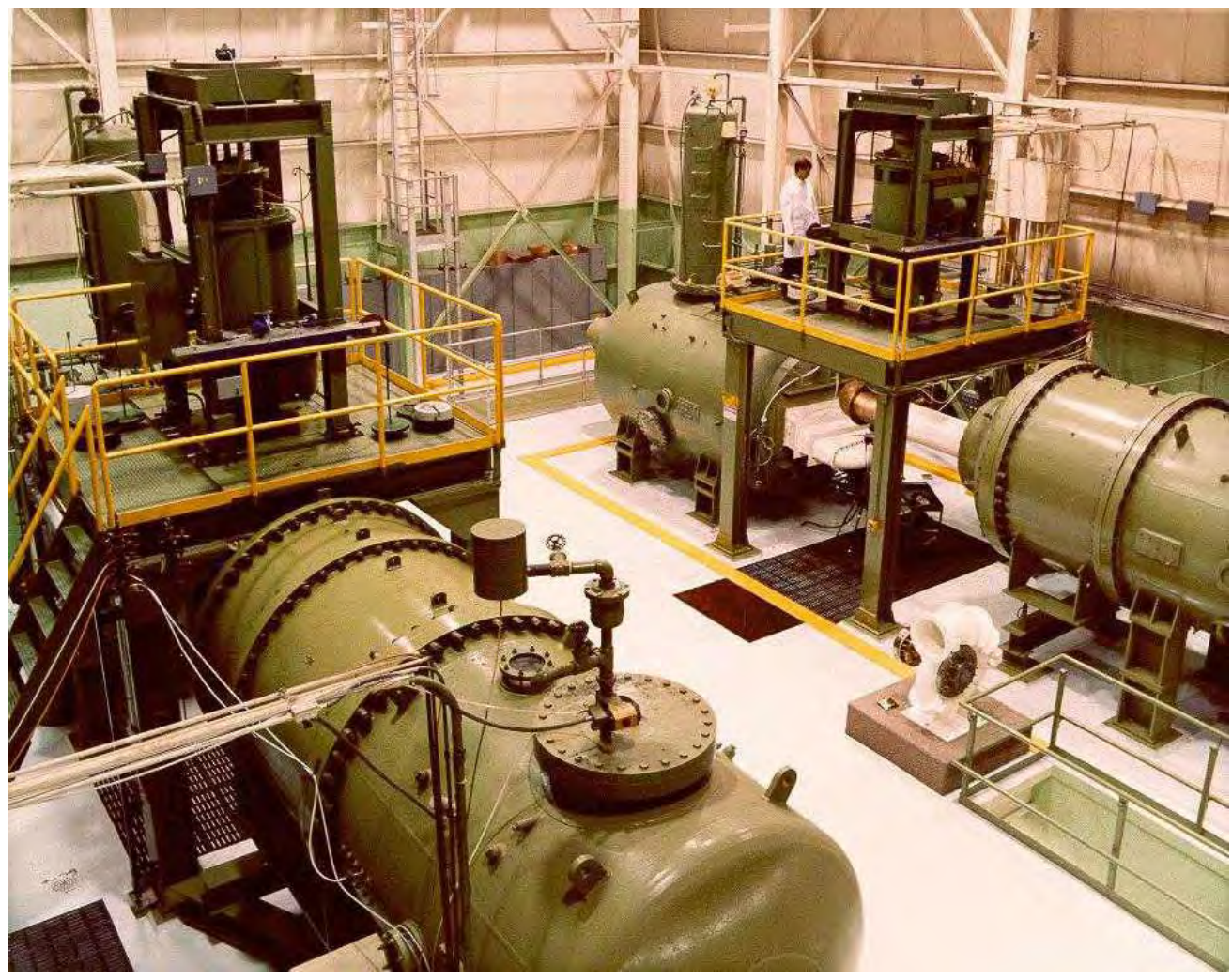

Figure 4-43

S. Morgan Smith Memorial Hydraulic Laboratory - Test Stands

In 1973, the S. Morgan Smith Memorial Hydraulic Laboratory was built in honor of the founder of the S. Morgan Smith Company which is now an operating unit of Voith Hydro. The final design of the Hydraulic Laboratory was based upon the most modern state-of the- art in test techniques, test stand operation, test equipment, electrical controls, and data acquisition systems. 


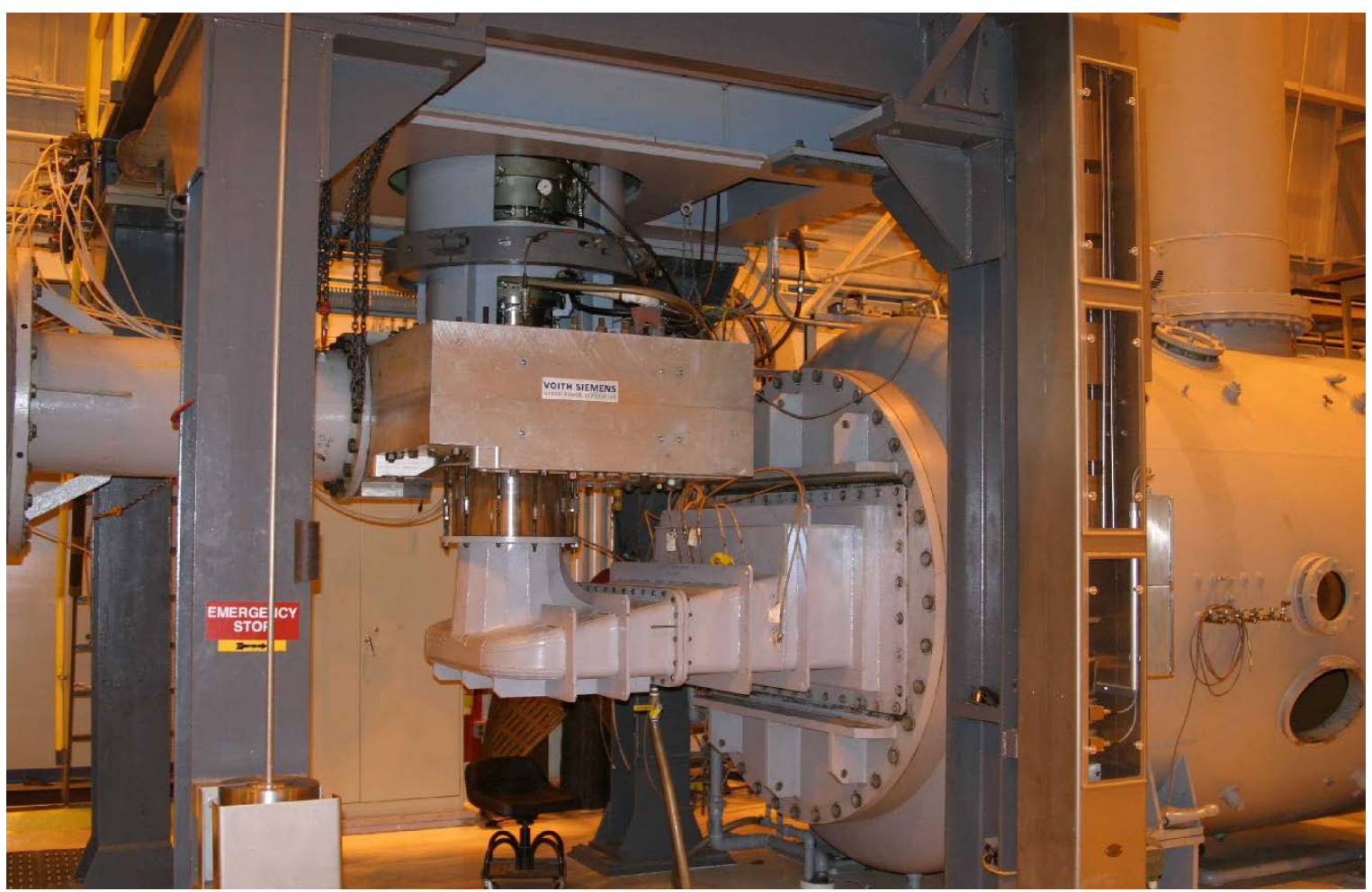

Figure 4-44

Model in Test Stand

Advancements in computers and technology allowed further upgrade to the laboratory in 1983, with the addition of a 5-axis milling machine, a 4-axis coordinate measuring machine, a new control panel and a second generation computer for the data acquisition system. Further system improvements to the controls of the dynamometers and service pumps were made in 1988. In 1994 a third generation computer was installed and in 1998, two new double suction service pumps and all valves and pipes were replaced in the pump room. New hydro-static bearings and new D.C. dynamometers were installed in 1998and 2005. A fourth generation computer was installed in 2004. These improvements greatly improved the capabilities of processing data in real time as well as post processing of data for graphic presentations of a wide variety of data. Performance data is fit and cross plotted by the computer, resulting in a more efficient, reliable and consistent presentation of data. The entire 4-quadrant pump/turbine test can be completed without shutting down at zero speed and restarting the dynamometer in the reverse direction.

\section{Operational Characteristics}

Prime requirements considered for the design and operation of the new laboratory facility were accuracy and repeatability of data obtained and ease of operation. Considerations regarding test head and model size were carefully made to arrive at a test system which would economically result in accurate prediction of prototype efficiency, cavitation, vibration, pressure surge, and general performance parameters, based on the model test results. The choices of test stand capabilities were also made so all test parameters, especially model size, test head, and Reynolds number, would meet or exceed the requirements of all official test codes for model turbine and pump/turbine testing worldwide. 
Based upon industry-wide experience with model and full-scale unit performance correlation, a remotely controllable test stand having a computerized data acquisition system was built with the capability of providing a maximum test head of $131 \mathrm{~m}$ (430 ft.) for model turbines and pump/turbines having turbine outlet diameters of not less than $0.25 \mathrm{~m}$ (10 in.) and utilizing up to $450 \mathrm{~kW}(600 \mathrm{hp})$ at speeds up to 2,000 RPM. Two service pumps supply flow rate up to 1.13 $\mathrm{m} 3 / \mathrm{s}$ (40 ft3/s) under a head of $61 \mathrm{~m}$ (200 ft.). Tests can be performed in either a closed-loop or open-loop configuration. Special effort was made in the design of the test stand to obtain a system capable of providing accurate and reliable cavitation tests over a wide range of turbine and pump/turbine designs with stable vacuum capabilities in the tail tank for visual cavitation observation.

A state-of-the-art data acquisition system, utilizing computer-controlled data sampling and processing, complements the test stand and contributes much to the accuracy and repeatability of the test results. Data are taken from the model by high-accuracy load cells, differential pressure transmitters, magnetic speed pickup, and electro-magnetic flowmeters. The data are sent to the computer and integrated. The results are printed and plotted on-line and saved in files for later analysis. Built into the test stand and data acquisition program is a system for rapid calibration of all test instrumentation.

To facilitate ease of operation and provide for rapid testing, the entire test stand can be operated from the control room, Figure 4-45. The service pumps and the dynamometer can be rotated in either direction and will operate at any fixed-speed between their minimum and maximum limits. The service pumps and tailwater pressure controller can also be placed under an alternate automatic mode where performance, cavitation and runaway speed tests can be run unattended. Additional controls are employed to maintain preset pressure and water level in the tail tank. The test circuit can be changed to any test configuration by the use of remotely-controlled valves.

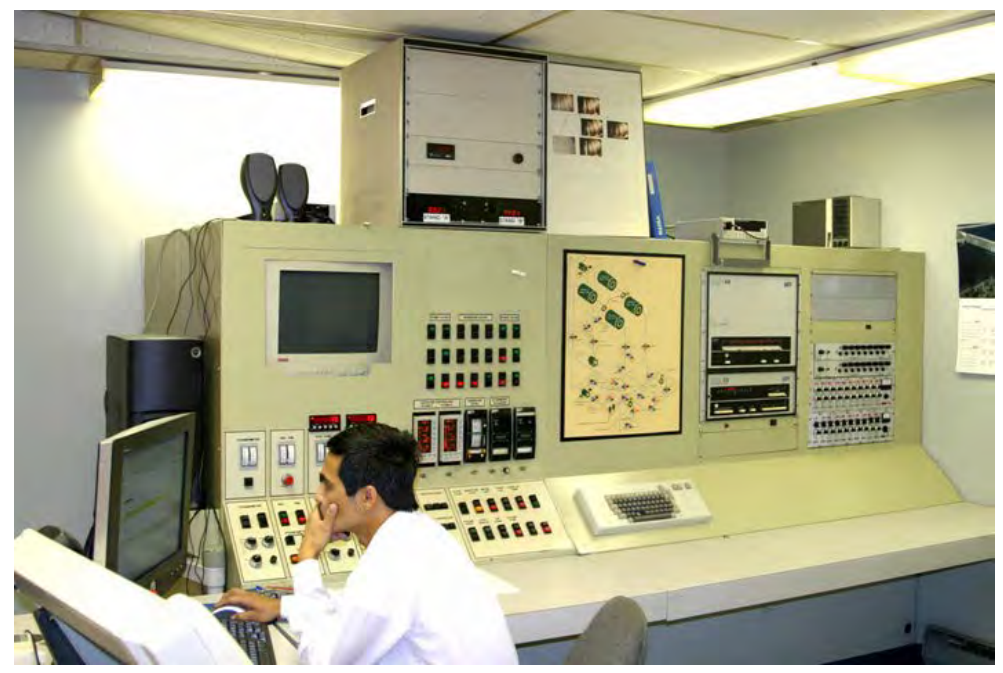

Figure 4-45

Control Room 


\section{General Arrangement of Test Laboratory}

The physical plant comprising the test laboratory is distributed over four floors. Figure 5-46 depicts a 2D elevation view of the lab. The first, or lowest, floor contains a $570 \mathrm{~m}^{3}(150,000$ gal.) reservoir to supply or store water for the test loop. The reservoir is designed to keep a minimum depth of $2 \mathrm{~m}$ (6 ft.) at the service pump intakes to insure adequate submergence of the pump suction inlets. At one end of the reservoir is a separate room containing the two service pumps and motors, and most of the piping and valves for the test circuits.

Although the second floor-level has been designed to accommodate future test stands, storage of laboratory equipment and model parts is the present use. Auxiliary equipment, including the test loop water chiller, vacuum pump, air compressors, and the drive units for the dynamometers and main pump motors are situated there.

On the third level is the model preparation area. Located there are machine tools and work areas for manufacturing, inspection, assembly, and maintenance of laboratory equipment. Both 5-axis milling machine and 4-axis coordinate measuring machine are also located on this floor. An enclosed electrical equipment room contains the main switchgear and motor-control center for the laboratory.

The fourth level contains two model test stands, instrumentation and control room, and offices. A bridge crane is used to move test stand equipment and to aid in model installation. All controls for operating and monitoring the test stand and auxiliary equipment are installed in the control room. Model test conditions are displayed and monitored in the control room.

Located at one end of the building, under the test-level offices, are a $190 \mathrm{~m}^{3}$ (50,000-gallon) volumetric basin and a control basin. The volumetric basin has a remotely-controlled drain and provisions for overflow. A flow diverter, mounted atop of the wall between the two basins, directs the water to the volumetric basin during calibration, and into the other basin at other times.

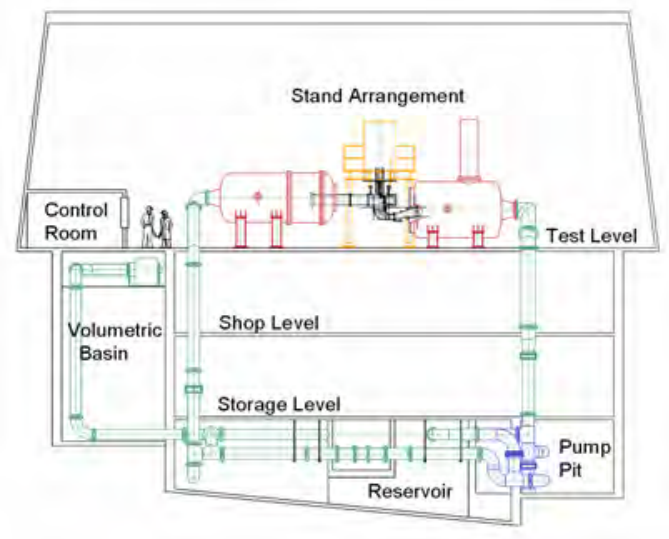

Figure 4-46

Elevation View (Schematic) 


\section{Test Circuit and Components}

The test circuit, Figure 4-47, has been specifically designed for conducting performance and cavitation tests on adequately-sized models of all types of reaction turbines, pump/turbines, and pumps at test heads which will allow accurate prediction of prototype performance based on model test results.

Piping in the test loop ranges from 0.46 to $0.56 \mathrm{~m}$ (18 to 22 inches) in diameter. Flexible pipecouplings are used in the test loop to minimize the effects of vibration and expansion/contraction and to allow rapid modifications to be made to the piping arrangement. Remotely-controlled butterfly wafer valves are used to change from one piping circuit to another.

The prominent components of the test circuit, located on the test level, are the high-pressure or head tanks, models, dynamometers, and low-pressure or tail tanks.

The head tank is designed for an internal pressure of $1380 \mathrm{kPa}(200 \mathrm{psi})$. The model end of the tank has a three-piece, triple-eccentric removable/rotatable door providing a wide range of model spiral case inlet locations without having to relocate the tank and attached piping.

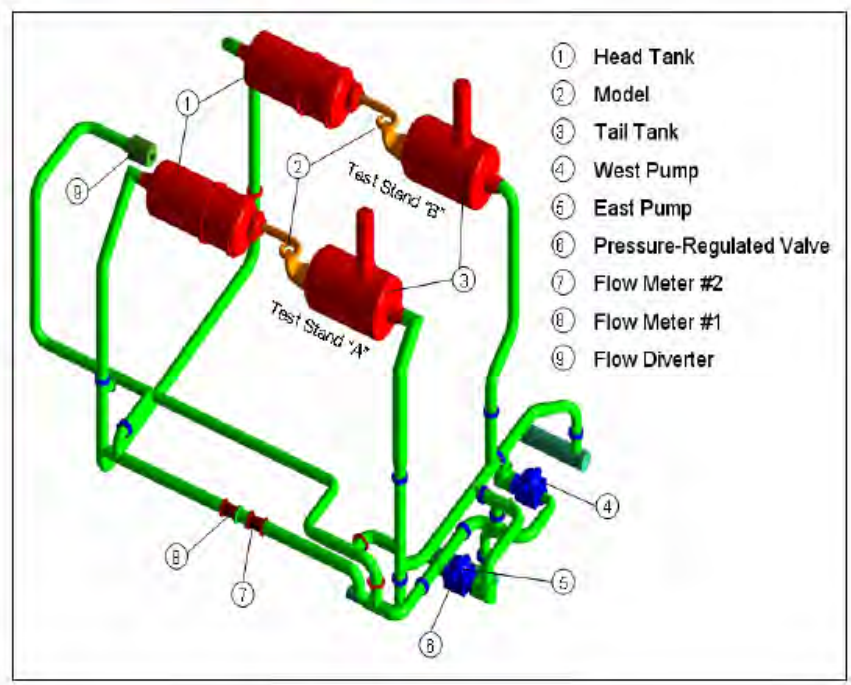

Figure 4-47

3D View of Test Circuit 


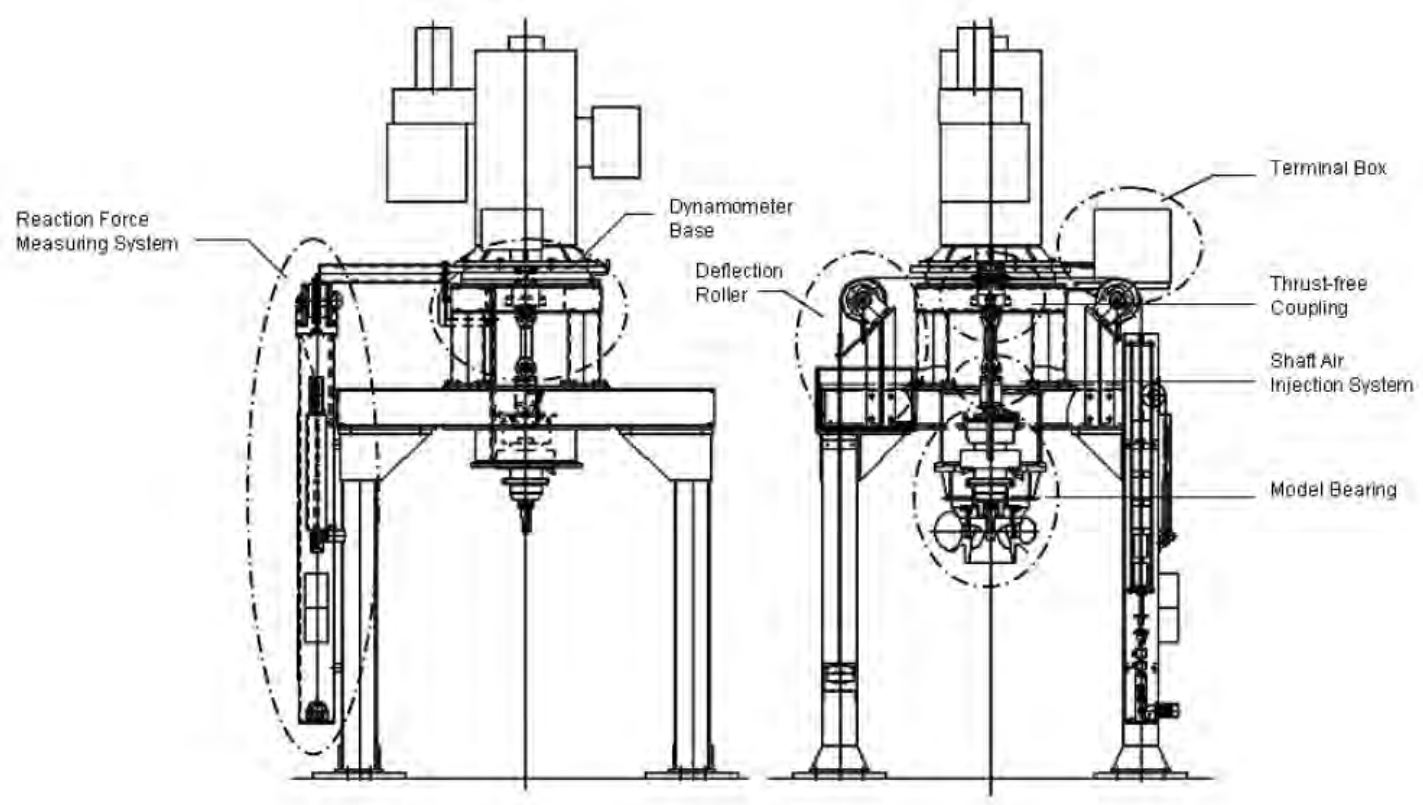

Figure 4-48

Dynamometer

The low-pressure tank is designed for an internal pressure of $345 \mathrm{kPa}$ (50 psi). The model end of the tank has a $1.7 \mathrm{~m}$ (68 inches) diameter flanged opening for insertion of draft tube at various heights without having to change the height of the tank. A perforated horizontal baffle is located in the upper section of the tank for stilling the air-water interface, and several windows are present for observation of conditions inside the tank.

The dynamometer and model are supported by a platform mounted on four high columns. This configuration allows clear access to the model for ease of assembly and disassembly and visual studies of cavitation and flow. The dynamometer frame is a sturdy weldment, which supports the vertically mounted motor/generator. The frame has accurately machined centering joints on its base for quick alignment and assembly to the model, Figure 4-48.

The $450 \mathrm{~kW}$ (600-hp) D.C. motor/generator in the dynamometer is capable of producing 3390 Nm (2500 ft.-lbs.) of torque at 1200 RPM. It can be operated as a motor or generator while rotating in either direction at speeds from 0 to 2000 RPM, see Figure 4-49. Power for the dynamometer is provided by Siemens controls. The two centrifugal service pumps, supplied by WDM, are horizontally-mounted seven-vane double-suction pumps, see Figure 4-51. They are coupled to $370 \mathrm{~kW}$ (500-hp) A.C. motor/generators capable of operating between 0 and 1200 RPM in either direction of rotation. The head and flow output of the pumps at 1200 RPM ranges from $131 \mathrm{~m}(430 \mathrm{ft})$ at $0.28 \mathrm{m3} / \mathrm{s}\left(10 \mathrm{ft}^{3} / \mathrm{s}\right)$ when operating in series, to $49 \mathrm{~m}(160 \mathrm{ft})$ at $1.6 \mathrm{~m} 3 / \mathrm{s}$ $\left(57 \mathrm{ft}^{3} / \mathrm{s}\right)$ when operating in parallel, Figure 4-50. Regulation of the pump output is normally accomplished by varying pump speed, but, in the event that additional regulation is required, a butterfly wafer valve downstream of the pump discharge can be used to develop head loss. Double suction diffusers are installed upstream of the pump inlets to assure uniform distribution of water entering the pumps. 
The dynamometer and service pumps act as a regenerative system. When the dynamometer produces power, it is delivered to the service pumps so the actual power required to operate the test stand is only that needed to make up the system losses.

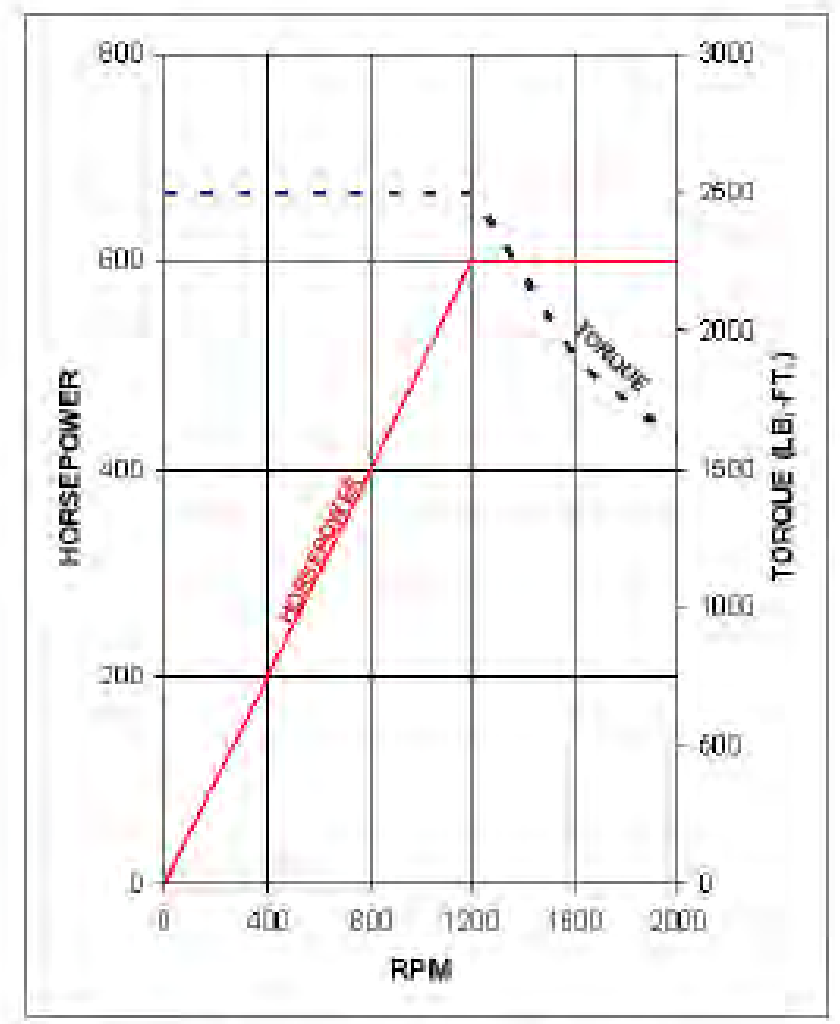

Figure 4-49

Dynamometer Performance Characteristics

The test circuit can be arranged as an open or closed loop system for flowmeter calibration, and for either turbine or pump testing. When operating for turbine testing in an open-loop system, water is drawn from the reservoir through either or both $0.91 \mathrm{~m}$ (36 in.) suction inlets to the service pumps, where it is then directed through a $0.51 \mathrm{~m}$ (20 in.) diameter pipeline and flowmeters to the head tank. From the head tank, the water flows through the turbine, giving up its hydraulic energy, and then discharges through the tailwater tank back into the reservoir.

When the test stand is operating for pump testing in the open-loop mode, the west pump draws water from the reservoir and boosts it up to the test level where it enters the low pressure tank. The model pump draws water from the tail tank and discharges it into the highpressure head tank. From the high pressure tank the water passes through the flowmeter, an energy dissipation valve, through the east pump and back into the reservoir. 


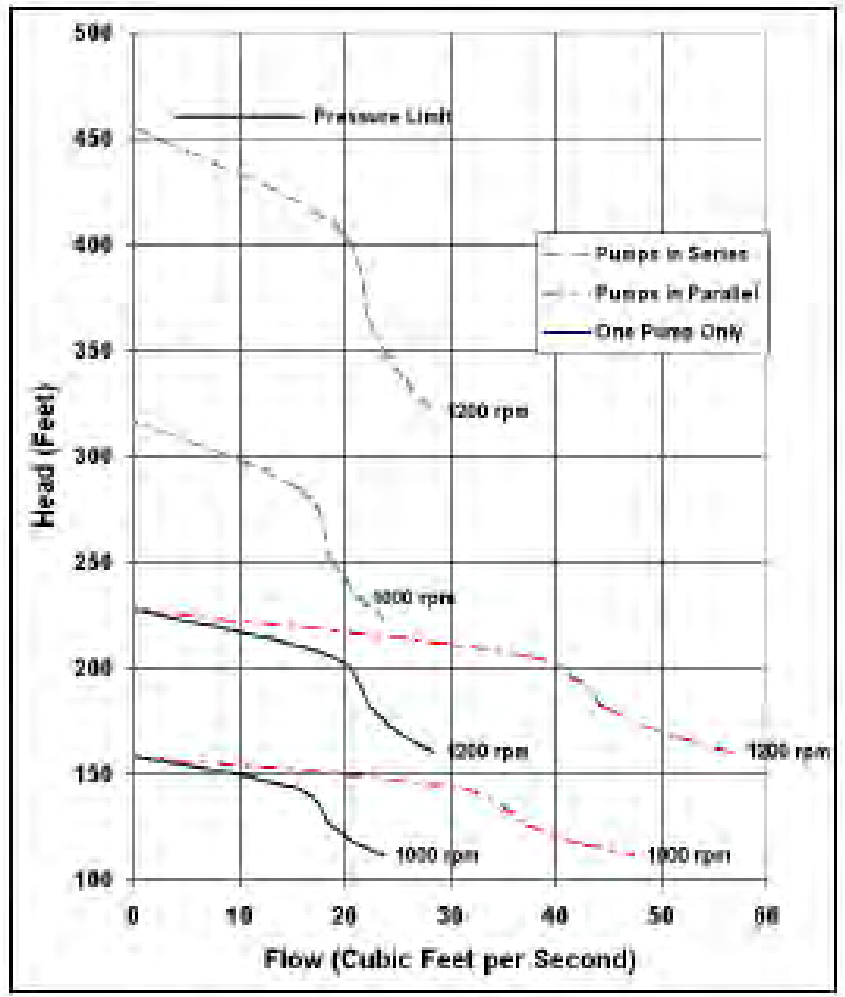

Figure 4-50

Service Pump Performance Characteristics

In the closed-loop model test configurations, the test circuit is set up as in the open-loop configurations except that the reservoir is bypassed and flow is returned to the service pumps.

The calibration circuit is also similar to the open-loop test modes of operation except that flow is directed through the flow diverter into either the control basin or the volumetric basin. The water in the volumetric basin is discharged into the reservoir following each calibration run. 


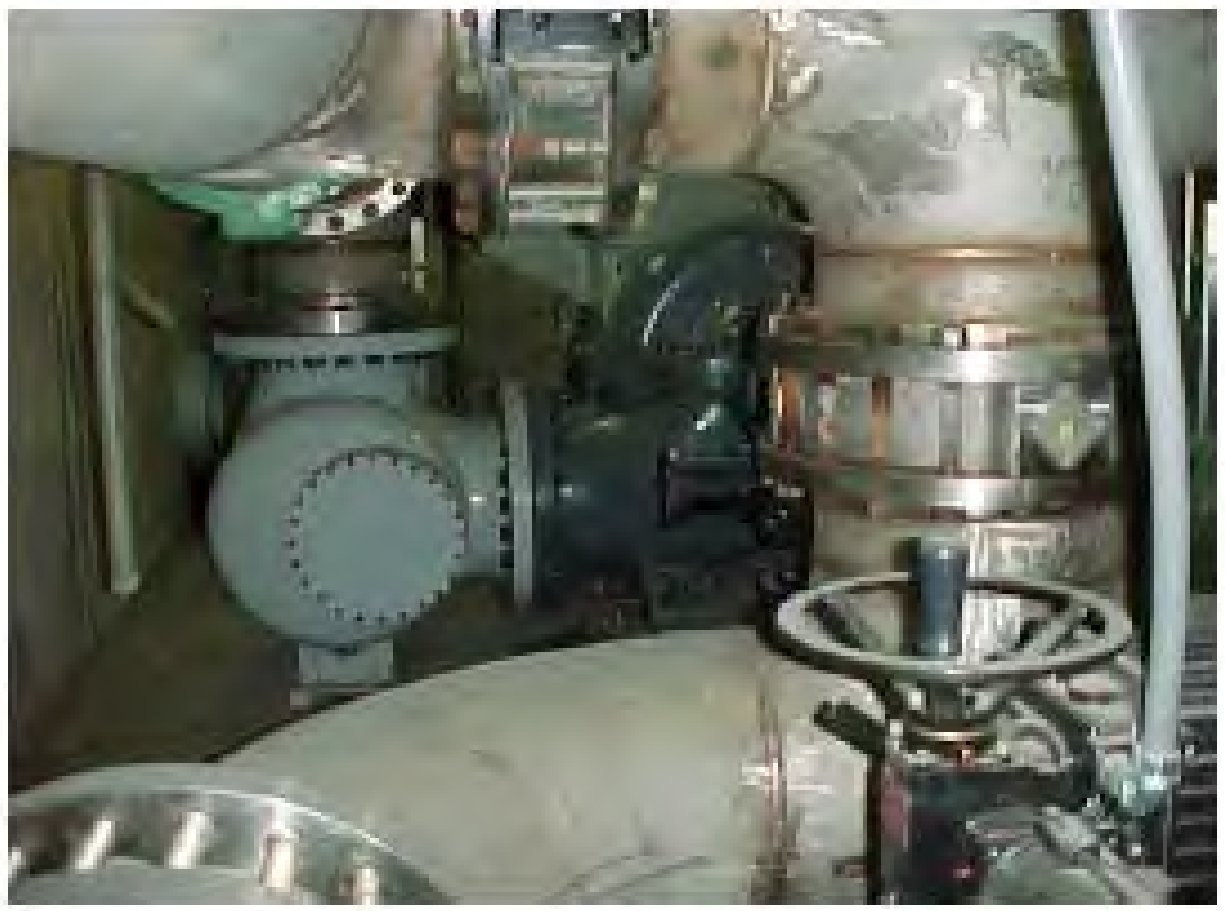

\section{Figure 4-51 \\ Pump room, First Floor}

\section{Data Acquisition System}

The feature of the hydraulic laboratory that makes it most convenient to operate is the automatic data acquisition system, Figure 4-52. The data acquisition system consists of a digital computer, signal conditioners, amplifiers and filters, 64 channel medium speed and a 32 channel high speed analog-to-digital converters, pulse counter, digital-to-analog outputs, crystal clock, TTL sensors, a twelve-parameter display, plotters, and printer, all assembled and integrated by the Hydraulic Laboratory. The system is capable of expansion to automate additional test stands or perform special hydraulic or mechanical tests involving frequency and vibration analysis, flow velocity distributions, etc.

Electrical signals from the test stand instrumentation are routed to the control room. Pulse-train signals, such as those received from the magnetic pickup to measure RPM and those from the electromagnetic flowmeter, are fed directly into the computer peripheral pulse-counter where they are counted for the desired length of time to obtain integration. The computer records time from a crystal clock. Analog signals are sent to the Neff analog-to-digital (A/D) converters where they are further amplified or attenuated and filtered as desired, and then converted to digital information.

One A/D converter has a 32 channel capability with potential expansion to 256 channels. Each channel has an analog output, which operates in parallel to the computer-bound signal, to provide a signal for monitoring with recorders or oscilloscopes. The A/D converter can sample up to 20,000 points per second. 
For very fast sampling rate, a separate dedicated 32- channel high-speed A/D converter is used. Locally stored data onboard memory chip located on the A/D card allows recording at an aggregate rate from dc to $250 \mathrm{kHz}$ for each channel simultaneously. Each channel includes 12 programmable gain steps and a low-pass Bessel filter with 4 program selectable cutoff frequencies. This converter is used to sample dynamic data such as pressure pulsation, shaft torque fluctuation, gate and blade torque, etc.

Following the raw data acquisition and digital integration, the integrated data are substituted into the appropriate equations to obtain processed test results. The desired output is then displayed on the test stand monitor, printed, plotted on an X-Y plotter, and saved on magnetic disk for future analysis. The data obtained from the test stand can be processed in seven basic modes:

In the "data scan" mode, the system takes data, processes them and updates the test stand status display panel where the characteristics of the model are indicated once each second.

In the "data acquisition" mode, the system integrates data over a period of 20 seconds by taking 1000 sequential readings across all data channels. It then prints, plots, and displays the test point results.

In the "automatic test" mode, the Digital-to- Analog converter controls the low pressure tank pressure and/or the service pump speeds to achieve the desired hydraulic condition. This is followed by the "data acquisition" mode.

In the "calibration" mode, the test technicians, conducts a series of calibration checks of all of the data-gathering transducers.

In the "diagnostic" mode, technicians can integrate status of A/D and D/A converters, TTL, crystal clock, and pulse counter for quality control and troubleshooting.

In the "post processing” mode, additional plots, prints, and files may be generated from stored data.

In the "utilities" mode, one can perform data management and a number of special purpose data-processing programs.

The seven operational modes of the data acquisition system are all contained in a single menudriven computer program through which the test operator can select any of the seven basic modes. 


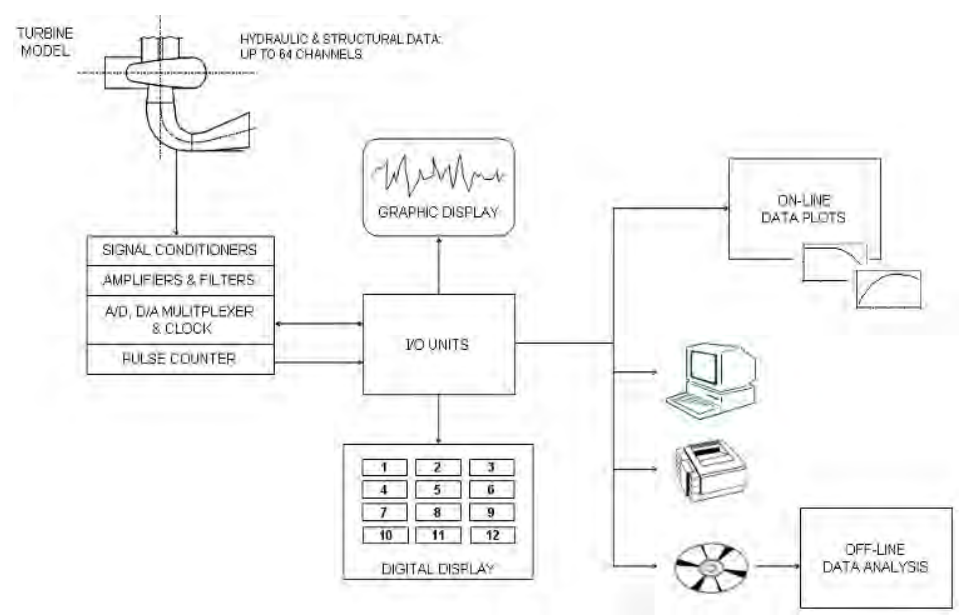

Figure 4-52

Data Acquisition System

\section{Test Stand Instrumentation}

To determine the model performance of a turbo-machine, five major parameters must be measured. They are: head, tailwater pressure, flow, torque, and the rotational speed. Air and water temperatures are also measured. In addition, the thrust exerted by the runner is measured to complement the picture of behavior. Extreme care must be taken in measuring model performance in order to obtain a high degree of accuracy and repeatability. This is accomplished by means of transducers that are among the best and most accurate available. The following section examines these transducers, giving particular emphasis to the ones that measure the five major parameters. It discusses their advantages, calibrations, and their displayed repeatability.

\section{Flow}

The flow in the test circuit is measured by two twenty-inch diameter, Asea Brown Boveri (formerly Fischer \& Porter) electromagnetic flowmeters, Model No. 10D1435, with Model No. 50PZ1000 Series Electronics. They are designed to measure flow in both directions up to 1.7 $\mathrm{m} 3 / \mathrm{s}\left(60 \mathrm{ft}^{3} / \mathrm{s}\right)$.

The flow-meter operates according to Faraday's Law of Induction, which states that the voltage induced in a conductor moving at right angles through a magnetic field is proportional to the velocity of the conductor through that field, Figure 4-53. The magnetic field is created by electromagnets. The water flowing through the meter serves as the conductor. The induced electromotive force is measured between two electrodes placed at ends of an axis perpendicular to both the velocity of liquid and the lines of magnetic flux. The potential sensed between the two electrodes is transmitted to a signal processor, which emits a pulse-train signal with a pulse rate proportional to the flow. This pulse signal is interfaced directly into the computer.

The basic advantages of this flowmeter are that:

There are no obstructions placed in the pipeline.

Flow can be measured in either direction. 
The meter generates an electrical output signal proportional to flow rate.

Note: Moreover, it is claimed by the manufacturer that metering accuracy is not affected by turbulence, changes in the patterns of flow velocity distribution, viscosity, or conductivity; reliable readings are obtained as long as the pipe is full. However, "in situ" calibrations make reliance on such claims unnecessary.

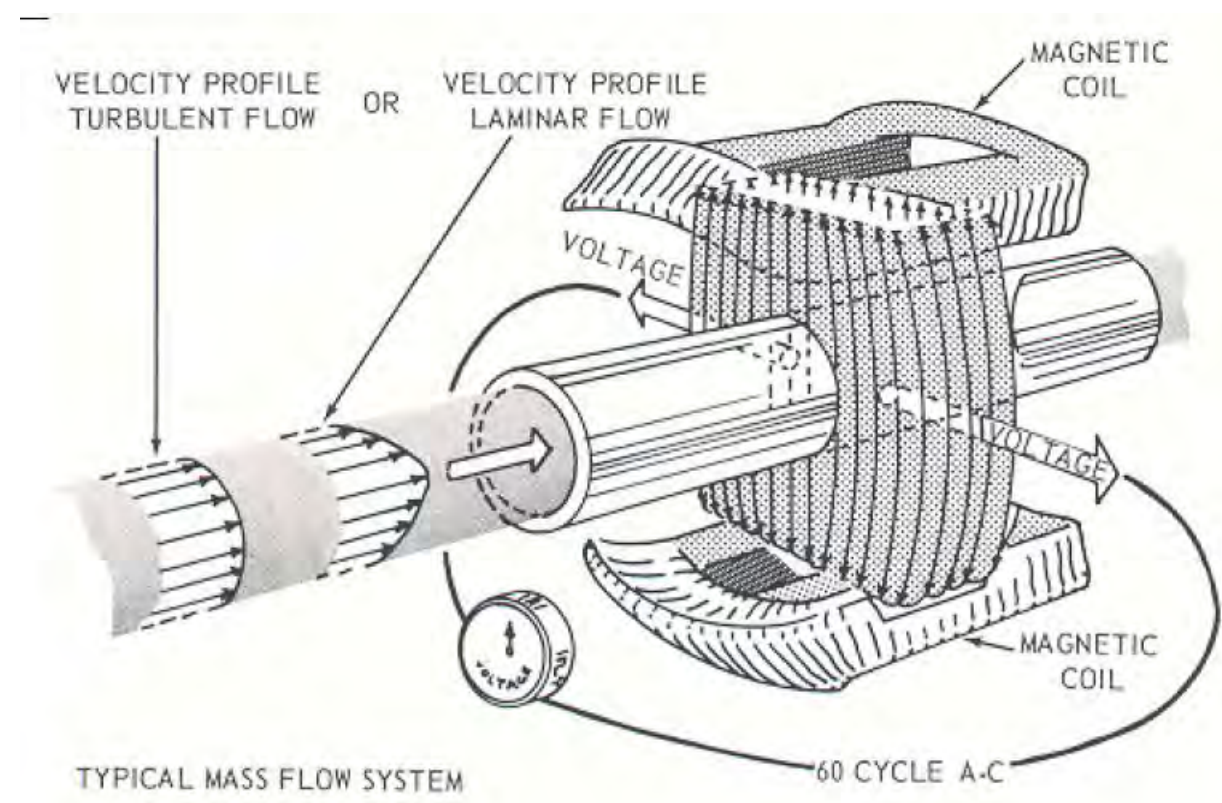

Figure 4-53

Operating Principle of Electromagnetic Flowmeter

The flowmeters are calibrated "in situ" against a $190 \mathrm{~m} 3$ (50,000 gal.) volumetric tank. The tank itself is calibrated by a $1,400 \mathrm{~kg}(3,000-\mathrm{lb}$.) capacity weigh tank. The weigh tank is used to weigh the water as the volumetric tank is filled, using a load cell, which was calibrated using a set of dead weights. These dead weights have been compared with the standards of the Bureau of Standard Weights and Measures, Commonwealth of Pennsylvania. All of these calibrations include temperature corrections.

The flowmeter calibration procedure begins by pumping water from the reservoir through the flowmeters and into the level control basin until the flow rate has stabilized. The flow diverter is then swung over to the volumetric tank. As the diverter passes midway through its stroke, a clock in the computer starts accumulating time and a counter in the computer starts counting the pulses from the flowmeter. When the volumetric tank is full (from one to fifteen minutes, depending on the flow rate), the diverter is switched back to the level control basin. At midpoint of the returning diverter stroke, the clock and the pulse counter are stopped. After the water surface has settled, the change in the height of water in the volumetric tank is measured by a $5.3 \mathrm{~m}$ water manometer. From the volumetric tank calibration curve, the volume is calculated and then divided by the time from the computer to obtain the actual flow rate. The measured flow rate is then obtained by dividing the accumulated pulses by the actual time, and the two flow rates are compared. This calibration is performed once every month, Figure 4-54. 


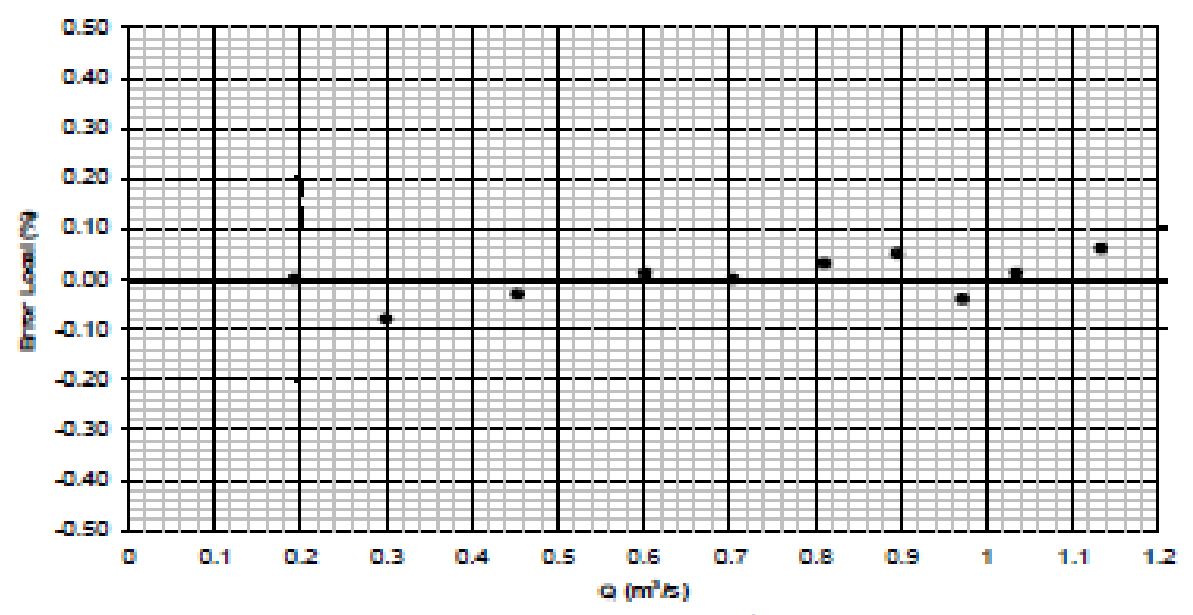

Fig. 12 - Typical Flow Calloration

Figure 4-54

Typical Flow Calibration

The flow through the test loop at the time of testing can also be measured directly by using the volumetric tank. This method of measuring flow is rarely used because of the length of time required to complete a test point.

b). Torque

Torque produced by the model is calculated from the forces applied on the load cells and the moment arm. The computer measures the change in load from the two cells and calculates the torque.

For measuring the reaction torque, the dynamometer is supported by a hydrostatic bearing and connected to two load cells in series via a lever arm and a steel strip. One cell is for efficiency calculation and the other is for backup and quality control. The horizontal force of the steel strip is changed to the vertical direction by using two hydrostatic pulleys.

One end is needed for the counterweight or for calibration of the load cells with masses, while the other end is connected to the load cells and the suppression masses. To reduce the friction of the hydrostatic bearings, the measuring device can be kept oscillated by a crank gear.

The friction torque of the model bearing is transmitted to the dynamometer by a connecting rod.

For reaching a very high degree of accuracy, the range of the load cells is chosen relatively small. If the maximum range of the load cells is nearly reached, calibrated suppression masses must be lowered on the weight box by using an electro-mechanical feeder.

A special terminal box, consisting of a static and pendulum part, is mounted for supplying the current to the dynamometer with low torque. The HBM load cells, Model No. Z3H3/1kN with a full load capacity of $100 \mathrm{~kg}$ (225 lbs), exhibit the following advantages:

1) Error ( $< \pm 0.018 \%)$, hysteresis $(< \pm 0.018 \%)$, and repeatability $(< \pm 0.01 \%)$ are excellent. 
2) Torque can be measured in either direction.

3) They generate an analog output signal proportional to load.

Note: Moreover, it is claimed by the manufacturer that they exhibit true linearity and have longtime stability and fatigue life, thermal stability, and barometric compensation. However, "in situ” calibrations on a regular periodic basis make reliance on such claims unnecessary.

The load cells are calibrated and checked for linearity and hysteresis once every fifteen days, see Figure 4-55. The standard used for these calibrations is a set of weights, which are accurate to $\pm 0.005 \%$. These weights are compared once every two years with the standards of the Bureau of Weights and Measures, Commonwealth of Pennsylvania.

An additional error, the uncertainty on the length of the dynamometer arm, is encountered when measuring torques. This error can be broken up into two parts, first a length measurement error of $\pm 0.02 \%$, and secondly, a thermal elongation of up to $\pm 0.033 \%$ due to temperature variation. The hydrostatic bearings and torque measuring system are supplied by Aströ.

c) Differential Pressure Head

The differential pressure head across the model is normally measured by two differential pressure transmitters. A 3.8m (150 inches) mercury manometer can also be used as an alternate instrument.

The transmitters are made by Rosemount, Model 3051C, with guaranteed accuracy of $\pm 0.05 \%$ of span. Increased range ability (100:1) provides optimum application.

The basic advantages of this method of measuring differential pressure head are that it has:

1) An electrical output signal proportional to the difference in pressure and having good resolution.

2) An electrical output signal independent of static pressure, which is very important during cavitation and runaway speed testing.

Note: Moreover, it is claimed by the manufacturer that these transmitters exhibit true linearity and have longtime stability, a very small thermal shift, and have negligible vibration effect. However, "in situ” calibrations on a regular periodic basis make reliance on such claims unnecessary.

The transmitters are calibrated against a 3.8m (150 in.) mercury manometer or a dead weight tester, manufactured by Pressurements Ltd. Calibrations of the transmitters, against the primary laboratory standard, are made once every fifteen days, see Figure 4-56. 


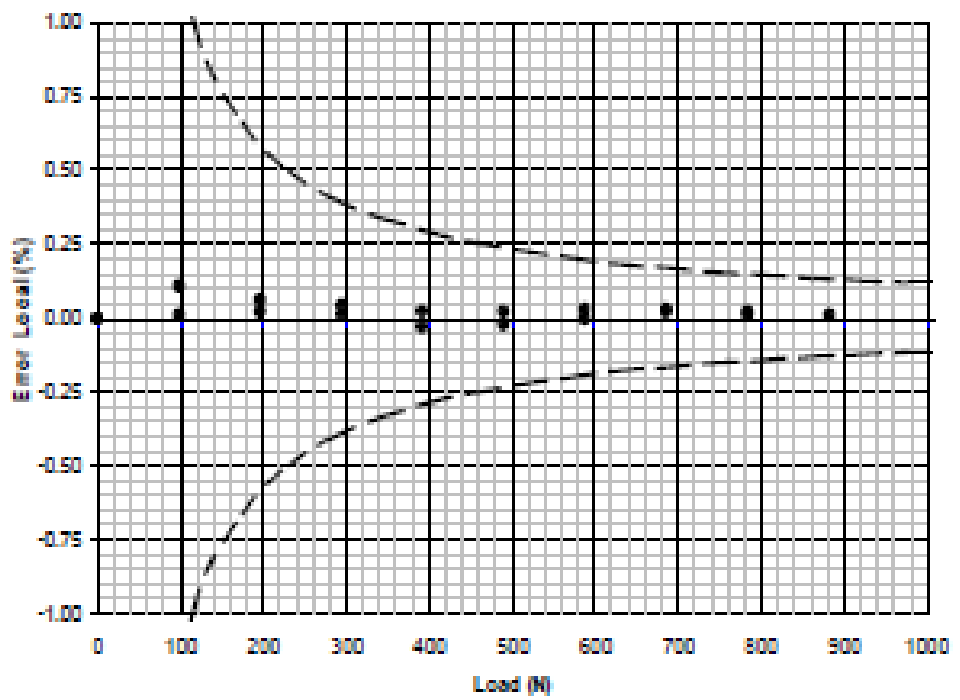

Figure 4-55

Typical Load Calibration

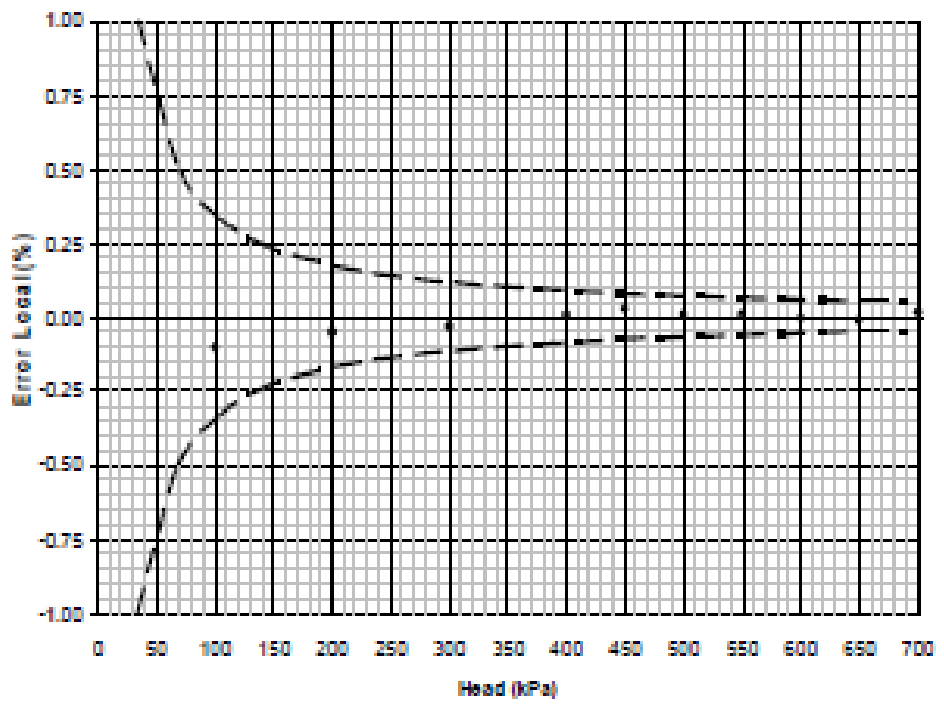

Figure 4-56

Typical Differential Pressure Head Calibration

d) Suction Head

Tailwater pressure is an important parameter when observing the cavitation performance of a turbo-machine. This measurement is normally made by the use of a Rosemount absolute pressure transmitter, model 3051CA. A back-up measurement can be made using a mercury manometer.

The advantages of this transmitter are that it has:

1. A negligible response to vibration. 
2. Good repeatability.

3. Negligible hysteresis effects.

4. Excellent stability.

The primary standard for calibration of this transmitter is a well-type mercury manometer. Calibration against the primary standard takes place once every fifteen days, see Figure 4-57.

e) Speed (RPM)

The rotational speed of the model is measured by an Airpax magnetic pick-up Model No. 40002. The pickup counts teeth on a sixty-tooth gear, which is attached to the dynamometer shaft. It is equipped with its own power supply that maintains a constant voltage output, regardless of the speed of the model. The pick-up is accurate to within \pm 1 count over any sampling period, which becomes a negligible error over a twenty-second data acquisition period.

\section{f) Hydraulic Thrust}

The hydraulic thrust on the runner is acquired by measuring the difference of the oil pressures of the upper and lower oil chambers of the cradle mounted hydrostatic bearing. The transmitter used is a Rosemount, Model 3051C, which is the same model as differential pressure transmitter. It is calibrated once every year against the laboratory weights. This transmitter exhibits essentially the same properties as the transmitter used to measure differential head.

\section{g) Temperature}

The air and water temperatures are measured by the use of resistance temperature sensors. They are calibrated once every year. The water sensor is located in the head tank and is accurate to within \pm 0 .3o C $( \pm 0.50 \mathrm{~F})$. It is used to correct automatically for variations in water density and vapor pressure due to temperature. 


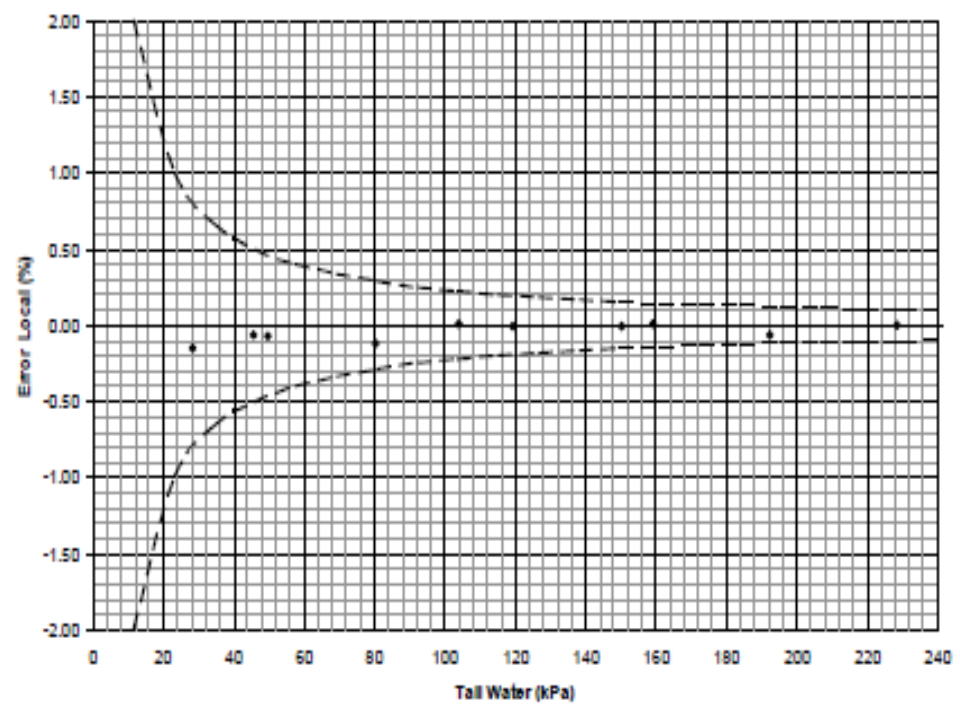

Figure 4-57

Typical Suction Head Calibration

\section{Data Reliability}

The electronic transducers and high-speed integration techniques associated with the computerized analysis of the transducer signals provide excellent data precision, yielding data points with very little scatter. However, the accuracy of the data points depends also upon the accuracy of the calibrations of the measuring instruments, i.e., transducers and amplifiers, electromagnetic flowmeter and converter, etc.

The accuracy of calibration is affected by two types of errors: random errors in the gathering of data and bias errors in the measuring methods, in the imperfect calibration standards, and in the determination of the constants (e.g., gravity, etc.). Bias error sources have been analyzed and considerable effort has been taken to eliminate significant ones. Random errors have been determined for each transducer from the results of continuing calibrations.

For a "typical" test point, the total uncertainty (or possible error) in efficiency is estimated at +/$0.20 \%$, as shown in Table 4-4 for 95\% probability. 
Model Test Report

Table 4-4

Total Estimated Error in Efficiency at 95\% Probability

TABLE 1: TOTAL ESTIMATED ERROR IN EFFICIENCY AT 95\% PROBABILITY

\begin{tabular}{|c|c|c|c|c|c|}
\hline Measurement & Flow & Head & Torque & Speed & Efficiency \\
\hline Transducers & $\begin{array}{c}\text { Electromagnetic } \\
\text { Flowmeter } \\
\text { +/- error in } \%\end{array}$ & $\begin{array}{c}\text { Differential } \\
\text { Head } \\
\text { transmitter } \\
+/ \text { - error in \% }\end{array}$ & $\begin{array}{c}\text { Load } \\
\text { Cell } \\
+/ \text { - error in \% }\end{array}$ & $\begin{array}{c}\text { Magnetic } \\
\text { Pick-Up } \\
+/ \text { - error in \% }\end{array}$ & $+/$ - error in $\%$ \\
\hline Primary standard & 0.005 & 0.02 & 0.005 & & \\
\hline $\begin{array}{l}\text { Load Cell Calibration for } \\
\text { Weight Tank }\end{array}$ & 0.080 & & 0.080 & & \\
\hline \begin{tabular}{|l} 
Fit Equation for Volume \\
versus Elevation
\end{tabular} & 0.064 & & & & \\
\hline $\begin{array}{l}\text { Reading the Reservoir } \\
\text { Elevation }\end{array}$ & 0.024 & & & & \\
\hline Data Acquisition System & 0.01 & 0.088 & 0.044 & 0.010 & \\
\hline Lever Arm & & & 0.020 & & \\
\hline Temperature Effect & & & 0.033 & & \\
\hline & & & & & \\
\hline $\begin{array}{l}\text { TOTAL SYSTEMATIC } \\
\text { ERROR (RSS) }\end{array}$ & 0.106 & 0.090 & 0.099 & 0.010 & 0.171 \\
\hline TOTAL RANDOM ERROR & & & & & 0.100 \\
\hline $\begin{array}{l}\text { TOTAL COMBINED } \\
\text { ERROR (RSS) } \\
\end{array}$ & & & & & 0.20 \\
\hline
\end{tabular}

\section{Model Manufacturing and Inspection}

a) 5-Axis Machining Center

A White Sundstrand 80 Omnimil is housed in the Laboratory. This milling machine is used for manufacturing model components such as runners, wicket gates, spiral cases, etc.

The capabilities of the machine are as follows:

- Work Envelope:

X-axis $1828.8 \mathrm{~mm}$ (72”)

Y-axis $1524.0 \mathrm{~mm}(60 ”)$

Z-axis 1371.6 mm (54”)

- Table Rotation: $360^{\circ}$ (360,000 positions)

- Head Rotation: $150^{\circ}$

- Rotary table diameter: 1066.8 mm (42”) 
- Load capacity: $6000 \mathrm{~kg}(12,000 \mathrm{lbs})$

b) Inspection and Measurement

A manual 3-axis Bendix Cordax 1800 series coordinate measurement machine provides inspection capabilities. These include measurements to inspect the shape of 3-dimensional surfaces of turbine blades and pump impellers, wicket gates, stay vanes, etc.

In addition, conventional inspections such as the determination of diameters, intersection of planes, squareness, etc. can be made. The capabilities of the machine are as follows:

- Work Envelope:

X-axis 1500 mm (59.1”)

Y-axis $1000 \mathrm{~mm}(39.4 ")$

Z-axis $700 \mathrm{~mm}(27.6 ”)$

Rotary table: $360^{\circ}$,

150 kg (300 lbs) load capacity

Main table: 1,000 kg (2000 lbs)

- Machine Specifications:

Resolution 0.0025 mm (0.00010”)

Linear Accuracy 0.0070 mm (0.00028”)

Repeatability 0.0025 mm (0.00010”) 


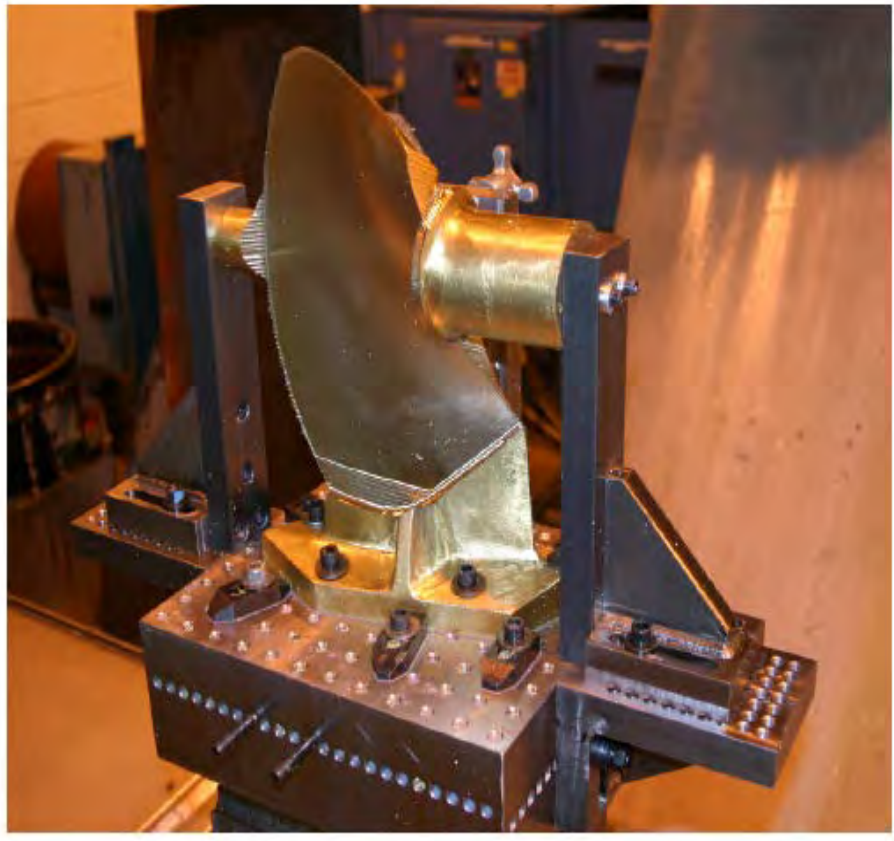

Figure 4-58

Five Axis Mill

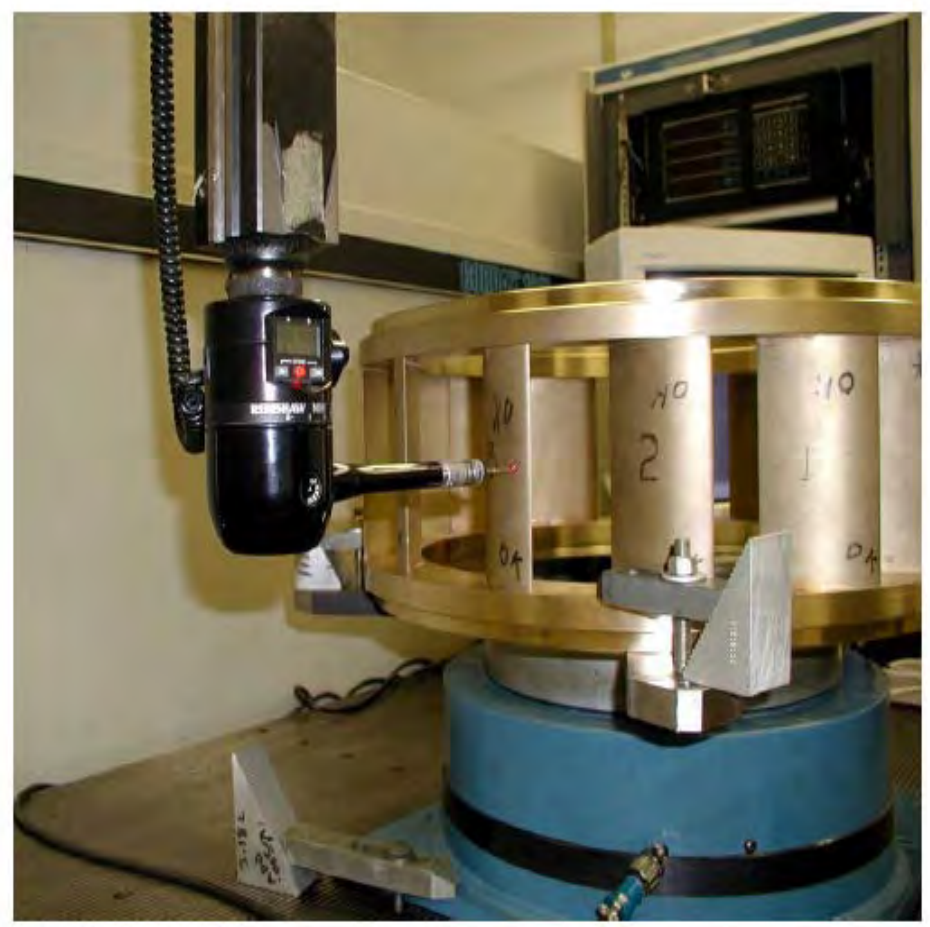

Figure 4-59

CMM 


\section{Specific Testing}

\section{Performance Testing}

Performance tests are performed over the operating range to determine a model's performance characteristics. The test data covers the expected prototype operating range with sufficient data taken above and below these levels to allow adequate definition of the operating characteristics.

Performance tests are run at fixed wicket gate position. Each wicket gate position is run across the head range by varying the speed of the service pumps while maintaining a constant rotational speed and a constant net positive suction head. Each wicket gate position is expected to consist of approximately 20 to 30 data points each resulting from a 20 second scan in which 1000 samples are taken and averaged for the performance calculations.

The units used to present performance are efficiency $(\eta \mathrm{m})$, energy coefficient $(\mathrm{E} \omega \mathrm{D})$, discharge coefficient $(\mathrm{Q} \omega \mathrm{D})$, and power coefficient $(\mathrm{P} \omega \mathrm{D})$, for the various gate rotations. These coefficients are defined as:

$$
\begin{aligned}
& \mathrm{E}_{\omega D}=\frac{\mathrm{g} \cdot \mathrm{h}}{\omega_{m}^{2} \cdot \mathrm{d}^{2}} \\
& \mathrm{Q}_{\omega \mathrm{D}}=\frac{\mathrm{q}}{\omega_{m} \cdot \mathrm{d}^{3}} \\
& \mathrm{P}_{\omega \mathrm{D}}=\frac{\mathrm{p}}{\rho_{m} \cdot \omega_{m}^{3} \cdot \mathrm{d}^{5}} \\
& \eta_{\mathrm{m}}=\frac{\mathrm{p} \cdot 100}{\rho_{m} \cdot \mathrm{g} \cdot \mathrm{h} \cdot \mathrm{q}}
\end{aligned}
$$

Where:

$$
\begin{aligned}
& \mathrm{d}=\text { Characteristic model diameter }(\mathrm{m}) \\
& \mathrm{g}=\text { Gravitational constant }\left(\mathrm{m} / \mathrm{sec}^{2}\right) \\
& \mathrm{h}=\text { Model net head }(\mathrm{m}) \\
& \omega_{\mathrm{m}}=\text { Model speed }(1 / \mathrm{sec}) \\
& \mathrm{p}=\text { Model power }(\mathrm{W}) \\
& q=\text { Model discharge }\left(\mathrm{m}^{3} / \mathrm{s}\right) \\
& \rho_{\mathrm{m}}=\text { Mass density of water }\left(\mathrm{kg} / \mathrm{m}^{3}\right)
\end{aligned}
$$


The configuration of our dynamometer allows for the recording of axial thrust with each data point. The entire motor generator to which the model runner is attached is suspended, thus any change in hydraulic thrust is directly measured. The differential pressure on the model shaft between the normally varying tailwater pressure and atmospheric pressure creates a thrust imbalance. To account for this imbalance a tailwater pressure correction is made to the measured thrust value.

\section{Cavitation Testing}

Cavitation tests are performed by setting a fixed wicket gate position and running the model at a constant net head while varying the absolute pressure in the tail tank in a closed loop test stand to vary the Thoma cavitation coefficient, sigma $(\sigma)$. The tailwater pressure is obtained from the pressure taps located on the tail tank. The draft tube cone is manufactured of transparent material permitting visual observation of the runner during testing.

The absolute pressure is lowered sufficiently to produce a drop in efficiency of at least one percent or to the limit of the test stand, which is $14 \mathrm{kPa}(2 \mathrm{psi})$. This limit allows the sigma level to be considerably less than plant sigma for testing purposes.

Sufficient data points are taken to define the values of $\sigma 0, \sigma \mathrm{s}$, and $\sigma 1$. The relationship of critical sigma to plant sigma is determined from this testing. Visual observation will be used to determine the onset of cavitation on both the entrance edge of the blades and area section of the blades and recorded as sigmabegin $\left(\sigma_{\mathrm{b}}\right)$

Data collection and sampling are identical to performance testing. Efficiency $(\sigma \mathrm{m})$, discharge $(\mathrm{Q} \omega \mathrm{D})$, power $(\mathrm{P} \omega \mathrm{D})$ versus sigma $(\sigma)$ are plotted.

The cavitation parameter used during testing is as follows:

$$
\begin{aligned}
& \sigma=\frac{\mathrm{h}_{\mathrm{b}}-\mathrm{h}_{\mathrm{v}}-\mathrm{h}_{\mathrm{s}}}{\mathrm{h}}=\frac{\mathrm{npsh}}{\mathrm{h}} \\
& \text { Where: } \\
& \mathrm{npsh}=\text { Net Positive Suction Head } \\
& \mathrm{h}_{\mathrm{b}}=\text { Barometric Pressure } \\
& \mathrm{h}_{\mathrm{v}} \quad=\text { Vapor Pressure } \\
& \mathrm{h}_{\mathrm{s}} \quad=\text { Submergence } \\
& \mathrm{h} \quad=\text { Net Head }
\end{aligned}
$$

\section{Runaway Speed Testing}

Runaway speed tests are performed by setting a selected gate position and running the model at constant speed and approximately zero torque while varying the absolute tail tank pressure in a 
closed test loop to vary the Thoma coefficient sigma. The accompanying turbine discharge and axial hydraulic thrust are also measured.

\section{Four Quadrant Testing}

This test starts in the normal pump quadrant with negative unit speed and negative unit flow. Starting at high flow rates, data are taken as the unit discharge is decreased incrementally until pump shut off head is reached as shown on Figure 4-60.

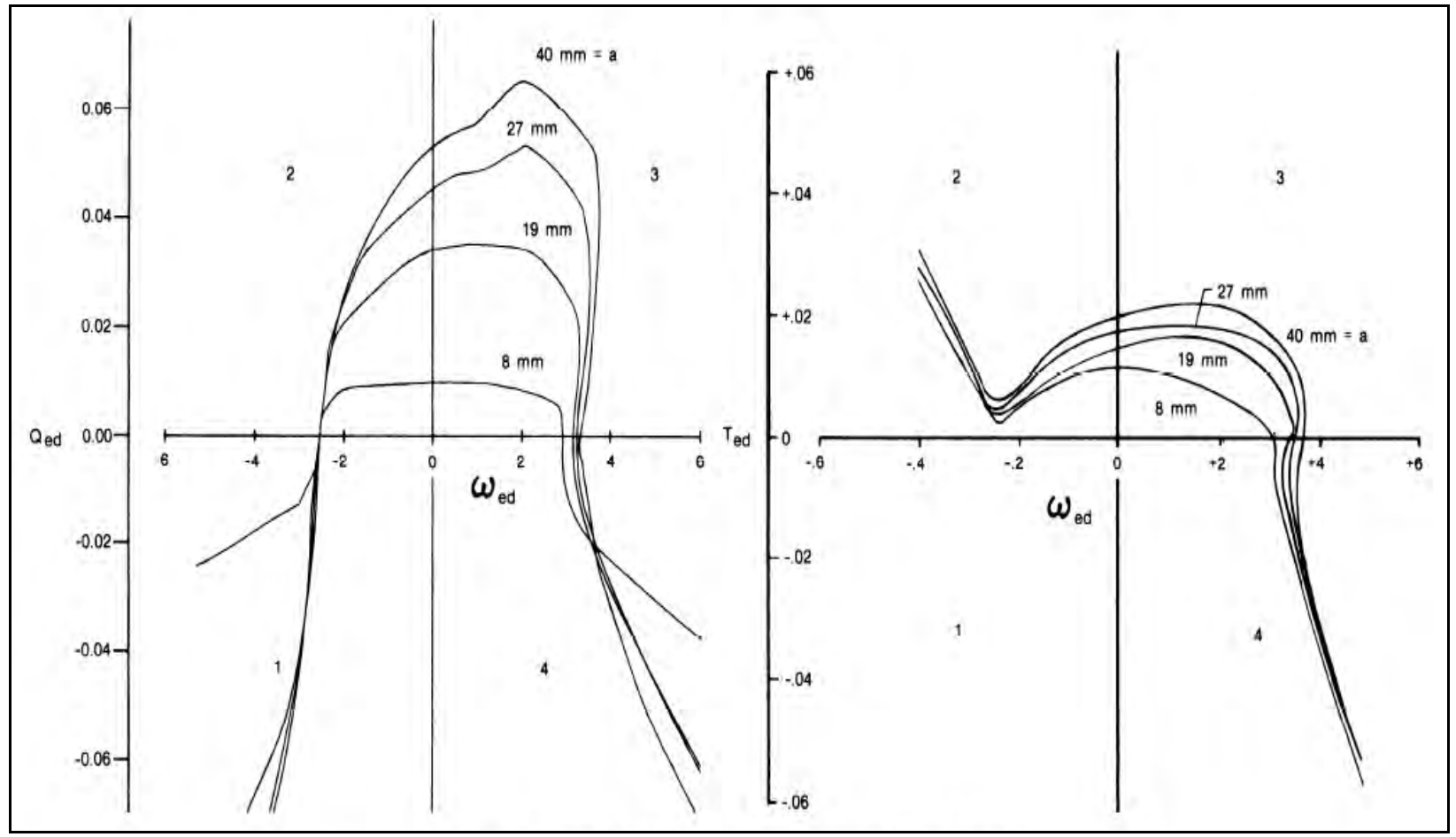

Figure 4-60

Typical Pump/Turbine Four Quadrant Characteristics

Next, the energy dissipation quadrant is tested. Like the normal pump it has negative unit speed but now the unit flow is positive. In this quadrant unit speed will be decreased until speed is zero. The unit speed changes from negative to positive while the unit flow remains positive as we enter the normal turbine quadrant. In the normal turbine quadrant the unit speed is increased until the normal turbine operating range is reached. The unit discharge is reduced to, and beyond, runaway speed until flow is zero. The final quadrant is tested in reverse pump quadrant where unit speed is positive and unit flow is negative.

\section{Pressure Pulsation Testing}

The pressure pulsations are measured by using dynamic pressure transducers flush mounted on the draft tube cone and other locations. The signal from each transducer can be low-pass filtered programmatically and measured by a high speed analog to digital converter. Digital data of the 
waveform can be saved and a Fast Fourier Transform (FFT) can be performed for frequency analysis.

\section{Wicket Gate Torque Testing}

Specially instrumented wicket gates are installed for torque testing. These instrumented gates have larger than normal gate end clearance to minimize friction. With the test stand running at constant speed and constant net positive suction head, data is gathered at various gate positions while maintaining a constant head across the model. Figure 4-61 shows a wicket gate instrumented with a strain gage for torque testing.

\section{Kaplan Turbine Blade Spindle Torque}

Instrumentation technique and calibration procedures are identical to those of wicket gate torque. These special blades are manufactured with larger trunnion clearance to minimize friction on the hub. Figure 4-62 shows a Kaplan turbine blade instrumented with a strain gage for torque testing. The blade spindle torques are measured at several blade rotations, including the minimum and maximum blade rotations.

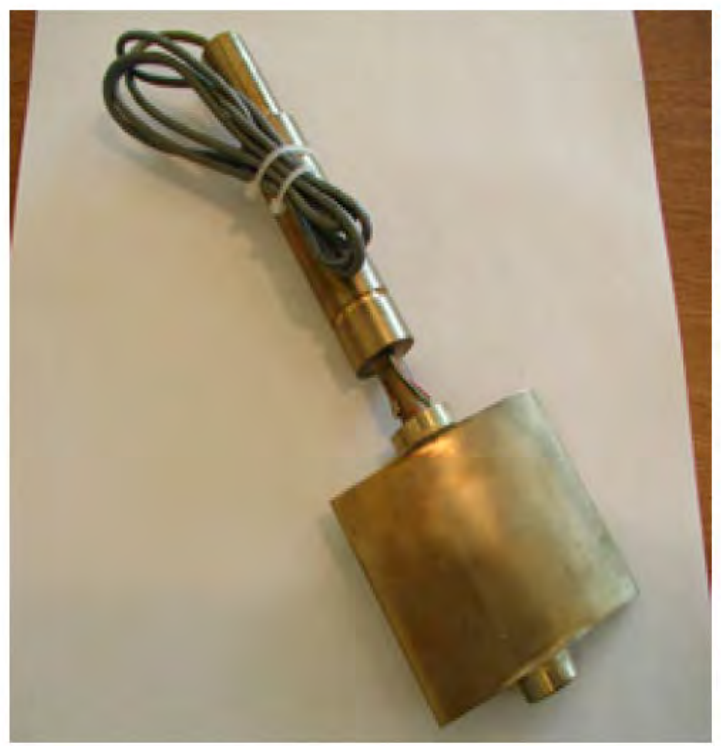

Fig. 19 - Wicket Gate Instrumented with Srain Gage for Gate Torque

Figure 4-61

Measurement

Wicket Gate Instrumented with Strain Gage for Gate Torque Measurement 


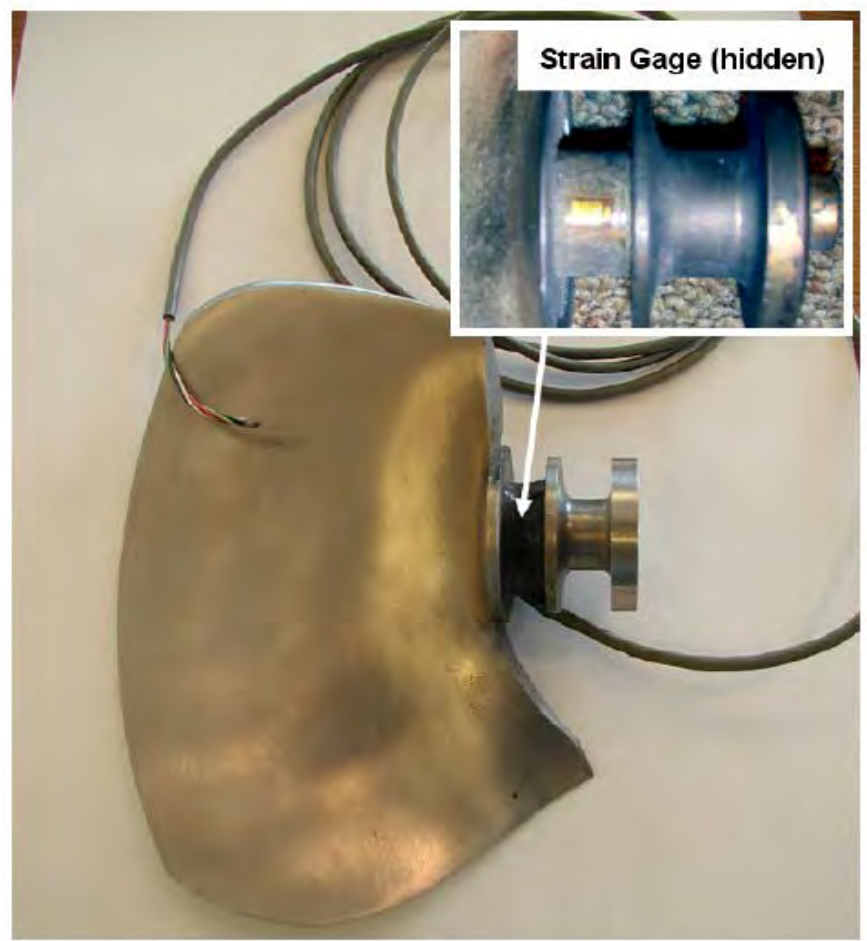

Fig. 20 - Kaplan Turbine Blade Instrumented with Strain Gage for Blade Torque Measurement

Figure 4-62

Kaplan Turbine Blade Instrumented with Strain Gage for Blade Torque Measurement 



\section{5 \\ CFD SIMULATIONS OF ALDEN TURBINE AND COMPARISON WITH PHYSICAL MODEL DATA}

\section{Introduction}

Physical model performance testing was conducted in 2010 on the Alden turbine as discussed in the previous section. The physical model included a length of the inlet penstock, the spiral case and distributor, the runner and the draft tube. These tests included determining the usual characteristics of efficiency and power versus flow and head at given gate openings. Other operating parameters were also recorded, such as axial and radial thrust, wicket gate torque, runaway speed, cavitation limits, draft tube pressure pulsations and transients. The data on efficiency and power, scaled up to prototype values, were used to compile the usual "hill chart" to visually show the best efficiency point (BEP) and the range of acceptable operating conditions.

At about the same time, Computational fluid dynamics (CFD) simulations of the entire turbine were initiated, from the penstock to the draft tube outlet and tail water. These simulations included the fluid filled spaces between the outer runner shroud and the casing, as well as between the head cover and the runner top, thereby including the same loss sources as in the physical model. The CFD simulations were conducted using FLUENT version 6.3.26. The CFD model consisted of about 19.5 million computational cells. The governing equations solved are Reynolds-Averaged Navier-Stokes (RANS) equations combined with turbulence modeling equations for three-dimensional (3D), steady-state, Newtonian, incompressible, and viscous flows without heat transfer. The shear stress transport (SST) k- $\omega$ two-equation turbulence model was used to calculate the turbulent kinetic energy $\mathrm{k}$ and its specific dissipation rate $\omega$, and $\mathrm{k}$ and

$\omega$ were used to obtain the turbulent eddy viscosity $v_{t}$. The mixing-plane approach was used to model the fluid around the rotating parts in the moving reference frame. Two mixing planes between the rotating and fixed portions of the turbine were used and profiles of each flow property were obtained by performing circumferential averages at specific axial or radial stations and these profiles were then used to update the boundary conditions at the upstream and downstream fluid zones of the mixing-plane interface. Actual field dimensions of the entire turbine were used in the simulations to avoid scale up issues. To run one operating condition, the wicket gate opening angle and runner rotating speed were fixed and the flow was independently selected, the simulation resulting in a total head across the turbine. The mechanical power out was calculated from multiplication of the runner torque caused by the pressure and viscosity forces and the shaft rotating speed, and the reported turbine efficiency was the ratio of that power to the available hydraulic power. 
Plotting the resulting efficiencies from both the physical model and the CFD simulations using non-dimensional head and flow coefficients, which included the turbine diameter and runner rotating speed, aided a direct comparison between the BEP operating conditions and maximum efficiency value. The general shape of the efficiency lines on the "hill chart" was also compared and these results are provided in herein.

\section{Numerical Model Description}

\section{Governing Equations}

It is important to determine the type of simulations to be conducted for flow in a hydraulic turbine at the beginning of the study. This determination included the following aspects:

- Which two-dimensional (2D), quasi-three-dimensional (Q3D), or full three-dimensional (3D) simulations are necessary? A 2D simulation may be used in the early design stage to obtain a typical 2D sectional blade shape. A quasi-3D simulation is actually a 2D simulation but extra source terms are added to account for acceleration and deceleration caused by rapid changing of geometry or flow boundary layers, and may be used to simulate flow with significant changes of flow path in the axial direction. The 3D complex geometry and the complicated 3D dynamic features of turbine flow do not allow a simplification to 2D or quasi-3D simulations for this study. Therefore, full 3D simulations are the only choice and were used in this study.

- Whether compressibility of the working fluid needs to be considered. All fluids are compressible to some extent. That means the changes in pressure or temperature will result in changes in fluid density. Water is the working fluid in hydraulic turbine and the changes in water density are sufficiently small to be ignored. Therefore, the flow was modeled as an incompressible fluid.

- Use of Newtonian or non-Newtonian fluid. Water is a Newtonian fluid. Its shear stress is essentially linearly related with strain by a coefficient of viscosity.

- Is the flow inviscid or viscous? In viscous flow, fluid friction has significant impacts on the fluid motion. The Reynolds number is usually used to evaluate whether viscous or inviscid equations are appropriate. Using the full scale turbine flow rate of $1500 \mathrm{cfs}$ and the inner diameter of the turbine just downstream of the runner blades of $9.88 \mathrm{ft}$, the flow Reynolds number, defined as $\operatorname{Re}=\rho U D_{H} / \mu$, in which $\mathrm{U}=$ mean velocity, $\rho=$ water density, $\mu=$ dynamic viscosity, $D_{H}=4 A / P_{W}=$ hydraulic diameter, $\mathrm{A}=$ area, $P_{W}=$ wetted perimeter, is found to be in the order of $1.8 \times 10^{7}$. This is much higher than the value of 2,000 that is usually used to determine the transition to turbulent flow. Although the high flow Reynolds number indicates that inertial forces are much more significant than the viscous (friction) forces, however, the presence of solid boundaries does require that fluid viscosity be included. The "no-slip" condition (velocities relative to solid walls are zero) can generate a thin boundary layer with large strain rate (velocity gradient), which will affect the outer fully-developed turbulent flow and generate internal eddies and losses. Evaluating the performance of the turbine requires calculating the total torque produced by the flow on the runner. The moment (torque) on the runner caused by the viscosity impacts negatively on the efficiency of the runner. Therefore, viscous flow was used for 
this study.

- Laminar or turbulent flow. Turbulence can usually be characterized by random eddies with different length scales. In turbulent flow any instantaneous quantity can be mathematically expressed as the summation of an average (mean) and a fluctuating term by the so-called Reynolds decomposition. Turbulent flow can be well described by the Navier-Stokes equation which is derived from Newton's Second Law of Motion. Judging from the flow Reynolds number of $1.8 \times 10^{7}$, the turbine flow in the present study is turbulent. This Reynolds number is too high for application of a Direct Numerical Simulation (DNS) due to the lack of current computer power. However, only the mean flow features are of interest in real-life engineering problems. Substituting the Reynolds decomposition into the instantaneous Navier-Stokes equations yields the ReynoldsAveraged-Navier-Stokes (RANS) equations. The averaging process creates a new term, Reynolds stress, in the equation system. The RANS equations used in this study combined with turbulence modeling provides an effective way to simulate the effects of turbulent flow.

- Steady (no variations with time) or unsteady (time varying) flow. Steady-state flow refers to the flow condition where flow properties (such as velocities, pressure, temperature) at any point in the system do not change over time. Most hydraulic turbine flow simulations are performed as steady-state simulations.

- Fluid temperature. Change of water temperature through the hydraulic turbine is negligible. There was no need to include the energy (or temperature) equation.

- Gravity effects. Gravity effects were included by turning on the gravity option in the operating conditions of the FLUENT model.

Based on the above consideration, the governing equations to be solved are the RANS and turbulence modeling equations for 3D, steady-state, Newtonian, incompressible, viscous flows without heat transfer.

\section{Turbulence Model}

The Boussinesq hypothesis is used to relate the Reynolds stress tensor in the RANS equations proportionally to the mean strain rate tensor via a scalar property called eddy viscosity $\mu_{t}$. This eddy viscosity becomes an unknown parameter and needs to be calculated. The turbulence model serves this purpose.

There is no single turbulence model that is best for all kinds of flow problems. Selecting a turbulence model is based on the physics of the problems to be solved, the level of accuracy required, available computer resources, allowed computing time, even personal preference and established practice for a specific class of flow problems.

It is a challenging task to select a suitable turbulence model for hydraulic turbine flow simulations. It is necessary to choose a more refined turbulence model to predict more complex flow patterns such as separating flows, rotating flows, and flows strongly affected by secondaryflows. The common choices for this kind of complex flows are the two-equation turbulence 
models. Two-equation turbulence models are widely used in real-life engineering problems. This usually includes the standard k- $\varepsilon$ model, Renormalization-group (RNG) k- $\varepsilon$ model, Realizable k- $\varepsilon$ model, standard k- $\omega$ model, shear-stress transport (SST) k- $\omega$ model, etc.

Two-equation turbulence models usually overproduce turbulent energy within regions with strong velocity gradients, such as the leading edge region, regions around shocks (flow separation) and in the suction peak on the suction side of the blade, and different models behave differently in these regions. It has been shown that the $k-\varepsilon$ model is useful for free-shear layer flows with relatively small pressure gradients but its accuracy has been shown experimentally to be reduced for flows containing adverse pressure gradients in wall-bounded and internal flows (Bardina, Huang and Coakley, 1997). Relatively, the standard k- $\varepsilon$ is probably the worst choice, its variant models (RNG and Realizable k- $\varepsilon$ models) may behave slightly better, the standard k- $\omega$ model can do a slightly better job than the standard k- $\varepsilon$ model, and the SST k- $\omega$ model is being more widely used.

It is often necessary to use a low Reynolds number turbulence model when complex secondary flows and separations are involved. The SST k- $\omega$ turbulence model (Menter 1993, 1994) uses the k- $\omega$ model formulation in the inner regions of the boundary layer and switches to the highReynolds number flow of the $\mathrm{k}-\varepsilon$ model in the outer part of the boundary layer. Hence, it is directly usable all the way to the wall through the viscous sub-layer as a low-Reynolds turbulence model without any extra damping functions. Meanwhile, it can avoid the common k$\omega$ model problem of being too sensitive to the inlet free stream turbulence properties in the outer parts of the boundary layer. The SST k- $\omega$ model receives popularity because of its good behavior in adverse pressure gradients and separating flows. Although the SST k- $\omega$ model does produce slightly larger turbulence levels in regions of stagnation or strong acceleration or deceleration, this tendency is much less pronounced than with a normal k- $\varepsilon$ model. Therefore, the SST k- $\omega$ model was selected for this study.

\section{Mixing-Plane Model}

In the present study the spiral case and distributor, draft tube and tailwater are stationary but the runner is a rotating part. The flow in stationary parts can be modeled as a stationary reference frame problem but for the flow in moving parts the equations of motion need to be modified to incorporate the extra acceleration terms due to the transformation from the stationary to the moving reference frame. Under most situations the moving parts make the flow problem unsteady when viewed from the stationary reference frame. However, the flow around the moving parts with certain restrictions can be modeled as a steady-state problem within the moving reference frame.

The entire turbine domain was split into three zones with well defined interfaces: the spiral case and distributor, the runner (including the outer annular space and head cover gap), and the draft tube and tailwater. The tailwater portion was not included in the energy calculation. The mixing-plane model was used to treat the interfaces between these zones. In the mixing-plane approach, each fluid zone is solved as a steady-state problem. The flow data at the mixing-plane interface are averaged (area-weighted) in the circumferential direction at both the outlet of the upstream fluid zone and the inlet of the downstream fluid zone at some prescribed iteration 
interval. These averaged data form profiles and these profiles are then used to update the boundary conditions at the upstream and downstream fluid zones of the mixing-plane interface.

\section{Mesh Development}

Figure 5-1 is a general view of the configuration of the simulated hydraulic turbine. The CFD model included a flow development inlet (penstock), followed by a transition to the rectangular semi-spiral case, the spiral case and distributor, the runner (including the annular space between the shroud and casing and the space below the head cover), a draft tube and a portion of the tail water. The inlet section is 5 diameters long $\left(D_{P}=4.936 \mathrm{~m}=16.193 \mathrm{ft}\right)$ and a uniform velocity distribution was established at its upstream inlet.

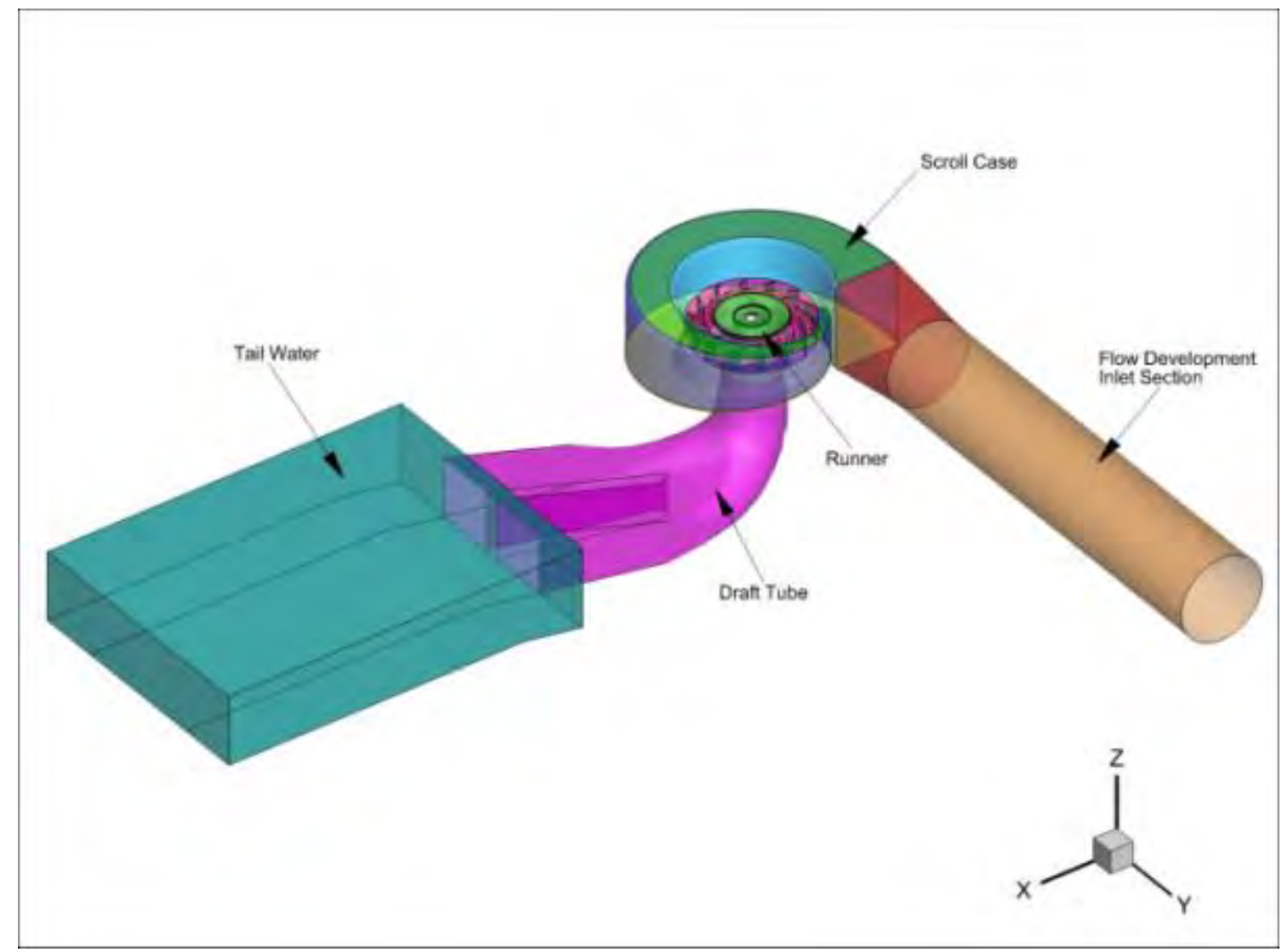

Figure 5-1

General Configuration of the Simulated Hydraulic Turbine

The penstock cross section transitions from circular, with a net area of $19.132 \mathrm{~m}^{2}\left(205.935 \mathrm{ft}^{2}\right)$, into rectangular, with a similar net area of $19.078 \mathrm{~m}^{2}\left(205.354 \mathrm{ft}^{2}\right)$. The rectangular shape is maintained in the spiral case but its net flow area is gradually decreased from the inlet by reducing the height and width, as shown in Figure 5-2 and Figure 5-3. 
CFD Simulations of Alden Turbine and Comparison with Physical Model Data

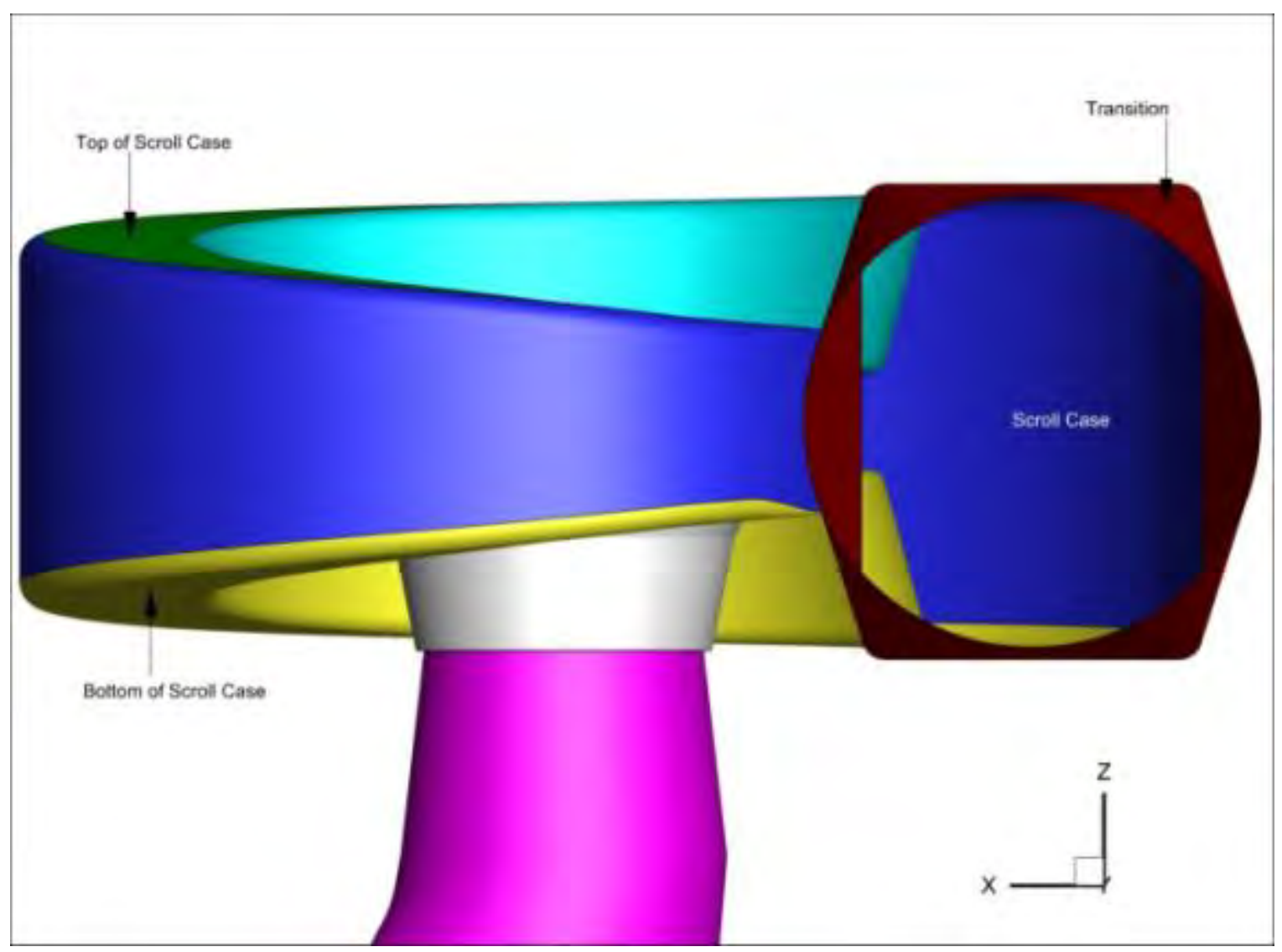

Figure 5-2

Vertical View of the Spiral Case: Gradual Decrease in Height 


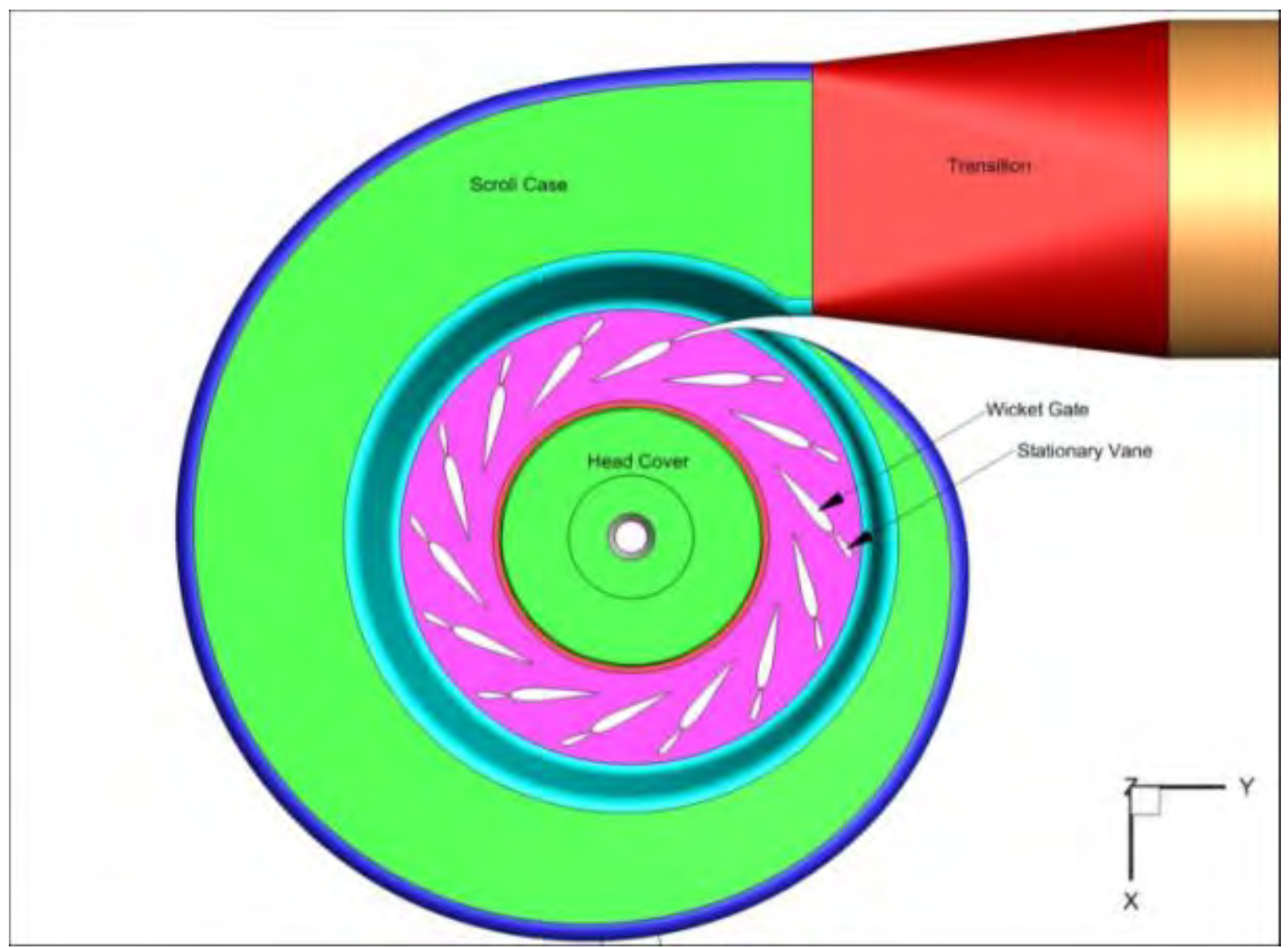

Figure 5-3

Plan View of the Spiral Case: Gradual Decrease in Width

The plan and vertical dimensions, in terms of the runner diameter $\mathrm{D}$, of the entire turbine are shown in Figure 5-4 and Figure 5-5. In these figures, $\mathrm{D}$ is defined as the diameter at the bottom of the leading edge $(\mathrm{D}=3.89 \mathrm{~m}=12.78 \mathrm{ft})$. 


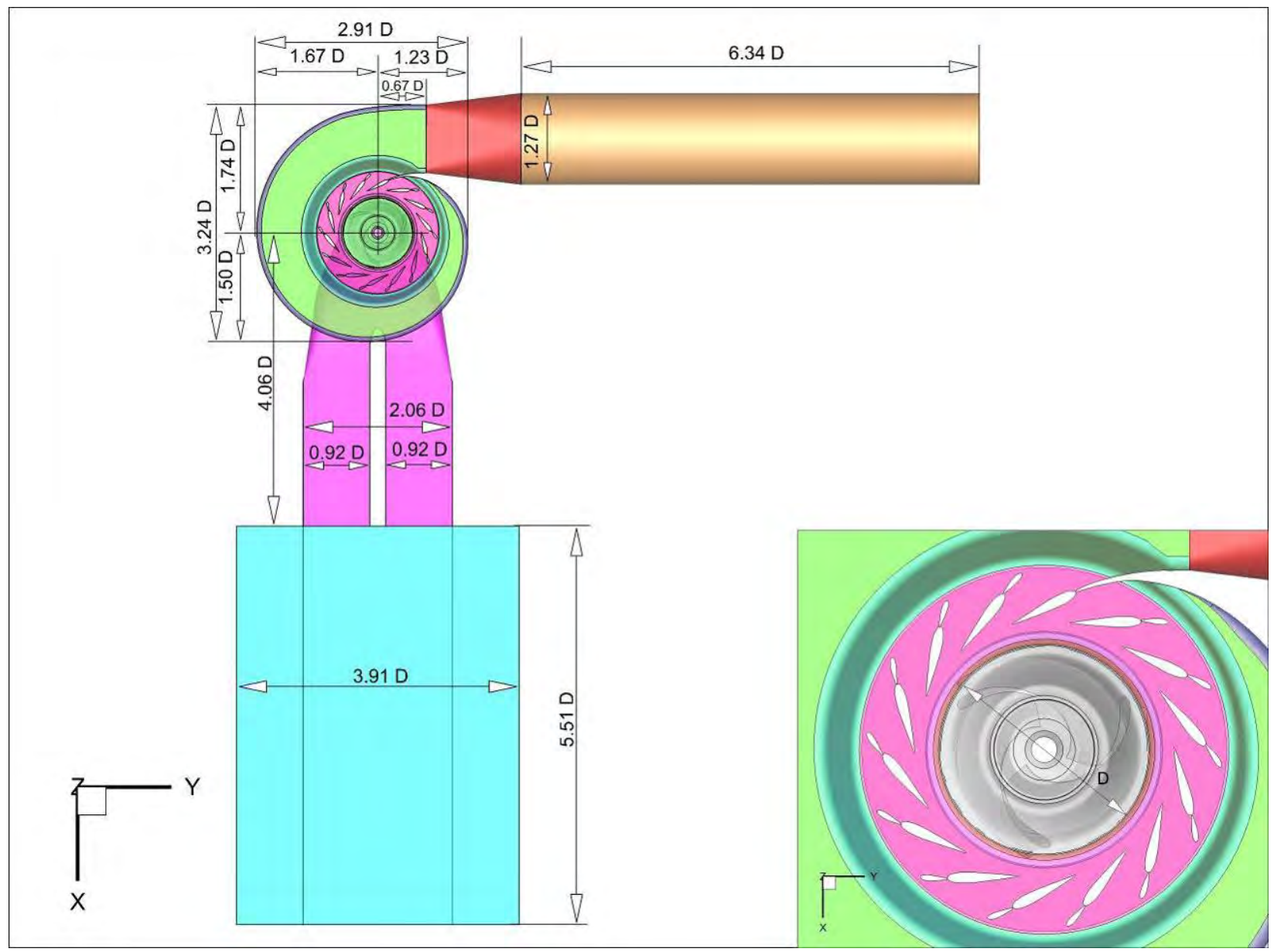

Figure 5-4

Plan Dimensions of the Turbine in Terms of the Runner Diameter D 


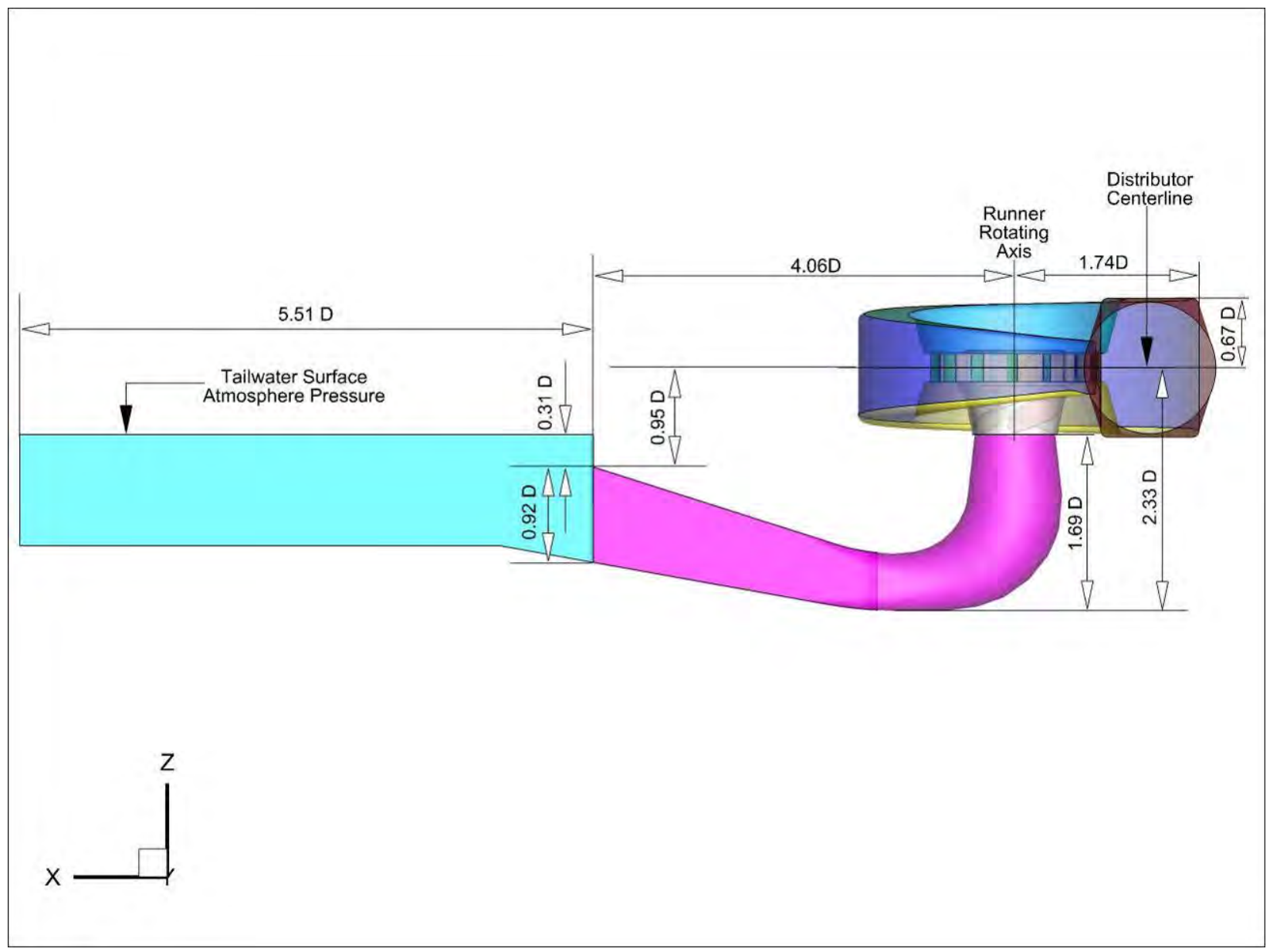

Figure 5-5

Vertical Dimensions of the Turbine in Terms of Runner Diameter D

Figure 5-6 shows an internal view of the turbine components simulated in the CFD model. The major components included the spiral case, stationary vanes, wicket gates, the three blades, crown, shroud, head cover, and draft tube. The crown, the three blades and the shroud are connected and rotate together. In order to include the same loss sources as in the physical model testing, the annular fluid filled side space between the outer runner shroud and the casing, and the fluid filled space between the runner top and the head cover (see Figure 5-7) were modeled. Although seals were not simulated, it was assumed they provided negligible leakage and these fluid filled spaces were assumed to have no through flow. 


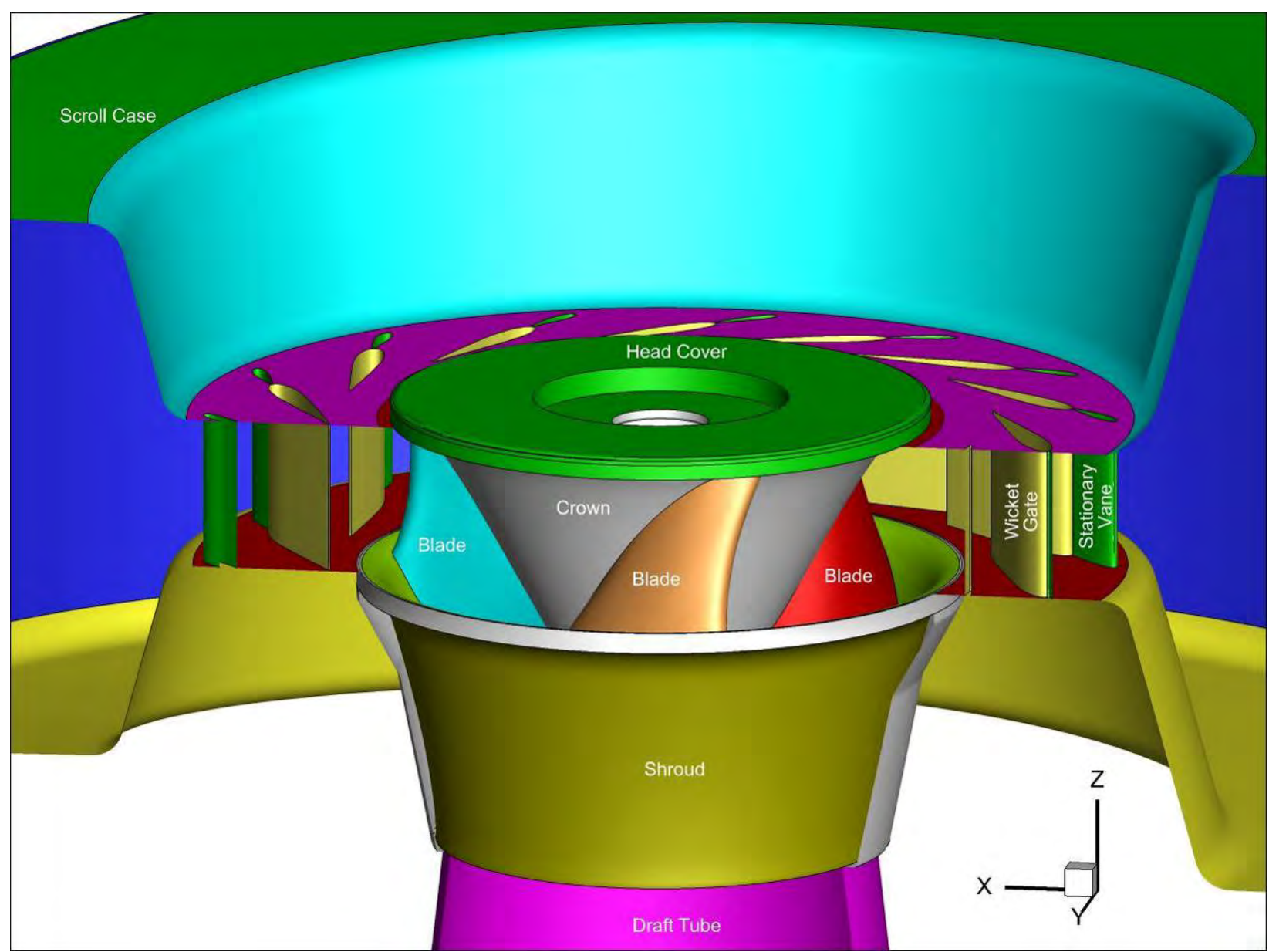

Figure 5-6

Internal View of Simulated Turbine Components: The Spiral Case, Stationary Vanes, Wicket Gates, Runner Blades, Crown, Shroud, Head Cover, and Draft Tube. 


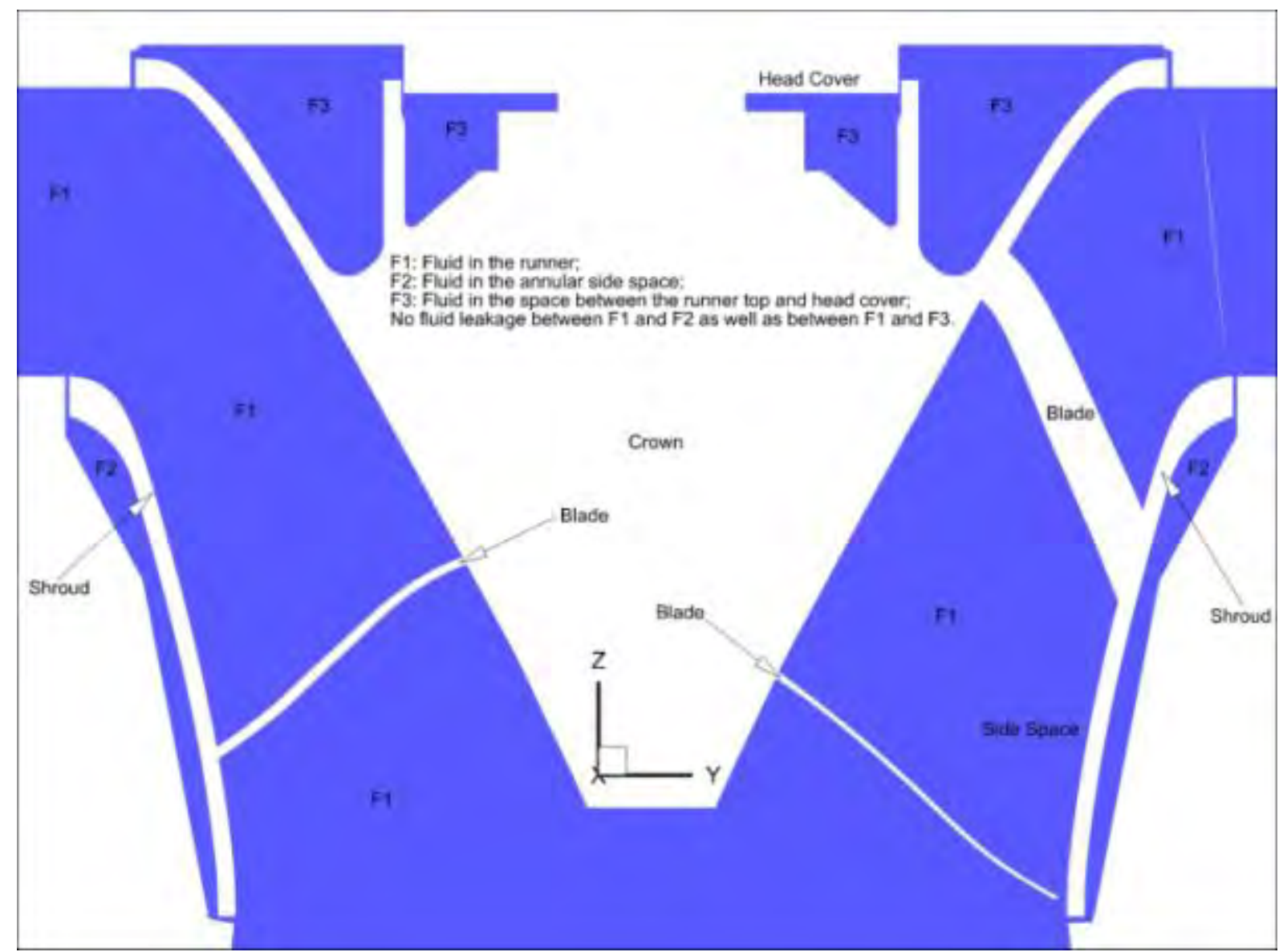

Figure 5-7

The Annular Space between the Outer Runner Shroud and the Casing, and Space between the Runner Top and the Head Cover

Mesh generation plays an important role in CFD simulations. Mesh quality is directly associated with the reliability of the results. An inappropriate mesh may lead to non-convergence or unrealistic results. A hybrid mesh structure was used to represent the complex geometry of the hydraulic turbine because a hybrid mesh provides the needed flexibility to simulate complex shapes. Mesh topology included tetrahedron, hexahedron, and prism/wedge shapes. The mesh included three parts: the spiral case, the runner, and the draft tube. The first mesh was constructed based on a wicket gate angle of 21.1 degrees from closed, matching the physical model testing best performance condition. The mesh consisted of 16,945,483 cells, in which the spiral case had 4,804,684 cells, and the runner (including the space between the runner top and the head cover, and between the runner shroud and the casing) had 5,165,217 cells, and the draft tube and the tailwater region had 6,975,582 cells. Several other wicket gate opening angles $\left(18^{\circ}\right.$, $20^{\circ}$, and $26^{\circ}$ ) were modeled. For each different wicket gate angle, the mesh was re-constructed accordingly. The mesh size was adjusted only in the spiral case and increased to about 7.4 million cells, resulting in the total mesh increasing to about 19.5 million cells. Figure 5-8 shows a general 3D view of the mesh looking from the top of the spiral case. Figure 5-9 shows another general 3D view of the mesh looking from the bottom of the spiral case and draft tube. Figure 5-10 shows a detailed view of the mesh on the wicket gates and stationary vanes and their vicinity. A detailed view of the mesh on the runner blades and shroud is provided in Figure 
5-11. Figure 5-12 shows the mesh on the head cover and crown with the cover removed for a better view of the mesh inside the space between the runner top and head cover.

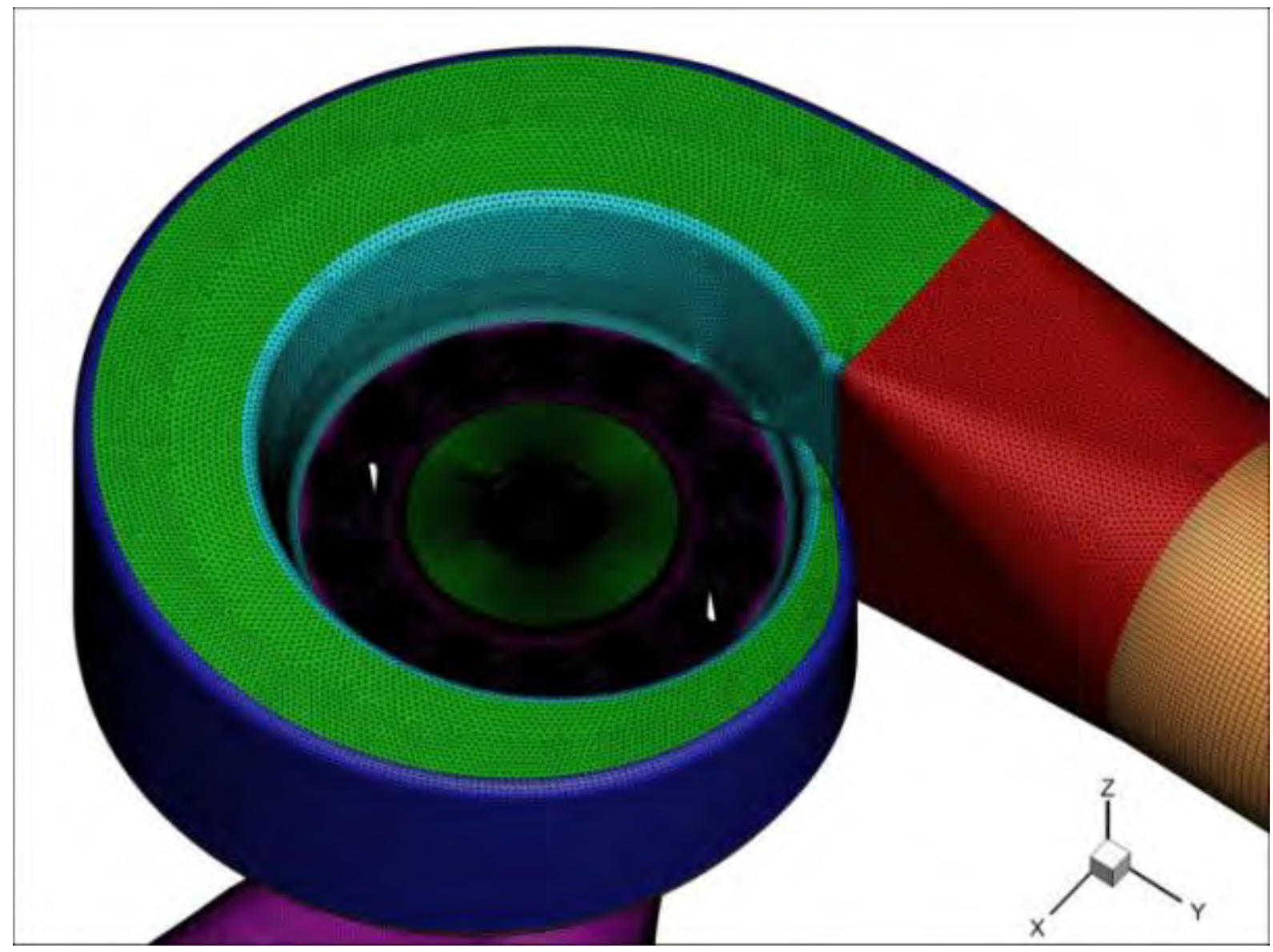

Figure 5-8

Mesh View from the Top of Spiral Case 
CFD Simulations of Alden Turbine and Comparison with Physical Model Data

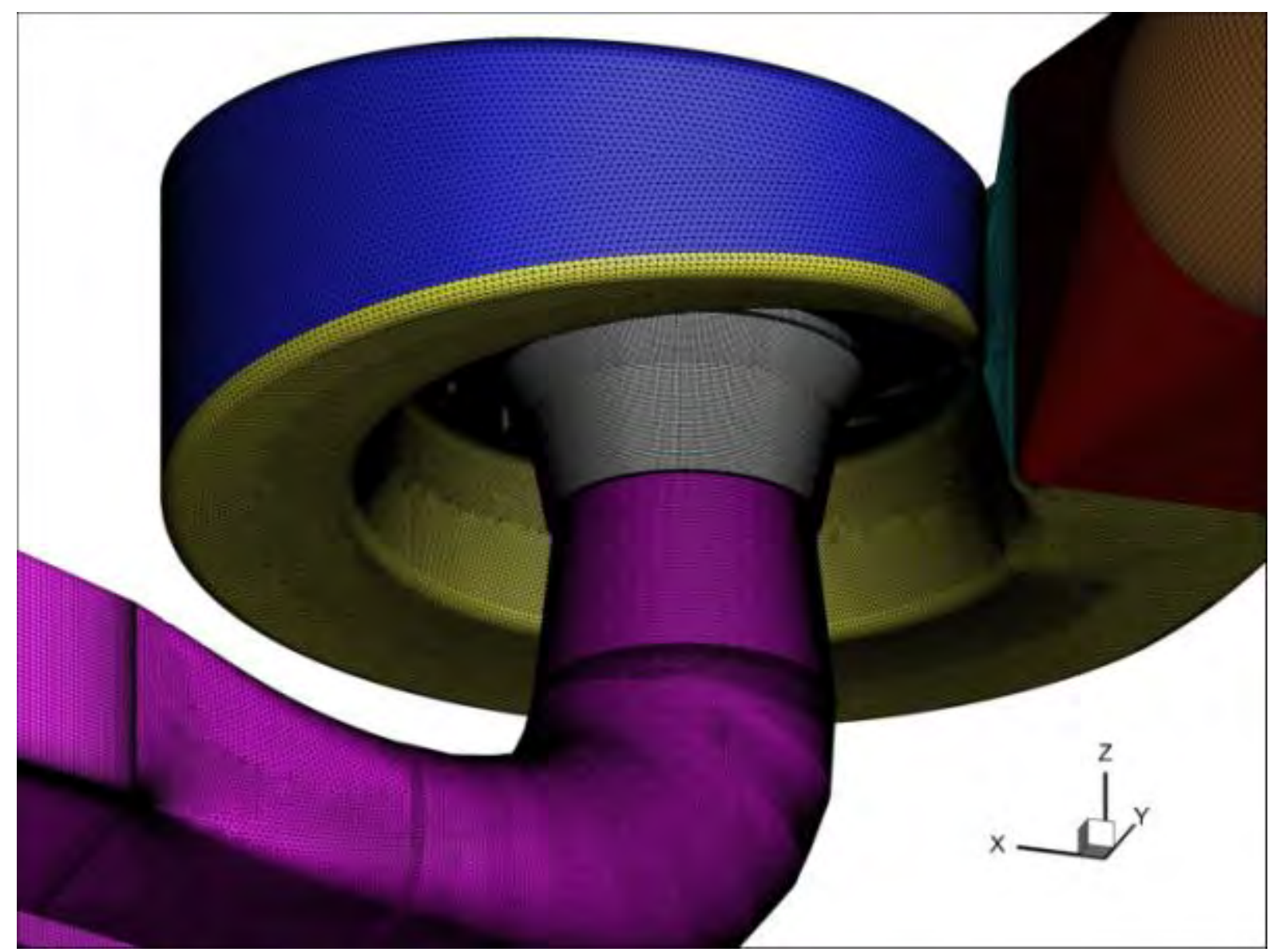

Figure 5-9

Mesh View from the Bottom of Spiral Case and Draft Tube 


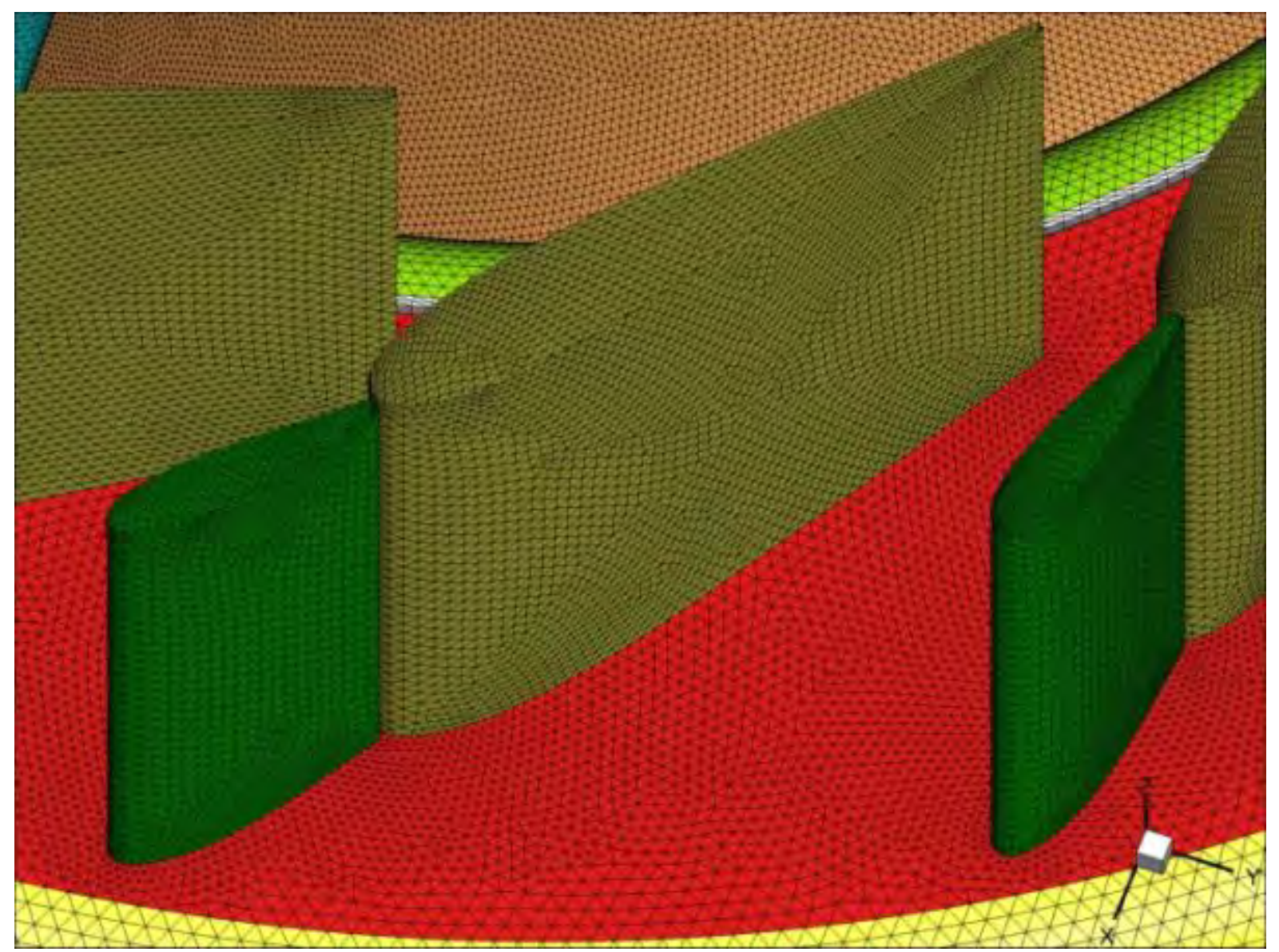

Figure 5-10

Detailed View of Mesh on Wicket Gates and Stationary Vanes and Their Vicinity 


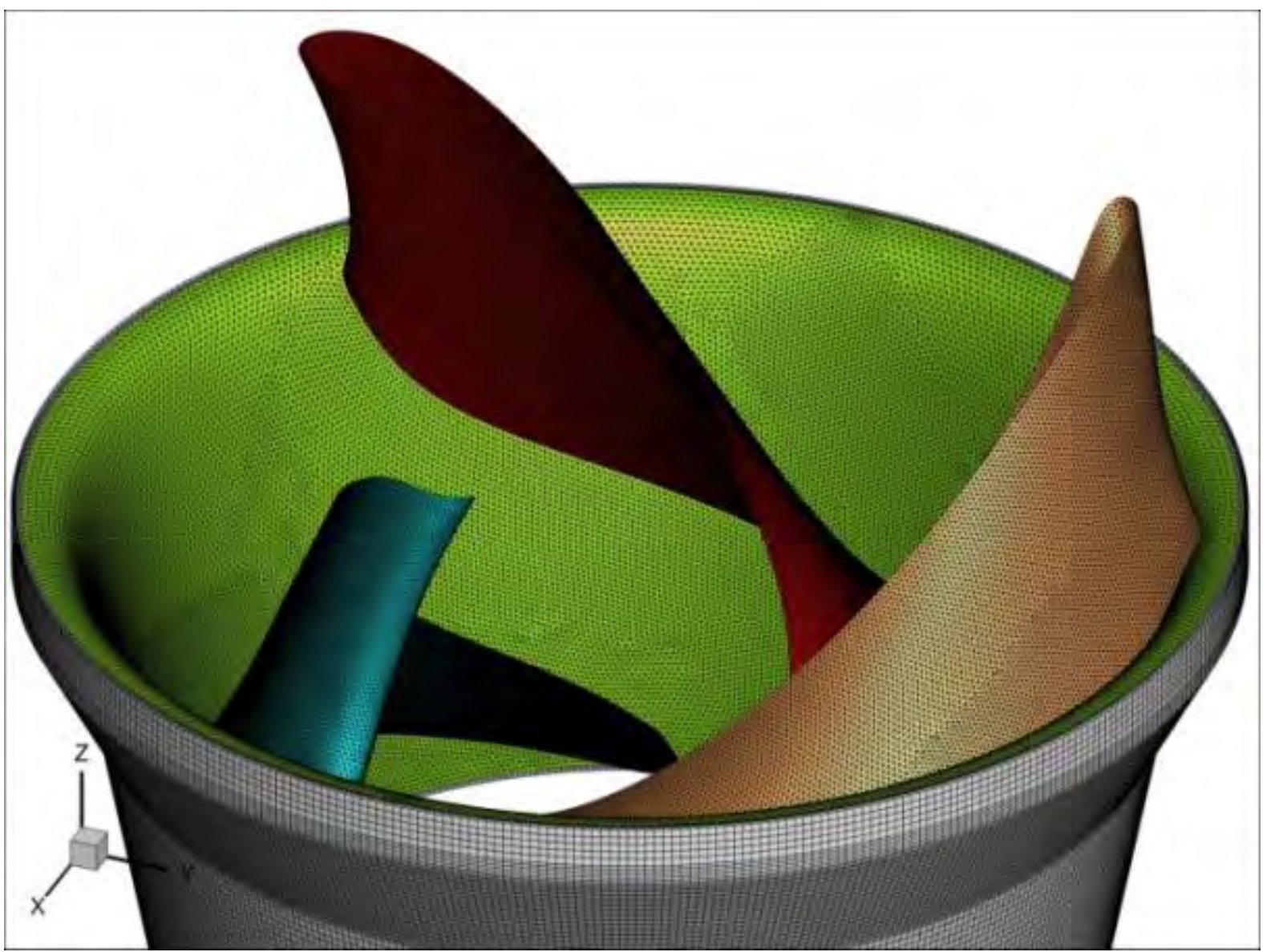

Figure 5-11

Mesh on the Runner Blades and Shroud 


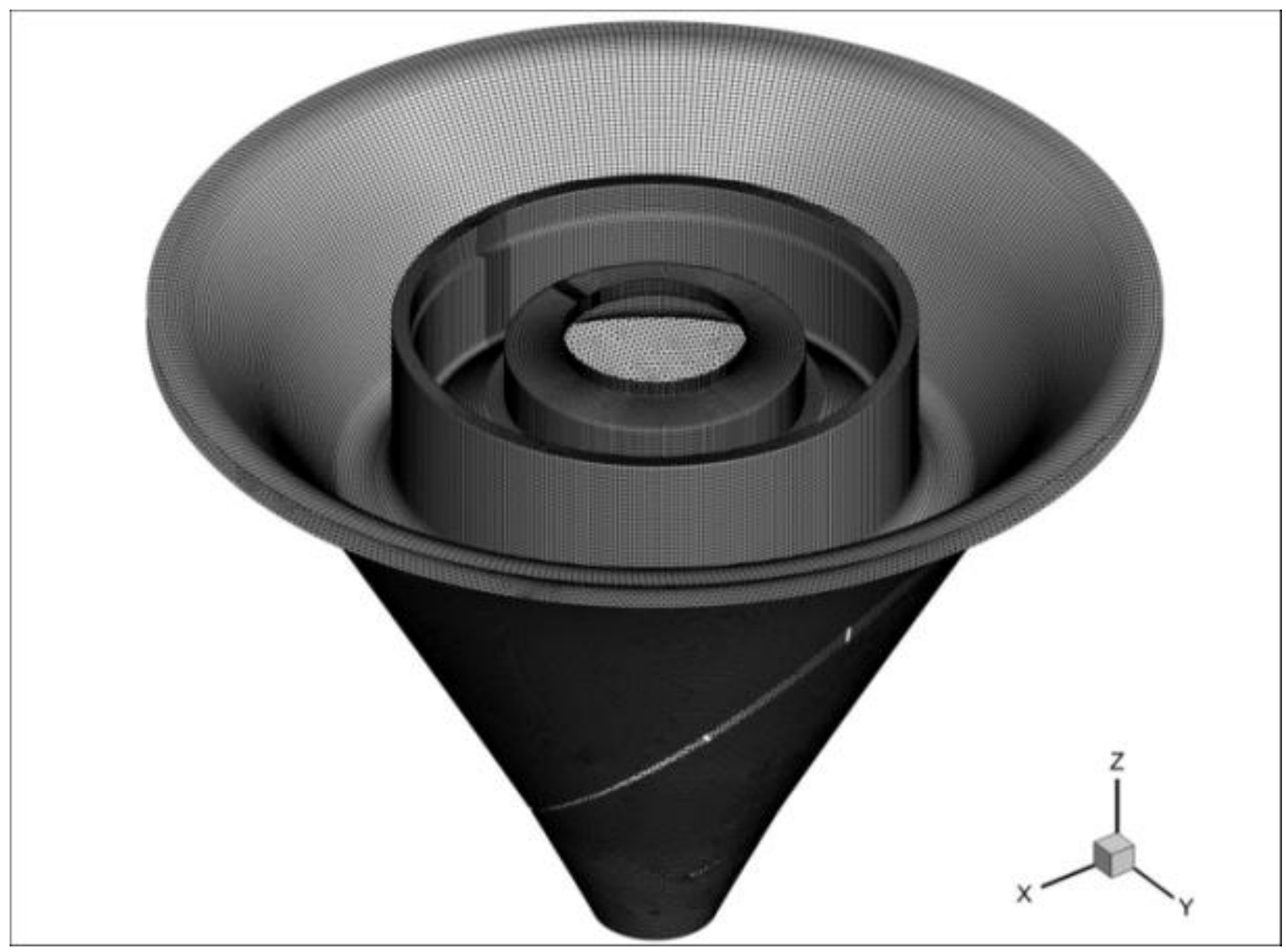

Figure 5-12

Mesh under the Head Cover (Top of the Runner) and the Crown

\section{Boundary Conditions}

The boundary conditions that were used are described as follows:

- Inlet Flow: A selected mass flow rate was introduced at the upstream penstock inlet cross section with a uniform velocity profile. The turbulence characteristics at the inlet are specified by selecting a turbulent intensity of $10 \%$ and a turbulent viscosity ratio of 10 . The turbulent kinetic energy $k$ and the specific dissipation rate $\omega$ are obtained from

$$
\begin{aligned}
& \mathrm{k}=\frac{3}{2}\left(I * U_{M}\right)^{2} \\
& \omega=\rho \frac{\boldsymbol{k}}{\mu}\left(\frac{\mu_{t}}{\mu}\right)^{-1}
\end{aligned}
$$

in which I= turbulence intensity, $U_{m}=$ average flow velocity, $\rho$ = water density, $\mu=$ water dynamic viscosity, $\mu_{t}=$ turbulent viscosity. 
- Outlet Pressure: The pressure was atmospheric at the top of the tail water region shown in Figure 5-5. A zero gauge pressure (the static pressure relevant to atmospheric pressure) distribution was applied on the downstream cross section of the tailwater. In Fluent, the hydrostatic head $\rho_{o} g z$ is included in the definition of pressure $p_{s}^{t}=p_{s}-\rho_{0} g z$ and is combined into the body force term $\left(\rho-\rho_{0}\right) g$ and the hydrostatic head can be excluded from the pressure calculation when the density is uniform $\left(\rho=\rho_{0}\right)$. Therefore, the input pressure $p_{s}^{z}$ should not include the hydrostatic pressure variation and the output of pressure $p_{s}^{z}$ will not show any influence of hydrostatic head. Assuming an input of zero gauge pressure $p_{s}^{\prime}=0$ means a hydrostatic pressure distribution at the downstream cross section of the tailwater. The target mass flow rate option was activated to allow for an adjustment of the outlet pressure $p_{s}^{z}$ so that the selected flow rate can be achieved. Figure 5-13 shows a vertical cross section of the final lateral pressure $p_{s}^{z}$ distribution at the tail water outlet for $\mathrm{Q}=1500 \mathrm{cfs}$ with gate opening angle of 21.1 degrees. The upper sub-plot is the pressure $p_{s}^{\prime}$ which does not include the hydrostatic pressure. The lower sub-plot is the pressure $p_{s}^{\prime}$ plus the hydrostatic pressure. The prescribed turbulence conditions were the same as for the mass flow inlet.
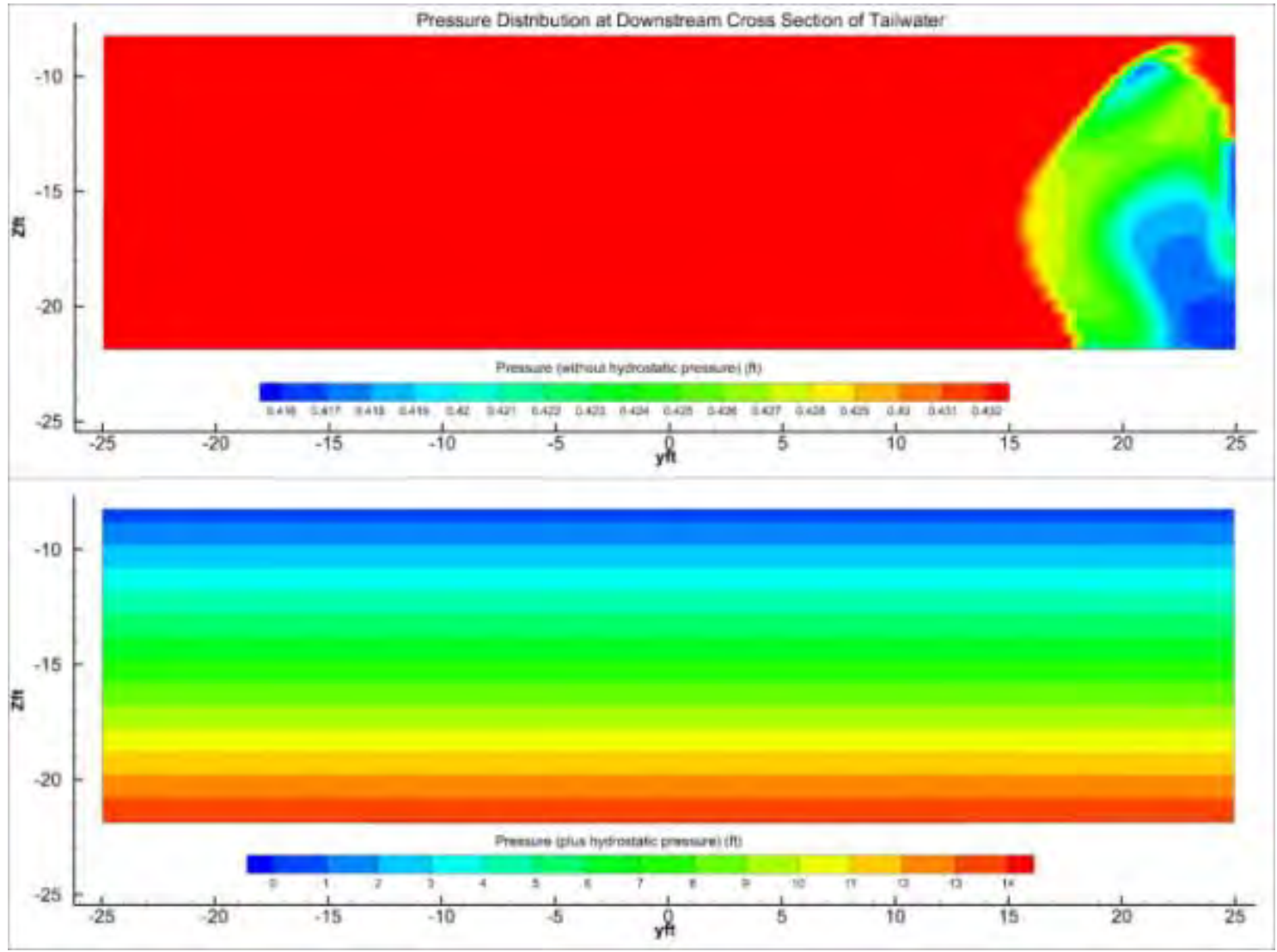

Figure 5-13

Pressure Distribution at Downstream Cross Section of Tailwater

- Stationary Surfaces: A "no-slip" condition was applied to all stationary surfaces. A hydraulically smooth wall assumption was used so the effect of wall roughness was ignored. 
- Moving Surfaces: Moving surfaces are all rotational in this study. They were specified with absolute rotational speed and rotation-axis origin and direction vector, with "no-slip" condition and zero wall roughness.

- Mixing-Planes: There were two mixing planes in the simulation (Figure 5-14). The first one was between the spiral case (all stationary parts) and the runner (rotational parts) and the second was between the runner (rotational parts) and the draft tube (stationary parts). Each paired mixing plane included an upstream side and downstream side. The geometry of the upstream and downstream sides were identical although this was not necessary. However, the meshes on the upstream and downstream sides were different. For each paired mixing plane, the upstream side was specified as a pressure outlet which was updated with the pressure at the radial-, tangential-, and axial-component of flow direction at the downstream side, and turbulence quantities were updated with the corresponding turbulent kinetic energy and specific dissipation rate at the downstream side. The downstream side was specified as a mass flow inlet, which was updated with the mass flux, pressure with radial-, tangential-, and axial-components of flow direction, and the turbulent kinetic energy and specific dissipation rate at the upstream side.

\section{Method to Calculate Turbine Efficiency and to Compile Hill Chart}

\section{Calculation of Turbine Efficiency}

The turbine efficiency $\eta$ is defined as the ratio of power delivered to the runner $\boldsymbol{P}_{\boldsymbol{W} \boldsymbol{D}}$ over the total available power which the flow provides $\boldsymbol{P}_{W T}$ :

$$
\eta=\frac{P_{W-D}}{P_{W T}}
$$

The power delivered to the runner is computed as the product of the torque $\mathrm{T}$ applied to the runner by the flow and the runner rotational speed n:

$$
P_{W_{-} D}=T \times n
$$

Eq. 5-4

The rotational speed $\mathrm{n}$ of the runner was known as an input to each run; the only unknown variable was the total torque T in order to obtain $\boldsymbol{P}_{\boldsymbol{W} \boldsymbol{D}}$.

The total moment vector $\overrightarrow{\boldsymbol{M}_{\boldsymbol{C}}}$ about a specified moment center $\mathrm{C}$ is computed by summing the cross product of the pressure vector $\overrightarrow{\boldsymbol{F}_{P}}$ and viscous force vector $\overrightarrow{\boldsymbol{F}_{V}}$ for each face of the runner with the moment vector $\overrightarrow{\mathbf{r}_{\mathrm{Co}}}$, which is the vector from the specified center $\mathrm{C}$ to the force origin O: 


$$
\overrightarrow{M_{C}}=\overrightarrow{r_{C O}} \times \overrightarrow{F_{P}}+\overrightarrow{r_{C O}} \times \overrightarrow{F_{V}}
$$

Eq. 5-5

The total torque $\mathrm{T}$ is the component of the total moment vector integrated in the plane perpendicular to the rotational axis.

The available power from the flow is the difference of the energy flux through the inlet and outlet surfaces:

$$
P_{W_{-} T}=P_{W_{-} F_{-} I n}-P_{W_{-} F_{-} \text {Out }}
$$

Eq. 5-6

The energy flux through a surface is computed from:

$$
P_{W_{-} F}=\int\left(\frac{P}{\rho}+\frac{|\vec{V}|}{2}\right) \rho(\vec{V} \cdot \vec{n}) d s
$$

\section{Eq. 5-7}

in which $\mathrm{P}=$ static pressure, $\rho=$ flow density, $|\overrightarrow{\boldsymbol{V}}|=$ total velocity (velocity magnitude), $\overrightarrow{\boldsymbol{V}}=$ velocity vector, $\overrightarrow{\boldsymbol{n}}=$ surface normal vector.

The turbine simulation included three components: the spiral case and distributor, the runner, and the draft tube and tailwater. The three components are separated in the model but flow parameters were transferred by using a pair of mixing planes between the spiral and runner as well as between the runner and draft tube, as discussed above and shown in Figure 5-14

The method of calculating the total available power from the flow was to add the available power of all the three components:

$$
\boldsymbol{P}_{W_{-} T}=\left(\boldsymbol{P}_{W_{-} I n}-\boldsymbol{P}_{W_{-} O_{u t}}\right)_{\text {scroll }}+\left(\boldsymbol{P}_{W_{-} I n}-\boldsymbol{P}_{W_{-} O_{u t}}\right)_{\text {Runner }}+\left(\boldsymbol{P}_{W_{-} I n}-\boldsymbol{P}_{W_{-} O_{u t}}\right)_{D_{\text {raft }} T \text { ube }}
$$

To calculate the total available power and the efficiency of the turbine, the draft tube component did not include the tailwater region. 


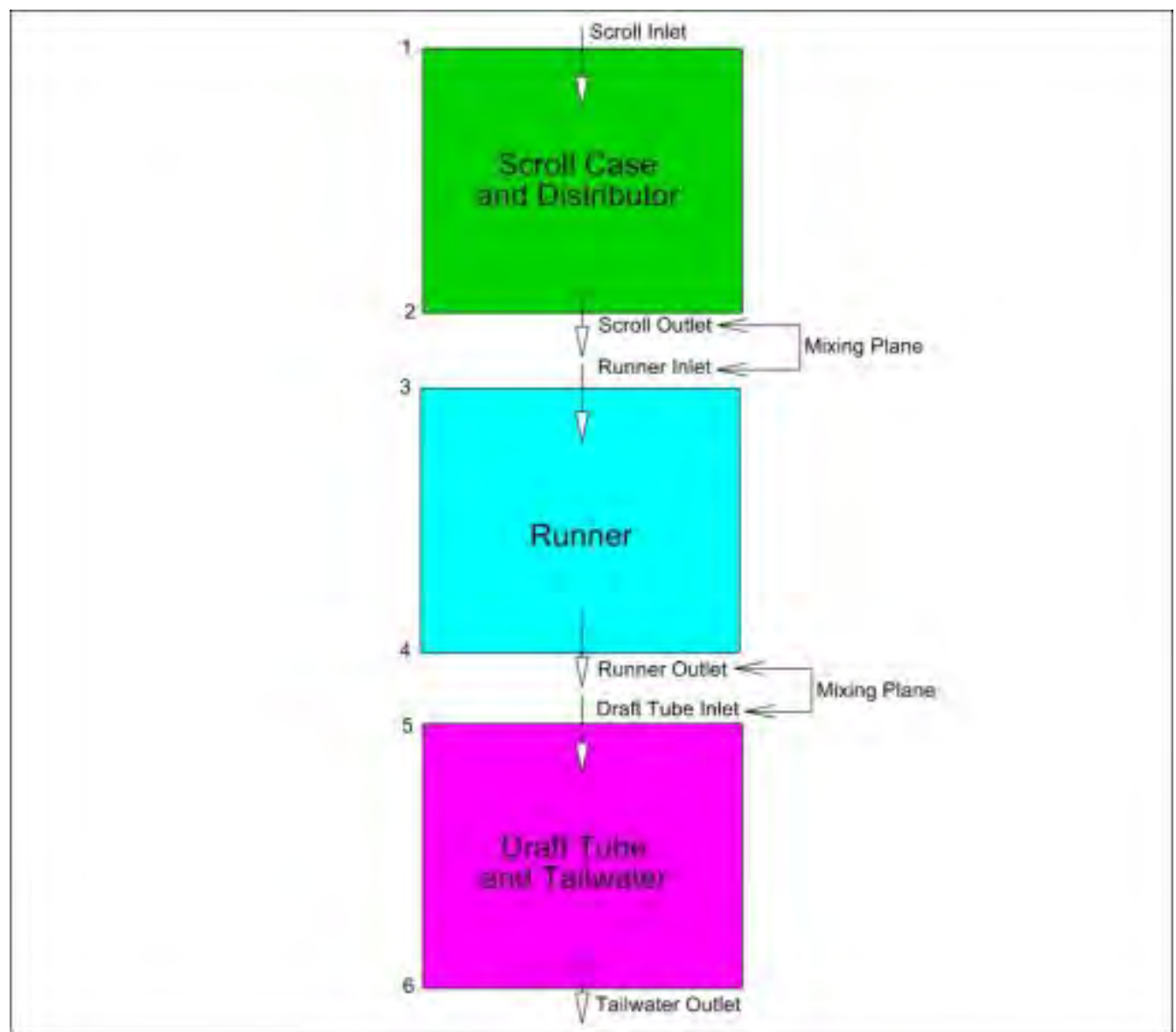

Figure 5-14

Schematic Diagram of the Three Turbine Components and Corresponding Mixing Planes

\section{Compilation of Hill Chart}

A dimensional analysis of the functional dependence of water head $\mathrm{H}$, power output $\boldsymbol{P}_{\boldsymbol{W} \boldsymbol{D}}$, flow rate $\mathrm{Q}$, characteristic turbine size $\mathrm{D}$, and runner rotating speed $\mathrm{n}$, leads to the following dimensionless similarity parameters:

- Flow Coefficient $\mathrm{C}_{\mathrm{Q}}$

$$
C_{Q}=\frac{Q}{n D^{3}}
$$

- Head Coefficient $\mathrm{C}_{\mathrm{H}}$

$$
C_{H}=\frac{g H}{n^{2} D^{2}}
$$

\section{Eq. 5-10}


- Power Coefficient $C_{\mathrm{P}}$

$$
C_{P}=\frac{P_{W_{-} D}}{\rho n^{3} D^{5}}
$$

Eq. 5-11

The efficiency $\eta$ of the turbine is a function of the discharge, head, and power coefficients:

$$
\eta=\frac{C_{P}}{C_{Q} C_{H}}=\frac{P_{W D D}}{\rho g H Q}
$$

Eq. 5-12

The total available head is

$$
H=\frac{P_{W_{-} T}}{\rho g Q}
$$

The general process to build up the "hill chart" was as follows:

1. Run the CFD model with rotating speed $\mathrm{n}$ and flow discharge $\mathrm{Q}$ until a converged solution is achieved;

2. Use Eq. 5-7 to calculate the energy flux (power) at the spiral case inlet and outlet, the runner inlet and outlet, and the draft inlet and outlet;

3. Use Eq. 5-6 and Eq. 5-8 to compute total available power ${ }^{W_{-} T}$ based on the results in the previous step 2);

4. Use Eq. 5-13 to compute the total available water head H;

5. Obtain the total torque on the runner based on calculations of the moment about the rotating axis of the runner according Eq. 5-5;

6. Calculate the total power delivered to the runner using Eq. 5-4;

7. Calculate the discharge coefficient CQ using Eq. 5-9;

8. Calculate the head coefficient $\mathrm{CH}$ using Eq. 5-10;

9. Calculate the efficiency $\eta$ using Eq. 5-3;

10. Repeat steps 1) through 9) for different flow discharges;

11. Repeat the full process for different gate opening angles;

12. Plot calculated $\mathrm{CQ}$ and $\mathrm{CH}$ for all the cases into a $\mathrm{CQ}$ vs. $\mathrm{CH}$ figure;

13. Interpolate and get contour lines of efficiency based on the CQ vs. $\mathrm{CH}$ figure to form a turbine performance "hill chart".

Since full scale dimensions of the turbine were used in the CFD simulations, no scale up is required and the CFD results can be compared directly to the scaled up data from the physical model tests. 


\section{Results and Discussions}

\section{Wicket Gate Opening Angle of 18 Degrees}

For this gate opening angle, four simulations were conducted. The calculated head and flow coefficients and comparison with the physical model test data are listed in Table 5-1 and shown in Figure 5-15 . In this figure, all the CFD results are superimposed on the test data "hill chart".

The four CFD results for 18 degrees (pink diamond shaped dots) are aligned with the slope of the test data line for that gate opening angle shown in Figure 5-15. Also, the CFD simulations indicated the turbine efficiency increased with increasing values of $\mathrm{C}_{\mathrm{H}}$ and $\mathrm{C}_{\mathrm{Q}}$ as did the test data. However, the CFD simulations are all slightly above the test result line. That means the CFD model predicted a slightly lower value of $C_{H}$ for a given $C_{Q}$, resulting in a slightly higher efficiency, see Table 5-1. There is some trend for the higher flows to give lower efficiency differences between the CFD model and test data. At the highest flow simulated, the difference in efficiency was $1.6 \%$.

Table 5-1

Efficiency Comparison for Gate Opening Angle of 18 Degrees

\begin{tabular}{|c|c|c|c|c|c|c|c|}
\hline $\begin{array}{c}18 \\
\text { dearees }\end{array}$ & Flow Rate & \multirow{2}{*}{$\mathrm{C}_{\mathrm{Q}}$} & H & \multirow{2}{*}{$\mathrm{C}_{\mathrm{H}}$} & \multicolumn{3}{|c|}{ Efficiency $\eta$} \\
\hline $\begin{array}{l}\text { Run \# } \\
\text { Index }\end{array}$ & cfs & & $\mathrm{ft}$ & & CFD & Testing & Difference \\
\hline 3 & 1213.4 & 0.0463 & 80.1 & 0.0999 & $90.83 \%$ & $88.30 \%$ & $2.53 \%$ \\
\hline 2 & 1290.8 & 0.0492 & 87.8 & 0.1096 & $92.19 \%$ & $90.30 \%$ & $1.89 \%$ \\
\hline 4 & 1316.6 & 0.0502 & 91.0 & 0.1136 & $92.13 \%$ & $90.80 \%$ & $1.33 \%$ \\
\hline 1 & 1368.3 & 0.0522 & 95.9 & 0.1197 & $93.36 \%$ & $91.75 \%$ & $1.61 \%$ \\
\hline
\end{tabular}




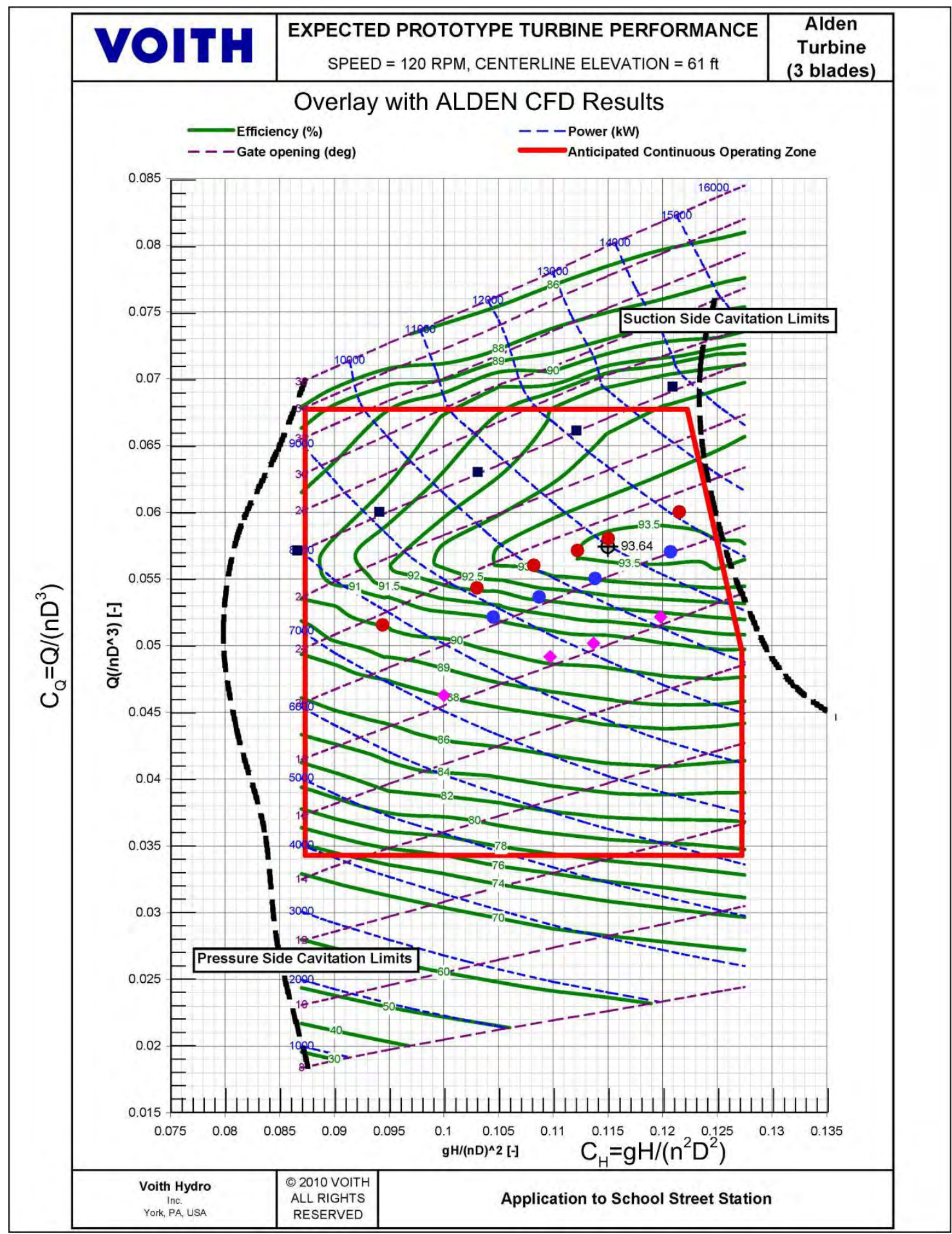

Figure 5-15

Hill Chart From Physical Model Data (Scaled up to Prototype) Overlaid with Alden CFD Results: The pink diamonds are for $18^{\circ}$ gate opening, the blue circles are for $20^{\circ}$ gate opening, the red circles are for $21.1^{\circ}$ gate opening, the dark blue squares are for $26^{\circ}$ gate opening. 


\section{Wicket Gate Opening Angle of 20 Degrees}

This gate opening angle was also simulated with four different discharges. The calculated similarity parameters and efficiencies and a comparison with the test data are listed in Table 5-2 and shown in Figure 5-15 (blue circles).

The four simulation points show a close alignment with the slope of the test data line. Again, the efficiency of higher flow rates matches the testing data better than the lower flow rates. The CFD model predicted efficiency is higher by only $0.44 \%$ than the test data for $\mathrm{Q}=1497.3 \mathrm{cfs}$. The CFD results of 20 degrees opening match the test data better than is the case for the gate opening angle of 18 degrees.

Table 5-2

Efficiency Comparison for Gate Opening Angle of 20 Degrees

\begin{tabular}{|c|c|c|c|c|c|c|c|}
\hline e & $\begin{array}{c}\text { Flow Rate } \\
0\end{array}$ & \multirow{2}{*}{$\mathbf{C}_{Q}$} & $\mathbf{H}$ & \multirow{2}{*}{$\mathbf{C}_{\mathrm{H}}$} & \multicolumn{3}{|c|}{ Efficiency $\eta$} \\
\hline $\begin{array}{l}\text { Run \# } \\
\text { Index }\end{array}$ & cfs & & $\mathrm{ft}$ & & CFD & Testing & Difference \\
\hline 2 & 1368.3 & 0.0522 & 83.7 & 0.1044 & $93.42 \%$ & $91.13 \%$ & $2.29 \%$ \\
\hline 3 & 1407.0 & 0.0537 & 87.0 & 0.1086 & $94.01 \%$ & $92.30 \%$ & $1.71 \%$ \\
\hline 1 & 1445.7 & 0.0551 & 91.1 & 0.1137 & $94.05 \%$ & $93.10 \%$ & $0.95 \%$ \\
\hline 4 & 1497.3 & 0.0571 & 96.6 & 0.1206 & $94.04 \%$ & $93.60 \%$ & $0.44 \%$ \\
\hline
\end{tabular}

\section{Wicket Gate Opening Angle of 21.1 Degrees}

A total of nine simulations were conducted for this gate opening angle. The calculated similarity parameters and efficiencies and a comparison with the test data are listed in Table 5-3 and shown in (red circles).

Among the nine simulations, three values of $\mathrm{C}_{\mathrm{Q}}$ and $\mathrm{C}_{\mathrm{H}}$ were too high to fit in the anticipated continuous operating zone marked in Figure 5-15. Therefore, these three runs are not used for comparison with the test results. In general, the remaining six CFD predicted efficiencies were very close to the physical model test results, as shown in Table 5-3. The difference in efficiency was somewhat higher by $2.47 \%$ only at the lowest flow and head.

The best efficiency point (BEP) as determined from the physical model data (scaled up to the prototype) had an efficiency of about $93.6 \%$ and occurred at this gate opening and values of $C_{Q}$ $=0.0574$ and $C_{H}=0.115$ (see Figure 5-15). These values fall in-between CFD runs 3 and 8 , and the average difference in efficiency between the CFD simulations and the test data in this region is only about $0.23 \%$. 
Table 5-3

Efficiency Comparison for Gate Opening Angle of 21.1 Degrees

\begin{tabular}{|c|c|c|c|c|c|c|c|}
\hline 21.1 & Flow Rate & & H & & & Efficienc & \\
\hline $\begin{array}{l}\text { Run \# } \\
\text { Index }\end{array}$ & cfs & & $\mathrm{ft}$ & & CFD & Testing & Difference \\
\hline 1 & 1353.8 & 0.0516 & 75.6 & 0.0943 & $92.77 \%$ & $90.30 \%$ & $2.47 \%$ \\
\hline 2 & 1425.0 & 0.0544 & 82.5 & 0.1029 & $92.90 \%$ & $92.25 \%$ & $0.65 \%$ \\
\hline 9 & 1471.5 & 0.0561 & 86.6 & 0.1081 & $93.71 \%$ & $93.20 \%$ & $0.51 \%$ \\
\hline 3 & 1500.0 & 0.0572 & 89.8 & 0.1121 & $93.28 \%$ & $93.50 \%$ & $-0.22 \%$ \\
\hline 8 & 1523.2 & 0.0581 & 92.1 & 0.1149 & $93.32 \%$ & $93.57 \%$ & $-0.25 \%$ \\
\hline 4 & 1575.0 & 0.0601 & 97.2 & 0.1214 & $93.41 \%$ & $93.36 \%$ & $0.05 \%$ \\
\hline 5 & 1807.1 & 0.0689 & 121.7 & 0.1519 & $92.82 \%$ & \multirow{3}{*}{\multicolumn{2}{|c|}{$\begin{array}{l}\text { Not Used for } \\
\text { Comparison }\end{array}$}} \\
\hline 6 & 2065.3 & 0.0788 & 151.1 & 0.1886 & $90.52 \%$ & & \\
\hline 7 & 2323.5 & 0.0886 & 180.3 & 0.2250 & $89.09 \%$ & & \\
\hline
\end{tabular}

\section{Wicket Gate Opening Angle of 26 Degrees}

This gate opening angle was modeled with five CFD simulations of different flows. The calculated flow and head coefficients and the efficiencies and a comparison with the test data are listed in Table 5-4 and shown in Figure 5-15 (dark blue squares).

Two points corresponding to flows of $1500 \mathrm{cfs}$ and $1823.3 \mathrm{cfs}$ are outside the anticipated continuous operating zone shown in Figure 5-15. Therefore, they are not used to compare with the physical test results. The CFD points for this gate opening show the best alignment with the physical test line compared to the other gate openings simulated, and the predicted efficiencies are close to the test data, as seen in Table 5-4. For this gate opening, CFD derived efficiencies for the lower flows match the physical data more closely than at the higher flows. 
Table 5-4

Efficiency Comparison for Gate Opening Angle of 26 Degrees

\begin{tabular}{|c|c|c|c|c|c|c|c|}
\hline $\begin{array}{c}26 \\
\text { dearees }\end{array}$ & Flow Rate & \multirow{2}{*}{$\mathrm{C}_{\mathrm{Q}}$} & H & \multirow{2}{*}{$\mathrm{CH}$} & \multicolumn{3}{|c|}{ Efficiency $\eta$} \\
\hline $\begin{array}{l}\text { Run \# } \\
\text { Index }\end{array}$ & cfs & & $\mathrm{ft}$ & & CFD & Testing & Difference \\
\hline 1 & 1500.0 & 0.0572 & 69.3 & 0.0865 & $90.65 \%$ & \multicolumn{2}{|c|}{$\begin{array}{l}\text { Not Used for } \\
\text { Comparison }\end{array}$} \\
\hline 2 & 1575.0 & 0.0601 & 75.3 & 0.0940 & $91.46 \%$ & $91.25 \%$ & $0.21 \%$ \\
\hline 3 & 1653.8 & 0.0631 & 82.5 & 0.1030 & $91.22 \%$ & $91.75 \%$ & $-0.53 \%$ \\
\hline 4 & 1736.4 & 0.0662 & 89.7 & 0.1120 & $91.17 \%$ & $92.25 \%$ & $-1.08 \%$ \\
\hline 5 & 1823.3 & 0.0695 & 96.8 & 0.1208 & $91.54 \%$ & \multicolumn{2}{|c|}{$\begin{array}{l}\text { Not Used for } \\
\text { Comparison }\end{array}$} \\
\hline
\end{tabular}

\section{Hill Chart Based on CFD and Comparison with Physical Test Data}

The area of the "hill chart" of most interest is the anticipated continuous operating zone, especially the region surrounding the best efficiency point (BEP). To compare the efficiency contours based on the CFD simulations with those obtained from the physical test data, it was necessary to derive contours of the efficiency by interpolation of the discrete CFD points. Because the CFD runs did not cover the entire anticipated continuous operating zone, a reduced area with discharge coefficient $\mathrm{C}_{\mathrm{Q}}$ range from 0.045 to 0.067 and head coefficient $\mathrm{C}_{\mathrm{H}}$ range from 0.093 to 0.122 was used for interpolation. The interpolation was performed using the software TECPLOT 360 by Tecplot Inc. The efficiency contours based on the interpolated CFD results are shown in Figure 5-16. Figure 5-17 shows a direct comparison between the CFD and test data "hill chart".

The CFD predicted efficiency contours are generally similar in shape compared to the physical test results. However, the CFD simulations tend to overestimate the flow and head range (area) of the highest efficiencies, with a displacement of that highest efficiency area to lower flows. More generally, the efficiency for low flows with the smaller gate opening angle was higher than derived from the physical data, especially for discharge coefficients $C_{Q}<0.055$.

It may be noted, however, that the efficiency contours are at intervals of only $0.5 \%$, which accentuates differences between the CFD and physical data. The peak efficiency of about $93.6 \%$ expected for the full scale turbine is well simulated by the CFD simulations. It may be concluded that the CFD simulations are most reliable in predicting the more controlled (coherent) flow patterns near the turbine design point.

Figure 5-18 shows the contours of efficiency differences between CFD and physical test data. This figure clearly show where the CFD had higher or lower efficiencies and by how much. Generally, the CFD simulations had higher efficiencies (positive values) at lower discharge coefficients (less than about 0.058 ) and lower efficiencies (negative values) at higher discharge coefficients (larger than 0.058). The zero difference line indicates the zones in which the CFD perfectly matched the physical test data. 


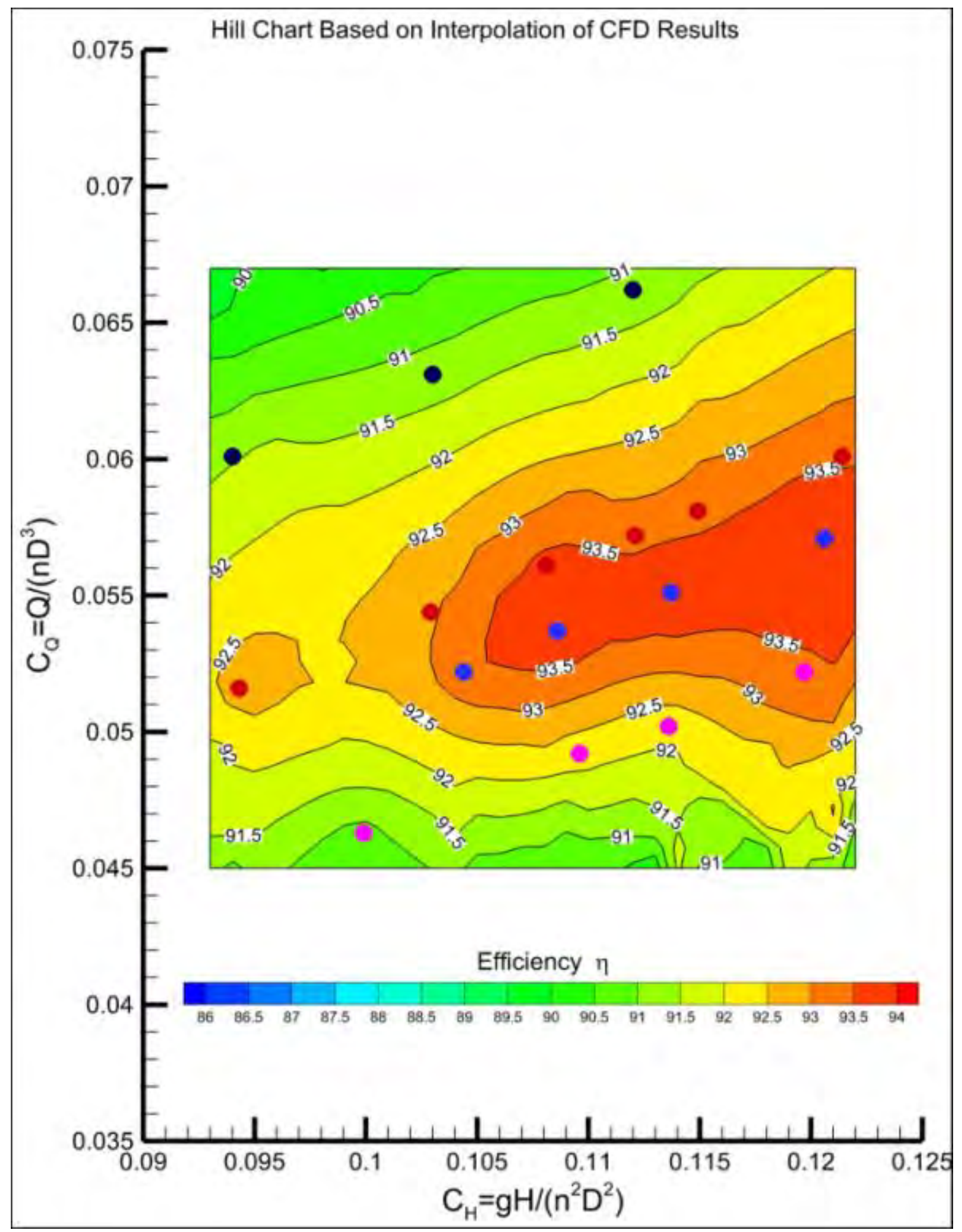

Figure 5-16

Efficiency Contours Based on Interpolation of CFD Results 


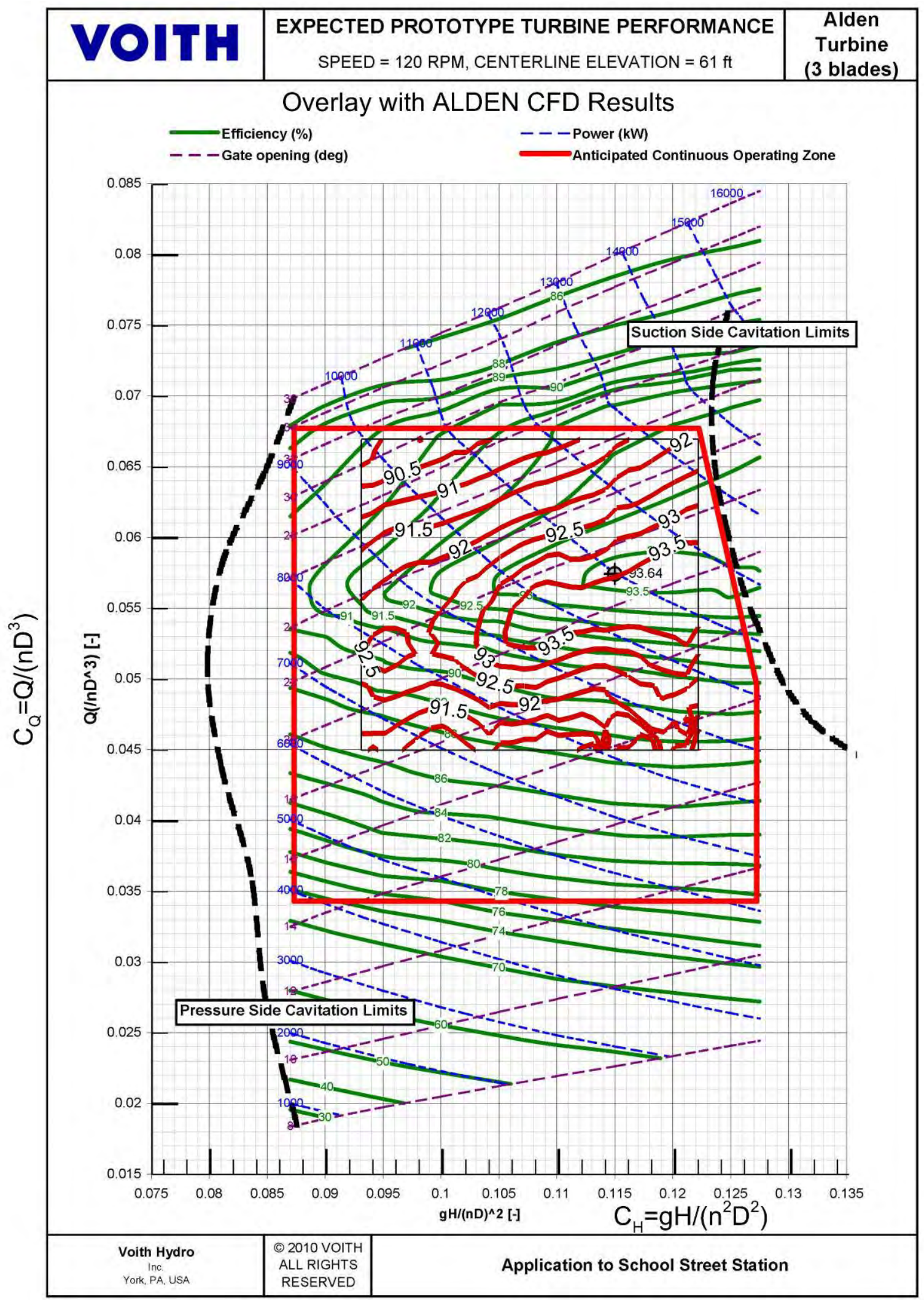

Figure 5-17

Comparison Between CFD Results and Test Data Hill Chart 


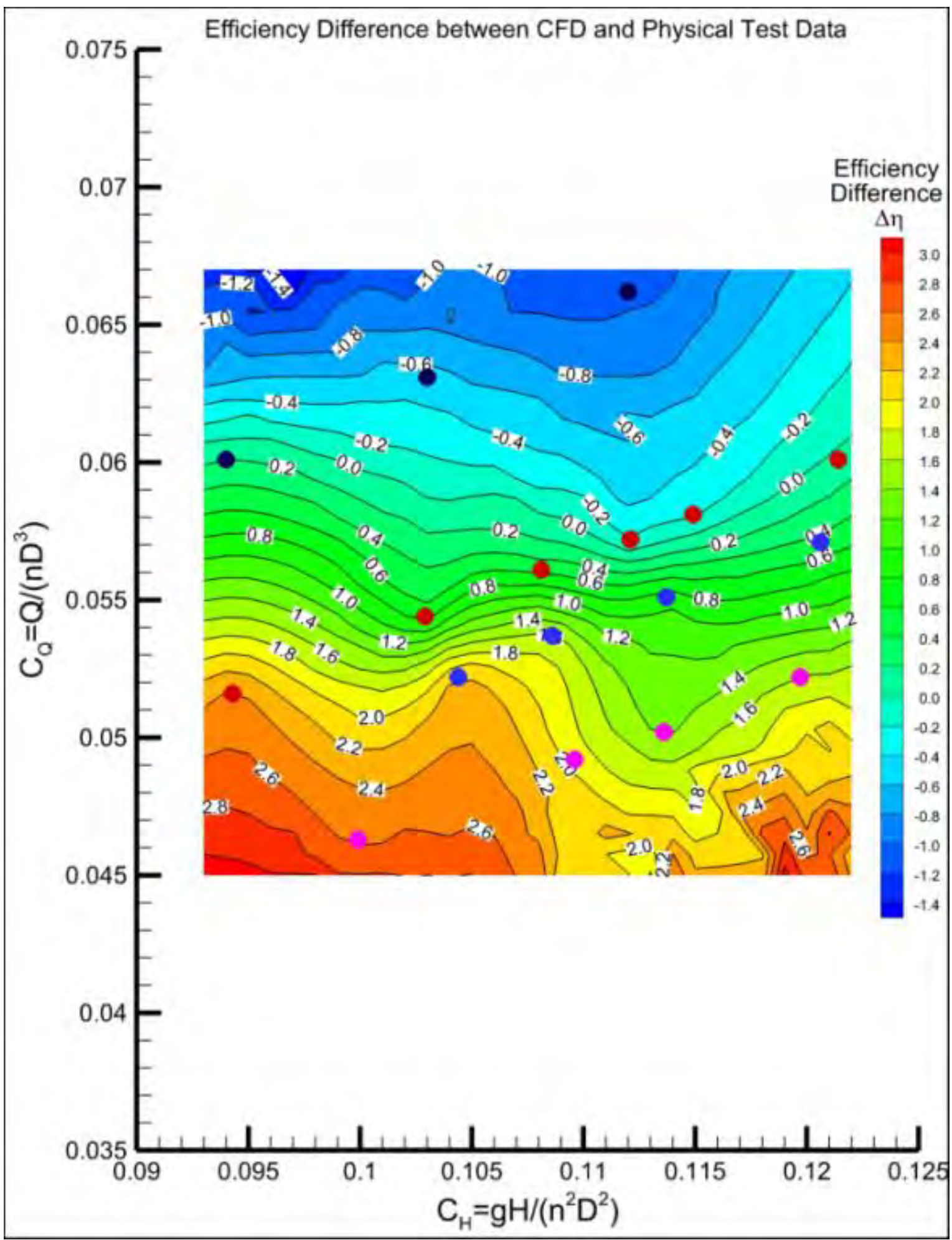

Figure 5-18

Efficiency Differences Between CFD and Physical Test Data (positive values mean CFD simulations had higher efficiencies; negative values indicate CFD simulations had lower efficiencies than physical test data) 


\section{Impact of Fluid in Space Between Shroud and Casing and Space Under Head Cover}

The pressure and viscosity of the fluid inside the annular space between the outer runner shroud and casing as well as the space between the runner top and head cover produce negative torque to the runner through the corresponding pressure and friction forces. To what extent these losses reduce the turbine performance (efficiency) is of interest. To better understand this phenomenon, three flow conditions were simulated with and without the runner annular space and head cover. The comparison of the corresponding turbine efficiencies, listed in Table 5-5, indicated that the fluid inside the runner side space and head cover does have an impact on the turbine performance. On average, the fluid shear in these spaces reduces the efficiency by about 1.4\%. Based on this comparison and the consideration that this loss source was included in the physical model testing, it was decided that the region of the runner side space and head cover should be modeled for all the remaining CFD runs, as indicated and included in the above presentation.

Table 5-5

Comparison of Turbine Efficiency with and without Fluid inside the Runner Side Space and Head Cover

\begin{tabular}{|c|c|c|c|c|c|c|c|c|}
\hline \multirow{2}{*}{21.1 degrees } & \multirow{2}{*}{ Flow Rate Q } & \multirow{3}{*}{$\mathrm{C}_{\mathrm{Q}}$} & \multicolumn{3}{|c|}{$\begin{array}{c}\text { with Runner Side Space and } \\
\text { Head Cover }\end{array}$} & \multicolumn{3}{|c|}{$\begin{array}{c}\text { without Runner Side Space } \\
\text { and Head Cover }\end{array}$} \\
\hline & & & Head H & & & Head H & & \\
\hline Run & cfs & & $\mathrm{ft}$ & $\sigma_{\mathrm{H}}$ & Lmoraty & $\mathrm{ft}$ & $\mathrm{C}_{\mathrm{H}}$ & EImLicticy \\
\hline 1 & 1500.0 & 0.0572 & 89.8 & 0.1121 & $93.28 \%$ & 89.2 & 0.1125 & $95.17 \%$ \\
\hline 2 & 1807.1 & 0.0689 & 121.7 & 0.1519 & $92.82 \%$ & 121.4 & 0.1531 & $93.82 \%$ \\
\hline 3 & 2065.3 & 0.0788 & 151.1 & 0.1886 & $90.52 \%$ & 149.9 & 0.1890 & $91.77 \%$ \\
\hline
\end{tabular}

\section{Summary}

Three-dimensional CFD models comprising the major components of the entire turbine, from the penstock to the draft tube outlet and tail water, were developed and connected by mixing planes. A series of simulations were conducted by solving the RANS equations for steady-state, Newtonian, incompressible, and viscous flows without heat transfer. The shear stress transport (SST) k- $\omega$ two-equation turbulence model was used to calculate the turbulence quantities. The mixing-plane approach was used for join fluid in the rotating parts (in the moving reference frame) and stationary parts. The model included the fluid filled annular side space between the outer runner shroud and the casing, as well as between the runner top and head cover, thereby including the same loss sources as in the physical model. The CFD simulations were conducted using FLUENT version 6.3.26 and consisted of about 17 to 19.5 million computational cells. A hybrid mesh structure was used to represent the complexity of the hydraulic turbine geometry with a mesh topology composed of tetrahedron, hexahedron, and prism/wedge shaped cells. Wicket gate opening angles of $18^{\circ}, 20^{\circ}, 21.1^{\circ}$, and $26^{\circ}$ were modeled. For each different gate opening, the mesh was re-constructed in the zone of the distributor. 
For each simulated operating condition, the wicket gate angle and rate of runner rotation (rpm) were fixed and the flow was independently selected and used as an input. The post-processing of the converged steady-state solutions of each operating condition produced the necessary values for calculation of the hydraulic turbine efficiency, including the mechanical power out (calculated from multiplication of the runner torque and the shaft rotation rpm) and the total available head across the turbine. The reported turbine efficiency is the ratio of that mechanical power out to the available hydraulic power.

The CFD runs did not cover the entire anticipated continuous operating zone of the turbine. A reduced area with a discharge coefficient range $C_{Q}=[0.045,0.067]$ and a head coefficient range $\mathrm{C}_{\mathrm{H}}=[0.093,0.122]$ was used to interpolate the CFD results to form a CFD derived "hill chart". The CFD hill chart is generally similar in shape to that derived from the physical model test results. However, the CFD model tended to over-predict the efficiency for low flows with small gate opening angles, especially for discharge coefficient $\mathrm{C}_{\mathrm{Q}}<0.055$. This resulted in a displacement of the CFD derived highest efficiency area to lower flows. The reasons for these differences are not clear at this time.

It may be noted that the plotted efficiency contours are at intervals of only $0.5 \%$, which accentuates visual differences between the contours from the CFD and physical data. The peak efficiency of about 93.6\% expected for the full scale turbine was well simulated by the CFD simulations. It may be concluded that the CFD simulations are most reliable in predicting the more controlled (coherent) flow patterns near the turbine design point.

In summary, this direct comparison between CFD simulations and physical model test data for a turbine provides useful information for turbine designers and researchers. The results of the comparison are encouraging. This kind of validation allows the developed CFD model to be used to explore other issues of concern, such as determining values for local pressures, pressure change rates, shear and the locations where related fish survival criteria are met or exceeded. 



\section{ALDEN ADVANCED HYDRO TURBINE DEVELOPMENT: POWER UNIT SCOPE DEFINITION, PRICING, AND SCHEDULE}

\section{Overview}

This chapter provides the requested budgetary and preliminary technical information for the Alden Advanced Hydro Turbine (AHT) installation at Brookfield Renewable Power's School Street Station site located on the Mohawk River in upstate New York, USA. The scope of supply outlined reflects the final turbine components identified in the hydraulic design and model test sections of the current report. This scope includes the turbine, generator, unit controls, limited balance of plant equipment, field installation, and commissioning anticipated for School Street Station.

The ancillary equipment scope is defined to provide all functions necessary for operation of the power unit. Those components which tie into plant systems (e.g., plant controls, generator step up transformer) or are highly site specific (e.g., power system stabilization) have not been included.

This scope has been priced to offer indicative pricing only. All prices are subject to review after final design and scope modification.

In addition to equipment pricing, a preliminary schedule is included for reference.

The following documents are and intended to clarify certain elements

- Unit arrangement drawing

2TFV00-0000-00714650 Rev -

- Single line diagram

2GSV00-0000-00709369 Rev E

\section{Equipment Description Overview}

The power unit portion of the scope is a vertical shaft Alden turbine in a two bearing arrangement connected to a synchronous generator. The turbine guide bearing is a water lubricated bearing. A combined thrust and guide bearing sits below the generator rotor on a thrust block which transmits all weight of the generator, rotating turbine components, and all hydraulic thrust loads to the generator foundation sole plates. 
The turbine runner is a custom designed Alden turbine designed to optimize fish passage. The spiral case and draft tube do not require steel lining due to the design criteria such as heads and water velocities. The wicket gates of the turbine are connected to the gate-operating ring by steel levers/links and the whole mechanism is controlled by pressurized oil operated servomotors. 
Alden Advanced Hydro Turbine Development: Power Unit Scope Definition, Pricing, and Schedule

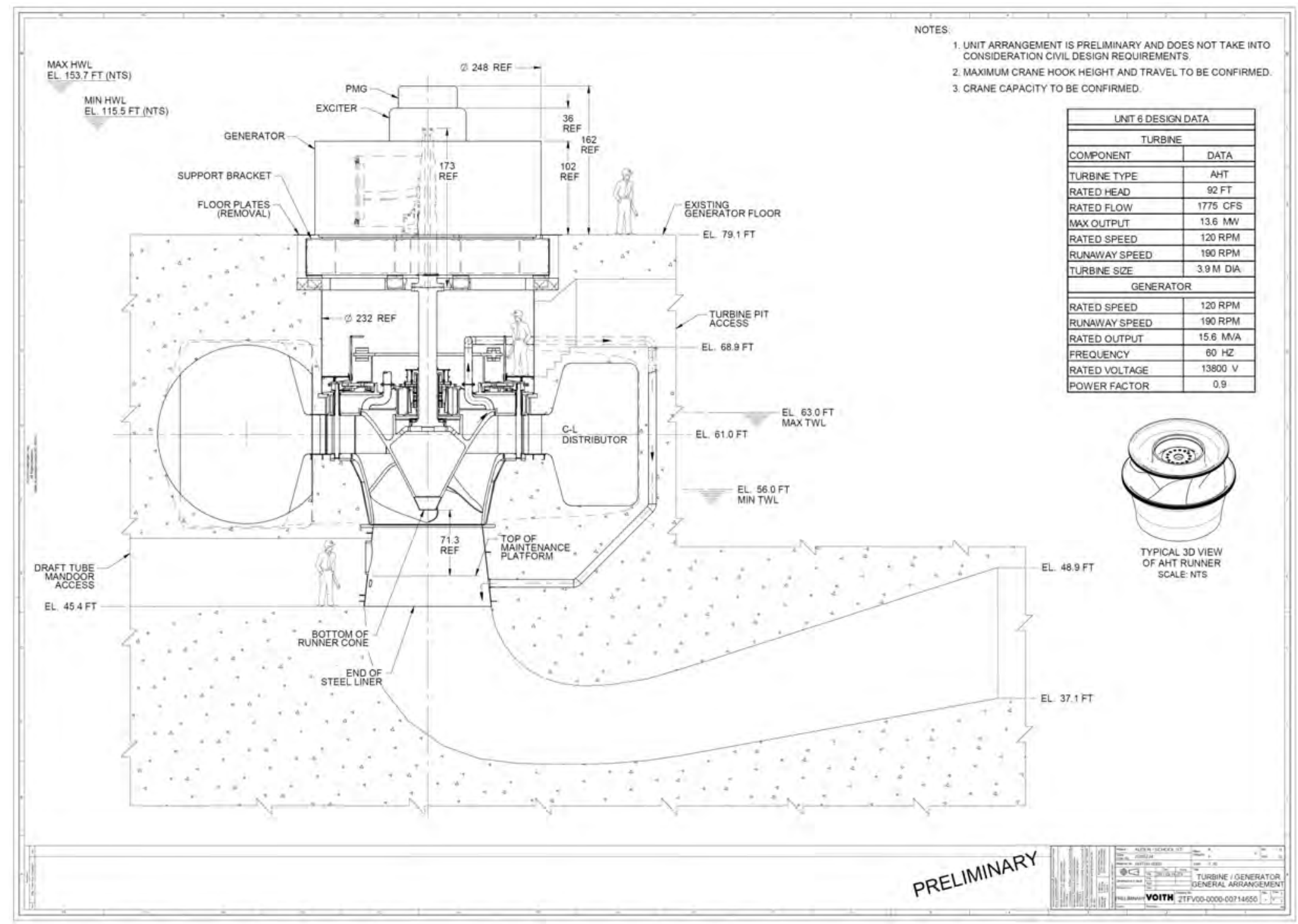

Figure 6-1

Unit Arrangement Drawing 


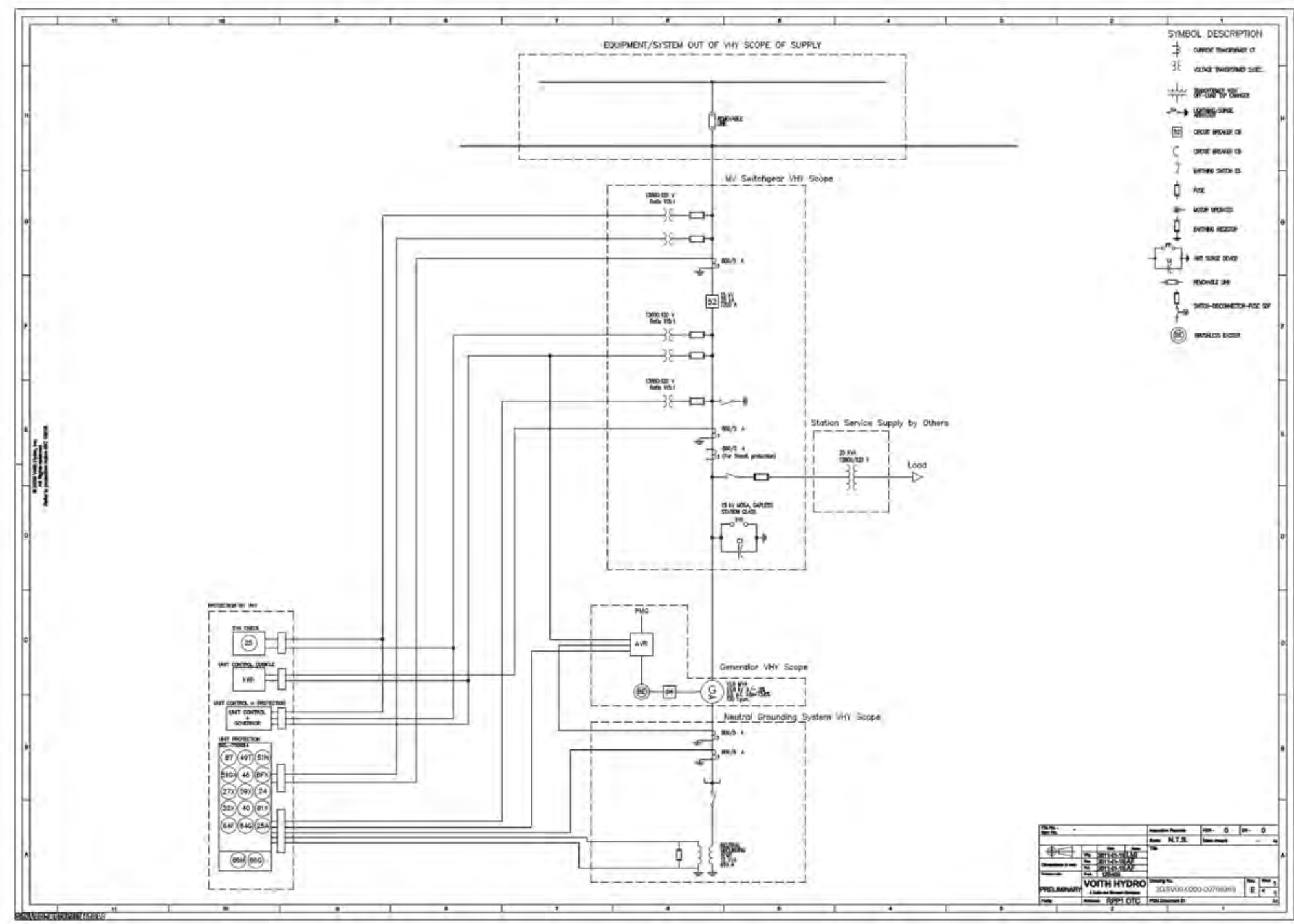

Figure 6-2

Single Line Drawing 
The generator stator contains individually insulated coils and is cooled by forced air. The rotor pole pieces will be insulated according to IEC standards and either built up directly from the ring or bolted on to the rotor frame. The generator is excited by means of a rotating brushless exciter mounted directly to the generator shaft.

Due to the rating and speed of the generator, Voith has determined the best solution for project economics is to provide a generator as a complete package from a manufacture whose products are tailored to the low-speed, low-output generator market. Voith has designed an interface with the generator to allow for future maintenance and removal of the turbine. For this design, the stator mounts on a removable lower bracket secured to the concrete foundation on the outside diameter of the turbine pit liner. The lower bracket will support the weight of the rotating components with maximum hydraulic thrust plus the weight of the stator. When removing the turbine for maintenance the rotor, stator, and lower bracket will have to be removed.

The controls and automation package is based on the Voith Hydro Standard Small Hydro Controls Package. The package contains Programmable Logic Control (PLC) based unit controls with integrated governor functionality. The package is fully compliant with the IEEE 125 performance requirements without using any proprietary hardware components.

All furnished equipment will be free from adverse vibrations. All turbine parts will be designed to withstand the maximum loads at normal service conditions as well as extraordinary conditions (such as water hammer or runaway speed) up to the guaranteed limits.

All descriptions of equipment in this document should be considered preliminary, proprietary, and subject to change during final design.

\section{Turbine Description}

\section{Runner}

The Alden AHT runner is a patented three (3) bladed Francis type runner which will be fabricated entirely of stainless steel cast and plate components: the thick entrance edge of the runner blades will be cast ASTM A743 CA-6NM while the remainder of the blade will be fabricated from A182 UNS 41500 plate. The runner blades will be welded to a crown and band cast from ASTM A743 CA-6NM.

The turbine water passages will be CNC milled and ground to within admissible tolerances according to IEC standards.

\section{Turbine Shaft}

The turbine shaft will be made of forged ASTM A668 Class D steel with flanges integrally forged at both ends. The turbine shaft will be direct coupled to the generator shaft and the Alden runner with pre-tensioned studs and drive sleeves or fitted bolts. The shaft will be equipped with a replaceable stainless steel sleeve at the packing box location. 


\section{Spiral Case}

Due to the designed conditions seen by the Alden turbine, the spiral case will be formed from concrete according to the hydraulic profile specified by Voith. The design requires a full spiral with rectangular cross sections and rounded corners.

The form work required to construct this spiral case is outside of the Voith scope.

\section{Stay Ring}

The stay ring will be constructed of welded ASTM A516 Grade 70 plate steel and will be anchored in concrete by steel anchor bolts. It will contain fourteen (14) fixed stay vanes whose hydraulic profile is specifically designed to optimize fish passage. The stay vanes will be fabricated from ASTM A516 Grade 70 steel.

\section{Wicket Gate Mechanism Assembly}

The wicket gates will be cast from ASTM A743 CA-6NM. The wicket gate bushings will be maintenance free, greaseless bushings. The stems of the gates will connect to a carbon steel operating ring through carbon steel links and levers. The operating mechanism will contain a shear pin safety device with an anti-flail device or bending links.

The entire wicket gate operating assembly will move by means of pressurized oil operated servomotors. The servomotors will have an adjustable throttling valve for wicket gate control and feedback device for stroke indication.

\section{Head Cover}

The turbine head cover will be fabricated from ASTM A516 Grade 70 plate steel. The design includes a replaceable stainless steel wearing ring, thrust relief, and an air admission system. Greaseless bushings for the fourteen (14) wicket gate trunnions are installed in the head cover. The head cover will be split in half for ease of shipping and will be assembled at site.

\section{Shaft Seal}

A packing box type shaft seal is included to seal the dry wheel pit from the wet, rotating components. The packing box will be fabricated from carbon steel plate. It will be made in two pieces for easy installation around the turbine shaft. The packing box sealing will be achieved with rows of PTFE impregnated, braided packing material. The packing box will have a flanged connection to attach to a cooling water line. Water for the packing box should be clean and free from any debris.

\section{Water Guide Bearing}

The turbine guide bearing will be a water lubricated bearing designed to support the shaft radially. Water for the guide bearing should be clean and free from any debris. 


\section{Bottom and Discharge Ring}

The bottom ring is integral with the discharge ring and fully embedded in concrete. It will be fabricated from ASTM A516 Grade 70 plate steel. The design includes a replaceable stainless steel wearing ring and air admission system. It will be made from carbon steel and furnished with maintenance free bushings for the wicket gate trunnions.

\section{Draft Tube}

A draft tube cone will be welded to the discharge ring. The cone offers a smooth hydraulic surface for the water leaving the Alden runner and will be made from carbon steel. All anchors and support structures are included in the Voith scope. The design includes a man door and locations for platform installation.

The remaining portion of the draft tube will be formed from concrete according to the hydraulic profile defined by Voith. Forming of the concrete for the draft tube will be by others.

A draft tube inspection platform will be supplied by Voith and will mount to the draft tube cone. This platform will allow inspection and maintenance of the runner from the draft tube side.

\section{Pit Liner}

A carbon steel pit liner will be supplied to line the turbine pit. The lining will have an opening to pass through servomotor piping with recesses to house the gate operating servomotors. A door will be included for personnel access.

\section{Installation and Maintenance Tooling}

All special tool, lifting, and maintenance devices for the turbine are included in the Voith scope of supply.

\section{Coating Standard}

All components will be supplied with the appropriate protective coating according to Voith standards. For a description of the coating, see the attached reference documents.

\section{Generator Description}

\section{Stator Frame}

The stator frame will consist of an assembly of welded, adequately sized steel plates, reinforced by rigid longitudinal and transverse ribs. The frame will be connected to the lower bearing bracket housing. Design of stator frame will be such that it will allow an adequate distribution of air flow from the rotating to the static components. 


\section{Stator Core}

The stator core will be constructed from high grade, low loss, non-aging silicon steel laminations. Air ducts in the stator core will be arranged to allow a uniform distribution of air for an efficient and smooth flow with minimized windage losses.

\section{Stator Windings}

The stator windings will be insulated with a specified insulation class in accordance with IEC or other standards. The generator stator windings will be star connected with the neutral point brought out to a suitable neutral grounding system. This system will consist of a properly sized neutral grounding transformer and resistor. The coils will be identical for all the stator windings and impregnated with high grade insulating varnish.

\section{Rotor Hub}

The generator rotor will be designed and constructed in accordance with the best modern practice and will withstand safely the specified runaway speed without exceeding the allowable unit stresses.

\section{Rotor Poles}

The pole pieces will be built up directly from the rim or bolted on to the rotor frame. The field winding will be insulated with the specified insulation class in accordance with IEC or other Standards, and will be capable of withstanding the normal mechanical stresses imposed by the specified runaway speed with special care being taken to prevent end turns from slipping or deforming due to centrifugal stresses on the connections. The windings will consist of copper strips directly wound on the poles according to the manufacturers standard practice, with insulating collars provided at the top and bottom of each field coil. Damper windings will be provided on the pole shoes capable of withstanding unbalanced short circuits.

\section{Generator Bearing}

The generator will be an umbrella-type construction with one lower thrust and guide bearing. The bearings will be oil lubricated and will be either self lubricated or supplied with their own lubrication pumping unit. Bearing sumps will require a water connection to circulate clean water through the internal cooling circuit.

The thrust bearing will be cooled by means of a single pass cooling circuit integral with the bearing surface. A flange connection will be included for clean water hookup.

\section{Generator Bearing Bracket}

The generator bearing bracket will be designed to mount to the foundation sole plates at a diameter larger than the turbine pit diameter. The lower bearing bracket will be adequately rigid so as to support the weight of all rotating components with maximum hydraulic thrust plus the generator stator. 
To remove the turbine head cover and runner for maintenance or inspection, the rotor, stator, and lower generator bearing bracket must all be removed.

\section{Generator Cooling}

The generator will be an air cooled. Ambient air will be forced by fan blades on the rotor over the stator frame. After exiting the stator frame, hot air can be vented into the powerhouse our outside. Duct work to vent the air external to the powerhouse is not included in the Voith scope.

\section{Generator Shaft}

The generator shaft will be made of forged steel, properly heat treated. It operates safely coupled with the rotor and turbine at any speed up to and including runaway speed without detrimental distortion or vibration. The shaft will be free of injurious flaws and imperfections, will be smoothly and accurately machined all over, and will be polished at the bearing surfaces and at accessible points for alignment checks. The amount of shaft runout will not exceed the tolerances recommended for generator shafts in the applicable standards.

\section{Excitation}

A brushless excitation system will be provided complete with an Automatic Voltage Regulator (AVR), rotating rectifying semiconductors and necessary connections. The brushless excitation will be provided to eliminate the need for brushes and slip rings.

\section{Generator Brake}

A brake will be included to bring the generator to a stop upon unit shutdown. The brake will be adequately sized to quickly stop the generator during turndown. The brake will be a caliper and disc type brake, actuated by a hydraulic cylinder and controlled by the unit HPU.

\section{Terminal Box}

All generator leads will terminate in a minimum number of terminal boxes mounted on the side of the stator frame.

\section{Soleplates}

The new generators will be supplied with soleplates and all required anchoring materials.

\section{Installation and Maintenance Tooling}

All special tool, lifting, and maintenance devices for the generator are included in the Voith scope of supply.

\section{Coating Standard}

All generator components will be supplied with the appropriate protective coating according to industry standards. 


\section{Automation Description}

\section{Unit Control and Digital Governor Panel}

A factory-assembled, metal-enclosed unit control bay will be supplied consisting of stationary structure(s) containing the following: selector switches, pushbuttons, relays, transducers, programmable logic controller, control power transformer, communication switches and modems (as required), and similar equipment. Included will be a programmable controller and ancillary hardware (such as operator interface terminal, input/output interfacing modules, mounting racks, PLC power supply, memory and memory protection circuitry, special interconnecting cables and connectors, etc.) and software program for controlling the unit equipment (such as start-up and shutdown of the turbines and unit equipment).

Any motor loads to be controlled by the unit PLC are expected to be connected to the unit PLC over a DeviceNet connection. Only unit motor controls are included in the scope the Voith scope.

A factory-assembled, metal-enclosed Excitation, Synchronization and Protection Control Bay will be supplied consisting of stationary structure(s) containing the following major components connected to the PLC over a DeviceNet, Modbus RTU or Ethernet connection:

- Automatic Voltage Regulator (AVR)

- Synchronizer

- Power monitor

- Control system power supplies (125/24 VDC)

- Generator Protection Relay

A human machine interface (HMI) is provided with the unit control panels and equipment and is mounted on the front of the control panels and equipment cabinet. The HMI is designed to provide information on the operation of the turbine. The HMI displays data, setpoints, governor modes, and alarm information. The HMI also provides basic control features to manually operate the governor. The controls and display are presented on a series of screens, with each screen designed to provide information related to one area of operation including governor control, alarm displays, and governor parameters.

\section{Generator Floor Remote I/O Panel}

Generator Floor Remote Panel will be designed with a NEMA 12 enclosure and include necessary I/O for transformer high temperature, alarms including trip and fault, brake release, generator breaker open -closed, lube oil system status, lube oil water flow, generator bearing oil flow -gear side -exciter side, lube oil sump levels, speed increaser oil flow, lube oil filter dirty, generator circuit breaker trip, brake solenoid set - release, start lube oil pump, phase A-B-C stator temperature, generator bearing temperature exciter side-gear side, thrust bearing temperature, shell bearing temperature, speed increaser bearing temp HS and LS. All I/O subject to requirements of the mechanical design. 
Also included in this panel will be a low frequency vibration module. This will allow for the connection of up to 2 vibration probes to monitor the status of the generating unit. Alarm, danger and fault signals will be inputs to the I/O modules in the same panel. In this way, an operator can be made aware of an abnormal vibration through the control system HMI.

\section{Turbine Remote I/O Panel}

Turbine pit remote panel will be designed with a NEMA 4 enclosure and include necessary I/O and communication wiring for all I/O located in or near the turbine area. All I/O subject to requirements of the mechanical design.

\section{Miscellaneous Remote I/O Panel}

A Miscellaneous remote panel will be designed with a NEMA 12 enclosure and include necessary I/O and communication wiring for all I/O located in or near the turbine area. All I/O subject to requirements of the mechanical design.

\section{Balance of Plant Description}

\section{Switchgear}

The switchgear consists of the generator circuit breaker, an earthing switch, metering instrumentation, surge arrestors and capacitors. The cubicle assemblies will be of the metal clad type and tested for arcing in accordance with the recommendations of IEEE C37.20.7.

\section{Neutral Connections}

The connections between the generator terminals and the switchgear as well as the neutral leads to the neutral grounding system will be by appropriately sized MV cables. The neutral grounding cabinet, including all PT and CTs are included in the Voith scope of supply.

\section{Motor Control Center}

A motor control center will be provided to control all Voith supplied motors. Any plant system motors will not be controlled by the unit MCC.

\section{Hydraulic Power Unit (HPU)}

Voith will supply a HPU to move the wicket gates by means of pressurized oil. The HPU will be supplied fully assembled and self contained.

A single HPU will control both the turbine wicket gates and the generator brakes. 


\section{Cooling Water System}

Voith will supply a cooling water system capable of pumping clean water to the necessary systems (thrust bearing, water bearing, and packing box). The cooling water system will draw water off the plant raw water system, filter it, and pump it to the required location.

\section{Vacuum Breaker and Silencer System}

A vacuum breaker will be provided to admit air beneath the head cover when the pressure drops below atmospheric pressure. A silencer is included to muffle the sound of the turbine while it is drawing air. Some piping is included so the turbine will draw air from outside the powerhouse.

\section{Interconnecting Cables and Piping}

All cabling will be adequately sized for the required current and voltage rating.

All necessary cabling and piping will be provided to make field connections between Voith supplied equipment (Voith-Voith connections). Any connections between Voith equipment and customer supplied equipment (Voith-Customer connection) are outside the Voith scope of supply.

\section{Single Line Diagram}

A single line diagram is attached to describe the Voith scope of supply.

\section{Field Work Description}

\section{Installation}

The unit installation will be performed according to the most advanced practices. Voith will perform the installation work with local craftsmen from various trades under the direction of experienced Voith Field Operations Supervisors. Voith will provide its own offices, furniture, telephone/telefax, secretary, etc to administer the equipment installation at site to install the turbines, generators, governors, excitation systems and unit control systems for one new generating unit at site.

All tooling, expendable materials, consumables, and special equipment required for the installation will be provided by Voith. The powerhouse crane, supplied by others, is to be made available to Voith to perform the installation of the equipment starting with the completion parts. Voith will provide a certified crane operator to operate the powerhouse crane during the equipment installation.

The following are excluded from the Voith scope of supply.

- Cranes, crane operators, and hoisting equipment for the embedded parts.

- Unloading, hauling to and from the powerhouse.

- Storage of equipment to be assembled and installed. 
- Installation of Stage I anchors, anchor bolts, embedded piping, grounding grid, piezometer piping, and/or plates, or conduits in Stage I concrete.

- Concrete embedment and/or grouting of embedded components.

- Form work, rebar, anchors, stripping of forms, supports for formwork, and/or cleanup of concrete.

The following services are assumed to be provided by the Owner.

- Adequate power supply, potable water, and air to perform the equipment installation services onsite at no cost to Voith.

- The powerhouse crane must be available (installed and tested) at the start of the completion parts. Voith will provide its own crane operator for the powerhouse crane to set the completion parts.

- Powerhouse crane capable of lifting the assembled rotor, with adequate clearance or head room for assembly of the Completion parts and Generator.

- Dewatering and/or maintaining the dewatered condition of the unit throughout the installation period. Voith will have the right to specify when the units are watered against the gates.

\section{Commissioning}

Voith will follow IEC Publication 60545 (Guide for commissioning, operation and maintenance of hydraulic turbines) and IEEE standard 1248 (Guide for the commissioning of electrical systems in hydroelectric power plants) during the commissioning of the turbine and the generator.

Commissioning includes a wet commissioning test procedure for the turbine and the generator, a test team of three individuals and test equipment for a three week period at any location in the continental US, and a commissioning test report.

A turbine index test is included in this estimate, but an absolute prototype turbine efficiency test is considered an optional item and is not included in this estimate. Generator air flow rate data, open circuit saturation testing and heat runs are included in the estimate, but special generator testing for efficiency and generator characteristics is considered an optional item and is not included.

Full commissioning of the Voith supplied unit controls package is included.

\section{Delivery Schedule}

The following is a preliminary schedule for installation of the School Street equipment. 
Table 6-1

Preliminary Schedule for Installation of the School Street Equipment

\begin{tabular}{|l|c|}
\hline \multicolumn{1}{|c|}{ Activity } & $\begin{array}{c}\text { Months from } \\
\text { Contract Award }\end{array}$ \\
\hline Definition of unit layout & 4 \\
\hline Embeds arrive at site & 14 \\
\hline Powerhouse crane available for Voith use & 22 \\
\hline $\begin{array}{l}\text { Equipment commissioned and handover to } \\
\text { Owner }\end{array}$ & 28 \\
\hline
\end{tabular}

The above schedule assumes that Stage I concrete is ready to receive power unit embeds when they arrive at site. The embeds will be set by use of a mobile crane which will be operated by the customer at no cost to Voith.

Time has been allotted for pouring of Stage II concrete, which is also outside of the Voith scope. This time will vary depending on the civil contractor.

The powerhouse crane must be properly installed and certified prior to the date shown above. Voith will use this crane to install non-embedded components.

Voith will commission all Voith-supplied equipment including the turbine, generator, controls, and balance of plant equipment. No equipment supplied by others is included in the installation or commissioning. It is assumed that this equipment will be commissioned by others in time for Voith scope of work.

\section{Price Schedule}

\section{Pricing}

The following is a budgetary price for all the Alden AHT generating equipment for installation at the School Street site. The scope is as defined in the preceding technical description.

- Total School Street Installed Equipment $\$ 19,885,000$

The price above includes all equipment, engineering, manufacturing, transportation, installation, and commissioning.

\section{Pricing Clarifications}

The following items pertain to commercial terms.

- Pricing is for budgetary purposes only and subject to fluctuations in foreign currencies.

- This pricing is on a present-day basis and is given in today's market conditions, i.e. USD valuation and material price indices. 
- Voith standard terms of sale apply.

- Taxes and duties have not been included.

- Neutral cash flow for the life of the project is assumed.

- The due dates for payment shall be net 30 days based on the date of invoice received and accepted by the Buyer or date of receipt of satisfactory goods.

- Price includes a one year warranty.

The following pertain to general scope clarifications.

- All project management, engineering, and transportation to job site is included.

- All civil works and powerhouse modifications are by others.

- Interconnecting wiring and piping for Voith-Voith connections is included.

- Interconnecting wiring and piping for Voith-customer connections is not included.

- Spare parts are not included.

- All additional items including charges will be invoiced as change orders at a mutually agreed upon price.

\section{Relative Pricing}

The Alden turbine is, by design, lower in power density than conventional turbines. The larger more slowly rotating equipment which allows for the enhanced fish passage performance also leads to a relatively more expensive turbine/generator solution. For the site conditions at School Street Station, sizing for a conventional Francis gives a 13 bladed $2.5 \mathrm{~m}$ runner rotating at 189.5 rpm. Sizing for a conventional Kaplan turbine gives a 5 bladed $2.7 \mathrm{~m}$ runner rotating at 276.9 rpm.

A comparison of the installed equipment price for the Alden Turbine vs. conventional hydro turbines is given in Table 6-1. Note that the prices are normalized according to that of the Alden turbine itself. 
Table 6-2

Alden Turbine Relative Pricing Comparison at School Street Station

\begin{tabular}{|c|c|c|c|}
\hline & Alden Turbine & $\begin{array}{c}\text { Conventional Francis } \\
\text { (same power) }\end{array}$ & $\begin{array}{c}\text { Conventional Kaplan } \\
\text { (same power) }\end{array}$ \\
\hline & \multicolumn{3}{|c|}{ SIZING } \\
\hline Diameter, [mm] & 3900 & 2510 & 2650 \\
\hline \multirow[t]{2}{*}{ Maximum Power, [MW] } & 13.6 & 13.6 & 13.6 \\
\hline & \multicolumn{3}{|c|}{ COSTING } \\
\hline Turbine & 1.00 & 0.50 & 0.55 \\
\hline Generator & 0.80 & 0.65 & 0.65 \\
\hline Installation and Comm. & 0.25 & 0.25 & 0.25 \\
\hline Automation / BoP & 0.25 & 0.25 & 0.25 \\
\hline Relative Cost & \multirow[t]{2}{*}{2.30} & 1.65 & 1.70 \\
\hline Premium for Alden & & $39 \%$ & $35 \%$ \\
\hline
\end{tabular}

The fully installed equipment price for the Alden turbine, including turbine, generator, unit controls, various BOP equipment, installation, and commissioning is roughly 35 - 40\% higher than what would be expected for a conventional Francis or Kaplan in a similar application. It should be noted that the relative pricing does not include any civil work. The larger size and slower speed of the Alden turbine allows for a higher setting relative to the tailwater. For School Street, the Alden distributor centerline is $5 \mathrm{ft}$ above tailwater, while the conventional Fancis centerline is anticipated to be set $2 \mathrm{ft}$ above tailwater. The conventional Kaplan centerline is set the lowest, falling $16 \mathrm{ft}$ below tailwater. The higher setting of the Alden turbine will result in less excavation and lower civil costs.

\section{Applicability to other hydro sites}

Although the Alden turbine was hydraulically and mechanically designed for a specific site condition, it represents a new turbine family with a range of head and flow applications. An overview of the anticipated turbine application range is given in Figure 7-3. 


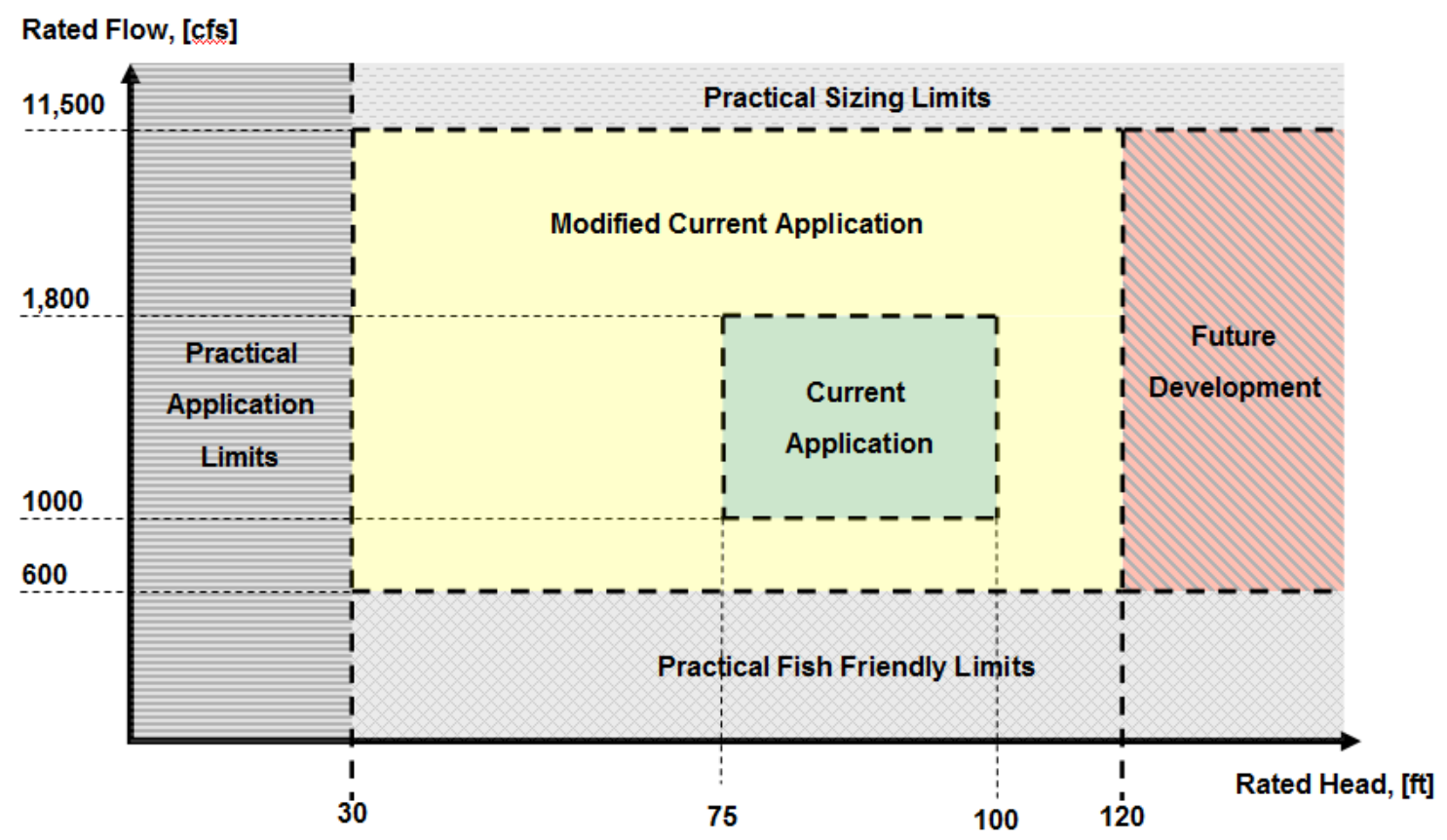

\section{Figure 6-3}

Alden Turbine Application Range

The green "Current Application" region spans from $75 \mathrm{ft} \leq \mathrm{H}_{\text {net }} \leq 100 \mathrm{ft}$ and represents the head range covered by the current design. The larger yellow "Modified Current Application” region can be accomplished through appropriate sizing and design modifications to the turbine. This region spans from $30 \mathrm{ft} \leq \mathrm{H}_{\text {net }} \leq 120 \mathrm{ft}$. At $120 \mathrm{ft}$ of net head, stress limitations of the current design limit applicability. It is anticipated that future design modifications to the turbine can extend the operation above $120 \mathrm{ft}$ of net head. Below $30 \mathrm{ft}$ of net head, turbine application switches to large bulb units.

The discharge range spanned by the Alden turbine falls between 600 and 11,500 cfs. The 11,500 cfs upper limit results from turbine manufacturing feasibility while fish friendly considerations associated with smaller turbine size occurs below $600 \mathrm{cfs}$. 



\section{SUMMARY AND NEXT STEPS}

Collaborative research funded by EPRI, DOE and industry has improved the performance characteristics of the Alden turbine while maintaining its fish-friendly characteristics. This research has resulted in the preliminary engineering required to make the turbine commercially available. Design modifications to the turbine components have improved the turbine efficiency to almost $94 \%$ at the selected design point, while providing the same or slightly improved fish survival characteristics. These turbine modifications were also selected to decrease manufacturing and supply costs, resulting in a solution that is significantly more competitive with conventional turbines. The improved Alden turbine is now available for commercial deployment.

Key findings of the engineering development of the Alden turbine include:

- Runner modifications to improve efficiency and fish passage environment included the following:

- Realignment of runner blades to reduce cavitation.

- Runner rotation speed increased from $112.5 \mathrm{rpm}$ to $120 \mathrm{rpm}$, to reduce generator costs while maintaining similar water to blade velocities.

- Blade shapes were modified to create more uniform axial and tangential velocity patterns leaving the runner, thus improving the flow pattern in the draft tube and increasing the turbine efficiency.

- Pressure and velocity gradients for fish survival in the runner were maintained or improved. The absolute minimum pressure was raised to one half atmosphere at the design point.

- Wicket gate shapes were simplified with thicker noses and the stay vanes were aligned with the gates.

- A simplified semi-spiral spiral case was developed to reduce the overall footprint of the turbine.

- Calculations show that the modified Alden turbine is expected to have the same or slightly improved fish friendly characteristics with improved turbine performance and efficiency.

- Finite Element Analysis (FEA) calculations were conducted for the turbine components to verify structural design criteria of stresses and deflections were met.

- Data were collected using a 1:8.7 model on performance, thrust, runaway speed, pressure pulsations, minimum pressures, cavitation and wicket gate torques to characterize the hydraulic behavior of the Alden turbine and identify the acceptable operating range. 
- Using the IEC step-up calculation methodology, the maximum calculated prototype efficiency will be $93.64 \%$ for the design net head and flow of $92.0 \mathrm{ft}$ and $1504 \mathrm{cfs}$, respectively.

- Cavitation, thrust, runaway speed, pressure pulsations and wicket gate torque values were observed to fall within or below the ranges expected for conventional radial flow machines.

- The scope of supply and pricing information for commercial application at School Street Station was determined to be roughly $\$ 1,450 / \mathrm{kW}$ with a total supply cycle of 28 months. This supply includes turbine, generator, unit controls, limited balance of plant equipment, field installation, and commissioning. This cost does not include civil structures.

- The predicted fish survival rate is $98.4 \%$ for $200 \mathrm{~mm}$ fish for the final turbine design (predicted survival reaches $100 \%$ for fish $100 \mathrm{~mm}$ and less in length). Note that fish $200 \mathrm{~mm}$ in length comprise more than $90 \%$ of fish entrained at hydro projects in the U.S. (Winchell et al. 2000).

- In general, the performance levels demonstrated for the modified turbine exceed levels anticipated prior to the current development work.

\section{Next Steps}

Concurrent with this DOE-funded study, EPRI conducted a separate study (EPRI 2011) to identify a demonstration project site for the installation and testing of the Alden turbine. In mid 2010, a solicitation was distributed to the hydropower industry for potential demonstration sites. A quantitative evaluation process was developed and implemented to objectively evaluate and rank the applications. Site visits to the five highest ranked candidate sites were conducted during the fall of 2010 to verify application information and collect additional project details. The five sites were then again quantitatively evaluated based upon applicant commitment, sizing and general layout of turbine and water conveyance, predictions of fish survival, and project development schedule. A final numeric ranking of the sites led to the selection of one site as the preferred location for development as a demonstration program for the Alden turbine. An alternate site was also identified in the event the preferred site could not be developed. In 2011, pending receipt of commitment from the preferred demonstration site host company, EPRI will assist the owner with activities that will further the design, installation, and funding of the field demonstration project.

In addition to the demonstration project, EPRI and the DOE held a workshop on environmentally-enhanced hydro turbines. A committee to help plan the agenda and content of the workshop was formed that included representatives from EPRI, DOE, the National Hydropower Association, U.S. Army Corps of Engineers and the U.S. Bureau of Reclamation. The workshop was conducted May 19 and 20, 2011 in Washington D.C. and covered the following topics:

- Successes in the development of environmentally-enhanced turbines

- How fish issues have been addressed for these turbines

- New turbine designs for downstream passage of fish 
- New turbine designs for improving water quality

- The tools available to verify turbine performance

- The next steps in getting these turbines installed in the field

Presentations for public download will be available in September 2011 at www.epriturbineworkshop.com. Extended abstracts of all presentations will be available for public download from EPRI at www.epri.com by December 2011.

\section{Tentative Schedule for Demonstration}

The following is a preliminary schedule of future demonstration project development events:

- 2011-2012: Corporate commitment to demonstration project, site engineering design, final turbine design, purchase agreement

- 2013: Turbine installation

- 2014-2015: Turbine performance testing 



\section{8 \\ REFERENCES}

Abernethy, C.S., Amidan, B. G. and Čada, G. F. 2002. "Simulated Passage Through A Modified Kaplan Turbine Pressure Regime: A Supplement to "Laboratory Studies of the Effects of Pressure and Dissolved Gas Supersaturation on Turbine-Passed Fish”, DOE/ID-10853. Prepared for the U.S. Department of Energy.

Amaral, S. G. Hecker, M. Metzger, and T. Cook. 2003. 2002 Biological Evaluation of the Alden/Concepts NREC Turbine. Proceedings of Waterpower XIII, HCI Publications, Inc., St. Louis, Missouri.

Amaral, S. V., G. E. Hecker, P. Stacy, and D. A. Dixon. 2008. Effects of leading edge turbine blade thickness on fish strike survival and injury. Proceedings of Hydrovision 2008. HCI Publications, St. Louis, Missouri.

ANSYS CFX Release 12.1 ANSYS CFX - Solver Modeling Guide. 2009. ANSYS Europe, Ltd. Canonsburg, PA.

Bardina J.E., P.G. Huang, and T.J. Coakley. 1997. "Turbulence Modeling Validation, Testing, and Development", NASA Technical Memorandum 110446.

Cook, T. C., G. E. Hecker, H. B. Faulkner, and W. Jansen. 1997. Development of a More Fish Tolerant Turbine Runner, Advanced Hydropower Turbine System. Prepared for the U.S. Department of Energy, Washington, D.C.

Cook, T. C., G. E. Hecker, S. V. Amaral, P. S. Stacy, F. Lin, and E. P. Taft. 2003. Final report - pilot scale tests Alden/Concepts NREC Turbine. Prepared for U.S. Department of Energy, Washington, DC. Contract No. DE-AC07-99ID13733.

Coutant, C. C., R. Mann, and M. J. Sale. 2006. Reduced spill at hydropower dams : opportunities for more generation and increased fish protection. Prepared for U. S. Department of Energy, Office of Energy Efficiency and Renewable Technologies by Oak Ridge National Laboratory, Oak Ridge, TN. Report No. ORNL/TM-2005/179.

Electric Power Research Institute (EPRI). 1998. Review of downstream fish passage and protection technology evaluations and effectiveness. Report TR-111517, Palo Alto, CA.

EPRI. 2007. Program on Technology Innovation: Redesign of the Alden/Concepts NREC Helical turbine for Increased Power Density and Fish Survival: Scroll Case Redesign. Prepared by Alden Research Laboratory, Inc., EPRI Report No. 1014810.

EPRI. 2008. Evaluation of the effects of turbine blade leading edge design on fish survival. Prepared by Alden Research Laboratory, Inc., EPRI Report No. 1014937. 
References

EPRI. 2009. Redesign of the Alden/Concepts NREC Helical Turbine for Increased Power Density and Fish Survival: Evaluation of Conceptual Prototype Turbine. Prepared by Alden Research Laboratory, Inc., EPRI Report No. 1015600.

EPRI. 2011. Demonstration Development Project: Solicitation and Selection of a Site to Test a Fish-Friendly Hydropower Turbine. Prepared by Alden Research Laboratory, Inc., EPRI Technical Update No.1022538.

Francfort, J. E., G. F. Čada, D. D. Dauble, R. T. Hunt, D. W. Jones, B. N. Rinehart, G. L Sommers, and R. J. Costello. 1994. Environmental mitigation at hydroelectric projects, Vol. II. Benefits and costs of fish passage and protection. DOE/ID-10360(V2). U. S. Department of Energy Idaho Operations Office, Idaho Falls, Idaho.

Guensch, G. R., R. P. Mueller, C. A. McKinstry, D. D. Dauble. 2002. Evaluation of Fish-Injury Mechanisms During Exposure to a High-Velocity Jet. U.S. Department of Energy, DOE/ID11072, PNNL-14173.

Hecker, G. E., and T. C. Cook. 2005. Development and Evaluation of a New Helical Fish Friendly Hydro-Turbine. Journal of Hydraulic Engineering 131(10): 835-844.

Hecker, G. E., and G. S. Allen. 2005. An Approach to Predicting Fish Survival for Advanced Technology Turbines. Hydro Review, November 2005, HCI Publications, Inc., St. Louis, Missouri.

Hecker, G. E., M. Frain, S. V. Amaral, G. S. Allen, D. A. Dixon, R. K. Dixon, and D. J. Cooper. 2009. The Alden/Concepts NREC Fish-Friendly Hydro Turbine: Progress from Design Concept to Working Demonstration Project. Proceedings of Waterpower XVI. PennWell Corporation, Tulsa, Oklahoma.

Lin, F. G. E. Hecker, and T. C. Cook. 2004. Understanding Turbine Passage Survival Using CFD. Proceedings of Hydrovision 2004, HCI Publications, Inc., St. Louis, Missouri.

Menter, F. R. 1993. "Zonal Two Equation k- $\omega$ Turbulence Models for Aerodynamic Flows," Paper No. 93-2906, presented at the AIAA 24111 Fluid Dynamics Conference, Orlando, FL.

Menter, F. R. 1994. " Two Equation Eddy-Viscosity Turbulence Models for Engineering Applications," AIAA Journal, Vol. 32, No. 8, pp. 269-289.

Neitzel, D.A., M.C. Richmond, D.D. Dauble, R.P. Mueller, R.A. Moursund, C.S. Abernethy, G.R. Guensch, and G.F. Cada. 2000. Laboratory Studies on the Effects of Shear on Fish: Final Report. U.S. Department of Energy, Idaho Operations Office, DOE/ID-10822, Idaho Falls, Idaho.

Nietzel, D. A., D. D. Dauble, G. F. Čada, M. C. Richmond, G. R. Guensch, R. P. Mueller, C. S. Abernethy, and B. Amidan. 2004. Survival Estimates for Juvenile Fish Subjected to a Laboratory-generated Shear Environment. Transactions of the American Fisheries Society 133:447-454.

Odeh, Mufeed, 1999. A Summary of Environmentally Friendly Turbine Design Concepts. Prepared for the U.S. Department of Energy, Idaho Operations Office. 
Office of Technology Assessment (OTA). 1995. Fish Passage Technologies: Protection at Hydropower Facilities. Congress of the United States, OTA-ENV-641, Washington, DC: U.S. Government Printing Office.

Sale, M. J. et al. 1991. Environmental mitigation at hydroelectric projects. Vol. I. Current practices for instream flow needs, dissolved oxygen, and fish passage. DOE/ID-10360, U.S. Department of Energy, Idaho Falls, Idaho.

Sale, M. J., G. F. Čada, and D. D. Dauble. 2006. Historical perspective on the U.S. Department of Energy's Hydropower Program. Paper presented at HYDROVISON 2006, Portland, OR. HCI Publications, Inc., Kansas City, MO.

Stephenson, John R. et al. 2010. “Assessing barotraumas in neutrally and negatively buoyant juvenile salmonids exposed to simulated hydro-turbine passage using a mobile aquatic barotraumas laboratory”, Fisheries Research 106(2010) p. 271-278.

Winchell, F., S. Amaral, and D. Dixon. 2000. Hydroeletric Turbine Entrainment and Survival Database: An Alternative to Field Studies. Proceedings of Hydrovision 2000. HCI Publications, Inc., St. Louis, Missouri. 


The Electric Power Research Institute Inc., (EPRI, www.epri.com) conducts research and development relating to the generation, delivery and use of electricity for the benefit of the public. An independent, nonprofit organization, EPRI brings together its scientists and engineers as well as experts from academia and industry to help address challenges in electricity, including reliability, efficiency, health, safety and the environment. EPRI also provides technology, policy and economic analyses to drive long-range research and development planning, and supports research in emerging technologies. EPRI's members represent more than 90 percent of the electricity generated and delivered in the United States, and international participation extends to 40 countries. EPRI's principal offices and laboratories are located in Palo Alto, Calif.; Charlotte, N.C.; Knoxville, Tenn.; and Lenox, Mass.

Together...Shaping the Future of Electricity

\section{Program:}

Waterpower

(C) 2011 Electric Power Research Institute (EPRI), Inc. All rights reserved. Electric Power Research Institute, EPRI, and TOGETHER...SHAPING THE FUTURE OF ELECTRICITY are registered service marks of the Electric Power Research Institute, Inc.

1019890 